Uta Zeuge-Buberl

\title{
Die Mission des
} American Board in Syrien im 19. Jahrhundert

Implikationen eines

transkulturellen Dialogs

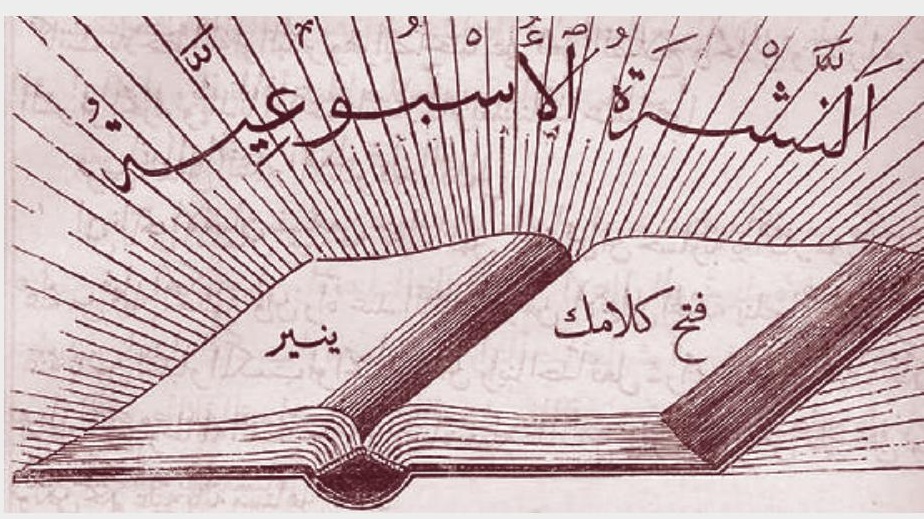

Missionsgeschichtliches Archiv - 26

Franz Steiner Verlag 
Uta Zeuge-Buberl

Die Mission des American Board

in Syrien im I9. Jahrhundert 


\section{MISSIONSGESCHICHTLICHES ARCHIV}

Studien der Berliner Gesellschaft für Missionsgeschichte

Herausgegeben im Auftrag des Vorstandes von

Andreas Feldtkeller, Irving Hexham, Ulrich van der Heyden,

Gunther Pakendorf und Werner Ustorf

Band 26 
Uta Zeuge-Buberl

\section{Die Mission des American Board in Syrien im 19. Jahrhundert}

Implikationen eines transkulturellen Dialogs 


\section{Veröffentlicht mit Unterstützung}

des Austrian Science Fund (FWF): PUB 332-G24

FயF

\section{Der Wissenschaftsfonds.}

Umschlagabbildung:

Titelbild der arabischen Missionszeitschrift Al-Našra al-Usbu 'īya (Wöchentliche Zeitschrift) mit einem Zitat aus Psalm II9,I30 ,fatah kalāmika yunayir" (wörtl.: das offenbar Werden deiner Worte ist erleuchtend).

Quelle: N.E.S.T. Special Collections.

Open Access: Wo nicht anders festgehalten, ist diese Publikation lizensiert unter der Creative Commons Lizenz Namensnennung o.4

Bibliografische Information der Deutschen Nationalbibliothek:

Die Deutsche Nationalbibliothek verzeichnet diese Publikation in der Deutschen Nationalbibliografie; detaillierte bibliografische Daten sind im Internet über $<$ http://dnb.d-nb.de> abrufbar.

Dieses Werk einschließlich aller seiner Teile ist urheberrechtlich geschützt. Jede Verwertung außerhalb der engen Grenzen des Urheberrechtsgesetzes ist unzulässig und strafbar.

(C) Franz Steiner Verlag, Stuttgart 2016

Lektorat: Ricarda Berthold

Satz: Claudia Rupp, Stuttgart

Druck: Offsetdruck Bokor, Bad Tölz

Gedruckt auf säurefreiem, alterungsbeständigem Papier.

Printed in Germany.

ISBN 978-3-5I5-II378-6 (Print)

ISBN 978-3-5I5-II458-5 (E-Book) 
Für Andreas, Jarik und Ylvi 



\section{GELEITWORT}

In vielen Regionen der Welt waren Missionare die ersten Menschen aus westlichen Kulturen, die so dauerhaft mit Menschen der einheimischen Gesellschaften zusammenlebten und zusammenarbeiteten, dass aus der Kulturbegegnung ein neues, transkulturelles Wissen entstehen konnte. Im günstigsten Fall kam es nicht nur zu einem Transfer von Wissen in beide Richtungen - dem Import von westlichen Wissensformen in andere Regionen der Welt und der Sammlung von Wissen über andere Kulturen, das in Europa und Nordamerika zugänglich gemacht wurde - sondern es entstanden neuartige hybride Formen von Wissen, die es ohne eine nachhaltige und wohlwollende Begegnung von Menschen aus verschiedenen Kulturen nicht hätte geben können.

Die Tätigkeit des American Board of Commissioners for Foreign Missions im Gebiet des heutigen Libanon ist für die Erforschung solcher Zusammenhänge ein besonders interessantes Beispiel. Einerseits war in der arabischen Welt eine alte Schriftkultur lebendig, weshalb die Missionare weniger in der Versuchung standen, sich selbst fälschlich als die einzig „Wissenden“ in der transkulturellen Begegnung zu verstehen. Andererseits waren die Wissenschaftssysteme in den Vereinigten Staaten von Amerika zu dieser Zeit noch so stark selbst erst im Entstehen begriffenen, dass dort weit weniger als in Europa der spezifische Beitrag von Missionaren und ihren Kooperationspartnern durch die ihr Wissen rezipierenden Universitätswissenschaftler verschleiert wurde.

Im Zentrum der hier vorgelegten Studie stehen die Biographien von vier Männern, deren Tätigkeit eng miteinander verwoben ist und die exemplarisch für den vergleichsweise günstigen Fall einer Kulturbegegnung stehen: die beiden amerikanischen Missionare Eli Smith und Cornelius van Dyck sowie die beiden christlichen, im Gebiet des heutigen Libanon tätigen Intellektuellen Butrus al-Bustani und John Wortabet. Was sie miteinander verbindet, sind außerordentliche Fähigkeiten in der Darstellung und Weitergabe einer Mehrzahl von Wissensbereichen aus ihrer jeweils eigenen Kultur in Kombination mit einer großen Offenheit, Neugier und Respekt für die jeweils andere Kultur. Die Begegnungen zwischen diesen Akteuren transkultureller Wissenserzeugung verlief keineswegs nur harmonisch und sie lässt sich bei aller produktiver Kooperation nicht reduzieren auf Beziehungen, die frei gewesen wären von jeglichem kolonialem Machtgefälle.

Dennoch lässt die von Uta Zeuge-Buberl geleistete Rekonstruktion der vier Biographien in ihrem gemeinsamen Kontext noch deutlicher hervortreten als dies bisher sichtbar war, dass pauschale Beurteilungen in keiner Weise hilfreich sind, wenn es um die Einschätzung des Beitrags von missionarischen Akteuren geht zu Prozessen der religiösen und kulturellen Überfremdung, der „Modernisierung“ mit ihren positiven und negativen Folgen, aber auch der Ermöglichung von Bildung und eigenständiger Handlungskompetenz. Vielmehr stellt sich die Situation 
an unterschiedlichen Orten und zu unterschiedlichen Zeiten auf sehr verschiedene Weise dar. Die hier vorgelegten biographischen Studien brechen diese Diskussion auf die Frage nach dem Beitrag einzelner Persönlichkeiten herunter und zeigen, wie stark die negativen und positiven Wirkungen missionarischen Handelns vom Zusammenspiel und der „Chemie“ individueller Menschen mit all ihren Charaktereigenschaften abhängig ist.

Der für weitere Forschungsarbeit auf diesem Gebiet wegweisenden Studie von Uta Zeuge-Buberl wünsche ich, dass sie durch die Veröffentlichung in der Reihe „Missionsgeschichtliches Archiv“ viele interessierte Lesende findet, die dadurch angeregt werden, Zusammenhänge der transkulturellen Wissenserzeugung im 19. Jahrhundert neu zu durchdenken.

Potsdam im Juni 2016 Andreas Feldtkeller 


\section{INHALTSVERZEICHNIS}

Abbildungsverzeichnis ............................................................................ 8

Abkürzungsverzeichnis ................................................................................ 9

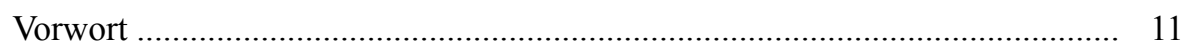

Einleitung

1. "[T]he rest of the world need[s] civilizing“- zwischen kultureller Arroganz und Liebe zur fremden Kultur .................................................... 13

2. Voraussetzungen des transkulturellen Dialogs .......................................... 18

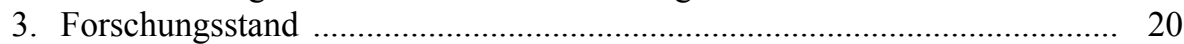

4. Ziele der Arbeit .................................................................................... 26

5. Inhaltlicher Überblick ............................................................................. 28

6. Hinweise zur Quellenlage und den methodologischen Schritten ................ 29

7. Hinweise zur Transliteration von Eigennamen und geografischen Bezeichnungen

Kapitel I: Die Mission des ABCFM in der osmanischen Provinz Syrien (1819-1870) ………………………………................................ 33

I.1. Die amerikanische Syrienmission - eine Erfolgsgeschichte? ................. 40

1. Die American Mission Press in Beirut

2. Die Missionsschulen ..................................................................... 46

3. „Satisfactory evidence of piety“Die Etablierung syrisch-protestantischer Kirchengemeinden ............ 52

4. Eine höhere Schule im „native style“ - Das Seminar in 'Abeih ........ 60

5. ,[W]e are making history out here very fast" Das Syrian Protestant College 64

6. „This field it seems to me to be unwise in us to forsake“Hoffnungen, Enttäuschungen und Meinungsverschiedenheiten in der Syrienmission

I.2. Kulturelle Transformationsprozesse in Syrien im 19. Jahrhundert .......... 75

1. Wichtige politische Entwicklungen ……………………………...... 75

2. Die Entstehung einer bildungsnahen Mittelschicht in Beirut ............. 78

3. Schulbildung im Osmanischen Reich .............................................. 80

4. Literarische und wissenschaftliche Gesellschaften .......................... 84

5. Syriens nahda: Eine Brücke zwischen Vergangenheit und Zukunft ... 91

6. Welche Rolle spielen amerikanische Missionare in Syriens nahda? ... 96 
Kapitel II: Missionare als Cultural Brokers …………................................... 98

II. 1. „Here may my last days be spent“- Eli Smith (1801-1857) .................... 103

1. Kurzbiografie ............................................................................... 103

2. „The outstanding figure of the early Syrian mission“ “........................ 105

3. Der American Arabic Type .............................................................. 109

4. Al-Kitāb al-Muqaddas - Die arabische Bibel ................................... 112

5. Die Herausgabe der ersten arabischen Zeitschrift in Syrien -

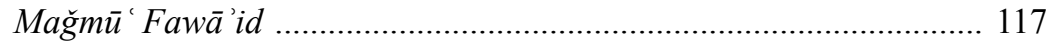

6. Biblical Researches in Palestine ..................................................... 121

7. Weitere Veröffentlichungen ........................................................... 124

8. Smiths Engagement in den Orient-Gesellschaften ............................ 127

9. Briefwechsel mit syrischen Freunden und Kollegen ........................... 129

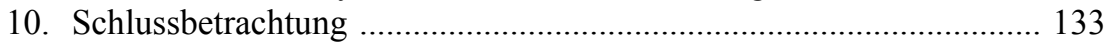

II.2. „,[He] had Arabic at his tongue's and fingers' ends“-

Cornelius Van Dyck (1818-1895) ........................................................ 135

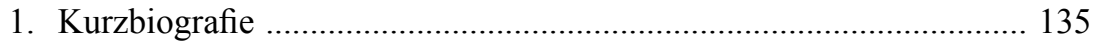

2. „Our policy has been a contracting not an extending policy“Van Dyck und die Syrienmission ...................................................... 136

3. Die Vollendung der arabischen Bibel ................................................ 146

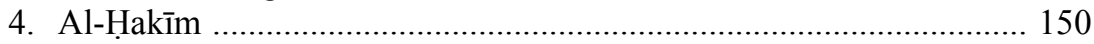

5. Von Ahbāar 'an Intišāar al-Inğ̄il fì Amākin Muhtalifa zu al-Našra al-Usbu ‘̀ya ................................................................. 162

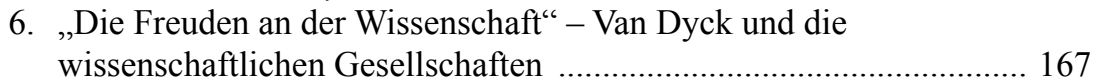

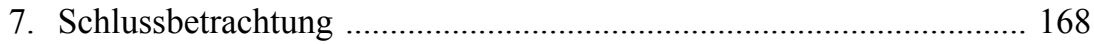

Kapitel III: Die Gemeinschaft syrischer Protestanten in der Contact Zone ....... 173

III.1. „Ein Mann, der seiner Zeit voraus ist“"?

Mu allim Buṭrus al-Bustānī (1819-1883) ............................................. 180

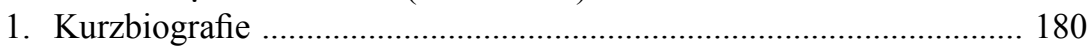

2. „May [he] live as burning and shining light [ ...] in this dark land“- Bustānīs Arbeit für die Mission ...................................... 181

3. Al-Madrasa al-Wațanìya - Modell für Säkularismus und nationale Verbundenheit

4. Hubb al-wațan (Die Liebe zur Nation) - Bustān̄̄s Karriere als Autor, Journalist und Herausgeber

5. Für Frauenbildung und kulturellen Fortschritt Bustān̄̄ und die literarischen Zirkel ................................................. 203

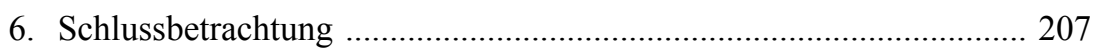

III.2. „He was truly the child of the mission“-

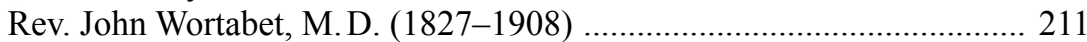

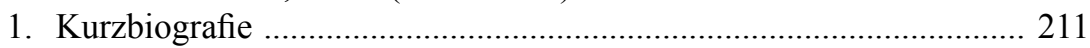

2. Ein Kind der Mission? ................................................................... 213 


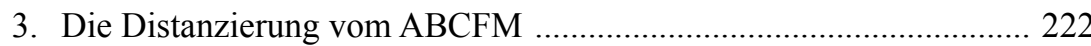

4. Die Rückkehr nach Beirut als Mediziner ......................................... 229

5. John Wortabet als Autor und Übersetzer .......................................... 236

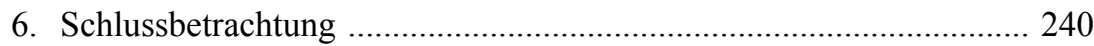

Fazit: Zwischenmenschliche Interaktion im Fokus moderner

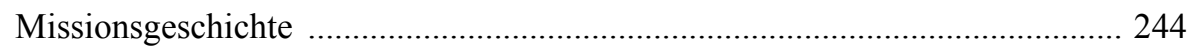

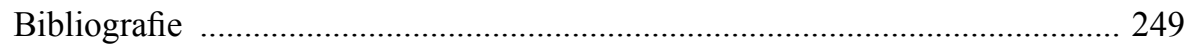

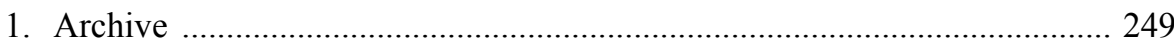

2. Deutsch-, englisch- und arabischsprachige Zeitschriften

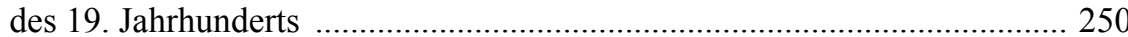

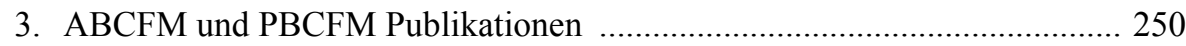

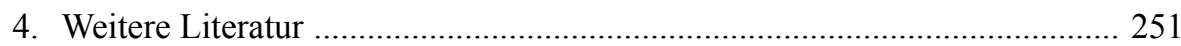

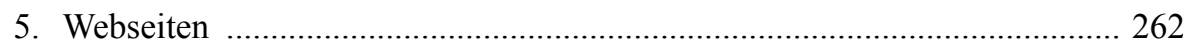

Anhang I: Die literarischen Beiträge von Smith, Van Dyck, Bustān̄̄ und Wortabet für die American Mission Press ................................................... 264

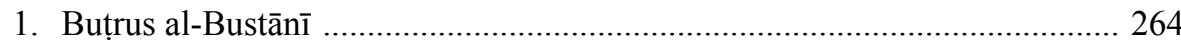

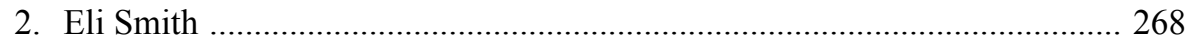

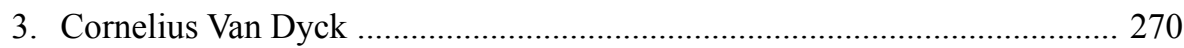

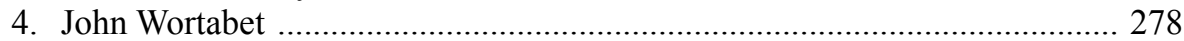

Anhang II: native helpers und protestantische Konvertitinnen und Konvertiten (1823-1900) ..................................................................... 282

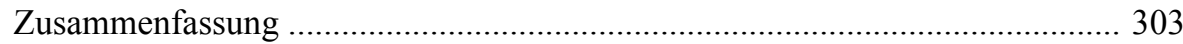

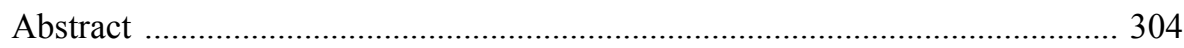

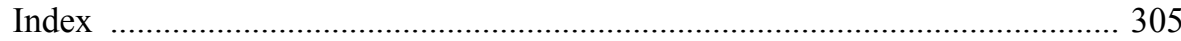




\section{ABBILDUNGSVERZEICHNIS}

Abb. 1: Landkarte mit wichtigen Orten der Syrienmission in der osmanischen Provinz Syrien

(Quelle: Marius König, Grafikdesign, Freiburg im Breisgau)

Abb. 2: Missionsseminar in 'Abeih

(Quelle: MH 64, 1868, S. 393)

Abb. 3: Rev. Eli Smith, D. D.

(Quelle: American University of Beirut, Special Collections, „Portrait of Eli Smith, $1800 \mathrm{~s}^{\text {(6) }}$

Abb. 4: Titelseite der Zeitschrift Mağmū' Fawā'id (1851)

(Quelle: Harvard Lamont Library)

Abb. 5: Rev. Cornelius Van Dyck, M.D., D. D., LH.D.

(Quelle: Yale Divinity School Library, Henry Harris Jessup Papers, RG 117, Box 10/44)

Abb. 6: Titelseite von Al-Našra al-Usbū ‘̄ya (9. Mai 1871)

(Quelle: N.E.S.T. Special Collections)

Abb. 7: Buṭrus al-Bustān̄̄

(Quelle: Yale Divinity School Library, Henry Harris Jessup Papers, RG 117, Box 10/44)

Abb. 8: Al-Madrasa al-Wațaīya (Schlafsäle für die jungen Schüler, Empfangshalle, Festsaal und Prüfungsraum, Büro und Wohnhaus des Präsidenten und seiner Familie)

(Quelle: al-Ğinān, 1873, S. 628b; Harvard Widener Library)

Abb. 9.: Al-Madrasa al-Wațanīya (Grundschule und Privatschulen sowie Spielräume für Sommer und Winter)

(Quelle: al-Ǧinān, 1873, S. 628d; Harvard Widener Library)

Abb. 10: Rev. John Wortabet, M.D.

(Quelle: Ġ.Y. Hūūrī, Al-rawād al-mu'assasūn li 1-Ǧāmi a al-Amīrikīya bi-Beyrūt/The founding fathers of the American University of Beirut: Biographies, Beirut 1992, 173)

Abb. 11: Die ersten Professoren des Syrian Protestant College, 1870-1874 (1. Reihe v. 1.: Cornelius Van Dyck, Daniel Bliss, John Wortabet; 2. Reihe v. 1.: David Stuart Dodge, George Post, Edwin Lewis, Harvey Porter) (Quelle: American University of Beirut, Special Collections, „Original Faculty Members, 1870-1874“") 


\section{ABKÜRZUNGSVERZEICHNIS}

AA

AAC Protokolle

ABCFM

$\mathrm{ABC}$

AUB

DMG

HHL

JAOS

$\mathrm{MH}$
Archiv der American University of Beirut/Libanon

Anglo-American Congregation, Records (1868-1905)

American Board of Commissioners for Foreign Missions

Archiv des ABCFM, zugänglich in der Harvard University, Cambridge/USA

American University of Beirut/Libanon

Deutsche Morgenländische Gesellschaft

Harvard Houghton Library (Harvard University, Cambridge/ USA)

Journal of the American Oriental Society

Missionary Herald: Monatliche Veröffentlichungen aktueller Berichte über die Missionen des ABCFM

NECB Protokolle National Evangelical Church of Beirut, Siğil al-waqā'i 'umdat kanīsa al-inğilīya al-wațanīya, min 19 ayār 1848 ilā 9 ayār 1922 (Verzeichnis der Protokolle des Komittees der Nationalen Evangelischen Kirche, vom 19. Mai 1848 bis 9. Mai 1922)

N.E.S.T. Near East School of Theology, Beirut/Libanon

NEST/SC Near East School of Theology Library/Special Collections

NLS, MS National Library of Scotland, Manuskript

PBCFM

ROS

Presbyterian Board of Commissioners for Foreign Missions

The Missionary Herald. Reports from Ottoman Syria 18191870, hrsg. von K. Salibi und Y. K. Khoury, 5 Bde., Beirut 1995

SPC Syrian Protestant College

TA

$\mathrm{UPC}$

Übersetzung aus dem Arabischen von Tarek Abboud ${ }^{1}$

United Presbyterian Church of Scotland

UPC-GMBM

ZDMG
United Presbyterian Church General Minute Book. Missions

Zeitschrift der Deutschen Morgenländischen Gesellschaft

1 Studentische Hilfskraft im DFG-Projekt „,Transatlantische Vernetzung von Institutionen des Wissens am Beispiel der Syrienmission des American Board“, Humboldt-Universität zu Berlin/Deutschland. 



\section{VORWORT}

Mein Auslandsstudienaufenthalt an der Near East School of Theolgy (N.E.S.T.), Beirut/Libanon im Rahmen des „Studiums im Mittleren Osten“ von 2005 bis 2006 war ohne Frage ein prägendes Erlebnis und hat die folgenden Jahre meines Theologiestudiums und darüber hinaus gehende Interessen, wie z. B. an der arabischen Sprache, stark beeinflusst. Bevor ich in den Libanon gereist bin, wusste ich wenig über die dort lebende christliche Minderheit und noch weniger über die kleinste Gruppe unter ihnen, die Protestanten. Wie ich erfuhr, begann ihre Geschichte im Nahen Osten erst im 19. Jahrhundert und dennoch haben sie großen Einfluss auf den Bildungsbereich des Landes genommen. Schon 2006 entstand daher der Wunsch, dieser Geschichte etwas genauer nachzugehen.

Die hier vorliegende Forschungsarbeit ist Bestandteil des von der DFG geförderten Projektes „Transatlantische Vernetzungen von Institutionen des Wissens am Beispiel der Syria Mission des American Board", das von März 2011 bis Januar 2015 von Prof. Dr. Andreas Feldtkeller, Lehrstuhl für Religionswissenschaft und Interkulturelle Theologie, Humboldt-Universität zu Berlin, geleitet wurde. Im Rahmen des Projektes konnten drei der ingesamt vier Auslandsreisen für die nötigen Archivrecherchen unternommen werden: in den Libanon (März 2013 und März 2014) und nach Großbritannien (Juni 2014). Der Forschungsaufenthalt an der Harvard University Cambridge/USA im Januar und Februar 2011 wurde mir durch ein vom DAAD verliehenes Kurzstipendium ermöglicht. Ohne die hier genannten finanziellen Unterstützungen wäre die Realisierung dieses Dissertationsprojektes nicht möglich gewesen.

Für die vielen Gespräche und wertvollen Ratschläge danke ich insbesondere meinen Fachkolleginnen Dr. Christine Lindner (New York/USA), Dr. Deanna Ferree Womack (Atlanta/USA), Dr. Julia Hauser (Kassel/Deutschland), Dr. Sarah Markiewicz (Berlin/Deutschland) und Dominika Hadrysiewicz (Berlin/Deutschland). Mein besonderer Dank gilt ebenso meinen arabischsprachigen Freundinnen und Freunden Nouhad Moawad, Midu Hafz, Ayman Sadek und meinem Kollegen Tarek Abboud. Sie haben mir viele Male bei Übersetzungen aus dem Arabischen geholfen.

Ich danke allen Mitarbeiterinnen und Mitarbeitern der Archive in der Harvard University, Cambridge/USA, der Near East School of Theology in Beirut/Libanon, der American University of Beirut/Libanon sowie der National Library of Scotland in Edinburgh/Großbritannien für die vielen hilfreichen Hinweise und gemeinsamen Recherchen.

Wien im April 2015 


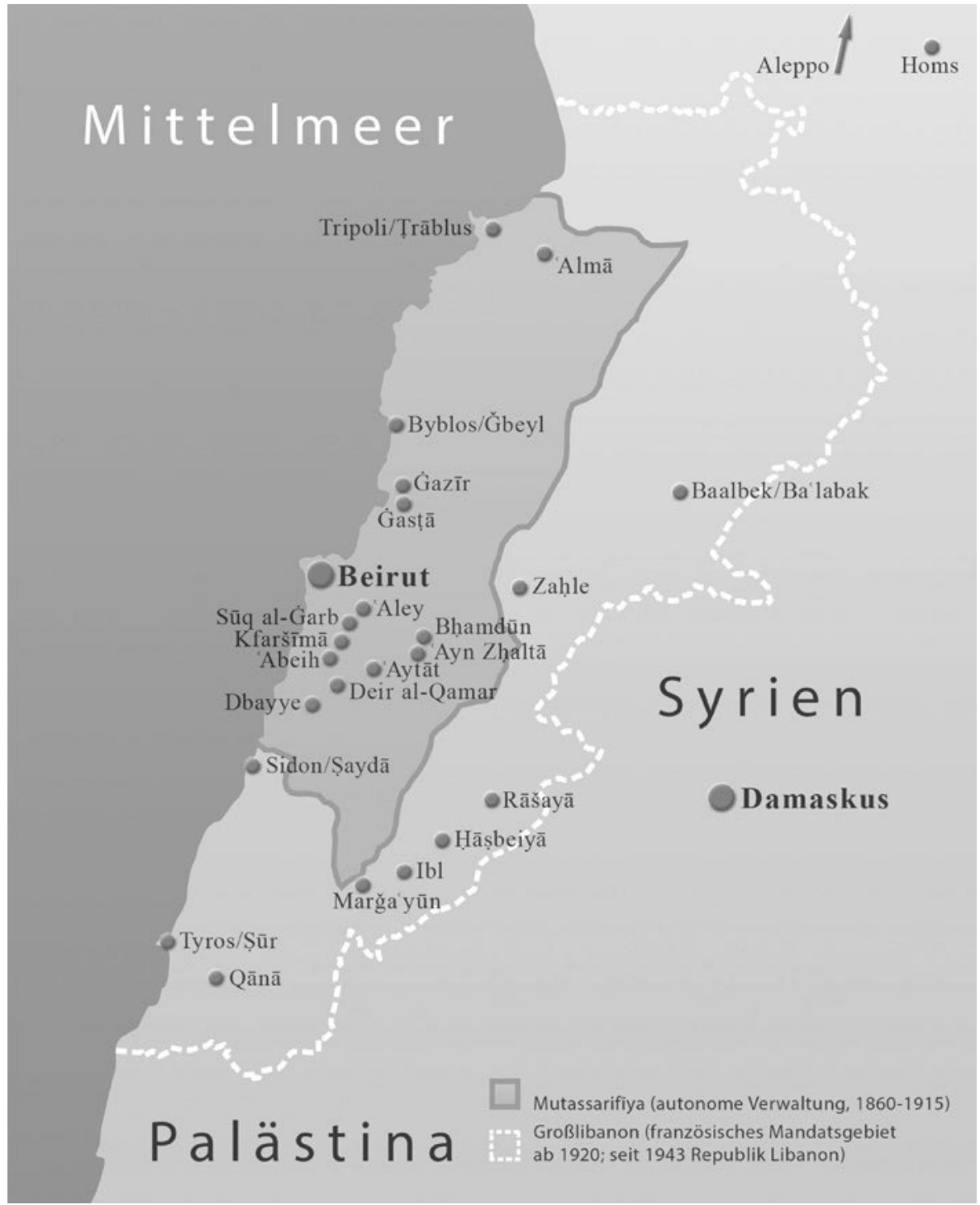

Abb. 1: Landkarte mit wichtigen Orten der Syrienmission in der osmanischen Provinz Syrien 


\section{EINLEITUNG}

„The importance of the Mediterranean, as a medium of access to a considerable portion of the great scene of action [...] will be felt by all" schreibt der Missionary Herald im Jahr 1819. ${ }^{1}$ Die Zeitschrift ist das Sprachorgan der missionarischen Auslandsunternehmungen des American Board of Commissioners for Foreign Missions (American Board, oder kurz: ABCFM), gegründet 1810 in Boston. Als größte interkonfessionelle, d. h. presbyterianische, kongregationalistische und reformierte Missionsgesellschaft in Nordamerika in jener Zeit ruft der ABCFM im Jahr 1819 die Palestine Mission ins Leben, die 1828 in Mission to Syria and the Holy Land umbenannt wird. Bis zum Jahr 1870, in dem die Verwaltung der Mission an den Presbyterian Board of Commissioners for Foreign Missions übergeben wird, werden über 80 Missionare, z.T. mit ihren Ehefrauen und Missionsassistentinnen ${ }^{2}$ in die Levante entsandt. Das Missionsfeld soll sich zunächst über die gesamte osmanische Provinz Syrien erstrecken, die die heutigen Gebiete des Libanon, Syriens, Israel/Palästinas sowie Jordaniens umfasst. Die Umbenennung der Mission in Syria Mission im Jahr 1842 verdeutlicht die geografische Einschränkung auf die Gebiete des heutigen Libanon und Teile der Republik Syrien. Im zeitlichen Rahmen von 1823, als die Missionsstation in Beirut errichtet wird, bis zum Ende des 19. Jh.s wird die Syrienmission des American Board Gegenstand dieser Untersuchung sein. Vor allem im englisch- und arabischsprachigen Raum wurde diese Mission dokumentiert und später in zahlreichen Studien aus missionsgeschichtlicher und soziologisch-kultureller Perspektive analysiert. Die englischsprachigen Quellen, die in Europa nicht zugänglich sind, sowie die für nur wenige Theologinnen und Theologen verständlichen, relevanten arabischen Texte wurden hier erstmalig in einer deutschsprachigen Untersuchung bearbeitet.

\section{1. ,[T]HE REST OF THE WORLD NEED[S] CIVILIZING“33 - ZWISCHEN KULTURELLER ARROGANZ UND LIEBE ZUR FREMDEN KULTUR}

Im Gespräch mit heute im Libanon lebenden evangelischen Christen oder auch Gläubigen anderer christlicher Konfessionen, die Kenntnisse über die Geschichte evangelischer Mission im Vorderen Orient besitzen, wird deutlich, dass die ameri-

1 Missionary Herald 15 (1819), in: Reports from Ottoman Syria 1, 1. Der Missionary Herald wird im Folgenden durch „MH“ abgekürzt, für den fünfbändigen Neudruck (Reports from OttomanSyria) der im MH gedruckten Berichte über die Syrienmission, herausgegeben von Kamal Salibi und Y.Q. Khoury, wird „ROS“ als Abkürzung verwendet.

2 Die Bezeichnung „Missionarin“ setzt sich erst mit dem beginnenden 20. Jh. durch. Frauen werden im 19. Jh. als female assistant oder female teacher eingestellt.

3 Bonk (1989), 239. 
kanischen Missionare ein Bild von sich hinterlassen haben, das auch gut 150 Jahre nach der Zeit, in der sie aktiv in Syrien waren, sehr ambivalent ist: Ihre Errungenschaften im Bildungsbereich prägen bis heute die libanesische Kultur und haben weitreichende Auswirkungen auch außerhalb der protestantischen Gemeinschaft. Andererseits wird im Rückblick häufig davon gesprochen, dass Missionare intolerant gegenüber den lokalen Religionsgemeinschaften aufgetreten seien und sich selbst als privilegiert im Verhältnis zur arabischen Kultur betrachteten.

Der libanesische Soziologe SAmIR KHALAF urteilt:

While gladly accepting their long exile from home [...] evangelists almost always considered themselves as aliens and strangers wherever they went. They resisted, in fact, any effort or temptation to get closer to, or acquire, even the superficial, exotic or outward artifacts of the native culture. ${ }^{4}$

Dabei sind es stets gut gebildete, engagierte junge Männer und Frauen, die der ABCFM ab 1819 in die Region entsendet. Zwar müssen sie zunächst die einheimische Kultur kennenlernen, um auf die Bedürfnisse der Einheimischen eingehen zu können, jedoch vermitteln sie auch ein Bild westlicher Überlegenheit und Arroganz gegenüber allem, was sich außerhalb ihrer hoch zivilisierten Welt befindet, so KHALAF weiter. ${ }^{5}$ Manche Missionare können selbst nach jahrzehntelanger Auslandsmission in Syrien die klassischen Vorurteile gegenüber ,den Arabern' nicht überwinden. ${ }^{6}$ Der Blick auf den Islam, eine Religion, die einer falschen Offenbarung folge und deren Prophet ein Betrüger sei, ändert sich auch nach langjährigen Kontakten mit Muslimen nicht. ${ }^{7}$ Diese Ansichten spiegeln sich nicht selten in den Missionarsberichten wider und werden dem westlichen Lesepublikum zudem in zahlreicher Reiseliteratur vermittelt, da ab Mitte des 19. Jh.s der Orient ${ }^{8}$ von Bürgern mittleren Standes in Europa und Nordamerika als neues Ziel von Bildungsreisen entdeckt wird. ${ }^{9}$ Zweifelsohne sind viele der äußeren Missionen im 18. und

4

5

6 Dass sich dies bis zum Ende des 19. Jh.s im Rahmen der amerikanischen Syrienmission nicht ändern wird, verdeutlicht Deanna Ferree Womack im dritten Kapitel ihrer voraussichtlich im März 2015 fertiggestellten Dissertation unter dem Titel Conversion, Controversy, and Cultural Production: Syrian Protestants, American Missionaries, and the Arabic Press, 1870-1914.

$7 \quad$ Khalaf (2001), 34

8 Unter „Orient“ versteht man in jener Zeit nicht nur die Gebiete in Vorderasien, sondern den gesamten von Europa aus gesehenen „Osten“ bis nach China und Indien. Der Begriff wird in dieser Untersuchung mit Rücksicht auf diese geografische Einordnung verwendet.

9 Laut Grafton (2009), 2 ist die Begeisterung für den Orient jedoch viel älter: ,the ,Orient ‘ has always carried a sense of fascination of the mysterious unknown: its people, their customs, and their religions“. Christliche Reisende und Missionare suchen in der Levante häufig nach Spuren aus biblischer Zeit. Die Meinung, dass sich die Region seit 1800 Jahren kaum verändert hat, ist weit verbreitet: „The manners, customs, and dresses of the people at Beyroot served to remind the Christian of the times of Christ, and led back the imagination through the lapse of eighteen hundred years to the thrilling events which transpired throughout the Holy Land. So few are the improvements made in art and agriculture, that one can easily fancy himself in the middle of the first century [...]." Daniel C. Eddy beschreibt hier die Eindrücke Sarah Smiths, der ersten Frau des Missionars Eli Smith: vgl. ders. (1850), 134. 
19. Jh. - mit wenigen Ausnahmen ${ }^{10}$ - sowohl von pietistisch-christlichem Gedankengut geprägt als auch von intoleranten Ansichten über andere Völker. Diese basieren jedoch nicht auf Rassenvorstellungen, was eine viel spätere Erscheinung ist, sondern auf dem Zustand der ,Zivilisierung ${ }^{6}{ }^{11}$ Missionare, Forscher, Kolonialpolitiker, Historiker und Philosophen in jener Zeit sind sich einig: „the rest of the world need[s] civilizing". ${ }^{12}$ Das Christentum spielt dabei für die Missionare natürlich eine tragende Rolle, es ist „,the elixir of the Western civilization“, „[1]ike a tonic, the purer it was the better it worked; and the more one took, the healthier one became." ${ }^{\text {"13 }}$ Einheimische Völker in Übersee sind daher nicht nur fremd, sondern bedürfen in den Augen der Missionare auch in höchstem Maße der rettenden christlichen Botschaft. ${ }^{14}$

Die Einstellung der amerikanischen Missionare der indigenen Bevölkerung Syriens gegenüber weist viele Parallelen zu kolonialen Interessen westlicher Mächte auf. ${ }^{15} \mathrm{Ihr}$ Überlegenheitsdenken und ihre Vorurteile könnten als kulturimperialistisches Vorgehen gedeutet werden. ${ }^{16}$ Die Missionare im Nahen Osten verfolgen jedoch keine politischen Interessen und lehnen dies auch vehement ab, gewisse kulturimperiale Grundeinstellungen können während der gesamten Syrienmission aber nicht abgelegt werden. Daher sollte man, wie SAmIR Khalaf es formuliert, lieber von einer „kulturellen Arroganz“ der Missionare sprechen. Eine politisch gesteuerte Einnahme von Territorien trifft hier sicher nicht zu. Statt einer Dominierung der fremden Kultur zielen Missionen auf eine moralische Umorientierung der Bevölkerung ab, so KHALAF weiter. ${ }^{17}$ Ihre Methoden kann man als ,callously ethnocentric and mindlessly romantic, at times poignantly altruistic and confusedly well-meaning" bezeichnen. ${ }^{18}$

10 Klaus Roeber berichtet bspw. in seinem Aufsatz über die Anfänge der Gossner Mission im 19. Jh. von einem respektvollen Umgang der Missionare mit den Religionen Indiens und dem darin von Anfang an geförderten interkulturellen und interreligiösen Dialog: vgl. Roeber (2012), 339-357. Auch der deutsche Missionar Detwig von Oertzen, der ab 1905 für die Deutsche Orientmission in Mahabad stationiert ist, macht es sich zum Ziel, mithilfe des Studiums der kurdischen Kultur und Sprache Stereotype „,vom ,Räubertum der Kurden“ aufzubrechen oder gar zu überwinden“: vgl. Tamcke (2012), 399.

11 Reeves-Ellington (2013), 126. In seinem Artikel über die sich ab dem 19. Jh. verstärkenden Sichtweisen westlich-evangelischer Christen zur Evangelisierung der Welt bezieht sich Andrew Witmer auf den von Rebecca Goetz hergestellten Zusammenhang, dass westliche Vorstellungen über heidnische Völker später in Konzepte über Rassen münden: vgl. Rebecca Anne Goetz, The Baptism of Early Virginia: How Christianity Created Race, Baltimore 2012, zitiert in: Witmer (2014), 896.

12 Bonk (1989), 239.

13 Ebd., 244.

14 Nielssen u. a. (2011), 10.

15 Homi Bhabha spricht hierbei von der „Festgestelltheit“ im kolonialen Diskurs, das Andere wird starr dargestellt, Stereotype werden dämonisch wiederholt: vgl. ders. (2000), 97. Mehr über die enge Verbindung zwischen europäischem Kolonialismus und missionarischer Arbeit in Afrika und Asien in: Bonk (1989), 91-155.

16 So Tibawi (1966), Hutchinson (1987) und Makdisi (2008).

17 Khalaf (2001), 116-117. Semaan $(1986,33)$ bezeichnet es ebenfalls als „cultural aggression of a very subtle kind“.

18 T. O. Beidelmann, Colonial Evangelism, Bloomington 1982, o. S., zitiert in: Khalaf (2001), 117. 
Missionare und Syrer ${ }^{19}$ treffen sich in einem besonderen sozialen Raum, den MARY LoUISE PRATT contact zone nennt: „[W]here cultures meet, clash, and grapple with each other, often in contexts of highly asymmetrical relations of power" ${ }^{20}$ Es gehört zu den Merkmalen der contact zone, dass der darin stattfindende Dia$\log$, auch wenn er fruchtbar sein mag, selten harmonisch verläuft. Die Missionare treten in diesen Raum keinesfalls mit der Einstellung ein, unvoreingenommen gegenüber dem Fremden aufzutreten, anderen Völkern gleiche Rechte zuzusprechen oder einzusehen, dass andere in der Lage sind, gleiche Fähigkeiten und Fertigkeiten wie man selbst zu entwickeln. Worte wie „Integration“ oder „religiöse Koexistenz“ stehen noch in weiter Ferne. Oder, um es mit Wanis SemaAns Worten zu sagen: Es gibt, angesichts des kommenden Millenniums und der Notwendigkeit zahlreicher Bekehrungen, keine Zeit für Analysen und Reflektionen über „what [is] culturally conditioned in their message and what [is] universally valid and true “. ${ }^{21}$ Amerika blickt auf eine junge Geschichte zurück, in der man mit den Ureinwohnern wenig tolerant umgegangen ist und deren Kultur als nicht erhaltenswert erachtet hat. ${ }^{22}$ Die Überzeugung der jungen Amerikaner als Auserwählte für die Etablierung ihres jungen Staates berufen zu sein, vermittelt ihnen das Gefühl, dass außerhalb ihres Bereichs Heidentum, Unwissenheit und Unzivilisiertheit herrschen. Das schlägt sich auch in der religiösen Erweckungsbewegung in den USA nieder: Besonders die neuenglischen Missionare im 19. Jh. fühlen sich zur Verbreitung ihrer Botschaft berufen. ${ }^{23}$

Neben Handelsreisenden, Forschern und Diplomaten gelten Missionare als cultural brokers (Kulturvermittler), ,who actively or deliberately transfer cultural messages or contents to a different environment" ${ }^{24}$ Diese Bezeichnung, die sich zunehmend in der Forschung zu interkulturellen Begegnungen in der Geschichte durchsetzt, ${ }^{25}$ trifft voll und ganz auf Missionare zu, deren Absicht es ist, wichtige Bestandteile ihrer Kultur zu vermitteln, indem sie Menschen einer anderen Kultur neue Interpretationen von Religiosität und Kenntnisse in verschiedenen Wissensbereichen nahebringen. In gleicher Weise ist das, was sie durch Feldforschung und Lebenserfahrung in der fremden Kultur zu Papier bringen, für Leserinnen und Leser in der Heimat zugänglich. Die Kulturvermittlung findet demnach in beide Richtungen statt.

Die in der jüngeren Forschung häufig aufkommende Frage, inwiefern die Missionare in Syrien kulturimperial und kolonial gehandelt haben, ist meines Erachtens

19 Zur Verwendung dieser Bezeichnung siehe Abschnitt 7 in der Einleitung.

20 Pratt (1991), 34; dies. (2008), 8: Zwar ist contact zone gleichbedeutend mit „,colonial frontier“, jedoch ist letzterer Begriff nur aus der europäischen Perspektive verständlich, während zur contact zone verschiedene Perspektiven gehören, d.h. auch die der außereuropäischen Teilhabenden.

21 Semaan (1986), 2.

22 Lindner (2009), 33: Sich als Amerikaner zu identifizieren, bedeutet ab dem 18. und 19. Jh. weiß und protestantisch zu sein. 1830 beschließt der Supreme Court, dass nur europäischstämmige Bürger Amerikaner seien. Damit wird der Ausschluss der Ureinwohner legitimiert (ebd., 38). Semaan (1986), 32.

24 Höh/Jaspert/Oesterle (2013), 9.

25 Koschorke (2012), 197. 
eine sehr einseitige Herangehensweise. ${ }^{26}$ Das soll keinesfalls bedeuten, dass dieser Aspekt, wie bereits erwähnt, außer Acht gelassen werden kann. Den Bildungssektor aufzubauen, gar zu dominieren, ist eine für diese Zeit durchaus übliche Methode europäischer Länder. So kann über einen längeren Zeitraum ökonomisch Einfluss auf ein Land genommen werden, statt eine militärische Besetzung binnen kurzer Zeit zu erzwingen. ${ }^{27}$ Der ABCFM wehrt sich aber von Anfang an gegen die Vorwürfe, koloniale Interessen der USA zu vertreten und ist sich der kulturimperialen Konnotationen missionarischen Handelns durchaus bewusst. Aus diesem Grund arbeitet man mit den Jahren verstärkt daran, weniger imperial aufzutreten und den Fokus allein auf das Predigen zu legen. ${ }^{28}$ Die Berichte, Briefe und Tagebücher, die die Missionare in ihrem Arbeitsfeld verfassen, enthalten in den Augen heutiger LeserInnen oftmals abfällige Beschreibungen der einheimischen Bevölkerung. Diese Beobachtungen geschehen jedoch aus dem Blickwinkel eines Menschen, der an seine Umwelt nur die eigenen Maßstäbe anlegen kann. Was die Missionare in der Heimat erfahren haben, wird im Missionsfeld als richtungweisend empfunden und universalisiert. ${ }^{29}$ Allerdings ist in Bezug auf den Umgang mit handschriftlichen Korrespondenzen der Missionare der ideologische Einfluss des American Board nicht zu unterschätzen: Durch Veränderungen der Wortwahl und gezielte Textkürzungen werden die Missionarsberichte im Missionary Herald oder in anderen Publikationen eingearbeitet, wie in dieser Untersuchung noch an einigen Stellen zu sehen sein wird. Dies geschieht oftmals vor dem Hintergrund, das amerikanische Lesepublikum von der fortlaufenden Notwendigkeit von Missionen im Ausland zu überzeugen und großzügige Geldgeber nicht zu verlieren.

Es sind die Missionare, die den Amerikanern philologisch, geografisch, historisch und kulturwissenschaftlich vermitteln, was den Vorderen Orient ausmacht. Sie prägen die Orientalistik in den USA nachhaltig und bilden über viele Jahrzehnte die erste und einzige Informationsquelle für fremde Kulturen. ${ }^{30}$ Man kann sagen, dass sie die ersten Diplomaten ihres Landes sind. Dabei ist es nicht selten im Bereich der Mission, dass sie als ,ambassadors for Christ ${ }^{\text {“ } 31}$, wie sie sich selbst oft bezeichnen, eine Liebe für Land und Leute entdecken. Das Engagement mancher amerikanischer Missionare reicht an einigen Stellen weit über ihren Aufgabenbereich hinaus

26 So auch bei Semaan (1986), 2: „Had the missionaries been historically and culturally conscious, they would have understood better and would have attempted to understand the histories and the cultures of the societies to which they went. [...] But alas, they were conditioned only of their own culture and not of its conditional nature."

27 Scholz (1997), 16-17.

28 Harris (1999), 96. Amerikanische Missionare werfen ihren französischen Kontrahenten sogar vor, durch ihre Arbeit eine imperiale Einflussnahme auf die Levante zu schüren: Lindner (2009), 134.

29 Semaan (1986), 3.

30 Die neuen Kenntnisse über die arabische Welt führen an zahlreichen Universitäten in Europa und Nordamerika zur Einführung des Faches Orientwissenschaft. Vgl. z.B.: Mangold, S., Eine ",weltbürgerliche Wissenschaft" - Die deutsche Orientalistik im 19. Jahrhundert (= Pallas Athene: Beiträge zur Universitäts- und Wissenschaftsgeschichte 11), Stuttgart 2004, 29-63.

31 MH 20 (1824), in: ROS 1, 235. 
und findet nicht immer Unterstützung vom ABCFM. Dieser Gesichtspunkt ist eine wichtige Voraussetzung für die hier erbrachte Analyse eines Kulturdialogs.

Die Auswahl der im Folgenden näher dargestellten Personen Eli Smith (18011857), Cornelius Van Dyck (1818-1895), Buțus al-Bustānī (1819-1883) und John Wortabet (1827-1908) hat sich durch ihre beeindruckenden Biografien und dem im Vergleich zu anderen einfacheren Zugang zu Quellenmaterial und Sekundärliteratur ergeben. Eli Smith und Cornelius Van Dyck treten durch ihre außergewöhnlichen Fähigkeiten in der arabischen Sprache sowie ihr Engagement im Bildungsbereich und in intellektuellen Kreisen Syriens hervor. Der berühmte syrische Gelehrte Buțrus al-Bustān̄̄ sowie John Wortabet, armenisch stämmiger Syrer, Ziehkind der Mission und später erfolgreicher Theologe und Mediziner, wachsen aus dem Arbeits- und Wirkungskreis von Smith, Van Dyck und ihren Kollegen heraus. Ihre Lebenswege sind ohne den Einfluss der amerikanischen Missionare undenkbar, auch wenn die Besonderheit dieser Persönlichkeiten darin besteht, sich ihnen nicht untergeordnet, sondern mit einem kulturell erweiterten Erfahrungshorizont erfolgreiche Karrieren erreicht zu haben.

\section{VORAUSSETZUNGEN DES TRANSKULTURELLEN DIALOGS}

In der jüngeren forschungsgeschichtlichen Entwicklung spielt das Phänomen der „Transkulturation“ eine zunehmend bedeutende Rolle. Es beschreibt „Prozesse der Übersetzung, Adaption, Neubildung und Aneignung“ in der Begegnung unterschiedlicher Kulturen, die harmonisierend aber auch widersprüchlich verlaufen können. ${ }^{32}$ Die Vielschichtigkeit der Transkulturationsprozesse trifft in jedem Fall auch auf die Begegnung der amerikanischen Missionare mit Syrerinnen und Syrern im Osmanischen Reich zu. Die interkulturelle Begegnung, die schließlich zu verschiedenen Dialogsituationen führt, wird durch diverse Beweggründe geleitet, mit der jeweils anderen Kultur in Kontakt zu treten: Der kulturelle Kontext der jungen Amerikaner, die sich für die Mission im Nahen Osten berufen fühlen, ist alles andere als der eines europäischen Großstädters des 19. Jh.s. Sie kommen häufig aus kleinen Städten, ihre schulische Ausbildung ist christlich geprägt und sie gelten als sehr fromme, höchst ambitionierte junge Missionare. Viele von ihnen haben eine universitäre Ausbildung genossen, die in jener Zeit nur zwei Prozent aller Amerikaner vorbehalten ist. ${ }^{33}$ Auch das Christentum hat noch einen besonderen Stellenwert: In den nordamerikanischen Staaten ist die Bibel fester Bestandteil des Unterrichts in den Schulen, die zu Beginn des 19. Jh.s noch unter kirchlicher Obhut stehen. ${ }^{34}$

„From our childhood our idea of the Christian religion has been identified with education, social order, and a certain correctness of morals and manners, in other

32

33

34

Khalaf (1994), 54-55; ders. (2001), 181.

Die staatliche Übernahme des Bildungsbereichs wird in Neuengland erst ab 1852 durchgesetzt: vgl. Morison (1956), 59. 
words, with civilization“"35, äußert Rufus Anderson, Chefsekretär des ABCFM. ${ }^{36}$ Jeder soll lesen und schreiben lernen, um eine religiöse Bildung zu erhalten und den für sich vorgesehenen Weg einschlagen zu können. ${ }^{37}$ Bildung bedeutet daher für die Amerikaner, religiöses und sachliches Wissen zu vereinen, sich aber auch nicht allein auf das Wissen über die Religion zu beschränken. ${ }^{38}$ Das Eine ist ohne das Andere nicht möglich oder führt auf Irrwege. Dieser Stellenwert des Wissens begleitet die Missionare selbstverständlich auf ihrer Reise in die Levante und bei der Gründung der ersten Missionsschule 1824. Im osmanischen Syrien finden die Amerikaner bei vielen Menschen Gehör und haben vor allem deshalb Erfolg im Bildungsbereich, weil politische Veränderungen und soziale Bedürfnisse, die immer besser artikuliert werden können, den Weg dafür ebnen. Die Provinz Syrien stellt, wie CHRISTINE LiNDNER es nennt, eine ,dynamische Umgebung“ dar. ${ }^{39}$

Der Ausbau der Häfen und die Öffnung der Märkte für transkontinentale Handelsaktivitäten fördern die Globalisierung und bilden dadurch eine Grundlage für politische und kulturelle Umbrüche, und das nicht nur im Osmanischen Reich, sondern auch in anderen Ländern Asiens und Afrikas. ${ }^{40}$ „It is not the Napoleonic invasion nor the Egyptian occupation in itself that brought about the racial transformation, but the opening of the way for cultural inflow that counted." ${ }^{\text {"4l }}$ Es findet ein Kulturdialog statt, weil die Amerikaner im Laufe der Jahre lernen müssen, dass sie nur durch respektvolles Verhalten zum Erfolg gelangen können. Ihre Dialogbereitschaft rührt zu Beginn allein von ihrer christlichen Überzeugung her. Andererseits erweisen sich syrische Christen und Muslime verschiedener Konfessionen ${ }^{42}$ für die Möglichkeiten, die die neue Religion bietet, als sehr gesprächsbereit. Ihre Motive, in den Dialog zu treten, sind häufig nicht nur religiöser Natur: Die Hoffnung auf eine bessere Zukunft, Auseinandersetzungen mit der eigenen Familie oder Chancen auf beruflichen Erfolg spielen ebenso eine Rolle. Nichtsdestotrotz ist der Anschluss an die neue protestantische Gemeinschaft mit Opfern verbunden: Die syrische Gesellschaft als kulturelle Einheit gibt es noch nicht. Tradition und Zusammengehörigkeitsgefühl sind an die Religion der Eltern gebunden. Protestantische Konvertitinnen und Konvertiten sind daher auch bereit, für ihre neu gewonnene Überzeugung bisher gekannte kulturelle Grenzen zu überschreiten. jede Familie dazu verpflichtet ist, ihren Kindern und ihren Bediensteten die Unterweisung im Lesen und Schreiben, in christlicher Lehre und den wichtigsten Gesetzen des Landes zu ermöglichen: vgl. Morison (1956), 66. Öffentliche Schulen werden jedoch in Massachusetts erst um 1820 eingeführt: vgl. Lindner (2009), 50.

38 Lindner (2009), 138.

39 Ebd., 105.

40 Conrad (2012), 999-1027.

41 Hitti (1957), 453.

42 Welche konfessionellen Gruppen sich besonders von der missionarischen Botschaft angesprochen fühlen, wird in der Einleitung zu Kapitel I erläutert. 


\section{FORSCHUNGSSTAND}

In den 1980er Jahren ist eine Tendenz zu verzeichnen, die Geschichte der Missionen aus postkolonialer Perspektive und in Gender-Studien scharf zu kritisieren und auch zu stereotypisieren. Im vergangenen Jahrzehnt ist man jedoch dazu übergegangen, ethnografische Schriften individuell zu betrachten und auch indigene Quellen hinzuzuziehen (Doumato, 2002). Es gilt, den einheimischen Mitarbeiterinnen und Mitarbeitern eine eigene Stimme zu verleihen, da ihre Einflüsse auf die Leistungen der Mission erheblich sind. Die Auswertung missionarischer Quellen obliegt heute nicht mehr nur der Missionswissenschaft, sondern ist auch für andere Bereiche wie für die Soziologie, Kulturwissenschaft oder Geografie interessant geworden. Es ist notwendig, den historischen und gesellschaftlichen Kontext des jeweiligen Missionslandes zu berücksichtigen, um die missionsgeschichtlichen Ereignisse besser verstehen zu können. Die Missionswissenschaft wird daher zunehmend im Rahmen der Interkulturellen Theologie wahrgenommen. ${ }^{43}$ Jeder Fachbereich hält seine eigenen Fragestellungen für die Handlungen und Auswirkungen westlicher Missionare in Übersee bereit. Nicht selten haben Missionare im Missionsfeld Pionierleistungen vollbracht, die sie nicht nur als Theologen, sondern auch als Geistes- und Naturwissenschaftler im Allgemeinen ausweisen. Missionsgeschichte versteht sich daher heute auch als Kultur- bzw. „Profangeschichte“, die verschiedene Blickwinkel einnehmen muss. ${ }^{44}$

Im Jahr 2010 fand in Zusammenarbeit des Lehrstuhls für Religions- und Missionswissenschaft sowie Ökumenik der Humboldt-Universität zu Berlin und der Berliner Gesellschaft für Missionsgeschichte eine internationale Konferenz zum Thema „Missionsgeschichte als Globalgeschichte. Transkulturelle Wissensaneignung und -vermittlung durch christliche Missionare in Afrika und Asien im 18. und 19. Jahrhundert“ in Berlin statt. ${ }^{45}$ Sie zeigte, ,dass auch die in anderen historischen Disziplinen diskutierten Fragen nach der Globalisierung der Welt im 18. und 19. Jahrhundert von der Missionshistoriographie mit interessanten Themenstellungen aufgegriffen worden sind“" ${ }^{46}$

Missionarische Bildungseinrichtungen, so die Organisatoren der Konferenz Ulrich VAN DER Heyden und ANDREAS FeldTKeller, sind Orte (oder contact zones) ${ }^{47}$, in denen westliche Bildungsinhalte mit denen der jeweiligen fremden Kultur verschmelzen und „daraus etwas für beide Seiten Neues“ entsteht. ${ }^{48}$ Wissen wird dabei erzeugt und transformiert, weshalb ,die missionarischen Bildungseinrichtungen als Knotenpunkte einer beginnenden Globalisierung von Wissen" betrachtet werden können. ${ }^{49}$

Hock (2011), bes. 21-23.

Rzepkowski (1995), 270-275.

Ebenfalls 2010 organisierte die Universität Zürich ein internationales Symposium unter dem Titel „Europe in China - China in Europe: Science and Technology as a vehicle to inter-cultural dialogue“. Vgl. dazu Widmer (2012).

Heyden/Feldtkeller (2012), 11.

Pratt (1991), 34; Marten (2011), 305.

Heyden/Feldtkeller (2012), 11.

Ebd., 12. 
Ein Überblick über die sehr umfangreiche Sachliteratur, die sich mit dem ABCFM beschäftigt und zahlreiche Chronologien der Syrienmission darstellt, kann an dieser Stelle nicht gegeben werden und ist auch nicht Ziel der Untersuchung. Wichtige Arbeitsgrundlagen bieten zum einen die von Kamal Salibi und YusuF KHOURY 1995 neu herausgegebenen Reports from Ottoman Syria, die dem Missionary Herald von 1819 bis 1870 entnommen wurden. Zum anderen stellt RuFus ANDERSON 1872 eine zweibändige History of the Missions of the American Board of Commissioners for Foreign Missions to the Oriental Churches zusammen, die die Syrienmission in den Kontext der Nahostmissionen einbindet und somit einen Vergleich zu anderen Missionen und ihrem Verlauf bietet. Der ebenfalls mit dem ABCFM verbundene amerikanische Missionar THOMAs LAURIE verfasst mit seinem umfangreichen und bedeutenden Werk Ely Volume (1881) eine übersichtliche Darstellung missionarischer Beiträge für die Naturwissenschaften, Geografie, Bibelübersetzung, Geschichte, Medizin u.v.m. Missionare tragen dadurch in jedem Fall zur gesellschaftlichen Erneuerung (regeneration) bei, wie LAURIE im Folgenden näher beschreibt:

Our missionaries go abroad to impart all that is good in our Christian civilization to other lands. In diffusing our ideas of the true office of government they secure the rights of the people and kindle a spirit of patriotism where previously it was unknown. [...] They carry our free popular education to quicken intellectual life; bring out to view the inherent evil of vice, slavery, and polygamy; elevate men's ideas of comfort, and so promote industry; they lift up woman from her degradation to her true place in the family; and so work out a nobler destiny for man wherever they go, even in this present life. ${ }^{50}$

Die erste und bisher auch einzige ausführliche, deutschsprachige Darstellung der amerikanischen Missionen im Orient erhält man durch Peter KAWERAU (Amerika und die Orientalischen Kirchen, 1958), ${ }^{51}$ der die theologischen und historischen Ursprünge nordamerikanischer Missionsarbeit und eine Chronologie der Ereignisse in den Nahostmissionen des ABCFM ausführlich darstellt. In der Hoffnung, ,Zeugnisse eines ursprünglichen und unverderbten Christentums“ ${ }^{\text {“ }} \mathrm{zu}$ finden, unternehmen die Missionare landeskundliche Studien, die die amerikanische Orientwissenschaft beeinflussen. ${ }^{52}$ Ähnlich wie in der Studie des palästinensischen Historikers Abdul Latif Tibawi aus dem Jahr 1966 (American Interests in Syria, 1800-1901) werden auch bei KAWERAU das über das Missionsziel hinausgehende kulturelle und soziale Engagement der Missionare nicht im Detail behandelt - eine Lücke, die die hier vorgelegte Arbeit anhand von Beispielen schließen möchte. TIBAwIs Studie schildert nichtsdestotrotz die kulturelle Arbeit der Amerikaner in Syrien viel ausführlicher als KAWERAU. Er will mit dem Vorurteil aufräumen, die Missionare hätten mit dem Druck von klassischer, arabischer Literatur zur Wiederbelebung

50 Laurie (1881), 473.

51 Julius Richter hat mit dem zweiten Band seiner Allgemeinen Evangelischen Missionsgeschichte aus dem Jahr 1930 zwar den Grundstein für die deutschsprachige Erforschung der Missionsarbeit im Orient gelegt, jedoch wird die amerikanische Mission in seinem Werk nur sehr oberflächlich behandelt: Richter (2006).

52 Kawerau (1958), 413-424. 
eines lang vergessenen arabischen Erbes beigetragen. ${ }^{53}$ TIBAWI grenzt sich damit von George Antonius' Untersuchung The Arab Awakening. The Story of the Arab National Movement (1938) ab, die in den verschiedenen Ereignissen westlicher Missionsarbeit und ägyptischer Besatzung die Wiege für die „rehabilitation of the Arabic language as a vehicle of thought" ${ }^{* 54}$ sieht. Den amerikanischen höheren Bildungseinrichtungen in Syrien misst Antonius zu Recht einen großen Beitrag zur Verbreitung von Wissenschaft und Literatur bei:

The educational activities of the American Missionaries in that early period, had among many virtues, one outstanding merit; they gave the pride of place to Arabic, and once they had committed themselves to teaching in it, put their shoulders with vigour to the task of providing an adequate literature. ${ }^{55}$

Abdul Latif Tibawi leitet ab den sechziger Jahren des vergangenen Jahrhunderts einen neuen Trend in der missionsgeschichtlichen Forschung über das 19. Jh. ein. Von nun an sind auch kritische Stimmen zu hören, die die Methoden analysieren, mit denen Amerikaner syrische Konvertiten zu Predigern ausbilden sowie kulturelle und wissenschaftliche Arbeit durchführen. Die Amerikaner vermitteln nicht nur die evangelische Glaubenslehre, sondern stellen sich auch als kulturell überlegen dar. TIBAWIs bereits genannte Studie von 1966 zeigt, dass der ABCFM gegenüber seinen Nachwuchspredigern absichtlich eine Hierarchie aufrecht erhalten will, die es einheimischen Predigern unmöglich macht, mit den amerikanischen Kollegen gleichbereichtigt zu arbeiten. Ussama MAKDISI, Professor an der Rice University in Houston, untersucht seit vielen Jahren die amerikanisch-missionarischen Tätigkeiten im Nahen Osten. In seinem 2008 erschienenen Buch Artillery of Heaven. American Missionaries and the Failed Conversion of the Middle East beschreibt MAKDISI das voreingenommene Auftreten der Missionare unter ,unzivilisierten und religiös verkommenen" Einheimischen und die damit einhergehende Idealisierung der amerikanischen Kultur und „Orientalisierung ${ }^{“ 56}$ der arabischen Welt. ${ }^{57}$ Kurz nach dem Eintreffen der ersten Missionare, so der Autor, seien die Mädchen und Jungen in den Schulen nach westlichen Maßstäben ,zivilisiert“ worden, eine fremde Kultur wird ihnen also anerzogen. MAKDISI stellt fest, dass man sich bisher zu sehr auf die amerikanische Seite der Geschichte konzentriert und dabei die vielfältigen, auch indigenen Quellen missachtet habe. Mit Faith Misplaced: The Broken Promise of

53 Tibawi (1966), 252-253: Schließlich hat es bereits vor der American Mission Press in Beirut andere Druckerpressen in Syrien gegeben. Im Laufe des 19. Jh.s haben sich vor allem Druckereien in Kairo und Istanbul durch den Druck klassischer Literatur einen Namen gemacht. Näheres dazu in Abschnitt I.1.1.

54 Antonius (1938), 40.

55 Ebd., 43.

56 Makdisi verwendet diesen Begriff im Sinne von Edward Saids Werk Orientalism (1978), in dem es um die seit Jahrhunderten bestehende verzerrte Darstellung der Länder im Nahen Osten und Asiens aus dem Blickwinkel der westlichen Welt geht. Eine ausführliche Analyse des USamerikanischen Orientlismus in der Literatur und Gesellschaft bieten: Malinie Johar Schueller, U.S. Orientalisms. Race, Nation, and Gender in Literature, 1790-1890, Ann Arbor ${ }^{4} 2001$; Heike Schäfer, America and the Orient, (= American Studies - A Monograph Series 130), Heidelberg 2006.

57 Makdisi (2008), 13. 
U.S.-Arab Relations: 1820-2001 (2010) setzt MAKDISI die Grundlagen, die er in Artillery of Heaven gelegt hat, fort. Die Syrienmission und ihr historischer Rahmen werden in den gesamtpolitischen Kontext arabisch-amerikanischer Beziehungen eingebunden. Im Mittelpunkt steht das Bild, das sich die arabische Welt im Laufe der Zeit von Nordamerika gemacht hat. Der Dialog zwischen den USA und dem Nahen Osten hat, vom heutigen Standpunkt aus betrachtet, nicht militärisch, sondern christlich ambitioniert begonnen. Die Missionare ,set in motion a long process of interaction between Americans and Arabs that gave birth to the first great idea of America in the Arab world". ${ }^{58}$ Trotz einer Reihe von Missverständnissen, die es im Laufe der Jahrzehnte zwischen beiden Kulturen gegeben hat, will MAKDISI zeigen, dass es sich bei den Veränderungen im Nahen Osten, die aufgrund westlichen Einflusses bereits im 19. Jh. begonnen haben, nicht um eine reine Adaption westlicher Ideen in der arabischen Welt handelt.

In seinem Sammelband Cultural Resistance: Global and Local Encounters in the Middle East (2001) bezeichnet der bereits erwähnte libanesische Soziologe Samir Khalaf die Vorgehensweise der Syrienmission in Sachen Bildung, Hilfsprogrammen und sozialer Anbindung als ,silent penetration“ oder „,cultural penetration“. Formen des „kulturellen Eindringens“, so KHALAF, „reach deeper into the ,soul of native societies" than the essentially , utilitarian economic and political forms of imperialism“" 59 Begleitet von christlicher Nächstenliebe und geringer kultureller Sensibilität vertreten die Missionare die Pflicht „to spread a nation's vision of society and culture to an alien and often subjected people“, 60 auch wenn sie sich zum Teil bewusst sind, dass man dabei einer Entfremdung der Einheimischen von der eigenen Kultur Gefahr läuft. KHALAF betont mehrmals, dass die Ergebnisse missionarischer Arbeit in Syrien letzten Endes weit von den ursprünglichen Intentionen des ABCFM entfernt sind. Sie sind sozusagen ,by-products of both their good intentions and their considerable ignorance of the areas they were seeking to evangelize“. 61

Trotz der Tendenz in der gegenwärtigen Missionswissenschaft, sich mehr und mehr den indigenen Konvertiten zu widmen, gibt es bisher kaum Studien über die Syrienmission, die auch syrischen Protestanten eine Stimme verleihen. Richtungweisend sind die zahlreichen Studien der amerikanischen Historikerin CHRISTINE B. LinDNER zum „Protestant Circle“ im 19. Jh., dem neben ausländischen Mitgliedern auch Syrerinnen und Syrer angehören. In ihrer Dissertation Negotiating the Field: American Protestant Missionaries in Ottoman Syria, 1823-1860 (2009) widmet sich LINDNER einzelnen Charakteren dieser Gemeinschaft und analysiert Netzwerke des Zusammenlebens. Ihr Ziel ist es darin, den Kontext der Begegnungen zwischen Amerikanern und Syrern darzustellen und die daraus entstandenen Beziehungen mit ihren Divergenzen zu analysieren, ,[i]nstead of only positing the question ,was missionary enterprise a tool of imperialism “ “. ${ }^{62}$ Die Amerikaner pflanzen ihrer Mei-

58 Makdisi (2010), 19.

59 Khalaf (2001), 33, 118-119, in Anlehnung an Schlesinger (1974), 365-373.

60 Khalaf (2001), 116.

61 Ebd., 134.

62 Lindner (2009), 5. 
nung nach nicht den amerikanischen Protestantismus in eine sterile und passive Gesellschaft ein. Die Auflösung der iqtā, d. h. des Verwaltungssystems im Libanongebirge, das lokalen Hierarchien in die Hände spielt, die wirtschaftliche Öffnung Syriens sowie die Veränderung der religiösen Identitäten im Laufe des 19. Jh.s spielen dabei eine große Rolle, sodass Syrerinnen und Syrer empfänglich für die Einflüsse der Amerikaner sind. ${ }^{63}$ Durch ihren Schwerpunkt auf der Genderfrage in der Mission zeigen sowohl ihre Dissertation als auch weiterführende Studien über Persönlicheiten wie z. B. Raḥīl 'Atā al-Bustānī ${ }^{64}$ oder Susan Wortabet ${ }^{65}$ einen $^{6}$ bisher völlig unbekannten Blickwinkel auf das Leben von syrisch-protestantischen Frauen im 19. Jh. ${ }^{66}$ Dass diese Frauen ebenso an missionarischer Verkündigungsarbeit sowie an schriftlichen Beiträgen für die Amerikanische Druckerei in Beirut beteiligt sind, zeigt Deanna Ferree Womacks Forschungsbeitrag Arab Women and Protestant Missions: Gendered Practices of Reading, Writing, and Preaching in Ottoman Syria, 1860-1914. ${ }^{67}$ Dieser ist Bestandteil ihrer gerade erst abgeschlossenen Doktorarbeit Conversion, Controversy, and Cultural Production: Syrian Protestants, American Missionaries, and the Arabic Press, 1870-1914.

Den Biografien männlicher syrischer Protestanten in der zweiten und dritten Generation widmet sich MARIA B. ABUNASSR in ihrer Dissertation The Making of Ras Beirut: A Landscape of Memory for Narratives of Exceptionalism, 1870-1975 (2013). Durch Interviews und private Memoiren folgt sie den Spuren von sechs syrischen Protestanten, die ihren Alltag in einem anglo-amerikanisch dominierten Rās Beirut, damals am Stadtrand von Beirut, bestreiten. ${ }^{68}$

Bei der Lektüre der Sekundärliteratur über Eli Smith, Cornelius Van Dyck, Buțus al-Bustān̄̄ und John Wortabet fällt auf, dass sich die Autorinnen und Autoren häufig einem bestimmten Aspekt in deren Leben widmen und ein umfassendes Bild über Lebensumstände, Konflikte und Freundschaften kaum erkennbar wird: Dagmar Glaß weist auf Smiths wichtige Rolle im Druck arabischer Literatur im Nahen Osten hin (Malta, Beirut, Leipzig and Beirut Again: Eli Smith, the American Syria Mission and the Spread of Arabic Typography in 19th Century Lebanon, 1998). Die Entwicklung des neuen arabischen Buchstabensatzes für die Amerikanische Druckerei in Beirut (American Arabic Type) hat Einfluss auf die Verbreitung arabischen Buchdrucks innerhalb und außerhalb Syriens sowie auf ,the emergence of Arabic periodicals, newspapers, but more to what we are now used to calling magazines. This is why Smith's endeavours in the spread of Arabic typography take on such a special meaning“. ${ }^{69}$ Der amerikanische Pfarrer RoBERT D. STODDARD, JR.

63 Ebd., 264.

64 Lindner (2014a). Rahīll ist die Ehefrau von Buțus al-Bustānī.

65 Die Ergebnisse dieser Studie werden beim Historikertag in Göttingen (September 2014) präsentiert. Susan Wortabet ist John Wortabets Mutter.

66 Vgl. auch Lindner (2011b) oder die beachtenswerte Recherche zu den syrisch-protestantischen Familien im 19. Jh: Lindner (2014b).

67 Ein gleichnamiger Vortrag wurde von ihr im Rahmen der Yale-Edinburgh Konferenz im Juni 2014 zum Thema „Gender and Family in the History of Missions and World Christianity“ gehalten.

68 Abunassr (2013), 132-183.

69 Glaß (1998a), 29. 
zeigt in seiner kurzen Studie The Rev. Eli Smith, 1801-1857: Evangelical Orientalist in the Levant (2009), dass Eli Smith durch seine Landes- und Sprachstudien als erster amerikanischer Orientalist in der Levante gelten kann, der für seine Nachfolger bereits einen hohen Maßstab gesetzt hat. Bis auf die in der Arbeit zu untersuchenden Quellen des ABCFM und einige biografische Notizen existieren keine weiteren thematischen Studien über diesen außerordentlichen Missionar in Syrien.

Zahlreicher gestaltet sich die Sekundärliteratur zu Cornelius Van Dyck, dem sich auch etliche arabischsprachige Autoren gewidmet haben. ${ }^{70} \mathrm{Er}$ ist aufgrund seiner Lehrtätigkeit am Syrian Protestant College ${ }^{71}$ sowie seiner Arbeit an verschiedenen Lehrbüchern bis heute eine bekannte Persönlichkeit im Libanon. Nach LUTFI M. SA'DIs Aufsatz von 1937 Al-Hakim Cornelius Van Alen Van Dyck (1818-1895) widmet sich der libanesische Historiker YūsuF QASMĀ Hū̃ōi in seiner Magisterarbeit von 1965 Al-Duktur Kurnilyus Fān Dayk wa nahḍa al-diyār al-šāmīya al- 'āmīya fì qurn al-tāsi' 'ašar (Dr. Cornelius Van Dyck und die Nahda im gesamten Syrien im 19. Jh., Neudruck: 1990) vor allem den wissenschaftlichen Errungenschaften Van Dycks. Gleiches unternimmt Dagmar GLAß in ihrem Aufsatz Der Missionar Cornelius van Dyck (1818-1895) als Lehrbuchautor und Förderer des arabischen Wissenschaftsjournalismus (1998). Van Dyck steht mit etlichen Protagonisten der syrischen nahḍ in Kontakt und trägt zur Förderung ihrer wissenschaftlichen Karrieren bei. GLAß sieht ihn als ,the most valuable and effective single influence ever exerted by a foreigner in the cultural development of the country “. 72

Über einen der einflussreichsten Intellektuellen in Syriens 19. Jahrhundert, den Gelehrten Buṭus al-Bustānī, gibt es zahlreiche Biografien und Forschungsbeiträge. ${ }^{73} \mathrm{Zu}$ den neuesten Werken zählt der von AdEL Beshara Ende 2014 herausgegebene Sammelband englischsprachiger Beiträge zu Bustān̄̄. Neben bereits bekannten Aufsätzen von AlBERT HourANI ${ }^{74}$ und STEPHEN SHEEHI ${ }^{75}$ bietet er auch neue Analysen von Bustānīs Reden und veröffentlichten Werken, die verdeutlichen, dass Bustān̄̄ den „Geist seines Zeitalters“ geprägt und viele Denker über das 19. Jahrhundert hinaus beeinflusst hat. ${ }^{76}$ ABDUl Latif TiBawi (The American Missionaries

70 Z.B. Mațar (1966); Tafīlì (2007).

71 Siehe dazu Abschnitt I.1.5 und II.2.4.

72 Glaß (1998b), 185.

73 Zu nennen wären hier bspw. die Dissertationen von John W. Jandora (1981) und Yūsuf Q. Hūrī (1995), sowie die Studien: Ğān Dāya, Al-mu 'allim Buțrus al-Bustānī. Dirāsa wa wațā 'iq (Der Gelehrte Buṭrus al-Bustānī. Studien und Dokumente (= Silsila Fağr al-Nahḍa 1), Beirut 1981; Fāris Qays, Ațar al-mu 'allim Buṭrus al-Bustānī fì nahḍa al-wațan̄̄ya fì Lubnān (Der Einfluss des Gelehrten Buṭus al-Bustānī in der Kulturbewegung des Libanon), Beirut 2005. Erstere drei Autoren stellen in ihren Arbeiten Quellenmaterial zur Verfügung, das bis dato schwer zugänglich war.

74 „Bustani’s Encyclopedia“.

75 „Butrus al-Bustani's Nafir Surriyah and the National Subject as Effect“.

76 Beshara (2014). Es steht außer Frage, dass es bisher an einem Aufsatzband über Būtrus alBustānī, der bisherige und aktuelle Forschungsergebnisse bündelt, fehlte. Jedoch ist bezüglich dieses Bandes kritisch anzumerken, dass von den Autorinnen und Autoren kaum Briefe von Bustānī, sei es an Missionare, den ABCFM oder das SPC berücksichtigt worden sind. Stattdessen bezieht man sich in vielen Fällen auf vergangene Auswertungen der Historiker Abdul Latif Tibawi und Ussama Makdisi. 
in Beirut and Butrus al-Bustani, 1963) sowie Ussama MaKdisi (Artillery of Heaven, 2008) haben sich erstmals kritisch mit der Rolle Bustānīs in der Mission und den durch die Zusammenarbeit gewonnenen Einflüssen auf den syrischen Gelehrten auseinandergesetzt. Für Tibawi ist „Bustānī’s story [...] an excellent example of the outcome of a successful and balanced interaction of Western ideas and methods with Arabic ideas and methods" ${ }^{77}$ während Makdisi näher auf die Differenzen zwischen dem gelehrten Protestanten und seinen amerikanischen Kollegen eingeht. Bustānīs ökumenische Einstellung ist zwar eher eine arabisch-amerikanische Synthese als nur arabisch oder nur amerikanisch, aber seine Vorstellung von einer friedlichen Koexistenz in Syrien steht unter der Prämisse einer säkularen Gesellschaftsstruktur, bei der die Nationalität in den Vordergrund und die religiöse Zugehörigkeit in den Hintergrund treten. Bustānī hat eine überaus positive Einstellung gegenüber kultureller Begegnung. Dies spiegelt sich inhaltlich auch in seinen Lexika und den von ihm herausgegebenen Journalen wider. Laut DAGMAR GLAß (Butrus al-Bustani [1819-1883] als Enzyklopädiker der arabischen Renaissance, 2008) findet in diesen Werken ein „doppelte[r] Transfer“ statt, d.h. durch „Zugriff auf westliches Fremdwissen und [...] Rückgriff auf orientalisches Eigenwissen“, auch wenn die dafür verwendeten Quellen europäischer und arabischer Literatur heute kaum mehr rekonstruierbar sind. ${ }^{78}$

Anders als Bustān̄ bleibt John Wortabet in der Forschung über die Syrienmission eine eher unbekannte Größe. Keine Studie hat sich bisher dem syrischen Protestanten und Mediziner ausführlich gewidmet. LINDNER (Negotiating the Field, 2009) führt die Wortabet-Familie erstmals in ihrer Dissertation ein und benennt Erfahrungen und Engagement in den jeweiligen Phasen amerikanischer Missionsarbeit. Mit einer weiteren Lebensphase Wortabets als Missionar in Aleppo beschäftigt sich der schottische Religionswissenschaftler und Historiker MiCHAEL MARTEN in seiner Untersuchung Attempting to Bring the Gospel Home. Scottish Missions to Palestine, 1839-1917 (2006). Von großer Bedeutung für das Verständnis der biografischen Stationen des armenischen Syrers sind die darin zitierten Briefauszüge Wortabets an die schottische Missionsgesellschaft, die im Zuge der Recherche auch persönlich eingesehen wurden.

\section{ZIELE DER ARBEIT}

Mehr als ein halbes Jahrhundert haben Missionare und ihre einheimischen Helfer in Syrien gearbeitet. Es soll daher die umfassende kulturelle Zusammenarbeit anhand der vier ausgewählten Personen exemplarisch dargestellt werden. Meines Erachtens zählen Smith, Van Dyck, Bustānī und Wortabet zu den interessantesten und einflussreichsten Protagonisten der amerikanisch-syrischen Begegnung. Jeder

77 Tibawi (1963), 182.

78 Glaß (2008), 123-124. Mit der Frage der Rekonstruierbarkeit verwendeter Quellen beschäftigt sich auch der an der Freien Universität Berlin studierende Arabist Michel Qabalan in seiner bald fertiggestellten Dissertation „The Da' irat al-Ma'ārif of Butrus al-Bustani: Encyclopedic Visions from the late Ottoman Levant". 
von ihnen hat einen großen Beitrag dazu geleistet, modernes Wissen und kulturelles Erbe in Syrien zu vereinen, natürlich mit jeweils eigenen Schwerpunkten und Nuancen.

Zahlreiche Forschungsarbeiten, die die Syrienmission missionsgeschichtlich darstellen, haben deutlich gemacht, dass noch viele offene Fragen bestehen und einige Aspekte oft nur oberflächlich untersucht wurden. Vor allem in den vergangenen 20 Jahren haben sich immer mehr Missionswissenschaftler, Historiker, Arabisten und Sozialwissenschaftler mit der Arbeit der Amerikaner im Osmanischen Reich und ihren Auswirkungen beschäftigt - das Thema scheint brisanter denn je. Viele dieser Studien haben zur Konkretisierung der hier behandelten Fragestellungen beigetragen und werden daher zum einen in diese Untersuchung eingearbeitet und zum anderen ergänzt oder weitergeführt.

Während Van Dyck und Bustānī zumeist im Zusammenhang mit der im 19. Jh. in Syrien (und Ägypten) sich vollziehenden Kulturrenaissance, der nahda ${ }^{79} \mathrm{Er}-$ wähnung in der o.g. Sekundärliteratur finden, sind Smith und Wortabet selten Gegenstand missionsgeschichtlicher Untersuchungen. Vor allem Letzterer soll hier erstmals ausführlich dargestellt und damit eine Lücke in der Forschung zur amerikanischen Syrienmission geschlossen werden.

Anhand dieser Untersuchung ist zu zeigen, dass die Ergebnisse missionarischer Arbeit nicht unbeabsichtigte ,Nebenprodukte' des Zusammenspiels von missionarischen Intentionen und kultureller Ignoranz sind, wie KHALAF es beschrieben hat (s. o.). Missionare haben zum einen häufig unterschiedliche Meinungen über die von der Missionsgesellschaft propagierte Praxis. Sie müssen daher als individuelle Akteure berücksichtigt werden ${ }^{80}$ Zum anderen sind die kulturellen Beiträge solch vielseitig interessierter Missionare alles andere als zufällig. Sie haben im Gegenteil einen großen Einfluss auf die syrische Kulturrenaissance (nahda). Diese Art von ,außerplanmäßigem ${ }^{81}$ Engagement lässt die Diskrepanzen zwischen einigen Missionaren vor Ort und der Verwaltung in Boston klar hervortreten, ein Aspekt, der bisher kaum näher betrachtet wurde. Theorie und Praxis sind in der Syrienmission keine konformen Größen. Die von Anderson beschriebenen Ziele können in Syrien nicht auf die gleiche Weise umgesetzt werden, wie in den folgenden Kapiteln noch $\mathrm{zu}$ sehen sein wird.

79 Merkmale und Meilensteine der nahda werden in Abschnitt I.2.5 ausführlich erläutert.

80 Wolcott an Anderson (Beirut, 1.6.1842): ABC 16.5., Vol. 3: ,There is union among us in sentiment, but there is also difference and divergence - particularly in respect to forms, organizations, adaptions etc. The destruction is generic - affects the tastes, habits, feelings and principles; - is partly original, and partly the result of circumstances. Both classes of sentiments [...] are founded on a large experience."

81 Anderson mahnt dazu 1845 an: ,[T] $[$ he missionary prepares new fields for pastors; and when they are thus prepared, and competent pastors are upon the ground, he ought himself to move onward [...]. And whatever may be said with respect to pastors, it is true of the missionary, that he is to keep himself as free as possible from entanglements with literature, science, and commerce, and with questions of church government, politics and social order." Vgl. Rufus Anderson, The Theory of Missions to the Heathen, A Sermon at the Ordination of Mr. Edward Webb, as a Missionary to the Heathen. Ware, Mass., Oct. 23, 1845, Boston 1845, zitiert in: Beaver (1967), 76 . 
Darüber hinaus gilt es in dieser Arbeit zu zeigen, dass die Begeisterung für Wissen und dessen Verbreitung sowohl den ausgewählten Missionaren wie ihren syrischen Kollegen zukommt und die Missionare dies nicht als Alternative zur misslungenen Bekehrungsarbeit gesehen haben.

Durch die Darstellung von Leben und Werk der Missionare Eli Smith und Cornelius Van Dyck sowie der syrischen Protestanten Buṭrus al-Bustānī und John Wortabet soll verdeutlicht werden, dass oftmals persönliche Verbindungen ausschlaggebend für eine interkulturelle Zusammenarbeit sind. Selbst wenn diese Verbindungen durch Tod, Konflikte oder räumliche Distanz aufgebrochen werden, ist eine dauerhafte Wirkung auf das Leben der syrischen Protestanten und amerikanischen Missionare erkennbar.

\section{INHALTLICHER ÜBERBLICK}

Im ersten Kapitel dieser Arbeit sollen wichtige Aspekte der Mission sowie der kulturelle und historische Kontext in Syrien verständlich gemacht werden. Dabei spielen nicht nur die Institutionalisierung missionarischer Arbeit in Form von Gemeindegründungen, Schulen, Hochschulen und einer Druckerei, sondern auch historische Ereignisse im Osmanischen Reich sowie soziokulturelle Veränderungen eine Rolle. Diese Elemente stehen in einem unmittelbaren Zusammenhang und können nicht als unabhängig voneinander betrachtet werden. Im zweiten Kapitel stellt sich die Frage, was Eli Smith und Cornelius Van Dyck dazu angetrieben hat, bis an die Grenzen der Belastbarkeit mit einem beispiellosen Arbeitseifer an Übersetzungen, arabischem Buchdruck und wissenschaftlicher Lehre zu arbeiten. Es soll die Besonderheit sowie die Motivation dieser beiden Persönlichkeiten, als cultural brokers aufzutreten, dokumentiert werden. Ihre Beiträge für Wissen und Wissenschaft können schließlich nicht hoch genug eingeschätzt werden. Das dritte Kapitel widmet sich den syrischen Protestanten innerhalb des Begnegnungsraumes, der contact zone. In den Schriften der Missionare treten diese häufig in den Hintergrund, obwohl sie Adressaten der Mission sind. Beispielhaft für ein Leben mit den Missionaren, aus deren Schatten sie schließlich heraustreten, sind die Biografien von Buṭrus al-Bustān̄̄ und John Wortabet. Es wird gezeigt, welchen Einfluss die Zusammenarbeit mit den Amerikanern auf diese beiden erfolgreichen Gelehrten hat. Kann der Kulturdialog mit ihnen als gescheitert angesehen werden, weil beide schließlich ihre eigenen Wege gehen?

Nach einer Zusammenfassung der Ergebnisse dieser Arbeit werden in Anhang I die literarischen Beiträge der vier ausgewählten Personen für die amerikanische Missionsdruckerei erstmals in dieser Konstellation aufgelistet und mit einem Kommentar versehen. Die dargestellten arabischen Bücher sind entweder Übersetzungen, Kompositionen von verschiedenen Werken anderer Autoren oder selbstverfasste Schriften, die angesichts ihres Umfangs und ihrer Rezeption als bemerkenswert gelten können. Da in den Veröffentlichungen der Missionsdruckerei häufig nur die Missionare als Herausgeber genannt werden, Autorenangaben gänzlich fehlen 
oder die häufig im Team ${ }^{82}$ erarbeiteten Übersetzungen syrische Helferinnen und Helfer nicht erwähnen, kann diese Auflistung nicht den Anspruch auf Vollständigkeit erheben.

Zahlreiche syrische Protestanten und Syrer, die für die Mission gearbeitet haben, jedoch nicht konvertiert sind, d. h. die von der Mission als native helpers oder native assistants bezeichneten Personen, werden in dieser Arbeit Erwähnung finden. Anhang II bietet daher die Möglichkeit, mehr über den biografischen Hintergrund dieser Menschen zu erfahren, über die mangels Quellen fast nichts bekannt ist. Auf diese Weise sollen Persönlichkeiten, die häufig im Schatten der Missionare stehen, sowie die Rollen, die sie innerhalb der syrisch-protestantischen Gemeinschaft erfüllen, in den Vordergrund treten.

\section{HINWEISE ZUR QUELLENLAGE UND DEN METHODOLOGISCHEN SCHRITTEN}

Wie bereits oben dargestellt, kann aus einer Vielzahl von aktuellen Studien und Analysen geschöpft werden, die es hier zu ergänzen gilt. Im Zuge der Recherchen für diese Untersuchung ist jedoch deutlich geworden, dass es an privaten Schriftdokumenten wie persönlichen Briefen an Familie, Freunde und Kollegen fehlt. Einzig der Nachlass von Eli Smith, der bisher nicht ausführlich aufgearbeitet wurde, ist vielversprechend. Im Rahmen dieser Arbeit konnten im Archiv des ABCFM, betreut von der Harvard University in Cambridge/USA, seine Dokumente und Briefe an Kollegen und Freunde in englischer und arabischer Sprache eingesehen und ausgewertet werden. Die Yale University besitzt darüber hinaus Smiths privaten Nachlass, in dem sich zahlreiche Briefe an seine Familie befinden. ${ }^{83}$ Eine zusätzliche Bearbeitung dieser Quellen hätte eine eigene, umfangreiche Untersuchung speziell zu Eli Smith nach sich gezogen. Bedauerlicherweise befindet sich im Archiv des ABCFM keine Sammlung von persönlichen Briefen von Cornelius Van Dyck, was jedoch nicht ausschließt, dass es solche gegeben hat. Auch mehrmalige Recherchen im Libanon haben wenig Persönliches über Van Dyck, Bustān̄̄ oder Wortabet zutage gebracht. Eine Rekonstruktion wie Smith, Van Dyck, Bustān̄̄ und Wortabet miteinander agiert haben, kann aufgrund der Quellenlage nur teilweise erfolgen. Vor allem anhand von Van Dycks Briefen an den ABCFM lassen sich sein persönlicher Werdegang sowie seine Standpunkte hinsichtlich westlicher Missionsstrategien nachzeichnen. Mithilfe der Lehrbuchliteratur, die er auf Arabisch

82 Smith an Anderson (Beirut, 13.3.1856): ABC 60 (105), (HHL). Originale Dokumente des ABCFM, die in der Harvard Houghton Library zugänglich sind, werden mit „,(HHL)“ gekennzeichnet, alle anderen Dokumente dieses Archivs wurden auf Mikrofilm eingesehen (siehe auch Bibliografie).

83 Siehe Yale Divinity School, Special Collections, Eli Smith Family Papers, Record Group 124, URL: http://drs.library.yale.edu:8083/saxon/SaxonServlet?style=http://drs.library.yale.edu: 8083/saxon/EAD/yul.ead2002.xhtml.xsl\&source=http://drs.library.yale.edu:8083/fedora/get/ divinity:124/EAD\&big $=\& a d v=\& q u e r y=\% 2522$ Eli\%20Smith $\% 2522 \&$ altquery $=\&$ filter $=\&$ hitP ageStart $=1 \&$ sortFields $=\&$ view $=$ all. (Stand: August 2013) 
verfasst hat, der Zeitungsartikel, die er in arabischen Periodika veröffentlicht hat sowie anhand von Äußerungen syrischer Zeitgenossen wird die persönliche Entwicklung Van Dycks während seines über fünfzig Jahre andauernden Aufenthaltes in Syrien erkennbar.

Ohne Zweifel sind die von Bustānī verfassten Schriftstücke sowie die über ihn bisher erschienene Sekundärliteratur sehr umfangreich. Im Rahmen dieser Untersuchung wurden die zentralsten Texte einbezogen und auf die Verhältnisbestimmung von Bustānī und dem ABCFM bzw. der anglo-amerikanischen protestantischen Gemeinde hin untersucht. Es ist bedauerlich, dass der persönliche Nachlass dieses großen Denkers des 19. Jh.s verschollen oder womöglich durch Kriege in dieser krisengeschüttelten Region zerstört worden ist. Durch Recherchen in den USA und im Libanon konnten zumindest wenige private Briefe und offizielle von Bustānī verfasste Korrespondenzen ausgewertet und erstmals übersetzt werden. An dieser Stelle können hoffentlich zukünftige Bemühungen heute noch lebender Mitglieder der Bustānī-Familie mehr ans Licht bringen.

Einen Einblick in den Konflikt zwischen John Wortabet und dem ABCFM, weswegen er zur schottischen Mission nach Aleppo wechselt, bieten etliche Briefe von Wortabet sowie die Protokolle der United Presbyterian Church of Scotland, zugänglich in der National Library of Scotland, Edinburgh/Großbritannien. Durch die wenigen Briefe Wortabets an den ABCFM sowie durch zahlreiche Berichte über ihn von amerikanischen Missionaren bzw. Lehrenden oder Verantwortlichen am SPC können seine Biografie und die damit verbundenen Hürden, denen Wortabet in seinem Leben ausgesetzt ist, erstmals zusammengetragen werden.

Will man sich mit evangelischen Missionsunternehmungen im Nahen Osten eingehender beschäftigen, so beherbergen die Archive an der American University of Beirut und vor allem an der Near East School of Theology wertvolle originale Dokumente, die bisher nur zu einem kleinen Teil digitalisiert und damit der Öffentlichkeit zugänglich gemacht wurden. ${ }^{84}$ Die Recherchen in beiden Archiven ergaben wertvolle Ergebnisse für diese Untersuchung.

Als weitere Quellen zur Untersuchung, inwiefern die Amerikaner in der syrischen Gesellschaft aufgenommen werden, dienen die Dokumente der syrischen Zeitzeugen, die durch die amerikanischen Bildungseinrichtungen zu bekannten Autoren und Journalisten geworden sind (Ğurğ̄ Zaydān, ${ }^{85}$ Gregory Wortabet, ${ }^{86}$

84 Beide Institutionen widmen sich seit einigen Jahren der Digitalisierung und Aufarbeitung ihrer Archive. Das Medizinische Institut der AUB unterhält seit 2011 eine Homepage, die auch medizinische Bücher von Missionaren sowie das am Syrian Protestant College (s. Abschnitt I.1.5) herausgegebene medizinische Journal al-Tabīb (der Arzt) zur Verfügung stellt: URL: http:// www.aub.edu.lb/sml/resources/Pages/HistoricalCollection.aspx (Stand: Mai 2014). Seit 2012 besteht an der N.E.S.T. das Projekt Preserving Protestant Heritage in the Middle East, das ForscherInnen zukünftig den Zugang zu einzigartigen Quellen der Geschichte des Protestantismus im Nahen Osten ermöglichen will: URL: http://protestantheritagenest.omeka.net (Stand: Mai 2014).

85 Zaydān studiert am Syrian Protestant College und gibt zahlreiche literargeschichtliche Werke heraus.

86 Nennenswert ist die zweibändige Monografie des Bruders von John Wortabet zu Syria and the Syrians (1856). Näheres zu Gregory Wortabet in Anhang II, Nr. 66. 
Fāris Nimr, Ya 'qūb Șarrūf, ${ }^{87}$ Habīb R.A. Effendi ${ }^{88}$ oder As'ad Y. Hayāṭ ${ }^{89}$ ). Nur vereinzelt finden sich im Archiv des ABCFM Briefe der native helpers, die, wie bereits angedeutet, zwar zur Zielgruppe der Mission gehören, häufig aber nicht selbst zu Wort kommen. Die rege Schreibtätigkeit Bustānīs und Wortabets bietet daher einen Einblick in die Gedankenwelt syrischer Protestanten im 19. Jh.

Die wichtigsten arabischsprachigen Quellen sowie relevante Sekundärliteratur konnten durch eigene Erarbeitungen ${ }^{90}$ oder durch die im Rahmen des DFGForschungsprojektes von Tarek Abboud ${ }^{91}$ angefertigten Übersetzungen in diese Untersuchung einbezogen werden. Es ist bedauerlich, dass Zeugnisse wie die von Amerikanern und Syrern verfassten Reden für die „Syrische Gesellschaft der Wissenschaften und Künste" oder die von Bustān̄̄ (in ihrer Botschaft immer noch aktuellen) verfassten elf Pamphlete Nafir Surīya (Syriens Weckruf) bisher in keiner veröffentlichten Übersetzung zugänglich sind.

\section{HINWEISE ZUR TRANSLITERATION VON EIGENNAMEN UND GEOGRAFISCHEN BEZEICHNUNGEN}

Das Transliterationssystem arabischer Namen, Ortsnamen, Buchtitel und Zitate richtet sich nach den Empfehlungen der Deutschen Morgenländischen Gesellschaft von 1935, die in einigen Fällen mehrere Optionen vorschlagen. ${ }^{92}$ In dieser Arbeit wird bspw. der Artikel al- vor sogenannten Sonnenbuchstaben nicht assimiliert, sondern ausgeschrieben (z.B. al-Surīya statt as-Surīya). Auf die Transliteration von Beirut als Beyrūt wird verzichtet und die im Deutschen übliche Schreibweise bevorzugt. Alle weiteren Ortsnamen entsprechen dem genannten Transliterationssystem. Namen von arabischen Autoren, deren Studien in englischer Sprache veröffentlicht wurden, werden nicht transliteriert, sondern gemäß der Autorenangabe wiedergegeben (z. B. Tibawi). Anders ist es im Fall eines arabischen Werkes (z. B. Zaydān). In den Quellen des ABCFM ist es üblich, die Namen syrischer Protestanten zu anglisieren bzw. nach unterschiedlichen Methoden zu transliterieren. Somit wurde Yuhannā Wurtabāt stets als John Wortabet geschrieben, seine Mutter Sardas wurde von den Missionaren häufig Susan genannt. Soweit die Recherchen es zulas-

87 Nimr und Șarrūf lehren beide am Syrian Protestant College. Sie werden ab 1876 die Herausgeber der berühmten Zeitschrift al-Muqtataf (die Auslese). Näheres dazu in Abschnitt I.2.5 sowie Anhang II, Nr. 62.

88 Als Befürworter protestantisch-kultureller Einflüsse in Syrien beschreibt der für einige Zeit in England lebende Syrer in seinem Reisetagebuch die Gepflogenheiten seiner Heimat (The Thistle and the Cedar of Lebanon, 1853).

89 In seinem Werk $A$ Voice from Lebanon, with the Life and Travels of Asaad Y. Khayat (London 1847) berichtet Hayāt, dass er mit zwölf Jahren bei den Missionaren Isaac Bird, William Goodell und Pliny Fisk Italienisch und Englisch gelernt habe. „, $[\mathrm{Mr}$. Bird] and his pious and accomplished lady were like parents to me.“ Ebd., 34-36. Mehr zu Hayāṭ in Anhang II, Nr. 35.

90 Sofern nicht anders angegeben, basieren die Zitate aus arabischsprachiger Literatur auf eigenen Übersetzungen.

91 Zitate aus den Übersetzungen von Herrn Abboud werden mit ,(TA)“ gekennzeichnet.

92 Brockelmann u. a. (1935). 
sen, wird in dieser Arbeit eine korrekte Transliteration des arabischen Namens zu finden sein. Besonders in Anhang II sind jedoch nicht vollständige bzw. fehlerhafte Namen syrischer Protestanten aufgrund der mangelnden Quellenlage möglich. Im Fall von John Wortabet wird die englische Variante beibehalten, da sie sich auch in der Sekundärliteratur durchgesetzt hat.

Da diese Arbeit im Fach Evangelische Theologie verfasst ist und sich zudem an ein breiteres Lesepublikum wendet, werden arabische Eigennamen sowie Titel von Quellen- und Sekundärliteratur zugunsten eines besseren Verständnisses im Textverlauf und in der Bibliographie in Klammern übersetzt.

Wie bereits oben erwähnt, bezieht sich das im Titel dieser Arbeit genannte geografische Gebiet Syrien nicht auf die heutige Arabische Republik Syrien, sondern auf die osmanische Provinz Syrien. Ab der zweiten Hälfte des 19. Jh.s ersetzt der geografische Name Sürīya (Syrien) die bisher verwendeten Beschreibungen für den osmanischen Verwaltungsbereich Bilād al-Šām, Barr al-Šäm oder auch 'Arabistān. 1865 werden die im 16. Jh. aufgeteilten, syrischen Provinzen Damaskus, Aleppo und Tripoli wieder zu einer großen zusammengelegt: der wilāyat Sürīya. ${ }^{93}$ Auch die Missionare sprechen ausschließlich von Syrien, wobei sie sich damit jedoch auf das biblische ${ }^{94}$ bzw. antike Syrien beziehen. ${ }^{95}$ Der Libanon, auf dessen heutigem Gebiet die Missionare maßgeblich aktiv sind, erhält im Laufe des 19. Jh.s zwar zunehmende Verwaltungsautonomie von Instanbul ${ }^{96}$, die auf diesem Gebiet lebenden Araber bezeichnen sich aber in keinem Fall als Libanesen, wie fälschlicherweise in mancher Sekundärliteratur zu lesen ist. Der Begriff Syrien wird im 19. Jh. immer mehr zum Begriff einer nationalen Identität. Um sich lokal von anderen Regionen des Osmanischen Reichs abzugrenzen, sehen sich die dort lebenden Menschen als „Syrer" (sūrī), wobei jedoch die religiöse Herkunft der christlichen und muslimischen Denominationen weiterhin identitätsstiftend bleibt. ${ }^{97}$ Ausgehend von ihrem Selbstverständnis als syrische Araber im Osmanischen Reich werden die Adressaten der amerikanischen Mission in dieser Untersuchung als Syrerinnen und Syrer bezeichnet.

93 Hitti (1959), 214; Rabinovich (1992), 43.

94 Z.B. Mt 4, 24; Lk 2, 2; Apg 15, 41.

95 Fruma Zachs geht sogar soweit zu sagen, dass die Missionare das Konzept „Syrien“ maßgeblich prägen: vgl. dies. (2001a), 147-155. Die Nationalismus-Bewegung ist aber vielschichtiger und lässt sich auf eine Folge von historischen Ereignissen zurückführen, die mit der wachsenden Unabhängigkeit der Region von der Hohen Pforte zusammenhängen. Den Missionaren kann daher nicht eine so weit reichende Einflussnahme zugestanden werden.

96 In den Quellen des ABCFM ist stets von Konstantinopel die Rede, im Arabischen wird in Bezug auf die Stadt sowohl von Konstantinīyā als auch Istambūl gesprochen. Da sich Istanbul in jener Zeit im Volksmund immer mehr durchsetzt, wird dieser Name hier beibehalten.

97 Zachs (2005). 


\section{KAPITEL I}

\section{DIE MISSION DES ABCFM IN DER OSMANISCHEN PROVINZ SYRIEN (1819-1870)}

Bereits im 16. und 17. Jh. ist die Levante Reiseziel westlich-protestantischer und -katholischer Geistlicher, die mit Schiffen europäischer Händler bzw. während und nach den Kreuzzügen die östliche Mittelmeerküste erreichen. Darunter befinden sich dominikanische und franziskanische Mönchsorden, anglikanische Kaplane der Church of England, die sich über 200 Jahre in Aleppo niederlassen und schließlich Jesuiten, die zwischen dem 17. und ausgehenden 18. Jh. als Fürsprecher des Christentums bei den unter der osmanischen Herrschaft geschwächten orientalischen Christen auftreten. ${ }^{1}$ Als der britisch-levantinische Handel gegen Ende des 18. Jh.s zum Erliegen kommt, müssen auch die Kaplane Aleppo wieder verlassen. ${ }^{2}$ Für die Jesuiten bedeutet die französische Revolution das Ende ihrer Mission Anfang des 19. Jh.s. ${ }^{3}$ Als sie nach etwa drei Jahrzehnten wieder in den Nahen Osten zurückkehren, werden sie von den katholischen Patriarchen in der Region mit einem neuen Auftrag bedacht: Die Jesuiten sollen sich der Ausbildung von Priestern widmen, um den Expansionsbestrebungen der Protestanten entgegenzuwirken. ${ }^{4}$ Bevor sie 1831 in Beirut eintreffen, haben sich bereits seit etwa einem Jahrzehnt protestantische Missionen aus England ${ }^{5}$ und Nordamerika in der arabischen Welt etabliert.

,[T] he whole mingled population [of Western Asia] is in a state of deplorable ignorance and degradation - destitute of the means of divine knowledge "6 , so erklärt es 1819 das Prudential Committee, der beratende Ausschuss des American Board of Commissioners for Foreign Missions, kurz ABCFM. Die Menschen in Westasien, so das Komitee weiter, müssen gerettet werden, indem man den dortigen Christen, Juden, Muslimen und Heiden die Gnade und Gunst Gottes „,by means of preachers, cate-

1 Murre-van den Berg (2006a), 4-5; Verdeil (2006), 23. Die anglikanischen Kaplane sind von 1597 bis 1782 in Aleppo stationiert. Erst eine kürzlich begonnene Studie des Australiers Andrew Lake über die ersten protestantisch-missionarischen Bestrebungen im Nahen Osten ruft in Erinnerung, dass protestantische Missionare in der arabischen Welt nicht erst im 19. Jh. aktiv werden: vgl. Lake (2013), 39-49.

2 Ebd., 47.

3 Murre-van den Berg (2006a), 4-5; Verdeil (2006), 23.

4 Daccache (2005), 698. Daher richtet sich die Mission der Jesuiten weniger an Muslime, sondern will die mit Rom unierten Kirchen gegen die Protestanten stärken: vgl. Verdeil (2006), 30.

5 Die Church Missionary Society ist zunächst in Palästina tätig, um dann 1860 eine Mission in Syrien aufzubauen: Hitti (1957), 448. Die United Presbyterian Church of Scotland unterhält in der zweiten Hälfte des 19. Jh.s ebenfalls eine Missionsstation in Aleppo. Näheres dazu in Abschnitt III.2.3.

6 MH 15 (1819), in: ROS 1, 6. 
chists, schoolmasters, and the press" verkündet. ${ }^{7}$ Mit Pliny Fisk und Levi Parsons sendet der ABCFM 1819 die ersten amerikanischen Missionare mit dem Auftrag in die Levante, die Menschen im Heiligen Land und seinen angrenzenden Regionen zum „wahren Glauben“ zu führen und die geografischen und kulturellen Bedingungen vor Ort zu studieren. Die Adressaten der amerikanischen Verkündigungsarbeit sind vor allem Juden, Muslime und „nominale Christen“, wie Menschen genannt werden, die zwar dem Namen nach Christen sind, deren religiöse Kenntnisse und Praktiken aber weit vom Christsein nach westlichem Verständnis abweichen. ${ }^{8}$ Für die Missionare sind die fundamentalen Glaubensunterschiede in Bezug auf Lehren und Zeremonien (z. B. Bilder- und Heiligenverehrung, Heilszuspruch durch Befolgung der Gesetze, Transsubstantiationslehre) inakzeptabel und müssen korrigiert werden. ${ }^{9}$ Die Verbreitung des Wortes Gottes soll das oberste Ziel der Mission sein. Denjenigen, die damit zum ersten Mal in Berührung kommen - darunter auch Christen -, bietet sich die Möglichkeit einer erlösenden Wiedergeburt. Als Pliny Fisk und Levi Parsons sowie ihre späteren Kollegen in Richtung Mittelmeer reisen, treibt sie ein rein christliches Motiv an: Fernab von dem Wunsch, den Arabern die weltlichamerikanische Lebenskultur aufzuzwingen, gilt es auf das Ende der Zeit hinzuarbeiten. Das „uneigennützige Wohlwollen“ (disinterested benevolence) und die für Puritaner typische postmilleniaristische Einstellung (d.h. das Kommen Christi nach dem Anbruch des Millenniums) sind die Pfeiler missionarischen Handelns unter den „verlorenen Seelen“.${ }^{10}$ Für die göttliche Vorsehung des kommenden Reiches genügt jedoch nicht allein die spirituelle Reformation, ,intellectual progress, and great social improvement" gelten als nützliche Begleiterscheinungen und zählen somit zu wichtigen Merkmalen des „missionarischen Zeitalters“. Durch sie kann der Weg zum Millennium bereits im Diesseits geebnet werden. ${ }^{11}$ In der als „Zivilisationsmission" bezeichneten Methodik, die sich ab Ende des 18. Jh.s durchsetzt, gehören „Erziehung, Wissenschaft [und] Kultur“ zu den Bestandteilen der missionarischen Botschaft. ${ }^{12}$ Es verwundert daher nicht, dass kulturelle Einflüsse aus Neuengland in vielerlei Hinsicht in die Missionsarbeit in der Levante eingehen.

Als Missionsgebiet sollen zunächst Teile der osmanischen Provinz Syrien vom Mittelmeer im Westen bis Damaskus im Osten und Jerusalem im Süden abgedeckt werden. Palästina und das Gebiet des heutigen Syriens werden 1843 an andere Missionsgesellschaften abgegeben, sodass sich der ABCFM in seiner Missionsarbeit auf die Gebiete zwischen Tripoli im Norden und Tyros im Süden sowie vom Mittelmeer bis nach Homs, Aleppo und Damaskus konzentriert. ${ }^{13}$ Der geografische Schwerpunkt liegt also nahezu auf dem Gebiet der heutigen Republik Libanon.

7 ABCFM (1835), 6; MH 15 (1819), in: ROS 1, 6.

8 Anderson (1872a), $x$.

9 Walker (1967), 217.

10 Theologisch gründet sich der ABCFM auf Samuel Hopkins (1721-1803) und sein Werk System of Doctrines. Sünde bedeutet demnach Selbstliebe und Eigennutz. Wer sündlos handeln möchte, führt ein Leben im Sinne der disinterested benevolence: vgl. Hopkins (1811), 291-297.

11 ABCFM (1853), 3; Boyer (1999), 140.

12 Trepp (2010), 239.

13 Laurie (1866), 3. 
Aufgrund politischer Spannungen und der häufig auftretenden Pest wird Jerusalem in dieser Zeit immer wieder verriegelt, wodurch sich der Aufbau einer festen Missionsstation im Heiligen Land fortwährend verzögert. ${ }^{14}$ Der frühe Tod Levi Parsons' am 10. Februar 1819 und der Plan des American Board, in der Levante endlich Fuß zu fassen, veranlassen dazu, Isaac Bird und William Goodell im Jahre 1823 nach Syrien zu entsenden. Sie sollen eine Missionsstation in Beirut etablieren, die zunächst als Sprungbrett für eine weitere Station in Jerusalem dienen soll, zu der es jedoch nicht mehr kommt. ${ }^{15}$ In den folgenden Jahren der Syria Mission sollen es noch 84 weitere Missionare und Missionarsfrauen, Assistentinnen sowie Missionsärzte werden, die Schulen für Mädchen und Jungen eröffnen, Internate gründen, den theologischen Nachwuchs fördern und den Weg für höhere Bildungsinstitutionen in Syrien ebnen. ${ }^{16}$

So wie in den Missionen des American Board in Armenien, unter den Nestorianern und Assyrern des heutigen Irak und Iran, unter den Juden in Anatolien und kurzzeitig in Palästina sowie unter den Bulgaren vermag es die Syrienmission nicht, viele Menschen für den evangelischen Glauben zu gewinnen. Nur Wenige konvertieren oder wollen sich zum Protestantismus öffentlich bekennen. ${ }^{17}$ In seltenen Fällen, wie der folgende Kommentar aus dem Jahr 1845 zeigt, kommt dies direkt im Missionary Herald zur Sprache. Negative Berichte bergen schließlich die Gefahr, die Glaubhaftigkeit des Missionsunternehmens zu mindern:

Our audiences are usually attentive, but we are obliged to lament that we have had no tokens of any special influences of the Spirit. We can report no additions to the number of our communicants, and there seems to reign around us an almost universal spiritual death. ${ }^{18}$

Sehr bald nach der Ankunft der ersten Missionare in Syrien muss die Zielgruppe auf die dort ansässigen Christen eingeschränkt werden. Die Missionierung unter den Ju-

14 Erneute Versuche der Missionsgesellschaft, den Missionar Thomson ab 1834 mit dem Aufbau einer Station in Jerusalem zu beauftragen, scheitern ebenso. Binnen 20 Jahren, so berichtet der Missionar Bird, haben etwa 20 Missionare ihr Leben in Jerusalem gelassen oder mussten aus der Stadt fliehen: vgl. Bird (1872), 298, 338-339. Nach dem osmanischen Gesetz ist zudem für Ausländer der permanente Aufenthalt in Jerusalem nicht erlaubt: vgl. Tibawi (1966), 189, 204.

15 Für Beirut sprechen die günstige geografische Lage, das gute Klima, die Nähe der Berge für Rückzugsmöglichkeiten im Sommer, die bessere Verbindung zu Europa über den Seeweg und das englische Protektorat, da die USA bis dahin noch keine diplomatischen Beziehungen zum Osmanischen Reich aufgebaut haben: vgl. MH 20 (1824), in: ROS 1, 220.

16 Jessup (1910b), 797-798.

17 Genauere Zahlen werden in den Missionsberichten gar nicht erst genannt. 1863 gehen der Missionar Bird und seine Frau von etwa 1000 Protestanten im Libanon aus: vgl. MH 69 (1863), in: ROS 5, 67-68. Ca. 500 oder 600 von ihnen sind mit der amerikanischen Mission verbunden, die Übrigen mit anderen Missionen (Wortabet, 1860, 413). Jessup (1910b, 641) berichtet, dass es 1897 sogar 7000 Protestanten waren. Zur Ungenauigkeit der Statistik schreibt Wortabet: „We cannot give the names of converts until they are dead or exiled. And to publish the names of the exiled might bring down wrath upon the heads of their relatives." Vgl. ders. (1860), 768. Schließlich drohen orientalischen Christen, die mit dem evangelischen Glauben sympathisieren, die Exkommunikation (z. B. MH 23 [1827], in: ROS 1, 469), der Ausschluss aus der Gemeinschaft (MH 24 [1828], in: ROS 2, 74), ein Handels- und Kaufverbot (MH 24 [1828], in: ROS 2, 23) oder sogar die Todesstrafe (MH 23 [1827], in: ROS 1, 443). 
den, die in Amerika große Unterstützung findet, erweist sich als nahezu unmöglich, ebenso die Bestrebungen, Muslime zum evangelischen Glauben zu bekehren. Die amerikanischen Missionare müssen erkennen, dass die Muslime ihre Religion als eine dem Christentum überlegene ansehen, die zudem durch die politische Führung des Osmanischen Reiches legitimiert wird. ${ }^{19}$ Nicht zuletzt steht auf das Konvertieren vom Islam zum Christentum die Todesstrafe. ${ }^{20}$ Begründet wird die Änderung der primären Zielgruppe damit, dass zuerst der desolate Zustand der orientalischen Christenheit behoben werden müsse bevor man sich den Muslimen widmen könne. ${ }^{21}$ „As corrupted Christianity had no power to check Mohammedanism at its rise, so it has had no tendency since to terminate it", erläutert Eli Smith in einer Predigt um ca. $1833 .{ }^{22}$ Schließlich erweisen sich besonders die Christen als empfänglich für die Missionsarbeit von Protestanten und Jesuiten. Als religiöse Minderheit, die weniger Rechte als die Muslime besitzen und häufig in Armut leben, erhoffen sie sich eine bessere Zukunft durch die neuen Bildungsangebote. ${ }^{23}$ Gleiches gilt für die Drusen, einer muslimischen Randgruppe, die sich durch den Kontakt mit den Amerikanern die Verbesserung der eigenen Lebensumstände erhoffen. Immer wieder berichten Missionare von drusischen Interessenten, die bereit seien zu konvertieren, um auf diese Weise der Militärpflicht zu entgehen und Zugang zu Bildung zu erlangen. ${ }^{24}$

Neben Sprachstudien und dem Aufbau des Missionshauses in Beirut mit weiteren Außenstationen im Umland arbeiten die Missionare in den ersten Jahren sehr enthusiastisch gegen das Unwissen über die Inhalte der Heiligen Schrift unter den einheimischen Christen an. Lesen und Schreiben ist nur wenigen vorbehalten, die Gottesdienste der orientalischen Kirchen werden zumeist in den alten Kirchendialekten abgehalten, sodass deren Inhalte den Gläubigen verborgen bleiben. ${ }^{25}$ Des Weiteren gibt es kaum Bücher, wie der Missionar Henry Harris Jessup im Rückblick schreibt: „Intellectually, the land was in utter stagnation. With the exception of the Koran and its literature among the Moslems, and the ecclesiastical books among the Oriental Christians, there were no books." 26

Eine Tradition des arabischen Buchdrucks gibt es nicht, noch bis zum Ende des 18. Jh.s gilt das Verbot der Hohen Pforte für Muslime - nicht aber für Christen und nicht-muslimische Gruppen ${ }^{27}$-, religiöse Literatur in der als heilig geltenden ara-

Van Dyck (o. J.), 6, 14. Während der ägyptischen Besatzung (siehe Abschnitt I.2.1) sind Drusen und Muslime dazu verpflichtet, den Militärdienst abzuleisten. Vgl. Thomas O'Dea, The Sociology of Religion, Prentice-Hall 1966, 60, zitiert in: Semaan (1986), 93: „[C]onversion - the acceptance of new religions - is itself closely related to the needs and aspirations which are highly affected by the social circumstances of the people involved."

25 MH 20 (1824), in: ROS 1, 266: „,They, worship they know not what““.

26 Jessup (1910a), 27.

27 Aus diesem Grund können Juden im 15. Jh. eine Druckerei in Konstantinopel einrichten: vgl. 
bischen Sprache in gedruckter Form zu verbreiten. ${ }^{28}$ Um ein Buch zu erstehen, das von einem Schreiber (warrāq) abgeschrieben wurde, muss man viel Geld zahlen. Bildung bleibt demnach einer reichen Elite vorbehalten. ${ }^{29}$

In den wenigen Schulen der Christen werden Teile der Bibel, vor allem aber die Psalmen als Lesebuch verwendet. ${ }^{30}$ Durch öffentliche Predigten, Bibelkreise in den eigenen Missionshäusern und vor allem durch die Versorgung mit arabischen Bibeln der Druckerpresse der British and Foreign Bible Society auf Malta in den zwanziger Jahren des 19. Jh.s werden mehr und mehr biblische Schriften und religiöse Traktate kostenlos unter die Menschen gebracht. ${ }^{31}$ Durch diese Begegnungen entstehen erste Dialoge, in denen nicht nur referiert, sondern über verschiedene Meinungen ernsthaft diskutiert wird. ${ }^{32}$ Der nächste Schritt ist der Aufbau von öffentlichen Schulen, deren Besuch allen Religionsgruppen offen sein soll. Muslimische Koranschulen (kutta $a b$ und madrasa $)^{33}$ sowie Grund- und höhere Schulen der jeweiligen christlichen Konfessionen in Syrien sind begrenzt und können kein flächendeckendes Schulangebot garantieren. ${ }^{34}$ An diesem Punkt sehen die amerikanischen Missionare ihre Chance.

Angesichts der Schriftverbreitung und der ersten sichtbaren Erfolge in der Bildungsarbeit bleiben heftige Reaktionen seitens geistlicher Oberhäupter der lokalen Religionsgemeinschaften verständlicherweise nicht aus. ${ }^{35} \mathrm{Hie} ß$ man die Missionare zu Anfang noch willkommen ohne zu ahnen, wozu sie in der Lage sind, so ist man

28 Auch Türkisch fällt unter dieses Verbot: vgl. Salibi (1965), 127-128. Schon ab 1727 darf nichtreligiöse Literatur auch auf Arabisch gedruckt werden, womit die Vormachtstellung religiöser Gelehrter im Bildungsbereich minimiert wird: vgl. Atiyeh (1995), 235.

29 Atiyeh (1995), 235.

30 MH 20 (1824), in: ROS 1, 249-250; MH 21 (1825), in: ROS 1, 318.

31 „Annals of the Syria Mission“, in: ROS 5, 259.

32 Smith (1833), 162-163.

33 Muslimische kuttāa oder auch maktab-Schulen sind Grundschulen, die vor allem in Dörfern und kleinen Städten zu finden sind. Madrasa-Schulen sind darauf aufbauende Lehranstalten, die oft in großen Städten etabliert werden: vgl. Diab/Wåhlin (1983), 108-109. Smith beklagt, der Lehrinhalt dieser Schulen „,was almost entirely limited to their religion, and made them disparage every other species of knowledge, and every source of information not Mohammedan. [...] They even cared not to know any thing of foreign nations; an almost entire ignorance of the geography of Europe was universal“" vgl. Smith (1833), 24. Die kuttää-Schulen sind den Kindern unterer Schichten vorbehalten, während wohlhabende muslimische Familien ihren Kindern Privatunterricht finanzieren. Bildung ist entweder Sache der Familien oder der Religionsgemeinschaft: vgl. Cioeta (1982), 40-41.

34 Salibi (1965), 125: Ende des 18. Jh.s haben von den maronitischen Schulen nur noch die Seminare 'Ayn Warqa und 'Ayn Trāz geöffnet. Tibawi (1966), 68: Mit der ägyptischen Verwaltung ab 1832 werden in Syrien zwar viele Internatsschulen eingerichtet, aber sie sind rein militärisch ausgerichtet und werden von Armeeoffizieren geleitet.

35 Der Missionary Herald dokumentiert jegliche Anfeindungen und Handlungen ausführlich und über viele Jahre: Im Jahr 1826 ergeht bspw. ein Aufruf des maronitischen Patriarchen gegen die Schriften der Missionare (vgl. MH 23 [1827], in ROS 1, 480-482): ,we heard of the arts and the blasphemous innovations of these deceivers, by which they degrade the Christian faith, and bring ruin to the Catholic religion and to the souls of men" (ebd., 481). Die Rum-Orthodoxe Kirche warnt ihre Gemeindeglieder vor den Missionsschulen und vor Konversationen mit den Amerikanern: vgl. MH 24 (1828), in: ROS 2, 9. 
nun über die öffentliche Beleidigung anderer Religionen in Wort und Tat erschüttert. ${ }^{36}$ Vor allem die Christen sehen in der Arbeit der „Biblishiyyün”,37 oder „Biblemen“"38 eine Gefahr für den Bestand ihrer Glaubensgemeinden. Missionare wie Eli Smith und William Goodell plädieren deshalb dafür, respektvoller aufzutreten und nicht durch provozierte Kontroversen gegen Gesetze zu verstoßen: ${ }^{39}$, ,[I]nstead of despising the national customs of the people and endeavoring to change them - in things morally indifferent, we treat them with due regard, and have respect to them in our conduct." 40

Darüber hinaus beginnen die Missionare, sich als Vermittler zwischen den miteinander oftmals verfeindeten Religionsgemeinschaften zu sehen und diese durch den evangelischen Glauben harmonisieren zu wollen: „But the task is, to fuse into one harmonious, evangelical church, these diverse and intensely antagonistic elements; to draw them into fraternal and confiding unity. "41 Diplomatische Bemühungen der Amerikaner, die manchmal zu Beschwichtigungsversuchen zwischen zwei zerstrittenen Religionsparteien führen, können ihnen ohne Zweifel auch Anerkennung unter ihren Gegnern verschaffen. ${ }^{42}$ Sie dürfen allerdings nicht darüber hinweg täuschen, dass andererseits anti-muslimische und anti-katholische Polemik in missionarischen Predigten, Traktaten und Stationsberichten religiöse Gemeinschaften vor Ort auch gegeneinander ausspielen. Wer den Amerikanern folgt, wird fortwährend mit diesen Ansichten konfrontiert und macht sie sich z. T. zu Eigen. ${ }^{43}$

36 Makdisi (2010, 30) spricht hierbei von einer Regel, die von allen Religionsgemeinschaften mehr oder weniger respektiert wird: „Do not openly blaspheme or insult other people's religions."

37 Tibawi (1966), 39: Der Begriff ist vermutlich eine Anlehnung an das Wort „Biblizist“ (vgl. „Biblici“ in MH 27 [1831], in: ROS 1, 287) und wird vor allem in den polemischen Reden und Schriften der arabischen Katholiken verwendet.

38 MH 21 (1825), in: ROS 1, 305 uvm. „Bible-men“ als Übersetzung von „Biblishiyyūn“ (s.o.) wird später von den Syrern als allgemeine Bezeichnung der Missionare verwendet, jedoch ohne polemische Konnotation.

$39,[$ W]e are determined not to call them forth into opposition by a proselyting and controversial course“, vgl. MH 26 (1830), in: ROS 2, 205. Es gilt, den Menschen das richtige Wissen zu vermitteln, sodass die Einheimischen im Zuge ihrer, Erleuchtung 'über Kontroversen selbst diskutieren können und dieser Impuls nicht von den Amerikanern ausgeht: so William Goodell im MH 26 (1830), in: ROS 2, 183-184. Badr (1992, 99) schreibt dazu, dass Goodell nicht wie Jonas King die Lehren anderer Kirchen öffentlich attackierte: „Goodell himself was a patient and domestic man." Näheres dazu in Abschnitt II.1.2.

40 So der erste Punkt der Resolution nach einer mehrtägigen, von Eli Smith geleiteten Generalversammlung verschiedener Missionsstationen im Mittelmeerraum von 1836: vgl. „Records of the Syrian Mission“"(22. April 1836, nachmittags): ABC 16.8.1., Vol. 8.1., 11.

41 Dennis (1872), 5; MH 20 (1824), in: $\operatorname{ROS~1,~268:~,preaching~,the~Gospel~of~peace“~to~these~men~}$ of cruelty and blood". McGilvary betont, dass die Schüler verschiedener Konfessionen in den Missionsschulen auf einer Basis von Toleranz und Vertrauen zusammenkommen können, was jedoch wenig Einfluss auf die politischen Unruhen im Land hat: vgl. McGilvary (1920), 19.

42 Sogar Führer verfeindeter Gruppen suchen 1843 Rat im Missionshaus und treffen dort zu gemeinsamen Gesprächen mit der gegnerischen Seite zusammen: vgl. MH 39 (1843), in: ROS 3, 367.

43 Khalaf $(2001,124)$ geht sogar so weit, zu sagen: „In doing so, they contributed, wilfully or otherwise, to sectarian discord." Diese Sichtweise würde eine sehr große Einflussnahme der Amerikaner auf die syrische Gesellschaft beinhalten, was meines Erachtens nicht der Fall ist. 
Im Laufe der Jahrzehnte sind die Missionare mit immer weniger Angriffen von Seiten der Religionsgemeinschaften konfrontiert. Einen großen Beitrag dazu leistet die politische Anerkennung der Protestanten als religiöse Gemeinschaft (millet) im Osmanischen Reich $1850 .{ }^{44}$ Als millet stehen sie unter dem Schutz des Sultans, besitzen mehr Rechte und genießen zudem die Anerkennung durch andere Religionsgemeinschaften.

Nichtsdestotrotz bemühen sich amerikanische Missionare mehr als ein halbes Jahrzehnt darum, nach dem Vorbild der ,Zivilisierung' und Christianisierung, Muster der amerikanischen Gesellschaft im Nahen Osten zu legen. ${ }^{45}$ Laut ABCFM soll der Schwerpunkt zunehmend auf der Predigtarbeit liegen, wobei zivilisierende Maßnahmen in den Hintergrund gestellt werden müssen. Gründe dafür sind zum einen der augenscheinliche Misserfolg im Bereich der Bekehrungsarbeit, ${ }^{46}$ aber auch das steigende Bewusstsein lokaler christlicher Kirchen für die Heilige Schrift, die auf Verlangen der Menschen nun häufiger gelesen und gepredigt wird. ${ }^{47}$ Darüber hinaus führen das immer weniger werdende Interesse an den Missionen sowie die Umstände des amerikanischen Bürgerkriegs (1861-1865) zu einer schwindenden Spendenbereitschaft der Heimatkirchen und Wohltäter, ohne die die Finanzierung von Auslandsmissionen unmöglich wird. ${ }^{48}$ Drastische Etatkürzungen haben daher vor allem Einfluss auf die von den Missionaren aufgebaute Bildungs-Infrastruktur. 1870 sieht sich der American Board gezwungen, die Verwaltung der Syrienmission an den Presbyterian Board of Commissioners for Foreign Missions (PBCFM) abzutreten. $^{49}$

Der erste Teil dieses Kapitels befasst sich mit der Frage, inwiefern die Syrienmission als Erfolgsgeschichte gelten kann. Die Etablierung der Missionsdruckerei,

44 Bereits 1835 erhoffen sich die Missionare unter Einsatz der amerikanischen Konsuln in Beirut und Jerusalem, dass ihnen der Status als millet zugesprochen wird: vgl. Tibawi (1966), 76-77, 109. Jede millet wird durch den jeweiligen religiösen Führer (wakil) verwaltet, der in Sachen Ehe, Scheidung, Erbe und anderen persönlichen Dingen Recht spricht: vgl. dazu Yazigi (1964), 13.

$45 \mathrm{Zu}$ den Punkten Christianisierung und ,Zivilisierung ' vgl. Jahresbericht des American Board von 1816 (hier in Bezug auf die Ureinwohner Amerikas), in: ABCFM (1834), 135.

461882 resümiert jedoch der ABCFM: „It was never contemplated that the missionary work should be continued in the empire till the great body of the people were evangelized." Vgl. ABCFM, Annual Report 1882, „Memorandum for Missions in the Turkish Empire and Recommendations", lxvi-lxxv, zitiert in: Walker (1967), 221.

47 „Report of Hasbeiya Station for the year 1852“": ABC 16.8.1., Vol. 4.1. (165): (Sidon) „The Greek Catholic bishop is not only compelled to preach, but also to preach from the Gospel in order to quiet the new demands of his people." Die neue arabische Bibelübersetzung der Mission wird auch von den orthodoxen Kirchen Syriens verwendet (siehe dazu Abschnitt II.2.3).

48 Grabill (1971), 23; Sharkey (2011), xii: „Not only did American churchgoers have the ,cash surpluses' that enabled them to donate to missions, but they had no embarassment about fund-raising - and even about ,conspicious financing " - when Christian causes were at stake.“

49 Anderson (1872a), viif: Die Missionen, die auch nach 1870 unter der Verwaltung des ABCFM stehen, finden unter den Armeniern, Griechen, Bulgaren, Muslimen und arabischsprachigen Christen der Osttürkei statt. Bis zum Ende des 19. Jh.s wächst auch unter der Leitung des Presbyterian Board die Zahl der Mitarbeiter in Syrien nicht an, es zeichnen sich ähnliche finanzielle Schwierigkeiten wie beim ABCFM ab: vgl. Tibawi (1966), 277. 
die zahlreichen gegründeten einheimischen Kirchengemeinden, die Missionsschulen sowie höhere Bildungseinrichtungen sprechen für sich. Nichtsdestotrotz werden die wenigen Konvertiten zum Dreh- und Angelpunkt von enttäuschten Hoffnungen und Meinungsverschiedenheiten. Die Diskrepanz zwischen Theorie und Praxis zeigt, dass die vom ABCFM angestrebte Missionsstrategie selten aufgeht. Einige Projekte der Syrienmission, wie z.B. der arabische Buchdruck, entwickeln zum Teil eine ungewollte Eigendynamik - ein Umstand, der nicht ohne die Einbettung in den politischen und kulturellen Gesamtkontext von Syrien im 19. Jh. betrachtet werden kann, wie im zweiten Teil dieses Kapitels dargestellt wird. Ab Mitte des 19. Jh.s wird Beirut zum Schauplatz internationaler Interessen, bei denen sich die großen Mächte gegenüberstehen: Großbritannien setzt sich für die Belange der Drusen ein, Frankreich für die mit Rom unierten Christen und Russland für das orthodoxe Christentum. Die Offenheit des Landes gegenüber fremden Einflüssen hat vielschichtige Gründe, die hier näher erläutert werden sollen. Es gilt, die politischen Ereignisse im Abriss darzustellen sowie ein Bild davon zu geben, wie sich der Bildungs- und Kulturbereich fernab von missionarischer Verkündigung entwickelt. Ohne die kulturelle Entwicklung in Syrien wären schließlich auch die Errungenschaften der Syrienmission im Bildungsbereich aufgrund mangelnder Finanzen völlig wirkungslos geblieben.

\section{I.1. DIE AMERIKANISCHE SYRIENMISSION - EINE ERFOLGSGESCHICHTE?}

\section{Die American Mission Press in Beirut}

Für die Amerikaner beginnt das Interesse für gedruckte Werke auf Arabisch erst mit der Arbeit ihrer Missionare in der Levante. ${ }^{50}$ Erste Versuche im 19. Jh., arabische Lettern in amerikanischen Büchern zu drucken, stehen weit hinter dem zurück, was Missionare binnen eines Jahrzehnts in Syrien erreichen. Während der Konferenz der ABCFM-Missionare auf Malta 1829 wird den Missionaren eines klar: ${ }^{51}$ Um ein gewisses Niveau an Schulbildung zu erreichen und dies auf einer soliden Basis aufzubauen, bedarf es großer Mengen von Schulbüchern, die - zumindest was die Ansprüche der Missionare anbelangt - in Syrien zu dieser Zeit noch nicht existieren. Seit 1822 richtet der ABCFM eine Druckerei auf Malta ein, die, von einem strategisch günstigen und politisch sicheren Knotenpunkt aus, alle Missionen im Mittelmeerraum mit Schriftstücken auf Englisch, Neugriechisch, Griechisch-Türkisch sowie Armenisch-Türkisch versorgt. ${ }^{52}$ Da die Amerikaner erst ab 1829 einen aus London kommenden arabischen Zeichensatz besitzen, den sie aus verschiede-

50 Krek (1992).

51 Anderson (1872a), 73: In einem der Beschlüsse auf Malta geht es um die Produktion von Schulbüchern für die Missionsschulen.

52 Anderson (1872a, 74) nennt im gleichen Atemzug auch Arabisch. Nach heutigem Forschungsstand ist aber bekannt, dass der arabische Drucksatz nicht vor 1836 zum Einsatz kommt: vgl. Krek (1992), 81. Näheres dazu in Abschnitt II.1.3. 
nen Gründen erst sieben Jahre später in Beirut anwenden, ${ }^{53}$ greifen sie bis dahin auf die Materialien der Church Missionary Society, British and Foreign Bible Society sowie der London Missionary Society auf Malta zurück, die religiöse Traktate, ${ }^{54} \mathrm{Bi}$ beln und Schulbücher in der arabischen, griechischen und italienischen ${ }^{55}$ Sprache umfassen. ${ }^{56}$ Die kostengünstigen Schriftstücke der Bibelgesellschaften in verschiedenen Sprachen sollen zur schnellen Verbreitung der darin enthaltenen Botschaften beitragen. ${ }^{57} 1833$ wird die maltesische Druckerei der Amerikaner auf Smyrna und Beirut aufgeteilt, wobei man sich in Beirut ab 1834 auf den arabischen Buchdruck konzentrieren will. Eli Smith übernimmt hier ab 1837 offiziell die Leitung. ${ }^{58}$ Bis der Druck in Beirut richtig anläuft, dauert es noch einige Jahre. ${ }^{59}$ Zum einen fehlt es an Übersetzern, die Materialien ins Arabische übersetzen können, zum anderen muss der defekte Schriftsatz aus London verworfen und ein neuer, zufriedenstellender erst entwickelt werden. ${ }^{60}$ Durch die Druckarbeit in der Mața'at al-Amrikān, ${ }^{61}$ der Amerikanischen Druckerei (engl. American Mission Press) in Beirut, verschafft sich die Mission ein hohes Ansehen über die Grenzen Syriens hinaus. ${ }^{62}$ Schließlich werden hier nicht nur religiöse Schriftstücke herausgegeben, sondern auch säkulare Literatur - ein Novum in Syrien! Das erste Buch, das nach der Eröffnung der Mis-

53 Zum einen trifft der Schriftsatz viel später als abgesprochen ein, zum anderen findet sich kein geeigneter Drucker, der der arabischen Sprache mächtig ist. Zudem gibt es 1829 noch keine arabische Übersetzung, die in den Druck gehen könnte: vgl. Roper (1998), 53-55, 57.

54 In der religiösen Literatur der evangelischen Missionsdruckereien fehlt es, neben den Verurteilungen der religiösen Praxis orientalischer Kirchen, keinesfalls an Polemik gegenüber der katholischen Kirche und der von ihr ausgesandten Missionare. Mehr dazu in Murre-van den Berg (2006b), 63-80.

55 In der ersten Hälfte des 19. Jh.s ist im gesamten östlichen Mittelmeerraum Italienisch die lingua franca, auch die Missionare unterrichten z. T. auf Italienisch. Später kommen dann Englisch und Französisch hinzu. vgl. Hitti (1957), 426; Lindsay (1965), 94.

56 Tibawi (1966), 80; Glaß/Roper (2002), 190-191.

57 Reeves-Ellington (2013), 83.

58 Die Druckerei in Smyrna wird bereits im Dezember 1833 eingerichtet: vgl. Anderson (1872a), 76.

59 Selbst im Jahr 1846 schreibt Van Dyck (o.J., 22): „The Press up to this time had done little comparatively $[\ldots]$ the books usefull were printed in Malta.“"

60 Roper (1998), 57. Zu den Gründen, warum der Schriftsatz aus London nicht verwendet werden kann, siehe Abschnitt II.1.3.

$61 \mathrm{Glaß}(1998 \mathrm{a}), 14$.

62 „Printing Establishment“ (o.O., o.D.): ABC 16.8.1., Vol. 4.1 (62): „The issues from our press are called for and highly prized in India, Egypt, and Constantinople, and we confidently expect that as missions multiply among the millions speaking the Arabic language, the demand for them, as well as their usefulness, will more and more increase."

Eine interessante Perspektive auf die Veröffentlichungen der American Mission Press zwischen 1834 und 1860 bietet die Kunsthistorikerin Hala Auji in ihrer Dissertation (2013). Sie kommt zu dem Ergebnis, dass sich die ersten gedruckten Werke bis Mitte der 1840er Jahre stark an den kalligraphischen Traditionen arabischer Manuskripte in Bezug auf Aufbau und Darstellung orientieren. Diese zielen ohne Frage darauf ab, das arabischsprachige Lesepublikum für sich zu gewinnen. Erst später weichen die kalligraphischen Layouts einfacheren Druckentwürfen, die sich an westlichen Modellen orientieren. 
sion Press 1836 gedruckt wird, ist eine arabische Grammatik des Gelehrten Nāṣīf al-Yāziğī, ${ }^{63}$ der viele Jahre für die Mission arbeitet. ${ }^{64}$

Smith ist 1834 davon überzeugt, dass der Druck von Schulbüchern zum Hauptgeschäft der Druckerei werden könnte. Schließlich sei das einzige Lesebuch für Kinder, das die Missionare in Syrien finden können, eine Zusammenstellung von Teilen aus dem Psalter. Es existieren weder eine Arithmetik, noch Geografie- oder Geschichtsbücher. ${ }^{65}$ Es ist daher Eli Smiths Wunsch, Bücher in der Landessprache zu produzieren, ${ }^{66}$ die sich inhaltlich nach europäisch-amerikanischen Standardwerken richten: ,With the means of transferring into Arabic the latest and best improvements of our own country in school-books, we might hope to give our schools a superiority in efficiency, that would aquire them favor in the eyes of all the people." 67

Er muss jedoch bald einsehen, dass die Übersetzungen von christlichen Romanen und Lesebüchern, die in England und den USA sehr beliebt sind, nicht genauso gut bei den Arabern aufgenommen werden: „Our modes of expression are foreign, our ideas and manner of reasoning are not suited to the apprehension of the people [...]. “68 Smith schmiedet deshalb neue Pläne, für deren finanzielle Unterstützung er auf die American Tract Society hofft:

We have therefore determined so far as we may be enabled to write books and tracts ourselves suited to their taste of mind. These will probably be the works which we shall value most, and when we have enough of them prepared, they will constitute a large part of what we shall need your society to help us in printing. ${ }^{69}$

Die Missionare sind jedoch kaum in der Lage, diesen Vorstellungen zu entsprechen, da der Mangel an guten Büchern für die Schulen groß ist und die Leserschaft ebenfalls stetig wächst. Was die Lehrbücher anbelangt, so sind es selten komplette Übersetzungen westlicher Werke, sondern Zusammenstellungen aus verschiedenen Sachbüchern zum gleichen Thema - arabische Literatur ist in diesem Fall nicht ausgeschlossen. Welche Literatur für diese aufwendigen Buchkompositionen genau verwendet wird, ist jedoch zumeist unbekannt.

Obwohl sich der American Board zu Beginn viel von der Schulbuchproduktion und ihrem über die Landesgrenzen hinausgehenden Einfluss verspricht, ${ }^{70}$ wendet

63 Kitāb fașl al-hițāb fì uṣūl lug àt al-a 'rāb (Abschließende Worte zu den Grundlagen der Sprache der Araber). Mehr zu Nāṣīf al-Yāziğī in Anhang II, Nr. 75.

64 Glaß/Roper, (2002), 190-191: „Dies war das erste säkulare arabische Buch, das im Libanon gedruckt wurde.“ ABCFM, Annual Report 1837, 61, zitiert in: Tibawi (1966), 82: Nach dem Druck der Grammatik mit 1000 Exemplaren erscheinen ebenfalls im Jahr 1836 die arabischen Übersetzungen des Gesangbuchs (200 Kopien), des Katechismus von Isaac Watts (1000 Kopien) sowie The Dairy Man's Daughter von Legh Richmond (1000 Kopien).

65 „On the Preparation of School-Books for Greeks, Armenians, \& Arabs, drawn up by Mr. Smith“" (Malta, 8.10.1829): ABC 16.6.3., Vol. 3: Laut Smith gibt es das klassische Unterrichtsfach „Geschichte“ in Syrien nicht. Die Menschen ziehen es vor, sich fiktive Geschichten zu erzählen, die häufig einen historischen Wahrheitsbezug haben.

66 Smith an Anderson (Beirut, 4.2.1834): ABC 16.8.1., Vol. 01 (74).

67 Ebd.

68 Smith an Hallock (New York, 17.4.1840): ABC 60 (105), (HHL).

69 Ebd.

70 Anderson an Smith (Boston, 19.1.1830): ABC 16.8.1. Vol. 8. 
sich das Blatt im Laufe der Jahre und Jahrzehnte. Der Druckereibetrieb muss laut Anordnungen aus Boston immer wieder auf die Veröffentlichung rein religiöser Literatur eingeschränkt ${ }^{71}$ bzw. manches Mal sogar ausgesetzt werden (s.u.). Es fehlt vor allem am Anfang an genügend Mitarbeitern, deren Finanzierung vom Board für eine gewisse Zeit nicht geleistet wird. Als Rufus Anderson 1843/44 die Levante besucht, schreibt er in seinem Bericht, die Druckerei erfordere zu viel Arbeit, die für die Bekehrungsarbeit nicht zur Verfügung steht. ${ }^{72}$ Andersons Ansicht nach scheinen die in Syrien stationierten Missionare eines nicht zu verstehen: ,the press should be kept strictly subservient to the pulpit“. ${ }^{73}$

Die fehlende Unterstützung für die American Mission Press in Syrien ist jedoch kein Einzelfall: Zu Anfang werden in vielen Missionen des ABCFM Druckereien eingerichtet. Schließlich erhöhe der Buchdruck die Chancen Gutes zu tun ,in an incalculable ration", wie im Jahresbericht des ABCFM von 1821 geschrieben wird. ${ }^{74}$ Die Stimme eines Missionars werde nur von Wenigen gehört, ,[b]ut tracts and books reach thousands“. ${ }^{75}$ Aus zwei Gründen wird der ABCFM diesbezüglich seine Meinung sehr bald ändern: Zum einen erweist sich die Verteilung von religiöser Literatur und Bibeltraktaten als nicht besonders effektiv. Zum anderen müssen die Druckereien und ihre Mitarbeiter unterhalten werden, was allein durch den Erlös des Buchverkaufs nicht gewährleistet werden kann. Ohne Frage sind die Missionsdruckereien durch hohe Nachfragen nach Sachliteratur ausgelastet, diese tragen jedoch nichts zum Ziel der Mission bei. ${ }^{76}$ Ab Mitte des 19. Jh.s setzt der ABCFM wie im Bereich Bildung (s. u.) eine geänderte Einstellung zur Druckarbeit in vielen Auslandsmissionen durch. 1861 berichtet Anderson, dass bereits fünfzehn Druckereien geschlossen bzw. an lokale Unternehmer verkauft worden seien, darunter in Smyrna (1853), Bombay (1858) und Manepy/Ceylon (1854/55). ${ }^{77}$ In Beirut wird die Arbeit zwischen 1839 und 1841 wegen Personalmangel und einem fehlenden Schriftsatz sowie zwischen 1844 und 1845 auf Andersons Anordnung hin ausgesetzt. Sie kann jedoch wieder aufgenommen werden. ${ }^{78}$

Angesichts der Restriktionen aus Boston ist es erstaunlich, welche Arbeit die American Mission Press in den darauffolgenden Jahren leistet. Im Jahr 1853 etwa werden 5008 Bücher und Traktate gedruckt, von denen über 4000 an Missionsstatio-

71 Auji (2013), 120.

72 Anderson (1844), 29; Anderson an die Syrienmission, (o. O., 22.10.1842): ABC 16.8.1., Vol. 8: "If it be so that your books (other than the Scriptures) extend the rage of exasperation beyond the controlling influence of your personal intercourse and living voice, - and especially if the preparation of books \& the superintendence of the press take up time, wh. ought to be devoted to oral instruction, - make less a time of the press." (Unterstreichungen in Zitaten aus Korrespondenzen sind stets Hervorhebungen des jeweiligen Absenders).

73 Anderson (1872a), 263.

74 ABCFM, Annual Report 1821, 201, zitiert in: Coakley (1998), 5.

75 Ebd.

76 Ebd.

77 Ebd. 6, 14-21.1843 spricht Anderson von 17 Druckereien in den Auslandsmissionen: Rufus Anderson an John Pickering (16.6.1843): ABC 1.1., Vol. 18, 130 (HHL).

78 MH 38 (1842), in: ROS 3, 338; Anderson (1844), 29. 
nen in Syrien, Ägypten, Irak und sogar Indien versandt werden. ${ }^{79}$ Darüber hinaus verfügt die Mission über ein Lager von Büchern aus missionarischen Druckereien auf Malta, in Kairo oder Konstaninopel, die von Beirut aus verschifft werden sollen. ${ }^{80}$ Nicht jedes Werk, das aus der eigenen Druckerpresse kommt, ist von der amerikanischen Mission selbst finanziert. Vor allem religiöse Literatur wird von der London Religious Tract Society, British and Foreign Bible Society, American Bible Society und der American Tract Society gefördert. ${ }^{81}$ Ab den 1860 er Jahren wird das Druckunternehmen fast nur von ausländischen Bibelgesellschaften und kaum noch vom ABCFM unterstützt. ${ }^{82}$ Zahlreiche syrische Autoren, unterstützt von lokalen Geschäftsleuten oder intellektuellen Vereinigungen, können die Druckerei mieten, um eigene Werke drucken zu lassen - eine zusätzliche Einnahmequelle für die ohnehin finanziell geschwächte American Mission Press. ${ }^{83}$ Für den Druck der meisten Lehrbücher für das 1866 gegründete Syrian Protestant College (SPC) kann die American Mission Press nicht aufkommen, da sie dafür nicht autorisiert ist. Cornelius Van Dyck, John Wortabet u.a. müssen zu Anfang den Druck ihrer Lehrbücher selbst finanzieren. ${ }^{84}$ Schließlich richtet der Stiftungsrat des SPC 1869 den Theodore Publication Fund speziell für die Finanzierung von Sachliteratur für das College ein. ${ }^{85}$ Die Produktion der Lehrbücher teilen sich die Amerikaner mit anderen lokalen Druckereibetrieben. ${ }^{86}$

Die American Mission Press ist trotz der besonderen Stellung, die sie ab Mitte des 19. Jh.s in Beirut einnimmt, nicht die erste, die in Syrien aktiv wird. Um 1830 gibt es etwa sechs, zum großen Teil in christlichen Klöstern befindliche Druckerpressen in Syrien und Palästina, die Teile der Bibel sowie liturgische Schriften in den jeweiligen Kirchendialekten und auf Arabisch drucken können. ${ }^{87}$ Nachdem die Amerikaner ihre Missionsdruckerei in Beirut etabliert haben, dauert es nur wenige Jahre bis auch die Jesuiten auf diesem Gebiet aufholen. Im Jahr 1848 richten sie ebenfalls eine Druckerei in Beirut ein. Die American Mission Press nimmt für die neu entstehenden einheimischen Druckereien eine Vorbildfunktion ein. ${ }^{88}$ Dazu zählen die für das arabische Journal Hadīqat al-Aḩbār (,Garten der Nachrichten“)

tischen (1872a), 230, Atiyeh (1995), 236-237. Der erste gedruckte Psalter wird im maronitischen Kloster St. Antonius in Quzhayā im Libanongebirge 1610 hergestellt. Das Buch, das in Karschuni (Arabisch in aramäischer Schrift) gedruckt wird, bleibt bis zur Mitte des 18. Jh.s ein Einzelfall. In einem weiteren Kloster in Šweir, östlich von Beirut in den Bergen, wird 1723 eine arabische Druckerpresse mit beweglichem Satz eingerichtet, die unter maronitischen Christen zunehmend das Bedürfnis weckt, die syrisch-aramäische Sprache ihrer Liturgie durch Arabisch zu ersetzen.

„Report of Beirut Station for the year 1853“ (Beirut, Januar 1854): ABC 16.8.1. Vol. 4.1 (152), 9. Tibawi (1966), 148.

Smith an Anderson (Beirut, 31.12.1842): ABC 16.8.1, Vol. 1 (159); Tibawi (1966), 250.

Van Dyck an Clark (Beirut, 25.1.1868): ABC 16.8.1., Vol. 7.2. (515).

Auji (2013), 129. usūl al-tašrīh (Verdeutlichung der Grundlagen der Anatomie), 1871: vgl. Tibawi (1966), 185. Näheres dazu in Anhang I.

SPC Jahresbericht (Juni 1869): ABC 16.8.2., Vol. 2, 8; Penrose (1941), 33.

Tibawi (1971), 16.

Einige davon unterstützt Smith mit Materialien und Beratungen: vgl. Abschnitt II.1.3. 
gegründete Al-Maṭa 'a as-Sūrīya („Die Syrische Druckerei“, 1857/58), die AlMațba 'a al- 'Umūmīya (,Die Öffentliche Druckerei“'), die von Buṭrus al-Bustān̄̄ und Halīl Sarkis im Jahr 1867 eröffnete Mațba'at al-Ma'ārif („Druckerei des Wissens“"), die 1876 ebenfalls von Halīl Sarkis etablierte Al-Mața 'a al-Adabìya (,Druckerei für Literatur“) sowie die von 'Abdul-Qādir Qabbāni 1874 eingerichtete Maṭba 'at Ğam 'iyāt al-Funūn (,Druckerei der Gesellschaft der Künste“). ${ }^{89}$

Die Pionierarbeit der American Mission Press in Syrien besteht zum einen darin, als wahrscheinlich erste Druckerei überhaupt ein vollständiges Schriftstück auf Arabisch herausgegeben zu haben. ${ }^{90}$ Zum anderen leistet sie als erster Druckereibetrieb auch kommerzielle Arbeit und nimmt, wie zuvor beschrieben, unabhängig von der Mission Druckaufträge von verschiedenen Gelehrten, Geschäftsleuten oder politischen Personen an. Trotzdem konzentriert sich ihre Arbeit auch nach dem Tod des Leiters Eli Smith im Jahr 1857 hauptsächlich auf die Produktion von religiösen Schriften. Es darf jedoch nicht der Eindruck entstehen, die American Mission Press habe als Erste die Wiederbelebung klassischer, arabischer Literatur gefördert. ${ }^{91}$ In den ersten Jahrzehnten werden ausschließlich religiöse und sachliche Bücher produziert, erst später kommen auch klassische Werke hinzu. ${ }^{92}$

Nur durch den Druck eines der bedeutendsten Vorhaben der Syrienmission, die neue Übersetzung der Bibel ins Arabische, kann die American Mission Press aufrechterhalten und ihr Bestehen vor dem ABCFM gerechtfertigt werden. ${ }^{93}$ Die Akribie und Beflissenheit, die v. a. Smith und Van Dyck in ihrer Beschäftigung mit der arabischen Sprache an den Tag legen, prädestinieren sie dafür, eine neue Bibelübersetzung zu erarbeiten, so wie es dem American Board schon im Jahre 1813 von einem Missionar in Indien ans Herz gelegt wird. ${ }^{94}$ Während der Übersetzung stehen Smith der Grammatiklehrer Nāṣịf al-Yāziğ̣̂ sowie Buṭrus al-Bustān̄̄, und Van Dyck ab 1857 der muslimische Gelehrte Yūsuf al-Asīr zur Seite. Die Veröffentlichung

89 Tibawi (1966), 166. Zur Übernahme des amerikanischen Zeichensatzes in einigen der genannten Druckereien siehe Abschnitt II.1.3. Die Jesuiten richten 1853 ihre Imprimerie Catholique in Beirut ein: Hitti (1959), 230. Ende des 19. Jh.s gibt es in Beirut und im Gebiet des Libanon zusätzlich zu den protestantischen und katholischen Druckereien bereits mehr als 20 Druckerpressen: vgl. Atiyeh (1995), 240.

90 Krek (1992), 85: Es ist unklar, ob die amerikanische Missionsdruckerei in Singapur, die Malaysisch mit arabischen Buchstaben druckt, bereits 1835 eigenständig einen Druck auf Arabisch herausgibt. Laut Krek sind die Beweise nicht eindeutig, ob Beirut oder Singapur der Vorrang zuteil wird.

91 Tibawi $(1971,15)$ betont, der Ruhm für die Herausgabe klassischer, arabischer Literatur „,must be shared between native scholars in Egypt and European orientalists" und darf daher nicht den Amerikanern zukommen.

92 Tibawi (1966), 252-253.

93 Siehe auch die Abschnitte II.1.4 und II.2.3.

94 Samuel Newell an den ABCFM (Ceylon, 20.12.1813), in: ABCFM (1834), 111. Auch der anglikanische Missionar Henry Martyn (1781-1812) schreibt, dass man mit einer arabischen Bibel Millionen von Menschen erreichen könne: vgl. Leavy (1995), 33. Schon 750 n.Chr. soll den arabischen Christen eine arabische Bibel vorgelegen haben. Die 1671 von Jesuiten übersetzte arabische Bibel war auch im 19. Jh. noch im Umlauf und wird zu Beginn von den Missionaren verwendet, bevor sie eine eigene Bibelübersetzung in Angriff nehmen: vgl. Kahle (1904), iiiiv. Mehr dazu in Abschnitt II.1.4. 
der sogenannten Van Dyck Bibel im Jahr 1865 macht die amerikanische Mission in der arabischsprachigen Bevölkerung, auch über die Grenzen Syriens hinaus bis nach Ägypten und Europa, bekannt. ${ }^{95}$ Doch der Erfolg kann über die Höhen und Tiefen, die das Unternehmen Missionsdruckerei begleiten, nicht hinwegtäuschen. ${ }^{96}$ Viele Missionare wollen die Druckerei nicht aufgeben und setzen sich für ihren Erhalt ein. Cornelius Van Dyck, der die Verwaltung der Druckerei von 1857 bis Anfang der 1870er Jahre innehat, schreibt 1868 an den neuen Korrespondenzsekretär des ABCFM Nathaniel G. Clark, dass der Bedarf an gedruckter Literatur hoch sei, die Missionsdruckerei ihn jedoch nicht decken könne:

Where is the Christian literature for the Arab race to come from? We can prepare books, and are preparing them, but how are they to be published? In the meantime a frivolous, semi-infidel, or infidel, cheap literature is springing up from little native presses, and we are doing next to nothing to meet the actual pressing demand for reading. We are educating minds and giving them no food. Never was the call for books, good books, of all kinds, so urgent. ${ }^{97}$

\section{Die Missionsschulen}

Eli Smith 1827 Beirut erreicht, notiert er, dass es bereits vierzehn Missionsschulen mit ingesamt 700 bis 800 Schülerinnen und Schülern gibt. ${ }^{98}$ Angesichts der Statistik von 1836, nach der gerade einmal zehn Schulen mit ingesamt 385 Kindern verzeichnet sind, scheint Smiths Hochrechnung stark übertrieben, zeigt jedoch, dass Zahlen und Statistiken in diesem Kontext mit Vorsicht zu betrachten sind. ${ }^{99}$ Zweifelsohne erfahren die amerikanischen Missionsschulen ein rasantes Wachstum, was jedoch auch seine Probleme birgt. Die Schulen erhalten zwar von verschiedenen Denominationen großen Zulauf, doch es mangelt bald an Geld, Lehrkräften und vor allem an Schulmaterialien. Die Missionarsberichte lesen sich über viele Jahre wie ein Hin und Her von Schulgründungen und -schließungen. Missionsschulen gelten unter vielen Missionen jener Zeit als Alphabetisierungsmaßnahmen, damit Jungen und später auch Mädchen lesen und schreiben lernen, um die Worte der Bibel selbst erfassen zu können. Der ABCFM erhofft sich zudem, dass die Schulen in Übersee zu Ausbildungsstätten für zukünftige Lehrer und Prediger werden, die den Missionaren helfend zur Seite stehen sollen. ${ }^{100}$

95 Goodsell (1959), 26.

96 Schon 1860 soll die Druckerei an einen Privatunternehmer verkauft werden, da die Kapazitäten unter den Missionaren erschöpft sind. Ende des 19. Jh.s übernimmt zwar ein privater Geschäftsmann die Verwaltung des Druckunternehmens, jedoch gehört die Druckerei weiterhin zur Mission: vgl. Jessup (1910a), 315. Sowohl die jesuitische als auch die amerikanische Druckerei sind noch bis in die 1960er Jahre aktiv: vgl. Hitti (1959), 230.

97 Van Dyck an N. G. Clark (Beirut, 25.1.1868): ABC 16.8.1., Vol. 7.2. (515).

98 Smith (1833), 166.

99 Laurie (1866), 18. Dass die Zahlen der Schulen und ihrer Schüler in verschiedenen Quellen der Missionsgesellschaft häufig divergieren, spricht Tibawi in seiner umfassenden Studie American Interests in Syria (1966) an mehreren Stellen an.

100 Anderson (1838), 109: „The rule is this; - That the system of education, in all its parts, so far as it is supported by the funds of the mission, should have a direct reference to the training up of native teachers and preachers." 
Isaac Bird und William Goodell eröffnen im April 1824 in ihrem eigenen Haus eine kleine Missionsschule, in der sie täglich sechs Kinder das Alphabet lehren. Als die Schüler weit genug sind, stellen die Amerikaner den Syrer Ṭannūs al-Haddād als Lehrer ein. Am 28. Juli 1824 wird in einem Außenbezirk von Beirut die erste amerikanische Schule mit sieben Schülern und ihrem einheimischen Lehrer eröffnet. ${ }^{101}$ Die Schule erfreut sich schnell großer Beliebtheit, schon im September liegt die Zahl der Schüler zwischen 50 und 60. ${ }^{102}$ Isaac Bird schreibt für den Missionary Herald 1824: „A thing so novel here as a free school established by strangers, could not fail to attract considerable notice." ${ }^{103}$ Das wirklich Neuartige an der Missionsschule ist die Aufnahme von Schülern aus allen religiösen Gruppen des Landes, allerdings betreten die Amerikaner mit der Gründung dieser Schule kein Neuland. Anders als in anderen Ländern stoßen Missionare hier auf eine jahrhundertealte Schriftkultur. Es gibt zwar etliche Schulen, jedoch ist Bildung in Syrien weder allen Kindern zugänglich noch hat sie im Vergleich zu den USA denselben hohen Status in der Gesellschaft. Die Missionare Bird und Whiting konstatieren 1831: „There is [...] a distressing apathy on the subject of education, among all classes of the people." ${ }^{104}$ Die existierenden christlich-orthodoxen Schulen und muslimischen Madrassen beschränken sich auf die eigenen Religionsgemeinschaften. ${ }^{105}$ Ganz abgesehen davon existieren in dieser Zeit keine vom Staat geförderten Schulen, Bildung bleibt nur einer gewissen Schicht vorbehalten. An diesem Punkt sieht die Syrienmission ihre Chance, allen den Zugang zur Bildung zu verschaffen und gleichzeitig über die Schulen ihre religiösen Botschaften zu verbreiten:

These children were running about the streets in all sorts of mischief; and almost as ignorant as the beasts of the field. No one cared for them. Now these people have come from a far country to teach them what will make them happy and useful. ${ }^{106}$

Die damaligen Missionsschulen können nicht als Schulen im klassischen Sinne bezeichnet werden. ${ }^{107}$ Dieser Umstand ist schon allein auf den Mangel an geeigneten Lehrern zurückzuführen. In den zunächst zwei bis drei Unterrichtsstunden bleibt gerade einmal Zeit für Leseübungen anhand von Auszügen aus der Bibel in Arabisch,

101 Bird und Goodell an Jeremiah Evarts (Beirut, 11.1.1825): ABC 16.6., Vol. 2. Das Missionshaus befindet sich zunächst außerhalb Beiruts und wird ab Herbst 1824 in die Stadt verlegt.

102 MH 21 (1825), in: ROS 1,317. 1825 sind es bereits 80 oder 90 Schüler, unter denen auch zwei Mädchen sind. Das Alter der Schülerinnen und Schüler liegt zwischen fünf und fünfzehn Jahren: vgl. MH 21 (Dez. 1825), 379 (soweit nicht anders vermerkt, sind diese und einige andere folgende Referenzen den originalen Ausgaben des Missionary Herald entnommen).

103 MH 21 (1825), in: ROS 1, 317.

104 MH 27 (1831), in: ROS 2, 292.

105 Jessup (1910a), 27.

106 So der einheimische Lehrer Țannūs al-Ḥaddād: MH 21 (1825), in: ROS 1, 318.

107 Lindsay (1965), 89; Khalaf (2001), 172: Die Unterbringung der Kinder von Hausangestellten oder Waisen kann man noch nicht als richtige Schule bezeichnen. Dagegen schreibt ReevesEllington (2013, 33), die meisten Missionsschulen sind zu Anfang „home schools that trained domestic help and taught basic literacy“. 
Italienisch oder Englisch, denen dann Erläuterungen religiöser Lehren folgen. ${ }^{108}$ Erst nach und nach werden Verbesserungen vorgenommen: Um das unregelmäßige Eintreffen von Schülern zu vermeiden, legt man die Unterrichtszeiten genau fest. Die Schüler werden in Klassen eingeteilt und die Zulassung eines Schülers unter vier Jahren wird untersagt. Zudem führt man ein Bewertungssystem sowie das leise Lernen ein, was den Missionaren unter den Arabern ein wichtiges Anliegen ist: ,it being a universal practice for all in a school to study aloud together, almost deafening their neighbors, to say nothing of their teacher and themselves". 109

Trotz der wachsenden Vielfalt an Schulfächern soll laut Anderson dem Predigen im Unterricht die Präzedenz gewährt werden. Durch die Lehrfächer können die Inhalte der Bibel lediglich leichter verständlich gemacht werden, so Anderson in seinem Aufsatz Missionary Schools. ${ }^{110}$ Es soll, wie schon oft geschehen, durch Betrachter von außen auf keinen Fall der Eindruck entstehen ,that modern missionaries among the heathen give too much attention to schools“. ${ }^{111}$ Dass die Schulen dennoch so großen Zulauf haben, hängt mit der Zurückhaltung der Missionare zusammen, den Schülern, und später auch Schülerinnen (s.u.), einen Glauben aufzuzwingen. Es scheint, dass einige Missionare schon in der Gründung von Schulen ihre Mission als erfüllt ansehen. Schließlich erweist sich die Arbeit unter den orientalischen Christen und Muslimen als schwierig, jegliche Reformbemühungen ${ }^{112}$ unter ihnen bleiben aus. ${ }^{113}$

Da der Andrang auf die erste Missionsschule so groß ist, sehen sich die Amerikaner darin bestätigt, dass weitere Schulen unabdingbar sind. Zudem erfüllen sie den Zweck ,to form habits of industry, and order, and domestic virtue in [the] pupils", wie Anderson es schon den ersten Missionaren Goodell und Bird mit auf den Weg gibt. ${ }^{114} 1859$ werden 33 Schulen mit etwa 1000 Schülerinnen und Schülern gezählt. ${ }^{115}$ Dabei besuchen nicht nur Kinder die Schulen, besonders in den entlegeneren Gebieten nehmen auch Erwachsene und ältere Menschen am Unterricht teil, um Lesen und Schreiben zu lernen. ${ }^{116}$ Angesichts der hohen Erwartungen der Missionare an ihre Schulen mahnt John Wortabet 1860 an, dass die Umstände nicht mit denen in Europa oder Amerika vergleichbar seien. Dortige Kinder wachsen in

108 MH 30 (1834), in: ROS 2, 391. Somit unterscheiden sich die Schulen anfangs nicht von den zuvor genannten $k u t ̦ a \bar{a} b$-Schulen für muslimische Kinder, außer dass sie bessere Räumlichkeiten und eine unentgeltliche Schulbildung bieten können: Cioeta (1982), 42.

109 MH 32 (1836), in ROS 3, 8. Die Disziplinierung der arabischen Kinder gehört für die Missionare zur notwendigen Maßnahme zur Zivilsierung der Bevölkerung: vgl. Smiths Bericht über die neue Missionsschule in Hāṣbeiyā (MH 41 [1845], in: ROS 3, 411): „From being as wild as Arab colts, they soon became quiet in conduct, abstaining from disorderly sports, and sometimes even reproving their elders for rudeness in speech and behavior.“

110 Anderson (1838), 104, 107-108.

111 Ebd., 87.

$112 \mathrm{Zu}$ Reformierung der orientalischen und katholischen Kirchen im Nahen Osten siehe Abschnitt 3 in diesem Teilkapitel.

113 Yazigi (1964), 17-18.

114 Zitiert in Harris (1999), 11.

115 Laurie (1866), 18.

116 „Report of the Hasbeiyan Station for 1851“: ABC 16.8.1., Vol. 4.1. (164). 
einem protestantisch geprägten Umfeld auf, was in Syrien nicht der Fall sei. Der Einfluss auf die Kinder könne daher nur bedingt sein, weil sie in den Elternhäusern oft gegenteilige moralische Sichtweisen erfahren. Ohne Zweifel sei die Grundschulausbildung wichtig, ,though to look for the results which are so different, would be to expect too much, and therefore to meet with disappointment". ${ }^{117}$

Trotz des geringen Bekehrungserfolgs lassen sich die Amerikaner nicht davon abhalten, einen neuen Bildungsbereich zu erschließen: Auch Mädchen sollen in Syrien die Möglichkeit erhalten, lesen und schreiben zu lernen. Erschüttert über die gesellschaftliche Stellung der Frau unter den Arabern und deren Überzeugung, dass es Frauen an intellektuellen Fähigkeiten fehle, fühlen sich die Missionare darin bestärkt, diese Vorurteile zu beseitigen. ${ }^{118}$ Die Förderung von Frauenbildung ist jedoch kein uneigennütziges Engagement für soziale Gerechtigkeit in Syrien. Die Bekehrung von Syrern ist nahezu sinnlos, wenn man syrische Mädchen und Frauen nicht ebenso für den evangelischen Glauben gewinnen kann. In den USA ist es die Vorstellung der Republican Mother, nach der Frauen in Sachen Bildung nicht hintanstehen dürfen, wenn sie für die Erziehung der zukünftigen Generationen verantwortlich sind: ${ }^{119}$,[I]f properly educated in solid Protestant values, they would be instruments of socialization and the potential founders of homes established on Christian virtues and principles." ${ }^{120}$

Die vermutlich erste Missionsschule, in der auch Mädchen zum Unterricht zugelassen sind - jedoch nicht die erste Mädchenschule in Syrien überhaupt ${ }^{121}$ gründen 1824 Isaac Bird und William Goodell in Beirut. ${ }^{122}$ Nach anfänglichem Misstrauen erfährt die von Eliza Thomson und Martha Dodge 1834 etablierte Mädchenschule in Beirut, ${ }^{123}$ die von der Missionarsfrau Sarah L. Smith weiter ausgebaut wird, positive Reaktionen in der Bevölkerung. ${ }^{124}$ Am 13. Dezember 1835 wird in Beirut ein Jungeninternat gegründet, das auf Anraten Rufus Andersons zu

117 Wortabet (1860), 385-386.

118 MH 20 (1824), in: ROS 1, 244. Ein griechisch-katholischer Priester wendet ein: „It is better for them to remain in ignorance, than to know how to read and write. They are quite bad enough with what little they now know. Teach them to read and write, and there would be no living with them“: vgl. MH 23 (1827), in: ROS 1, 391. Dennis (1872), 24: „It was argued that to teach her would tend to the disruption of society, to the disorganization of society, to the unsexing of women.“Vgl. auch Jessup (1910a), 27: „The first missionaries could not hear of a woman or girl in the land who could read."

119 Klaiber (2009), 308.

120 Fleischmann (2006), 268; Reeves-Ellington (2013), 24. Natürlich fördert auch das amerikanische Frauenbild jener Zeit nicht gerade die individuelle Freiheit der Frau, wie Scholz (1997, 239) richtig bemerkt: Frauen haben kein Wahlrecht und ihre Aufgabenbereiche liegen allein innerhalb der Familie, die als göttliche Institution die Basis der Gesellschaft darstellt.

121 Lindner (2014a), 51 (Anm. 26): Es besteht in dieser Region bereits seit dem 17. Jh. die Tradition der Mädchenerziehung durch katholische Nonnen.

122 Tibawi (1966), 32: Ohne eine Quelle zu nennen, schreibt Tibawi von einer scheinbar gemischten Klasse mit sechs Jungen und Mädchen. Goodell berichtet 1826 von lediglich einer Schülerin: vgl. MH 22 (1826), in: $\operatorname{ROS} 1,380$.

123 Lindner (2011b), 83.

124 MH 31 (1835), in: ROS 2, 420; „Annals of the Syria Mission“: ROS 5, 263. Die Female School wird später zum Female Seminary umbenannt, im 20. Jh. trägt sie den Namen Beirut College 
einem Seminar mit theologischer Ausrichtung gemacht werden soll. ${ }^{125}$ Die Jungen erhalten in dem auf Englisch geführten Lehrplan Geografie-, Astronomie- und Sprachunterricht von Eli Smith. ${ }^{126}$ In den Mädchenschulen beschränkt sich das Angebot zunächst auf Lesen, Stricken, Nähen und Kochen, später kommen Arabisch, Arithmetik, Geografie und Geschichte hinzu. ${ }^{127} 1846$ gründet Henry De Forest mit seiner Frau ein Mädcheninternat in Beirut ,to train up these girls to be industrious and neat housewives, not learned but not ignorant women, sensible, practical characters". ${ }^{128}$ Die minderwertige Stellung der Frauenbildung in der Gesellschaft macht es schwer, syrische Lehrer in den Mädchenschulen zu halten. Daher beziehen diese Lehrkräfte zu Anfang häufig das doppelte Gehalt ihrer Kollegen in den Jungenschulen. ${ }^{129}$

Sofern es die Schulmaterialien und das Vorhandensein von qualifizierten Lehrkräften erlauben, nehmen sich die Amerikaner ab 1836 vor, die Schulen nach einem für das Land neuen, amerikanischen Modell zu verändern. „From these schools will come our readers, hearers, and pious converts", so der Missionar William M. Thomson. ${ }^{130}$ Eli Smith betont schon 1828, dass der Erfolg dieser Schulen von einer ausreichenden Menge an Schulbüchern abhänge: ${ }^{131}$

I do not know how far the Committee wish [sic] us to publish school-books, such as small spelling books, Arithmetics, Geographies and Grammars, and should like instructions on this point. It is one of great importance, and needs careful consideration. For as education is almost entirely neglected, so there are very few, I had almost said no school-books of any value in Greek, Turkish, Armenian, or Arabic. ${ }^{132}$

Für die religiöse Unterweisung benutzen die Amerikaner englischsprachige Literatur, deren Satzstrukturen einfach zu erfassen und deren religiöse Inhalte schnell einzuprägen sind. John Bunyans The Pilgrim's Progress (1678), Mary M. Sherwoods Little Henry and his Bearer (1814), Legh Richmonds The Dairyman's Daughter (1814) sind Geschichten für Kinder und junge Menschen, die in verschiedenen Missionen zur Anwendung kommen. ${ }^{133}$ In den ersten Jahrzehnten, in denen Eng-

for Women bis sie schließlich 1973 in die Lebanese American University für Frauen und Männer umbenannt wird: vgl. Fleischmann (2006), 265-267.

125 Anderson an die Syrienmission (Boston, 26.12.1836): ABC 2.1.1., Vol. 01 (HHL).

$126 \mathrm{MH} 32$ (1836), in: $\operatorname{ROS} 3,1$.

127 MH 30 (1834), in: ROS 2, 391; Tibawi (1966), 125.

128 Aus einem Brief von Henry De Forest an Anderson ('Abeih, 15.8.1850), zitiert in: Yazigi (1964), 44. Siehe auch: ABCFM (1856), 20; MH 46 (1850), in: ROS 4, 107. Das Internat besteht bis 1854, als De Forest aus gesundheitlichen Gründen abreisen muss: vgl. Jessup (1910a), 95.

129 Ob diese Praxis auch später beibehalten wird, ist nicht bekannt. Vgl. Smith (1833), 166.

130 MH 32 (1836), zitiert in: $\operatorname{ROS} 3,20$.

131 Diese Ansicht ist jedoch nicht neu. Schon Pliny Fisk und Levy Parsons argumentieren 1821 ähnlich: vgl. MH 17 (1821), in: ROS 1, 46.

132 Smith an Anderson (Malta, 18.11.1828): ABC 16.6, Vol. 3 (164), 5. (Hier wie in folgenden Zitaten aus den Korrespondenzen der Missionare wurden die Hervorhebungen durch den jeweiligen Autor selbst getätigt.)

133 Lindner (2009), 140. Laut einem Bericht von Smith aus dem Jahr 1844 stellt sich jedoch heraus, dass sich diese Geschichten, deren christlich-moralische Botschaft charakteristisch ist, als 
lisch noch Unterrichtssprache ist, können diese Bücher im Original gelesen werden. Ab den 1840er Jahren erfordert die Umstellung ${ }^{134}$ auf Arabisch als Lehrsprache die Erarbeitung von Übersetzungen. ${ }^{135}$ The Dairyman's Daughter gehört zu den ersten arabischen Büchern, das die amerikanische Druckerei in Beirut 1836 veröffentlicht, ${ }^{136}$ The Pilgrim's Progress wird im Jahr 1844 von Buțus al-Bustānī übersetzt und von der Druckerei vervielfältigt. ${ }^{137}$ Inwiefern jedoch auch Lehrbücher aus Ägypten benutzt werden, ist nicht erwiesen. Die 1822 in Ägypten gegründete Druckerei Būlāq produziert besonders in den 1830er Jahren u. a. Lehrbücher über Medizin, Sprachen, Geschichte und Geografie, die während der ägyptischen Besatzung (1831-1840) nach Syrien gelangen. ${ }^{138}$

Es steht außer Frage, dass die von den Amerikanern geförderten Schulen nicht die einzigen in Syrien bleiben. Bis Mitte des 19. Jh.s herrscht zunächst ein großes Defizit an Einrichtungen für höhere Bildung. ${ }^{139}$ Nachdem sich die Jesuiten in der Levante neu etablieren konnten, gründen sie ab den 1850er Jahren Schulen, die den amerikanischen Einrichtungen qualitativ um nichts nachstehen. In Kairo und Beirut existieren letztlich mehr von Frankreich initiierte Schulen als von einer anderen ausländischen Organisation. ${ }^{140}$ Andere christliche Konfessionen in Syrien beginnen ebenfalls, sich im Schulbereich zu engagieren, vor allem um die Kinder aus den eigenen Gemeinden nicht an die Amerikaner zu verlieren. Nach dem Bürgerkrieg zwischen Maroniten und Drusen im Libanongebirge 1860 gelangt die Mission an einen Tiefpunkt. Sie müssen fast alle Schulen schließen, da die Finanzierung aus Boston ausbleibt:

Thus a great many of their former pupils in the primary schools and some of those in the seminaries became prospective, if not actual, pupils at other schools: Catholic, non-American Protestant and native. Members of the mission were naturally pained to witness such developments. ${ }^{141}$

Der ,virtual withdrawal from the department of primary education“, wie es Henry Harris Jessup 1865 für den Missionary Herald schreibt, ist nicht mehr aufzuhalten. ${ }^{142} 1865$ gibt es in Beirut keine Missionsschule mehr. Einzig das nach 1860 von dem syrischen Konvertiten Mihā’̄il 'Aramān übernommene, ehemalige Mädchen-

nicht sehr nützlich erweisen: vgl. Smith, „Report of Works Printed at the Missionary Press in Beirut" (1844): ABC 16.8.1., Vol. 1 (28).

134 Die Streitfrage um Englisch als Unterrichtssprache betrifft auch andere Missionen wie z. B. die ABCFM Mission in Indien: vgl. Harris (1999), 135-141.

135 Ğuha (2004), 147-148.

136 Tibawi (1966), 82.

137 Siehe Anhang I.

138 Tibawi (1971), 16.

139 Thomson schreibt dazu 1844: „If the state of general education in this country was such that youth could be found sufficiently educated in other schools to qualify them for the sacred office, as far as literary attainments are concerned, it would probably not be wise to establish a seminary of our own." Vgl. W.M. Thomson, ,Report of the Committee on the Seminary location" (11.4.1844): ABC 16.8.1., Vol. 1 (24). Näheres zum Missionsseminar s. u.

140 Makdisi (2010), 73: Auch im Bereich Frauenbildung sind die Franzosen sehr aktiv.

141 Tibawi (1967), 268.

142 MH 61 (1865), in: ROS 5, 116. 
internat der Mission, das sich nahezu selbst finanziert und von der Syrienmission in allen Belangen gefördert wird, ${ }^{143}$ sowie die von Buṭus al-Bustānī 1862 etablierte Nationalschule bleiben Lichtblicke für die Mission.

Was die höhere Bildung in Syrien anbelangt, so erreicht die Syrienmission beachtliche Ziele, wie im Folgenden zu sehen sein wird. Auf dem Gebiet der Grundschulausbildung können die Missionare die stärker werdende Konkurrenz jedoch nicht einholen. ${ }^{144}$

\section{3. „Satisfactory evidence of piety“ ${ }^{\text {“145 }}$}

Die Etablierung syrisch-protestantischer Kirchengemeinden ${ }^{146}$

1847 ergreift ein kleiner Kreis syrisch-protestantischer Konvertiten die Initiative zur Gründung einer evangelischen Kirche in Syrien, die heute den Namen National Evangelical Church of Beirut trägt. Dabei sieht es der American Board bei der Aussendung der ersten Missionare in Richtung östliche Mittelmeerküste überhaupt nicht vor, evangelische Kirchengemeinden vor Ort zu etablieren, geschweige denn Proselytismus zu betreiben und damit Mitglieder anderer christlicher Konfessionen abzuwerben. ${ }^{147}$ Für die Amerikaner stehen soteriologische Aspekte im Vordergrund. ${ }^{148}$ Es gilt Muslime und Juden zu bekehren, christliche Kirchen jedoch

143 Mihāàil 'Aramān ist ehemaliger Schüler des amerikanischen Jungeninternats in Beirut und unterrichtet danach im Seminar in 'Abeih (siehe Anhang II, Nr. 9). Nach 1860 soll das Mädcheninternat, das bis 1854 von De Forest geleitet wird, neu eröffnet werden, jedoch unter der Bedingung des ABCFM, dass dort weder Englisch noch Französisch gelehrt werde. Da dies für die Missionare vor Ort als unmöglich erscheint, entscheidet man sich, ein unabhängiges Mädcheninternat aufrecht zu erhalten, das 'Aramān leitet und in dem ausschließlich einheimische Lehrer unterrichten (z. B. 'Aramāns Frau Lulu sowie Rufka Gregory, ein Ziehkind der Missionsfamilie Whiting). 1870 wird das Internat vom Women's Board of Missions übernommen, der dem PBCFM untergeordnet ist. Vgl. MH 61 (1865), in: ROS 5, 116; MH 63 (1867), in: ROS 5, 172; Van Dyck an Clark (Beirut, 25.1.1868): ABC 16.8.1., Vol. 7.2. (515); Jessup (1910a), 222-223; Tibawi (1966), 163. Mehr dazu in Abschnitt II.2.2.

144 Auch Katholische Missionen sind auf diesem Gebiet sehr erfolgreich. Die Sisters of Charity und Nonnen von St. Joseph unterhalten ebenfalls Mädchenschulen im Land: vgl. Tibawi (1966), 67. Doch nicht nur die Katholiken werden als Konkurrenz empfunden, auch europäische Protestanten stören nach Andersons Meinung bei dem, was die Amerikaner aufgebaut haben: ,zealous Protestant educators, from different parts of Europe, were becoming so numerous at Beirût as to embarass the mission in its natural development": vgl. Anderson (1872b), 362.

145 „Records of the Syrian Mission“(22.4.1836): ABC 16.8.1., Vol. 8.1., 11: Genügende Frömmigkeit sowie der Wille, sich den Protestanten anzuschließen, sind die Grundvoraussetzungen für die Aufnahme in die Missionskirche (s.u.).

$146 \mathrm{Zu}$ diesem Thema siehe auch die Abschnitte III.1.2 und III.2.3 sowie Zeuge-Buberl (2015b).

147 MH 26 (1830), in: $\operatorname{ROS} 2$, 205: ,Our object is not to pull down or build up a sect, but to make known and inculcate the great fundamental truths of the Gospel“; Anderson (1872a), 47: ,The admission of converts into the church without regard to their previous ecclesiastical relation was a practical ignoring of the old church organization in the region. It was so understood, and the spirit of oppression and persecution was roused to the utmost."

148 „Our object was higher than ecclesiastical; it was the salvation of souls“: vgl. Smith an Paxton (Smyrna, 24.1.1837): ABC 16.5.1. (174). 
sollen von innen heraus reformiert werden, ohne die Gründung separater Kirchen zu forcieren. ${ }^{149} \mathrm{Ab}$ den $1840 \mathrm{er}$ Jahren wird von Rufus Anderson jedoch eine Kursänderung in die Wege geleitet: Eine Abspaltung von den traditionellen Kirchen sei möglich, sollte eine Kirchenreform nicht durchgeführt werden können. ${ }^{150}$ Für die Missionare scheint die Zeit dafür noch nicht reif zu sein. Erst ab 1845/1846 - und mit zunehmendem Druck vom ABCFM ${ }^{151}$ - wird vermehrt darüber diskutiert, wie eine Kirchengründung zu organisieren sei, da auch die Zahl der einheimischen Protestanten wächst und die Gemeindemitglieder eine Kirche wünschen, zu der sie sich rechtlich und öffentlich bekennen können: „If we remain in our present unorganized state, we shall be weak in ourselves and appear so to those around us. "152 Eine Kirchengründung auf Veranlassung der Missionare hin wäre schon allein daran gescheitert, dass man sich nicht auf die konfessionelle Ausrichtung hätte einigen können: Schließlich besteht der American Board aus Mitgliedern mit kongregationalistischer, presbyterianischer und reformatorischer Prägung. ${ }^{153} 1847$ machen die syrischen Protestanten den ersten Schritt und verfassen die Kirchenordnung für eine kongregationalistische Beiruter Gemeinde, die etwa im März 1848 gegründet wird. ${ }^{154}$ Die Syrisch-Evangelische Kirche (al-Kanīsa al-Inğīlīya al-Sūrīya) oder auch Beirut Church ${ }^{155}$ besteht zu Anfang aus fünfzehn männlichen und vier weiblichen Mitgliedern. ${ }^{156}$ Die Kernaussagen evangelischer Theologie werden in die für die Gemeindemitglieder zu unterzeichnenden Dokumente Confession of Faith und

149 Der Impuls für die „divine, renovating power“, die die Kirchen von innen reformieren soll, muss jedoch von außen kommen: vgl. MH 35 (1839), in: ROS 3, 161, 163; Badr (2006), 225. Was die Mission genau unter der Reformierung der Orientalischen Kirchen versteht, wird nie im Detail erklärt. Es bleibt bei allgemeinen Formulierungen wie: „reviving the knowledge and spirit of the Gospel to reform it“, den individuellen Mitgliedern soll mehr Verantwortung in der Kirchenverwaltung übertragen werden: vgl. Anderson (1872a), 130, 296.

150 Anderson an die Syrienmission (Boston, 11.1.1840): ABC 16.8.1., Vol. 8.1., zitiert in: Badr (1992), 203.

151 Der zunehmende Druck hat mit der weitaus erfolgreicheren Mission unter den Armeniern zu tun. 1846 wird die erste armenisch-protestantische Kirche in Istanbul gegründet: vgl. Anderson (1872a), 417-419.

152 MH 44 (1848), in: ROS 4, 51.

153 Smith an Anderson (Beirut, 26.4.1842): ABC 16.8.1., Vol. 1 (150): „Some of us are conscientious congregationalists and cannot be accessory to the formation of a presbyterian congregation here; part are presbyterians and know not how to appreciate congregationalism." Vgl. auch Smith an Anderson (Washington, 18.4.1846): ABC 16.8.1, Vol. 3.1. (116), 6-7. Anderson vertritt die Ansicht, dass die verschiedenen Formen von Protestantismus, wie sie während und nach der mittelalterlichen Reformation entstanden sind, nicht durch die Missionare vermittelt werden sollen. Die Entscheidung für eine theologische Ausrichtung soll den indigenen Christen überlassen werden: vgl. Harris (2004), 63.

154 Petition und Konstitution der Kirche sind abgedruckt im MH 44 (1848), in: ROS 4, 50-56. Die Petition wird am 9. Februar der Mission vorgestellt, am 19. Mai hat der Ältestenrat seine erste Sitzung. Ein offizielles Gründungsdatum ist jedoch nicht bekannt. Vgl. NECB Protokolle (19.5.1848), 1.

155 Nicht zu verwechseln mit der amerikanischen Mission Church: vgl. Lindner (2011b), 72-73.

1561849 sind es 27 Mitglieder: zehn aus der griechisch-orthodoxen Kirche, vier Melkiten, vier Maroniten, fünf Armenier, drei Drusen, ein Syrisch-Orthodoxer. Vgl. Anderson (1872a), 374. 
Covenant integriert. ${ }^{157}$ Die einheimische Gemeinde ist nicht zu verwechseln mit der Mission Church, die 1823 von den Missionaren Bird und Goodell gegründet wird. Mit der Formierung der syrisch-protestantischen Gemeinde organisiert sich schließlich die Missionskirche zur Anglo-American Congregation. ${ }^{158}$ Die beiden Gemeinden teilen sich von nun an die Kapelle (seit 1869 eine Kirche) ${ }^{159}$ und halten jeweils englische und arabische Gottesdienste ab. Da es bisher keinen syrischen Protestanten gibt, der den Missionaren als qualifiziert genug gilt, der Beirut Church als Pfarrer vorzustehen, werden William M. Thomson und ab 1849 George B. Whiting zu Pfarrern (acting pastor) ${ }^{160}$ der Kirche eingesetzt. ${ }^{161}$ In den nächsten Jahren folgen weitere Kirchengründungen in Haṣbeiyā (1851, 16 Mitglieder), Aleppo (1852, 6 Mitglieder), 'Abeih (1852, 8 Mitglieder), Sidon (1856, 7 Mitglieder), 'Almā (1858, 9 Mitglieder) und 'Ain Zhaltā (1864). ${ }^{162}$ Später werden diese Gemeinden zwar nach der presbyterianischen Kirchenordnung strukturiert, jedoch sollen Namen und jegliche spezifisch evangelische Tendenzen vermieden werden. Statt presbyterianisch nennen sich die Gemeinden mağma' al-mašyaha (Versammlung der Ältesten). ${ }^{163}$

Welche Hürden die Konvertiten bei ihrem Übertritt nehmen müssen, wird von beiden Seiten offensichtlich unterschiedlich wahrgenommen. Für die Missionare kommt der gewonnene, neue Glaube einer moralischen Läuterung der Syrer gleich: ,[T] he drunkard soon forsook his cups, the knave became an honest man, the profane ceased to swear, and the name Protestant became synonymous with all that was trustworthy and commendable." ${ }^{64}$ Mit der Idolatrie der orthodoxen Kirchen,

157 Lindner (2009), 151. Beide Dokumente sind abgedruckt in: Wortabet (1860), 407-411.

158 Syrienmission an Anderson (Beirut, 20.3.1848): ABC 16.8.1., Vol. 4.1. (21); Copeland (1974), 8. Heute ist die englischsprachige Gemeinde als International Community Church bekannt.

159 Dabei handelt es sich um das heute noch bestehende, neu restaurierte Kirchengebäude im Stadtzentrum von Beirut: vgl. Copeland (1974), 12.

160 Die Bezeichnung deutet darauf hin, dass der amtierende Pastor nur stellvertretend eingestellt ist und seine Zeit nicht voll und ganz der Gemeinde widmen kann, da er als Missionar entsandt wurde: vgl. Copeland (1974), 29. Der erste ,Vollzeit“"-Pastor der syrisch-protestantischen Gemeinde in Beirut wird 1890 Yūsuf Badr (siehe Anhang II, Nr. 15).

161 Im Gespräch sind vorher John Wortabet, Mihāènl 'Aramān, Elyās Fawāz, Tannūs al-Haddād sowie Būṭus al-Bustānī: vgl. Badr (1992), 291-294. Näheres dazu in den Kapiteln III.1. und III.2.

162 Laurie (1866), 14; MH 47 (1851), in ROS 4, 147; MH 48 (1852) in: ROS 4, 178; MH 52 (1856), in: ROS 4, 248; MH 54 (1858), in: ROS 4, 315; MH 60 (1864), in: ROS 5, 95.

163 Jessup (1910b), 475. In ihrer Dissertation geht Deanna Ferree Womack genauer auf die Umstrukturierungsmaßnahmen der evangelischen Kirchen in Syrien nach presbyterianischen Vorbild durch die Amerikaner ein und analysiert im Detail den dadurch offen ausgetragenen Konflikt zwischen der Beiruter Kirchengemeinde und der Syrienmission: vgl. Womack (2015).

164 So Laurie zu den Konvertiten des kleinen Ortes Ḥāṣbeiyā: vgl. Laurie (1866), 15. In seinem Bericht für das Jahrestreffen der Syrienmission 1850 findet der Amerikaner Whiting wesentlich mildere und freundlichere Worte für die Neuzugänge in der Beiruter Gemeinde: „In regard to the spiritual condition of the church, while there are, on the one hand, some things to deplore; such as the want of more spirituality, zeal and love; there are, on the other, many things calling for devout thankfulness, and tending to encourage our hopes. The members of the church generally, have shown a becoming interest in the means of grace and all the ordinances of the gospel“: vgl. MH 46 (1850), in: ROS 4, 104. 
der katholischen Hörigkeit gegenüber Kirchenoberen sowie der Ignoranz gegenüber der Heiligen Schrift als Quelle des Heils verbindet sich für die Missionare die pure Sündhaftigkeit. ${ }^{165}$ Diese kann nun als überwunden gelten. ${ }^{166}$ Eine solche dualistische Sichtweise ist charakteristisch für missionarische Unternehmungen dieser Zeit. Die Auffassung über die „Herausführung der Sünder aus der Dunkelheit ans Licht" entbehrt jeglichen Respekts gegenüber den historisch gewachsenen orientalischen Kirchen: ,The same that leads me to give a poor, blind beggar in the streets a few paras $[. .$.$] . In the same manner, I see you here spiritually blind, and poor [...]$ and I come to put into your hands the bread of eternal life."167

Für die syrischen Protestanten andererseits bedeutet die neue Religion den Bruch mit der seit Jahrhunderten gepflegten Tradition ihrer Familien. Das Zugehörigkeitsgefühl manifestiert sich anhand der Religion. Zum ersten Mal wird über die Lehren des bisher praktizierten Glaubens reflektiert, zum ersten Mal wird in Bibelkreisen über die Inhalte der Bibel geredet und argumentiert. Die evangelische Kirche sieht sich als neuer Ort des Miteinanders. Der Missionar Henry Harris Jessup schreibt, es sei der einzige Ort, ,where converts from all these warring sects sit together as brethren“. ${ }^{168}$ Die Missionare sind sich bewusst, dass sie als ,visitors from another planet" gelten. Ihre Adressaten werden jedoch von Kindheit auf in einem völlig falschen Glauben erzogen, ,instilled into their minds by parental instruction“, ,an opprobrium threatens them, should they change their religion for ours, bringing not only contempt upon themselves, but also disgrace upon their families". 169

Dies ist jedoch nicht der einzige Grund, warum die evangelische Gemeinde nur langsam wächst. 1850 gibt es nur eine einheimische Kirche und keinen einzigen Syrer, der in das Pfarramt ordiniert wurde. Für das verzögerte Wachstum der neuen evangelischen Kirche sind die Missionare schließlich selbst verantwortlich. Bevor Interessenten als Mitglieder in die Kirche aufgenommen werden können, wird zunächst der Ernst ihres Anliegens sowie der Grad ihrer Frömmigkeit (evidence of piety) geprüft. Sichtbare Zeichen für eine Heilserfahrung können jedoch nur durch ein Erweckungserlebnis zutage treten. Die gängige Praxis, wie sie auch in der amerikanischen Heimatkirche gilt, lautet: „,revival - conversion - public confession“. ${ }^{170}$

165 MH 20 (1824), in: ROS 1, 231. Nicht selten finden sich im MH Lasterkataloge, die die Bevölkerung beschreiben sollen, ,astonishing pride, jealousy, dishonesty, treachery, falsehood, and hypocrisy“ sind dabei die zentralen Worte: vgl. MH 32 (1836), in: ROS 3, 30. Was die Syrer praktizieren, sei ,irreligion“: vgl. MH 25 (1829), in: ROS 2, 180.

166, ,T] Turning the heart from the love of sin to the love of holiness“, vgl. MH 22 (1826), in: ROS 1,349 .

167 So der Missionar Jonas King im Gespräch mit einem griechisch-katholischen Priester: vgl. MH 21 (1825), in: ROS 1, 326.

168 Jessup (1910a), 83.

169 Smith (1833), 154. Smith ist sich der Schwierigkeiten durchaus bewusst, die das Konvertieren mit sich bringt. 1828 berichtet er dem Missionary Herald, dass syrische Protestanten keine Arbeit finden und sozial ausgegrenzt werden. Die Familie des Konvertiten versucht, ihn mit allen Mitteln von seiner Entscheidung abzuhalten, um nicht Schande über sich zu bringen: vgl. MH 24 (1828), in: ROS 2, 23.

170 Badr (1992), 266. 
Ist solch eine innere Reife nicht erkennbar, bestehen Zweifel am festen Glauben der neuen Kandidatinnen und Kandidaten. Nicht jeder Missionar sieht diese Praxis als sinnvoll für das Gedeihen der syrisch-evangelischen Kirche an. Cornelius Van Dyck plädiert dafür, dass ein Bekenntnis zu Jesus Christus ausreiche, Eli Smith ${ }^{171}$ und andere hingegen befürchten, dass eine Kompromisslösung den Sinn der missionarischen Botschaft gefährde, sind sich aber bewusst, dass eine radikale Durchsetzung der eigenen Prinzipien den einheimischen Konvertiten nicht zugute komme. ${ }^{172}$ Darüber hinaus sind sie sich im Klaren, dass die Syrer eine andere Vorstellung von Frömmigkeit haben. ${ }^{173}$ Einige Missionare wie z. B. Simeon H. Calhoun lassen sich nicht von ihrer traditionellen Haltung abbringen und fordern das individuelle Erweckungserlebnis als unumgehbare Voraussetzung für die Aufnahme in die Glaubensgemeinschaft. ${ }^{174}$ Rufus Anderson spricht die Thematik schließlich in einem langen Schreiben vom 27. Juni 1850 an. Der Stillstand in den einheimischen Gemeinden ist für den American Board nicht mehr länger zu dulden. Selbst wenn es in einigen Fällen der Konvertiten zu einem Fehlverhalten gekommen ist, so sei dies kein Grund, anderen Interessenten die Aufnahme in die Kirchengemeinde zu verweigern. Schließlich fordert Anderson seine Kollegen in Syrien dazu auf, das Risiko in Kauf zu nehmen. In Boston hat man bereits seit einiger Zeit den Eindruck, so Anderson, als sei die Syrienmission ,too conservative; too cautious in its progress; too distrustful of its converts“". ${ }^{175}$

Der Grund für das vorsichtige Vorgehen einiger Missionare ist im Kernprogramm des ABCFM zu finden: Anfang der 1840er Jahre entwickelt Anderson das sogenannte „Drei-Selbst-Programm“ (three-self-program). Es umfasst die Vorstellung von der Eigenverwaltung indigener, evangelischer Gemeinden im Missionsfeld. Ihr Charakter soll self-governing, self-supporting und self-propagating sein. ${ }^{176}$ „Such churches, and only such, are the life, strength, and glory of missions“, so Anderson. ${ }^{177}$ Nach der Bekehrung der Einheimischen und der Ausbildung des theologischen Nachwuchses sollen die Gemeinden imstande sein ohne ausländische Hilfe weiter zu existieren. Auch finanziell ginge für den ABCFM die Rechnung auf: Hunderte junge Menschen zu native agents auszubilden und die ein-

171 Smiths Position ist 1836 noch weitaus liberaler gegenüber Interessenten für die Kirchengemeinde: ,if any are excommunicated from the church we may admit them to our church“: vgl. Smith an Paxton (Smyrna, 24.1.1837): ABC 16.5.1. (174).

172 Näheres dazu in Abschnitt II.1.2.

173 Badr (1992, 306-307) zufolge bevorzugen die Christen im Nahen Osten eine eher theologisch orientierte Frömmigkeit. Smith berichtet demnach, dass Christen theologische Kontroversen als lebendige Form von Frömmigkeit verstehen: vgl. Smith an Anderson (Washington, 18.4.1846): ABC 16.8.1., Vol. 3.1 (116).

174 Badr (1992), 241.

175 Anderson an die Syrienmission (Boston, 27.6.1850): ABC 2.1.1., Vol. 13 (HHL).

176 Aus: R. Anderson, Foreign Missions: Their Relations and Claims, New York 1869, zitiert in: Beaver (1967), 97. Interessanterweise haben Henry Venn, Sekretär der englischen Church Missionary Society und Rufus Anderson vom ABCFM unabhängig voneinander diese Theorie erarbeitet: vgl. C.P. Williams, The Ideal of the Self-Governing Church: A Study in Victorian Missionary Strategy, Leiden 1999, zitiert in: Tjelle (2014), 41 (Anm. 68).

177 Anderson, Foreign Missions, zitiert in: Beaver (1967), 98. 
heimischen Prediger und Pastoren sowie ihre Familien zu unterstützen, wäre günstiger als wenige Missionare zu unterhalten, die ihren Lebensstandard womöglich nicht aufgeben möchten. ${ }^{178}$ Doch wie der Historiker PAUL W. HARRIS richtig urteilt, steht die native agency eher für den Bedarf an Effizienz als für die Gleichstellung mit den Missionaren. ${ }^{179}$ Dieser Sachverhalt zeigt sich schon an der ersten Hürde für die Umsetzung des Drei-Selbst-Programms: Die Gemeinden können aufgrund ihrer Unerfahrenheit nicht von Anfang an unabhängig sein. Es scheint daher nicht verwunderlich, dass Anderson eine gewisse hierarchische Ordnung aufrechterhalten möchte, laut der einheimische Pfarrer den Missionaren untergeordnet sind, die ihnen als ,ecclesiastical father and adviser“ beratend zur Seite stehen. ${ }^{180}$ Den Grund für diese Abhängigkeit beschreibt Anderson 1848 folgendermaßen: „Considering the weakness and waywardness so generally found in men just emerging from heathenism, native pastors must, for a time, and in certain respects, be practically subordinate to the missionaries, by whom their churches were formed [...]."181

Das Kontrollverhalten der Missionare weitet sich auch auf die Kirchenmitglieder aus. Nur fromme und ehrliche Christen sind in der Lage, sich am Aufbau einer sich selbst verwaltenden Kirche zu beteiligen. Das Problem liegt schließlich an einer sehr inkonsequenten Umsetzung des Programms durch Rufus Anderson. Anstatt die Missionare von einheimischen Predigern und ordinierten Pfarrern klar $\mathrm{zu}$ trennen, wie er es 1845 selbst formuliert, ${ }^{182}$ werden die Zuständigkeitsbereiche vermischt und syrische Theologen als nicht gleichwertig angesehen. ${ }^{183}$ Innerhalb der Syrienmission gibt es geteilte Meinungen: Einige wehren sich dagegen, einem ordinierten, syrischen Pastor die volle Verantwortung für seine Gemeinde zu übergeben, ${ }^{184}$ andere wiederum fordern, dass er in keinem Abhängigkeitsverhältnis zur Mission stehen solle. ${ }^{185}$ Dies gilt auch für John Wortabet, der nach seiner

178 So die Hochrechnung nach Anderson in seinem „Proposal for raising up a Native Ministry in the several Missions“(o. O., o.D.): ABC 16.8.1., Vol. 8, abgedruckt im MH 37 (1841), 186189.

179 Harris (1999), 162.

180 Beaver (1967), 99; Harris (2004), 63-64. In diesem Fall trifft die Einschätzung von Paul W. Harris über Anderson zu: „Rufus Anderson articulated an ideology that appeard respectful of other cultures while remaining fundamentally Eurocentric in its orientation, and he propounded a theory that sought to foster native agency by supressing indigeneous aspirations": vgl. ders. (1999), 162-163.

181 Erschienen im „Annual Report“ des ABCFM von 1848, zitiert in: Beaver (1967), 123.

182 „The Society sends forth men to be evangelists, rather than permanent pastors; and when pastors are required by the progress and success of the work, it seeks them among native converts on the ground. And herein it differs from the appropriate usages of the Home Missionary Society, which, operating on feeble churches with Christian communities [...] sends forth its preachers all to become settled pastors as soon as possible.“ Zitiert in: Beaver (1967), 81.

183 Anders sieht es in der Mission unter den Armeniern aus. Dort wehren sich amerikanische Missionare vehement gegen die Ungleichbehandlung ihrer Brüder im Glauben: vgl. Harris (2004), 71.

184 Diese Haltung trifft nicht nur auf die amerikanischen Missionare zu. Auch bei den Kaiserswerther Diakonissen in Beirut ab den 1860ern gibt es Vorbehalte, Schülerinnen zu gleichwertigen Diakonissen auszubilden: Hauser (2008), 230.

185 Van Dyck an Anderson ('Abeih, 17.8.1850): ABC 16.8.1., Vol. 5 (320). Näheres zu diesem Schreiben in Abschnitt II.2.2. 
Ordination zwar pastor (arab.: $r \bar{a} \mathfrak{l}^{186}$ der Kirchengemeinde in Hāṣbeiyā genannt wird ${ }^{187}$ in den Protokollen der Syrienmission jedoch den Status eines „Evangelist“", d. h. eines Predigers hat. ${ }^{188}$ Widersprüchliche Aussagen darüber, welches Amt Wortabet tatsächlich bekleidet, sind auch in den folgenden Jahren zu finden. Während der Stationsbericht aus Hāṣbeiyā von 1853 Wortabet „Reverend“ nennt, ${ }^{189}$ wird er 1855 im Missionary Herald als „one native preacher“ aufgeführt. ${ }^{190}$ Als wiederum 1864 Salība Ğerawān zum native pastor in Homs ordiniert wird, verweist der Jahresbericht des ABCFM darauf, dass Wortabet bereits elf Jahre zuvor diese Ordination zuteil wurde. ${ }^{191}$ Schließlich gibt es beim ABCFM sehr wohl eine Unterscheidung zwischen lizensierten Predigern und ordinierten Pfarrern, ${ }^{192}$ jedoch ist bei der Lektüre der Missionsquellen aufgefallen, dass beide Termini nicht immer korrekt angewendet werden. Im Falle Wortabets scheint man sich in der Tat nicht sicher zu sein, ob er schlicht als Prediger gilt, dessen Verantwortungsbereich beschränkt ist, oder als ordinierter Pfarrer, dem die gleiche Verantwortung zusteht wie den amerikanischen Missionaren. Schließlich agiert er in Hāṣbeiyā als einheimischer Pfarrer, jedoch mit weniger Verantwortung als er sich gewünscht hätte. Wortabets Rückzug von der Mission 1859 sowie Andersons Reflektion darüber ein Jahr später weisen darauf hin, dass die Syrienmission Wortabet nicht den Status zusprechen konnte, den er als ausgebildeter Theologe verdient hätte: ${ }^{193}$ „What would probably have been the effect, if, [...] he [sc. Wortabet] had been installed really and fully as the pastor of the church at Hasbeiya?"194

186 Im einem Schreiben der Syrienmission von 1886 über die Notwendigkeit einheimischer Pastoren, werden diese als $r \bar{a}$ in bezeichnet, was auch „Hirte“ bedeutet: vgl. Syrienmission (1886), 10. William Thomson, erster Pfarrer der einheimischen Beirut Church gilt als qasis (engl. minister, reverend), wobei der erste einheimische Pastor der Beirut Church 1890, Yūsuf Badr, ebenso qasis genannt wird: NECB Protokolle (19.5.1848), 2, 67.

187 MH 49 (1853), in: ROS 4, 188.

188 „Records of the Syria Mission 1853-1860“ (24.3.1853): ABC 16.8.1., Vol. 8.1., 7.

189 MH 50 (1854), in: ROS 4, 210.

190 MH 51 (1855), in: ROS 4, 218.

191 „Fifty-Fourth Annual Report of the American Board of Commissioners for Foreign Missions 1864 “, 91.

192 „Proposal for Raising up a Native Ministry in the Several Missions“, in: MH 37 (1841), 187. Für die Presbyterianer hält der Pfarrer (pastor) das höchste Amt in einer Gemeinde inne, während Prediger als Probekandidaten (probationer) gelten, die nach zufriedenstellender Probezeit ins Pastorenamt ordiniert werden können: vgl. Presbyterian Church in the USA (1841), 407408, 431.

193 Ähnliche Beobachtungen macht Liebau (2008, 132) in der Dänisch-Englischen-Halleschen Mission (oder „Tranquebarmission“, 1706-1845).

194 Anderson an die Syrienmission (Boston, 8.6.1860): ABC 2.1.1., Vol. 26 (HHL), (eigene Hervorhebung). Näheres zu dieser Auseinandersetzung zwischen Wortabet und der Mission in Abschnitt III.2.3. Anderson ist bemüht, neue ordinierte Pfarrer nicht zu verlieren. 1862 schreibt er an die Mission, dass die zwei Kandidaten, die für die Ordination in Frage kommen, möglichst zeitnah einer Gemeinde zugeteilt werden sollen. Andernfalls stehen sie in keiner eindeutigen Verbindung zur Mission und verlieren möglicherweise ihre Motivation: vgl. Anderson an die Syrienmission (Boston, 21.3.1862): ABC 2.1.1., Vol. 28. 
Eine weitere, schwierige Frage ist die Bezahlung der einheimischen Pastoren. Gemäß Andersons three-self-program sollen die self-governing Gemeinden für das Gehalt ihrer Pastoren aufkommen können. Die jungen Gemeinden sind dazu jedoch noch nicht in der Lage, ${ }^{195}$ weshalb sie auf die finanzielle Unterstützung der Amerikaner angewiesen sind und damit auch weiterhin ihrer Kontrolle unterliegen. Van Dyck argumentiert, dass die finanzielle Abhängigkeit der jungen Gemeinden nicht gleichbedeutend mit einem Herrschaftsanspruch der Mission sein sollte:

What infant church in these days supports its own pastor entirely? If the Board is willing [...] a part of the funds should be thus expended, shall we stand in the way? Because the Board aids in the support of the pastor must the church therefore be in bondage to the Mission so as to damp and cramp its every movement which is the case, even when the pastor is one [of] your own members?

Anderson spricht sich für eine begleitende Hilfe durch die Missionare aus und ist sogar bereit, Geld für den Aufbau indigener Kirchen zu leihen oder zu gegebenem Zeitpunkt sogar zu spenden, jedoch müssen die syrischen Protestanten ihre Kirche in naher Zukunft selbst finanzieren. Solange die einheimischen Gemeinden finanzielle Hilfen aus dem Ausland beziehen, behält sich die Mission das Recht auf Verwaltung und auf die Ein- bzw. Absetzung des Pastors. ${ }^{197}$ Darüber hinaus gibt es Stimmen, die Zweifel daran hegen, dass Spiritualität und Willenskraft der syrischen Protestanten ausreichen, um finanzielle Selbstständigkeit zu erlangen. Eine dieser kritischen Stimmen ist Dr. Bacon, Mitglied der American Home Missionary Society und Berater des American Board, der die Missionen in Westasien 1850 besucht. Die Initiative, so Bacon, müsse von den Syrern kommen, auch wenn er von diesem Pflichtbewusstsein überhaupt nichts verspüre. ${ }^{198}$

Sind sich der ABCFM und Anderson zu Beginn noch einig, dass es die Aufgabe der Missionare sei, einheimische Geistliche zu fördern und das Missionsfeld zu verlassen, so muss sich Anderson 1861 eingestehen, dass ,[t] $]$ his imperfect state of the native churches, and the circumstances in which they exist, have made it difficult for the missions to reach a point where these churches might be safely left, even after the native community had become Christianized“". ${ }^{199}$ Bis 1870 gibt es von Seiten des ABCFM keine Aussage darüber, wann dieser Zeitpunkt gekommen ist. ${ }^{200}$

4. Eine höhere Schule im „native style“- Das Seminar in "Abeih

195 Jessup (1910a), 155: „In fact, no effort had been made up to this time to enforce or induce self-support in the feeble native churches. Nothing was paid for their preaching and education."

196 Van Dyck an Anderson ('Abeih, 17.8.1850): ABC 16.8.1., Vol. 5 (320).

197 Schriftlich festgesetzt im Programmheft über die Notwendigkeit einheimischer Pfarrer und Kirchen: Syrienmission (1886), 11.

198 Anderson an die Syrienmission (Boston, 11.7.1851): ABC 16.8.1., Vol. 8 (4).

199 ABCFM (1863), 250.

200 Bonk (1989), 161: Der Umgang mit einheimischen Gemeinden ändert sich auf dem gesamten Gebiet der Missionsarbeit in Europa und Amerika zum Ende des 19. Jh.s. Bei der Missionskonferenz in New York 1900 ist man sich einig, dass missionarische und einheimische Verwaltungsgremien unabhängig voneinander arbeiten sollen. Einheimische Gemeinden bewahren ihren kulturell eigenen Charakter, wenn sie nicht von der Andersartigkeit der Missionare beeinflusst werden. 
Es sei unabdingbar, so Anderson in seiner Programmschrift Missionary Schools (1838), dass höhere Bildungseinrichtungen Bestandteil der Missionen sind. Ohne sie gäbe es weder theologischen Nachwuchs, noch Lehrkräfte für die Missionsschulen. Auf diese Weise könne der Weg zu einer eigenständigen christlichen Gemeinde geebnet werden. ${ }^{201}$ Nichtsdestotrotz gibt es um 1860 nur sechs Seminare in den rund 27 Auslandsmissionen des ABCFM. ${ }^{202} 1837$ wird das zwei Jahre zuvor gegründete Jungeninternat in Beirut in Mission Seminary umbenannt, eine Institution, in der zukünftige einheimische Prediger und Missionare in englischer Sprache ausgebildet werden sollen. ${ }^{203}$ In der Region entstehen in Jerusalem 1842 und auf Malta 1846 durch die Engländer ähnliche Colleges, die allerdings nicht lange bestehen bleiben. ${ }^{204}$ Auch das Seminar in Beirut scheitert an der Verwirklichung seiner Zielsetzung, begabte Nachwuchsmissionare auszubilden und muss im August 1842 schließen. ${ }^{205}$ In einem Bericht anlässlich des Besuches von Rufus Anderson 1844 wird über die Gründe ausführlich reflektiert: Die Schüler sind bei Aufnahme nicht nur zu jung gewesen und haben zu wenig Vorkenntnisse mitgebracht, auch der zu westlich gehaltene Rahmen - Englisch als Unterrichtssprache sowie die Autorität der Missionare - haben in den Schülern eine Affinität für alles Westliche und eine Ignoranz gegenüber der eigenen Kultur hervorgerufen.

Mit Veränderung der politischen Situation des Landes und der steigenden Nachfrage nach Übersetzern für europäische Geschäftsleute und Militärs werden nach und nach Schüler des Seminars abgeworben, bis von den zu Anfang über 60 Internatsschülern 1842 nur noch 12 übrig bleiben. ${ }^{206}$ Sein Besuch in der Levante 1843/44 veranlasst Anderson dazu, neben dem Drei-Selbst-Programm für eine weitere Missionsstrategie einzutreten: die Vermeidung der "De-Nationalisierung“ (denationalisation) der arabischen Bevölkerung. ${ }^{207}$ Während der ABCFM in den ersten Jahren seines Bestehens bei der Missionierung der Indianer auf die Anglisierung der Einheimischen setzt (,they will more readily become assimilated in habits and manners to their white neighbors"), ${ }^{208}$ soll in den Auslandsmissionen die einheimische Sprache als Predigt- und Lehrsprache erhalten werden. Anderson zeigt sich erschüttert über die Verwestlichung der Kinder und Jugendlichen in den

201 Anderson (1838), 110.

202 Wortabet (1860), 358.

203 Yazigi (1964), 32: Damit erweitert sich der Stundenplan und umfasst nun Arabisch, Englisch, Geografie, Astronomie, Geschichte und Kirchengeschichte, Mathematik, Rhetorik (,which in the Arab sense is a popular study“), Philosophie, Textkomposition und Übersetzung, Bibelstudien und sakrale Musik.

Unter dem Begriff „Seminar“ ist eine auf den Beruf des Predigers vorbereitende Einrichtung zu verstehen, in der aber auch andere Fächer gelehrt werden. Für die Verwirklichung dieses Konzeptes ist eine Anbindung an ein Internat unerlässlich: vgl. dazu Sabra (2009), 13-14.

204 Tibawi (1966), 168: Das Jerusalemer College schließt nach dem Tod des Schulleiters 1845, das College auf Malta schließt vermutlich aus finanziellen Gründen.

205 W. M. Thomson, „The Committee in the results of the Seminary submit[s] the following report“ (6.4.1844): ABC 16.8.1., Vol. 1 (23).

206 Ebd.

207 Anderson (1869), 99.

208 „Minutes of the Seventh Annual Meeting“(1816), in: ABCFM (1834), 136. 
syrischen Missionsschulen: „I found in Syria, that the pupils of the old mission seminary at Beirût were so anglified in their ideas and tastes that they became disgusted with their countrymen, and even with their noble Arabian tongue, and were unfitted in great measure for doing good to their people [...]." ${ }^{209}$

Die Schließung des Beiruter Seminars gilt als vorübergehend, jedoch nur unter der Prämisse ,to get it out of Beirut". ${ }^{210}$ Der kleine Ort 'Abeih, südlich von Beirut, halb in den Bergen gelegen, zeigt sich als besonders geeignet. Ab 1843 werden Van Dyck, Thomson und Bustānī dort stationiert, um eine Schule zu gründen, die schließlich $1846^{211}$ in einem neuen Gebäude zum Missionsseminar ausgebaut wird. ${ }^{212}$ Der Schwerpunkt der Einrichtung, die einer Highschool entspricht, ${ }^{213}$ soll nun noch stärker auf die theologische Ausbildung gelegt werden, als es in Beirut der Fall war. ${ }^{214}$ Ganz im Sinne Andersons ist die Ausbildung dort in ihrer Aufmachung rein Arabisch: „The education was to be essentially Arabic, the clothing, boarding and lodging strictly in the native style, and the students were to be kept as far as possible in sympathy with their own people." ${ }^{215}$ Die englische Sprache wird fortan nur in Grundlagen gelehrt. Nicht zuletzt kann man die Studierenden dadurch von der Lektüre europäischer Autoren wie Engels, Marx oder Charles Darwin abhalten, die in den Augen der Missionare destruktive und anarchische Ideologien verbreiten. ${ }^{216}$ Es soll in jedem Fall vermieden werden, dass die Studierenden - wie in Beirut - aufgrund äußerer Einflüsse dem Seminar fernbleiben.

Anders als in den Missionsschulen wird im Seminar nun strikter auf die Evangelisierung der Studenten geachtet, Fasten- und Festtage der anderen Religionen werden nicht berücksichtigt. Man nimmt sich vor, Bewerber nur aufzunehmen, wenn sie ihren eigenen Kirchen entsagen, ${ }^{217}$ was jedoch nicht konsequent durchgesetzt werden kann. Wie lange ein Studium in 'Abeih dauern soll, ist zunächst noch nicht klar und soll erst mit der Erfahrung im Laufe der Zeit entschieden werden. ${ }^{218}$ Im Gegensatz zur Unterrichtssprache entspricht der Lehrplan den Gepflogenheiten einer guten amerikanischen Ausbildung zu jener Zeit. Man beginnt mit den Fächern: systematisches Studium der Bibel, Arabische Grammatik, Arithmetik und Geografie. ${ }^{219}$ Den Stundenplan teilen sich zunächst Van Dyck und Bustānī, wobei

209 Anderson an die Mission der Sandwich Inseln (o. O., 19.7.1845): ABC 2.1.1., Vol. 8.

210 Van Dyck (o. J.), 12.

2111846 eröffnen die Jesuiten ebenfalls ihr Seminar in Gazīr nördlich von Beirut, in dem neben dem Nachwuchs der lokalen Geistlichen auch Laien aufgenommen werden, durch die sich das Seminar größtenteils selbst finanzieren kann: vgl. Verdeil (2006), 26. 1875 zieht das Seminar nach Beirut und wird zur heute noch bestehenden Université de S. Joseph: vgl. Hourani (1954), 36.

212 MH 40 (1844), in: ROS 3, 388-389; Jessup (1910a), 107.

213 ABCFM, Annual Report 1868, 50.

214 MH 43 (1847), in: ROS 4, 2-4.

215 Anderson (1872a), 273.

216 Ğuha (2004), 148.

217 Yazigi (1964), 36.

218 Fünf bis zehn Jahre werden bspw. für die Ausbildung zum Pfarrer veranschlagt, wobei nach dem Abschluss des Seminars zusätzlicher Privatunterricht bei den Missionaren die Regel ist: MH 37 (1841), 187.

219 MH 43 (1847), in: ROS 4, 2. 
Letzterer morgens Arabische Grammatik sowie Arithmetik lehrt und Van Dyck am Nachmittag Bibelkunde und Geografie. ${ }^{220}$ Später kommen die Fächer Astronomie, Trigonometrie, Rhetorik, Englisch sowie Verslehre als Teil des Grammatikunterrichts hinzu: ${ }^{221}$ „It is, we suppose, the only institution in Syria where the true principles of science are taught." 222 Eine Gefahr, dass die religiöse Unterweisung den anderen Studien nachstehen könnte, sieht der American Board nicht. „The plain, simple theology of the Scriptures can be taught to youth, and even to heathen youth, in every stage of their education. “223 Um die Gefahr dennoch zu bannen, nimmt man sich ab 1850 vor, den Lehrplan des Seminars noch mehr auf Theologie auszurichten und die anderen Fächer als dem Hauptfach untergeordnet zu deklarieren. ${ }^{224}$ Was die Ausstattung des Seminars anbelangt, so kann es sich kaum mit dem amerikanischen Standard messen. Bis auf die arabische Grammatik gibt es zu Anfang kein Lehrbuch für die Schüler in 'Abeih:

[A]11 instruction must be given orally, and the pupils make the books as they proceed, under the direction of the teacher, which takes more time than would otherwise be necessary during the time of instruction, and throws upon the teacher a great amount of study, to ensure the necessary accuracy in thus preparing text books for future use. ${ }^{225}$

Von 1846 bis 1849 wird die Highschool von Cornelius Van Dyck und von 1849 bis 1875 von seinem Kollegen Simeon H. Calhoun geleitet. ${ }^{226}$ In ihren statistischen Aufzeichnungen werden die $\mathrm{Zu}$ - und Abgänge der Schüler regelmäßig dokumentiert: Kurz nach der Eröffnung befinden sich in der ersten Unterrichtsklasse weniger als zehn Schüler, mit jedem Schuljahr steigt jedoch das Interesse an einer höheren Ausbildung. Im Jahr 1876 werden 29 neue Schüler zu den 20 bereits in 'Abeih studierenden aufgenommen. Die Schüler sind zwischen 11 und 30 Jahren alt, wobei man sich nach einigen Jahren vornimmt, keine Jungen mehr unter 14 Jahren aufzunehmen. 1847 bemerkt Van Dyck in seinem Bericht über das Seminar, dass sie leider von keinem offiziellen Fall des Konvertierens berichten können. Alle Schüler sind ihrer bisherigen Konfession treu geblieben, auch wenn sie ein starkes Interesse an den biblischen Gesprächskreisen und Andachten zeigen. ${ }^{227}$ Trotz der gezielt evangelisch-theologischen Ausrichtung bezeichnen sich im Jahr 1875 nur 12 von 20 Schülern als Protestanten, von den 29 im selben Jahr aufgenommenen Neuzugängen sind es ebenfalls nur 12. Dennoch ist das Seminar für alle Konfessionen geöffnet: So gehen dort sowohl Maroniten und Rum-Orthodoxe als auch Drusen und schiitische oder sunnitische Muslime zur Schule. Die Klassenstärken scheinen regelmäßig zu schwanken. In den jährlichen Aufzeichnungen ist zu lesen, dass besonders nach den Ferien einige Schüler gar nicht erst nach 'Abeih zurückkehren,

220 Van Dyck an Anderson ('Abeih, 9.11.1846): ABC 16.8.1., Vol. 5 (315); Yazigi (1964), 36.

221 MH 46 (1850), in: ROS 4, 111.

222 Ebd., 112-113.

223 Anderson (1838), 110.

224 MH 46 (1850), in: ROS 4, 113.

225 MH 43 (1847), in: ROS 4, 3.

226 „Abeih Seminary Records“ (1848-1878): ABC 16.8.1., Vol. 8.

227 „State and Prospects of the Seminary“: MH 43 (1847), in: ROS 4, 26. 


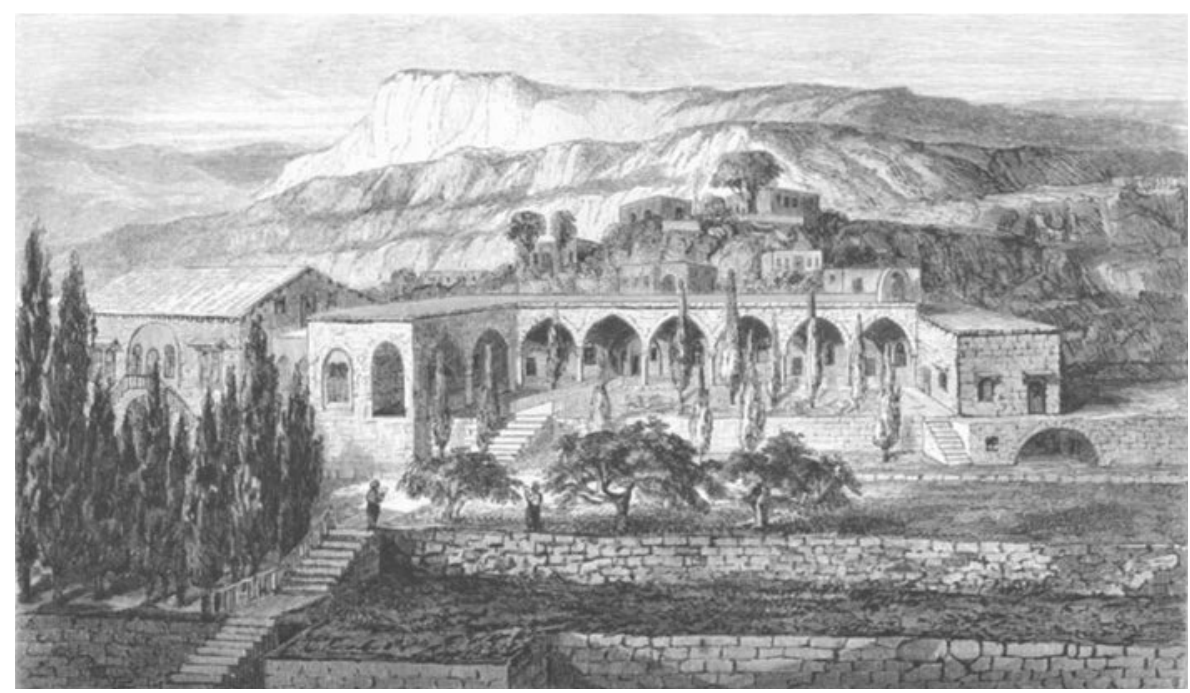

Abb. 2: Missionsseminar in 'Abeih

ohne Begründungen zu nennen. ${ }^{228}$ Bürgerkriegsähnliche Fehden, die Syrien während dieser Zeit immer wieder heimsuchen, sowie familiäre Probleme, die mit dem Studium an einer konfessionell anders ausgerichteten Schule zu tun haben, mögen dabei eine Rolle spielen.

Von den 117 Absolventen, die das Seminar in 'Abeih zwischen den 1850er und 1870er Jahren zu verzeichnen hat, schlagen etwa zwei Drittel die berufliche Laufbahn des Lehrers ein. Nur bei einigen wenigen wird in der Auflistung neben dem Beruf Lehrer auch der des Predigers genannt. Einige Absolventen werden von Beruf auch Drucker. ${ }^{229}$ Van Dyck resümiert 1868: „No institution which we have yet had has brought out these pastors and preachers." ${ }^{230}$ (Abb. 2)

Gegen Ende der 1860er Jahre scheint das Schicksal des Seminars besiegelt. Die sinkende Nachfrage in den ohnehin mittellosen evangelischen Kirchengemeinden im Land zieht auch ein Ausbleiben neuer Seminarkandidaten nach sich. Mit der Gründung des Syrian Protestant College im Jahr 1866 gehört das Seminar in 'Abeih zu den Einrichtungen, die Schüler auf das Studium im College vorbereiten sollen. $\mathrm{Ab} 1869$ wird in das Seminar eine eigenständige Theologische Schule mit zwei Fachrichtungen integriert: Biblische Geschichte, Exegese und Kirchengeschichte. ${ }^{231}$ Prediger und Pfarrer sollen von nun an innerhalb von drei Jahren die höchstmögliche Ausbildung erhalten, nicht wie zuvor nur Grundlagenwissen erlangen. ${ }^{232}$

228 „Abeih Seminary Records“(1848-1878): ABC 16.8.1., Vol. 8.

229 „Catalogue of the pupils who have entered the Seminary“, in: „Abeih Seminary Records“: ABC 16.8.1., Vol. 8.

230 Van Dyck an Clark (Beirut, 29.4.1868): ABC 16.8.1., Vol. 7.2. (516).

231 „General Letter of the Syria Mission“ (Beirut, 20.1.1869): ABC 16.8.1., Vol. 6 (26); Sabra (2009), 21.

232 Sabra (2009), 22. 
Nachdem der erste Jahrgang 1872 graduiert hat, fehlt es wiederum an neuen Bewerbern. Das Seminar zieht 1873 erneut nach Beirut, um näher am SPC zu sein und dort möglicherweise neue Kandidaten für das eigene Studium zu gewinnen. ${ }^{233}$ Das College möchte das Seminar Ende der 1860er Jahre als offizielle Vorbereitungseinrichtung (Preparatory Department) für ein Studium am SPC sehen. Die Finanzierung dafür soll jedoch von der Mission getragen werden, da man dort die völlige Eingliederung in das College kritisch sieht. ${ }^{234} 1874$ erkennt schließlich James S. Dennis, Leiter des Theologischen Seminars, dass das Fortbestehen seiner Einrichtung nur durch die Integration in das SPC möglich ist. ${ }^{235}$ Daniel Bliss, Präsident des SPC, schreibt daher 1874: ,the College is a power now - and the Mission will be glad yet to avail itself of our influence. If the Theological Seminary succeeds it will be because of the College“". ${ }^{236}$ Schließlich wird das Seminar erst 1881 in das SPC integriert und zieht auf dessen Campus. Der fortwährende Mangel an Kandidaten für das Theologiestudium und der gescheiterte Versuch, das College und das Seminar zu einer Einheit zu formen, führen zur Schließung des Missionsseminars im Jahr 1893 und einem gesonderten Weiterbestehen der daraus hervorgehenden Theologischen Schule. ${ }^{237}$

\section{5. ,[W]e are making history out here very fast" ${ }^{\text {¿238 }}$ Das Syrian Protestant College}

Am 3. Dezember 1866 wird die wohl bedeutendste Einrichtung der Syrienmission in Beirut ${ }^{239}$ feierlich eröffnet: das Syrian Protestant College (SPC, arab.: Madrasa al-Kullīya al-Sürīya al-Inǧilìya). Die in den Missionsschulen ausgebildeten jungen Männer können an dieser Institution nach amerikanischem Vorbild ein vier- oder mehrjähriges Studium absolvieren und in Berufe gehen, die das Land, durch seine rasante Entwicklung, dringend nötig hat. ${ }^{240}$ Das College trägt zwar in seinem Titel die Bezeichnung „Protestant“, jedoch soll es von Anfang an für alle Konfessionen

233 Jessup (1910b), 812; Sabra (2009), 31. Dreizehn der Kandidaten, die im Jahr 1872 am SPC aufgenommen werden, kommen z. T. aus 'Abeih und z. T. von den schottischen Missionschulen: vgl. Bliss (1993), 244 (Nr. 51).

234 Daniel Bliss an seine Frau Abby (Beirut, 17.11.1873), in: Bliss (1993), 122; Daniel Bliss an Abby Bliss (6.1.1874), in: ebd., 166.

235 Daniel Bliss an Abby Bliss (Beirut, 7.2.1874), in: ebd., 191.

236 Daniel Bliss an Abby Bliss (Beirut, 7.3.1874), in: ebd., 216.

237 Sabra (2009), 34. Danach entschließt man sich, aus dem Seminar erneut eine theologische Sommerschule außerhalb Beiruts zu machen und eröffnet das Seminar 1894 in Sūq al-Garb. 1905 zieht die Schule erneut nach Beirut um, wo sie bis heute ihren festen Standort hat: vgl. Lindsay (1965), 166.

238 Daniel Bliss an Abby Bliss (Beirut, 5.12.1873), in: Bliss (1993), 136.

239 Anders als im Falle des Missionsseminars in 'Abeih entscheidet man sich hier bewusst für Beirut, dem ein weltlicheres Flair nachgesagt wird. Bücher und Unterrichtsmaterialien sind zudem leichter erhältlich: vgl. ABCFM an die Syrienmission (o. O., 1862): ABC 76 (HHL).

240 „Prospectus and Programme of the Syrian Protestant College Institute, Beirut“: ABC 16.8.1., Vol. 6 (110). 
des Landes zugänglich sein, so wie es für die bisherigen Schulen und Internate der Amerikaner üblich ist.

The college will be conducted on strictly christian $[s i c]$ and evangelical principles, but it will not be sectarian in such a sense as to exclude from it pupils from any of the various sects of the country, christian, or non-christian, who will conform to its rules and regulations. ${ }^{241}$

Als das einzige zugelassene religiöse Buch wird die Bibel im College regelmäBig gelehrt. Für die Unterweisung in biblischer Literatur und religiöser Disziplin gemäß den protestantischen Richtlinien wird in den kommenden Jahren der zum Präsidenten des SPC ernannte Daniel Bliss verantwortlich sein. ${ }^{242}$ Bibelgespräche und tägliche Andachten werden zum festen Bestandteil des Colleges und sind für jeden Studenten, unabhängig von seiner Konfession, verpflichtend. ${ }^{243}$

Cornelius Van Dyck, William Thomson und Daniel Bliss sind maßgeblich an der Gründung des SPC beteiligt. ${ }^{244}$ Ein College dieser Art ist bisher in keiner Auslandsmission des ABCFM gegründet worden. Rufus Anderson kritisiert die Pläne der Missionare jedoch scharf:

The apparent necessity of such an institution at the present time was regarded as an evil [...] that an institution under the virtual control of the mission, which in its practical tendencies shall hinder you in laying the foundations of a simple, contended, independent, native pastorate all over your field, and of self-governed, self-contained churches, would be a still greater evil. [...] should there be anything of this nature in your proposed institution, it will be a fruitful source of mischief. ${ }^{245}$

Unter der Bedingung, dass das SPC nicht zum American Board und der Syrienmission gehört sowie von einer gesonderten Verwaltung, bestehend aus Protestanten mit mehrheitlich amerikanischen Missionaren, die des Arabischen mächtig sind, getragen wird, stimmt das Prudential Committee dem Antrag der Missionare zu. ${ }^{246}$ Dabei ist zu Anfang gar nicht klar, ob diese Institution von Amerikanern oder Syrern geleitet werden soll. Jessup berichtet in einem Brief an John Wortabet, der sich in Aleppo befindet, im Jahr 1862: ,[I]mmediate steps [are] taken to establish a large Protestant native institution in Beirut of a high order, with the coöperation [sic] of all the missions in Syria, Palestine, and Egypt. “247

241 „Prospectus and Programme“: ABC 16.8.1., Vol. 6 (110).

242 Ebd.

243 Anderson (2011), 59. Für jüdische, muslimische und christlich-orthodoxe Studenten werden individuell Bedingungen ausgehandelt, sodass sie an bestimmten Festtagen abwesend sein dürfen. Derartige Zugeständnisse möchte das College jedoch nicht verschriftlichen, da die Studierenden keinesfalls Anspruch auf erlaubte Abwesenheit erheben dürfen: vgl. Scholz (1997), 131-132.

244 Die Quellen sprechen zumeist nur von Daniel Bliss und allgemein von den Missionaren in Syrien, die diese Idee getragen haben. Es sind aber vor allem Van Dyck und Thomson, die sich jahrelang für die Gründung einer höheren Schule einsetzen: vgl. Diab/Wåhlin (1983), 116 (zitiert aus: Šahīn Makārīūs, „Al-ma arīf fī Sūrīya“ [Bildung in Syrien], in: al-Muqtațaf 7 [1882/1883], 388).

245 Anderson an die Syrienmission (Boston, 21.3.1862): ABC 76 (HHL).

246 „Minutes of the Meeting on 18 March 1862“: ABC (,Records of the Prudential Committee“), Vol. 11, zitiert in: Tibawi (1967), 270.

247 Jessup (1910a), 239. 
Es ist geplant, dass Buțrus al-Bustān̄̄ den Missionar J. Edwards Ford nach England begleitet, um für die Institution zu werben. Doch man entscheidet sich gegen eine syrisch-amerikanische Kooperation mit der Begründung: „A native school, founded and supported by natives, should be under native control. A foreign school, founded by foreign funds, should be under foreign control." ${ }^{248}$ Das College soll schließlich europäisch-amerikanisch werden, ,in order that we may control it and that it may not work against us“. ${ }^{249}$ Daher reist Daniel Bliss 1862 nach Ford in die USA und 1864 nach England, um dort die nötigen Spenden zu sammeln und eine zu große Einflussnahme von Seiten syrischer Aristokraten zu verhindern. ${ }^{250} 1863$ erlässt der Staat New York eine Gründungsurkunde des SPC und es wird ein Stiftungsrat (Board of Trustees) eingerichtet, der sich um die Finanzierung des Colleges unabhängig vom ABCFM kümmern wird. ${ }^{251}$

Bemerkenswerterweise beschränken sich die Gründe für die Etablierung einer höheren Bildungseinrichtung, die Daniel Bliss und seine Kollegen in Beirut 1862 beim ABCFM vorbringen und später in der Satzung schriftlich festlegen, nicht nur auf den Wunsch, die Existenz einer protestantischen Gemeinschaft in Syrien zu sichern. ${ }^{252}$ Auch die Auswirkungen auf das ganze Land und seine Gesellschaft werden in den Blick genommen. Gut ausgebildete Lehrer, Geistliche, Sekretäre, Übersetzer, Autoren, Dolmetscher, Rechtsanwälte, Richter, Ingenieure und Ärzte, die im ganzen Land gebraucht werden, sollen am SPC studieren und für das Wohlergehen des Landes und der Arabisch sprechenden Bevölkerung sorgen. ${ }^{253}$ Professuren für die Fächer Arabische Sprache und Literatur, Mathematik, Astronomie, Ingenieurwesen, Chemie, Botanik, Naturwissenschaften, Moderne Sprachen, Medizin sowie Jura werden eingerichtet. ${ }^{254}$

Um den Zugang zur Bildung für jeden zu gewährleisten, soll das Studium so wenig wie möglich kosten. Durch Stipendien aus dem In- und Ausland sollen talentierte Bewerber gefördert werden, damit sie einen Beitrag zu ihrer Gesellschaft leisten können. ${ }^{255}$ Wohlwollende Förderer aus Europa und Amerika interessieren sich nun für die Etablierung einer Wissenskultur (nach westlichem Vorbild) in Vorderasien, wie Bliss 1862 berichtet: „,T]here is manifested at the present time, an earnest desire on the part of many benevolent persons in England and elsewhere to see such an institution commenced, and willingness to aid in its endowment. “256

248 Ebd., 240.

249 Bliss an Anderson (Sūq al-Ġarb, 13.6.1862): ABC 16.8.1., Vol. 4.1.

250 Ebd.; Penrose (1941), 13-17.

251 SPC Jahresbericht (2.4.1963): ABC 16.8.2., Vol. 2; Penrose (1941), 14: Der Board of Trustees besteht im April 1863 aus William A. Booth (Vorsitzender), William E. Dodge, David Hoadley, Simeon B. Chittenden, Abner Kingman, Joseph S. Ropes.

252 ABCFM an die Syrienmission (Boston, 18.3.1862): ABC 76 (HHL).

253 „Reasons for the establishment of a Syrian Protestant College“: ABC 16.8.1., Vol. 6.

254 „Prospectus and Programme“: ABC 16.8.1., Vol. 6 (110).

255 American University of Beirut, History, URL: http://www.aub.edu.lb/main/about/Pages/history. aspx (Stand: Juli 2012). Auch unter der Leitung des Presbyterian Board werden von Seiten der Mission nach 1870 Studierende gefördert: vgl. SPC Jahresbericht (o. D., 1882): ABC 16.8.2., Vol. 2, 61 .

256 Daniel Bliss, „Extracts from Massachusetts“ (27.1.1862): ABC 76 (HHL). 
$\mathrm{Zu}$ Beginn, als eine syrisch-amerikanische Kooperation noch zur Debatte steht, wird von Seiten des ABCFM sogar die Wahl eines syrischen College-Präsidenten erwogen. ${ }^{257} \mathrm{Zu}$ viele Gegenstimmen in der Verwaltung wissen dies jedoch zu verhindern. Später wird dieser Schritt damit gerechtfertigt, dass sich sogar die Syrer für ein ausländisch geführtes College entschieden hätten, da einer solchen Institution mehr Vertrauen entgegengebracht werden könne. ${ }^{258}$ Zum Verwaltungsgremium (Board of Managers) in Beirut gehören u.a. die Missionare William M. Thomson, Cornelius Van Dyck, Henry H. Jessup sowie der Leiter des Missionsseminars in 'Abeih Simeon H. Calhoun. Zusammen mit anderen britischen Missionaren, amerikanischen und britischen Konsuln sowie britischen Geschäftsleuten sitzen insgesamt 18 Personen im Gremium. ${ }^{259}$ Bei der Gründung des Colleges bestehen demnach die Verwaltung und die Lehrerschaft bis auf die zwei arabischen Tutoren, Nāṣịf al-Yāziğ $\bar{i}^{260}$ für Arabisch und As'ad al-Šadūd̄īîn für Mathematik, ${ }^{262}$ ausschließlich aus Amerikanern. Im Laufe der Jahre kommen einige syrische Dozenten und Tutoren hinzu, jedoch erhält allein John Wortabet, der mit Van Dyck am medizinischen Institut lehrt, 1867 einen Professorentitel. ${ }^{263}$ Trotz der Zielsetzung im Programmheft von 1863, in nahezu allen Instituten ,educated and pious natives of the country" als Professoren und Lehrer einzusetzen „to assume the entire management of the institution as soon as possible“, ${ }^{264}$ schlägt das SPC einen völlig anderen Kurs ein. Etwa 40 Jahre später ist man immer noch davon überzeugt, dass eine Professorenschaft, bestehend aus Amerikanern und Europäern, nur von Vorteil für die Institution sein kann - ein unter syrischen Dozenten und Studierenden höchst umstrittenes Thema. ${ }^{265}$ Erst ab 1909 wird der erste syrische Dozent (für Arabisch) auf eine volle Professur berufen, weitere Syrer folgen ihm. ${ }^{266}$

$\mathrm{Zu}$ Beginn wird die arabische Sprache als Unterrichtssprache festgelegt, die Ausbildung ist derart ausgerichtet ,not to denationalize [the students] by the aquisition of foreign and expensive tastes and habits “ ${ }^{267}$ Dieses Vorhaben entspricht Andersons Vorstellungen, jedoch kann es nicht durchgehalten werden. Die arabische Sprache erweist sich schließlich als Defizit für eine qualitativ hohe Ausbildung. Zum einen erfordert sie, dass auch die nicht-einheimischen Lehrenden auf hohem

257 ABCFM an Bliss und Thomson (1861): ABC 76 (HHL).

258 So Bliss in den Reminiscences (1920), 165.

259 Yazigi (1964), 39. Laut Programmheft des Colleges („Prospectus and Programme“: ABC 16.8.1., Vol. 6 [110]) aus dem Jahr 1863 soll es nur dieses eine Gremium gegeben haben. Später kommt der Stiftungsrat in New York (Board of Trustees) hinzu.

260 Siehe Anhang II, Nr. 75.

261 Siehe Anhang II, Nr. 55.

262 Tibawi (1967), 276.

2631883 gibt es zehn amerikanische Professoren, Assistenzprofessoren und Tutoren sowie fünf syrische Lektoren und Lehrer: vgl. SPC Jahresbericht (1883): ABC 16.8.2., Vol. 2. Die Gleichstellung der arabischen und amerikanischen Lehrenden erfolgt erst mit der Umbenennung des Colleges in die American University of Beirut 1920.

264 „Prospectus and Programme“: ABC 16.8.1., Vol. 6 (110).

265 Mehr dazu in: Scholz (1997), 319-323.

266 Khalaf (1994), 66.

267 „Prospectus and Programme“: ABC 16.8.1., Vol. 6 (110). 
Sprachniveau ihr Unterrichtsfach unterrichten können. Zum anderen erschweren es die Lehrmaterialien, sich auf die arabische Sprache zu beschränken. Fachliteratur, die sich auf dem neuesten Stand befindet, ist vor allem auf Englisch. So wird zwischen den Jahren 1874 und 1883 die allmähliche Umstellung auf Englisch als offizielle Institutssprache durchgeführt. ${ }^{268}$ Ohne die Beherrschung dieser Sprache hätten die Studierenden keinen Zugang zu modernem Wissen und müssten sich auf Bücher beschränken ,,saturated with errors in religion, morals law, politics, medicine and social life“, wie Daniel Bliss, der selbst wenig Sachverständnis im Arabischen besitzt, im Jahr 1876 erläutert. ${ }^{269}$ Schließlich kann neue arabische Literatur nur dadurch entstehen, so der College-Präsident weiter, indem arabische Autoren durch die englische Sprache Zugang zum modernen Wissen erlangen: „If Arabic literature is ever to be enriched by books [...] these books must be written by the natives them-selves. “270 Die Sprachumstellung ermöglicht nun auch die Aufnahme von Absolventen anderer missionarischer Colleges in Istanbul (Robert College) und 'Aintab (Central Turkey College) sowie nicht-arabischer Bewerber aus anderen Ländern. ${ }^{271}$ Unter den Missionaren in Syrien gibt es jedoch auch Proteststimmen, die über die Umstellung empört sind, schließlich werden einige Absolventen aus 'Abeih, wo auf Arabisch gelehrt wird, dem College anvertraut. ${ }^{272}$ Für die amerikanischen Missionsschulen gilt Arabisch weiterhin als Unterrichtssprache. ${ }^{273}$

Das Ausbildungssystem des Colleges richtet sich völlig nach dem amerikanischen, was ihm den ambivalenten Ruf einer exzellenten Bildungsstätte im Nahen Osten verschafft, in der, so die Gegner, die Studierenden aber auch von ihrer Herkunft entfremdet werden. ${ }^{274}$ Für Außenstehende und Familienangehörige ist die Disziplin, die von den Studierenden verlangt wird, befremdlich: Vier Jahre lang müssen die College-Studenten ihren Studien ununterbrochen nachgehen, noch dazu getrennt von ihren Familien. ${ }^{275}$ Nicht in jedem Fall ist die ausländische Verwaltung des SPC von Nachteil: Neueste Instrumente und Lehrmaterialien werden regelmäBig beschafft, Missionare, Lehrende und Studierende tragen zu Pflanzen-, Tier-, Fossilien- und Mineralsammlungen bei, ${ }^{276}$ Sach- und Buchspenden aus den USA oder z. B. von der London Religious Tract Society sowie der British and Foreign Bible vergrößern den Fundus und den Bibliotheksbestand. ${ }^{277}$ Die besten Absolventen

268 Ğuha (2004), 150-151: Bei der Gründung des SPC wäre diese Maßnahme undenkbar gewesen, da die ersten Bewerber für das College keine genügenden Sprachkenntnisse in Englisch hatten.

269 SPC Jahresbericht (18.7.1878): ABC 16.8.2., Vol. 2, 45; Womack (2012), 9.

270 SPC Jahresbericht (18.7.1878): ABC 16.8.2., Vol. 2, 45.

271 Ğuha (2004), 162.

272 Tibawi zitiert aus dem Archiv des PBCFM (Index Vol. 4, Nr. 141: W. W. Eddy, 30.7.1878): vgl. ders. (1967), 281 (Anm. 50); Ğuha (2004), 163.

273 Womack (2012), 8.

274 Scholz (1997), 276-277.

275 Khalaf (1994), 63. 1869 berichten die Missionare, die Disziplinierung am College sei stärker als in den USA. Im Unterschied zu amerikanischen Colleges wird neben Französisch und Englisch auch Latein gelehrt: vgl. „Annual Report of Beirut Station, 1869“: ABC 16.8.1., Vol. 6 (39).

276 SPC Jahresbericht (Juni 1869, u.v. m.): ABC 16.8.2., Vol. 2 , 7.

277 „Statement of the Condition of the College“ (15.1.1869) und Jahresbericht (1886): ABC 16.8.2., Vol. 2, 5-6 und 96. 
haben die Möglichkeit, weiterführende Studien in den USA oder andernorts aufzunehmen. ${ }^{278}$ Auch wenn sich das College vorerst nicht mit westlichen Universitäten messen kann, so wird das Niveau mit Zunahme der Ausstattung allmählich gesteigert. Auf eigene Kosten richtet Van Dyck 1873 eine Sternwarte, das Lee Observatory, für den Astronomie-Lehrstuhl ein. ${ }^{279} \mathrm{Im}$ Laufe der Jahre hält die Sternwarte per Telegramm z. T. täglichen Kontakt zu gleichen Einrichtungen in Istanbul, Wien, London und Washington, um die gemessenen Daten auszutauschen. ${ }^{280}$

Für die puritanisch geprägten Amerikaner stellt die Verbindung von Wissenschaft und evangelischen Prinzipien, die das College in seiner Präambel enthält, keinen Gegensatz dar. Wissen im umfassenden Sinne fügt sich völlig in das evangelisch-christliche Weltbild ein. Die von den Missionaren und Lehrenden des SPC propagierte ,Wahrheit' „encompassed all ,correct' knowledge; religious doctrines, common-sense beliefs, and scientific theories". ${ }^{281}$ Bliss schreibt zur Interaktion von Glauben und Wissen: „Belief without knowledge may become a degrading, wicked superstition; with knowledge, it becomes a rational faith, soaring far above the knowledge, from which it started in its upward flight. “282

Als das College 1866 mit nur 16 Studenten eröffnet wird, erfreut es sich schnell größter Beliebtheit in der Bevölkerung. Das College öffnet von Anfang an seine Türen auch für Juden, Schiiten, Sunniten und Drusen. Bei der Grundsteinlegung für das Hauptgebäude auf dem 1871 neu erworbenen Gelände ${ }^{283}$ in Rās Beirut erklärt Bliss feierlich:

This College is for all conditions and classes of men without regard to colour, nationality, race or religion. A man white, black or yellow; Christian, Jew, Mohammedan or heathen, may enter and enjoy all the advantages of this institution for three, four or eight years; and go out believing in one God, in many Gods, or in no God. But it will be impossible for any one to continue with us long without knowing what we believe to be the truth and our reasons for that belief. ${ }^{284}$

Bliss' propagierte Offenheit muss jedoch immer vom letzten Satz dieser viel zitierten Rede her gelesen werden: Der Ausgangspunkt ist die evangelische Glaubenslehre. Obwohl sich das College durch seine Bibelgespräche und Andachten erhofft, Studenten für den evangelischen Glauben zu gewinnen, kann die tatsächliche Zahl der evangelischen Syrer, die am College studieren, als niedrig eingeschätzt werden. ${ }^{285}$ Schließlich finden sie in den Jahresberichten des Syrian Protestant College

278 Bliss (1920), 188.

$279 \mathrm{Zu}$ gegebenem Zeitpunkt besitzt das SPC nicht die finanziellen Mittel für die Einrichtung einer Sternwarte. Nach Van Dycks Kündigung wird die Ausstattung 1883 von ihm abgekauft: SPC Jahresbericht (10.7.1883): ABC 16.8.2., Vol. 2, 77.

280 SPC Jahresbericht (1877): ABC 16.8.2., Vol. 2, 38.

281 Reuben (1996), 2; Anderson (2011), 4.

282 Rugh (1956), 66.

283 Durch die zunehmende Öffnung des Osmanischen Reiches für Europa ist es für Ausländer ab der zweiten Hälfte des 19. Jh.s möglich, Grundstücke zu erwerben und diese steuerfrei zu halten. Eine wichtige Voraussetzung für die Etablierung des SPC: vgl. Tibawi (1966), 171.

284 Bliss (1920), 198.

285 Keines der evangelischen Colleges in den USA jener Zeit, wie Betty Anderson betont, verfolgt solche Bekehrungsbestrebungen wie das SPC in Beirut: vgl. dies. (2011), 3. 
kaum noch Erwähnung. ${ }^{286}$ Bis zum akademischen Jahr 1882/1883 stellt das SPC immer wieder einheimische Lehrer ein, die nicht der evangelischen Kirche angehören und zeigt sich so weltoffen, wie Bliss es im Jahr 1871 bekundet. Das Blatt wendet sich allerdings im Zuge der Affäre um den Chemie- und Geologieprofessor Edwin Lewis. Dieser hält im Juli 1882 eine Rede zur Examensfeier zum Thema „Knowledge, Science, and Wisdom“. ${ }^{287}$ Darin erläutert er die bewundernswerte Arbeit britischer Wissenschaftler wie Charles Darwin und anderen, die durch ihre Theorien über mögliche Ursachen von Phänomenen in der Natur aufklären. Nicht erst jetzt zeigt sich die Spaltung des Colleges in zwei Lager: einem konservativen unter Präsident Bliss, Prof. George Post, Prof. Harvey Porter sowie den Missionaren William Eddy und Henry Harris Jessup und einem liberalen unter Cornelius und William Van Dyck, John Wortabet, Edwin Lewis u. a. ${ }^{288}$ Lewis, der von der Collegeleitung wegen seines liberalen Verhaltens bereits vorher als Unruhefaktor eingestuft worden war, wird von einigen Seiten harsch attackiert. ${ }^{289}$ Auch die Syrienmission, unter der Wortführung von James S. Dennis, greift Lewis in öffentlichen Erklärungen an. ${ }^{290}$ Schließlich reicht Lewis seinen Rücktritt ein, der ohne Einspruch vom Stiftungsrat in New York akzeptiert wird: „Lewis’ resignation accepted takes effect at once - Salary to January forty pounds passage. Seventy-five pounds additional." ${ }^{291}$ Mit Lewis gehen ebenfalls etliche Studierende, die das Verhalten der Leitung des Colleges als anmaßend empfinden, ihren Professor mitten im Semester und kurz vor den Prüfungen zur Kündigung zu drängen. ${ }^{292}$ Ihre Petitionen für die Wiedereinstellung von Professor Lewis und die Beschwerden, im Stich gelassen worden zu sein, finden bei Bliss und seinen Kollegen jedoch kein Verständnis. Auch die Syrer Ya'qūb Șarrūf und Fāris Nimr, die nicht nur als Lehrer im naturwissenschaftlichen Institut des Colleges arbeiten, sondern seit 1876 ebenso die wissenschaftlich-handwerkliche Zeitschrift Al-Muqtataf herausgeben, sprechen sich für Lewis aus. Ihre Entlassung vom College hindert sie nicht daran, weiterhin informative Artikel zur Darwinschen Theorie in ihrer Zeitschrift zu veröffentlichen. ${ }^{293}$ Das College zieht aus dem Vorfall seine Konsequenzen: Zum einen werden die Arbeitsverträge fortan auf vier Jahre statt wie bisher auf 29 Jahre befristet, was enge Verbindungen zwischen Studierenden und Professoren verhindern soll. ${ }^{294} \mathrm{Zum}$ anderen werden ab 1883 alle Lehrenden dazu verpflichtet, eine Unterschrift unter die Declaration of Principles zu leisten, die nicht nur eine Mitgliedschaft in einer evangelischen Kirche voraussetzt, sondern ein Bekenntnis zum evangelischen Glauben sowie zu den missionarischen Zielen des Colleges fordert. ${ }^{295}$ "The orthodoxy of

286 Vgl. ABC 16.8.2., Vol. 2.

287 Ğuha (2004), 51-52.

288 Ebd., 54.

289 Ebd., 56-58.

290 Bliss (1993), 233 (Nr. 9).

291 „A Statement. 1883 by the President of the Board of Managers“: ABC 16.8.2., Vol. 2, 69.

292 Ebd.

293 Tibawi (1967), 287.

294 Tafîlì (2007), o. S.

295 SPC Jahresbericht (1883): ABC 16.8.2., Vol. 2, 80. Die einheimischen Lehrer Ya'qūb Șarrūf und Fāris Nimr werden daraufhin entlassen: vgl. Tibawi (1967), 289. 
the College must be identical with that of the American Presbyterian Mission“, so David Stuart Dodge vom Board of Trustees. ${ }^{296}$ Das College und die Mission, mittlerweile geleitet vom Presbyterian Board of Commissioners for Foreign Missions (PBCFM), gehen nun wieder aufeinander zu. Schon 1863 haben die am Aufbau des SPC beteiligten Missionare dafür plädiert, nur Lehrende am College einzustellen, die sich zum evangelischen Glauben bekennen. ${ }^{297}$ Die Einführung der Klausel 20 Jahre später deutet auf eine Kursänderung hin, der Liberalismus am College wird zurückgedrängt. Nach ihrer Entlassung im Jahr 1883 veröffentlichen Ya qūb Șarrūf und Fāris Nimr auch einige kritische Artikel über das SPC und seine Vorgehensweisen in der Lehre. Besonders nach den Ereignissen in den Jahren 1882 und 1883 ist für die Herausgeber klar, dass das College sein ursprüngliches Ziel verfehlt hat:

All our high schools in Egypt and Syria boast of such religious freedom except the school which is foremost among them, for it has abandonded its policy ... turned away from its original purpose of spreading learning and sought to impose a particular creed on its pupils. ${ }^{298}$

Auch der Entschluss gegen die arabische Sprache als Unterrichtssprache stößt auf große Kritik:

Some foreigners who come to spread learning in the Near East had abandoned the system of teaching through the medium of its languages. For they wanted to save themselves the effort of study and of writing books, and to safeguard for themselves, generation after generation, the teaching posts ... as a preliminary to the enhancement of the prestige of the state for which they desire to establish at least some moral influence, since language is a pillar of state. ${ }^{299}$

Schließlich wird die Religionsklausel für die Lehrerschaft mit der Amtsübergabe an den neuen College-Präsidenten Howard Bliss, Sohn von Daniel Bliss, im Jahre 1902 aufgehoben. ${ }^{300}$ Trotz der Kontroversen, die Șarrūf und Nimr mit dem College führen, sind sie weiterhin davon überzeugt, dass das SPC eine der wichtigsten Bildungseinrichtungen im Mittelmeerraum ist. ${ }^{301}$ Als erste Syrer wird ihnen 1890 die vom College verliehene Ehrendokorwürde zuteil. ${ }^{302}$

1920 wird das SPC in eine Universität umstrukturiert und heißt von nun an American University of Beirut. Die Universität verlässt den Kurs einer missionarischen Einrichtung und entwickelt sich zu einer Institution, die heute für freies Denken und die Förderung von Toleranz im Umgang mit Anderen steht. ${ }^{303}$

296 Dodge an Bliss (Watch Hill, 21.8.1882): AA.2.3.1.4.3.

297 Jessup (1910a), 274. Die gleiche Praxis verfolgt der ABCFM schließlich in den Missionsschulen. Nach Andersons Orientreise 1843/44 fordert er, dass in den Schulen nur noch evangelische Christinnen und Christen lehren dürfen: vgl. Anderson (1844), 29. Die Maßnahme hat etliche Schulschließungen zur Folge, da es an Lehrkräften fehlt.

298 Al-Muqtațaf 9 (1884-1885), übersetzt und zitiert in: Tibawi (1967), 289.

299 Ebd.

300 Grabill (1971), 29.

301 Makdisi (2010), 71.

302 Ebd., 74.

303 Anderson (2011), 5. American University of Beirut, Mission Statement, URL: http://www.aub. edu.lb/main/about/Pages/mission.aspx (Stand: Juli 2012). 
6. ,This field it seems to me to be unwise in us to forsake“304 - Hoffnungen, Enttäuschungen und Meinungsverschiedenheiten in der Syrienmission

Während des 19. Jh.s kann sich der ABCFM den Raum des Vorderen Orients durch weitere Missionsstationen erschließen: William Goodell ist in Armenien erfolgreich, Jonas King arbeitet in Griechenland, Eli Smith und Gray Otis Dwight unternehmen Reisen in den heutigen Irak, Justin Perkins und das Ehepaar Grant missionieren unter den Nestorianern in „Urumia“ (heute: Urmia im Iran). ${ }^{305}$ Flächendeckende Erfolge sind jedoch in keiner Missionsstation zu verzeichnen, es fehlt an finanziellen Mitteln und neuen Bewerbern aus der Heimat. ${ }^{306}$ Angesichts dessen lesen sich die von Enthusiasmus und Hoffnung geprägten Berichte im Missionary Herald, die selbst im letzten Jahr der vom ABCFM verwalteten Syrienmission 1870 noch abgedruckt werden, ${ }^{307}$ nahezu als Illusion. Andere Töne erklingen in den mahnenden Rundschreiben von Rufus Anderson („Our mission in Syria has not yet made a fair experiment of what a mission can do“) $)^{308}$ oder in mit „confident“ oder „private“ markierten Briefen von Missionaren, in denen interne Probleme offen angesprochen werden. Zum einen versucht Anderson, den Enthusiasmus einiger Missionare in Sachen Schulausbau, arabischem Buchdruck und sonstige kulturelle Arbeit in die Schranken zu weisen. Zum anderen zeigt sich die Gruppe der in Syrien stationierten Missionare in manchen Sachverhalten wie z.B. im Aufbau einheimischer Kirchen als nicht sehr homogen. Gleiches gilt schließlich auch für die vom ABCFM propagierte Missionsstrategie, die sich im Laufe der Jahrzehnte ändert. 1810 ist im Panoplist, dem Vorgänger-Periodikum des Missionary Herald noch zu lesen: „It is education which forms the Mohommetan [sic] and Pagan, the Jew and Christian. [...] The savage and the man of civilized society are formed by education." ${ }^{\text {309 }}$ Mit der ersten Auslandsmission in Bombay, in der man sich für die Gründung kostenfreier Schulen einsetzt, wächst in den USA und beim ABCFM das Bewusstsein, dass Missionsschulen als Teil der Auslandsarbeit unabdingbar sind. Zunehmende Erfahrungen im Ausland führen jedoch zum Umdenken beim ABCFM: „[T]he early missionary practice of taking science and civilization as companions to their religion not only proved to be the most troublesome and expensive but also the least productive." 6310

304 Anderson an die Syrienmission (On Board the Turkish Steamer, 23.4.1844): ABC 16.8.1., Vol. 8.

305 Die Mission in Urumia wird 1870 ebenso an den Presbyterian Board abgegeben.

306 Der Aufwand für die Westasienmission steigt ab 1830 zunehmend. Um 1860 wendet der ABCFM $45 \%$ seines Etats und Personals für die Missionen im Mittleren Osten auf: vgl. Perry (1974), 275. Im Missionary Herald wird mehrmals dazu aufgerufen, sich als Missionar für die Levante zu bewerben: MH 43 (1847), in: ROS 4, 15-16; MH 51 (1855), in: ROS 4, 229: „But for means, for instruments, for laborers, we look imploringly to that loved land which we have left. We want men, MEN, MEN!“‘.

307 MH 66 (1870), in: ROS 5, 347: „There is hardly a mission of the Board which has had a more checkered history; but the real promise of the field was never, probably, greater than now."

308 Anderson an die Syrienmission (Boston, 22.10.1842): ABC 16.8.1., Vol. 8.

309 ABCFM (1810), 517.

310 Lindsay (1965), 50, 54, 153. Davon ist Jessup auch Ende des 19. Jh.s noch überzeugt, obwohl sich der PBCFM wieder mehr im Bildungsbereich einsetzt: „Education is only a means to an 
Sowohl in Neuengland als auch in anderen Missionskreisen macht sich die Einsicht breit, dass Missionsschulen eine überflüssige Größe in den teuren Auslandsmissionen darstellen. ${ }^{311}$ Bildung scheint auf einmal verpönt zu sein. ${ }^{312}$ Andersons Forderungen nach einer Beschränkung auf Bekehrungsarbeit und die Nutzung der Schulen als Predigtorte für Kinder und Eltern werden daher ab den 1840er Jahren zunehmend lauter. 1856 erklärt der ABCFM ,civilization is not conversion!“313 Das einzige Ziel sei es nun, die Konvertiten in einheimischen, evangelischen Kirchen zu versammeln und ihnen einheimische Pfarrer vorzusetzen. ${ }^{314}$

Als sich 1842 abzeichnet, dass das Beiruter Missionsseminar aufgrund mangelnder Schülerzahlen schließen muss, ergreift Anderson die Gelegenheit und äußert: ,If your pupils in the Seminary are a constant annoyance and cost more oblique [?] and opposition than they are at present worth, dispense with the Seminary.“315

Auch die Missionsdruckerei und die aufwendigen Übersetzungsarbeiten stellen eine Gefahr für das Gelingen des Missionsunternehmens dar. Sie nehmen zu viel Zeit ein, die für die Bekehrung von Einheimischen verwendet werden könnte:

I ought perhaps to say, that the labors of this mission, as a whole, seemed [...] to have been somewhat less adapted than was desirable to excite religious feeling among the people. So far as there was this defect, (and the brethren freely admitted its existence,) it has been in part owing to the absorbing demands of the press on some of the brethren, and of education on others; and in parts, it may be, to habits of preaching and laboring that arose under past unfavorable states of the field and of the mission. ${ }^{316}$

Anderson will in jedem Fall verhindern, dass Beirut eine schlichte „book-making station" und 'Abeih eine reine „educating station" wird. ${ }^{317}$ Buchdruck und Schulbildung werden nicht mehr als notwendige Basisarbeit für die Bekehrung der Bevölkerung angesehen. In Beirut sieht man das anders, wie der Kommentar von Smiths erster Frau Sarah deutlich macht:

end in Christian missions, and we do not hesitate to say that such a mission has stepped out of the Christian and missionary sphere [that] aim[s] to have the best astronomers, geologists, botanists, surgeons and physicians in the realm for the sake of the scientific prestige and worldwide reputation.": vgl. Jessup (1910a), 592.

311 Harris (1999), 39, 55.

312 Erst Ende des 19. Jh.s kommt es zu einem erneuten Umdenken in den westlichen Missionsgesellschaften. Die Missionen haben zwar in erster Linie das Ziel der Christianisierung, aber Bildung sei der Hebel, der alles in Bewegung setze. „[W] $[\mathrm{W}$ at could be higher than western civilization? Western education was the ladder which led up to influence, affluence, and general enlightenment": vgl. Bonk (1989), 161-162.

313 ABCFM, The Divine Instrumentality for the World's Conversion, Boston 1856, 4, zitiert in: Lindsay (1965), 154. Ebenfalls 1856 veröffentlicht das Prudential Committee seine Outlines of Missionary Policy. Darin heißt es: „Missions are instituted for the spread of a scriptural, selfpropagating Christianity. This is their only aim. Civilization, as an end, they never attempt; still they are the most successful of all civilizing agencies." Zitiert in: Harris (1999), 149.

314 Anderson an die Syrienmission (Boston, 27.6.1850): ABC 2.1.1., Vol. 13 (HHL).

315 Anderson an die Syrienmission (Boston, 22.10.1842): ABC 16.8.1., Vol. 8.

316 Anderson (1844), 26.

317 Anderson an die Syrienmission (Boston, 6.11.1851): ABC 2.1.1., Vol. 15 (HHL). 
$[R]$ especting the succes of our labors, I would say, that with our press, schools, preaching, conversation, and other social intercourse, in which we are busy from morning till night, we feel that a broad foundation is being laid, upon which, at some future day - God knows when - a glorious superstructure will be raised. ${ }^{318}$

Doch die Erfolge sollen nicht erst in ferner Zukunft erkennbar sein. Kurz vor Andersons Reise in die Levante 1843/1844 sind der American Board sowie einige junge Missionare in Syrien unsicher, ob die Syrienmission fortbestehen kann. Während die Seniormissionare in Beirut schließlich vom Erfolg der Mission überzeugt sind, zeigen sich jüngere Mitarbeiter völlig desillusioniert. ${ }^{319}$ Eli Smith schreibt daher am 5. November 1842 an Anderson: ,let me beg you with tears on behalf of the dying souls around me [...] not to give up your hopes of this mission". ${ }^{320}$ Nach seinem Besuch in Syrien zeigt sich Anderson von Land und Leuten begeistert und gibt der Mission eine weitere Chance. ${ }^{321}$ Seine Hoffnungen werden jedoch enttäuscht. 1855 reist er erneut in die Levante, um zu wiederholen, was die Missionare vermutlich nicht einsehen wollen: ,[T] he governing object of every mission and of every missionary should not be to liberate, to educate, to enlighten, to polish, but convert men. “322

Uneigennützigkeit, Philanthropie, Erbauung und Aufklärung allein reichen nicht aus, um die Mission voranzubringen, so der Chefsekretär. ${ }^{323}$ Derartige Anschuldigungen haben die im Bildungsbereich äußerst engagierten Missionare Calhoun, De Forest, Smith oder Van Dyck vermutlich schwer getroffen. Es geht Anderson nicht um die gegenwärtigen Fortschritte, die durch die Lehrtätigkeiten und die Verbreitung von Büchern durchaus erkennbar werden, sondern um den Nutzen für die Ewigkeit. Wohlgesinnte Förderer werden nur für den Moment zufrieden sein, aber , , $[\mathrm{t}]$ hey will soon grow weary of the repeated calls made upon their benevolence". 324

Was die Amerikaner sowie deren Ehefrauen und Assistentinnen in Syrien aufbauen können, lässt sich jedoch nicht in Zahlen von Konvertiten fassen. Die Einflüsse der missionarischen Bildungsinstitutionen auf Generationen junger Sy-

318 Hooker (1840), 323. Laut Andersons Schilderung in seiner History of the Missions to the Oriental Churches waren viele Missionare der Meinung, dass die Bildungsarbeit im gleichen Verhältnis zum Predigen steht: vgl. Anderson (1872a), 263.

319 Elias Beadle bittet Anderson 1842, die Mission wieder verlassen zu dürfen: vgl. Anderson an Smith (Boston, 24.10.1842): ABC 2.1.1., Vol. 5 (HHL). Samuel Wolcott und Leander Thompson sind ebenso unzufrieden und verlassen Beirut 1843, nachdem sie Anderson über die Perspektivlosigkeit der Mission berichtet haben: vgl. Wolcott an Anderson (Beirut, 1.6.1842): ABC 16.5., Vol. 3: „The present state of our whole field [...] is one which sinks into unimportance.“; Badr (1992), 225-226.

320 Smith an Anderson (Beirut, 5.11.1842): ABC 16.8.1., Vol. 1 (157).

321 Anderson an die Syrienmission (On board the Turkish steamer, 23.4.1844): ABC 16.8.1., Vol. 8.

322 ABCFM (1856), 9. Was die Jungen- und Mädchenseminare anbelangt, so bekräftigt Anderson: „They are not mere educational establishments; the mission should not regard them as such, nor the Board support them as such $[\ldots]$.. Es geht nicht darum, auszubilden, ,but to make wise unto salvation": ebd., 11-12.

323 ABCFM (1856), 10.

324 Ebd., 11. 
rerinnen und Syrer treten deutlich zutage, werden dem eigentlichen Missionsauftrag jedoch nicht gerecht. ${ }^{325}$ War die Mission also doch ein Erfolg? Dem American Board bleibt 1870 nichts anderes übrig als den eigentlichen Misserfolg als Erfolg zu deklarieren:

There are the results of labors hitherto put forth - the converts gathered into churches, the communities of Protestants formed, the schools established, the books printed, the knowledge diffused, the prejudices broken, the broad deep foundations laid of civilization, science and religion, during forty-eight years of labor. ${ }^{326}$

Im Folgenden wird noch zu prüfen sein, ob die Aussage eines drusischen Sheikhs, die das Resümee der Mission im Missionary Herald von 1870 schmückt, der Wahrheit entspricht: ,[T]he American missionaries alone had done more good in this land, by educating and civilizing the people, than Greeks, Catholics, Maronites and Druzes all together. “327

\section{I.2. KULTURELLE TRANSFORMATIONSPROZESSE IN SYRIEN IM 19. JAHRHUNDERT}

Beirut was at once the product, the object, and the project of imperial and urban politics of difference. Overlapping European, Ottoman, and local civilizing missions competed in the political fields of administration, infrastructure, urban planning, public health, education, public morality, journalism, and architecture. ${ }^{328}$

\section{Wichtige politische Entwicklungen}

Im Jahr 1516 wird die Provinz Syrien von den Osmanen eingenommen und in verschiedene Herrschergewalten (wilāya) unterteilt. Das wilāya Damaskus umfasst u. a. die Städte Tyros, Sidon, Beirut, das Libanongebirge und die Beqā-Ebene im Osten des heutigen Libanon. Innerhalb des Libanon werden wiederum lokale Gouverneure eingesetzt, darunter der reformfreudige Drusenfürst Emir Bašir II. (17941840), der zum maronitischen Christentum konvertiert und für die Unabhängigkeit der Justiz von Feudalherren und religiösen Führern eintritt. Aufgrund innerer Unruhen flieht Emir Bašir II. Ende der zwanziger Jahre des 19. Jh.s in die osmanische Provinz Ägypten, wo er sich mit dem dortigen Gouverneur (walī) Muhammad 'Alī verbündet, dessen Sohn Ibrahīm 1831 für die Unabhängigkeit Ägyptens gegen die osmanischen Armeen in Palästina einmarschiert und bis 1832 in das gesamte syrische Gebiet vordringt. Trotz der militärischen Einnahme erfährt das Land in dieser Zeit einen wirtschaftlichen und kulturellen Aufschwung, der an die Gegebenheiten

325 Khalaf (2001), 134: „much of what they did, indeed the very location of field stations and specific outcomes of their labours was largely unintended, by-products of both their good intentions and their considerable ignorance of the areas they were seeking to evangelize".

326 MH 66 (1870), in: ROS 5, 256.

327 MH 55 (1859), in: ROS 4, 346.

328 Hanssen (2006), 4. 
in der ägyptischen Gesellschaft angeglichen wird. ${ }^{329}$ Eli Smith schreibt dazu 1833: „And to their effect doubtless, in part, is to be ascribed the tolerance of religious discussion under that government [...]. The extension of Egyptian rule over Syria has undoubtedly given these increased facilities for missionary operations. “330

Ibraḥīm stärkt die lokale Verwaltung, setzt sich gegen Korruption ein, baut repräsentative Gremien in großen und kleinen Städten auf, er fördert die religiöse Toleranz zwischen Muslimen und Christen und sorgt für das industrielle Wachstum in der Region. Mit der Vergrößerung des Beiruter Hafens expandiert ebenfalls der Seidenexport des Landes. ${ }^{331}$ Doch die syrische Bevölkerung leidet auch unter der ägyptischen Besatzung. Hohe Steuerauflagen, die Wehrpflicht, die Aufrechterhaltung feudaler Strukturen sowie die Einmischung in konfessionelle Fehden durch gezielte Waffenlieferungen führen 1840 zu einer Rebellion von Maroniten, Drusen, Schiiten und Sunniten gegen Muhammad 'Alī und seinen Sohn Ibrahīm. ${ }^{332}$ Durch ein Bündnis mit Istanbul, unterstützt von England und Österreich, werden der Beiruter Hafen bombardiert und die ägyptischen Truppen zurückgedrängt. ${ }^{333}$ Die von den Ägyptern angestoßenen Reformimpulse können von der osmanischen Regierung jedoch nicht mehr aufgehalten werden. ${ }^{334}$

Durch österreichische Einflussnahme wird schließlich das Libanongebirge in zwei politische Einheiten ( $q \bar{a}$ 'immaqāmīya) unterteilt, innerhalb derer den Drusen und Maroniten jeweils eine gewisse Eigenverwaltung zugesprochen wird. ${ }^{335}$ Die ungleiche Verteilung wirtschaftlicher und politischer Kräfte auf die beiden Verwaltungsgebiete ebnet zum einen den Weg für ein konfessionell geprägtes politisches System im Land und führt zum anderen immer wieder zu Auseinandersetzungen zwischen Drusen und Maroniten. Schließlich münden zahlreiche gewalttätige Aufstände in den 1840er und -50er Jahren in den Bürgerkrieg von 1860, ${ }^{336}$ dessen Hö-

329 Im Zuge des Ägyptenfeldzugs Napoleons (1798-1801) hat Frankreich einen großen Einfluss auf die kulturelle Entwicklung Ägyptens, besonders während der Herrschaft von Muhammad 'Alī. Die Auswirkungen sind in Syrien jedoch nicht vor der ägyptischen Besatzung in den 1830er Jahren zu spüren: vgl. Fāris (1958), 380.

330 Smith (1833), 216.

331 Traboulsi (2007), 12.

332 Dazu Eli Smith im Jahr 1833: „[T] poverty, and wretchedness. [...] We hear much of the improvements of Mohammed Ali, but all are intended to increase his power and his income, none for the benefit of his people."Vgl. ders. (1833), 26-27.

333 Traboulsi (2007), 12-13.

334 Jandora (1981), 12.

335 Drusen und Maroniten wird jeweils ein Vertreter (wakīl) bei der Hohen Pforte zugeteilt: vgl. Traboulsi (2007), 16.

336 U.a. geraten Drusen und Maroniten 1842 und 1845 aneinander: vgl. MH 38 (1842), in: ROS 3, 324-325; MH 41 (1845), in: ROS 3, 442-443. Die Konflikte zwischen beiden Religionsgruppen werden von der osmanischen Regierung zusätzlich dadurch geschürt, dass sie die Macht der Maroniten und Drusen aufbrechen wollen, um ihre Politik der Zentralisierung und Osmanisierung fortführen zu können: Hitti (1959), 226.

Anlass für den Bürgerkrieg 1860 ist der erneute Angriff der Maroniten auf drusische Dörfer. Mithilfe Englands und der osmanischen Regierung schlagen die Drusen heftig zurück: vgl. Richter (2006), 115. 
hepunkte die von Drusen verübten Massaker an Christen im Libanongebirge und in Damaskus darstellen. ${ }^{337}$ Das Jahr 1860 wird zum politischen, sozialen und kulturellen Wendepunkt des Landes. Gestützt durch europäische Mächte werden die beiden $q \bar{a}$ 'immaqāmīya zu einem Verwaltungsgebiet (mutassarifìya) mit eingeschränkter Autorität innerhalb des osmanischen Reiches zusammengefügt. Damit wird der Weg in die Autonomie des Libanon geebnet, da er nun seine eigene Judikative und Exekutive besitzt. ${ }^{338}$ Der mutassarifíya steht ein administratives Konzil mit zwölf Mitgliedern (sieben Christen und insgesamt fünf Muslimen und Drusen) vor, ${ }^{339}$ wodurch die Mitwirkung führender Geistlicher in der Politik der Region gemindert wird. ${ }^{340}$ Dieser Umstand hat großen Einfluss auf die zunehmende Akzeptanz neuer Religionsgruppen (z. B. der Protestanten) und ihre politische Legitimierung. Sozialer und wirtschaftlicher Aufschwung, Wachstum im Bereich der Landwirtschaft sowie die Steigerung der Grundstückspreise um etwa hundert Prozent prägen diese Zeit im Libanongebirge. ${ }^{341}$ Dennoch kann das neue Verwaltungssystem die konfessionellen Fehden nicht verdrängen.

Mit dem Abzug der Ägypter vollzieht sich eine gesamtpolitische Veränderung im Osmanischen Reich, die sich vor allem in der ab 1839 beginnenden Reformperiode, genannt Tanzīmāt (Anordnungen), abzeichnet. Sie kann als letzter Versuch des Reiches verstanden werden, den spürbaren Zerfall des Machtbereichs aufzuhalten und den Forderungen der europäischen Länder zu entsprechen. ${ }^{342}$ Im Zuge dieser Reformen wird die Ungleichbehandlung nicht-muslimischer Religionsgemeinschaften beendet und somit neben anderen Gesetzen das Recht auf Glaubensfreiheit für jeden garantiert. Zwei wichtige Reformpapiere sind an dieser Stelle besonders hervorzuheben, die das seit dem frühen Mittelalter bestehende millet-System ${ }^{343} \mathrm{ab}$ geschafft und damit die Akzeptanz einer sich neu bildenden protestantischen Gemeinschaft in Syrien gefördert haben: 1839 wird das Hatt-l Scherīf von Gülhane (das edle Handschreiben von Gülhane) unterzeichnet, das allen Bürgern des Reiches den Schutz von Leben und Eigentum zuspricht, ${ }^{344}$ und 1856 tritt das HattHümāyūn (das Großherrliche Handschreiben) in Kraft, womit allen Bürgern im

337 Traboulsi (2007), 32-35. Ausführlicher zu den Ereignissen um 1860 in: Makdisi (2000).

338 Hourani (1954), 32-33.

339 Traboulsi (2007), 43.

340 Für Jessup (1910a, 218) ist die neue Verwaltungsinstanz ein Zeichen für den nahenden Aufschwung Syriens: „A stable, free, and virtually independent government was established in Lebanon. This was politically and socially the greatest boon to Syria in modern times. It is the freest, most peaceful and prosperous province in the empire, and is envied by the other provinces. It opened the way for the vigorous and industrious people to improve their property without fear of armed horsemen, tithe gatherers, extortioners and bribe-taking officials. No longer do mercenary judges and arbitrary rulers intimidate witnesses and corrupt the tribunals."

341 Hitti (1957), 442-444.

342 Lindner (2009), 80: ,[T] The Tanzimat era was a period of negotiation between the Ottoman Porte and his subjects (and amongst the subjects) to navigate and delineate the ever-shifting distributions of political power." Vgl. auch Hourani (1954), 30.

343 Jede millet (Religionsgruppe) wird durch den jeweiligen religiösen Führer verwaltet, der in Sachen Ehe, Scheidung, Erbe und anderen persönlichen Dingen Recht spricht: vgl. dazu Yazigi (1964), 13; Tibawi (1966), 109.

344 Tibawi (1969), 95. 
Reich das osmanische Untertanenrecht zugesprochen wird. Die Gleichstellung aller Ethnien und Religionsgruppen ermöglicht die Teilhabe an allen öffentlichen Berufen sowie am Militärdienst, was den millet vorher verwehrt war. ${ }^{345}$ Dies betrifft auch die Protestanten, die sechs Jahre zuvor noch durch diplomatische Bemühungen der Briten als millet eingestuft wurden. Nun gilt auch für sie die Gleichstellung mit allen Bürgern des Osmanischen Reiches. ${ }^{346}$

\section{Die Entstehung einer bildungsnahen Mittelschicht in Beirut}

Unter Muḥammad 'Ālī und seinem Sohn Ibraḥ̄m wird Beirut während der Besatzungszeit zum Zentrum der ägyptischen Regierung in Syrien und löst damit Damaskus und Akko als Provinzzentren des Bilād al-Šām ab. Strukturelle Veränderungen wie der Hafen- bzw. Straßenausbau sowie ein Abwassersystem verbessern die Lebens- und Hygienebedingungen in Beirut erheblich. ${ }^{347}$ Diese Umstände führen zu einem stetigen Bevölkerungswachstum innerhalb der Stadt. Besonders Christen, die zumeist im Import und Export arbeiten, sind als erfolgreiche Händler im internationalen Handelsverkehr und im steigenden Import europäischer Waren tätig. ${ }^{348}$ Viele von ihnen haben Missionsschulen besucht und arbeiten darüber hinaus als Dolmetscher für ausländische Konsulate, als Schriftsteller, Büroangestellte sowie als Vermittler zwischen europäischen Investoren und lokalen Einzelhändlern, da sie des Arabischen sowie vieler europäischer Sprachen mächtig sind. ${ }^{349}$ Für die amerikanische Mission bedeutet das Abwerben ihrer Schüler, wie im Fall des Beiruter Jungenseminars, dass jahrelang vergebens in die Schulen investiert wurde. Die politischen Veränderungen und die Öffnung des Marktes haben aus dem ruhigen Beirut einen umtriebigen Ort werden lassen, so die Amerikaner: „Beirut was a comparatively quiet and retired place. It constantly changed for the worse by the increase of foreigners, sailors and soldiers, until the time of the English invasion, when every bad influence multiplied to an indefinite and most fatal degree. ${ }^{\text {(350 }}$

345 Ebd., 177. Bereits 1853 erlässt Sultan 'Abdul Meğid ein Sendschreiben an den wakīl der Protestanten mit folgenden Worten: „es [ist] [...] der Kernpunkt Meiner Wünsche [...], dass alle Classen Meiner Unterthanen eines vollkommenen Schutzes geniessen und besonders in ihren religiösen Gebräuchen und Angelegenheiten, wie es von jeher üblich war, ohne Ausnahme völlig unangefochten bleiben [...]. Da Ich Mir es ferner zur Aufgabe gemacht habe, auch die für Meine treuen protestantischen Unterthanen in Betreff ihrer speciallen Confessions- und Cultusangelegenheiten von Mir ertheilten besonderen Bewilligungen zu bewahren": vgl. „Neue Verordnung des Sulțân 'Abdulmeǵîd seiner protestantischen Unterthanen“, in: ZDMG 9 (1855), 844-846.

346 Lindner (2009), 86; Kawerau (1958), 479-480.

347 Lindner (2009), 95. Doch auch nach dem Abzug der Ägypter ist die osmanische Regierung besonders aufgrund der Präsenz westlicher Missionen bestrebt, „to perform and offer modern urban services": vgl. Hanssen (2006), 120-122 (hier: 122).

348 Zachs (2005), 39-41. Einige Händler haben Verbindungen zur protestantischen Gemeinschaft und sind teilweise sogar Mitglieder in der Beiruter Kirchengemeinde: vgl. Lindner (2009), 97.

349 Zachs (2005), 55-59.

350 ABCFM, Annual Report (1844), 133. 
Für die Syrienmission wird Beirut zu einer weltlichen, aber aufgrund seiner geopolitischen Lage unabdingbaren Missionsstation. Nichtsdestotrotz tragen auch die Absolventen der missionarischen Einrichtungen zur Entwicklung Beiruts bei. Viele in der Stadt lebende Christen repräsentieren die neue wohlhabende Mittelschicht, deren Bedarf an Schulbildung für die eigenen Kinder fortwährend steigt. ${ }^{351}$ Auch die vielen blutigen Auseinandersetzungen zwischen Christen und Drusen, vor allem in den Jahren zwischen 1840 und 1860 führen zur Abwanderung christlicher Familien aus dem Libanongebirge und dem Šuf, einem vornehmlich drusischen Gebiet südöstlich von Beirut. Somit wächst zwischen 1858 und 1863 die Einwohnerzahl Beiruts von 50.000 auf 70.000 an, ${ }^{352}$ was auch daran liegen mag, dass internationale Hilfsprogramme vor allem in der Stadt die Flüchtlinge ärztlich versorgen und finanziell unterstützen. ${ }^{353}$ Um 1860 ist das Bedürfnis nach Bildung so groß wie nie zuvor. Nicht nur der Ausbau der ökonomischen Infrastruktur verlangt nach neuen Berufszweigen und Kenntnissen europäischer Sprachen, auch der allmähliche Zusammenbruch tribaler und feudaler Strukturen durch die mutassarifiya und damit der Einflussnahme der führenden Geistlichen auf ihre Gemeindemitglieder führt zu einem Andrang bei westlich-missionarischen sowie osmanischen Schulen. ${ }^{354}$

„Christian schools have multiplied, the Turkish schools for boys and even girls are crowded with pupils, newspapers are published and read, and there is friendly intercourse between Moslems, Christians and Jews. “355 Diese positive Einschätzung Jessups im Jahr 1860 soll nicht darüber hinwegtäuschen, dass die amerikanische Mission in Sachen Grundschulbildung den Anschluss in den Nachkriegsjahren verpasst. Starke Etatkürzungen führen dazu, dass fast alle Missionsschulen, die während des Bürgerkriegs schließen mussten, geschlossen bleiben. ${ }^{356}$ Der 1861 beginnende Bürgerkrieg zwischen den US-amerikanischen Nord- und Südstaaten verursacht massive finanzielle Engpässe in den Missionsunternehmungen des ABCFM: „No boarding-schools could be reopened - no new books published no new missionaries sent out. "357 Angesichts der vielen christlichen Flüchtlinge in der Stadt können die Amerikaner die Gunst der Stunde nicht für sich nutzen und ihre Evangelisierungsarbeit fortsetzen. Viele Missionare engagieren sich zwar in den von westlichen Mächten initiierten Hilfsprogrammen, jedoch sehen sie für sich kaum noch eine Perspektive. ${ }^{358}$

351 Laut Hitti $(1959,231)$ herrscht in Syrien zuvor eine Zweiklassengesellschaft, zum einen Aristokraten, Geistliche und Großgrundbesitzer und zum anderen Bauern, Handarbeiter und Arme.

352 Ende des 19. Jh.s beträgt die Einwohnerzahl Beiruts etwa 120 000: Hitti (1959), 232.

353 Hanssen (2006), 141. Nach 1860 machen es sich britische, amerikanische und deutsche Missionare zur Aufgabe, die Opfer des Krieges mit Kleidung, Nahrung und Medizin zu versorgen. Sie schließen sich zu einem Relief Committee zusammen, das Gelder sammelt, um die Hilfsprogramme in der Stadt und im ganzen Land zu finanzieren: vgl. Jessup (1910a), 209, $213,251$.

354 Lindsay (1965), 172.

355 Jessup (1910a), 218.

356 Jessup (1910a, 239) schreibt dazu an anderer Stelle: „November, 1861, was a period of great anxiety. The Board had cut off $\$ 6,000$ from our mission funds. We were all overworked.“

357 Ebd., 213.

358 Lindsay (1965), 175; Jessup (1910a), 234: „But the relief work we were engaged in in Syria was a duty so high and pressing we had to choke down our eagerness to go home and do our share.“ 
Into the vacuum, however, came British and German agencies which supplied relief and schools, indigenous elements made their own attempt, an independent American university was called into existence, and French Catholics found a fertile field in which society's appetite had been whetted by the influence of the French occupation. ${ }^{359}$

Vor allem die bevorstehende Eröffnung des Syrian Protestant College verschafft der Mission wieder neuen Auftrieb. Was die gesellschaftlichen Umbrüche anbelangt, so spielen die Amerikaner durchaus eine Rolle. Sie arbeiten mit angesehenen Intellektuellen ihrer Zeit zusammen und engagieren sich auch außerhalb der Syrienmission im aufblühenden Bildungsbürgertum Beiruts.

\section{Schulbildung im Osmanischen Reich}

In Sachen Schulbildung nimmt das Osmanische Reich seinerzeit durchaus keine Sonderstellung ein. Das 19. Jh. zeichnet sich durch die Bildung eines flächendeckenden, religionsunabhängigen, öffentlichen Schulsystems in Nordamerika, ganz Europa, im Osmanischen Reich, im Iran und später auch in China aus. ${ }^{360}$ Man kann also nicht davon ausgehen, dass ohne die Missionsschulen indigene Initiativen für eine solide Grundschulbildung ausgeblieben wären, sie haben sie lediglich beschleunigt. In der Tat besteht im Osmanischen Reich ein Ungleichgewicht zwischen christlichen Bildungseinrichtungen, die von Europa und Nordamerika gefördert werden, und muslimischen Schulen, in denen es schlichtweg an qualifizierten Lehrkräften mangelt. Hinzu kommt der Widerstand der muslimischen Gemeinschaft ( 'ulamā), die das System der Koranschulen (madrasa) nicht aufgeben will. ${ }^{361}$ Die osmanische Regierung befürchtet, gegenüber den Christen immer mehr ins Hintertreffen zu geraten. ${ }^{362}$ Doch in Istanbul wird nur zögerlich darauf reagiert. Erst 1869 wird ein öffentliches Schulgesetz eingeführt, das durch die Förderung säkularer Bildung und die Reformierung der Koranschulen gekennzeichnet ist. ${ }^{363}$ Durch die Bildungsreform innerhalb der Tanżimāt-Reformen soll gegenüber Europa demonstriert werden, dass man Bildung und Kultur in ausreichendem Maße fördern möchte. ${ }^{364}$

359 Lindsay (1965), 180.

360 Deguilhem (1998), 224.

361 Scholz (1997), 39.

362 Deguilhem (1998), 229.

363 Somel (2001), 83: Mit der Bildungsgesetzgebung soll die Grundschulausbildung nicht mehr in den Händen der Religionsgemeinschaften liegen, sondern verstaatlicht werden. Die Gesetze können gesehen werden ,as a part of the Ottomanist project by trying to integrate Muslim, non-Muslim and foreign schools within a legal framework, and to found government schools for non-Muslim communities“.

364 Somel (2001), 17; Diab/Wåhlin (1983), 109: Im Zuge der Gesetze werden vier Schulformen entworfen: eine vierjährige Grundschulausbildung (ibtid $\bar{a} \hat{\imath})$, eine militärisch geprägte Volksschule (rušdìya), sowie eine vorbereitende Schule ( $\left.i^{\prime} d \bar{a} d \bar{l}\right)$ für die Oberschule bzw. das Gymnasium (sultānn $\bar{l}$. Gegenüber den traditionellen Koranschulen (kuttāa $b$ und madrasa) sind die Curricula dieser Schulen viel umfangreicher. Zur Grundschulbildung kommt Arithmetik, Geschichte, Geografie und Hygiene hinzu, in der Oberschule werden Mathematik, Physik, Chemie, Biologie, Staatsbürgerkunde, Türkisch, Französisch und andere Sprachen gelehrt. 
Leider kann das Gesetz nicht in allen Provinzen konsequent genug umgesetzt werden. ${ }^{365}$

In der Gesellschaft herrscht bis zur Mitte des 19. Jh.s die Überzeugung, dass Bildung eine Angelegenheit der Familie und der religiösen Gemeinschaften, jedoch nicht des Staates sei. ${ }^{366}$ Daher werden in der ersten Hälfte des 19. Jh.s zahlreiche Schulen eröffnet, deren Träger ausländische Organisationen ${ }^{367}$ oder einheimische kirchliche Institutionen sind, ${ }^{368}$ die sich insgesamt stark am europäischen Bildungskanon orientieren. ${ }^{369}$ Die Motivation, Missionsschulen zu gründen hat neben der bereits beschriebenen Intention, die Bevölkerung zu alphabetisieren, um ihr die Bibel näher zu bringen, auch noch eine andere Ursache: So inakzeptabel wie der Irrglaube der orientalischen Christen ist den protestantischen Missionaren auch die Einflussnahme katholischer Missionen. Oftmals wird nicht unweit einer amerikanischen Missionsschule auch eine jesuitische eröffnet und andersherum. Dieses Konkurrenzverhalten ist für die syrische Bevölkerung durchaus von Vorteil. ${ }^{370}$ Darüber hinaus lässt sich beobachten, dass die Amerikaner im Laufe der Zeit eine gewisse Monopolstellung im Bildungsbereich für sich beanspruchen, und das, obwohl der ABCFM die Bildungsarbeit einschränken will: Beispielhaft dafür sind die sogenannten „Libanon-Schulen“, eine Initiative der syrischen Brüder Sulaymān und Elyās al-Șalībī sowie des Engländers John Lowthian. Sulaymān ist Absolvent des Seminars in 'Abeih und hegt schon sehr früh den Wunsch, als Missionar unter den eigenen Landsleuten zu arbeiten. ${ }^{371}$ Die Salīîi-Brüder und Lowthian planen, vor allem in entlegeneren Dörfern im Inneren des Landes Schulen zu errichten, die Kindern aller Religionsgemeinschaften eine Schulbildung fern von Konvertierungsbestrebungen bieten sollen. ${ }^{372}$ Strukturell und inhaltlich orientieren sich die Libanon-Schulen stark an den amerikanischen Missionsschulen. ${ }^{373} \mathrm{Zu}$ den bevorzugten Materialien gehören die von der British and Foreign Bible Society

365 Cioeta (1982), 42.

366 Cioeta (1982), 40.

367 So z. B. die von den Schotten unterstützten Libanonschulen (s. u.), die von Quäkern errichteten Schulen in Brummāna, eine ganze Reihe britisch-syrischer Schulen, die Internate der Kaiserswerther Diakonissen, Schulen der Church of Scotland sowie von individuellen Missionaren eröffnete Schulen: vgl. Womack/Lindner (2014), 130-131.

368 Der Journalist Šahīn Makārīūs stellt in seinem Artikel „Bildung in Syrien“ eine Liste der Schulen zusammen, die in den verschiedenen großen und kleinen Städten des Landes gegründet wurden. Für Beirut nennt er nach den Missionsschulen eine 1860 von Engländern gegründete Internatsschule für Mädchen, die griechisch-orthodoxe Zahrat al-Ihsānn-Schule (Blume der Barmherzigkeit), die vom griechisch-katholischen Patriarchen 1865 gegründete Patriarchatsschule (arab. Batriyarkiya), die 1874 vom maronitischen Patriarchen etablierte „Schule der Weisheit“" sowie die staatlich-militärische rušdīya-Schule: vgl. „Al-ma arīf fī Sūrīya“ (Bildung in Syrien), in: al-Muqtațaf 7 (1882/1883), 389-390, zitiert und übersetzt in: Diab/Wåhlin (1983), 117. Staatliche Schulen befinden sich zudem in Tripoli, Sidon, Tyros sowie in den Regionen 'Aqqar, Beqā' und Marğa yūn: vgl. Matthews/Akrawi (1949), 407 (Anm. 1).

369 Um 1875 gibt es in fast jedem christlichen Dorf eine Grundschule: vgl. Cioeta (1982), 41.

370 Womack (2012), 14.

371 Abu-Husayn (1998), 207.

372 Ebd., 205.

373 Ebd., 207. 
sowie der American Mission Press produzierten Bücher wie die Bibel, Kleiner Katechismus von Assembly und John Bunyans The Pilgrim's Progress. ${ }^{374}$ Darüber hinaus werden die für diese Zeit gängigen Schulbücher für Geografie, Grammatik und Arithmetik verwendet, die vor allem die Amerikaner erarbeitet haben und die Libanon-Schulen zum halben Preis erstehen können. ${ }^{375} \mathrm{Zu}$ Beginn erhoffen sich die Gründer der einheimischen Schulen organisatorische Unterstützung von der amerikanischen Syrienmission, die jedoch keine Verantwortung für Projekte übernehmen möchte, die außerhalb ihrer absoluten Kontrolle liegen. ${ }^{376}$ Als Sulaymān al-Salībī nach abgeschlossenem Studium in 'Abeih die Predigerstelle in Akko ablehnt und stattdessen erklärt, weiterhin Leiter seiner Schule in Bhūwāra bleiben zu wollen, zeigen einige Missionare dafür kein Verständnis. ${ }^{377}$ Dabei entstehen vor allem in den Gegenden neue Schulen der Salībī-Brüder, wo Missionare keinen Zugang haben, ${ }^{378}$ um 1867 sind es bereits 21 Schulen. ${ }^{379}$ In Sūq al-Ġarb eröffnen Lowthian und die Salībī-Brüder 1854 eine höhere Schule, deren Ruf bald mit dem des Seminars in 'Abeih verglichen werden kann. ${ }^{380}$ Trotz aller Differenzen ergibt sich in den ersten Jahren eine fruchtbare, wenn auch nicht immer kritiklose Zusammenarbeit zwischen den Libanon-Schulen und der Syrienmission. ${ }^{381}$ Nach dem Tod von Lowthian und Sulaymān al-Ṣalībī sowie dem Rückzug von Elyās al-Ṣalībī aus den Geschäften, wird 1873 in einer Kommission bestehend aus der Free Church of Scotland, den amerikanischen Missionaren sowie einigen Professoren des SPC über das Fortbestehen der Schulen beraten. ${ }^{382}$ Die Schulen, deren Grundbesitz nicht rechtmäßig ist, werden geschlossen, zwei der übrigen Schulkomplexe gehen 1888 und 1900 an die presbyterianische Mission. ${ }^{383}$ Es ist auffällig, dass der Missionary Herald die Șalībī-Schulen nur ein einziges Mal erwähnt. ${ }^{384}$ Offenbar werden sogar

374 Ebd., 216-217.

375 Salibi (1965), 137.

376 Smith an Young (Beirut, 21.7.1855): ABC 60 (105), (HHL).

377 Abu-Husayn (1998), 208.

378 Ebd., 214.

379 Salibi (1965), 136.

380 Ebd., 136.

381 Abu-Husayn (1998), 205, 210. Genaueres geht aus Briefen von Eli Smith an Cuthbert Young in England nicht hervor. Jedoch hält Smith Elyās, der in England ist, um Spenden zu sammeln, für nicht vertrauenswürdig. Viele Gerüchte werden von den Salībīs, Smith zufolge, in die Welt gesetzt, die nicht der Wahrheit entsprechen. Simeon Calhoun, Leiter des Seminars in 'Abeih, weigert sich, ins Komitee der Libanon-Schulen gewählt zu werden: vgl. Smith an C. G. Young (Bhamdūn, 22.9.1854) und (Beirut, 21.7.1855) und (Beirut, 4.3.1856): ABC 60 (105), (HHL). Probleme mit Sulaymān im Speziellen deuten auch Leserbriefe aus einer unbekannten amerikanischen Zeitschrift an: vgl. ABC 16.8.1., Vol. 6 (112).

382 Abu-Husayn (1998), 205, 210.

383 Jessup (1910a), 384: Dazu zählen die Gebäude in Dur al-Šweir und Sūq al-Ġarb. Bei der Übergabe stellen die Schotten zur Bedingung, die Komplexe ausschließlich für missionarische Zwecke zu nutzen.

384 MH 65 (1869), in: ROS 5, 229: „Dr. Post has preaching at his house every Sabbath, which is attended by about $40[\ldots]$ half of this number are the boys of the school, the teacher of which is a Christian man, and takes a good deal of pains to teach the children aright. The school belongs to the Suleebas.“; vgl. Abu-Husayn (1998), 206. 
syrisch-protestantische Schulinitiativen als Konkurrenz empfunden. In einem Brief von 1855 dementiert Smith diese Vermutung, die auch von den Engländern geäuBert wird, und fügt hinzu, dass nur der ABCFM in der Lage sei, Bildungsinstitutionen zu errichten, die beständig seien. Kleinere Initiativen wie die der Salībī-Brüder können schnell entmutigt werden, da das Arbeitsfeld Syrien zu klein sei, um es sich mit anderen Organisationen zu teilen, so Smith. ${ }^{385}$ Dass ähnliche Diskrepanzen zu den indigenen Schulen von Mihāè 1 ' Aramān ${ }^{386}$ und Buṭus al-Bustānī ${ }^{387}$ bestehen, wird im Folgenden noch zu sehen sein.

Vor allem in den 1880er und 1890er Jahren entstehen viele staatliche, muslimisch geprägte Schulen in Syrien, die die Vorrangstellung der Missionen im Bildungsbereich endgültig zurückdrängen sollen. Sie bedienen jedoch ausschließlich die muslimische Bevölkerung, staatliche Schulen für Christinnen und Christen gibt es bis zum Ende des 19. Jh.s in Syrien nicht. ${ }^{388}$ Zwei der wenigen privaten, muslimischen Schulinitiativen sind besonders erwähnenswert: In der Nationalen Islamischen Schule in Tripoli (1845-1909), die von Husayn al-Ǧisr gegründet wird, werden neben Religions- und Französischunterricht auch moderne wissenschaftliche Lehrinhalte vermittelt. Neuere verfasste und übersetzte Werke wie die von Cornelius Van Dyck ${ }^{389}$ werden dafür herangezogen. Darüber hinaus wird 1878 von muslimischen Reformdenkern und Intellektuellen die Islamische Gesellschaft für mildtätige Zwecke (Ǧam 'iyat al-Maqāṣid al-Hayrīya al-Islāmīya) ${ }^{390}$ gegründet. $^{391}$ Ihr Ziel ist es, moderne Bildung gemäß den osmanischen Reformgedanken und islamischen Moralvorstellungen anzubieten. Die vier privaten Schulen in Beirut, Sidon und Tripoli unterscheiden sich in ihrem Curriculum stark von den traditionellen muslimischen Schulen sowie den missionarischen Einrichtungen. ${ }^{392}$ Die Gesellschaft hat es sich darüber hinaus zum Schwerpunkt gemacht, Schulbildung für Mädchen, die auch noch in dieser Zeit unter vielen Muslimen verpönt ist, besonders zu fördern. ${ }^{393} 1881$ gibt es in Syrien 21 moderne muslimische Grundschulen für Jungen (mit ungefähr 2300 Schülern) und sieben Schulen für Mädchen (mit etwa 900 Schülerinnen). ${ }^{394}$

385 Smith an Young (Beirut, 21.7.1855): ABC 60 (105), (HHL).

386 Siehe Abschnitt II.2.2.

387 Siehe Abschnitt III.1.3.

388 Jessup (1910b), 790.

389 Näheres zu Van Dycks Karriere als wissenschaftlicher Autor in Abschnitt II.2.4.

390 Mehr zur Gesellschaft in: Cioeta (1982), 40-55.

$391 \mathrm{Zu}$ den Gründungsmitgliedern zählt auch Husayn Bayhūm, der in den Jahren zuvor bereits eng mit Buțrus al-Bustānī zusammenarbeitet und seine Ideen über die Einheitlichkeit einer syrischarabischen Heimat teilt, sowie Yūsuf al-Asīr, Van Dycks Assistent in der Übersetzung der arabischen Bibel: vgl. Atiyeh (1995), 240; Hanssen (2005), 170.

392 Salibi (1965), 140; Hanssen (2005), 155; Womack (2012), 13-14.

393 Hanssen (2005), 155. Die Gesellschaft, die die Schulen durch Spenden wohlhabender Familien finanziert, kann ihre Arbeit aufgrund des fehlenden Interesses unter der muslimischen Bevölkerung für Bildung nicht fortsetzen: vgl. Cioeta (1982), 48.

394 So 'Abd al-Qādir al-Qabbāni in der muslimischen Zeitung Tamarat al-Funūn: vgl. Cioeta (1982), 50. 


\section{Literarische und wissenschaftliche Gesellschaften ${ }^{395}$}

You will be interested to learn that we have a little Society of Arts and Sciences at Beirût. It was formed a year ago, and has now reached a position, which seems to promise its permanency, and gives us confidence to speak of it. It was formed in consequence of the urgent sollicitation of intelligent natives, chiefly young men, desirous of knowledge. ${ }^{396}$

Diese Worte richtet Eli Smith am 12. Februar 1848 in einem Brief an die 1845 gegründete Deutsche Morgenländische Gesellschaft (DMG), die ihn noch im selben Jahr in ihrer Zeitschrift veröffentlicht. Ein Ereignis, das in den Kreisen der Orientalisten in Europa und den USA für erfreute Reaktionen sorgt: eine wissenschaftliche Gesellschaft in Syrien! ${ }^{397}$ Missionare wie William M. Thomson, Eli Smith und Cornelius Van Dyck gehören zu denen, die das Bedürfnis haben, den Wissensaustausch auf höherer Ebene zu betreiben, als es die Schulen oder die biblischen Kreise im Missionshaus ermöglichen. So entsteht 1847 die Al-Ǧam ‘̀ya al-Surīya li l- 'Ulūm wa l-Funūn (Syrische Gesellschaft der Wissenschaften und Künste) ${ }^{398}$, zu deren Mitgliedern amerikanische und europäische Staatsbürger zählen sowie viele syrische Intellektuelle, unter ihnen auch diejenigen, die mit der Syrienmission in Verbindung stehen. ${ }^{399} \mathrm{Ob}$ der Impuls für eine solche Vereinigung zuerst von den Missionaren oder von ihren syrischen Freunden ausgeht, kann nicht mit Sicherheit gesagt werden. Folgende Notiz findet sich in einem Schreiben aus Beirut an das Verwaltungsgremium des ABCFM in Boston 1842:

Messrs. Van Dyck, L. Thompson and De Forest were appointed a Committee to take the preparatory steps for the formation of a Society for Scientific purposes. The Committee subsequently [?] and a Society was formed to the election of Mr. Smith as President, Mr. Wolcott as secretary and Van Dyck as treasurer. ${ }^{400}$

Andererseits hat der libanesische Historiker George Antonius für seine Untersuchung The Arab Awakening (1938) ein unveröffentlichtes Dokument im Archiv der N.E. S. T. vom 21.4.1842 ausfindig gemacht, das besagt, Nāṣîf al-Yāziğī und Buṭrus al-Bustān̄̄ hätten einen Antrag für die Gründung einer Gelehrtenvereinigung ge-

395 Siehe auch: Zeuge (2014).

396 Fleischer (1848), 378. Im Anhang dieses Briefes von Eli Smith befinden sich „Das Statut der Gesellschaft“ sowie der „Bericht des zur Untersuchung des Zustandes der Bibliothek im J. 1847 niedergesetzten Special-Comité's“, von Nāṣif al-Yāziğ̄i und Tannūs al-Haddād auf Arabisch verfasst und von Dr. Haarbrücker ins Deutsche übersetzt: ebd., 379-384.

397 Hanssen (2006), 5: Intellektuelle Vereinigungen gibt es schon vor dem 19. Jh., aber nicht in der Form und mit einer solchen transformativen Kraft für die Gesellschaft wie es diese und weitere wissenschaftliche Vereinigungen vermögen.

398 In der Satzung trägt die Gesellschaft den Titel Ğam ‘̄ya Sūrīya li-Iktisāb al- 'Ulūm wa l-Funūn (,Die Syrische Gesellschaft für die Aneignung der Wissenschaften und Künste“): Hुūrī (1990b), 19. Bei den Mitgliedern der Gesellschaft und auch in der Forschung hat sich die o. g. etwas kürzere Bezeichnung eingebürgert.

399 Ḩūrī (1990b), 18: Buṭrus al-Bustānī, Salīm Nawfal, Elyās Fawwāz, 'Abdallah al-Witwāt, Nāṣīf al-Yāziğī, John Wortabet, Mīhāàñl 'Aramān. Zu den Personen siehe Anhang II.

400 In: „The following proceedings of the General Meeting have been ordered to be sent to the Prudential Committee“ (Beirut, 24.4.1842): ABC 16.8.1., Vol. 1 (27). 
stellt, ohne jedoch ihre Vorstellungen und Ziele dafür näher zu beschreiben. ${ }^{401}$ Es ist daher sehr wahrscheinlich, dass der Impuls für die Gründung der späteren Syrischen Gesellschaft sowohl von amerikanischer als auch von syrischer Seite kommt. ${ }^{402}$ Schließlich bestätigt dies auch der Journalist Šahīn Makārīūs, der in seinem 1883 veröffentlichten Artikel „Bildung in Syrien“ schreibt: „Dr. Van Dyck was thinking of establishing a society to educate the young men of Syria. He cooperated with Rev. Thomson and teacher Butrus al-Bustānī; and they established in Beirut in 1847 a society which they named ,The Syrian Society“." "403 Rufus Anderson findet für die außergewöhnliche Initiative seiner Missionare, die sich schon im Jahr 1842 andeutet, nur kritische Worte:

\begin{abstract}
How will your society for scientific purposes operate as an example to other missions: and if such societies should be known to the churches to exist in the missions what would be the effect? A word to the wise: The thing has not attracted the attention of the Committee. I merely throw out these two queries for your consideration. ${ }^{404}$
\end{abstract}

Der Sekretär des ABCFM wird sich in seiner Korrespondenz mit Syrien kein weiteres Mal über die wissenschaftliche Gesellschaft äußern. In Syrien scheint man dies jedoch gelassen zu sehen. Bereits ein Jahr vor der Gründung der Syrischen Gesellschaft, machen Bustān̄̄, Van Dyck und einige andere den Versuch, eine wissenschaftliche Gesellschaft mit dem Namen Mağma' al-Tahdīib (Gesellschaft für Bildung) in 'Abeih zu etablieren. In einem Brief, den Bustānī am 10. Januar 1846 an Smith schreibt, berichtet er, dass er als Vorsitzender dieser Gesellschaft die Hoffnung habe, ,that it would serve the evangelical cause““ ${ }^{405}$ Der Brief enthält eine Liste der Mitglieder sowie die Satzung im Detail. ${ }^{406}$ Das Ziel der Vereinigung sei es, so Punkt zwei, „den Geist zu erziehen und nützliches Wissen zu erlangen““. ${ }^{407}$ Bis auf den Hinweis, dass in der ersten Sitzung darüber debattiert wird, ob die Haltung von Sklaven rechtens sei, ist nichts über die inhaltliche Arbeit der Mağma al-Tahdī̄ bekannt. ${ }^{408}$ 'Abeih ist jedoch ein kleiner Ort und Bustānī sowie Van Dyck haben Mühe, genügend Interessenten für ihren wissenschaftlichen Zirkel zu finden. ${ }^{409}$ Dies mag einer der Gründe sein, warum die Gesellschaft nur kurz besteht und schließlich 1847 als Syrische Gesellschaft der Wissenschaften und Künste in Beirut neu aufgebaut wird. ${ }^{410}$

401 Antonius (1938), 51. Das Dokument konnte im Laufe der Archivrecherchen jedoch nicht ausfindig gemacht werden.

402 Zachs (2005), 149.

403 Š. Makārīūs, „Al-ma arīf fī Sūrīya“ (Bildung in Syrien), in: al-Muqtațaf 7 (1882/1883), 387, übersetzt und zitiert in: Diab/Wåhlin (1983), 116.

404 Anderson an die Syrienmission (Boston, 22.10.1842): ABC 16.8.1., Vol. 8.1.

405 Tibawi (1963), 161.

406 In der Einleitung von Hūrī (1990b) werden die Gesellschaft und ihre Satzung kurz vorgestellt. Bustānī und Van Dyck befinden sich zu dieser Zeit in 'Abeih, wo sie das Seminar leiten.

407 H̆ūrī (1990b), 5.

408 Bustān̄̄ an Smith (Beirut, 10.1.1846): ABC 50, zitiert in: Tibawi (1963), 161.

409 Makārīūs (1883), 387.

410 Nāṣīf al-Yāziǧñi, Buțus al-Bustānī, John Wortabet, Gregory (oder Krikūr) Wortabet, Henry De Forest, Cornelius Van Dyck, Ṭannūs al-Ḥaddād und Eliās Fawwāz gehören sowohl dieser Ver- 
Weitere Vorbilder findet die Syrische Gesellschaft vermutlich auch in Europa und Amerika. Die dort gegründeten orientalischen Gesellschaften American Oriental Society (1842), Syro-Egyptian Society (1844) sowie Deutsche Morgenländische Gesellschaft (1845) haben in ihren Satzungen ähnliche Ziele verankert wie die 1847 in Beirut gegründete Gesellschaft: 1. die Förderung des Studiums der nahöstlichen Kulturen und Sprachen, 2. das Verfassen und Sammeln von Literatur über den Nahen Osten zu den Themen Geschichte, Philologie, Kultur und Archäologie und schließlich 3. das Anlegen einer eigenen Bibliothek, die für alle Interessenten zugänglich gemacht werden soll. ${ }^{411}$ Als ,erstgebornen Sohn des abendländischen wissenschaftlichen Associationsgeistes in Westasien“ begrüßt die DMG den Neuankömmling im Kreise der wissenschaftlichen Gesellschaften. ${ }^{412}$ Die Kontakte, die zuvor schon zwischen einigen Missionaren als Korrespondenten und den orientalischen Gesellschaften in Europa und Amerika bestehen, können nun vertieft werden. In seiner Jahresrede von 1852 betont der zweite Präsident der Syrischen Gesellschaft, Eli Smith, die Bedeutung der Vernetzung der einzelnen Gesellschaften untereinander: „Und so erntet einer das, was ein anderer gesät hat, [denn] er verzichtet darauf, durch wiederholte Nachprüfungen Zeit zu verschwenden. Dann kann er auf der Stufe weitermachen, auf der sein Kollege aufgehört hat, um [so noch] mehr neue Erkenntnisse zu erlangen. “413

Fortan gilt es, aktuelle Ergebnisse aus der Welt der Wissenschaft auch in der arabischen Welt zu verbreiten. Syrien steht in dieser Zeit erst am Anfang einer globalen Vernetzung von Wissensmedien. Bis sich das Zeitungswesen in dieser Region etabliert, wird noch etwa ein Jahrzehnt vergehen (s.u.). Durch die Verbindung zu anderen orientalischen Gesellschaften besteht nun die Möglichkeit, die Bibliothek der Gesellschaft in Beirut mit arabischer Literatur zu bestücken. Diese kommt neben den Druckarbeiten der American Mission Press u. a. auch aus Europa, wo man sich seit einiger Zeit dem Neudruck von klassischer, arabischer Literatur widmet. ${ }^{414}$ Viele dieser Werke wurden vor einigen Jahrhunderten in Manuskriptform nach Europa gebracht und kehren nun gedruckt und gebunden wieder zurück. Innerhalb Syriens ,die Belebung des allgemeinen Bedürfnisses Wissen und Erkenntnisse zu erlangen" voranzubringen, wie Eli Smith es in seiner Jahresrede vor den Mitgliedern der Syrischen Gesellschaft formuliert, soll auf zwei Wegen erreicht werden: Einerseits durch ,,Vorträge, für die wir unsere Türen für jeden, der zuhören möchte, öffnen“, und schließlich durch den „Druck unserer Arbeiten, d.h. die Herausgabe sowohl der verfassten Artikel [...] als auch der Reden, die von Zeit zu Zeit in unse-

einigung als auch der ein Jahr später gegründeten Syrischen Gesellschaft an: Ḩūrī (1990b), 5-6.

411 Vgl. „Constitution of the American Oriental Society, Adopted April 7, 1843“, in: JAOS 1 (1843), vi-viii; „Syro-Egyptian Society“: ABC 60 (144), (HHL); DMG (1846), 143-144; Hūrrī (1990b), 19-21.

412 „Die Gesellschaft der Künste und Wissenschaften in Beirut“, in: ZDMG 2 (1848), 379. Die Formulierung zeigt, dass die nur kurz bestehende Mağma' al-Tahdī $b$ außerhalb Syriens gar nicht wahrgenommen wird.

413 E. Smith, „Huṭba al-ra'îs al-sanawīya sana 1852“ (Jahresrede des Vorsitzenden für das Jahr 1852), in: Hูūrī (1990b), 23.

414 Ebd., 25. 
ren Sitzungen gehalten wurden“. 415 Die Vielfalt geschichtlicher Zeugnisse ,eingraviert in Steine und Wände und vergraben in Bergen und Hügeln“ gilt es ans Licht zu bringen, da sich bisher von der einheimischen Bevölkerung nur wenige dafür interessiert haben. ${ }^{416}$

Die Mitglieder der Syrischen Gesellschaft treffen sich einmal monatlich und bieten darüber hinaus, wie von Eli Smith zuvor erwähnt, jedem Interessenten, der nicht zur Gesellschaft gehört, alle zwei Wochen öffentliche Vorträge an, die immer mehr Aufmerksamkeit finden. ${ }^{417}$ Inhaltlich sind sie stark von der Thematik des geschichtlichen Umgangs mit Wissen in Syrien und der Notwendigkeit der Reformierung einer Wissenskultur in allen gesellschaftlichen Schichten - bei Männern und bei Frauen - geprägt. ${ }^{418}$ Hinzu kommen Vorträge über neueste Erkenntnisse in den Naturwissenschaften ${ }^{419}$ oder über literarische ${ }^{420}$ und geschichtliche ${ }^{421}$ Themen.

1854 zählt die Gesellschaft 42 Mitglieder, darunter vier amerikanische Missionare und vier ausländische Geschäftsleute. ${ }^{422}$ Sie bilden eine Plattform des rein wissenschaftlichen Austausches zwischen Ost und West. Angesichts der Probleme, die im Umgang mit syrisch-protestantischen Schulen oder einheimischen Missionshelfern bestehen, die sich für das Pfarramt qualifizieren, ist erstaunlich, dass Amerikaner und Syrer in diesem Rahmen auf gleicher Ebene über wissenschaftliche und kulturelle Themen debattieren können. Die Liste der Reden zeigt, dass man sich nicht nur auf die europäische oder amerikanische Wissenschaftsgeschichte konzentriert, sondern Fragestellungen, die die arabische Kultur betreffen, sehr häufig im Mittelpunkt stehen. Mit einem Blick auf die Entwicklung in den westlichen Ländern plädieren syrische und amerikanische Vortragende gleichsam für die Notwendigkeit des Fortschritts in den Bereichen Wissen und Wissenschaft für Syrien. ${ }^{423}$ Das wichtigste Medium für die Verbreitung neuer und auch vergessener Wissensinhalte, so sind sich die Mitglieder einig, ist selbstverständlich die arabische Sprache, da der

415 Ebd., 25.

416 Ebd., 24.

417 Smith an die DMG (Bḥamdūn 16.8.1852), in: ZDMG 7 (1853), 108: „Vergangenen Winter waren unsere ordentlichen Versammlungen etwas schwach besucht, aber die öffentlichen Vorlesungen zogen weit mehr Zuhörer an als früher."

418 C. Van Dyck, „,F̄̄ lad̄āt al- 'ilm wa fawā' idihi“ (Über die Freuden an der Wissenschaft und ihren Nutzen), in: Ḩūrī (1990b), 25-32; J. Wortabet, ,Miqdār ziyādat al- ilm fī Sūrīya fī had̄a l-ǧîl wa 'ilaluhā" (Das Ausmaß des Wachstums der Wissenschaft in Syrien in diesem Jahrhundert und seine Ursachen), in: ebd., 33-34; B. Bustānī, „Hitạāb fī ta 'alīm al-nisā'“ (Rede über die Ausbildung von Frauen), in: ebd., 45-54.

419 Vgl. B. Bustānī, „Iktašafāt ğadīd“ (Neue Erfindungen), in: ebd., 25; S. Naufal, „F̄̄ ușūl alšarā'i ' al-țabi 'ìya“ (Über die Grundlagen der Naturgesetze), in: ebd., 36-44.

420 Vgl. B. Bustān̄̄, „Al-Ḥarīî̀“, in: ebd., 77-78; N. al-Yāziğ̄ì, ,Qasīda fī wadā‘ Wilyam Ṭumsun“ (Ein Gedicht zum Abschied von William Thomson), in: ebd., 83-84.

421 Ğ. Zawīn, „Huṭ̂ba fī tārīh Sūrīya“ (Rede über die Geschichte Syriens), in: ebd., 181-183.

422 Ebd., 18.

423 Wortabet, „Miqdār ziyādat al- 'ilm“, in: Huūrī (1990b), 35: „es hat eine andere Geschichte für Syrien begonnen - eine Geschichte des Lichts. Ja, es ist noch eine Dämmerung und dieser folgt nichts anderes als ein [Sonnen-]Aufgang. Wir haben genug geschlafen und da nun die Sonne aufgeht, lasst uns aufstehen und es tatkräftig anpacken; wir haben viel verpasst und es liegt viel vor uns, bis wir das Erwünschte erreichen.“ 
Nutzen der Gesellschaft vor allem für syrische und weniger für westliche Interessen erbracht werden soll. ${ }^{424}$ Allerdings ist der arabische Sprachschatz zu dieser Zeit für die Beschreibung neuer wissenschaftlicher Erkenntnisse z. T. nicht gerüstet. Es fehlt der Sprache schlicht an fachlichen Termini, so Van Dyck:

[Das kommt nicht daher], weil es unzählige Mängel und Fehler in dieser Sprache gibt, sondern es resultiert aus dem Mangel an Beschäftigung mit ihr sowie aus dem Fortschritt der Wissenschaften und Künste mit [gleichzeitiger] Vernachlässigung der Sprache. Nun müssen wir westliche Termini einführen, die aus anderen Sprachen übernommen wurden, mehrheitlich aus der griechischen. ${ }^{425}$

Mit Rückbezug auf das reiche geistige Erbe geht es den Mitgliedern der Gesellschaft nicht nur um die Anpassung der arabischen Sprache an moderne Erfordernisse, sondern auch um die Wiederbelebung der Literatur und damit des Wissensschatzes der vergangenen Jahrhunderte. ${ }^{426}$ Eli Smith oder seine Kollegen Cornelius Van Dyck und William Thomson nehmen in ihren Reden keinesfalls die Position des aus dem Okzident kommenden Missionars ein, dessen Erfahrungen aus der Heimat der einzige Weg für die Belebung einer arabischen Wissenskultur in Syrien sein soll. Auch wenn die Gesellschaft keine Muslime zu ihren Mitgliedern zählt, betont Eli Smith, dass die religiöse Orientierung in der Arbeit der Gesellschaft völlig in den Hintergrund treten solle - gegenüber Missionsschulen und dem späteren SPC nimmt die Gesellschaft demnach eine Sonderstellung ein. ${ }^{427}$ Themen sollten sachlich und neutral diskutiert werden, ohne religiöse Überzeugungen in die Argumentation einzubringen, so Smith:

Ich muss Sie nicht daran erinnern, dass Sie die Methoden unserer Arbeit kennen. Unsere Richtlinien verbieten es uns, sich bei allem, was diskutiert wird [...] den [Lehr-] Meinungen der religiösen Gruppen, die sich durch verschiedene Konfessionen unter den Menschen dieses Landes auszeichnen, zu widersetzen. Ich rate Ihnen, mit allem Ernst an diesem Grundsatz festzuhalten, sodass unsere Sitzungen im Allgemeinen durch Liebe und Harmonie gekennzeichnet sind. So können alle, die dem Wissen und [seinem] Nutzen zugetan sind, mit gesundem Herzen daran teilnehmen, unabhängig davon, welche konfessionelle Position sie einnehmen. Sie finden bei

424 Y.Q. al-Hูurī, „Maqdama. Al-ḥayāt al-fikrīya fĩ l-qarn al-tāsi ' 'ašr fì 1-diyār al-šāmīya“ (Einleitung. Das Intellektuelle Leben im 19. Jahrhundert auf dem Gebiet Syrien), in: ders. (1990b), 12.

425 Van Dyck, „Fī lad̄āt al- 'ilm wa fawā' idihi“, in: ebd., 32.

426 Smith, „Huțba al-ra'îs al-sanawīya”, in: ebd., 24 „Obwohl es in Ihrer Sprache in der heutigen Zeit nicht viel anspruchsvolle Literatur gibt, finden sich in der alten [Literatur] Verwandtschaften und Verbindungen zu einigen Sprachen, deren Werke in früheren Jahrhunderten zu uns kamen. Dadurch sind sehr genaue Sprachstudien möglich. So bietet Ihre Sprache einige Gelegenheiten, Licht auf verborgene Ausdrücke aus den toten Sprachen zu werfen. Wir meinen, dass die auf Stein gezeichneten Bilder, die Inschriften auf Ruinen, die Erklärungen in den [alten] Büchern oder die Aussagen in Ihren gedruckten Werken, deren Sammlung für Sie leicht möglich wäre, selten von den Menschen in Ihrem Land in Erinnerung gebracht werden. Es könnte einen großen Vorrat an Wissen geben, wie er bei den Menschen in anderen Ländern zu finden ist."

427 Antonius schreibt zur christlichen Ausrichtung dieser und der 1850 gegründeten jesuitischen Gesellschaft: ,[R]eligious prejudice was still dominant and the Moslems and Druzes had stood out. The fact that these societies were founded under the auspices of missionaries had made them still more unpalatable to the non-Christians elements.“: vgl. Antonius (1938), 53. 
uns einen öffentlichen Ort, wo sich Gleichgesinnte die Hand geben und ein Ziel haben, welches ihnen in gleicher Weise am Herzen liegt. ${ }^{428}$

Es ist sehr wahrscheinlich, dass sich Smiths Forderung auf vergangene Debatten bezieht, in denen die Religion zum Streitpunkt geworden ist. Dabei ist höchst bemerkenswert, dass die für die Missionare immer wieder betonte Einheit von Glaube und Wissenschaft hier aufgebrochen wird. Darüber hinaus deutet Smiths Appell auf eine gewisse kulturelle Sensibilität hin, da konfessionelle Streitigkeiten im Libanongebirge etliche Male zu kriegsähnlichen Auseinandersetzungen führen. Nichtsdestotrotz wird von Außenstehenden immer wieder vermutet, dass die Gesellschaft, „obgleich [sie] rein wissenschaftlich ist [...] eine dem Protestantismus günstige Tendenz haben könnte“. ${ }^{429}$ Dieses Gerücht hat mit Smiths Bedauern auch dazu geführt, dass ,[z]wei andere, von den Griechen und Katholiken uns entgegengesetzte Gesellschaften [...] uns einige unserer Mitglieder entzogen" haben. ${ }^{430}$

Im Jahr 1852, in dem die Gesellschaft noch aktiv ist, gibt Buțus al-Bustān̄̄ in einem Band achtzehn ausgewählte Reden heraus, die während der Mitgliederversammlungen vorgetragen wurden. ${ }^{431}$ Noch im selben Jahr stellt die Gesellschaft ihre Aktivitäten ein. Aus einem Brief von Eli Smith an den deutschen Orientalisten Prof. Rödiger aus dem Jahr 1856 wird deutlich, dass es keine direkte Auflösung der Gesellschaft gegeben hat:

Ich bedaure sagen zu müssen, dass unsre Literary Society ausser dem ersten Heft ihrer Verhandlungen noch nichts wieder publiciert, auch seit langer Zeit keine Versammlungen gehalten hat. Da Hr. Thomson abwesend ist und ich wegen meiner schwankenden Gesundheit mich nicht viel damit befassen kann, findet sich niemand, der die Sache fördern möchte. ${ }^{432}$

Angesichts des Arbeitspensums, mit dem sich Smith als Leiter der Missionsdruckerei und der Bibelübersetzung konfrontiert sieht, verwundert Šahīn Makārius' Einschätzung von 1883 nicht, dass die Gesellschaft aufgrund von Smiths fehlendem Enthusiasmus Stück für Stück aufgelöst wird. Van Dyck unternimmt noch den

428 Smith, „Huṭba al-ra'īs al-sanawīya“, in: Hūūī (1990b), 25.

429 Smith an die DMG (Bḥamdūn 16.8.1852), in: ZDMG 7 (1853), 108.

430 Ebd. Mit der katholischen Gesellschaft ist die von den Jesuiten 1850 gegründete $A l-\breve{G} a m$ ‘̀ya aš-Šarqīya (Die Orientalische Gesellschaft, s. u.) gemeint. Welche Gesellschaft den „Griechen“ zugeordnet wird, ist nicht bekannt.

431 Ein weiterer Band ist in Planung, wird jedoch nicht mehr realisiert: vgl. Smith, „Huțba al-ra' '̄s al-sanawīya“, in: Hūrrī (1990b), 24. Laut Quellen des ABCFM plant eine gewisse Mrs. Ebenezer Burgess, der Syrischen Gesellschaft eine Druckerpresse zukommen zu lassen, die zwar der Mission gehören soll, aber - verwaltet von zwei Missionaren und drei Syrern - für den Druck der Veröffentlichungen der Gesellschaft gedacht ist. Die als Burgess Press bezeichnete Druckerei soll durch ihre Einnahmen finanziell unabhängig sein und allein der Syrischen Gesellschaft dienen: vgl. „Conditions on which Mrs. Ebenezer Burgess gives a Press to the Syrian Society at Beirût Feb. 7, 1851“: ABC 2.1.1., Vol. 14 (HHL). Da Bustānīs Veröffentlichung in der Amerikanischen Druckerei herausgegeben wird und sich die Gesellschaft wenig später auflöst, kommt die Burgess Press offenbar nie zum Einsatz. Die Initiative ist jedoch ein Zeichen dafür, dass man in den USA reges Interesse an dem außermissionarischen Engagement von Smith u. a. hegt.

432 Smith an Prof. Rödiger (Beirut 7.5.1856), in: ZDMG 10 (1856), 820. 
Versuch, die wichtigsten Aufgaben von Smith zu übernehmen, doch sein Einsatz für das Missionsseminar in 'Abeih ist so zeitraubend, dass auch er scheitert. ${ }^{433}$

Bis auf die von Bustān̄̄ veröffentlichten Reden ist bisher nichts über etwaige Debatten in den insgesamt 53 Mitgliedersitzungen bekannt oder herausgegeben worden. Inwiefern die Mitglieder also über die Zukunft Syriens und die Reformierung des Bildungsbereichs diskutiert haben, bleibt im Verborgenen. Dabei ist es ursprünglich vorgesehen, ,die Vorträge und Diskussionen schriftlich zu publi-

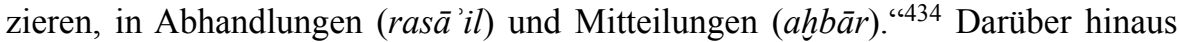
schweigen die offiziellen Berichte der Missionare an den ABCFM und ebenso die Rückantworten aus Boston über die Arbeit einer wissenschaftlichen Gesellschaft, die einige Missionare maßgeblich mitgetragen haben. Dies zeigt zwar, dass die Syrische Gesellschaft außerhalb des Interessengebietes des ABCFM steht, aber es verdeutlicht auch das private Engagement der in Syrien lebenden Amerikaner für die kulturellen Belange ihrer einheimischen Mitarbeiter und Freunde.

Der Syrischen Gesellschaft folgen in den kommenden Jahrzehnten weitere wissenschaftliche und literarische Zirkel mit ähnlichen Zielsetzungen. Unter der Federführung des jesuitischen Paters de Prunieres wird schon 1850 die nur für Christen zugängliche Al-Ğam '̌ya al-Šarqīya (Die Orientalische Gesellschaft) ins Leben gerufen. Sie setzt sich ebenfalls aus Syrern und Ausländern zusammen und organisiert Vorträge für jede Mitgliedersitzung. Über die vermutlich nur bis 1852 bestehende Orientalische Gesellschaft gibt es ebenso wenig Aufzeichnungen und Überlieferungen. ${ }^{435}$ Die konfessionellen Grenzen überwindet erstmals die Ğam '̌yat al-'Ilmīya al-Sūrīya (Die Wissenschaftliche Syrische Gesellschaft), zu deren Mitgliedern Christen, Drusen und Muslime zählen. Die Gesellschaft ist zu zwei verschiedenen Zeitperioden aktiv (von 1857 bis etwa 1860 und von 1868 bis 1869), da sie ihre Aktivität wegen des Bürgerkriegs von 1860 einstellen muss und erst 1868 eine neue Genehmigung von der osmanischen Regierung erlangen kann. ${ }^{436}$ In der zweiten Phase kommen vor allem die Lehrer von Bustān̄is 1862 gegründeter Nationalschule zusammen, wobei Muhammad Amīn Arslān erster Vorsitzender sowie Bustani und der muslimische Reformdenker Husayn Bayhūm Vereinsdirektoren werden. ${ }^{437}$ Die Gesellschaft zählt bald mehr als 150 Mitglieder, die v.a. aus Beirut, aber auch aus Damaskus, anderen syrischen Städten, Istanbul und Ägypten kommen. ${ }^{438}$ Sie beschäftigt sich mit vielfältigen Bereichen wie syrischer Archäologie, griechischer

433 Makārīūs (1883), 387.

434 Glaß (2004a), 125.

435 Antonius (1938), 52-53.

436 Raffoul (2014), 149. Historiker wie Antonius (1938, 53), Hanssen (2006, 169) und Tibawi (1969, 160) sprechen fälschlicherweise von verschiedenen Gesellschaften mit jeweils einer Schaffensperiode. Die Journalisten Ya qūb Șarrūf und Fāris Nimr bestätigen jedoch in ihrem Nachruf auf Bustān̄i, dass er Mitglied in der ersten und zweiten Ğam '̄yat al- 'Ilmīya al-Sūrīya gewesen sei: dies. (1883), 5. Auch Zachs $(2005,52)$ führt die Gesellschaft mit zwei Schaffensperioden an. Yusūf Qasma Hūrī hat die Reden der zweiten Gesellschaft 1990 in einem Band herausgegeben: vgl. ders., A'māl al-Ǧam '̄yat al- 'Ilmīya al-Sūriya, 1868-1869, Beirut 1990.

437 Hanssen (2005), 153.

438 Zaydān (1913), 69-70; Hūūī (1990c), 218-219: Zu den Mitgliedern zählen ebenso Halīl alHuūrī, Mihāà īl Mīšāqa, Salīm al-Bustānī und John Wortabet. 
Philosophie oder der Übersetzung von europäischer Sachliteratur. Der Historiker Jens HANSSEN fasst zusammen: ,In sum, the Syrian Scientific Society engaged in an antiquity-referential discourse of their society and a Western-referential discourse of progress, modernity, and civilization." ${ }^{439}$ ABDUL LATIF TIBAWI urteilt darüber hinaus, dass keine andere Vorgängergesellschaft so viel Einfluss auf die arabische Gesellschaft gehabt habe. ,[It] stressed the historic contributions of the Arabs to arts and sciences and urged their descendants to emulate them in the establishment of schools and learned societies. “440 Trotz der bemerkenswerten Arbeit dieser sowie vieler anderer Gesellschaften wird auch die Wissenschaftliche Syrische Gesellschaft bald aufgelöst. ${ }^{441}$ Die meisten Gesellschaften bestehen aufgrund des abnehmenden Interesses und mangelnder finanzieller Unterstützung oft nur für kurze Zeit. ${ }^{442}$ Ihnen folgen wiederum andere, die ebenso zu wichtigen Bestandteilen der ab Mitte des 19. Jh.s beginnenden Kulturrenaissance, der nahḍ, werden. ${ }^{443}$

\section{Syriens nahda: Eine Brücke zwischen Vergangenheit und Zukunft}

Wirtschaftliches Wachstum, die Neuordnung der sozialen Strukturen, eine mit der mutassarifiya beginnende Periode friedlicher Koexistenz ${ }^{444}$ sowie die Gleichstellung der Christen mit den Muslimen im Osmanischen Reich durch das Hatt- $l$ Hümāyūn Gesetz ${ }^{445}$ beeinflussen natürlich auch die kulturelle Entwicklung, vor allem im westlichen Syrien. Mit dem Ausbau des Schulsystems und der Vernetzung mit der Welt durch Handel, Zeitungen und Bücher kann in Syrien und Ägypten eine gesamtkulturelle Bewegung nicht mehr aufgehalten werden - Beirut und Kairo werden zu Zentren für Literatur und Wissenschaft. Was die Missionare zuvor schon

439 Hanssen (2006), 169.

440 Tibawi (1969), 160.

4411875 gründen ehemalige Mitglieder der Wissenschaftlichen Syrischen Gesellschaft - darunter auch Fāris Nimr, Ibrahīm al-Yāziǧī, Ya qūb Șarrūf und Šahīn Makārīyūs - die Geheimgesellschaft Ğam '̌̀ya Sürīya (Syrische Gesellschaft), deren Ziel es ist, die Abtrennung von Syrien und Libanon vom Osmanischen Reich zu beschleunigen und damit dem Bedürfnis der Menschen nach Freiheit gerecht zu werden: vgl. Antonius (1938), 84; Raffoul (2014), 150.

442 Salīm Farı̄ğ, Mitglied der Gesellschaft bemerkt 1869, dass viele Gesellschaften bereits aufgehört haben zu existieren. „For it is easy for all of us to meet at the beginning of the matter, but we find it less easy to keep the obligations of these meetings ... I hope that this society's path will not be like earlier ones that have fallen": übersetzt und zitiert in Holt (2009), 42.

$443 \mathrm{Zu}$ nennen wäre hierbei z. B. die Ğam 'iyat al-Funūn (Gesellschaft der Künste, 1875), die sich aus ehemaligen, vor allem sunnitischen Mitgliedern - unter ihnen auch Yūsuf al-Asīr (siehe Anhang II, Nr. 3) - der 1857 oder 1868 gegründeten Ğam 'ìyat al- 'Tlmìya al-Sūrìya zusammensetzt. 'Abd al-Qādir al-Qabbānī, ehemaliger Bustānī-Schüler, sowie Van Dycks Mitarbeiter in der arabischen Bibelübersetzung, Yūsuf al-Asīr, werden die Herausgeber der von der sunnitischen Gesellschaft veröffentlichten Zeitschrift Tamarāt al-Funūn (Früchte der Kunst): Hanssen (2006), 169-170; vgl. auch Zaydān (1913), 70-76.

444 Salibi (1965), 116.

445 Glaß (2004a), 76. 
beobachtet haben, entspricht der Tatsache: Kulturell gesehen lag Syrien brach, ${ }^{446}$ was sich aber nun durch die nahda binnen kurzer Zeit ändert. Nahḍa bedeutet „Aufschwung“ und „Erwachen“, wird aber zumeist mit „,arabische Renaissance“ übersetzt. ${ }^{447}$ Sie steht für die Rückbesinnung auf das kulturelle Erbe, aber auch für die Entwicklung zu einer modernen arabischen Gesellschaft, die ihre Vorbilder in westlichen Modellen sieht. ${ }^{448}$ Die nahda sollte nicht als Antwort auf die Einflussnahme des Westens, sondern als Resultat des fortwährenden Austausches zwischen Ost und West gesehen werden. ${ }^{449}$ Die Bewegung hat ungefähr ab Mitte des 19. Jh.s ihren Anfang genommen. Für den Historiker ĞĀN DĀYA ist die Gründung der bereits erwähnten Mă̌ma al-Tahd̄īb im Jahr 1846 der Anlass für Syriens kulturelle Renaissance. ${ }^{450}$ Zweifelsohne haben viele Ereignisse dazu beigetragen, wie Ğurğì Zaydān als Zeitgenosse der nahḍ zu berichten weiß: ${ }^{451}$ die Gründung moderner Schulen, die Entwicklung des Druck- und Pressewesens, literarische und wissenschaftliche Gesellschaften, der Zugang zu öffentlichen Bibliotheken ${ }^{452}$ und Museen sowie die Einführung unbekannter Theater- und Romanliteratur. ${ }^{453}$ Im Zuge der kulturellen Blüte und der Bildung einer intellektuellen Elite wird der Ruf nach Zugehörigkeit zu einem arabischen Vaterland (wațan), das für mehr Unabhängigkeit von Istanbul steht, immer lauter. ${ }^{454}$ Themen wie die Verantwortung jedes einzelnen

446 Hourani (1954), 36: „[T]he creative use of the classical Arabic language had almost entirely ceased. The old authors were scarcely read; such poetry and prose as were produced were imitations of archaic models; except for religious schools, which mainly confined themselves to the memorization of the Quran, no sort of literary education existed.“

447 Tomiche (1993), 900: Der Begriff Renaissance ist insofern strittig, als er auf die europäische Renaissance im 16. Jh. verweist und die nahda von Europa her definiert. Im arabischen Raum wird daher die Übersetzung mit „Erwachen“ als geeigneter empfunden. Siehe auch Philipp (1979), 7. Die Übersetzung „Kulturrenaissance“ hat sich jedoch im deutschsprachigen Raum weitestgehend durchgesetzt, weshalb sie hier beibehalten wird.

448 Tomiche (1993), 901.

449 S. Abou, Le bilingualisme arabe-français au Liban, Paris, 1962, 176, in: Scholz (1997), 13. Vgl. dazu Conrad (2012), 999-1027: Die Annahme, die Aufklärung hätte sich von Europa aus ausgebreitet, gilt in der heutigen Forschung als überholt. Aufklärung und Zivilisierung werden in außereuropäischen Gesellschaften als nahezu gleichbedeutend verwendet. Aufklärerische, d.h. kultur-transformatorische Prozesse sind das Resultat des globalisierten Handels sowie des Reformdenkens in politisch instabilen Ländern. Dies trifft, wie oben beschrieben, auch auf die Veränderungsprozesse im Osmanischen Reich zu.

450 Dāya (2007).

451 Zaydān (1913), 14-16.

452 Bis zu dieser Zeit existieren Bibliotheken nur in Klöstern oder befinden sich im Privatbesitz.

453 Der Autor und Journalist Salīm al-Bustān̄̄, Sohn von Buțus al-Bustān̄i, prägt erstmalig die Romanform in der arabischen Literatur, die sich am westlichen Stil orientiert. Die Protagonisten in al-Bustān̄̄s Romanen kritisieren den Despotismus unter den Führenden der Gesellschaft und stehen für die zivilisierenden Faktoren von Wissen und rationalem Denken: vgl. Tomiche (1993), 902; Traboulsi (2007), 65.

454 In der Mitte des 19. Jh.s hat der syrische Patriotismus eine starke arabische Ausrichtung, die für Christen und Muslime gleichsam gilt. Syrien grenzt sich nicht nur als territoriale Entität vom Osmanischen Reich ab, sondern auch als Historische. Erst nach dem Ersten Weltkrieg kommt die Nationalismus-Bewegung - v. a. als islamische Panarabismus-Bewegung richtig zur Geltung: vgl. Rabinovich (1992), 44. 
Bürgers für die Zukunft des Landes, Offenheit für moderne Strömungen, aber auch altruistische Liebe zur Heimat, Emanzipation und Bildung von Frauen und schließlich die Frage nach der eigenen Identität ${ }^{455}$ spielen dabei eine zentrale Rolle. ${ }^{456}$ Der junge Autor Ibrahīm al-Yāziğ̄̄, Sohn des Literaten Nașîf al-Yāziğ̄̄, 457 zitiert in einer Versammlung der o.g. Ğam '̄yat al- 'Ilmīya al-Sūrīya im Jahr 1868 aus dem Gedicht eines anonymen arabischen Autors: „Arise, O Arabs, from sleep awake! Knee-deep we've sunk in misery's lake. “458

Für die kulturelle Weiterentwicklung ist die Flexibilität und Vielseitigkeit der arabischen Sprache unabdingbar: Daher wird der Sprachschatz durch neue Fachtermini erweitert und einige Worte erhalten neue Bedeutungen. ${ }^{459}$ Für ein besseres Verständnis ist die Vereinfachung der Syntax vonnöten, wobei einerseits Wörter aus dem Dialekt entlehnt werden, andererseits jedoch die poetische Rhetorik, wie sie der arabischen Sprache zu Eigen ist, beibehalten wird. Auf diese Weise können wissenschaftliche Sachverhalte besser dargestellt und zum anderen Romane und Theaterstücke als neue literarische Formen sprachlich gestaltet werden. ${ }^{460}$ Während der nahḍ spielen Zeitungen und Zeitschriften eine viel größere Rolle als Bücher, da sowohl die Neuartigkeit des Printmediums Aufmerksamkeit auf sich zieht, als auch der Verbreitungsgrad von Nachrichten und Wissenswertem größer ist. ${ }^{461} \mathrm{Zu}$ den Herausgebern der ersten arabischen Zeitungen in Syrien gehören vor allem private christliche Unternehmer, was auch auf das Zugeständnis von gleichen Rechten für Christen durch das Hatt-ı Hümāyūn Gesetz zurückzuführen ist. ${ }^{462}$ Viele von ihnen haben missionarische Bildungseinrichtungen besucht oder für die amerikanische Mission gearbeitet. Halīl al-Hūrī, der in den 1860er Jahren als Lehrer in 'Abeih arbeitet, gibt ab 1858 die erste syrische Zeitung heraus und nennt sie Hadìqat al-

Näheres zur syrisch-arabischen Nationalbewegung in: G. Antonius, The Arab Awakening. The Story of the Arab National Movement, London 1938; S. Sheehi, Foundations of Modern Arab Identity, Florida 2004 u. v.m.

455 Dazu Sheehi (2004), 5: „, [T]he process of redefining identity vis-à-vis a torrent of local and global changes is not exclusive to the cultures and societies of South West Asia. Similar activities were occuring throughout much of the world in the like-minded reform." Dazu zählen u.a Indien, Iran, die Philippinen, China und Japan.

456 Hanssen (2006), 6.

457 Zu Nașīf al-Yāziğ̄̄ siehe Anhang II, Nr. 75.

458 Übersetzt und zitiert von Hitti (1957), 477: ,The political awakening, with the urge to throw off the Ottoman yoke, was a natural sequence to the intellectual awakening." Vgl. auch Tibawi (1971), 18.

459 Hitti (1957), 477; Zachs (2005), 72-73: Zum Inbegriff für die syrische Heimat als eigene Entität innerhalb des Osmanischen Reiches wird wațan (Heimat, Vaterland). Hinzu kommen in der Presse und in öffentlichen Reden häufig verwendete Worte wie wațanīya (Nationalismus), umma (Nation, statt „religiöse Gemeinschaft“) sowie tamaddun (Zivilisation). Mehr zu den Begriffen in Abschnitt III.1.4 und 5.

460 Tomiche (1993), 901-902.

461 Glaß (2004a), 6. Zudem werden Zeitungen in Kaffeehäusern oder im Familienkreis häufig laut vorgelesen.

462 Glaß (2004a), 76. Zur Entwicklung des Zeitungswesens in Ägypten siehe Zaydān (1913), 52 54. Elshakry (2007), 198: „Beirut soon became the centre of the print revolution in the Arab lands: twenty-five periodicals, for example, were founded there between 1852 and 1880 , compared with thirteen in Cairo and ten in Alexandria.“ 
Ahbār (Garten der Neuigkeiten, 1858-1911), ,welche das arabische Zeitungsmodell fundamental erneuert [...] und das ägyptische Pressemonopol“" bricht. ${ }^{463} \mathrm{Ihr}$ kommt das Prädikat zu, die erste gedruckte, nicht-staatliche, d.h. unabhängige, Zeitung in Syrien zu sein, die außerhalb Istanbuls erscheinen darf. ${ }^{464}$ Al-Hūrīs Plan, die Zeitung von der American Mission Press drucken zu lassen, kann aus unbekannten Gründen nicht realisiert werden kann. Schließlich gründet er seine eigene Druckerei (al-Mațba 'a al-Sürīya), in der er ebenfalls den amerikanischen Schriftsatz verwendet, dessen Schriftbild die entstehende Presselandschaft in der zweiten Hälfte des 19. Jh.s prägen wird. ${ }^{465}$ Auch Buṭrus al-Bustānī und sein Sohn Salīm gehören zu den Herausgebern führender Journale: Ab 1870 erscheinen die Zeitschriften al-Ǧinān (Die Gärten) und al-Ğanna (Der Kleine Garten) sowie ab 1871 die zusammen mit Bustānīs Cousin Sulaymān al-Bustānī viermal wöchentlich erscheinende Zeitung al-Ǧunayna (Der Garten). ${ }^{466} 1876$ gründen die am SPC lehrenden Syrer Ya 'qūb Șarrūf und Fāris Nimr ein Journal für Wissenschaft und Handwerk mit dem von Van Dyck inspirierten Namen al-Muqtataf (Die Auslese). Die Autoren hoffen, ,that this journal will meet with the approval of the public and will encourage the reader to acquire scientific knowledge and to strengthen industry“". 467 Van Dyck unterstützt die beiden Syrer bei der Realisierung ihres Projektes, indem er den Druck des Journals in der Amerikanischen Druckerei initiiert und sich um die Veröffentlichungserlaubnis bei der osmanischen Verwaltung kümmert. ${ }^{468}$ Aber auch die amerikanische Mission leistet ihren Beitrag zum arabischen Pressewesen: Das erste gedruckte arabische Periodikum in Syrien überhaupt hat die Handschrift von Eli Smith. Mit einem Team von Übersetzern und Autoren gibt er von 1851 bis 1856 sechs Ausgaben von Mağmū' Fawā'id (Sammlung nützlicher Lektionen) heraus. Diese enthalten sowohl Geschichten mit religiösen Botschaften als auch Artikel mit populärwissenschaftlichen Inhalten. ${ }^{469} 1863$ ruft die Syrienmission ein weiteres Missionsblatt ins Leben, das sich inhaltlich sehr an der Mă̌mū' Fawāyid orientiert und amerikanischen religiösen Periodika ähnelt: Ahbār 'an Intišār alInğìl fì Amākin Muhtalifa (Kunde über die Verbreitung des Evangeliums an verschiedenen Orten). Ab 1868 erscheint das Missionsblatt monatlich unter dem neuen Namen al-Našra al-Šahrīya (Monatliche Zeitschrift), ab 1871 dann wöchentlich als al-Našra al-Usbu ‘̄ya (Wöchentliche Zeitschrift). ${ }^{470}$

Mit der Machtübernahme von Sultan Abdülhamid II. (1876-1909) verschärft sich die Pressezensur im Osmanischen Reich zunehmend, was sich sehr zum Nachteil für christliche Bürger auswirkt. ${ }^{471}$ Beirut kann bis 1888 eine Sonderstellung

463 Glaß (2001), 30; Zachs (2004), 29.

464 Zaydān (1913), 51-52; Glaß (2001), 37-42; Glaß (2004a), 9-10: In jener Zeit leistet das private, arabische Zeitschriftenwesen mehr als staatliche Zeitungen.

465 Halīl al-Hurī an Eli Smith (o. O., 9.6.1856): ABC 50, Box 3 (HHL); Glaß (1998), 27-28; Glaß (2001), 37; Glaß/Roper (2002), 193-194.

466 Ayalon (1995), 34-36; Glaß (2004a), 135-139. Siehe auch Abschnitt III.1.4.

467 So die Übersetzung von Elshakry $(2007,200)$ aus der Einleitung von al-Muqtațaf 1 (1876), 1.

468 Elshakry (2007), 201.

469 Näheres dazu in Abschnitt II.1.5.

470 Siehe dazu Abschnitt II.2.5.

471 Zachs (2005), 213. 
einnehmen, da sich Halīl al-Hūrī, ehemaliger Lehrer im Seminar in 'Abeih und Herausgeber von Had̄̄qat al-Ahbār, als Zensor (maktūb̆̌̆ $)^{472}$ sehr moderat zeigt. ${ }^{473}$ Seine Nachfolger haben schließlich weniger Nachsicht und kritische Zeitungen und Journale, zu denen auch der Muqtataf zählt, werden eingestellt. Viele syrische Intellektuelle, wie auch Șarrūf und Nimr, zieht es daher in das liberalere Ägypten, wo sie ihre Periodika weiter veröffentlichen können. ${ }^{474}$ Auch die von der Mission herausgegebenen Periodika unterliegen dieser Pressezensur. Jegliche Äußerungen über den Propheten Muhammad, über Sultane des osmanischen Reichs oder die Abbildung geografischer Karten, die der osmanischen Politik widersprechen könnten, sind untersagt. Das hat Einfluss auf alle aus dem Ausland importierten sowie die von der Missionsdruckerei in Beirut herausgegebenen Bücher. Vor jedem Druck muss ein Manuskript nach Istanbul gesandt werden, um dort schließlich genehmigt, korrigiert oder gar abgelehnt zu werden. ${ }^{475}$ Im Jahr 1873 führt der Auftragsdruck eines polemischen Schreibens des syrisch-katholischen Priesters Sabūnğ̄ gegen den maronitischen Bischof zu einem Eklat. ${ }^{476}$ Der Priester lässt das Buch auf eigene Kosten in der American Mission Press drucken, ${ }^{477}$ woraufhin der für die Region zuständige Pascha die einmonatige Schließung der Druckerei sowie eine Geldstrafe fordert. Van Dyck, der die Druckerei zu der Zeit leitet, fordert den Pascha auf, die Angelegenheit über das amerikanische Konsulat zu regeln, was dieser auch tut. Nachdem der Konsul Kontakt mit Van Dyck aufgenommen hat, erklärt der Missionar in fünf Punkten, dass man sich immer an das Gesetz des Landes halte, jedoch keine Verantwortung für Literatur übernehme, die von Privatpersonen in der Druckerei in Auftrag gegeben wird. Die Druckerei, so Van Dyck, gehöre fünf großen englischen und amerikanischen Gesellschaften ,and [...] we could not take the responsibility of closing it" “. ${ }^{478}$ Die politischen Entwicklungen im Land haben

472 Atiyeh (1995), 241.

473 Glaß (2004a), 90: Al-Hūrīi ist dafür bekannt, mehr Verwarnungen als Verbote zu erteilen. Sein Ruf scheint jedoch nicht unumstritten, wie ein Kommentar von Daniel Bliss deutlich macht. Als 1873 für das Amt des Pressezensors Yūsuf al-Asīr vorgeschlagen wird, der Van Dyck in der Bibelübersetzung unterstützt hat, urteilt Bliss: „A Mohammedan is far better than that miserable renegade of a so-called Christian." Vgl. Bliss an seine Frau Abby (13.8.1873), in: Bliss (1993), 48.

474 Näheres zur Zensur und den Zeitungsneugründungen in Ägypten in: Glaß (2004a), 90-95. Die Pressefreiheit in Ägypten wird durch britische Einflussnahme garantiert: Hitti (1957), 477.

475 Jessup (1910a), 434.

476 Das Pamphlet ist ein Antwortschreiben auf die verbalen Attacken des maronitischen Bischofs gegen die syrisch-katholische Kirche. Sabūnğī stellt darin die kanonisierte Heiligkeit von Yuhanna Marūn in Frage, dem Gründer der maronitischen Kirche. Während das Schreiben des Bischofs zuvor kein Aufsehen erregt, wendet sich der Ärger der Maroniten aufgrund des in der American Mission Press gedruckten Pamphlets gegen die Druckerei selbst. In Folge der Ereignisse erfreut sich das polemische Schreiben Sabūnğis nun größter Beliebtheit: vgl. „A Missionary Press Closed“, in: New York Times (12.7.1874), 4: AA.7.1./American Mission Press Beirut.

477 Wie bereits in Abschnitt I.1.1 beschrieben, können Privatleute ihre Bücher auf eigene Kosten in der American Mission Press drucken lassen.

478 Daniel Bliss an Abby Bliss (16.3.1874), in: Bliss (1993), 225; Daniel Bliss an Abby Bliss (18.3.1874), in: ebd., 226. 
die Arbeit der Mission nicht unbedingt vereinfacht. Aufgrund ihrer Beliebtheit und des guten Rufes ihrer Institutionen können sie jedoch aus einer gewissen Sicherheit heraus agieren.

\section{Welche Rolle spielen amerikanische Missionare in Syriens nahda?}

Die in der Forschung viel diskutierte Frage, inwiefern die amerikanischen Missionare einen Beitrag zu Syriens nahḍa geleistet haben, findet positive, aber auch kritische Antworten. Letztlich gibt es keinen Konsens, ob sie durch Schulen und Buchdruck die Basis für die kulturellen und politischen Umbrüche im Land geschaffen haben ${ }^{479}$ oder ob man ihren Beitrag als relativ betrachten muss, da die Missionare ein rein christliches Ziel verfolgt haben, also nicht als Förderer von liberalen, säkularen Strömungen in einem multireligiösen Kontext aufgetreten sind. ${ }^{480}$ Meines Erachtens kann die Antwort zwischen beiden Positionen gefunden werden, weil amerikanische Missionare sehr unterschiedlich mit der arabischen Kultur umgegangen sind. Konservative Mitarbeiter des ABCFM vertreten die Ansicht: „,[w]e do not find [...] that Christ or his Apostles made any inventions or discoveries in the arts and sciences, or sought directly to promote literature." Daher könne der ABCFM keine ,society for promoting civilization, or literature, or the arts“" sein. ${ }^{481}$ Anders verhält es sich mit Missionaren wie Smith, Van Dyck oder Thomson, die sich für die Förderung der arabischen Kultur einsetzen und diese sehr schätzen. Sie engagieren sich in wissenschaftlichen Zirkeln und setzen sich für die Modernisierung der arabischen Sprache ein, Smith durch die arabische Bibelübersetzung und Van Dyck durch das Verfassen unzähliger Lehrbücher.

Die missionarischen Bildungseinrichtungen, aus denen Literaten, Wissenschaftler und Journalisten hervorgehen, sowie die von Amerikanern und Syrern initiierten literarischen und wissenschaftlichen Gesellschaften fügen sich in eine Bewegung ein, die mit der Öffnung des Nahen Ostens für den Westen und mit dem langsamen Verfall der osmanischen Vorherrschaft begonnen hat. Die Syrienmission gibt, wenn auch nicht von Boston gewünscht, Impulse für die Bewegung und setzt dort an, wo es Lücken im Bildungsbereich zu füllen gilt. Daher haben die Amerikaner weder die nahḍ maßgeblich geprägt, noch spielen sie eine unbedeutende Rolle. Bei christlichen Zeitzeugen wie Šahīn Makārīūs (1853-1910) und Ğurğì Zaydān (1861-1914) ist die Arbeit der Syrienmission sehr hoch angesehen. In Makārīūs' Studie über Bildung in Syrien setzt er, was das 19. Jh. anbelangt, sofort bei den Missionaren und ihren Schulen an. Rückständigkeit und Verfall Syriens ,did not vanish before the arrival of the foreigners, who gave new life to the remnants of her

479 Antonius (1938), 43, 54; Fāris (1958), 386-395; Salibi (1965), 116.

480 Makdisi (2004), 209-211. Ein Gegner der Behauptung, die Missionare hätten durch Schulen und die Druckerei einen großen Beitrag zur nahḍa und der Wiederentdeckung des arabisch-literarischen Erbes geleistet, ist Tibawi (1971), 16.

481 ABCFM, Annual Report 1856, 64. 
[sc. Syrien] science, and supported by the civil rule her printing presses and schools multiplied and her publishing increased“". ${ }^{82}$

Zaydān urteilt, dass ausländische Missionare ein bedeutendes Element, ja sogar die Stützpfeiler in Syriens nahda bilden. ${ }^{483}$ Beide haben zwar keine unmittelbare Verbindung zur Syrienmission, die positive Rezeption der Missionsarbeit wird jedoch sehr deutlich. Die Missionare selbst schreiben sich eine tragende Rolle in der syrischen Kulturrenaissance zu:

It is the unanimous testimony of intelligent natives of all sects that the intellectual awakening of modern Syria is due, in the first instance, to the schools of the American missionaries. They were the first and have continued for over sixty years, and most of the institutions now in existence in Syria, native and foreign, have grown out of them or have been directly occasioned by them. ${ }^{484}$

Nichtsdestotrotz ist man innerhalb der Syrienmission auch nach vielen Jahrzehnten davon überzeugt, dass ein neues, syrisches Volk und ein neues Syrien nicht aus politischen Umbrüchen oder wirtschaftlichen Entwicklungen hervorgehe, „,but by the spread of the Gospel of Jesus Christ" . ${ }^{485}$ Dass sich diese Vorstellung nicht bewahrheitet, zeigen die folgenden vier Biografien. Sie sind eng mit den kulturellen Transformationsprozessen in Syrien verbunden und ihre Erfolgsgeschichte setzt da an, wo es nicht mehr um die Verkündigung des Evangeliums von Jesus Christus geht.

482 Makārīūs, „Al-ma arīf fĩ Sūrīya“ (Bildung in Syrien), in: al-Muqtațaf 7 (1882/83), 385, übersetzt und zitiert in: Diab/Wåhlin (1983), 115.

483 Zaydān (1913b), 52: „,wa qad ra'ayt 'an nahụa Surīya al-'ilmīya kān al-'āmil al-akbar fỉha ğamā' at al-mubaširīn al-ağānib”; ders. (1903), 422: „Anhum bila ḩilāfin min akbarun da 'ā' imun hadihi l-nahḍa al- 'ilmīya."

484 Jessup (1910b), 594.

485 Ebd., 783. 


\section{KAPITEL II}

\section{MISSIONARE ALS CULTURAL BROKERS}

Evangelische und katholische Missionen im 18. und 19. Jh. sind durch den Erstkontakt mit anderen, nahezu unbekannten Kulturen zu cultural brokers, kulturellen Vermittlern ${ }^{1}$, - oder wie MAKDISI sagt zu ,avatars of modern science, technology, and spirituality“ und ,apostles of progress“ ${ }^{\text {" }}$ - geworden. Ihre Missionsstationen stellen „Kontakträume“ dar, ${ }^{3}$,, in between“ spaces“ bzw. contact zones ${ }^{4}{ }^{\text {die }}$ sich als eine Art Schnittstelle zwischen westlich-europäischem Denken und indigenen Kulturen präsentieren. Darin gehört es zum Alltag des Missionars, die einheimische Kultur so gut wie möglich kennenzulernen, um Wege und Strategien für die missionarische Arbeit zu ergründen. Generationen von Missionaren in Übersee setzen sich für einen Wissensaustausch in den Bereichen Bildung, westliche Wissenschaften, Philologie, Medizin, Handwerk und Technik ein oder exportieren kulturelle Errungenschaften wie z.B. das Klavier. ${ }^{5}$ Als erster Missionar, der die Verbreitung der christlichen Botschaft mit Hilfe der Wissenschaft vorantreibt, gilt der von 1583 bis 1610 in China lebende Jesuit Matteo Ricci. Ricci ist bewandert in Astronomie, Mathematik sowie Geografie und übersetzt etliche Werke in die chinesische Sprache. ${ }^{6}$ Die Wissenschaftsjournalistin Michela Fontana schreibt dazu: „He thought that if the Chinese accepted and admired Western sciences as part of Western culture, they could also be convinced to accept the Christian religion. " ${ }^{\text {"7 }}$ Einheimische durch Bildungsangebote für sich zu gewinnen, wird schließlich in den folgenden zwei Jahrhunderten zur gängigen Praxis westlicher Missionen. Des Weiteren zeigt sich, dass in den Missionen kaum noch „Sünde“ und „Gnade“ als

1 Höh/Jaspert/Oesterle (2013), 9.

2 Makdisi (2010), 48.

3 Koschorke (2012), 197.

4 Marten (2011), 305.

5 Koschorke (2012), 197. In Syrien führen die Missionare bspw. die Kartoffel (1827), den Fotoapparat (1854), Kerosin- und Öllampen (1865) sowie Metallnägel, Nähmaschinen und die Kastenorgel ein: vgl. Jessup (1910a), 360-361.

Verschiedene Aspekte missionarischer Forschungsarbeit, jedoch ohne Berücksichtigung des Kulturtransfers, beleuchtet der Sammelband von Johannes Triebel (Hg.), Der Missionar als Forscher. Beiträge christlicher Missionare zur Erforschung fremder Kulturen und Religionen (= Missionswissenschaftliche Forschungen 21), Gütersloh 1988. Zur Forschungsarbeit der dänisch-halleschen Missionare vgl. Liebau (2006).

6 Fontana (2012), 24; Collani (2012), 115: Ricci übersetzt bspw. Euklids sechs Bücher zur Geometrie und verfasst Bücher über Mathematik und Arithmetik. Vgl. dazu Van Dycks Buch über die Grundlagen der Geometrie (Kitāb fi l-ușūl al-handasīya), siehe Anhang I. Mehr über die bemerkenswerte Bildungsarbeit der Jesuiten in China im 16. und 17. Jh. in: Collani (2012).

7 Fontana (2012), 27. 
zentrale Begriffe gelten, sondern vielmehr die kulturellen Phänomene „Rückschritt" und „Fortschritt“. ${ }^{8}$ Fortschritt ist nur durch Bildung möglich und „Wissen“ wird zu einem alles beherrschenden Thema.

Auch die Herausgabe von missionarischen Periodika gehört zu den interessanten Merkmalen kultureller Vermittlungsarbeit von evangelischen und katholischen Missionen in außereuropäischen Ländern. Oftmals sind Missionare die Ersten, die gedruckte Journale in englischer und später in der indigenen Sprache produzieren. ${ }^{9}$ Als Herausgeber der Missionsblätter Mağmū 'al-Fawā'id und Ahbār 'an Intišār fì Amākin Muhtalifa, später al-Našra al-Usbu ‘̄ya, können Eli Smith und Van Dyck das Zeitungswesen in Syrien nachhaltig beeinflussen und bilden damit ein wichtiges Bindeglied zwischen der skriptographischen und typographischen Darstellung arabischer Werke. ${ }^{10}$ Derartige Beispiele finden sich in vielen britischen und amerikanischen Missionen im 19. Jh., um hier nur einige zu nennen: Bereits im Jahr 1815 veröffentlichen britisch-protestantische Missionare mit dem China Monthly Magazine (Cha-shi-su Mei-yue Tong-ji-zhuan) das erste chinesische Periodikum. ${ }^{11}$ Die gleiche Leistung vollbringen 1844 amerikanische Missionare in Thailand mit dem Bangkok Recorder. ${ }^{12}$ Zudem erscheint in Istanbul, ebenfalls unter der Federführung amerikanischer Missionare, von 1864 bis 1871 der bulgarisch-sprachige „Tagesstern“ (Zornitsa). ${ }^{13}$

In nahezu allen Missionsperiodika liegt der Schwerpunkt auf religiösen und erbaulichen Texten. Schließlich werden Zeitungen innerhalb der Familien und Dorfgemeinschaften weitergereicht und gelangen dadurch leichter in Umlauf als ein Buch (wie z. B. die Bibel). Da die wenigen einheimischen Prediger oftmals nicht alle entlegenen Gegenden besuchen können, werden die Zeitungsartikel in den jungen christlichen Gemeinden als eine Art Predigtersatz vorgelesen. ${ }^{14}$ Darüber hinaus soll die zunehmende Themenvielfalt sowohl Männer und Frauen als auch Kinder ansprechen. Leicht verständliche Kurzgeschichten mit illustrativen Darstellungen,

8 Semaan (1986), 33.

9 Koschorke (2012), 198. 1840 wird von der ABCFM-Mission in Urmia eine Druckerei etabliert, die Werke auf Persisch, Türkisch und Neuaramäisch druckt. Im Rückblick schreibt der PBCFM in seinem Jahresbericht von 1920: ,[I] thas for years printed perhaps the most influential newspapers available in Syriac." Vgl. PBCFM, Annual Report (1920), 305, zitiert in: Malick (2008), 15.

10 Im Rahmen des bereits genannten DFG-Forschungsprojekts „Transatlantische Vernetzung von Institutionen des Wissens am Beispiel der Syria Mission des American Board“ wird es eine ausführliche Studie zu den arabischsprachigen Missionsperiodika der Syrienmission, zunächst unter Leitung des American Board und später des Presbyterian Board, geben.

11 Zhang (2007), 3.

12 Koschorke (2012), 200.

13 Reeves-Ellington (2011), 212: „The magazine advocated female education [...] and promoted the idea that educated women were essential to spiritual regeneration and national progress through their work as mothers and teachers." Zum Thema Frauenbildung siehe auch die Abschnitte I.1.2 und III.1.5. Die Liste einheimischsprachiger Periodika in amerikanischen Missionen ließe sich noch fortführen. Als zwei weitere Beispiele wären noch die armenische Wochenzeitung „Avedaper“ sowie die griechisch-türkische Zeitung „Angeliaphoros“ zu nennen: vgl. PBCFM (1923), 27. 
wissenschaftliche Artikel und alltägliche Ratschläge zu Gesundheit, Haushalt und Familie gehören zum festen Repertoire der Missionsblätter.

Missionare vermitteln jedoch nicht nur westliche Kulturgüter in ihrem Missionsfeld, sondern gelten auch als Korrespondenten für Wissenschaftler und Interessierte in der Heimat. Gelehrte und Professoren, die selbst nicht reisen können, wenden sich vermehrt ab dem 17. und 18. Jh., v. a. aber im 19. Jh. an Missionare, um Informationen $\mathrm{zu}$ erhalten und Feldforschungen in Auftrag zu geben. ,Standardisierte Fragebogen [europäischer Wissenschaftler sind] dabei stets ein beliebtes Hilfsmittel“", so der Historiker ReInHARDT WendT. ${ }^{15}$ Wer nicht direkt mit den Missionsgesellschaften oder Missionaren in Übersee in Kontakt tritt, kann sich missionarischer Publikationen in Form von ,,publizierten Briefen, Zeitschriftenbeiträgen und Einzelstudien“ bedienen. ${ }^{16}$ Umgekehrt werden Missionare durch ihre guten Kontakte zu Gelehrten im Westen auch mit „Geräten, Literatur und Materialien“ versorgt. ${ }^{17}$ Sozial-anthropologische Beobachtungen in den Publikationen der Missionare sind jedoch nicht neutral und orientieren sich stark an den ideologischen Richtlinien der Missionsgesellschaften. Die ,andere' Kultur wird von einem bestimmten Blickwinkel aus betrachtet. Solche Werke sowie durch Händler und Reisende nach Westen gelangende Informationen über die außereuropäische Welt verändern zunehmend die abendländische Weltsicht. Das „Bedürfnis nach neuen Interpretationsmustern und Klassifikationssystemen“" soll einer Welt gerecht werden, „die im Zuge der europäischen Expansion vielfältiger und unübersichtlicher“ wird, so WENDT weiter. ${ }^{18}$

Das wissenschaftliche Engagement amerikanischer Missionare in Syrien wird auch vom ABCFM gefördert, insofern es dem wissenschaftlichen Austausch mit den USA dienlich ist. Dem eigenen Interesse $\mathrm{zu}$ folgen und individuelle Studien $\mathrm{zu}$ betreiben, wird sogar als willkommene Abwechslung im sonst sehr mühseligen Missionsalltag beworben. Schließlich sind Wissenschaft und Religion voneinander nicht zu trennende Größen, wie der Missionar Henry Harris Jessup schreibt: ${ }^{19}$

I would cordially recommend to every young man going out as a missionary to study some branch of natural science. Let him pursue it in his missionary field as a means of recreation, mental invigoration, relief from the routine of regular duties, and a means of gaining enlarged ideas of the power, wisdom and goodness of God, who creates alike the Book of Nature and the Book of Revelation. ${ }^{20}$

Darüber hinaus werden den Missionaren im Missionsfeld vielseitige Aufgaben abverlangt, für die sie nur zum Teil ausgebildet sind: sie sind Prediger, Seelsorger, Schuldirektoren, Lehrer, Druckermeister, Autoren, Übersetzer, Korrespondenten, Forscher und ortskundige Fremdenführer zugleich.

16 Ebd.

17 Liebau, „Mission und Forschung“, in: dies. (2006), 161.

18 Wendt (2001), 14.

19 Siehe dazu auch die Einleitung.

20 Jessup (1910a), 128. 
Ihre allgemeine Bildung und Belesenheit unterscheidet sie oft von den Menschen, denen sie in Syrien begegnen. In den USA gehören sie schließlich zur gut ausgebildeten Elite, während die Mehrheit der Bevölkerung im Nahen Osten kaum gebildet ist. Dadurch gelangen sie stetig in Versuchung, überheblich gegenüber denen aufzutreten, die nicht christlich und ,zivilisiert' genug erscheinen. Manche halte diese Einstellung davon ab, sich innerhalb der anderen Kultur sozial zu verhalten, mahnt der syrische Konvertit John Wortabet an und urteilt: „Such persons have evidently mistaken their calling." Der Missionar gefährde seine Arbeit, wenn er den Konvertiten fortwährend das Gefühl der Vormachtstellung vermittle. „This naturally engenders a spirit of jealousy and opposition among the native Protestants", so Wortabet weiter. ${ }^{21}$ Als cultural brokers und Botschafter Jesu Christi müssen Missionare fortwährend kulturell sensibel agieren, worauf sie in ihrem Studium keineswegs vorbereitet werden. Eli Smith und sein Kollege William Goodell haben sich Anfang der 1830er Jahre auf diesen konfliktreichen Lernprozess eingelassen und erkannt, dass sie nur Erfolg haben werden, wenn sie sich ganz auf die Gegebenheiten des menschlichen Miteinanders in Syrien einlassen. ${ }^{22}$

Missionare werden in dem neuen Kontakt- bzw. ,Zwischen'-raum mit zweierlei Herausforderungen konfrontiert: Einerseits müssen sie sich mit der fremden Kultur vertraut machen, dürfen aber ihre Zielvorgaben als Missionare nicht aus den Augen verlieren. Andererseits fühlen sie sich zunehmend von der Heimatkultur entfremdet, obwohl die Sehnsucht nach Rückkehr groß ist. Missionare, die häufig in der Heimat als Helden verehrt werden, ${ }^{23}$ müssen lernen, ihren Weg zwischen der eigenen und der fremden Kultur zu finden und dabei die Vorbildfunktion für daheim gebliebene Christen aufrechtzuerhalten. Ein Missionar in Übersee zu sein, wird als Berufung gesehen. Es bedeutet schließlich, uneigennützige, christliche Nächstenliebe tagtäglich zu leben und sein Herkunftsland um des anderen Willen zurückzulassen, so wie Jesus dies getan hat. ${ }^{24}$ Es ist eine Berufung, der man nur durch persönliche Einbußen folgen kann. Als Missionar lebt man in einer fremden Kultur unter zumeist schwierigen klimatischen Bedingungen, über Jahre und Jahrzehnte fern von Familie und Freunden. Während den männlichen Missionaren mit ihrer Ausbildung in der Heimat ein guter Beruf beschieden wäre, gibt es im Missionsfeld weder berufliche Aufstiegschancen, noch ist das Gehalt vielversprechend. ${ }^{25}$ Die Gehälter der Missionsgesellschaften genügen oft nur für die Ausstattung des Missionshauses und zur Versorgung der eigenen Familie. Reisekosten in die Heimat müssen gesondert beantragt werden - die Schiffsreisen in das Missionsfeld in Übersee sind oftmals Reisen ohne Rückfahrschein. Durch die hohe Sterblichkeitsrate unter Missionaren, vor allem aber unter ihren Ehefrauen und Kindern, wird von den Missionaren eine gewisse Aufopferungsbereitschaft verlangt, die auch für die

21 Wortabet (1860), 378.

22 Siehe Abschnitt II.1.2.

23 Tjelle (2014), 10.

24 Semaan (1986), 156: vgl. 1 Kor 9, 20-23.

25 Tjelle betont hierbei, dass die Maskulinität von Missionaren dadurch keinesfalls infrage gestellt wird. Es gibt verschiedene Formen von Maskulinität, die sich nach Kontext und sozialer Interaktion richten: vgl. dies. (2014), 1-2, 8, 149. 
daheimgebliebenen Familienmitglieder mit Sicherheit eine Bürde ist. ${ }^{26}$ Sobald sie sich mit der fremden Kultur vertraut gemacht haben und ihre Missionsstation beziehen, sehen sie sich mit einer höchst verantwortungsvollen Arbeit konfrontiert. Von dieser erwartet die Missionsgesellschaft schnelle Erfolge (,the calls for labours are so pressing and so constant" $).{ }^{27}$ Nicht nur physische sondern auch psychische Erkrankungen der Missionare und ihrer Ehefrauen werden von den Missionsärzten attestiert, ${ }^{28}$ aus den Korrespondenzen an den American Board geht ebenso deutlich hervor, dass fast alle an die Grenzen ihrer Belastbarkeit gelangen und häufig um eine Auszeit bitten. Kurz vor der Genehmigung seiner USA-Reise schreibt bspw. Eli Smith an Anderson im Jahr 1845:

With my feeble health and delicate nerves [...] I can no longer do the work that desolves upon me. [...] The amount of work too has not been small. I have in my hands alone more than a hundred and forty sheets of letters and other documents written and received since the first of October. My mind needs unbending to a degree to which I find it impossible here to bring about. This alone is a sufficient reason for my retiring for a season. ${ }^{29}$

Im Jahr 1861, in dem sich die Mission ohnehin in einer schwierigen finanziellen Situation befindet, berichtet Jessup über Van Dyck: „We were all overworked. The great work of the mission, the translation of the Scriptures was in jeopardy. The health of Dr. Van Dyck was very precarious. He suffered from severe headaches, was thin and weak, and had serious effusion in his joints. "30

Im Folgenden soll gezeigt werden, dass die individuelle Arbeit der Missionare berücksichtigt werden muss, um sich ein umfassenderes Bild von den Leistungen der Syrienmission, seien sie intendiert oder unabsichtlich, machen zu können. ${ }^{31}$

26 Die ersten amerikanischen Missionare in Syrien und im Heiligen Land versterben schon nach wenigen Jahren Aufenthalt (Levi Parsons, 1820-22; Pliny Fisk, 1820-25). Einige Missionarsfrauen sterben in Folge von Krankheit oder im Kindbett. Dazu zählen u. a.: Sarah L. Smith (1834-36), Eliza N. Thomson (April bis Juli 1834), C.E. Wolcott (1840-41), Maria W.C. Smith (1841-42). Vgl. Jessup (1910b), 797-798.

27 Van Dyck an Anderson (Sidon, 30.9.1852): ABC 16.8.1., Vol. 5 (327).

28 Van Dyck an Anderson (Sidon, 17.2.1853): ABC 16.8.1., Vol. 5 (328): „My wife [...] is subject to frequent attacks of acute Neuralgia and has been so ever since we (?) find that damp, leaky house, the first winter we spent in Abeih [...].“ Am 5. Oktober 1859 berichtet Van Dyck vom Fall „of our Missionary sister Mrs. Jessup“, „the main sympton was the mental derangement“. Heftige Streitigkeiten in dem Dorf, in dem sich die Jessups aufhalten, haben bei Mrs. Jessup Angstzustände ausgelöst und Van Dyck empfiehlt die Abreise in die USA: ebd. (350).

29 Smith an Anderson (Beirut, 28.1.1845): ABC 16.8.1., Vol. 3.1. (102). Siehe auch: Van Dyck an Anderson (Deir al-Qamar, 6.8.1841): ABC 16.8.1., Vol. 2 (204); Van Dyck an Anderson (Sidon, 30.9.1852): ABC 16.8.1., Vol. 5 (327).

30 So Jessup im Jahr 1861, in: ders. (1910a), 239.

31 Zachs (2005), 290: „Every missionary was a world of himself, with his own charakter and understanding and should be examined as such.“

einen besonderen Charakter der Basler Mission in Indien um ca. 1870 schreibt der Historiker Reinhard Wendt: ,„Verse will eben der Hindu'. Ferdinand Kittels missionarische und philologische Arbeit zwischen Basler Konzepten und einheimischer Kultur“, in: Zeitschrift für Mission 27/1 (2001), 27-45. Kittel entdeckt durch die Missionsarbeit seine Leidenschaft für die Philologie und widmet sich mehr und mehr wissenschaftlichen Studien während er seine missionarischen Aufgaben absichtlich vernachlässigt. 
Unterschiedliche Charaktere frommer Amerikaner versammeln sich im Missionsfeld Syrien. Während die einen Vorurteile gegenüber „minderwertigen“ Kulturen zu bestätigen suchen, bewegen sich andere in einer Art Grenzzone zwischen Loyalität zur Heimat und zunehmender Sympathisierung mit der Gastkultur. Durch kulturelle Sensibilität und fleißiges Selbststudium haben Eli Smith und Van Dyck Beachtliches geleistet. Dies geschieht jedoch nicht ohne eine gewisse Entfremdung von der eigenen Heimat, die sich allerdings auch produktiv auswirkt (Van Dyck: „I have become very much Syrianized“). Sowohl Eli Smith als auch sein jüngerer Kollege Cornelius Van Dyck entscheiden sich bewusst für ein Leben in Syrien und das nicht nur, weil sie sich als christliche Missionare dazu berufen fühlen. ${ }^{32}$

\section{1. „HERE MAY MY LAST DAYS BE SPENT“33 - ELI SMITH (1801-1857)}

\section{Kurzbiografie $\mathrm{i}^{34}$}

Eli Smith wird 1801 in eine einfache Schuhmacherfamilie aus Northford/Connecticut geboren, studiert zunächst bis 1821 am Yale College, ${ }^{35}$ arbeitet für zwei Jahre als Lehrer in den Südstaaten ${ }^{36}$ und graduiert 1826 am Andover Theological Seminary $^{37}$ in Boston. ${ }^{38}$ Am 23. Mai 1826 beginnt seine Reise im Auftrag der Syrienmission, die ihn zunächst als Associate Editor für die Druckarbeiten nach Malta und daraufhin für Sprachstudien nach Ägypten sowie Beirut führt. ${ }^{39} 1829$ verlässt er Malta endgültig und begibt sich mit dem Missionarskollegen H.G. O. Dwight auf die Reise nach Persien durch Armenien und Georgien, um zu erkunden, ob eine Mission unter den Nestorianern erfolgreich sein könnte. Resultat dieser Reise ist schließlich das zweibändige, 1833 veröffentlichte Werk „Missionary Researches in Armenia“". Ein ähnliches Projekt, jedoch mit einer rein wissenschaftlichen Zielsetzung, unternimmt er 1838 und 1852 zusammen mit dem New Yorker Professor

32 Smith schreibt im MH 39 (1843), in: ROS 3, 377: „Here my last days may be spent.“; Van Dyck vor seiner Rückkehr nach Syrien 1867: „I have left my heart in Syria and thither I must return“, zitiert in: Jessup (1910a), 108.

33 Ein Zitat von Smith im MH 39 (1843), in: ROS 3, 377

34 Im Gegensatz zu anderen Missionaren der Syrienmission wie z. B. Pliny Fisk oder Levi Parsons gibt es keine Memoiren über Eli Smith, die posthum vom ABCFM über ihn veröffentlicht werden. Laut Anderson (1872b, 324) war es nie Smiths Absicht, Memoiren über sein Leben zu veröffentlichen, da er auch kein Tagebuch führte.

35 Leavy (1995), 30-31: In Yale fasst Smith den Beschluss, Missionar zu werden. Seine Entscheidung ist stark von der Biografie des Missionars Henry Martyn (1781-1812) beeinflusst, der in Indien und Persien gearbeitet hat.

36 Free Church of Scotland (1857), 237.

37 Dexter (1913), 80.

381850 wird Smith überraschend der Doktortitel in Theologie vom Williams College verliehen, jedoch ist nicht bekannt für welche Leistung. Smith kommentiert dies kurz in einem Brief an Buṭrus al-Bustānī: ,I'm not deserving of any such title.“ Vgl. Smith an Bustani (Bḥamdūn, 12.10.1850): ABC 50 (HHL); Dexter (1913), 82.

39 „Obituary Notice of Rev. Eli Smith D.D.“: ABC 16.8.1., Vol. 5 (227); Laurie/Jessup, „A Brief Cronicle of the Syria Mission“: ABC 88 (HHL); Jessup (1910a), 53. 


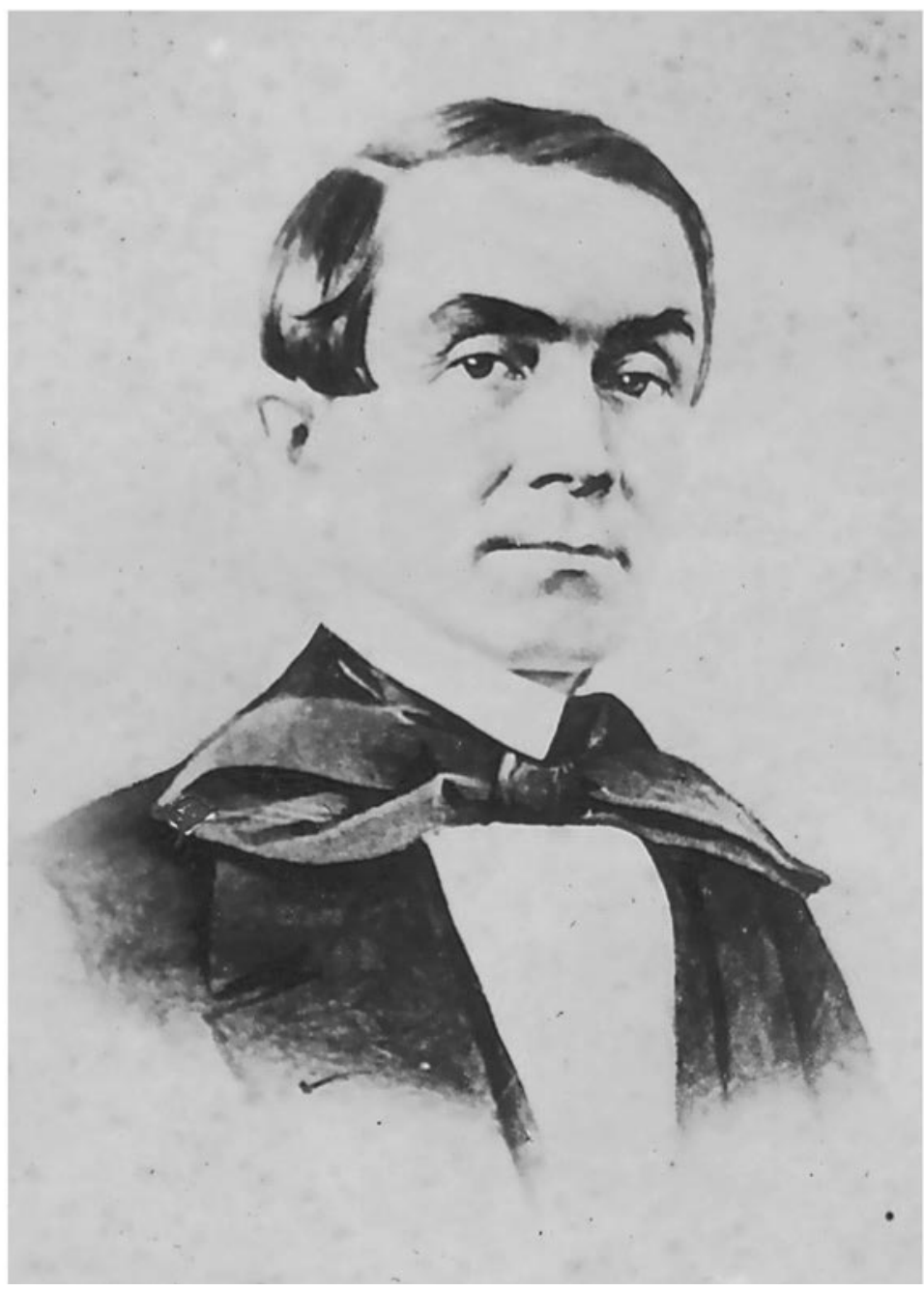

Abb. 3: Rev. Eli Smith, D.D.

für Biblische Literatur, Edward Robinson. Ihre Reisen in die Gebiete des Heiligen Landes veröffentlichen sie in den drei Bänden „Biblical Researches in Palestine, and in the Adjacent Regions“.

1834 eröffnet Smith zusammen mit seiner ersten Ehefrau, der Missionarin Sarah Lanman Huntington Smith, eine Mädchenschule. Noch im selben Jahr übernimmt er die Leitung der Amerikanischen Druckerei in Beirut und widmet sich fortan der Herausgabe religiöser und sachlicher Literatur auf Arabisch. Schließlich beauftragt ihn der ABCFM 1844 an einer neuen Bibelübersetzung ins Arabische zu arbeiten. 
Die ungewohnten Lebensumstände in Syrien führen zum frühen Tod der ersten beiden Ehefrauen von Smith, Sarah Lanman ${ }^{40}$ und Maria Ward Chapin ${ }^{41}$. 1847 heiratet er schließlich Mehitable Simpkins Butler, mit der er zwei Töchter und vier Söhne bekommt. ${ }^{42}$ Nach lang andauernder Krankheit und nicht vollendeter Arbeit an der Bibelübersetzung stirbt er schließlich am 11. Januar 1857 in Beirut an Magenkrebs ${ }^{43}$ und wird auf dem Anglo-Amerikanischen Friedhof in Beirut/Zoqāq alBlāṭ begraben. ${ }^{44}$ (Abb. 3)

\section{2. „The outstanding figure of the early Syrian mission“ $“ 45$}

Für die ersten zwei Generationen von amerikanischen Missionaren in Syrien ist Smith eine Art Leiter, Vorbild und Mentor. Als noch unauffälliger und frommer Yale-Student von etwa 20 Jahren beginnt er sich für die Biografie des anglikanischen Priesters Henry Martyn zu interessieren, der als Kaplan der British East India Company Indien und Persien bereiste, wie Margareth Leavy in ihrer Biografie über Smiths Jahre in Yale schreibt.

Martyn was a scholar of broad interests and a man of great sensibility. [...] While serving as chaplain with the East India Company, he had translated the Bible into Hindustani, then, with the object of perfecting his Persian and Arabic for further translations, he traveled to Tabriz and Persia $[\ldots]^{46}$

40 Eine ausführliche Darstellung Sarah Smiths und den Einfluss von Frauen auf die amerikanischmissionarische Arbeit in Syrien bietet Lindner (2010). Sarah verstirbt nach nur zwei Jahren Ehe im Jahr 1836: vgl. Hooker (1839), 366. Da sie kinderlos bleibt, nimmt sie 1834 das syrische Mädchen Raḥil 'Ațā in die Familie auf, um es nach protestantischen Prinzipien zu erziehen. Diese Praxis ist für Missionsfamilien in Syrien nicht unüblich: vgl. Hooker (1839), 379-380; Lindner (2011), 41-42. Näheres dazu in der Einleitung von Kapitel III.

41 „Obituary Notice“: ABC 16.8.1., Vol. 5 (227). Maria stirbt nach etwa einem Jahr Ehe 1842 und hinterlässt ein Kind, das in die Obhut der Missionarsfrau Mrs. De Forest gegeben wird: vgl. Van Dyck (o. J.), 17. Es obliegt demnach nicht den Missionaren, ihre Kinder allein aufzuziehen. Inwiefern Eli Smith in die Erziehung seines halbwaisen Kindes involviert ist, ist nicht bekannt.

42 Dexter (1913), 82: Einer seiner Söhne verstirbt noch im Kindesalter. Die drei anderen Söhne machen sich im akademischen Bereich einen Namen. Charles, der Älteste, wird Professor in Yale, Edward Robinson Kunstkenner und Benjamin Eli Herausgeber des „Century Dictionary": vgl. Jessup (1910a), 147.

43 Cornelius Van Dyck hat ihn nach seinem Tod obduziert und findet im unteren Magenbereich einen Tumor „nearly as large, as the egg of a goose“: vgl. MH 53 (1857), in: ROS 4, 273.

44 „Obituary Notice“: ABC 16.8.1., Vol. 5 (227). Der Friedhof wird im 20. Jh. verlegt und befindet sich heute in der Nähe des Beiruter Nationalmuseums. Smiths dritte Frau Hetty reist mit den Kindern nach seinem Tod zurück in die USA: vgl. „Missionaries' Children Returned to the United States, 1832-1881, Record of Grants, etc.“( (o. O., o. D.): ABC 77.8.2 (HHL), zitiert in: Lindner (2014a), 58.

45 So die Einschätzung des Autors David H. Finnie (1967), 196.

46 Leavy (1995), 33. 
Es wird sich zeigen, dass Smiths Biografie viele Parallelen zu Martyns Leben aufweist. ${ }^{47}$ Aufgrund seiner sprachlichen Fähigkeiten, die er schon in Yale und Andover bewiesen hat, ${ }^{48}$ schickt ihn der ABCFM in die amerikanische Druckerei auf Malta. Smith soll Daniel Temple, den Leiter der Druckerei, vertreten als dieser eine Reise nach Frankreich plant. Die Reise wird jedoch verschoben und Smith fühlt sich schnell unterfordert. ${ }^{49}$ Gegen Temples Willen und ohne den ABCFM zu informieren, reist er Ende 1826 nach Beirut, um sich der arabischen Sprache zu widmen. ${ }^{50}$ Die Wintermonate verbringt er beim syrischen Missionslehrer Tannūs al-Haddād und dessen Frau. 1828 drängt ihn schließlich der ABCFM zur Rückkehr nach Malta. Er werde dort dringend gebraucht, da die amerikanische Druckerei nun einen arabischen Font aus England (s.u.) erhalten hat. Smith fühlt sich jedoch nicht genug vorbereitet, den Druck von arabischer Literatur zu beaufsichtigen. Sein verfrühter Einsatz auf Malta sei nur von Nachteil für die Qualität der arabischen Schriftstücke, so Smith:

I consider it that a broad foundation be laid under the best circumstances to qualify me to issue judicious, well adapted, and accurate publications that I look upon months and even years spent in doing this well, while the same length of time prematurely employed in a hasty issue of ill adapted and inaccurate publications is worse than thrown away. ${ }^{51}$

Smiths Neigung zur Perfektion wird sich auch in den folgenden Jahren in seiner Arbeit widerspiegeln. Immerhin kann er den American Board davon überzeugen, dass es noch einiger Vorbereitungen bedarf, um akkurate arabische Übersetzungen anzufertigen, die schließlich den Erfolg der Mission garantieren. Der Druck von arabischer Literatur auf Malta wird vorerst verschoben. ${ }^{52}$ In den ersten Monaten in Syrien investiert Smith viel Zeit in das Erlernen der arabischen Sprache und es wird sich zeigen, dass ihn sein Perfektionismus und Fleiß weiter als seine amerikanischen Kollegen bringen. „Many of us have envied my husband the results of that diving among Arab roots“, so Smiths erste Frau Sarah. ${ }^{53}$ Smith bleibt nicht lange auf Malta, bricht auf nach Griechenland und erkundet ab 1830 Armenien, Georgien und Persien, um mit seinem Kollegen Dwight neue Missionsgebiete zu erschließen.

47 Auf einer Reise durch Anatolien 1830 besucht Smith Martyns Grab in Tokat: „Little did I think, - when, by reading the life of that excellent man in my senior year in college, I was first inclined to a missionary life, - that Providence would ever put it in my way to visit his tomb. [...] I might be endued with more of his spirit, so that, if my life be prolonged, it may be as usefully spent as his, if death await me, I may be as well prepared for it as he was." Vgl. $\mathrm{MH}$ 26 (1830), in: ROS 2, 270.

48 Ein ehemaliger Freund aus den Studienjahren in Yale schreibt über Smith: „A sagacious observer [...] so diligent and thorough in study, so exact and methodical in his habits of thought, so clear in his conceptions, so retentive in his memory, so earnestly conscientious, so humble and simple in his self-consecration to the service of Christ.": vgl. Free Church of Scotland (1857), 237.

49 Leavy (1993), 7.

50 Ebd., 8.

51 Smith an Anderson (Malta, o. D. 1828): ABC 16.6.3 (164/1), zitiert in: Leavy (1993), 9.

52 Ebd., 10.

53 Hooker (1839), 330. 
1832 reist er für etwa ein Jahr in die USA, um eine Ehefrau zu finden, ${ }^{54}$ danach kehrt er 1834 mit Sarah Smith nach Beirut zurück, wo er schließlich die arabische Druckerei der Mission aufbauen soll. ${ }^{55}$

Zurück in Beirut nimmt Smith seine Arabischstudien wieder auf und ist bald in der Lage, seinen Kollegen Unterricht zu erteilen: ${ }^{56}$,[H]aving in view the more strictly literary department of our operations, he was naturally and necessarily led to pursue the study of Arabic and kindred languages to an extent hardly necessary, however desirable, for becoming a good speaker, or a good preacher. ${ }^{657}$ Der begabte Missionar beschäftigt sich nicht nur aus persönlichem Interesse intensiv mit Hocharabisch und der im osmanischen Syrien gesprochenen Umgangssprache. Sein Ziel ist es, die in der Druckerei herausgegebene christliche Literatur der Sprache der Syrer anzupassen: ,[T] $[$ hey are to be addressed, not in the language of books, but to be talked to as they talk, in their own idiom, and with their own accents and tones, which are acquired the more perfectly, the earlier in life they are attempted." 58

Smith ist Zeit seines Lebens ein überzeugter Missionar und weiß, dass die Menschen in Syrien nicht nur kulturell, sondern vor allem christlich erweckt werden müssen. Dies kann jedoch nicht durch öffentliche Angriffe auf die Glaubensdoktrinen der Kirchen Syriens erreicht werden, wie es zu Beginn von den amerikanischen Missionaren praktiziert wird, sondern durch behutsames und überlegtes Handeln, davon ist Smith überzeugt: ,[W]e shall take them by the hand and gently lead them to Christ". 59

Dass diese Strategie nicht bei jedem auf Wohlwollen trifft, zeigt die Auseinandersetzung zwischen Smith und dem Amerikaner Rev. John D. Paxton, der 1836 nach Syrien reist, um die dortigen Missionare freiwillig zu unterstützen. Immer wieder debattiert Paxton mit den Missionaren über deren Vorgehensweise im Missionsfeld und fordert sie auf, viel aggressiver zu predigen und weniger Augenmerk auf die Bildungsarbeit zu legen. ${ }^{60}$ Schließlich sei das Ziel, die christlichen Kirchen von innen reformieren zu wollen, der falsche Ansatz, so Paxton weiter. Die Missionare sollten die Konvertiten dazu drängen, eine eigene Kirche zu gründen und notfalls die ihrer alten Religion „niederzureißen“. ${ }^{61}$ Smith tritt Paxtons Anschuldigungen in einem Brief vom 24. Januar 1837 entgegen, freundlich aber bestimmt. ${ }^{62}$ Er gebe Paxton durchaus Recht, dass mehr gepredigt werden müsse - ein Thema, das, wie bereits beschrieben, die Mission bis zum Ende ihres Bestehens begleiten wird. Allerdings hält er die Herangehensweise, die Paxton vorschlägt, für nicht sehr

54 MH 28 (1832), in: ROS 2, 311; Leavy (1993), 11.

55 „Report on the Printing Establishment, adapted by Syrian Mission, for Dr. Anderson“ (o. O., o.D.): ABC 16.8.1., Vol. 4 (62).

56 Smith and Rev. J.D. Paxton (Smyrna, 24.1.1837): ABC 16.5.1. (174); MH 31 (1835), in: ROS 2, 419: „I have for some time given the best hours of every day to teaching Arabic to two or three of our number, who are not yet proficients in it.“

57 „Obituary Notice“: ABC 16.8.1., Vol. 5 (227).

58 Smith (1840), 9.

59 Smith an Paxton (Smyrna, 24.1.1837): ABC 16.5.1. (174).

60 Badr (1992), 149-150.

61 Paxton an Dwight (2.1.1837): ABC 16.5.1. (173), zitiert in: Badr (1992), 151.

62 Smith an Paxton (Smyrna, 24.1.1837): ABC 16.5.1. (174). 
effektiv. Die Missionare in Syrien haben sehr früh erkannt, dass ein aggressives Auftreten das Gegenteil bewirkt. „[R]eal Christian love ought to be the character of a missionary“ setzt Smith Paxton entgegen. Zwar müsse man die Menschen auf ihre Sünden hinweisen, jedoch sei der Erfolg größer, wenn mögliche Konvertiten selbst zu der Überzeugung kämen, dass die bisherige religiöse Praxis falsch sei. Paxton fordert die Missionare auf, gerade heraus und nicht heimlich (,underhandedly“), dreist (,bold“) und nicht zu vorsichtig aufzutreten. Smith weist ihn darauf hin, dass das Verständnis von Sünde unter den syrischen Christen anders sei. Paxton mag Idolatrie als unerträgliche und größte Sünde ansehen, für Christen in Syrien gehöre dies aber zur Normalität, wie Smith weiter schreibt. Der einzige Weg, ihnen ins Bewusstsein zu reden, sei es, auf die persönlichen Sünden aufmerksam zu machen. Selbst wenn Syrerinnen und Syrer, die sich von der Botschaft der Missionare überzeugt zeigen, die Messen ihrer Kirchen weiterhin besuchen, sich aber gemäß der Schrift verhalten, so kann dies von der Mission nur begrüßt werden. ${ }^{63}$ Smith betont hier sowie auch häufig an anderer Stelle, ${ }^{64}$ dass Veränderungen nur langfristig möglich seien: „[W]e must not try to do it all at once.“65 1851 bemerkt er in einem Brief an Anderson, dass man von der ersten Generation der Konvertiten noch nicht viel erwarten könne, jedoch ist er sicher, dass die zweite und dritte Generation $\mathrm{zu}$,,able and distinguished men "66 heranwachsen werde. Smith und sein Kollege William Goodell können die offizielle Stellungnahme des ABCFM von 1838, unter der Federführung von Rufus Anderson, zum Umgang mit anderen syrischen Christen nachhaltig beeinflussen. Die Missionstaktik soll zurückhaltend und respektvoll sein: ${ }^{67}$ „Our strength lies in doing much with little noise." ${ }^{68}$ In einem privaten Schreiben äußert sich Anderson gegenüber Smith bezüglich Paxtons Verhalten: Es müsse zwar mehr gepredigt werden, so Anderson, aber Paxtons „boldness is courage without discretion“. Nichtsdestotrotz lassen Paxtons scharfe Kritiken bei Anderson die Frage aufkommen, ob sie auf ein Problem hindeuten, dass tatsächlich existiere. ${ }^{69}$

Smith gilt Zeit seines Lebens als Verfechter der Theologie der puritanischen Väter Neuenglands, die Verkündigung der christlichen Botschaft bleibt sein oberstes Ziel. An zweiter Stelle jedoch stehen die Mittel, durch die dieses Ziel erreicht werden kann: Bildung, Buchdruck und eine Kultur des Wissens. „Upon [the] system of divine truth his own hopes of life rested, and it was this which he earnestly labored, for thirty years to infuse into the Arabic literature, and transplant into the hard and stony soil of Syria's moral desert." ${ }^{\text {'70 }}$

64 MH 38 (1842), in: ROS 3, 342: ,when a favorable juncture occurs [...] perhaps we find the seed we had sown has sprung up and attained to considerable growth.“

65 Smith an Paxton (Smyrna, 24.1.1837): ABC 16.5.1. (174).

66 Smith an Anderson (Beirut, 17.6.1851): ABC 16.8.1., Vol. 5 (199).

67 Badr (1992), 133-146, 162.

68 Smith an Paxton (Smyrna, 24.1.1837): ABC 16.5.1. (174).

69 Anderson an Smith (14.6.1837): ABC 2.1.1., Vol. 01 (HHL).

70 „Obituary Notice“: ABC 16.8.1., Vol. 5 (227). 


\section{Der American Arabic Type}

Zwei Druckereien machen sich ab den 1820ern einen Namen im arabischen Buchdruck: einerseits die 1822 gegründete ägyptische Druckerei Būlāq, im gleichnamigen Stadtteil von Kairo, ${ }^{71}$ und andererseits die Missionsdruckerei der englischen Church Missionary Society auf Malta, wo seit 1825/26 auch arabische Bücher herausgegeben werden.72 Der zunehmende Bedarf an arabischen Büchern für die Missionsschulen und die missionarische Bekehrungsarbeit veranlassen den ABCFM schließlich dazu, 1834 in Beirut die Mața 'at al-Amrīkān, die Druckerei der Amerikaner bzw. American Mission Press, zu eröffnen. ${ }^{73}$ Sie zieht zunächst in das Erdgeschoss des dreistöckigen, vom Missionar Isaac Bird erbauten Hauses (im Volksmund Burğ Bird genannt) ein, das als Hauptsitz der Mission gilt. ${ }^{74}$

Smith ist sich bewusst, dass die Araber ein anspruchsvolles Lesepublikum sind und dass die bisherigen missionarischen Schriftstücke auf Arabisch nicht der gewohnten Ästhetik des arabischen Schriftbildes entsprechen, die man von Kalligrafien und alten Manuskripten gewohnt ist. Selbst die zu dieser Zeit in Europa befindlichen Zentren für arabischen Buchdruck in Wien, Paris, Leiden, London und Leipzig haben noch keinen zufriedenstellenden Schriftsatz entwickelt, der sich langfristig durchsetzen kann. ${ }^{75}$ Dieser Umstand und Smiths Wille, von den Druckereien der englischen Missionen auf Malta unabhängig zu werden, veranlassen ihn dazu, einen eigenen Schrifttyp für die amerikanische Druckerei in Beirut zu entwerfen. ${ }^{76}$ Der vom Engländer Richard Watts produzierte arabische Schriftsatz, den die englischen Missionen auf Malta verwenden, steht zwar den Amerikanern seit 1828/29 zur Verfügung, ${ }^{77}$ er kommt in der amerikanischen Druckerei auf Malta jedoch nicht mehr zum Einsatz und wird in Beirut erst zwei Jahre nach der Eröffnung der American Mission Press 1836 verwendet. Zu Anfang fehlt es jedoch an einem fähigen Drucktechniker, der Arabisch beherrscht, Druckstempeln für kleine Buchstaben, die für Randbemerkungen und Zitate verwendet werden, sowie einem großen Buchstabensatz. ${ }^{78}$ Smith schätzt die Lettern aus London als höchst fehler-

Glaß (1998a), 13

Ebd., 10.

73 Ebd., 14: Die Druckerei wurde zum Teil auch al-Matba 'a al-Amrīkīya („Amerikanische Druckerei“) genannt. Mit Eröffnung der American Mission Press verlagert sich der arabische Buchdruck der amerikanischen Mission völlig nach Beirut: vgl. Tibawi (1963), 174.

74 PBCFM (1923), 4.

75 MH 40 (1844), in: ROS 3, 387: „There is a good font at Paris, understood to have been made under the direction of the celebrated Arabic scholar, De Sacy; another, perhaps equally good, exists in London; while Germany has two, both of them very good, one prepared at the expense of the Prussian government, for the Prussian universities, and the other from the celebrated foundry of Tauchnitz in Leipzig. But none of these are satisfactory to the Arabs themselves, who are fastidious in their taste, and great admirers of fine manuscripts. Not more satisfactory to them are the fonts used in their own printing offices at Constantinople and Cairo."

$76 \mathrm{Glaß}(1998 \mathrm{a}), 19$

77 Ebd., 12.

78 Tibawi (1966), 71; Roper (1998), 54. 
haft ein. ${ }^{79}$ Für die Entwicklung eines neuen Zeichensatzes lässt sich der Leiter der Beiruter Druckerei von etlichen arabischen Schriftbildern in Manuskripten, Kalligrafien und gedruckten Werken inspirieren, die dem gelehrten, arabischen Lesepublikum vertraut sind. Als Smith 1829 das syrische Kloster Mār Yuhannā al-Šweir besucht, wo es eine der wenigen Druckerpressen im Lande gibt, ${ }^{80}$ fällt ihm auf, dass der Schriftsatz den europäischen Ausgaben weit überlegen ist: ,,[C]ertainly the form of the letter is far superior to that of any other which I have seen. The types are cast in the convent after the model of a distinguished Arabic penman. " 81

Bereits 1835 reist der in Beirut neu eingestellte Drucker George Badger zu privaten und klösterlichen Druckereien in diesem Gebiet, um Stempel und Matrizen zu erhalten, aus denen er Gussformen fertigt. ${ }^{82}$ Die daraus entstehenden Zeichen sollen zusammen mit Watts Schriftsatz als Übergang dienen bis ein zufriedenstellender, eigener Schriftsatz hergestellt wird. Ab 1836 bereist Eli Smith im Auftrag der Druckerei Orte wie Kairo, Damaskus, Aleppo, Jerusalem und Istanbul, um dort verschiedene Schreiber aufzusuchen und Manuskripte zu sammeln. Der Plan, diese zu einer neuen Schriftart zusammenzufügen, scheitert jedoch vorerst, da er auf der Schiffsreise in der Nähe von Smyrna (heute Izmir) Schiffbruch erleidet und alle Dokumente unwiederbringlich verloren gehen. ${ }^{83}$ Er reist daher erneut nach Istanbul, um weitere 200 Schriftmodelle zu sammeln. Schließlich kann der in Smyrna ansässige Typograf der amerikanischen Mission, Homan Hallock ${ }^{84}$, die Stempel nach Smiths Vorgaben schneiden. Prof. Edward Robinson, der mit Smith 1838 eine Reise durch Palästina und Syrien unternimmt (s. u.) und seine Recherchen für die Erstellung einer Topografie Palästinas in Deutschland fortsetzt, stellt den Kontakt zwischen Smith und den deutschen Orientalisten Emil Rödiger, Heinrich Leberecht Fleischer, August Tholuck sowie zum in Leipzig ansässigen Verleger und Drucker Karl Tauchnitz her. ${ }^{85}$ Es ist nun alles für Smiths Reise nach Deutschland vorbereitet und neben Besuchen bei den renommierten Orientalisten jener Zeit, lässt Smith die geschnittenen Schriftsätze von Tauchnitz in Matrizen gießen. ${ }^{86}$ Das Ergebnis ist der amerikanisch-arabische Schriftsatz, der „American Arabic Type“67. Smith sendet eine erste Probe an seinen Freund und Kollegen Tannūs al-Haddād in Syrien, damit

79 Smith an Anderson (o. O., 13.7.1835): ABC 16.8.1., Vol. 1 (89). Auch die Church Missionary Society, die Watts Buchstabensatz verwendet, ist nicht mit dem ,ausländischen Aussehen“ der arabischen Buchstaben zufrieden und arbeitet ab 1838 an einem eigenen Schriftsatz: vgl. Glaß (1998a), 12.

80 Atiyeh (1995), 237: Die Druckerei wird 1723 von 'Abdallah Zah̄ir eingerichtet.

81 MH 25 (1829), in: ROS 2, 158.

82 Roper (1998), 59.

83 Glaß (1998a), 20; Stoddard (2009), 214.

84 Hallock wird Smith später nach Beirut folgen und ihn für kurze Zeit der Druckerei unterstützen: vgl. MH 29 (1833), in: ROS 2, 353.

85 Robinson an Smith (o.O., 14.11.1838): ABC 60 (63), (HHL); vgl. auch Emil Rödigers Briefe von 1838 an Smith: ABC 60 (65), (HHL).

86 MH 40 (1848), in: ROS 3, 387; Jessup (1910a), 55; Glaß/Roper (2002), 191. Auch das günstige Preisangebot veranlasst die Amerikaner dazu, sich für eine Herstellung in Deutschland zu entscheiden: vgl. G.B. Whiting/G. Hurter, ,Report of Works Printed at the Missionary Press in Beirut" (1844): ABC 16.8.1., Vol. 1 (28). 
dieser ein Urteil über sie abgebe. Al-Haddād antwortet Smith im April 1839: „In regard to the Arabic letters, we have found the specimen [printing] thereof which you sent for our consideration rather deficient: the length and thickness of letters are not in the right proportion .... ${ }^{88 ،}$

Es ist unklar, ob der Schriftsatz nach dieser Beurteilung überarbeitet wird. Fest steht jedoch, dass der American Arabic Type erst 1841 nach Beirut kommt, um dort in der Druckerei verwendet zu werden. Trotz allem kann die Druckerei nicht so effektiv arbeiten, wie Smith es sich wünscht. Es fehlt immer noch an einem geeigneten Druckermeister und vielen fähigen Mitarbeitern. Homan Hallock, der Smith bei der Herstellung des Schriftsatzes geholfen hat und in Smyrna stationiert ist, möchte nicht nach Beirut kommen. ${ }^{89}$ George P. Badger, der sich als sehr fähig und beflissen erweist, will 1836 nach nur einem Jahr in Beirut wieder abreisen. ${ }^{90}$ Erst 1841 findet sich mit dem Briten George Hurter ein Druckermeister, der die immer wieder unterbrochene Arbeit in der Beiruter Druckerei aufnimmt. ${ }^{91}$ Deshalb werden in Beirut zwischen den Jahren 1835 und 1842 nur 29 Schriftstücke gedruckt, zu denen neben biblischen und fromm religiösen Texten drei Fibeln, zwei Grammatiken, eine Arithmetik und ein Medizinbuch gehören. ${ }^{92}$

Trotz dieser Umstände wird das amerikanische Schriftbild über die Grenzen Syriens bis nach Alexandria und sogar Bombay bekannt. Der neue Schriftsatz wird sehr positiv aufgenommen und die Schrift der Bücher ist nicht nur ,,more beautiful than the old", sie ist auch aufgrund ihrer Ähnlichkeit zur Kalligrafie für den Schulgebrauch und für das Schreibenlernen besonders geeignet, so George Hurter und der Missionar Whiting. ${ }^{93}$

$\mathrm{Ab}$ den fünfziger Jahren des 19. Jh.s entwickelt sich die American Mission Press zu einer führenden Institution der Buchdrucktechnik. ${ }^{94}$ In einem Schreiben an Rufus Anderson vom 26. Dezember 1853 berichtet Smith, dass er sogar von Einheimischen gebeten wurde, bei der Einrichtung einer neuen Druckerei in Beirut hinsichtlich der Besorgung von Druckmaschinen behilflich zu sein und die Matrizen der Amerikaner für den Guss des Schriftsatzes auszuleihen. ${ }^{95}$

Demnach profitierten nicht nur die Ma'ārif-bzw. die Adabīya-Druckerei, sondern auch die von Muslimen geführte Funūn-Druckerei von den technologischen

88 Tannūs al-Haddād an Smith (13.4.1839), zitiert in: Tibawi (1966), 86.

89 Hallock reist jedoch nach der Fertigstellung des Schriftsatzes in die USA, um nach denselben Matrizen für den American Board arabische Buchstaben zu schneiden und zu gießen. Die Buchstaben werden jedoch etwas kleiner angefertigt als der Beiruter Schriftsatz: vgl. Rufus Anderson and John Pickering (16.6.1843): ABC 1.1., Vol. 18, 132 (HHL).

90 Roper (1998), 58-59.

91 MH 37 (1841), in: ROS 3, 308-309.

92 Roper (1998), 58.

93 Whiting/Hurter, „Report of Works Printed at the Missionary Press in Beirut“ (1844): ABC 16.8.1., Vol. 1 (28).

94 Glaß (1998a), 25; Roper (1998), 57.

95 Smith an Anderson (Beirut, 26.12.1853): ABC 16.8.1., Vol. 1 (208). Aus einem Brief von Halīl al-Hurī an Eli Smith (o.O., 9.6.1856) geht hervor, dass er vorhat, für den Druck seines neuen arabischen Journals den amerikanisch-arabischen Schriftsatz käuflich zu erwerben: ABC 50, Box 3 (HHL). 
Schrittmacherdiensten der Missionare bzw. vom Techniktransfer aus dem Westen in den Osten, ${ }^{96}$ wie die Arabistin DAGMAR GLAß und der Historiker GeOFFrey Roper feststellen.

Beim Vergleich verschiedener christlicher Periodika aus dieser Zeit zeigt sich, dass der American Arabic Type den Lesenden sehr vertraut gewesen sein muss. ${ }^{97}$ Jessup urteilt selbstbewusst: ,The type of the Beirut Press is becoming more and more widely regarded as the best Arabic type in the world." 98 Sogar Arabisten in Europa bekunden ihr Interesse am Schriftsatz der Amerikaner und schätzen ihn als den bisher besten ein. ${ }^{99}$ Bis Mitte der 1850er Jahre kann Smith die Ausstattung der American Mission Press vervollständigen. Dafür werden noch weitere Zeichensätze gegossen, ,different sizes and [...] new characters [...] permit a wider variety of publications“". ${ }^{100}$ Die Aufrüstung der Druckerpressen mit Dampfmaschinentechnik im Jahr 1854 führt zu einem effizienteren Arbeiten. ${ }^{101}$

Durch die Entwicklung einer schnelleren Drucktechnik gegen Ende des 19. Jh.s werden vereinfachte Setztechniken und weniger aufwendige Schriftbilder erforderlich, ,the ornamental ligatures are more and more being laid aside“. ${ }^{102}$ Der American Arabic Type kommt schließlich aus der Mode.

\section{Al-Kitāb al-Muqaddas - Die arabische Bibel}

Schon zu Beginn des 19. Jh.s erkennt der berühmte anglikanische Pastor Henry Martyn, der Smith und vielen weiteren Generationen von Missionaren als Vorbild dient, dass die Übersetzung der Bibel in die arabische Sprache zu den wichtigsten Aufgaben christlicher Verkündigung gehört: ,We can begin to preach to Arabia, Syria, Persia, Tartary, part of India and China, half of Africa and nearly all the sea-coasts of the Mediterranean, including Turkey. "103 Smith, der sich eingehend mit Martyn beschäftigt hat, mag sich in Syrien an diese Worte erinnert haben. Fest steht, dass die Entwicklung eines neuen, ästhetisch schönen arabischen Schriftsatzes nicht nur für die Produktion christlicher Traktate und Schulbücher gedacht ist, sondern die Heilige Schrift soll in einer Form erscheinen, die dem Geschmack der Araber schon rein äußerlich entspricht.

96 Glaß/Roper (2002), 193-194. Die Mațba'at al-Ma 'ārif („Druckerei des Wissens“) wird 1867 von Buṭrus al-Bustānī und Hualīl Sarkīs eröffnet; Halīl Sarkīs eröffnet zudem 1876 die alMațba 'a al-Adabīya (,Druckerei für Literatur“); die Funūn-Druckerei existiert ab 1874.

97 Glaß (1998a), 27-28: Auch Bustānīs berühmte Enzyklopädie Dā'irat al-Ma 'ārif präsentiert sich im Schriftbild des American Arabic Type.

98 Jessup (1910a), 362.

99 Ebd. Emil Rödiger schreibt schon 1838 an Smith, dass er hoffe, Tauchnitz möge den Schriftsatz doppelt gießen, da die Druckerei in Deutschland „,eine größere Textschrift und eine Notenschrift" benötige. Ob Smith dieser Bitte nachgekommen ist, ist nicht bekannt: vgl. Rödiger an Smith (Halle, 11.11.1838): ABC 60 (65), (HHL).

100 Leavy (1993), 12.

101 MH 50 (1854), in: ROS 4, 214; Tibawi (1966), 134.

102 Hall (1885), 285.

103 MH 30 (1834), in: ROS 2, 390. 
Als sich Rufus Anderson 1844 in Syrien aufhält, wird in einer Generalversammlung beschlossen, eine neue arabische Bibelübersetzung unter der Leitung von Eli Smith in Angriff zu nehmen. ${ }^{104}$ Die bisherige katholische Fassung von 1671 erscheint dem mittlerweile versierten Arabisten Smith als schädlich für das Verständnis der Heiligen Schrift unter den Syrern:

The whole version is not in a classical style. The structure of the sentences is awkward, the choice of words is not select, and the rules of grammar are often transgressed. We have been ashamed to put the sacred books of our religion, in such a dress, into the hands of a respectable Muhammedan or Druze and felt it our duty to accompany them with an apology. ${ }^{105}$

Eine weitere Übersetzung, die der Mission in Kopie zur Verfügung steht, ist das 1727 von der London Society for Promoting Christian Knowledge veröffentlichte Neue Testament auf Arabisch. Jedoch erweist sich auch diese Version als unbrauchbar, wie Smith berichtet: „It was corrected from the Paris and London Polyglotts, by Solomon Negri, and conformed with great strictness to the Greek original. But in this very strictness the corrector erred, for there is always a stiffness about it, and not unfrequently the idiom is quite foreign." 106

Die amerikanische Mission strebt nach einer Bibelübersetzung, die für den gesamten Text eine einheitliche Phraseologie bietet, im Gegensatz zu den verschiedenen Übersetzungsversionen, die die Mission verwenden muss. ${ }^{107} 1848$ werden Eli Smith der bekannte syrische Dichter - und beste arabische Grammatiker seiner Zeit - Nāṣīf al-Yāziğ̄̄in, sowie Buṭrus al-Bustān̄̄, Arabischlehrer der Mission, zur Seite gestellt. Das Arbeitspensum ist so hoch, dass Smith bald über fehlende Helfer klagt. Ein Missionar sollte sich allein der Übersetzung widmen, ohne andere Aufgaben übernehmen zu müssen, so Smith $1844 .{ }^{108}$ Der ABCFM kann und will auf Smiths Vorstellungen jedoch nicht eingehen. Smith, Bustān̄̄ und al-Yāziğ̣̂ müssen sich daher auch anderen Aufgaben widmen, weshalb man sich die Zusammenarbeit der drei nicht als kontinuierlich vorstellen kann. Selten arbeiten sie gemeinsam an einem Ort, stattdessen werden die Entwürfe hin und her gesandt, um dann schriftlich besprochen zu werden. ${ }^{109}$ Beginnend mit dem Alten Testament, arbeiten sie sich Stück für Stück durch die Bibel: Als Erstes übersetzt Bustān̄̄, der sich zuvor in das biblische Griechisch und Hebräisch eingearbeitet hat, einzelne Textpassagen. ${ }^{110}$ Durch seine Ausbildung an der maronitischen Hochschule 'Ayn Warqa ist

104 „Preface“, in: Smith / Van Dyck (1900).

105 „Report of Rev. Eli Smith, D. D., in March 16th, 1844, on the existing Arabic Versions of the Scriptures“, in: Smith / Van Dyck (1900), 1-2: Die katholische Fassung wurde im Auftrag des damaligen Erzbischofs von Damaskus, dem Maroniten Sarkis al-Rūr, nach der Vorlage der Vulgata in Auftrag gegeben. Kahle (1904), III-IV: Die evangelischen Missionen im 19. Jh. drucken jene Version ohne die Apokryphen.

106 „Report of Rev. Eli Smith on existing Arabic Versions“, in: Smith / Van Dyck (1900), 2.

107 „Dr. Smith's Report on the Translation of the Scriptures, April 1854“, in: Smith / Van Dyck (1900), 8.

108 „Report of Rev. Eli Smith on existing Arabic Versions“, in: Smith / Van Dyck (1900), 3.

109 Das geht aus dem Briefwechsel zwischen Bustān̄̄ und Smith hervor: z. B. Bustān̄̄ an Smith (Sūq al-Ġarb, 18.7.1855): ABC 50, Box 3 (HHL).

110 „Smith's Report, 1854“, Smith / Van Dyck (1900), 8: „The advantages of this proceeding are: First, giving to the work a native coloring which a foreigner could not so easily accomplish. 
Bustān̄̄ vermutlich mit älteren Bibelversionen und -manuskripten vertraut. ${ }^{111}$ Die Vorübersetzung gehen dann Smith und al-Yāziğ̄i auf theologische Richtigkeit und sprachliche Nähe zum Originaltext durch. Im dritten Schritt erhält Bustān̄ die korrigierten Passagen von Smith und arbeitet Textelemente aus alten arabischen Manuskripten ein. Diese Manuskripte sind zum Teil bis zu 500 Jahre alt und enthalten meist nur Teile der Heiligen Schrift, die sich häufig am Text der Vulgata, aber auch manchmal an der Peschitta orientieren. ${ }^{112}$ Unter erneuter Konsultation verschiedener Ausdrucksweisen in den Manuskripten sieht Smith Bustān̄̄s Wortwahl durch. Ziel ist es, aus den verschiedenen Übersetzungen der vergangenen Jahrhunderte eine Einheit zu formen, die bei allen Konsens findet. ${ }^{113}$ Letztlich prüfen Smith und al-Yāziğì erneut Grammatik und Lexikografie des Textes, damit er den Geschmack des Lesers trifft. Al-Yāziğ̄i führt schließlich die Reinschrift durch. ${ }^{114}$

Als Leiter der American Mission Press ist es auch Smiths Aufgabe, Fachliteratur für die Missionsbibliothek zu sammeln. Allein für die Bibelübersetzung stellt er einen Apparat textkritischer und linguistischer Fachliteratur zusammen, wie man ihn nur in den europäischen und amerikanischen Bibliotheken finden kann, ,scarcely valued or even understood, by the average missionary or clergymen at home“. 115 $\mathrm{Zu}$ den Nachschlagewerken zählen die neuesten Lexika für biblische Sprachen aus Europa sowie ältere und neuere arabische Grammatiken. ${ }^{116}$ Schließlich werden die ersten Druckfassungen an Christen und Muslime in Beirut, Damaskus, Aleppo, Jerusalem Ägypten sowie an Orientalisten in Deutschland gesandt, mit der Bitte, nötige Korrekturvorschläge zu machen. „Many minds, native and foreign, were thus brought to bear upon the work“, ${ }^{117}$ wie Van Dyck später schreibt. Smith ist ebenso die Meinung von ungebildeten Syrern wichtig, weshalb er seine Entwürfe regelmäßig drei bis vier Einheimischen zukommen lässt, ,in order to obtain their criticisms on the intelligibility of the language, and acceptableness of the style, to common readers". ${ }^{118}$ Für den Fall, dass sie Redewendungen und Wörter nicht verstehen, werden fehlerhafte Passagen zugunsten des allgemeinen Verständnisses geändert. ${ }^{119}$ Die arabische Wortwahl soll schließlich auch von der ,einfachen“ Bevölkerung verstanden werden. Anstatt z. B. den alttestamentlichen Gottesnamen JHWH zu transliterieren, entscheidet sich Smith für die unter den Arabern gängige

Second, bringing into it the terms and phrases in common and good use to express the ideas of the original $[\ldots]$. “

111 Binay (2012b), 78.

112 „Smith's Report, 1854“, in: Smith / Van Dyck (1900), 6-7: Manche der Manuskripte sind in Neuauflagen erschienen, die von europäischen Orientalisten herausgegebenen wurden. Binay (2012a), 16.

113 „Smith’s Report, 1854“, in: Smith / Van Dyck (1900), 8.

114 Ebd., 9.

115 Hall (1885), 284.

116 Eine Aufzählung der verwendeten Fachliteratur findet sich in: „Smith’s Report, 1854“, in: Smith / Van Dyck (1900), 5-7.

117 „Dr. C.V.A. Dyck’s Report on the Translation, April 29th, 1863“, in: Smith / Van Dyck (1900), $15-16$.

118 ABCFM (1856), 35.

119 Kahle (1904), V. 
Bezeichnung rabb (HERR) für das höchste existierende Wesen. ${ }^{120}$ Die aufwendige Korrekturarbeit sowie das Versenden der Korrekturbögen ziehen die Arbeit an der Bibel in die Länge. Aber der Zeitaufwand lohnt sich, denn dadurch wird ermöglicht, „dass dieser Styl allen einigermaßen verständigen Arabern, wenigstens von Aegypten bis Mesopotamien, ungefähr gleichmäßig zusagt". ${ }^{121}$ Vergleicht man schließlich die Übersetzung der Amerikaner mit älteren Bibeleditionen, so zeigt sich, dass sie mehr eine Art Revision als eine völlig neue Übersetzung der Bibel in die arabische Sprache darstellt. ${ }^{122}$

Die Arbeit an der arabischen Bibel erweist sich für Smith auch weiterhin als äußerst mühsam und kräftezehrend. Nach einigen Jahren stellt ihn die Zusammenarbeit mit Nāṣîf al-Yāziğī nicht mehr zufrieden und

it was soon found that in the terms of natural history and certain other sciences, as well as in the technicalities of different trades and professions, and in other like matters, his knowledge was indistinct and often very defective. And to search out, and rightly select words of this kind, has cost me much time. ${ }^{123}$

Immer wieder muss Smith die Passagen, die al-Yāziğ̄i zuvor übersetzt hat, erneut korrigieren: ,The translation [...] come[s] out, in very many passages, wide of the original meaning, and the force of the sentiment [is] lost."124 Smiths Kollegen zeigen wenig Verständnis für dessen Kritik an al-Yāziğī: ,,This part of my work I think some of my brethren do not, perhaps, fully appreciate. They would confide too much in Nâsîf, and expect more from him than they will realize." ${ }^{25}$

Hinzu kommt, dass Smith oftmals nur zwölf Verse pro Tag fertigstellen kann. ${ }^{126}$ Später werden Kollegen und Freunde berichten, dass er große Probleme hatte, sich zwischen Synonymen zu entscheiden, wie Isaac Hall von der American Oriental Society schreibt:

Some of the missionaries who believe in rapid work have said to me that he was therein a prey to indecision [...] his (unfinished) Old Testament manuscript, as I have been told by those who saw it, often had a column of synonyms six or seven deep and high, above and below nearly every important word in the line. ${ }^{127}$

Andererseits setzen Smith und sein Team auch bewusst Wörter ein, die aus dem Sprachgebrauch verschwunden sind, jedoch aus dem Bedeutungszusammenhang verstanden werden können: ,[T]rusting to the future enlightenment of the nation to bring back the language again nearer to its classical richness and purity." ${ }^{\text {"128 }}$ Durch

120 „Dr. Van Dyck’s Letter to Dr. S. Jessup, Sept. 8th, 1888, called out by Letter of Dr. Bruce, of Persia, asking the views of the Syria Mission on the subject“, in: Smith / Van Dyck (1900), 32.

121 Smith an die DMG (Beirut, 9.5.1856), in: ZDMG 10 (1856), 813.

122 Binay (2012a), 15.

123 „Smith’s Report, 1854“, in: Smith / Van Dyck (1900), 9; siehe auch „Letter from Dr. Smith on the Printing Establishment“" (Beirut, 16.10.1855): ABC 16.8.1., Vol. 5 (216).

$124 \operatorname{ABCFM}(1856), 34$.

125 Ebd.; siehe auch „Dr. Van Dyck's History of the Arabic Translation of the Scriptures, March 7th, 1885,“ in: Smith / Van Dyck (1900), 29.

126 Anderson an die Syrienmission (Boston, 11.7.1851): ABC 16.8.1., Vol. 8 (4).

127 Hall (1885), 283.

128 „Smith’s Report, 1854“, in: Smith / Van Dyck (1900), 10. 
das Versenden der Korrekturbögen zeigt sich, dass die Sprache der Bibelübersetzung allgemein verständlich ist und Smith erhofft sich, dass sie durch ihre Verbreitung mehr erreichen wird als nur die christliche Botschaft zu verkünden:

Und so glauben wir auch, dass diese im Allgemeinen die Gestalt ist, zu welcher die Sprache, mit dem Wiedereintritte des Volkes in die Reihe der gebildeten Nationen, sich ihrerseits erheben wird, nur dass vielleicht mehr muhammedanische Phraseologie, als wir angenommen haben, in diese Neubildung eingehen wird. ${ }^{129}$

Gegenwärtig gibt es noch keine veröffentlichte Forschungsarbeit, die anhand von Sprachstudien belegen kann, inwiefern die amerikanische Bibelübersetzung zur Entwicklung der arabischen Sprache in der zweiten Hälfte des 19. Jh.s beigetragen hat. ${ }^{130}$

Trotz unermüdlicher Arbeit kann Smith die Übersetzung nicht mehr vollenden. Ein Besucher, der etwa 1856 für einige Wochen in Smiths Haus wohnt, schreibt über den Zustand des Missionars: ,[f]eeble, attenuated, and under the necessity of guarding his precarious health with constant care". ${ }^{131}$ Bevor Smith 1857 stirbt, hat er mit seinem Team das gesamte Neue Testament, den Pentateuch sowie die Prophetenbücher Hosea, Joël, Amos, Obadjah, Jona, Micha, Nahum und Jesaja (bis Kapitel 52) durchgearbeitet. ${ }^{132}$ Noch am Sterbebett teilt er seinem Kollegen Wilson mit, dass die Veröffentlichung der Bibel nicht in seinem Namen geschehen solle. Smith sieht sich nur für die bereits gedruckten Texte verantwortlich (Genesis, Exodus, Matthäus bis Kapitel 12), alle übrigen Entwürfe gelten seiner Meinung nach als unvollendet. ${ }^{133}$ Anderson bemerkt dazu später leicht zynisch:

It did not please the Lord to grant the earnest desire of Dr. Smith to live and complete his translation of the Scriptures; and it must be admitted, that his ideal of perfection in the work was such, that it is doubtful whether he ever could have been satisfied that his entire translation was ready for publication. ${ }^{134}$

Van Dyck, der die Übersetzung ab 1857 fortsetzt, muss nun große Teile der Bibelübersetzung von Smith neu durchsehen. Dabei stellt sich heraus, dass sich Smiths Übersetzung des Neuen Testaments nicht auf den damals gültigen textus receptus bezieht, sondern stattdessen neueste Forschungsergebnisse der Theologen Konstantin von Tischendorf, Samuel Pl. Tregellus, E. Lachmann und Henry Alford berücksichtigt worden sind. Alle vier Theologen arbeiten auf der Grundlage von Recherchen in alten griechischen Bibelmanuskripten (u. a. im Codex Sinaiticus) an einer neuen Ausgabe des griechischen Neuen Testaments. ${ }^{135}$ Die amerikanische Bibelgesellschaft, mit deren Geldern die arabische Bibel gedruckt werden soll, verbietet

129 Smith an die DMG (Beirut, 9.5.1856), in: ZDMG 10 (1856), 813.

130 Die Ph.D-Studentin Rana Hisham Issa (Universität Oslo) wird jedoch voraussichtlich 2014 ihre Doktorarbeit zum Thema „Arabia Minor: The Arrival of the Bible to the Arabic Language in 19th Century Lebanon“ einreichen: vgl. URL: http://www.hf.uio.no/ikos/english/research/ doctoral-degree-and-career/phd-projects/issa-rana/index.html (Stand: August 2014).

131 Free Church of Scotland (1857), 238.

132 Van Dyck (Beirut, 19.5.1859), in: „Eulogies“: ABC 60 (139), HHL.

133 „C.V.A. Dyck's Report, 1863“, in: Smith / Van Dyck (1900), 15.

134 Anderson (1872b), 327.

135 „C.V.A. Dyck’s Report, 1863“, in: Smith / Van Dyck (1900), 15; Hall (1885), 279. 
deshalb den Druck von Smiths Neuem Testament, da er nicht dem textus receptus entspricht. ${ }^{136}$ Ein Komitee bestehend aus Missionaren der Syrienmission begutachtet die Übersetzungstexte von Smith und bittet die Bibelgesellschaft darum, die neutestamentlichen Texte lediglich korrigieren zu dürfen, statt sie zu verwerfen, denn ,in regard to the translation of the New Testament [...] the committee are unanimously of the opinion that it has been made with great care and fidelity, and that it could, with comparatively little labor be prepared for the Press [...]“. 137

Die Basis, die Smith legt, wird als „von unschätzbarem Wert“ eingestuft. 138 Van Dyck kann zwar einiges daraus übernehmen, muss bei vielen neutestamentlichen Büchern jedoch von vorn beginnen. Würde er zu sehr Rücksicht auf Smiths Entwürfe nehmen, zöge sich die Arbeit noch länger hin, so sein Urteil. ${ }^{139}$

\section{Die Herausgabe der ersten arabischen Zeitschrift in Syrien - Mağmū 'Fawà 'id}

Am 30. April 1851 beschließt die Syrienmission in ihrem Jahrestreffen „to commence printing a series of religious pamphlets, to consist of miscellaneous articles". Obwohl das Editing Committee der Mission (d.h. Eli Smith, George Whiting und Henry De Forest) mit der Herausgabe des Blattes beauftragt wird, ${ }^{140}$ liegt der Hauptteil der Arbeit bei Smith. ${ }^{141}$ Schließlich gilt er in späterer Literatur auch als alleiniger Herausgeber. ${ }^{142}$ Dem Missionsblatt oder religious pamphlet wird bisher zu wenig Bedeutung beigemessen, dabei ist es in der Tat die erste gedruckte periodische Schrift auf Arabisch in Syriens neunzehntem Jahrhundert. ${ }^{143}$ Dem Genre nach ist sie eine mağalla, eine Zeitschrift, die wie in Europa, eine Mischung aus Wissenswertem und Unterhaltung darstellt. ${ }^{144}$ Der Name dieser Zeitschrift ist Programm: „Sammlung nützlicher Lektionen“ (Mağmū 'Fawā'id), denn in den insgesamt nur sechs Ausgaben, die zwischen 1851 und 1856 im Buchformat $(12,5 \times 23 \mathrm{~cm})$ erscheinen, findet sich eine vielseitige Zusammenstellung von infor-

136 Es wird später fälschlicherweise angenommen, dass Smiths Manuskripte aus diesem Grund zerstört wurden wie Isaac Hall in JAOS 13 (1889, viii-ix) erläutert. Jedoch bleiben sie erhalten, obwohl die Übersetzung für die Mission als unorthodox gilt: vgl. Binay (2012b), 75-76.

137 „Van Dyck’s History, 1885 “, in: Smith / Van Dyck (1900), 26.

138 Ebd., 27.

139 Ebd. Näheres zu Van Dycks Arbeit an der Bibelübersetzung in Abschnitt II.2.3.

140 „General Letter, after annual meeting of 1851“ (Beirut, 30.4.1851): ABC 16.8.1., Vol. 4.1. (45).

1411855 schreibt Smith: „Of the Editing Committee, I have uniformly been the active member to do the work. The other members have ordinarily done little more than give advice.“ Vgl. „Letter from Dr. Smith on the Printing Establishment" (Beirut, 16.10.1855): ABC 16.8.1., Vol. 5 (216).

142 Ṭarrāzī (1913), 53-54; Hūrūi (2003), 301; Dāg̀īr nennt in seiner Auflistung arabischer Periodika gar keinen Herausgeber: vgl. ders. (1978), 252, Nr. 1550.

143 Glaß (2001), 29. Ayalon definiert Mağmū' Fawà'id nicht als erstes arabisches Periodikum, da die Zeitschrift nicht indigen sondern eine missionarische Publikation sei. Demnach spricht er der von Halīl al-Ȟūrī ab 1858 herausgegebenen Zeitung Hadīqat al-Ahbār (Garten der Nachrichten) zu, ,the first journalistic undertaking in Lebanon“ zu sein: vgl. ders. (1995), 31, 34.

$144 \mathrm{Glaß}$ (2004a), 8. Mağalla oder ğurnāl als Bezeichnungen für eine Zeitschrift setzen sich erst ab 1884 durch: vgl. Dāya (2008). 
mativen Artikeln und vor allem predigtartigen Essays oder kleinen Geschichten mit praktisch-theologischen Pointen. ${ }^{145}$ So wie im späteren von der Mission herausgegebenen Blatt al-Našra al-Usbu ‘̌ya fehlen Angaben zum Herausgeber, es gibt kein Editorial (wie z. B. später bei Bustānīs Zeitschrift al-Ǧinān, 1870) und die Verfasser der jeweiligen Artikel bleiben anonym. Al-Rifā' 'īs Beschreibungen zufolge hat kein syrischer Intellektueller den Redaktionskreis der Zeitschrift je betreten, schließlich drehten sich alle Themen rund um die Arbeit der amerikanischen Missionare. ${ }^{146}$ Dieser Aussage widerspricht der Jahresbericht der Mission von 1851, in dem jedes Mitglied der Mission eingeladen wird, Artikel je nach Belieben beizutragen „or to procure from native friends“. ${ }^{147}$ Sehr wahrscheinlich haben syrische Helfer einige Artikel entweder selbst verfasst, aus dem Englischen übersetzt oder arabische Entwürfe der Missionare überarbeitet. ${ }^{148}$ Schließlich werden die zahlreichen Bücher für die American Mission Press häufig im Team erarbeitet, wie Smith an Anderson 1856 schreibt. ${ }^{149}$ Eine Unterscheidung zwischen den Autoren, und vermutlich auch Autorinnen $^{150}$, ist daher nicht mehr möglich. ${ }^{151}$ (Abb. 4)

Seine Vorbilder hat das Missionsblatt vermutlich in amerikanischen christlichen Periodika, die eher ein breiteres Publikum ansprechen. ${ }^{152}$ Zum einen werden Essays dargeboten, die - teils auch unterhaltsam - zum Allgemeinwissen beitragen sollen: z. B. die Vorteile medizinischer Kenntnisse, ${ }^{153}$ geografische Anmerkungen zu Tageslängen an verschiedenen Orten der Welt, ${ }^{154}$ die Geschichte Phöniziens, ${ }^{155}$ das Klima ${ }^{156}$ oder der Entdecker Christoph Kolumbus ${ }^{157}$. Zum anderen gibt es alltagstheologische Betrachtungen: bspw. von der Bedeutung, sich selbst zu kennen; ${ }^{158}$ warum die Bibel das wichtigste Zeugnis ist; ${ }^{159}$ was Gelehrte über Armut und Reich-

145 Glaß (2004a), 132. Die Ausgaben sind jeweils zwischen 16 und 32 Seiten lang. Ayalon (1995, 34) geht fälschlicherweise von vier Heften aus.

146 Al-Rifā‘̄̄i (1969), 48.

147 „General Letter, after annual meeting of 1851“ (Beirut, 30.4.1851): ABC 16.8.1., Vol. 4.1. (45).

148 Bustān̄̄ liest bspw. nicht nur Korrektur für die Bibelübersetzung, sondern auch für andere Veröffentlichungen der Druckerei. 1855 berichtet Smith von Milham Šemayil, der halbtags angestellt ist, um Korrektur zu lesen: „Letter from Dr. Smith on the Printing Establishment“ (Beirut, 16.10.1855): ABC 16.8.1., Vol. 5 (216).

149 Smith an Anderson (Beirut, 13.3.1856): ABC 60 (105), (HHL).

150 Auch die Missionarsfrauen bzw. Missionsassistentinnen und syrische Protestantinnen haben sich an den Buch- und Zeitschriftenpublikationen beteiligt: Näheres dazu in Womack/Lindner (2014). Siehe auch der Eintrag zu Hannī Wortabet in Anhang II, Nr. 67.

151 Gleiches gilt für die missionarische Zeitschrift Zahrire d-Bahra (persisch für ,Sonnenstrahlen“), die die Missionare des ABCFM in Urmia herausgeben: vgl. Murre-van den Berg (2011), 189.

152 Z.B. der von der American Tract Society herausgegebene American Messenger (1843-1876), der sowohl religiöse Neuigkeiten, christliche Erzählungen als auch Wissenswertes für Jung und Alt darbietet: vgl. Brown (2004), 157.

153 „Nașā’ iḥ țibbīya“ (Medizinische Ratschläge), in: Mağmū' Fawā’id 1 (1851), 1-3.

154 „Fawā’ id ğuġrāfìya“ (Geografische Angaben), in: Mağmū' Fawā’id 2 (1852), 14.

155 „Tārīh fīnīqīya“ (Phönizische Geschichte), in: Mağmū' Fawā’id 2 (1852), 19-24.

156 „Fī l-hawā'“ (Über das Klima), in: Mağmū ' Fawā'id 3 (1855), 30-31.

157 „Fī Hurīstūfūrus Kūlūmbūs“ (Christoph Kolumbus), in: Mağmū’ Fawā’id 4 (1855), 9-10.

158 „Ma arifa al-d̄āt“ (Wissen über sich selbst), in: Mağmū' Fawā’ id 2 (1852), 15-18.

159 „Așdaq al-šuhūd“ (Das wichtigste Zeugnis), in: Mağmū‘ Fawā’id 2 (1852), 6. 


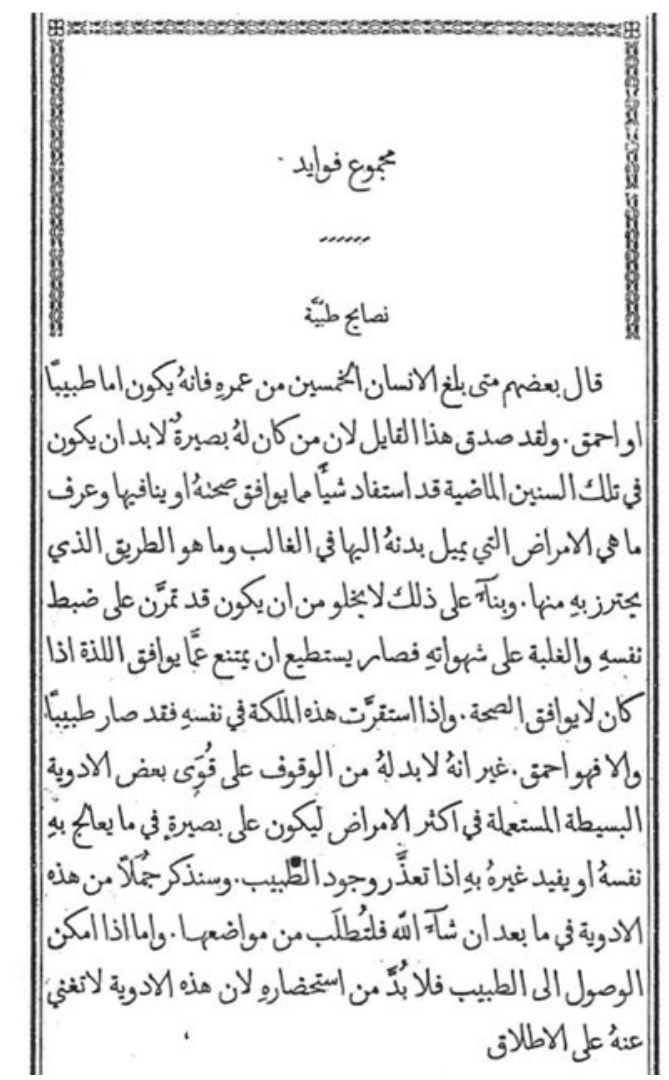

Abb. 4: Titelseite der Zeitschrift Mağmū 'Fawā'id (1851)

tum, Streit und Versöhnung sagen; ${ }^{160}$ wie man von kleinen Sünden schnell zu gröBeren gelangen kann; ${ }^{161}$ warum es wichtig ist zu beten ${ }^{162}$ und welche Eigenschaften ein Christ haben sollte ${ }^{163}$. Auch das Thema „Wissen“, das in der Syrischen Gesellschaft der Wissenschaften und Künste häufig angesprochen wurde, ${ }^{164}$ darf nicht fehlen: In Form von 20 Ratschlägen (,nașā 'iḥ“) macht der Autor des Artikels in der Ausgabe Nr. 3 darauf aufmerksam, durch welche Methoden man sich Wissen aneignen kann. ${ }^{165}$ Dabei wird betont, dass das Zusammenleben verschiedener Menschen mit unterschiedlichen religiösen und wissenschaftlichen Ansichten zur Erweiterung des Horizonts beitragen könne (,wa tatașa 'a 'uqūlnā'). ${ }^{166}$ Die Bot-

160 „Mawā' iz adabīya“ (Moralische Ermahnungen), in: Mağmū‘ Fawā’id 2 (1852), 12-13.

161 „Man tahāwan fì l-ṣag̉ā ir yasqaṭ rawīdan rawīdan fì l-kabā' ir“ (Wer kleine Sünden missachtet, wird allmählich großen Sünden verfallen), in: Mağmū' Fawā’ id 1 (1851), 4-5.

162 „Yağib an nușallī [...]“" (Wir müssen beten), in: Mağmū' Fawā'id 2 (1852), 24.

163 „F̄̄ șafăt al-masīḥī“ (Über die Eigenschaften eines Christen), in: Mağmū' Fawā’id 4 (1855), 21.

164 Siehe Abschnitt I.2.4.

165 „Nașā’ iḥ“ (Ratschläge), in: Mağmū' Fawā’id 3 (1855), 25-30.

166 Ebd., 25. 
schaft ist eindeutig: Die Begegnung von Kulturen ist förderlich für die Wissensaneignung. Frauenbildung wird darüber hinaus ebenso zum Thema gemacht. Anhand einer anekdotenhaften Erzählung über einen Indianerstamm wird gezeigt, dass die Bildung von Frauen unerlässlich ist, da sie für die Erziehung der Kinder verantwortlich sind, ${ }^{167}$ ein Aspekt, der in Bezug auf die Mädchenschulen der Mission in dieser Untersuchung bereits erläutert wurde. ${ }^{168}$ Im vorletzten Artikel der letzten Ausgabe von Mağmū' Fawā'id von 1856 wird die Bedeutung des Buches für die Menschen hervorgehoben, ein Thema, das Smith sehr am Herzen liegt. Der Autor richtet sich in einem einfachen Arabisch direkt an die LeserIinnen und Leser: ${ }^{169}$

Wenn du falsch liegst oder unwissend bist, schauen sie [sc. die Bücher] dir nicht mürrisch ins Gesicht und lachen nicht über dich. [...] Ihnen ist deine Hautfarbe nicht wichtig, sondern sie eröffnen dir ohne Stimme ihre Herzen und laden dich ein, die Bedeutung ihrer Wörter zu ergründen. ${ }^{170}$

Ein Buch bietet schließlich Bildung für Jedermann, ist frei zugänglich, zeitlos und stetig in seiner Aussage. ${ }^{171}$

Trotz des kurzen Bestehens der Zeitschrift und der wenigen veröffentlichten Hefte stellt Mă̌mū 'Fawā'id als Pionierleistung, ,in der Entwicklung der syrischen, arabischen bzw. muslimischen Pressekommunikation" eine entscheidende Zäsur dar. ${ }^{172}$ Als nichtstaatliches, wenn auch nicht indigenes, Kommunikationsmedium und „kulturtechnologisches Novum“, ${ }^{173}$ wie DAGMAR GLAß urteilt, hat die Zeitschrift den Weg für weitere Periodika geebnet, die zunächst von syrischen Christen und später auch von Muslimen ins Leben gerufen werden. ${ }^{174}$ Mit dem Ziel der Zeitschrift zu informieren und zu unterhalten, gelangt erstmals der Magazintyp aus Europa in den Nahen Osten. ${ }^{175}$ Zweifelsohne zielt Mağmū ' Fawā'id auf ein rein christliches, wenn nicht sogar allein protestantisches Lesepublikum ab. Demnach will sie Bildung und biblische Lehre in den eigenen Kreisen verbreiten, um die Missionsarbeit zu unterstützen. Die Zeitschrift besteht insgesamt fünf Jahre, ${ }^{176}$ was

167 „Fī fawā’ id al- 'ilm“ (Über den Nutzen von Wissen), in: Mağmū' Fawā’id 4 (1855), 13.

168 Siehe Abschnitt I.1.2.

$169 \mathrm{Im}$ Vergleich zu anderen Artikeln erscheinen Wortwahl und Satzstruktur sehr einfach. Es ist davon auszugehen, dass ein Amerikaner, vielleicht sogar Smith selbst, Autor dieses Artikels ist.

170 „Fā' idat al-kutub” (Der Nutzen von Büchern), in: Mağmū' Fawā’ id 6 (1856), 24.

171 Ebd.

172 Glaß (2001), 31-32.

173 Ebd., 36.

$174 \mathrm{Zu}$ christlichen und muslimischen Periodika: siehe Abschnitt II.2.5.

175 Glaß (2004a), 124; Ami Ayalon (1995, 34) misst dem Missionsblatt nur eine sehr geringe Bedeutung zu: „It turned out to be a disorganized effort with little impact that died out after four issues, and merits mention only because it is sometimes considered , the very first and earliest of all Arabic-language periodicals“"“ Tibawi $(1966,137)$ schlussfolgert in wenigen Worten: „The main aim was obviously to spread a religious message, not to promote general education for its own sake."

176 Es ist zu beobachten, dass viele christliche Periodika in den USA im 19. Jh. sehr kurzlebig sind, was vermutlich mit dem sich noch in der Entwicklung befindenden Zeitschriftenwesen zusammenhängt: vgl. EBSCO Information Services, Thematic Collection from AAS Historical Periodicals: General Interests Christian Periodicals, 1743-1889, URL: http://www.ebscohost.com/ titleLists/gic-coverage.pdf (Stand: Juni 2014). 
angesichts von Smiths Arbeitspensum und seines sich verschlechternden Gesundheitszustandes im Jahr 1856 erklärt werden könnte. Es wird sieben Jahre dauern, bis die Syrienmission ein weiteres Missionsblatt unter dem Namen Ahbār 'an Intišăr al-Inğil fì Amākin Muhtalifa (Kunde über die Verbreitung des Evangeliums an verschiedenen Orten) herausgibt. ${ }^{177}$

Das Verdienst, ein zweisprachiges und säkular geprägtes Journal schaffen zu wollen, wäre, noch vor Halīl al-Hūūī, der ab 1858 die Zeitung Hadīqat al-Ahbār herausgibt, ${ }^{178}$ beinahe Salīm Naufal zugekommen. Naufal, ein Syrer, der offenbar für eine gewisse Zeit in London gelebt hat, nimmt 1851 Kontakt mit Eli Smith auf: „I would not write to you if it weren't for your reputable diligence and your care for this country's prosperity." Schon seit einiger Zeit spielt Naufal mit dem Gedanken, eine zweisprachige Zeitung herauszugeben, ,in the hope that its benefits would go beyond this part of the world“. ${ }^{179}$ Er hat bereits mit dem Briten Colonel Charles Churchill, einem ehemaligen, in Syrien lebenden Offizier, ${ }^{180}$ Kontakt aufgenommen und erhofft sich von Smith, dass dieser mit Churchill und anderen wichtigen Personen in den USA und Europa über eine finanzielle Unterstützung für das Projekt berate. Das einmal wöchentlich erscheinende Journal soll Themen zu Politik, Kultur und Wirtschaft enthalten und von der American Mission Press gedruckt werden, so Naufal. ${ }^{181}$ Bedauerlicherweise ist kein Antwortschreiben von Smith in dieser Angelegenheit überliefert und es bleibt unklar, warum Naufals Vorhaben nicht in die Realität umgesetzt wird.

\section{Biblical Researches in Palestine}

Schon in frühen Jahren gilt Smith als Ansprechpartner für Gelehrte aus den USA und Europa, was seinen übermäßigen Fleiß auszeichnet. Als er 1832 in die USA reist, besucht Smith seinen früheren Lehrer und Freund Edward Robinson, zu jener Zeit Professor für Biblische Literatur am Union Theological College in New York. Robinsons Fachwissen und Smiths Erfahrungen, die er während seiner Reise mit Dwight durch Armenien und Persien gesammelt hat, führen beide zu der Idee, gemeinsam vom Sinai bis nach Jerusalem zu reisen. „The particular department of Biblical Geography is one in which I have long felt a deeper interest than almost any other brand of biblical literature", so Smith in einem Brief an Robinson aus dem Jahr 1837. ${ }^{182}$ Mit Smith als Landeskundigen und vor allem als versierten Sprachexperten sieht Robinson den Weg geebnet für die Biblical Researches in

177 Näheres dazu in Abschnitt II.2.5.

178 Siehe Abschnitt I.2.5.

179 Naufal an Smith (London, 1.8.1851): ABC 50 (HHL). (TA)

180 Makdisi (2008), 170.

181 Naufal an Smith (London, 1.8.1851): ABC 50 (HHL): „The foreign version's economic section would include news on the economy in Syria while the Arabic version would include economic news from around the world. The literary section would present the detailed history of Arabs, while the political section would include the Istanbul periodical, entitled ,Splendor of the East'." (TA)

182 Smith an Robinson (Smyrna, 10.11.1837): ABC 16.8.1., Vol. 1 (109). 
Palestine ${ }^{183}$ Am 12. März 1838 verlassen sie Kairo und machen sich auf den Weg zur arabischen Halbinsel. Robinson, der zuvor in den USA und in Deutschland nahezu alles recherchiert und gelesen hat, was über das Heilige Land geschrieben wurde, möchte auf den Wegen gehen, die zuvor schon Forscher und Reisende erkundet haben. ${ }^{184}$ Es ist Robinsons und Smiths Ziel, ,to lay open the treasures of Biblical Geography and History still remaining in the Holy Land; treasures which have lain for ages unexplored, and had become so covered with the dust and rubbish of many centuries, that their very existence was forgotten". 185

Jeder biblische Ort soll geschichtlich beleuchtet werden, um seine frühere Bedeutung zu ergründen. ${ }^{186}$ Durch dieses Vorhaben wird Robinson zum Gründer der modernen Palästinologie. Die Karten des antiken Palästinas, die von beiden erarbeitet werden, erweisen sich als dichter und genauer, als sie es erwartet haben. ${ }^{187}$ Schließlich liefert Smith die Details ,that made the book so outstanding": ${ }^{\text {“ }}$ B8 Bereits vor der Reise recherchiert er in Aufzeichnungen von ausgebildeten Einheimischen die Ortsnamen und führt sie in einer Liste an, die er schließlich während der Forschungsreise durch Befragung der Einwohner erweitert und korrigiert. Diese Arbeit kann auch für den ABCFM hilfreich werden, denn es soll in den Veröffentlichungen des American Board in den kommenden Jahren eine einheitliche Schreibweise der arabischen Dörfer und Städte geben, deren englische Transliteration der ursprünglichen arabischen Schreibweise sehr nahe kommt. ${ }^{189}$ Aber auch archäologisch gibt die zweibändige Erstausgabe der Biblical Researches viel her, wie der Biblische Archäologe JAMES B. PRITCHARD 1958 schreibt: „Leaving the beaten paths of former travelers, Robinson and Smith discoverd many formerly unknown sites and made scores of identifications of ancient places which have stood up under the more controlled methods of the archeologists." $" 190$

Während ihrer Reise führen Smith und Robinson jeweils separat ein eigenes Reisetagebuch, um Zeit und Ort des Aufbruchs, Temperatur, genaueste Beschreibungen der Blickrichtungen von verschiedenen Aussichtspunkten sowie die Preise der Unterkünfte, aber auch die Eigenarten und Verhaltensweisen der Menschen, de-

183 Robinson/Smith (1860a), 1-2. Noch ein Jahr zuvor scheint die Realisierung des Vorhabens ungewiss. Smith schreibt 1837 an Robinson, dass er aus Verantwortung für seine Arbeit in der Druckerei und angesichts des Arbeitspensums nicht reisen kann. Später revidiert er jedoch seine Absage, da der ABCFM seine Zusage für die Reise erteilt: vgl. Briefwechsel zwischen Robinson und Smith (1837): ABC 16.8.1., Vol. 1 (10). Anderson befürwortet die Reise, da die Unkosten nicht vom finanziell stark belasteten ABCFM getragen werden müssen: vgl. Anderson an die Syrienmission (Boston, 23.4.1838): ABC 2.1.1., Vol. 1 (HHL).

184 Robinson/Smith (1860a), xii, 178: „This whole region [sc. 'Arabah], up to the present time, has been a complete terra incognita to geographers. Not that travellers had not already crossed it in various directions; for Seetzen in 1807 had gone from Hebron to the convent of Sinai; and Henniker in 1821 [...] had passed from the convent to Gaza."

185 Ebd., xi.

186 Ebd., ix.

187 Pritchard (1958), 57.

188 Aus einem Brief von Norman Lewis an David Finnie (9. Oktober 1964), in: Finnie (1967), 202 (Anm.).

189 Robinson/Smith (1860a), ix-x.

190 Pritchard (1958), 59. 
nen sie begegnen, sorgfältig aufzuschreiben. ${ }^{191}$ Darüber hinaus scheuen sich beide in ihren Beschreibungen auch nie davor, der Leserschaft die bedauerlichen Kontraste deutlich zu machen, die zwischen der Geschichte glorreicher, antiker Orte und ihrem gegenwärtigen verfallenen Zustand bestehen.

It is impossible to wander around these scenes and behold these hoary yet magnificient ruins, without emotions of astonishment and deep solemnity. Every thing around testifies of vastness, and of utter desolation. Here lay once that mighty city, whose power and splendour were proverbial throughout the ancient world. ${ }^{192}$

Während für Smith klar ist, dass sich Religion und Kultur in der Levante in einem desolaten Zustand befinden, sind Robinsons Motive weniger christlich als rein historisch. ${ }^{193}$ Die Biblical Researches werden zu einem viel gelesenen Werk. Robinsons und Smiths Faszination für die Geschichtsträchtigkeit der Orte, die Vielfalt der Landschaften sowie für das abenteuerliche Reisen in einer fremden Welt begeistern offenbar das Lesepublikum. ${ }^{194}$ Auf den insgesamt 1214 Seiten der zwei Bände finden sich sehr detaillierte Reiseaufzeichnungen, die dem Leser Landschaft und Natur lebhaft vor Augen führen:

The village ['Anāta] lies where the broad ridge slopes off gradually towards southeast. On this side are tilled fields, and we had passed several others on our way. The grain was still standing; the time of harvest not having yet come. [...] Thus er-Râm (Ramah) bore N. N.W. on its conical hill; and Jeba' (Geba) was before us, bearing N. $10^{\circ}$ E. [...]. ${ }^{195}$

In seiner Zeit gilt das Werk als Vorreiter für die sich erst in den Kinderschuhen befindenden orientalischen Studien in Nordamerika, so die Zeitschrift der Deutschen Morgenländischen Gesellschaft im Jahr 1847. ${ }^{196}$ Für die verbesserte topografische Erschließung der arabischen Halbinsel und des Heiligen Landes erhält Robinson 1842 die Goldmedaille der Royal Geographic Society in London und ist hoch angesehen in der Fachwelt der altorientalischen Studien, auch über das 19. Jh. hinaus: „The works of Robinson and Smith alone surpass the total of all previous contributions to Palestinian geography from the time of Eusebius and Jerome to the early nineteenth century“, so der amerikanische Archäologe W.F. Albright. ${ }^{197}$ Aber Smiths Leistung wird selbst im 20. Jh. nicht minder bewertet. Ein britischer Gelehrter schreibt 1964: Smiths Liste der Ortschaften sei ,unique. ... No one else (to my knowledge) did anything similar for several decades. ... As material to be

191 Robinson/Smith (1860a), 32; Pritchard (1958), 59, 61.

192 Robinson/Smith (1860a), 20.

193 Ebd., 31: „As is the case of most of my countrymen, especially in New England, the scenes of the Bible had made a deep impression upon my mind from the earliest childhood; and after in riper years this feeling had grown into a strong desire to visit in person the places so remarkable in the history of the human race. [...] With all this, in my own case, there had subsequently become connected a scientific motive."

194 DMG (1847), 150.

195 Robinson/Smith (1860a), 438.

196 „Die orientalischen Studien in Nord-Amerika“, in: ZDMG 1 (1847), 87.

197 Aus: W. F. Albright, Archaeology of Palestine, 1956, 25, zitiert in: Finnie (1967), 181; Pritchard (1958), 57. 
used in building up a picture of the human and economic geography of the country in the 1830's they are first rate". .198

1851 bestärkt Rufus Anderson seinen Freund Edward Robinson - der mittlerweile Präsident der American Oriental Society ist ${ }^{199}$ - erneut Recherchen zur Topographie des Heiligen Landes zu unternehmen und dafür gegebenenfalls an der Universität zu kündigen, wenn der zeitliche Rahmen einer Freistellung nicht ausreichen sollte. Anderson verspricht, Robinson für die Planung der Reise nach Syrien behilflich zu sein. ${ }^{200} 1852$ erreicht Robinson Syrien und nimmt unter Smiths Mithilfe eine Überarbeitung der Biblical Researches, im Besonderen der Karten, Pläne und Ortsnamen, vor. Da die erste Auflage von 1841 mittlerweile bereits vergriffen ist, gibt es einen weiteren Grund eine neue Auflage in den Druck zu geben. 1856 erscheinen die Biblical Researches in zwei Bänden. ${ }^{201}$ Als Ergänzung für Gelehrte in Ost und West lässt Robinson Eli Smith in Beirut eine separate Liste arabischer Namen und Orte drucken, die der neuen Edition als Appendix angefügt wird.

\section{Weitere Veröffentlichungen}

Ähnlich wie seine Kollegen in der Syrienmission hat sich Smith auch als Autor von Büchern und Aufsätzen über vielseitige Themen einen Namen gemacht, von denen hier einige zu nennen sind: 1833 werden in einem Band drei seiner Predigten und zwei Ansprachen, die er während seines USA-Aufenthaltes 1832/1833 gehalten hat, veröffentlicht: Missionary Sermons and Addresses. ${ }^{202}$ Darin berichtet er von seinen ersten Jahren in Syrien und den überwiegend schlechten Erfahrungen, die er mit den Muslimen - , a noble race [...] withered and blasted by their false religion" 203 - und den Christen gemacht hat, deren Zustand sogar noch besorgniserregender sei und sie daher mehr missionarische Zuwendung benötigten als die Muslime. ${ }^{204}$ Seine Beschreibungen zur Lage von Frömmigkeit und Glauben unterscheiden sich hierbei kaum von denen der anderen Missionare im Missionary Herald oder in diversen Autobiografien. ${ }^{205}$ In seiner Predigt „Farewell request on

198 Finnie (1967), 202 (Anm.).

199 Anderson an Robinson (Boston, 10.6.1846): ABC 2.1.1., Vol. 25 (HHL); Robinson an Anderson (New York, 17.6.1844): ABC 10, Vol. 36 (158), (HHL).

200 Anderson an Robinson (Boston, 3.1.1851): ABC 2.1.1., Vol. 14 (HHL).

201 E. Robinson, Biblical Researches in Palestine and in the Adjacent Regions. A Journal of Travels in the 1838 by E. Robinson and E. Smith. With new maps and plans, 2 Bde., Boston 1856.

202 Das Werk wird ins Deutsche übersetzt und erscheint $1836 \mathrm{im}$ „Magazin für neueste Geschichte der evangelischen Missions- und Bibelgesellschaften“ (Erstes Quartalsheft).

203 Smith (1833), 17.

204 Der desolate Zustand der Christenheit, so Smith, ermögliche überhaupt erst das Fortbestehen des Islam: ebd., 64.

205 Khalaf (2001), 120: „Even Eli Smith, often singled out for his balanced and conciliatory views, fell prey to this contemptous language". Zu den Autobiografien siehe z.B.: William Goodell, The Old and the New; or, The Changes of Thirty Years in the East, with some Allusions to oriental Customs as elucidating Scripture, New York 1853; Isaac Bird, Bible Works in Bible Lands; or, Events in the History of the Syria Mission. Fully Illustrated, Philadelphia: Presbyterian Board of Publication, 1872. 
behalf of the Syrian Mission“206 zeigt sich Smith in den ersten Jahren seiner Arbeit in Syrien erschüttert über das religiöse und moralische Befinden der Bevölkerung. Die Umstände, dass man kaum fromme Mitmenschen finde (,No example of devoted active piety [...]. No just ideas of Christian consistency in the public mind“), ${ }^{207}$ riefen bei den Missionaren Gefühle der Einsamkeit, Selbstzweifel und sogar Glaubenszweifel hervor: „The missionary, more than all other men perhaps, needs to use constant watchfulness and diligence that his faith fail not, and his love grow not cold.“ ${ }^{208}$

Erwähnenswert ist Smiths Darstellung eines typischen Tagesablaufs, wie ihn die Missionare in Syrien erfahren. Die Menschen, so Smith, seien sehr bereitwillig, viele Stunden mit den Missionaren zu verbringen, ,,so little is time valued by them“. Es ist ein Kommen und Gehen im Missionshaus und manchmal kommen Gäste auch nachts aus Angst gesehen zu werden. Die „family prayers“, zu Beginn noch im kleinen Kreis gehalten, werden nach kurzer Zeit zu einer öffentlichen Veranstaltung, bei der die Anwesenden Bibelverse lesen und, nach einer kurzen Auslegung von einem der Missionare, über die Texte gesprochen und diskutiert wird. ${ }^{209}$ Smith empfindet diese Diskussionsrunden als sehr ,interessant und anregend“:210 „The Arab mind is of a cast to add to the interest of such exercises. Active and ingenious in its character, its fertile invention is ever bringing forward some new theory or explanation of Scripture. “211 So gesehen erweisen sich die Bibelkreise und Gebetsversammlungen als Foren für einen Dialog zweier verschiedener Kulturen, so wie es ihn in Syrien bisher noch nicht gegeben hat.

Für Nachwuchsmissionare verfasst Smith zwei Anleitungen, in denen die Arbeit der Missionen veranschaulicht und damit verbundene Erwartungen, aber auch Probleme dargestellt werden: Trials of Missionaries (1832) und The Missionary Character (1840). Es ist letzterem Werk anzumerken, dass Smith reflektierter in den Dialog mit den Einheimischen tritt, wenn er bspw. dazu rät, nicht zu voreingenommen an die neue Kultur heranzutreten, wie er es schon gegenüber Paxton im Jahr 1837 geäußert hat (s. o.).

In his partialities [the missionary] should not be narrow-minded. We naturally think our own country the best in the world; the best in its soil, its scenery, its climate, its government, its people. [...] But will you let this American partiality bias your feelings and govern your deportment in the missionary field? [...] Better is it for the missionary to feel himself a citizen of the world. ${ }^{212}$

Für die amerikanische religiöse Quartalszeitschrift Bibliotheca Sacra, die durch ihre vielseitigen wissenschaftlichen Artikel ein breiteres Lesepublikum als der Missionary Herald zu erreichen vermag, verfasst Smith ebenfalls Artikel. Einer seiner Beiträge handelt über die Herstellung von Wein in den verschiedenen Gebieten des

206 Smith (1833), 131-182.

207 Ebd., 143.

208 Ebd., 144.

209 Ebd., 160-162.

210 Ebd., 162.

211 Ebd., 163.

212 Smith (1840), 14 (eigene Hervorhebung). 
Libanongebirges. Die Themenwahl lässt vermuten, dass Smith, der keinen Alkohol trinkt und sich auch nicht für einen Weinkenner hält, von der Redaktion der Zeitschrift beauftragt wurde, darüber zu schreiben. ${ }^{213}$

Auch wenn man in der Syrienmission in den ersten Jahren die Einführung arabischer Musik in die evangelischen Gottesdienste kritisch betrachtet, so fühlt sich Smith „,in consequence of the necessities of my calling“214 dazu verpflichtet, mit $A$ Treatise on Arab Music (1851) eine weitere beachtliche Übersetzungsarbeit über ein ihm fremdes Fachgebiet zu leisten und diese im Journal of the American Oriental Society (JAOS) zu veröffentlichen. A Treatise on Arab Music ist die Arbeit von Smiths Freund Mih̄ầ̄ 1 Mišāqa aus Damaskus, mit dem Smith in regem Briefkontakt steht (s. u.). ${ }^{215}$ Mišāqa beschreibt in seinem Traktat (Al-risāla al-šihābìya fì l-șinā a al-mūsīqùya, ca. 1840) ${ }^{216}$ die Besonderheit der arabischen Komposition und ihrer Tonleitern sowie die Eigenschaften traditioneller arabischer Instrumente. In der Einleitung erklärt Smith, vorher selbst kein Kenner der arabischen Musiktheorie, zu seiner Übersetzungstechnik: „In translating, I have abridged his work a good deal, have not always observed his order in the arrangement of the sections, and have frequently taken the liberty to express his thoughts in my own style." ${ }^{\text {"217 Es }}$ wird deutlich, dass er sich für diese Übersetzung sehr intensiv mit Musiktheorie und Mišāqas Aufsatz befasst haben muss, um bestimmte Teile sinngemäß und für die amerikanische Leserschaft verständlich darzustellen. Durch seine guten Kontakte zum Yale College unterstützt Smith Mišāqā ebenfalls bei der Recherche, indem er ihm zwei arabische Manuskripte zukommen lässt, die für Mišāqa in Damaskus nicht zugänglich waren. Aus einem davon übersetzt Smith selbst einige Kapitel, um sie in die Übersetzung von Mišāqas Arbeit einfügen zu können. ${ }^{218}$

Für die American Mission Press erarbeitet Eli Smith auch einige arabische Werke wie die theologischen Traktate Kitāb al-mabāhit fí ittiqūāàt ba 'ad al-kanā is (Untersuchungen über die Dogmen einiger Kirchen, 1854) und Al-bāb al-maftūh fì a'māl al-rūh (Die offene Tür - Die Werke des Heiligen Geistes; mit Bustani erarbeitet und 1843 sowie 1863 herausgegeben). Zusammen mit Bustānī und al-Yāziǧĩ überarbeitet Smith das bereits 1836 von der Church Missionary Society auf Malta

213 Smith (1846). Im selben Band der Zeitschrift gibt Smith in einem anderen Aufsatz einen historischen Überblick über die christlich-muslimischen Beziehungen im Osmanischen Reich und das Entgegenkommen der türkischen Regierung gegenüber den Protestanten: vgl. ders., „Turkish Toleration“, in: Bibliotheca Sacra and American Biblical Repository 3, 390-397.

214 Smith (1851), 173: Die arabische Musik in den evangelischen Gottesdienst einzuführen, ist den Missionaren bis dahin nicht gelungen: „The mission with which I am connected, has not yet succeeded in introducing singing into Arabic worship. [...] not only do we find the singing of the Arabs no music to us, but our musicians have found it very difficult, often impossible, to detect that nature of their intervals, or imitate their tunes."

215 Smith (1851), 174: ,[he] is my personal friend and correspondent, and one of the most intelligent of his nation whom I have known“. Unter den arabischen Briefen in Smiths Nachlass finden sich etliche an und von Mišāqa: vgl. ABC 16.8.1., Vol. 5; ABC 50, Box 1-2 (HHL).

216 Das Manuskript befindet sich im Besitz der N.E. S. T.: MS Nr. AP-7.

217 Smith (1851), 174.

218 Ebd., 200: „From this I have translated most of the chapter in rhythm, and also the section on the ancient guitar, dealing as freely with it in translating, as with Meshâkah's work." Es handelt sich um ein Manuskript aus dem Jahr 666, Autor und Titel werden nicht genannt. 
gedruckte Gesangbuch für den Gottesdienst Tarnīmāt li l- 'ibāda $\left({ }^{1} 1851\right)$. Darüber hinaus übersetzt Buṭrus al-Bustān̄̄ ein von Smith zusammengestelltes Lehrbuch für den Schulgebrauch: „Führung des Verstandes zu den Grundlagen der Arithmetik“ (Kitāb dalīl al-ṣawāb fì 'ilm al-hisāb, 1837). ${ }^{219}$

\section{Smiths Engagement in den Orient-Gesellschaften}

Eli Smith nimmt eine führende Rolle in der Korrespondenz zwischen westlichen, orientalischen Gesellschaften und der Syrischen Gesellschaft der Wissenschaften und Künste (1847-1852) ein, wie bereits in Abschnitt I.2.4 dargestellt wurde. Als Verwalter der Missionsbibliothek und Zuständiger für den Buchdruck ist er per se für die Anschaffung neuer Studien und den Versand von eigenen gedruckten Werken zuständig. ${ }^{20}$ Das gilt nicht nur für den Kontakt mit der DMG, sondern vermutlich auch für die Syro-Egyptian Society, die 1844 in London gegründet wird und deren Präambel sowie Mitgliederliste sich in Smiths Nachlass befinden. ${ }^{221}$ Eli Smith ist ebenso Korrespondenzmitglied der 1842 gegründeten American Oriental Society und wird somit beauftragt, regelmäßig Berichte an die Leitung der Gesellschaft zu senden. Rufus Anderson, der zu den fünf Direktoren der Gesellschaft zählt, möchte seine Missionare im Ausland für den wissenschaftlichen Austausch in der Heimat gewinnen. Daher schreibt er 1843 an Smith:

The Address of Mr. Pickering before the American Oriental Society will show you the existence and objects of that new association. The Society may be made an exceedingly useful instrument, and I hope you will write for it, and induce other members of the mission to do the same. [...] Contributions of this sort will be gratefully received, and scarcely anything in the way of a contribution to the stock of knowledge can come amiss. ${ }^{222}$

„Corresponding Members“ sind ebenso die Missionare in Syrien Simeon H. Calhoun, William Goodell, Henry De Forest, William M. Thomson, Cornelius Van Dyck sowie Henry Harris Jessup. Im JAOS sind nun regelmäßig Reiseberichte, Abschriften von archäologischen Inschriften, Übersetzungen von arabischen Traktaten sowie Bekanntgaben über den Druck von Werken syrischer und amerikanischer Autoren in der American Mission Press zu lesen. ${ }^{223}$ Der Bibliothek der American Oriental Society werden aus Beirut ebenso Kopien der Neudrucke sowie Abschrif-

219 Näheres zu diesen Werken in Anhang I.

220 Zahlreiche Briefe von Smith an Anderson enthalten Bücherlisten, um deren Beschaffung Smith bittet. Diese Bücher sind sowohl für die Missionsbibliothek als auch als Übersetzungshilfen für arabische Lehrbücher gedacht: vgl. Smith an Anderson (Boston, 19.4.1841): ABC 16.8.1., Vol. 1 (139). Smith nimmt auch Buchbestellungen von syrischen Helfern entgegen und leitet diese an den ABCFM weiter: vgl. Smith an Anderson (Beirut, 16.12.1848): ABC 16.8.1., Vol. 1 (176).

221 „Syro-Egyptian Society“: ABC 60 (144), (HHL).

222 Anderson an Smith (Boston, 21.8.1843): ABC 60 (1), (HHL).

$223 \mathrm{Zu}$ den Korrespondenzmitgliedern vgl. JAOS 2 (1851), xxxvi und JAOS 9 (1866), 1xx. Beiträge der Missionare im Journal: Smiths Übersetzung des „Treatise on Arab Music“ (s.o.); H.A. De Forest, „Notes of a Tour in Mount Lebanon and to the Eastern Side of Lake Hûleh“, in: JAOS 2 (1851), 237-247; ders., „Notes on the Ruins in the Bûksa'a and in the Belâd Ba'albek“, in: JAOS 3 (1853), 349-366; ders., „Phoenician Inscriptions of Sidon“, in: JAOS 5 
ten von arabischen Manuskripten zugetragen. ${ }^{224}$ Wie in dieser Zeit unter den Missionen üblich, ${ }^{225}$ senden die Amerikaner in Syrien ebenfalls archäologische Fundstücke an die American Oriental Society, wie z. B. antike Gegenstände aus Bronze aus dem Libanongebirge, ${ }^{226}$ ein Steinquader mit einer griechischen Inschrift, ${ }^{227}$ aber auch zeitgenössische Zeugnisse syrischer Traditionen wie z. B. eine Kopfbedeckung, die von verheirateten Frauen im Libanongebirge getragen wird. ${ }^{228}$

Bevor Smith Ende 1839 nach Deutschland reist, um die arabischen Schriftsätze von Karl Tauchnitz in Leipzig gießen zu lassen, vermittelt ihm Edward Robinson die Kontakte zu den deutschen Orientalisten Heinrich Leberecht Fleischer, später Gründer der DMG, sowie Emil Rödiger, ebenso Mitglied der DMG. ${ }^{22}$ Smith bleibt nach seinem Besuch in Deutschland weiterhin in Kontakt mit Fleischer und Rödiger. Als sich 1845 die DMG zu ihrer Gründungssitzung in Leipzig zusammenfindet, wird Smith als Korrespondenzmitglied eingetragen. ${ }^{230}$ Die Gesellschaft ist weniger an Smiths Arbeit als Missionar, als vielmehr an seinen wissenschaftlichen Tätigkeiten in Syrien interessiert. Die von der DMG herausgegebene Zeitschrift veröffentlicht daher einige Male übersetzte Auszüge aus Briefen von Eli Smith. Sie verdeutlichen wie sehr sich Smith darum bemüht, fachliche Fragestellungen der Gesellschaft aufzugreifen und dafür, auch unter syrischen Freunden oder Gelehrten, Recherchen zu betreiben. ${ }^{231}$

Ich forsche unablässig nach phönicischen Schriftmonumenten, aber ohne Erfolg. Die hiesigen Juweliere kaufen öfter nicht blos [sic] alte Münzen sondern geschnittene Steine auf. Vor einiger Zeit hörte ich von zwei Steinen mit ähnlicher Schrift wie die, welche Sie für althebräisch er-

(1856), 227-259; C. Van Dyck, „On the Present Condition of the Medical Profession in Syria“, in: JAOS 3 (1853), 561-591.

224 JAOS 9 (1866), viii: „From Rev. H.H. Jessup, dated Beirut, Sept. 19th, 1866: ,I take pleasure in sending you, for the Society, the first volume of Mr. Butrus Bistany's new Arabic lexicon, the Muhît el Muhit. Mr. Bistany is going on with publishing of the two remaining volumes as rapidly as possible. The price to non-subscribers will be four pounds Sterling for the three volumes. I think you will be pleased with it."“

225 Nielssen u. a. (2011), 7: „Why was collecting material culture seen as a missionary task? Missionary collectors clearly formed a part of what has been termed the ,culture of travelling ' in a general sense. In the nineteenth century, collection was a most common activity among travellers. [...] The importance granted to the collection of ethnographic artefacts is underlined by the fact that some of the missionary societies even founded their own museums."

226 „Additions to the Library and Cabinet of the American Oriental Society. May 1849 - February, 1851. I. By Donation“, in: JAOS 2 (1851), xxxii.

227 „Additions to the Library and Cabinet of the American Oriental Society. March, 1851 - April, 1852 “, in: JAOS 3 (1853), iv.

228 ,Additions to the Library and Cabinet of the American Oriental Society. May 1849 - February, 1851. I. By Donation“, in: JAOS 2 (1851), xxxii.

229 Robinson an Smith (o. O., 14.11.1838): ABC 60 (63), (HHL); Rödiger an Smith (Halle, 11.11. und 25.11.1838), (Halle 12.10.1848): ABC 60 (65), (HHL).

230 Auch Edward Robinson ist Korrespondenzmitglied: vgl. DMG (1846), 152.

231 Um mehr über ein altes Manuskript über Arithmetik zu erfahren, werden Mihā̄āl Mišāqāa, Nāṣif al-Yāziğī, Mahūd Efendy (,der gelehrteste [...] Muslim [...] in Damaskus") und Buțrus alBustānī befragt: vgl. Smith an die DMG (Beirut, 3.8.1850), in: ZDMG 4 (1850), 519-520. 1850 sendet Smith Kopien von dreizehn Manuskripten mit lateinischen und griechischen Inschriften, die sein Kollege Henry De Forest gesammelt hat, nach Leipzig: vgl. ZDMG 4 (1850), 144. 
kannten; sie waren bei einem Juwelier in Damask gesehen worden, aber sie waren verkauft und verschwunden, ehe ich danach fragen konnte. Ueber die von Ihnen bezeichneten Inschriften bei

'Amschît und in Seilûn habe ich noch nichts ermitteln können. ${ }^{232}$

Auch die Bibliothek der Syrischen Gesellschaft der Wissenschaften und Künste wird durch Smiths Vermittlung mit Buchsendungen der DMG erweitert. Im Jahr 1848 wird aus Deutschland berichtet:

Einstweilen haben wir der neuen, vielversprechenden Gesellschaft, der wir freudig die Hand bieten, die ersten beiden von unserer Gesellschaft unterstützten Werke - Cazwini's Athar al - bilâd von Wüstenfeld und Nasif's ${ }^{233}$ Epistola critica von Mehren - für ihre Bibliothek zugeschickt $[\ldots] .{ }^{234}$

Wie aus den gesammelten Unterlagen des Nachlasses von Eli Smith hervorgeht, tauschen die Syrienmission und die DMG fortan regelmäßig Bücher, Neudrucke und Abschriften von archäologischen Inschriften aus - eine frühe Form wissenschaftlicher Vernetzung zwischen Deutschland und dem Vorderen Orient. ${ }^{235}$ Emil Rödiger, der mit Smith im persönlichen Briefkontakt steht, weiß Smiths Engagement sehr zu schätzen: „Ihre Mittheilungen haben für die deutschen Orientalisten das größte Interesse, und ich bitte Sie recht dringend, dass Sie auch ferner uns unterstützen wollen.“ ${ }^{236}$

\section{Briefwechsel mit syrischen Freunden und Kollegen}

Smiths schriftliche Korrespondenzen finden schließlich nicht nur mit dem ABCFM oder namhaften Wissenschaftlern in Europa und den USA statt. Etliche, im Archiv des ABCFM befindliche arabische Briefe zeugen von einem regen Briefkontakt des Missionars innerhalb Syriens, v. a. mit den native helpers der Mission. ${ }^{237}$ Un-

232 Smith an die DMG (Beirut, 3.8.1850), in: ZDMG 4 (1850), 520, übersetzt von Emil Rödiger. Laut Auskunft der Universitätsbibliothek Halle, in deren Obhut sich das Archiv der DMG befindet, existieren keine Originale der in der ZDMG abgedruckten Briefe von Smith an die Gesellschaft.

233 Gemeint ist Nāṣī al-Yāziğì.

234 Fleischer (1848), 78-79.

235 Prof. Dr. R. Anger, Bibliotheksbevollmächtigter der DMG (Leipzig, 15.4.1853): ABC 60, Box 1 (20), (HHL).

236 Rödiger an Smith (Halle, 12.10.1848): ABC 60 (65), (HHL). Aus dem Brief geht auch hervor, dass Smith Rödiger dabei unterstützt hat, Materialien zum Neusyrischen zusammenzustellen, die Rödiger für den Druck einer „grammatisch-lexicalische[n] Darstellung“ der Sprache verwenden möchte.

237 Ein weiterer Nachlass von Eli Smith mit Briefen der Familie sowie privaten Fotografien, zusammengestellt von seiner Urenkelin Margaret Russel Leavy, befindet sich in der Yale Divinity School in New Haven/USA, URL: http://drs.library.yale.edu:8083/HLTransformer/HLTrans Servlet?stylename=yul.ead2002. xhtml.xsl\&pid=divinity:124\&query=whiting\&clear-stylesheetcache $=$ yes\&hlon=yes \&filter=fgs.collection:\%22Divinity\%20Library\%22\&hitPageStart=1 (Stand: August 2011).

Smith schreibt 1845 an Anderson, dass er für einige Zeit eine Pause benötige und in die USA reisen möchte, da er seit vergangenem Oktober etwa 100 Briefe und Dokumente verfasst habe: vgl. ABC 16.8.1., Vol. 3 (102). 
ter der losen und ungeordneten Sammlung, die bisher wenig Beachtung gefunden hat, gibt es auch Briefentwürfe von Smith selbst, die einen persönlichen Einblick in seine Gedankenwelt sowie seine Arabischkenntnisse ermöglichen. Von keinem anderen Missionar in Syrien beherbergt der ABCFM einen solchen Briefnachlass. Dies bedeutet jedoch nicht, dass Smith ein Einzelfall ist. Neben den dienstlichen und privaten Briefen, die die Missionare regelmäßig in die Heimat schreiben, findet ebenso ein reger Briefaustausch innerhalb der protestantischen Gemeinschaft in Syrien statt, wie CHRISTINE LINDNER es darstellt:

The exchange of letters was an important medium through which members of the Protestant Circle constructed and strengthened their community. The use of letters to convey information was not a new concept introduced by the ABCFM missionaries to Ottoman Syria. Rather ,the novelty of the Protestants" letter writing resided in their wide-spread use of letters, for written correspondences were exchanged by most members of the Circle, not just its elite members. ${ }^{238}$

Darüber hinaus ist bekannt, dass Van Dyck in Korrespondenz mit dem damaszenischen Historiker Mih̄ā'̄1 Mišāqa steht. ${ }^{239}$ Henry Harris Jessup berichtet ebenfalls, arabische Briefe mit „Abu Selim“, d.h. Buțus al-Bustān̄̄, dem Vater von Salīm, ausgetauscht zu haben: ,A missionary who cannot himself write a letter in the vernacular is greatly crippled and embarrassed in his work. "240

Eli Smith steht mit den einheimischen Protestanten Antonius Yannī, ${ }^{241}$ Šahīn Barakat, ${ }^{242}$ Muhammad Qāsim, ${ }^{243}$ Sūleimān al-Salībī, ${ }^{244}$ sowie den Mitarbeitern Elyās Fawāz, ${ }^{245}$ Tannūs al-Ḥaddād, ${ }^{246}$ Nāṣîf al-Yāziğ̄i, Buṭus al-Bustān̄̄, Mīḥail Mišāqa und John Wortabet in Kontakt. Nur in einigen wenigen Fällen, wie z. B. bei Wortabet oder Bustānī, werden auch englische Briefe ausgetauscht. ${ }^{247}$ In den Briefen geht es entweder um das Wohlergehen der eigenen Familie, das Vorankommen in der missionarischen Arbeit, den Austausch von Büchern und Arbeitsmaterialien oder um negative Erfahrungen, die mit Gegnern der Mission gemacht werden. Im Briefwechsel mit Bustānī werden oftmals die nächsten Arbeitsschritte in der Bibelübersetzung besprochen bzw. Übersetzungsentwürfe angehängt. Aus einem Brief von Bustān̄̄ vom 18. Juli 1855 geht hervor, dass er plane, ein neues Lexikon zu ver-

238 Lindner (2009), 127. Einige Briefe von syrischen Protestanten werden auch für den Missionary Herald übersetzt: z. B. MH 25 (1829), in: ROS 2, 170-174; MH 27 (1831), in: ROS 2, 272-273. In Smiths Nachlass in der Harvard Houghton Library findet sich ebenso ein handschriftlich verfasstes, arabischsprachiges Heft, in dem Elyās Fawāz und Jacob Gregory Wortabet über ihre Arbeit als Prediger des evangelischen Glaubens im Jahr 1829 in Saida berichten: vgl. ABC 50, Box 1 (HHL).

239 Smith an Mīšāqa (o. O., 16.4.1849): ABC 50, Box 1 (HHL); Van Dyck an Anderson ('Abeih, 28.7.1851): ABC 16.8.1., Vol. 5 (323).

240 Jessup (1910a), 115.

241 Siehe Anhang II, Nr. 73.

242 Ebd., Nr. 16.

243 Ebd., Nr. 49.

244 Siehe Abschnitt I.2.3 und Anhang II, Nr. 52.

245 Ebd., Nr. 22.

246 Ebd., Nr. 31.

247 Vgl. dazu ABC 60 (12) und (98), (HHL). In ABC 50 befinden sich keine arabischen Briefentwürfe von Smith an Wortabet. Vermutlich hat Smith ihm auf Englisch geantwortet. 
fassen, das die Unübersichtlichkeit arabischer Nachschlagewerke korrigieren und sich strukturell an westlichen Lexika orientieren soll. ${ }^{248}$ Es ist davon auszugehen, dass sich Smith und Bustānī mehrere Male über dieses Projekt ausgetauscht haben, denn der Bedarf an einem solchen Nachschlagewerk ist hoch. ${ }^{249}$ Es kann demnach kein Zufall sein, dass 14 Jahre nach diesem Brief, im Jahr 1869, der erste Band von Bustānīs Wörterbuchs Muḥ̣̂t al-Muhịt (Der Umfang des Ozeans) in der American Mission Press erscheint, 1870 folgt der zweite. ${ }^{250}$

Besonders regen Briefkontakt pflegt Smith zum damaszenischen Historiker Mīhā'îl Mišāqa, einem griechisch-katholischen Gelehrten, der 1848 zum evangelischen Glauben konvertiert. ${ }^{251}$ Darin geht es vor allem um den Austausch von Schriften und Büchern sowie häufig um die Schwierigkeiten, die Mīšāqa aufgrund seines Konvertierens widerfahren, u.a. um eine schriftliche Auseinandersetzung mit dem griechisch-katholischen Patriarchen Maximus. ${ }^{252}$ Smith erweist sich nicht nur als Seelsorger für Mišāqa ${ }^{253}$ sondern ermutigt ihn auch, weiter als Historiker und Autor zu arbeiten. ${ }^{254}$ Einige seiner Werke werden auch dann in der American Mission Press gedruckt. ${ }^{255}$ Dazu schreibt Smith im April 1849:

Hochverehrter, lieber Bruder, Herr Mīhāà îl [...], ich war sehr erfreut über die Ankunft Ihres Schreibens [...]. Die beigefügten Bögen habe ich mit sehr [viel] Freude gelesen. [...] Sie haben auch einige Fehler erwähnt, die beim Druck Ihres Schreibens passiert sind. [...] Sie werden keinen Zweifel daran haben, dass wir alle uns voll und ganz bemühen, dass kein Fehler mehr passiert [...]. ${ }^{256}$

248 Bustānī an Smith (Sūq al-Ġarb, 18.7.1855): ABC 50, Box 3 (HHL).

249 In der Briefsammlung gibt es dazu jedoch keine Hinweise.

250 Näheres dazu in Abschnitt III.1.4.

251 Siehe Anhang II, Nr. 46; mehr zu Mišăqa in: Zachs (2001b).

252 Smith an Mišãqa, (o. O., 8.6.1849 und 14.7.1849): ABC 50, Box 1 (HHL). Aus den Briefen geht hervor, dass Mišāqa zahlreiche solcher Briefwechsel führt. Zum Disput mit Patriarch Maximus: vgl. Wortabet (1860), 88, 366. Im Missionary Herald schreibt Smith 1849: „Mr. Meshakah favors me with a copy of all the correspondence between him and his antagonist, and also of his journal. The whole is deeply interesting, both from the ability he displays, and the deep Christian sincerity that moves him. The Protestant spirit, in the best sense, has got a firm hold of him. Every word of the documents in my hands deserves to be translated and printed at home." Vgl. MH 45 (1849), in: ROS 4, 83.

Smith leitet auch Kommentare von anderen Syrern, die sich zu Mišāqas Schriften äußern, an den Autor weiter: vgl. Smith an Mišāqa (o. O., 4.6.1849): ABC 50, Box 1 (HHL).

253 Smith an Mišāqā (o.O., 16.4.1849): ABC, Box 1 (HHL): „Ihre Weisheit, Ihr Gerechtigkeitssinn, den Sie ohne Furcht verteidigen, wird Sie führen und Sie werden mit der Hilfe des Geistes Gottes über alles siegen, was sich Ihnen entgegen stellt.“

254 Smith schreibt an einen unbekannten Adressaten in Beirut: „I particularly urged him to the use of his pen in the production of writing that would enlighten the people. This suggestion he felt the importance of, \& I think he will attend to it." Vgl. ders. (Damaskus, 6.12.1848): ABC 16.8.1., Vol. 1. Mišāqā wird zu einem wichtigen Historiker in der zweiten Hälfte des 19. Jh.s.

255 Z.B. Al-dalīl ila țā at al-inğ̌̉l (Anleitung zum Gehorsam gegenüber dem Evangelium), Beirut 1849; Tabri'at al-mațūm mimmā qadāfahu bihi al-bațriyark Maximus Mazlūm (Freisprechung des Angeklagten von den Vorwürfen des Patriarchen Maximus Mazlūm), Beirut 1854; Kašf 'an niqāb 'an wağh al-masīh al-kadăāb (Die Enthüllung des Gesichtes des Antichristen), Beirut 1860: vgl. Graf (1951), 299.

256 Smith an Mišãqā (o. O., 16.4.1849): ABC, Box 1 (HHL). 
Darüber hinaus verteilt Smith auf einer Reise nach Jerusalem Druckausgaben eines Buches von Mišāqā, um mit Leuten darüber ins Gespräch zu kommen. „Auf meiner Reise habe ich einige Kopien vom ersten Teil Ihres Buches in Jerusalem und Jaffa verteilt. Ich fand, dass sich diejenigen, die erleuchtet sind [al-mutanawwirin min $a l-n \bar{a} s]$ sehr darüber gefreut haben und hoffe, dass sie einen Nutzen daraus ziehen können." 257

Für John Wortabet ist Smith Lehrer, Mentor und Freund zugleich. Zwischen 1848 und 1856 stehen die beiden in engem Briefkontakt. Neben den gewöhnlichen Berichten zur eigenen Arbeit enthalten Wortabets Briefe auch persönliche Notizen zu den Familien der beiden Männer. Wortabet, der seine Briefe stets mit „your obedient Servant" unterschreibt, ist dankbar für den fruchtbaren Austausch mit dem erfahrenen Missionar: „I beg to express my sincere thanks for all your kind wishes and interest in me. It is a great consolation, as it is a blessing for me to think that I enjoy an interest in the prayers of such men as yourself; and I hope that I may still continue to enjoy the same." 258

Ein klassischer, arabischer Brief, so Henry Harris Jessup, besteht damals üblicherweise aus drei Teilen:

[A] long, flowery, poetical introduction covering one-third of the page, a similar conclusion covering the last third, and a brief letter in the middle. Important business, however, was written in a postscript diagonally across the right hand bottom of the page, and this was the part generally read by the receiver. ${ }^{259}$

Lange Briefe mit wenig Inhalt sowie diagonal geschriebene Notizen finden sich auch in den Briefen in Smiths Nachlass. Auch Smith bedient sich hin und wieder einer blumigen, etwas umständlichen Ausdrucksweise, wie sie in Briefen von Mišāqāa, Bustānī oder Yannī zu lesen ist. Was die Begrüßungs- und Schlussformeln anbelangt, so finden sich viele Ähnlichkeiten zwischen Smith und seinen Brieffreunden: Für gewöhnlich überschreibt Smith einen Brief mit „Ğanāb al-ah alağl al-muhtaram“ (i. e.: Sehr verehrter, lieber Bruder) oder „Ğanāb al-muhib al$\bar{a}^{\prime} z$ al-muhtaram" (i. e.: Sehr verehrter, lieber Freund), Mišāqā beginnt ebenfalls mit „Ğanāb sayyidī al-muhtaram“" (Sehr geehrter Herr). Sodann fährt Smith mit den Begrüßungsworten fort: „Nuhib taqdīm katrat al-ašwāq al-qalbìya a rud innahu..." (Wir möchten viele herzliche Grüße übersenden [und] ich teile [Ihnen] mit, dass...). Mišāqā wiederum schreibt: „Nuhib hadā wāğibāt al-ikrām wa ğazīl al-šauq al-wäfir [...] a'ruḍ annī..." (Wir möchten Ihnen [unseren] Respekt und viele liebe Grüße überbringen [...], ich teile [Ihnen] mit, dass...). Auch in den Schlussformeln ähneln sich Smiths und Mišāqās Worte: Während Smith mit „Wa ațāl Allah baqākum" (Gott möge Ihnen ein langes Leben geben) schließt, formuliert

257 Smith an Mīšāqa (o. O., 14.5.1849): ABC 50, Box 1 (HHL). Vermutlich handelt es sich dabei um die Schrift Al-dalīl ilā ță 'at al-inğ̌̀l (s. Anm. 255 in diesem Kapitel), die 1849 in Beirut gedruckt wird.

258 Wortabet an Smith (Hāașbeiyā, 13.1.1852): ABC 60 (98), (HHL). Mehr zur Korrespondenz zwischen Smith und Wortabet in Abschnitt III.2.2.

259 Jessup (1910a), 115. 
Mišāqa „Wa dāma baqākum“ ([ER] möge Ihr Leben lang werden lassen). ${ }^{260}$ Auch wenn sich Smiths Arabisch - zumindest in den Briefentwürfen - als nicht fehlerfrei erweist, ist er stets bemüht, gängige Umgangsformen zu wahren und sich als Anteil nehmender, interessierter Brieffreund zu zeigen. Seine Briefsammlung ist ohne Frage ein besonderes Zeugnis transkultureller Verständigung.

\section{Schlussbetrachtung}

Wo sind die Finger, die Einzigartiges vollbracht haben, mit Tinte sind sie [über das Papier] geflogen und haben Wahres und Weises [geschrieben]?

Wo ist die Zunge, die uns gestern [noch] vertraut war wie eine süße Quelle, die alles erzählte, was man [hören] wollte?

Wo ist jenes Herz, durch das man erleuchtet wurde so wie ein Stern, der in der Dunkelheit aufleuchtet?

Wo ist dein hoher Eifer, der dem Eifer einer Armee gleichkommt, wenn sie kämpft?

Wer sonst stand mit [solcher] Weisheit da, die du gehabt hast! Und auf wessen Entdeckung [verschiedener] Dinge kann man sich [nun] stützen?

Wem vertraut man [nun] schwere Arbeiten an und wer löst mit seinem Wissen komplizierte Probleme? ${ }^{261}$

Šeih Nāṣīf al-Yāziğ̄i, Dichter, Sprachgelehrter und ehemaliger Helfer in der Druckerei, verfasst diese Eulogie anlässlich des Todes von Eli Smith im Januar 1857. Wie gezeigt wurde, ist Smith für viele zum Mentor, Ratgeber und Freund geworden. Dies trifft besonders auf die syrischen Mitarbeiter der Mission Buṭus al-Bustānī und John Wortabet zu, wie im Folgenden noch zu sehen sein wird. Für Smith sind sie die besten Übersetzer, auf die die Mission Press nicht verzichten kann. ${ }^{262}$ In ihnen sieht er fähige Kandidaten für das einheimische Pastorenamt und wird nicht müde, sie darin zu bestärken, die theologische Ausbildung abzuschließen und sich ordinieren zu lassen. ${ }^{263}$ Trotz der freundschaftlichen Briefe, die Bustānī und Wortabet mit Smith austauschen, gibt es theologische Meinungsverschiedenheiten, was das Verhältnis zwischen Missionar und native pastor anbelangt. Smith erhofft sich zwar, dass die Mission bald einen einheimischen Pfarrer ordiniert, auf die qualitativ hochwertige Arbeit eines amerikanischen Missionars sollte dennoch nicht verzichtet werden, wie er 1851 an Anderson schreibt:

When it has been contended that we should give up our pulpit to a native pastor, and be hearers ourselves, lest if we continue to preach, he in contrast, will not be sufficiently respected to attract an audience, I have objected; because if we, in consequence of our training in a Christian land, and of our careful theological education, are able to preach better than these, at the best,

260 Smith an Mīšāqa (Beirut, 14.3.1853; 25.4.1853; 11.11.1853); Mīšāqa an Smith (o. O., 3.6.1853): ABC 50, Box 1 (HHL).

261 Eulogie für Eli Smith von Nāṣîf al-Yāziǧĩ (1857): ABC 50, Box 1 (HHL).

262 Smith an Anderson (Beirut, 13.3.1856): ABC 16.8.1., Vol. 5 (225).

263 Smith an Anderson (Beirut, 17.6.1851): ABC 16.8.1., Vol. 5 (199). Näheres dazu in den Abschnitten III.1.2 und III.2.2. 
very imperfectly trained preachers, I do not think it right to have our mouths closed in order to carry out a theory. ${ }^{264}$

Smiths Werdegang als Missionar ist trotz seines frommen Glaubens und der Konformität mit den theologischen Vätern des ABCFM nicht ohne Widersprüche. 1832 predigt er noch vor amerikanischem Publikum:

You go not to study ancient Greece and Palestine, nor present workings of human nature, any farther than you will ever have an occasional regard to the one for the illustration of Scripture, and will find an understanding of the other an essential help to your missionary success. ${ }^{265}$

Es zeigt sich, dass Smiths Studien im Laufe der kommenden Jahrzehnte weit über das nötige Wissen für die Verkündigung der Heiligen Schrift hinausgehen. Smith scheint hin und her gerissen. Noch am Sterbebett überkommen ihn Schuldgefühle wegen seiner vielen Interessen, die er außerhalb der Mission verfolgt hat. Nicht ohne Grund werden diese Worte der Selbstkritik von der Redaktion des Missionary Herald in der Todesanzeige von Smith eingefügt: „He had tried, he said, to serve Christ, and had labored long and hard, but his motives, he now felt, had been too often unworthy and selfish.“"266

Smiths ehemaliger Kollege William Goodell, der nun für den ABCFM unter den Armeniern missioniert, spricht in einem Nachruf seine Bewunderung für dessen Sprachkenntnisse aus, die er sich durch großen Fleiß angeeignet habe. Allerdings betont Goodell, dass es stets eine Gratwanderung sei, wenn man der Missionsarbeit und den landeskundlichen Studien gleiche Aufmerksamkeit widmen will: ,Sometimes, too, the circumstances of a mission may be such, that is, the religious interest may be so great, and the field so wide, that the translator much at once shut [sic] up his books, and go out to help gather the harvest. ${ }^{267}$

Schließlich kann zu Recht behauptet werden, Smith habe eine wichtige Rolle in der kulturellen Renaissance in Syriens neunzehntem Jahrhundert gespielt. ${ }^{268}$ Schon allein die Entwicklung des American Arabic Type, die Arbeit an vielfältigen arabischen Büchern für die Druckerei sowie die Verantwortung für das erste arabische Missionsblatt haben Generationen von Syrerinnen und Syrern beeinflusst. Über Nāṣîf al-Yāziǧñs Gedichtband, dessen Druck in der American Mission Press von einem privaten Kaufmann finanziert wird, schreibt er 1856 an die DMG: „Abgesehen von dem Werthe des Buches an und für sich, verdient dieses Aufstreben zur Schöpfung einer neuen National-Literatur gewiss alle Anerkennung und Förderung.“269 Es darf darüber hinaus nicht vergessen werden, dass Smith Bildung und Fortschritt immer im Kontext der christlichen ,Zivilisierung' sieht, kulturelle Erweckung kann

264 Smith an Anderson (Beirut, 17.6.1851): ABC 16.8.1., Vol. 5 (199).

265 Smith (1832), 6; ebd., 11: „You must study practically from observation, as well as theoretically from books, the highly artificial attitude in which their false religion has placed them."

266 MH 53 (1857), in: ROS 4, 289.

267 William Goodell, „Memoir“ (Konstantinopel, 14.5.1859): ABC 60, Box 3 (139), (HHL). William Goodell ist von 1827 bis 1828 Smiths Kollege in Syrien.

268 Antonius (1938), 37-38: Smith initiierte,,a revival of the Arabic language and, with it, a movement of ideas which was to leap from literature to politics' and [...] lead to distant results“. Siehe auch: Pritchard (1958), 58; Stoddard (2009), 221.

269 Smith an die DMG (Beirut, 9.5.1856), in: ZDMG 10 (1856), 813. 
zur religiösen Erleuchtung führen. Schon als er sich 1829 für die Produktion von Schulbüchern in der Syrienmission einsetzt, argumentiert er, dass die Fächer Geografie und Geschichte das Denken erweitern und junge Menschen dazu ausbilden, „to think for themselves on the subject of religion“. 270

In Anbetracht seiner Beiträge für die Orientwissenschaft im 19. Jh. und des wissenschaftlichen Netzwerks, das er zwischen Syrien und Europa sowie den USA aufrecht erhält, kann man Smith in der Tat als „ersten wahren Orientalisten“ sehen. ${ }^{271}$,[T]he ,Arab race is my favorite“" wird er 1850 im New York Morning Herald schreiben, ,they had literature and poetry, ,the soul of sublimity“, a record of achievement in science, mathematics, philosophy, and history, and an Arabic language that made English sink, into insignificance before its beauty and force“" 272

Als es 1843/44 um die Existenz der Syrienmission geht, wird deutlich, wie sehr sich Smith mit seiner Arbeit identifiziert und dass er, wenn nötig, auch allein weiterkämpfen will: „Abandon Syria! It is a thing I had never dreamed of. Not a single missionary principle I have ever adopted could favor such a step. [...] NEVER! [...] Here may my last days be spent. If others will hold on with me, well; if not, let me wear out alone." 273

\section{II.2. ,[HE] HAD ARABIC AT HIS TONGUE’S AND FINGERS’ ENDS“'274_- CORNELIUS VAN DYCK $(1818-1895)^{275}$}

\section{Kurzbiografie}

Cornelius Van Alan Van Dyck wird am 13.8.1818 in Kinderhook/New York als Sohn von niederländischen Einwanderern geboren. Er studiert Medizin am Jefferson College in Philadelphia und unterrichtet mit 18 Jahren in einer Mädchenschule Chemie. ${ }^{276}$ Ausgesandt von der Dutch Reformed Church im Auftrag des ABCFM erreicht er am 1.4.1840 mit einigen anderen neuen Missionaren Syrien, um fortan als Missionsarzt zu arbeiten. ${ }^{277}$ Bei seinen Missionarskollegen holt er seine theologische Ausbildung nach und wird am 14. Januar 1846 in 'Abeih ordiniert. ${ }^{278}$ Zudem

270 „On the Preparation of School-Books for Greeks, Armenians, and Arabs, drawn up by Mr. Smith“ (Malta, 8.10.1829): ABC 16.6.3., Vol. 3.

271 So Finnie (1967), 196.

272 Makdisi (2008), 196, zitiert aus: New York Morning Herald (19 May 1850), 1, 3-4, in: Yale Divinity School Library, Special Collections, Eli Smith Family Papers, RG 124, Box 3/2.

273 Smith in MH 39 (1843), in: ROS 3, 377.

274 Zitat eines syrischen Dichters, dessen Name nicht genannt wird, über Van Dyck, in: Hall (1885), 285.

275 Eine englische Zusammenfassung dieses Kapitels unter dem Titel „I have left my heart in Syria: Cornelius Van Dyck and the American Syria Mission“ ist Anfang 2015 im Cairo Journal of Theology erschienen: vgl. Zeuge-Buberl (2015a).

276 Jessup (1910a), 104-105.

277 MH 36 (1840), in: ROS 3, 222.

$278 \mathrm{MH} 42$ (1846), in: ebd., 482. 
ist er Doktor der Theologie, ${ }^{279}$ Doktor der Literaturwissenschaft, ${ }^{280}$ Bachelor in Jura und Ehrendoktor in Humanwissenschaften. ${ }^{281}$ Van Dyck hat sich in verschiedenen Stationen seines Wirkens in Syrien einen Namen gemacht: 1846 bis 1850 leitet er das Missionsseminar in 'Abeih und erarbeitet dafür zahlreiche Lehrbücher auf Arabisch. Zusammen mit William M. Thomson und John Wortabet baut er danach evangelische Gemeinden in Sidon, Hāṣbeiyā und Umgebung auf. Als Eli Smith stirbt, setzt er die Übersetzung der Bibel fort und vollendet sie 1865. Er leitet über viele Jahre die amerikanische Missionsdruckerei und rettet sie vor der Schließung. Von 1866 bis 1883 lehrt er als Professor für Medizin und Astronomie am Syrian Protestant College. Neben dieser Arbeit ist er über Jahrzehnte praktizierender Arzt, Gelehrter, Autor und Übersetzer.

1842 heiratet Van Dyck Julia Abbot, die Tochter des verstorbenen englischen Konsuls, mit der er sechs Kinder hat. ${ }^{282}$ Am 13. November 1895 erliegt Cornelius Van Dyck im Alter von 77 Jahren einer starken Darmblutung in Folge einer Typhuserkrankung. ${ }^{283}$ Hunderte von Menschen begleiten den Trauerzug des wohl bekanntesten amerikanischen Missionars in Syrien. (Abb. 5)

\section{2. „Our policy has been a contracting not an extending policy“ ${ }^{\text {284 }}$ Van Dyck und die Syrienmission}

Mit gerade einmal 21 Jahren erreicht Cornelius Van Dyck 1840 Syrien. Zusammen mit Henry De Forest, der 1842 anreist, sollen sie als Missionsärzte den hohen Bedarf an medizinischer Versorgung innerhalb und außerhalb der Mission decken. ${ }^{285}$ „American medicine at the time was hardly ,scientific“; doctors still bled patients for all manner of ailments so that the American doctor had little edge over the native

279 Während seines Aufenthaltes in New York 1865 erhält er diesen Titel vom Rutgers College in New Jersey: vgl. Union Theological Seminary (1937), xxx.

280 Der Titel wird ihm 1890 ebenfalls vom Rutgers College verliehen: ebd.

281 Die letzten beiden Titel erhält er von der University of Edinburgh, den Ehrendoktor 1892: vgl. Jessup (1910a), 73; Union Theological Seminary (1937), xxx.

282 Julia Abbott lebt von 1827 bis 1918. Vgl. Jessup (1910a), 107; Sa'di (1937), 39-40; Bliss (1993), 252: Die gemeinsamen Kinder heißen Henry Laurence (1843-1883), Edward Abbott (1846-19??), William Thomson (1857-1939), Ellen Maria (1848-1849), Eliza Ann bzw. Lizzie $(\dagger 1936)$ sowie Florence Katherine (1871-1908). William Van Dyck studiert selbst am SPC und ist dort für mehrere Jahre Lektor. Von 1920-27 hat er eine Professur für Zoologie an der nun umbenannten American University of Beirut inne. Auch sein älterer Bruder Edward lehrt ca. 1870/71 Englisch und Latein am SPC: vgl. Jahresbericht SPC (27.6.1871): ABC 16.8.2., Vol. 2, 18. Edward arbeitet später als Übersetzer im Amerikanischen Konsulat in Beirut, als Vizekonsul in Kairo/Ägypten sowie als Lehrer in einer ägyptischen Regierungsschule: vgl. Union Theological Seminary (1937), 52.

283 Jessup (1910a), 110.

284 Van Dyck an Anderson ('Abeih, 17.8.1850): ABC 16.8.1., Vol. 7.2. (320).

285 Murre-van den Berg nennt dies einen Säkularisierungstrend in den Nahostmissionen: Die Gewährleistung medizinischer Versorgung, durch die auch Muslime in Kontakt mit der Mission treten, ,required a different type of missionary, a woman or man who had been educated as a doctor or teacher, not as minister or evangelist“", vgl. dies. (2006a), 8. 


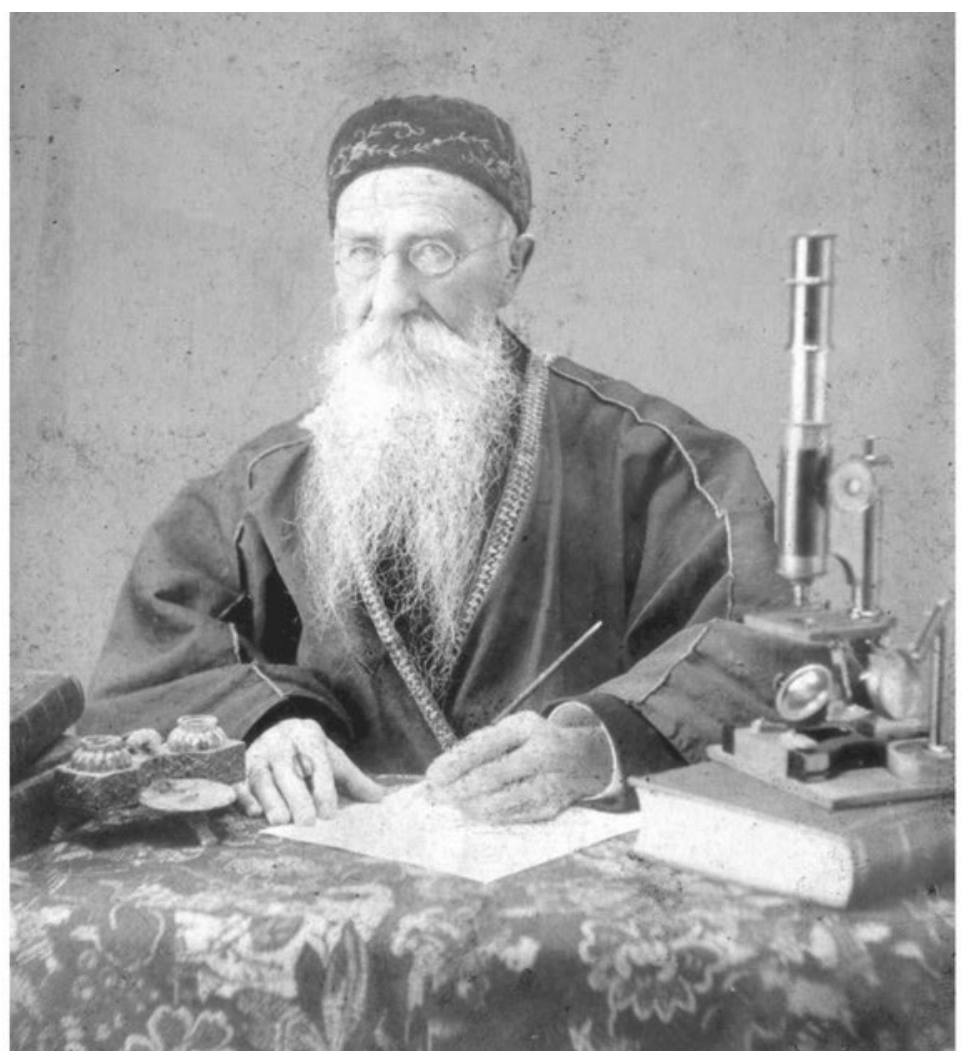

Abb. 5: Rev. Cornelius Van Dyck, M.D., D.D., LH.D.

practitioner", so das Urteil des Historikers RoBert L. DANIEL. ${ }^{286}$ Van Dyck ist demnach ein durchschnittlicher Arzt, hat weder ein theologisches College besucht, noch ist er der arabischen Sprache mächtig. Diese Umstände sollen sich bald ändern.

Dabei gestalten sich die ersten Monate in Syrien für Van Dyck als äußerst schwierig und wenig aussichtsreich. Schon nach kurzer Zeit beklagt er sich bei Rufus Anderson über völlige Überarbeitung, da er Tag und Nacht von Patienten aufgesucht werde und sein eigener gesundheitlicher Zustand sich permanent verschlechtere. Als Missionsarzt berichtet er ausführlich von den Krankheiten seiner Kollegen, die sowohl physischer als auch psychischer Natur sind. Dabei wird deutlich, dass die Amerikaner nicht nur am veränderten Klima, sondern insgesamt an Erschöpfung durch Überarbeitung leiden. Anderson hat dafür wenig Verständnis. Bereits 1841 beantragt Van Dyck, in die USA reisen zu dürfen, um eine Harnröhrenstriktur auszukurieren und sich richtig behandeln zu lassen. ${ }^{287}$ Der Antrag

286 Daniel (1964), 82.

287 Van Dyck an Anderson (Deir al-Qamar, 6.8.1841): ABC 16.8.1., Vol. 2 (204). Im selben Jahr möchte ihn die Syrienmission in Aleppo stationieren, wozu es jedoch nicht kommt: vgl. MH 37 (1841), in: ROS 3, 306. 
wird jedoch vom Prudential Committee abgelehnt. Da in den ersten Jahren wenig Briefe von Van Dyck nach Boston adressiert sind und man demnach im Missionary Herald selten von Van Dyck liest, ${ }^{288}$ ermahnt Anderson den Nachwuchsmissionar über viele Jahre, regelmäßiger zu schreiben und über seine Arbeit zu berichten. ${ }^{289}$ Van Dyck erklärt: ,[I]t has been no want of respect, which has influenced me, nor has it been indolence; but simply an unwillingness on my part to inflict upon others an illegible scroll of trite expressions, or information, previously communicated by others." 290 Van Dyck ist jedoch nicht der einzige Missionar, der seinen Pflichten, Bericht zu erstatten, nur selten nachkommt. Als Anderson 1844 von seiner Reise in die Levante zurückkehrt, schreibt er an die gesamte Syrienmission: „If you will have the churches take a deep interest in your mission you must take pains to write frequently and with care, for publication. There is no use in reasoning against this necessity, and a wise man will not attempt it." ${ }^{\text {"291 }}$

Da die Mission nun jeden Mann für die Verkündigungsarbeit braucht, empfiehlt der American Board den Missionsärzten Van Dyck und De Forest, zusätzlich theologische Studien zu betreiben, um als Prediger arbeiten zu können. ${ }^{292}$ Dabei war es sogar der Wunsch von Van Dycks Vater, der als Landarzt arbeitete, seinen Sohn als Pastoren zu sehen. Schon sehr früh hegt Van Dyck jedoch andere Pläne und möchte Medizin studieren. ${ }^{293}$ In Syrien bietet sich ihm nun eine zweite Chance und er beginnt von Anfang an mit der Lektüre theologischer Werke. Die Entscheidung für die Ordination fällt ihm jedoch nicht leicht. Ein Jahr bevor Cornelius Van Dyck ordiniert wird, schreibt er Anderson: ,[A]t present my whole heart is drawn towards the sacred office. But the required qualifications, the responsibilities, the magnitude of work are points which make me hesitate. "294 Der Wille, den Menschen von der Botschaft Jesu Christi zu berichten, ist schließlich stärker als seine Zweifel, ob er den Ansprüchen dieses Amtes genügen kann. Letztlich wird Van Dyck Recht behalten, was seine Zweifel anbelangt. Die Anforderungen an ihn als Arzt und Geistlichen sind so hoch, dass er immer wieder gesundheitlich darunter leidet. ${ }^{295}$

Mit der Neueröffnung des Missionsseminars in 'Abeih'296 entdeckt Van Dyck seine Leidenschaft als Lehrer. In den USA hatte er bereits Chemie an einer Mädchenschule unterrichtet, nun leitet er ein ganzes Seminar und strukturiert zusammen

288 Eine erste persönliche Notiz liest man sogar erst 1847, d. h. sieben Jahre nach Van Dycks Ankunft in Syrien: vgl. MH 43 (1847), in: ROS 4, 2-4.

289 Van Dyck an Anderson (Aitāt, 5.9.1842): ABC 16.8.1., Vol. 2 (206); Van Dyck an Anderson (Beirut, 30.10.1845): ABC 16.8.1., Vol. 3.1. (142).

290 Ebd.

291 Anderson an die Syrienmission (On board the Turkish Steamer, 23.4.1844): ABC 16.8.1., Vol. 8.

292 Ebd.

293 Anderson, „Memorandum of Discussions with the Missionaries during my visit to the Levant in 1843-1844": ABC 30.10., Vol. 3, 34 (HHL).

294 Van Dyck an Anderson (Beirut, 30.10.1845): ABC 16.8.1., Vol. 3.1. (142).

295 Van Dyck an Anderson ('Abeih, 5.10.1847): ABC 16.8.1., Vol. 5 (314).

296 Siehe dazu Abschnitt I.1.4. Die Missionare Whiting und Thomson sowie Van Dyck als Missionsarzt werden bereits 1843 beauftragt, in 'Abeih eine Station aufzubauen: vgl. MH 39 (1843), in: $\operatorname{ROS} 3,384$. 
mit Būṭrus al-Bustānī, der ihm seit 1841 ein enger Freund ist, den Lehrplan: Bustānī unterrichtet die Studenten in Arithmetik, arabischer Grammatik sowie Wortbedeutung (,necessary on account of the scarcity of dictionaries in the language") $)^{297}$ und Van Dyck in Geografie und Bibelkunde. Wie bereits erwähnt, besitzt die Mission in dieser Zeit noch keine eigenen Lehrbücher bis auf eine arabische Grammatik. Die Lehrbücher entstehen im Verlauf des Unterrichts, was dazu führt, dass die Vermittlung des Lehrstoffs oft doppelt so lange dauert und dem Lehrenden viel Selbststudium abverlangt, „to ensure the necessary accuracy in thus composing text books for [the] future“" ${ }^{298}$ Van Dyck erarbeitet während dieser Zeit Schulbücher für Geografie, Algebra, Geometrie, Logarithmus, Trigonometrie und natürliche Philosophie. Jessup schreibt dazu rückblickend:

His geography of Turkey, Asia Minor, Syria and Palestine, is a thesaurus of graphic description, and full of apt quotations in poetry and prose from the old Arab geographers and travellers. The people delight in it and quote it with admiration. I found it to be one of the best possible reading books in acquiring a knowledge of the Arabic vocabulary. 299

Offiziell übernimmt Van Dycks Kollege Simeon H. Calhoun ab 1849 die Leitung des Seminars, aber das Aufgeben seiner Lehrtätigkeit fällt nicht nur Van Dyck schwer, auch einige seiner Kollegen sind gegen die Entscheidung des American Board, den Missionar und Arzt nach Hāașbeiyā oder Damaskus zu senden, um dort Stationen aufzubauen. Grund für Van Dycks Einwände sind Bedenken über Calhouns fachliche Fähigkeit, die Kurse auf gleichem Niveau fortzusetzen. Er habe den ersten und zweiten Jahrgang komplett unterrichtet und die Lehrbücher selbst entworfen, so Van Dyck. Calhoun kenne weder die Fachbegriffe, noch habe er das Wissen eines ganzen Kursjahres. ${ }^{300}$ In den ersten vier Jahren hat sich Van Dycks Name mit dem Ruf des Seminars verbunden und ist unter den Syrern in der Umgebung von 'Abeih und darüber hinaus zu einer Garantie für Qualität und gute Ausbildung geworden. Van Dyck ist sich dessen durchaus bewusst und plädiert dafür, dass sich Calhoun erst einmal einen Namen machen muss, damit er das Seminar mit Erfolg weiterführen kann. Der talentierte Missionsarzt ist nun schon 10 Jahre in Syrien und zeigt sich sichtlich selbstbewusst und überzeugt von seinen Fähigkeiten. Van Dyck weiß zwar, dass er nicht für immer im Seminar bleiben kann, doch angesichts der gegenwärtigen Strategie der Mission, angeordnet vom American Board, äußert er offen: „Under the present system I am unwilling to go to Damascus, Hasbeiya or any where else either permanently or temporarily. Under a free system (you will not misunderstand the expression) I am ready to go where it shall be thought best." ${ }^{\text {"301 }}$

Das „freie System“, von dem Van Dyck hier spricht, bezieht sich auf den Umgang der Mission mit einheimischen Konvertiten und neu gegründeten Kirchengemeinden wie in Abschnitt I.1.3 bereits erläutert wurde: Das Problem ist zum einen die von einigen Missionaren zu streng gehaltene Prüfung wahrer Frömmigkeit bei

297 Van Dyck an Anderson ('Abeih, 9.11.1846): ABC 16.8.1., Vol. 5 (315).

298 Ebd.

299 Jessup (1910a), 107. Mehr zum Geografiebuch (Kitāb al-mir' āt al-wadīya fi l-kurat al-arḍ̂yya, erste Auflage von 1852) in Anhang I.

300 Van Dyck an Anderson ('Abeih, 17.8.1850): ABC 16.8.1., Vol. 5 (320).

301 Ebd. 
Bewerbern für die evangelische Kirche, und zum anderen die Ansicht, dass die bisher noch finanziell von den Amerikanern abhängigen Kirchengemeinden der uneingeschränkten Kontrolle der Mission unterstehen. Van Dyck spricht in einem als ,privat“" gekennzeichneten Brief vom 17. August $1850 \mathrm{sehr}$ offen über seine Meinung, die sich von der einiger anderer Kollegen deutlich unterscheidet. Es wird hierbei klar, dass nicht Anderson den strikten Umgang mit einheimischen Protestanten und Kirchengemeinden fordert, im Gegenteil: er mahnt fortwährend an, die Kirchen zu füllen und einheimische Pastoren zu ordinieren. Viele der Missionare jedoch hegen Zweifel an der Spiritualität der Bewerber für die Kirchengemeinde, wobei Van Dyck dementiert, dass das mangelnde Vertrauen gegenüber neuen Konvertiten unbegründet sei: ,there is no want of confidence“. ${ }^{302}$ Zweifelsohne ist der Beweis von genügender Frömmigkeit Voraussetzung für die Mitgliedschaft in der evangelischen Kirche, so sehen es auch die einheimischen Protestanten, aber die Maßstäbe müssen anders gesetzt werden. Der Umgang mit dem eigenen Glauben ist kulturell verschieden. So sieht es auch Van Dyck: „Again we (the missionaries) are foreigners - our support, our connections, our friends, our ideas and ways of thinking, our education [...], are foreign - we are not the men to set our judgement upon this people [...]." ,[A] certain religious experience to which we have been accustomed" sollte nicht von den Syrern auf gleiche Weise verlangt werden, so Van Dyck weiter. ${ }^{303}$ Die anscheinend ungenügende Frömmigkeit ist es, die bei vielen Missionaren die Befürchtung hervorruft, dass eine große Verantwortung in den Händen der syrischen Protestanten sehr schnell zu deren Unabhängigkeit führen könnte. Ihnen ist es lieber, überfürsorglich zu sein und die feste Bindung zwischen Kirche und Mission aufrecht zu erhalten. Diese Umstände führen ab 1848 zu einem Schwund möglicher Kandidaten für das einheimische Pastorenamt, da sie sich in ihrer Freiheit eingeschränkt fühlen, wie bei Bustān̄̄ und Wortabet noch zu sehen sein wird. Die einheimischen Helfer sind entmutigt und rechnen damit, von der Mission für höhere Ämter abgelehnt und sogar entlassen zu werden. Statt eines Wachstums in den Gemeinden verlieren sie Mitglieder. Statt einheimischer Pfarrer stehen ihnen amerikanische Missionare vor. Van Dyck urteilt offen und deutlich: „Our policy has been a contracting not an extending policy, we cut off native helpers here and there, and pray that the Lord would raise up laborers into the harvest. “304

Anderson hat die Merkmale, an denen man die „credible profession of piety“ messen soll, nicht genau definiert. Seine Missionare in Syrien fühlen sich zu übereifrigem Handeln genötigt, da Anderson ihnen 1844 unmissverständlich erklärt, ,the Mission could not be maintained a year, if it were known that they received persons to the ordinances on other grounds than a credible profession of faith. " 305

302 Ebd.

303 Ebd.

304 Ebd.

305 Anderson an die Syrienmission (On board the Turkish Steamer, 23.4.1844): ABC 16.8.1., Vol. 8. Andersons Bedenken basieren u. a. auf Berichten von Samuel Wolcott, der von 1840 bis 1843 in Syrien stationiert ist und fast nur Negatives über die Gemeindemitglieder der Missionskirche zu berichten weiß. Viele seien weder fromm, noch hätten sie einen besonders ehrenhaften Charakter: vgl. Wolcott an Anderson (Beirut, 1.6.1842): ABC 16.5., Vol. 3. 
Ein weiterer Vorfall scheint einige Missionare in ihrem Handeln nur zu bestärken: Während Andersons Besuch in der Levante 1843/44, bei dem lange Debatten über weitere Vorgehensweisen in der Mission geführt werden, wird ein Fall diskutiert, der sich 1839 ereignet hat. Die Missionare Thomson, Hebard und Lanneau hatten sich dafür entschieden, eine Gruppe von Drusen, die sich als Bekehrte sahen, taufen zu lassen, ohne jedoch Nachweise über deren Frömmigkeit zu haben. Im Gegensatz zu Anderson und Dr. Hawes, der ihn begleitet, sowie den Missionaren Whiting, De Forest oder Smith (,He fears the effect of introducing men who are not pious.“), ${ }^{306}$ stellt sich Van Dyck auf Thomsons Seite und argumentiert, dass eine Ablehnung der Gruppe die Konvertiten völlig desillusioniert hätte. Sie hatten ihre Glaubensgemeinschaft verlassen und standen nun, im Falle einer Ablehnung, ohne Religion da. Daher plädiert der Missionsarzt in solch einem Fall für die Aufnahme in die Missionskirche unter der Voraussetzung, dass ihnen die evangelischen Lehren erläutert werden. ${ }^{307}$ Es zeigt sich, dass sich Van Dyck und Thomson für die individuelle Prüfung der Konvertiten einsetzen, da allgemeine Regeln auf Besonderheiten in den einzelnen Fällen nicht anwendbar sind. Die individuelle Handhabung von Mitgliedsanträgen für die Missionskirche geht Anderson jedoch anscheinend zu weit. Van Dycks Beitrag wird von ihm in seinem Protokoll der Diskussionen mit einem in Klammern stehenden Kommentar versehen:

[He appears to favor the administering (of) the ordinances to men before they give good evidence of piety. He would have a much lower degree of evidence, and would make baptism a means of bringing men out, and making nominal Christians. He would administer the ordinance of baptism to those who declare their belief in Christianity, and so become the means of making them disciples and bringing them under instruction. $]^{308}$

Andersons Meinung nach haben die orientalischen Christen eine höchst gefährliche Ansicht in Bezug auf Taufe ,as they believe in its regenerative power, and it will never be proper for us to yield to this error or countenance it in any way" 309 Schließlich sollen den nominalen Christen im Land nicht noch weitere hinzugefügt werden, die sich Protestanten nennen. Anderson ist überzeugt, dass bei seiner Abreise 1844 nun alle Meinungsverschiedenheiten geklärt seien. ${ }^{310}$ Es zeigt sich jedoch, dass die konservative Linie der Syrienmissionare auch in den folgenden Jahren eine übertriebene Praxis der Frömmigkeitsbeweise betreibt. Der Sekretär des ABCFM sieht seinen Plan für eigenständige, einheimische, protestantische Gemeinden in Syrien gefährdet. ${ }^{311}$ Wie bereits erwähnt, mahnt auch Van Dyck an,

306 Anderson, „Memorandum of my visit to the Levant“: ABC 30.10., Vol. 3, 17-21 (HHL).

307 Eli Smith ist hier anderer Meinung, obwohl er, wie nahezu alle Syrienmissionare, dafür plädiert, sich um die Gruppe aus Hāașbeiyā dennoch zu kümmern: „Christian marriage and burial we could give to all; but baptism and the Lord's supper were only for those whose hearts were renewed by the Holy Ghost, which there was no reason to believe was now the case with any of them."Vgl. MH 41 (1845), in: ROS 3, 400.

308 Anderson, „Memorandum of my visit to the Levant“: ABC 30.10., Vol. 3, 15 (HHL).

309 Anderson an die Syrienmission (On board the Turkish Steamer, 23.4.1844): ABC 16.8.1., Vol. 8.

310 Ebd.

311 Anderson an die Syrienmission (Boston, 27.6.1850): ABC 2.1.1., Vol. 13 (HHL). 
dass sie Gemeindemitglieder und Pfarramtskandidaten verlieren, wenn es so weiter gehe wie bisher. Anderson präzisiert nun seine Ansicht gegenüber der Mission und in persönlichen Briefen, wie auch hier an Van Dyck:

It seems to me that we must run risks [...]. We must run risks in admitting native converts into the church - in ordaining them as ministers, and as pastors - in setting them up as organized and recognised Christian churches, with places of worship and a stated native ministry. ${ }^{312}$

Andersons Worte scheinen etwas zu bewirken. Alle Hoffnungen konzentrieren sich nun auf John Wortabet, der 1853 zum Prediger (evangelist) ordiniert wird. ${ }^{313}$ Van Dyck ist ab 1851 bereit, sich versetzen zu lassen und wird, nach gescheiterten Verhandlungen für eine feste Station in Damaskus, ${ }^{314}$ zusammen mit seinem Schwiegervater und Kollegen William M. Thomson ${ }^{315}$ und ihren Familien in Hāṣbeiyā stationiert, wobei sie in Sidon wohnen. Wortabet assistiert den beiden und konzentriert sich vor allem auf den Aufbau der Kirchengemeinde in Hāạbeiyā.

Van Dycks Freude an der Arbeit in Sidon und Umgebung scheint nur für kurze Zeit anzuhalten. Noch 1851 werden er und Thomson in einem allgemeinen Schreiben Andersons an die Syrienmission darüber informiert, dass das Prudential Committee die Kürzung ihrer Gehälter in Erwägung ziehe, da sie nun ihrer Meinung nach weniger Ausgaben in Sidon haben werden. Van Dycks Gehalt soll von \$1050 auf $\$ 850,{ }^{316}$ und wenige Monate später nochmals auf $\$ 700^{317}$ gekürzt werden. Van Dyck zeigt sich verletzt. Zum einen, weil Anderson dieses Vorhaben in einem unpersönlichen Schreiben gegenüber allen Missionaren ankündigt. Zum anderen wirft er Anderson und dem Prudential Committee mangelndes Vertrauen vor:

Do you suppose that, after a years residence in Sidon, if I had found that my family could be comfortably supported on $\$ 600$ or $\$ 700$ I would still asked [sic] for $\$ 850$ ? I cannot believe that there is a missionary in the service of the Board in whom you have so little confidence. ${ }^{318}$

Da er auf diese Weise nicht für seine Familie sorgen kann, bittet er das Prudential Committee, ihn rechtzeitig über solche Schritte zu informieren, damit er die nötigen

312 Anderson an die Syrienmission (Boston, 11.7.1851): ABC 16.8.1., Vol. 8 (4). Vgl. auch Anderson an die Syrienmission (Boston, 27.6.1850): ABC 2.1.1., Vol. 13 (HHL).

313 Näheres dazu in Abschnitt III.2.2.

314 Grund für das Scheitern ist offenbar der Missmut der bereits in Damaskus stationierten Missionare der Church Missionary Society, die die Pläne der Amerikaner als Konkurrenzkampf empfinden. Die einheimischen Protestanten in Damaskus sind unzufrieden mit den dortigen Missionaren und wenden sich hilfesuchend an die Amerikaner: vgl. Van Dyck an Anderson ('Abeih, 12.11.1847 und 28.7.1851): ABC 16.8.1., Vol. 5 (323 und 324); Anderson an die Syrienmission (Boston, 11.7.1851): ABC 16.8.1., Vol. 8 (4); Anderson an die Syrienmission (Boston, 6.11.1851): ABC 2.1.1., Vol. 15 (HHL).

315 Dieses Verwandtschaftsverhältnis kommt dadurch zustande, dass Thomson 1835 die Witwe des englischen Konsuls Peter Abbott heiratet, deren Tochter Julia 1842 mit Van Dyck vermählt wird: vgl. Jessup (1910a), 107.

316 Anderson an die Syrienmission (Boston, 11.7.1851): ABC 16.8.1., Vol. 8 (4).

317 Van Dyck an Anderson (Sidon, 11.2.1852): ABC 16.8.1., Vol. 5 (326).

318 Ebd. Aus einem Rundschreiben Andersons an die Syrienmission vom 1. Oktober 1851 geht hervor, dass Van Dycks Gehalt trotz der Einwände $\$ 775$ betragen wird. Im Vergleich dazu erhält Eli Smith als Leiter der Syrienmission \$ 1000: ABC 16.8.1., Vol. 2. 
Vorbereitungen treffen, d.h. eventuell eine zusätzliche Beschäftigung annehmen könne. ${ }^{319}$

1857 muss Van Dyck Sidon verlassen, um nun die Übersetzung der Bibel in Beirut fortzusetzen. Er hätte gern von Sidon aus gearbeitet, jedoch erweist sich das als unmöglich. Van Dycks und Thomsons Nachfolger in Sidon, William Eddy, hat schließlich große Schwierigkeiten, Zugang zu den dort lebenden Menschen zu finden, die Van Dyck buchstäblich verehren. ${ }^{320}$ Nur ungern verlässt der Missionar und Arzt seinen Posten im Süden des Landes, obwohl er weiß, wie wichtig der kommende Arbeitsauftrag in Beirut ist, und dass allein er die Übersetzungsarbeit fortführen kann: „I have left a pleasant residence, an interesting field, a delightful work, for the whirl of the multitude, the case hardened and the dusty roads and lanes of Beirut. Neither personally nor as regards my family am I pleased with the change. “" ${ }^{\text {“21 }}$ Beirut als kulturelles Ballungszentrum Syriens wird Van Dyck schließlich die Möglichkeit bieten, sich weiter zu entfalten und mehr als ein Missionsarzt zu sein.

Mit Van Dycks neuem Aufgabenbereich ist auch die Leitung der American Mission Press verbunden und es liegt nun an ihm, weiterhin für die Aufrechterhaltung der Druckerei zu kämpfen, die der American Board eigentlich schließen möchte. Allein die Fortsetzung der Bibelübersetzung kann, wie bereits dargestellt, die Existenz der Druckerei für die nächsten Jahre rechtfertigen. Doch Van Dyck erkennt schon 1857 die aussichtlose Situation: „I hope the time is not far distant when we shall be able to dispose of the whole printing establishment and have all our work of

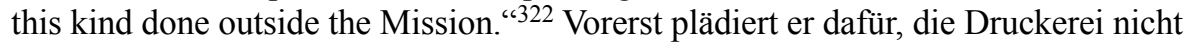
in die Berge zu verlegen, wie es der ABCFM plant. „The press is at present and for years has been, the only hold we have upon Beirut." ${ }^{623}$ Sie ist zudem das einzige Mittel, das die amerikanische Mission von anderen Missionen abhebt. ${ }^{324}$ Anderson und das Prudential Committee lassen sich davon nicht beirren, die Druckerei wird kaum mehr finanziell unterstützt, einen großen Teil der Finanzierung der Druckausgaben leisten nun die europäischen und amerikanischen Bibelgesellschaften. ${ }^{325}$ Den Missionaren gehen die Bücher aus. Es kommen Anfragen aus dem In- und Ausland, Lehrbücher wie Grammatiken, Geografiebücher oder Lesefibeln sind fortwährend ausverkauft. ${ }^{326}$ Die neue Bibelübersetzung kann zudem nur gedruckt werden, wenn

319 Van Dyck an Anderson (Sidon, 11.2.1852): ABC 16.8.1., Vol. 5 (326).

320 „Without doubt they are, for the present, disappointed and grieved at Dr. Van Dyck's removal“, so Eddy im MH 54 (1858), in: ROS 4, 299.

321 Van Dyck an Anderson (Beirut, 31.10.1857): ABC 16.8.1., Vol. 5 (344).

322 Van Dyck an Anderson (Beirut, 31.10.1857): ABC 16.8.1., Vol. 5 (344). Etwa Ende des 19. Jh.s wird die Amerikanische Druckerei von einem unabhängigen Geschäftsmann geleitet, gehört jedoch weiterhin der Mission: vgl. Jessup (1910a), 631.

323 Van Dyck an Anderson (Beirut, 31.10.1857): ABC 16.8.1., Vol. 5 (344).

324 Van Dyck an Anderson (Beirut, 14.6.1862): ABC 16.8.1., Vol. 7.2. (498).

325 Van Dyck an Clark (Beirut, 25.1.1868): ABC 16.8.1., Vol. 7.2. (515): „The Board has given us the pittance of $\$ 1000$ perhaps sometimes much less [...] we have never had enough to keep alive anything more than a miserable one."

326 Van Dyck an Anderson (Beirut, 24.7.1861): ABC 16.8.1., Vol. 7.2. (495): „But as there seems little prospect of enlarging, can we not be kept going at least at the rate at which we have been 
eine neue Druckerpresse angeliefert wird, da die alte fast nur noch Fehldrucke produziert. $^{327}$ Van Dycks Bitten und verzweifelte Fragen (,What shall we do?“6) ${ }^{328}$ finden kein Ende. Aus Verzweiflung wird Provokation: „Cut down! - Cut down!“, so zitiert er die Aufforderungen des Board, die Druckereiaktivitäten herunterzufahren. Die Druckerei darf vom Verkauf eingenommenes Geld nicht ohne Genehmigung für den Druck neuer Bücher ausgeben. Van Dyck äußert sich 1864 zynisch, wer es schon gemerkt hätte, wenn das Geld einfach für dringend benötigte Bücher ausgegeben worden wäre. Er hakt nach: ,[W]ill the P[rudential] C[ommittee] give the permission asked and allow us to print one Hymn Book with clear consciences; or shall we have to do it without such permission and guilt our consciences as we best can?“329 Die Vorgehensweise des ABCFM ist für Van Dyck nicht mehr nachvollziehbar. Die Missionierung und die Bildungsarbeit vor Ort können ohne die theologischen Bücher, Bibeln und Gesangbücher nicht fortgeführt werden. In weiser Voraussicht erkennt Van Dyck, dass letztlich die Druckarbeit der Amerikaner alle Bemühungen der Syrienmission überdauern werde: ${ }^{330},[\mathrm{~B}] \mathrm{y}$ the end of another quarter of a century, the only means the American Board will have for impressing the then living and the future generations of the Arabic speaking races will be the Christian literature which it has been and shall be the means of producing. "331

Mit Beendigung der Bibelübersetzung bietet sich für Van Dyck die Möglichkeit, im Zuge eines USA-Aufenthaltes von 1865 bis 1867 Abstand von der Syrienmission und ihren Problemen zu nehmen. Während er die Anfertigung der Metallplatten für die arabische Bibel in New York beaufsichtigt, nimmt er nebenbei einen Lehrauftrag am Union Theological Seminary in New York für Hebräisch an. Zudem bringt er sein medizinisches Wissen auf den neuesten Stand und promoviert darüber hinaus im Fach Theologie am Rutgers College in New Jersey. ${ }^{332}$ Im Union Theological Seminary ist man sehr angetan von Van Dyck und es wird ihm eine Professur angeboten. Nach zwei Jahren Abwesenheit wird ihm jedoch eines klar: „I have left my heart in Syria and thither I must return. " ${ }^{333}$ Schließlich ist man in Syrien schon seit einiger Zeit in Sorge, Van Dyck kehre nicht mehr zurück und entscheide sich stattdessen für eine andere Anstellung in den USA. Der schwache Zustand der Mission und die niederdrückende Situation machten es unabdingbar, dass Van Dyck in Syrien präsent sei, so die Missionare in einem Brief von $1866 .{ }^{334}$

moving for several years past. Quite a number of our standard works which are daily called for are out of print $\&$ we have not the means to issue new editions."

327 Van Dyck an Anderson (Beirut, 15.5. und 14.6.1862): ABC 16.8.1., Vol. 7.2. (497 und 498).

328 Van Dyck an Anderson (Beirut, 24.7.1861): ABC 16.8.1., Vol. 7.2. (495).

329 Van Dyck an Anderson (Beirut, 30.8.1864): ABC 16.8.1., Vol. 7.2. (501).

330 Ende des 19. Jh.s steht die Druckerei besser da denn je. William Eddy berichtet stolz in einer Dankesrede zu Van Dycks fünfzigjährigem Jubiläum in Syrien, dass die Druckerei mittlerweile vier dampfbetriebene und sechs handbetriebene Druckerpressen unterhält: vgl. Presbyterian Church in the USA (1890), 290.

331 Van Dyck an Anderson (Beirut, 30.8.1864): ABC 16.8.1., Vol. 7.2. (501).

332 Van Dyck an Clark (New York, 17.4.1867): ABC 16.8.1., Vol. 7.2. (514); Union Theological Seminary (1937), xxx.

333 Jessup (1910a), 108.

334 Clark an Van Dyck (Boston, 15.8.1866): ABC 2.1.1., Vol. 31 (HHL). 
Als Van Dyck schließlich 1867 zurückkehrt, bahnen sich neue Diskrepanzen mit der Leitung des ABCFM an. Die Missionsgesellschaft will das von Mihāâ̄l 'Aramān ${ }^{335}$ geführte Mädcheninternat, das von der Syrienmission gefördert wird, jedoch ab 1867 finanzielle und personelle Probleme hat, wieder ,re-amerikanisieren“, wie es Van Dyck nennt. Die einheimische Schule, deren Leitung und Lehrerschaft aus Syrerinnen und Syrern besteht und sich selbst finanziert, soll nun vom American Board gefördert und mit amerikanischem Lehrpersonal ausgestattet werden. Van Dyck hält dem entgegen:

Then it's to come back an Americanized school - supported in large part at least by the Board? [...] I call it a failure, and I'd rather shut up or give the building to the Syrian Protestant College than to try to make an Americanized female boarding school of it. [...] If we can do anything towards making them support their own institutions let us do it. ${ }^{336}$

Die amerikanische Führung einer Bildungsinstitution sei keine Garantie für Erfolg, so Van Dyck weiter. Schließlich habe De Forests Mädcheninternat aufgrund des Misserfolgs 1854 ebenfalls schließen müssen. Der ABCFM zeigt sich kompromissbereit: Der Fortbestand der Unabhängigkeit des Internats wird durch zusätzliche Spendengelder aus den USA und von durch Syrien reisenden Touristen unterstützt. Das einheimische Lehrpersonal wird zwar mit wenigen europäischen bzw. amerikanischen Lehrenden ergänzt, Arabisch bleibt aber Unterrichtssprache. Nach langjähriger Unabhängigkeit wird die Mädchenschule schließlich in die Obhut des Presbyterian Women's Board of Missions gegeben. ${ }^{337}$

Vermutlich ist Van Dyck erleichtert darüber, dass sich ihm mit der neuen Anstellung am Syrian Protestant College, wo er zusammen mit John Wortabet seit Ende 1867 das medizinische Institut aufbaut, neue berufliche Perspektiven eröffnen. Trotz eines klärenden Gesprächs im Jahr 1867 mit dem seit 1866 amtierenden, neuen Sekretär Nathaniel Clark in den USA über Van Dycks zusätzliche Gehaltsbezüge am College, ${ }^{338}$ sieht er sich 1869 erneut mit dem Vorwurf konfrontiert, zu viel Gehalt vom SPC zu beziehen. Van Dyck kündigt an, dass er fortan am College mehr arbeiten werde, wenn ihm die ohnehin schon geringe Bezahlung vom ABCFM gekürzt werde. ${ }^{339}$

Van Dyck hat von der Syrienmission weitaus mehr erwartet und ist in vielerlei Hinsicht enttäuscht worden. Die Missionsarbeit in Syrien habe ihm viel bedeutet, wie er in seinem Abschiedsbrief an die Verwaltung des American Board 1869 schreibt. ${ }^{340}$ Auf die Frage hin, ob er die Verbindung zum ABCFM beenden und sich gänzlich dem SPC widmen möchte, antwortet er „No! I have served the Board $\underline{30}$ years [...] and I hope to die in its service." ${ }^{341}$ Sollte Van Dyck Dissonanzen ver-

335 Siehe Anhang II, Nr. 9.

336 Van Dyck an Clark (Beirut, 25.1.1868): ABC 16.8.1., Vol. 7.2. (515).

337 Jessup (1910a), 225-226. Von 1868 bis 1895 übernimmt Miss Eliza D. Everett die Leitung des Female Seminary, später American School for Girls: vgl. Bliss (1993), 237 (Nr. 16).

338 In der Tat bittet Van Dyck Bliss ausdrücklich um weniger Gehalt als seine anderen Kollegen am College. Statt \$ 1000 erhält er \$ 800: vgl. 'Ağulūnī (1964), 6.

339 Van Dyck an Clark (Beirut, 24.2.1869): ABC 16.8.1., Vol. 7.2 (519).

340 Van Dyck an Clark (Beirut, 31.8.1870): ABC 16.8.1., Vol. 7.2. (520).

341 Ebd. 
spüren, so weiß er, Haltung zu bewahren. Fest steht, dass der Missionary Herald bei der Wiedergabe von Van Dycks Abschiedsbrief in der Ausgabe von 1870 einen wichtigen Satz auslässt: Man liest dort „Now the tie is severed! ... “342 In der Tat fügt Van Dyck im Brief an den Sekretär Clark an: ,... and the question of remaining in connection with the Mission is an open one. "343

1870 berichtet Daniel Bliss, dass Van Dyck nun in der Lage sei, eine volle Professorenstelle am Syrian Protestant College anzunehmen, was zeigt, dass Van Dycks Arbeitgeber nun nicht mehr die Syrienmission sein wird. ${ }^{344}$ Er leitet die American Mission Press bis Anfang der 1870er Jahre und kommt hin und wieder seinen Aufgaben als ordinierter Pfarrer nach. ${ }^{345}$ Die Umstände bedeuten jedoch keinen Kontaktabbruch mit der Syrienmission; dort weiß man seine Dienste und seine Leistungen für den Bildungsbereich durchaus zu schätzen.

\section{Die Vollendung der arabischen Bibel}

Während Eli Smith in der ersten Generation amerikanischer Missionare sein sprachliches Talent beweist, führt Van Dyck in der zweiten Generation dieses Erbe weiter und perfektioniert seine Fertigkeiten in der arabischen Sprache. Zwischen 1840 und 1857 studiert er Arabisch bei Nāṣîf al-Yāziğī, Būṭus al-Bustānī sowie Yūsuf al-Asīr, seine Frau Julia vermittelt ihm Kenntnisse in der Umgangssprache. ${ }^{346}$ Van Dyck beherrscht insgesamt zehn Sprachen, darunter Syrisch, Hebräisch, Griechisch, Französisch, Italienisch und Deutsch. ${ }^{347}$ Seine Studenten werden später über ihn sagen, dass er immer ein Notizheft bei sich hatte, in dem sich Eintragungen von ihm und Nāṣîf al-Yāziğī von arabischen Qasiden und Poesie-Auszügen befanden. Diese vermag Van Dyck zu verschiedenen Anlässen regelmäßig wiederzugeben. ${ }^{348}$

Es verwundert daher nicht, dass die Mission nach Smiths Tod Van Dyck dazu auserkoren hat, die Übersetzung der Bibel zu beenden. Van Dyck war Smiths Lieb-

342 MH 66 (1870), in: ROS 5, 254.

343 Van Dyck an Clark (Beirut, 31.8.1870): ABC 16.8.1., Vol. 7.2. (520).

344 SPC Jahresbericht (24.6.1870): ABC 16.8.2., Vol. 2, 14. Makdisi (2010, 46) kommentiert dazu: ,[he] repudiated what he saw as missionary arrogance“.

345 Aufgrund von Van Dycks angeschlagener Gesundheit berät man am SPC 1871 darüber, ihn von den Pflichten in der Druckerei zu entbinden: vgl. „Minutes of General Faculty“ (15.11.1871): AA.3.4.2. Im Jubiläumsbericht der American Mission Press von 1923 gibt es widersprüchliche Aussagen darüber, bis wann Van Dyck die Druckerei tatsächlich leitet. In der Statistik wird er von 1857 bis 1870 als Leiter aufgeführt (PBCFM, 1923, 39). Im geschichtlichen Überblick des Rev. March berichtet dieser von seiner Begegnung mit Van Dyck im Jahr 1873 im neu errichteten Druckereigebäude. Van Dyck befand sich in seinem Büro und war mit Rechnungen, Korrespondenzen, Korrekturlesen und Schreiben beschäftigt (ebd., 6-7).

346 Jessup (1910a), 106; Tibawi (1967), 265; Kades (1997), 55.

347 Șarrūf/Nimr (1896), 2; Jessup (1910a), 73.

348 Aus einer Rede von Y. Șarrūf anlässlich der Einweihung der Büsten von Van Dyck und Wortabet 1913, in: Al-Kullīya 4/6 (April 1913), zitiert in: Hūurī (1992), 177. Vgl. Jessup (1910a), 107: „He soon mastered the best productions of Arabic poetry and literature, and by his wonderful memory could quote from the poetry, proverbs, history and science of the Arabs in a way which completely fascinated the Syrian people." 
lingsschüler und der einzige Autor, dessen Arbeiten durch die Druckerei gingen, ohne von Smith Korrektur gelesen zu werden. ${ }^{349}$ Anderson schlägt schon 1851 vor, dass Van Dyck aufgrund seiner Vertrautheit mit arabischen Dichtern bei der Übersetzung der poetischen Bibeltexte wie den Psalmen oder Hiob mithelfen könnte. ${ }^{350}$ Jedoch steigt Van Dyck, der als Missionar und Missionsarzt andere Aufgaben zu erfüllen hat, erst nach Smiths Tod in das Übersetzungsprojekt ein. Statt Nāṣîf alYāziğî, mit dessen Leistungen Smith zuletzt nicht mehr zufrieden ist, und Būtrus al-Bustānī, der sich nun anderer Arbeit widmet, stellt Van Dyck den muslimischen Gelehrten Yūsuf al-Asīr ein. Der aus Sidon stammende Syrer studierte zuvor Jura sowie Islamische Theologie an der Kairoer Al-Azhar Universität und bewegt sich in den Gelehrtenkreisen Ägyptens und Syriens. Er arbeitet darüber hinaus eine Zeit lang für die osmanische Regierung sowie als Arabischprofessor, u. a. an Bustān̄̄s 1862 gegründeter Nationalschule. ${ }^{351}$ Als einer der ersten muslimischen Intellektuellen schließt er sich in Syrien der christlich dominierten Kulturbewegung an. ${ }^{352}$ Van Dyck, der eine hohe Meinung von al-Asīr und seinen sprachlichen Fertigkeiten hat, ${ }^{353}$ entscheidet sich bewusst für einen muslimischen Mitarbeiter: „I preferred a Muslim to a Christian, as coming to the work with no preconceived ideas of what a passage ought to mean, and as being more extensively read in Arabic." ${ }^{“ 354}$ Es ist al-Asīrs Aufgabe, die von Van Dyck übersetzten Texte Korrektur zu lesen und ausländische Ausdrucksweisen umzuformulieren. ${ }^{355}$ Neben al-Asīr, der Van Dyck bis zur Vollendung der Bibel assistiert, ${ }^{356}$ werden vermutlich noch weitere, namentlich nicht genannte Korrekturleser beschäftigt. 1861 schreibt Van Dyck an Anderson, dass er angesichts der mühevollen Arbeit, mehr Helfer einstellen würde, wenn er könnte. 357

Smiths Entwurf des Neuen Testaments ist, wie bereits beschrieben, nahezu unbrauchbar, da sich dieser nicht am textus receptus orientiert. ${ }^{358} \mathrm{Um}$ die Arbeit seines Vorgängers dennoch zu würdigen, erhält Van Dyck die Erlaubnis der American Bible Society, die das Übersetzungsprojekt finanziell unterstützt, Handschriften - seien es griechische, syrische oder arabische -, die vom griechischen Text abweichen, in Fußnoten vermerken zu dürfen: „I availed myself largely of

349 Hall (1885), 285. An seinem Sterbebett zeigt sich Smith äußerst dankbar angesichts der Fürsorge und der regelmäßigen Besuche durch Van Dyck: „Obituary Notice of Rev. Eli Smith D. D.“": ABC 16.8.1., Vol. 5 (227).

350 Anderson an die Syrienmission (Boston, 17.7.1851): ABC 16.8.1., Vol. 8 (4).

351 Zaydān (1903), 149.

352 Binay (2012b), 82; Salibi (1965), 145.

353 Ebd.

354 Hall (1885), 280.

355 Sa'di (1937), 28. Aus Van Dycks Briefen an den ABCFM bzw. offiziellen Berichten über die Bibelübersetzung geht nichts Genaueres über Yusūf al-Asīr und seine Mitarbeit hervor. Selbst Ğurğĩ Zaydān, Historiker, Literat und ehemaliger Student von Van Dyck, erwähnt in einer Kurzbiografie über Yūsuf al-Asīr nichts über seine Mitarbeit bei der Bibelübersetzung: ders. (1903), 148-150.

356 Jessup (1910a), 106.

357 Van Dyck an Anderson (Beirut, 24.7.1861): ABC 16.8.1., Vol. 7.2. (495).

358 Siehe Abschnitt II.1.4. 
this permission. “359 Somit können aktuelle Forschungsergebnisse der Textkritik, die Smith unbedingt berücksichtigen wollte, eingearbeitet werden. Smiths Methodik, Übersetzungsentwürfe an verschiedene Adressaten zu senden, wird von Van Dyck übernommen. Somit erhält ein Kreis von etwa dreißig Personen, darunter sämtliche Missionare in der arabischen Welt, einheimische Gelehrte und Arabisten in Deutschland, regelmäßig Korrekturbögen. ${ }^{360}$ Van Dyck bemerkt dazu in einem Brief an die American Bible Society: „These all come back with notes and suggestions, every one of which must be well weighed. Thus a critic, by one dash of his pen, may cause me a day's labour, and not till all is set right, can the sheet be printed. "361 Nach neuesten Untersuchungen der Arabistin SARA BINAY stimmt Van Dycks Übersetzung der Evangelien sogar zu über 95 Prozent mit dem Entwurf von Smith überein, mehr als zuvor angenommen: „There is a proof that Cornelius Van Dyck really reread their translation but only in a few cases did he have to implement corrections, some based on his comparison with the recognised Greek text and some in matters of Arabic style. “362

Was den Stil des Arabischen angeht, so hat Smith bereits die Weichen gestellt: Unter den Missionaren sind sich alle einig, dass ein einfaches, pures Arabisch, ,free from foreign idioms“ die beste Entscheidung sei. Es gibt zwar Vorschläge, den Stil dem Koranarabisch anzugleichen ,i.e., Islamic, adopting idioms and expressions peculiar to Mohammedans“, jedoch haben sich alle christlichen Gelehrten dagegen ausgesprochen, so Van Dyck. ${ }^{363}$ Es geht den Verantwortlichen der neuen Bibelübersetzung wohl auch darum, anstatt der poetischen und sehr komplexen arabischen Sprache des Koran, die nur Gebildeten zugänglich ist und deren Worte vielfach veraltet sind, durch ein einfacheres und für jeden verständliches Arabisch zu ersetzen. Einzig in den poetischen Teilen der Bibel entscheidet man sich für einen höheren Sprachstandard, damit sie dem Stil des griechischen oder hebräischen Originaltextes entsprechen. ${ }^{364}$

Im Frühjahr 1860 geht das Neue Testament in den Druck. Es wird Van Dyck von verschiedenen Personen geraten, auch eine vokalisierte Edition des Neuen Testaments herauszugeben. Grund ist nicht nur die Anlehnung an den vokalisierten Koran, um leichter Muslime zu erreichen. Durch den Gebrauch des vokalisierten Textes in den Schulen wird auch die korrekte Aussprache der Wörter gefördert. ${ }^{365}$

359 Hall (1885), 279.

360 Über die Adressaten zu Smiths Zeiten gibt es keine Informationen. Zu den deutschsprachigen Arabisten zählen Prof. Fleischer (Leipzig), Prof. Rödiger (Halle, Berlin), Prof. Flügel (Dresden) sowie der Bibliothekar der Wiener Hofbibliothek Dr. Behrnauer: „Dr. Van Dyck’s History of the Arabic Translation of the Scriptures, March 7th, 1885“, in: Smith / Van Dyck (1900), 28.

361 Zitiert in: Jessup (1910a), 75.

362 Binay (2012b), 81. Hall hatte demgegenüber 1885 noch geschrieben: „From various sources I have learned that the New Testament translation of Dr. Eli Smith was actually not used by Dr. Van Dyck."Vgl. ders. (1885), 282.

363 „Van Dyck’s History, 1885“, in: Smith / Van Dyck (1900), 28.

364 Ebd.

365 Van Dyck and Rev. Doct. Brigham (Beirut, 31.12.1857): ABC 16.8.1., Vol. 5 (345). Vgl. dazu Sa'di (1937), 29: „In works of great importance, such as the Qur’ān (or Korán), or of especially 
Die Weiterarbeit am Alten Testament erweist sich auch für Van Dyck als mühselige Aufgabe. Aus diesem Grund reist er 1860 nach Österreich und Preußen, um mit Orientalisten in Wien, Leipzig, Dresden und Halle über Textschwierigkeiten zu sprechen. ${ }^{366}$ Am 23. August 1864 kann Van Dyck schließlich die Übersetzung des letzten Satzes von Maleachi abschließen. Sein Sohn Edward wird später berichten, dass er an diesem Abend auf seinen Vater wartete, der auf den Balkon des Hauses getreten sei und gesagt habe: „Edward, it is finished. Thank God! What a load is off me! I never thought I was going to live to finish this work.“"367

Im März 1865 ist die erste Gesamtausgabe der arabischen Bibel gedruckt. Anhand der Anordnung der Seiten ist bei dieser Ausgabe sogar noch zu erkennen, an welcher Stelle Eli Smiths Übersetzung aufhört und Van Dycks beginnt. ${ }^{368}$ Im Sommer 1865 reist Van Dyck nach New York, um mit Hilfe des Tiefdruckverfahrens ${ }^{369}$ die Herstellung von Metallplatten für einen schnelleren Druck der Bibel in Auftrag zu geben. Somit können die Platten beliebig oft vervielfacht und wieder verwendet werden - der Verbreitung der Bibel steht nun nichts mehr im Weg. Auch die British and Foreign Bible Society erhält ein Duplikat der Platten. Bis zum Jahr 1910 wird es ca. 32 Editionen und über 900000 gedruckte Exemplare der Smith-Van DyckBibel geben. ${ }^{370}$ Die gedruckte arabische Bibel der Amerikaner gehört zur meist gelesenen Version der Heiligen Schrift in ihrer Zeit. ${ }^{371}$ Wie bereits in Abschnitt II.1.4 erläutert wurde, kann die Bibel letztlich nicht als klassische Übersetzung aus den ursprünglichen Sprachen gesehen werden, da mit Rücksicht auf arabische Manuskripte bereits bestehende Phraseologien eingearbeitet wurden und somit dem Leser aufs Neue begegnen.

Im 19. Jh. gibt es sogar zwei weitere arabische Bibelübersetzungen, die jedoch längst nicht so beliebt sind wie die Bibel der Amerikaner: Etwa um dieselbe Zeit wie Eli Smith beginnen Fāris al-Šidyāq und der Engländer Samuel Lee im Auftrag der Church Propagation Society (vornehmlich) die englische King James Bibel in die arabische Sprache zu übersetzen. Obwohl die Version 1851 und 1857 in London gedruckt wird, findet sie kaum Gebrauch. ${ }^{372} 1881$ bringen die Jesuiten ebenfalls eine Übersetzung heraus, die überwiegend von Ibrahīm al-Yāziğì, dem

high quality, such as the acknowledged peaces of Arabic literature, all the vowel-points, short as well as long, must be fully indicated."

366 Sa'di (1937), 28-29. Die Kontakte zu den deutschen Orientalisten werden auch durch Van Dycks Mitgliedschaft in der DMG gepflegt. Der Austausch mit den deutschen Orientwissenschaftlern kommt jedoch nach der Übergabe der Mission an den Presbyterian Board zum Erliegen: vgl. Kawerau (1958), 422.

367 Hall (1885), 286.

368 Ebd., 280-281.

369 Das von Van Dyck als electrotype printing bezeichnete Verfahren basiert auf der Technik der Radierung. Mit Hilfe von manuellen und elektrischen Werkzeugen werden die jeweiligen Zeichen in eine Metallplatte aus Kupfer oder Zink eingeritzt, die sich später in einer säurehaltigen Flüssigkeit vertiefen. Vgl. Grabowski/Fick (2010), 103-106.

370 Jessup (1910a), 77.

371 Glaß (1998a), 26. Nach seiner Rückkehr aus den USA 1867 äußert Van Dyck: „No literary work of the century exceeds it in importance and it is acknowledged to be one of the best translations of the Bible ever made“: vgl. Jessup (1910a), 77.

372 Hall (1885), 279. 
Sohn des Gelehrten Nāṣịf al-Yāziǧñ, erarbeitet wird. Van Dyck kann jedoch kaum Unterschiede zwischen al-Yāziğīs Text und seiner Übersetzung erkennen: „It is a fair translation generally, and only differs in very slight particulars from mine (so far as I have traced it), [...] and that only for the sake of differing from the Protestant Version." ${ }^{373}$ Doch Van Dyck liegt falsch. Die jesuitisch-arabische Bibel ist keine Revision der Smith-Van Dyck-Bibel, sondern eine eigene Übersetzung. Auch wenn es viele Ähnlichkeiten zur evangelischen Bibel gibt, ${ }^{374}$ unterscheidet sie sich in zahlreichen Textstellen und weist ein fließendes, anspruchsvolleres Arabisch auf. Die Version wird zwar vor allem von Intellektuellen und Gelehrtenkreisen bevorzugt, jedoch wird die sprachliche Nähe zu den Originaltexten zugunsten einer besseren Ausdrucksweise vernachlässigt, sie gilt als „,freier und weniger textgebunden“"375.376

Selbst in den orthodoxen Kirchen Syriens und bei den Kopten in Ägypten wird die amerikanische Bibelübersetzung übernommen. ${ }^{377}$ Die maronitische Kirche hingegen verwendet bis in die heutige Zeit die Fassung der Jesuiten. Die Smith-Van Dyck-Bibel gilt auch heute noch als sogenannter textus receptus der Protestanten im Libanon, in Syrien und Palästina/Israel. ${ }^{378}$ Obwohl Van Dyck fortwährend darauf besteht, Smith bei jeder Gelegenheit als Autor zu nennen, ${ }^{379}$ geraten Smiths Pionierleistungen zunehmend in Vergessenheit. Vor allem aber die Zusammenarbeit mit den syrischen Gelehrten al-Yāziğḡì, al-Bustānī und al-Asīr, die einen nicht unerheblichen Teil zur Perfektionierung der Übersetzung beigetragen haben, findet selten Erwähnung. ${ }^{380}$ Die arabische Bibelübersetzung der amerikanischen Missionare wird schließlich gemeinhin als „Van Dyck-Bibel“ bekannt.

\section{Al-Hakīm}

Viele arabische Autoren, die über Van Dycks Leben und Werk geschrieben haben, nennen ihn al-Hakim, den Weisen. Traditionell bezieht sich dieser Titel auf Mediziner, die auch in anderen Naturwissenschaften bewandert sind, wie es im Mittelalter oft der Fall war. Van Dyck, der sich in Medizin, Chemie, Astronomie, Mathematik, Theologie sowie in den Rechtswissenschaften auskennt, kann also mit Recht diesen Titel tragen.

Zweifelsohne liegen Van Dycks größte Leistungen im wissenschaftlichen Bereich und damit im rationalen Denken. Er habe sich dabei, so sein späterer Schüler

373 Van Dyck in: ebd., 280.

374 Binay (2012a), 13-14.

375 Glaß (1998a), 27.

376 Thompson (1956), 29-31.

377 Jessup (1910a), 78: Der griechisch-orthodoxe Priester und Gelehrte Ğubrīn Ğubara äußert bei einer öffentlichen Rede 1865: ,they have given us a translation so pure, so exact, so clear, and so classical, as to be acceptable to all classes and sects“.

378 Grafton (2009), 88.

379 Șarrūf/Nimr (1896), 4; Jessup (1910a), 109.

380 Binay (2012b), 83-84. 
Ğurğĩ Zaydān, niemals von seinem religiösen Glauben beeinflussen lassen ${ }^{381}$ Die Erkenntnis der Syrienmission, dass es im Bildungssektor in Syrien an vielerlei Materialien fehle, macht sich Van Dyck zu eigen. Wie kein anderer vor ihm setzt er sich für die Förderung der naturwissenschaftlichen Bildung ein und ist bis heute ein vielgelesener Name in arabischen Historiographien über das 19. Jh.

1853 wird Van Dycks Artikel über die gegenwärtigen Bedingungen des Arztberufes in Syrien im JAOS veröffentlicht. ${ }^{382}$ Darin zeigt sich, dass er sich ausgiebig mit der Geschichte der arabischen Medizin ${ }^{383}$ befasst und fortwährend nach Manuskripten klassischer Gelehrter wie Avicenna, Abucalsis, Avenzoar, Averroes sowie Rhazes forscht. ${ }^{384}$ Obwohl Avicenna bei arabischen Medizinern immer noch sehr beliebt ist, kann Van Dyck keine vollständigen Manuskripte seiner Werke ausfindig machen. ${ }^{385}$ Anders verhält es sich mit Übersetzungen griechischer Gelehrter wie Hippokrates, Aristoteles, Paracelsus sowie Galenos, die sich ebenfalls großer Beliebtheit erfreuen. Van Dyck bemerkt dazu kritisch, es komme in Syrien häufig vor, dass allein schon der Besitz solcher Manuskripte den Besitzenden zum Arzt mache. ${ }^{386}$ Das Wissen um die Medizin in der arabischen Welt befindet sich in einem desolaten Zustand. ${ }^{387}$ Unwissenheit, falsche Behandlungen und der Aberglaube, dass eine posthume Autopsie zur Verstümmelung des Toten führe, obwohl sie über das Krankheitsbild genau aufklären könnte, ${ }^{388}$ begründen Van Dycks eigene Mission, der medizinischen Wissenschaft zu neuem Aufschwung zu verhelfen. „[T]he West has plundered the East of a large part of its literature“, so Van Dyck in seinem Artikel für das JAOS. Zweifelsohne sind die Schätze arabischer Gelehrter durch den Neudruck in europäischen Druckereien nicht verloren gegangen und für jeden in den Bibliotheken Europas zugänglich. ${ }^{389}$ Jedoch kann man von einer „Ausplünderung“ sprechen, da diese Neuauflagen nicht mehr den Weg zurück in die arabische Welt gefunden haben. Die Vernachlässigung von Bildung unter osmanischer Herrschaft hat ebenfalls ihren Teil dazu beigetragen. Erst unter Muḥammad 'Ālī beeinflussen die Franzosen im beginnenden 19. Jh. die Entstehung der ersten Medizinschulen in Ägypten. Absolventen übersetzen bis Mitte des 19. Jh.s über 60 renommierte, europäische Werke in die arabische Sprache. ${ }^{390}$ Auch wohlhabende Syrer studieren an diesen Hochschulen, doch die Unwissenheit der Bevölkerung

381 Philipp (1979), 34.

382 Van Dyck (1853), 561-591.

383 Er beschäftigt sich hierfür u. a. mit dem Werk von Ibn Hallikān „Memoirs of the eminent men of Islamism“: vgl. ebd., 562.

384 Ebd., 561.

385 In seinem Besitz befindet sich eine arabische Ausgabe von Avicennas „Kanon“, die 1593 in Rom gedruckt wurde: aus einer Rede von Y. Șarrūf anlässlich der Einweihung der Büsten von Van Dyck und Wortabet 1913, in: Al-Kullīya 4/6 (April 1913), zitiert in: Huūrī (1992), 177.

386 Van Dyck (1853), 570.

387 Auch in Amerika und Europa sind medizinische Erkenntnisse auf einem Stand, der noch nicht als moderne Medizin bezeichnet werden kann. Selbst die Missionsärzte haben in vielen Fällen noch den Aderlass praktiziert: vgl. Daniel (1964), 82.

388 Van Dyck (1853), 574-578.

389 Ebd., 569.

390 Sa'di (1937), 22. 
über Medizin bleibt bis Mitte des 19. Jh.s bestehen. Zudem sind die Übersetzungen der Ägypter laut Van Dyck noch nicht ausgereift. Man habe sich nicht genügend den arabischen Termini für Krankheiten und medizinische Sachverhalte gewidmet, so Van Dyck. Es werden sowohl westliche Begriffe für Krankheiten eingeführt, die bereits ein arabisches Pendant haben, als auch neue Termini durch die Transliteration oft derart entfremdet, dass sie weder für das europäische, noch arabische Auge wiedererkennbar sind. ${ }^{391}$ Die Einführung lateinischer Begriffe ist zwar unausweichlich, wenn es sich um neue wissenschaftliche Erkenntnisse handelt, für bereits bekannte Sachverhalte bemüht sich jedoch Van Dyck, adäquate arabische Wörter zu finden. ${ }^{392}$ Mit der Herausgabe von al-Rāzīs Manuskript über Masern und Pocken 1872/3 (Kitāb fi l-ğadari wa l-ḥaṣba li l-Rāzî̀) möchte Van Dyck auf die Aktualität des im 9./10. Jh. entstandenen Werkes aufmerksam machen, in dem Behandlungsmethoden beschrieben werden, die in der westlichen Medizin besonders ab dem 19. Jh. wieder Anwendung finden. ${ }^{393}$ Al-Rāzī ist der erste, so Van Dyck in seiner Einleitung, der über diese Krankheiten geschrieben hat. In einem von Van Dyck hinzugefügten kritischen Apparat erläutert er nicht mehr gebräuchliche Ausdrucksweisen, fügt eine Bibliographie von übersetzten, griechischen Werken in die arabische Sprache hinzu, kommentiert die medizinischen Ansichten al-Rāzīs und korrigiert sie gegebenenfalls, wenn sie nicht mehr dem neuesten wissenschaftlichen Stand entsprechen. ${ }^{394}$

Van Dycks Wirken als Autor bezieht sich jedoch nicht nur auf medizinische Werke. In vierzig Jahren verfasst oder übersetzt er etwa 13 theologische Schriften und ca. $23^{395}$ wissenschaftliche Sachbücher ins Arabische, die sich mit Geografie, Geologie, Algebra, Geometrie, Chemie, Physik, Astronomie, Dichtkunst und Dialektik befassen. Nur wenige sind reine Übersetzungen, die meisten sind Sammlungen bereits bekannter und aktueller wissenschaftlicher Fakten, wobei Van Dyck in jeder Einleitung dem Leser seine persönliche Meinung über die

391 Van Dyck (1853), 570.

392 Z. B. ḩunāq (Diphterie): vgl. Ğaḥā (1992). Huūrī (1990a), 108-109: Van Dyck konsultiert etliche arabische Manuskripte, um eine Auswahl von Fachtermini zu treffen.

Eine allgemeine Analyse von Übersetzungsmethoden wissenschaftlicher Terminologie in die arabische Sprache und dabei auftretenden Schwierigkeiten gibt M. S. Elshakry, „Knowledge in Motion: The Cultural Politics of Modern Science Translations into Arabic“, in: ISIS 99/4 (Dezember 2008), 701-730.

393 Van Dyck (1853), 562. Van Dyck erläutert in der Neuauflage von al-Rāzīs Werk, dass man sich in den vergangenen Jahrhunderten von den von al-Rāzī vorgeschlagenen Behandlungsmethoden abgewandt und andere dafür eingeführt habe, die oftmals zum Tod führten. Erst im 19. Jh. sei die Medizin zu den von al-Rāzī beschriebenen Methoden zurückgekehrt: vgl. Hูūrī (1965), 399.

394 Ebd., 398-400.

395 Eine genaue Zahl gibt es nicht, da zum einen seine Autorenschaft in manchen Fällen nicht eindeutig geklärt ist (siehe Anhang I), zum anderen gibt es noch drei weitere Manuskripte, die

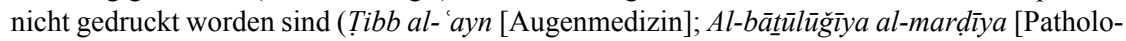
gie zu Krankheiten]; Al-bātūūūğ̌̀ya al- 'àma [Allgemeine Pathologie]: vgl. Hূūrì (1965), 418. Zum Manuskript „Amrād al-'ayn" s. u. Glaß (1998b, 187) spricht von 29 Büchern auf Arabisch und 20 Aufsätzen in arabischen Periodika. 
Wichtigkeit des jeweiligen Buches nahebringen möchte. ${ }^{396}$ Dabei bemüht er sich stets, den bekannten arabischen Sprachschatz mit verschiedenen Wissenschaften in Einklang zu bringen. In seinem 1851 erschienenen Geografie-Lehrbuch Kitāb al-mir'āt al-waḍ̄ya fi l-kurat al-ardīya (wörtl.: „Der klare Spiegel, der die Erde reflektiert", d. i. Klarstellungen zur Geografie) - das im Übrigen auf seine Vorliebe für poetische Buchtitel hinweist - wird diese Intention sehr deutlich: Um Verständnisschwierigkeiten mit neuen Termini zu vermeiden, bietet er häufig Synonyme an (für ğabal al-nār [Feuerberg]: barkān [Vulkan]; für al-bahr al-muhịt [Ozean]: al-ūqūyannuss). ${ }^{397}$ Ausländische Eigennamen werden zum Teil übersetzt, zum Teil transliteriert (nahr al-missīsibī [Fluss Mississipi], ğabal al-alb [Alpengebirge]). In anderen Lehrbüchern wie z.B. „Grundlagen der Chemie“ (Ușūl al-kimīya, 1869) oder „Grundlagen der Astronomie“ (Ușūl 'ilm al-hai' a, 1874) ist er aufgrund seiner Belesenheit in den Werken arabischer Gelehrter des Frühmittelalters in der Lage, bereits bekannte Fachtermini zu belassen (z. B. al-kibrit $=$ Schwefel; al-fidda $=$ Silber; $z i$ 'baq = Quecksilber; 'uțärid = Merkur) und nur die durch Transliteration zu ersetzen, die im arabischen Sprachraum völlig unbekannt sind. ${ }^{398}$ Handelt es sich um ältere, eher unbekannte Formulierungen auf Arabisch, so fügt Van Dyck einen erläuternden Kommentar hinzu. Viele seiner Bücher sind Nachschlagewerke für Schülerinnen und Schüler sowie Studierende. Sie informieren nicht nur über den aktuellen Entwicklungsstand in der Welt der Wissenschaft, sondern referieren auch über Aussagen arabischer Gelehrter aus den vergangenen Jahrhunderten und deuten auf die immer noch bestehende Aktualität ihrer Erkenntnisse hin: In seinem letzten Buch von 1893 über Astronomie ${ }^{399}$ bspw. bemerkt er, dass seine Aufzählung von arabischen Gelehrten, die besonders zur Zeit der Abassiden gelebt haben, nur ein Bruchteil derer sei, die zur Verbesserung der Wissenschaft in der arabischen Welt beigetragen haben. ${ }^{400}$

Anlässlich des 125-jährigen Jubiläums der AUB sowie der Eröffnung der sogenannten „Augenbank“401 im Universitätskrankenhaus 1992, wird Van Dycks Manuskript über Augenkrankheiten (Amräd al- 'ayn) neu herausgegeben. In einem Artikel der Zeitung al-Anbìya ' (1992) über die Veröffentlichung des Manuskripts wird die Genialität des Autors herausgestellt. Van Dyck muss etliche neue Begriffe für die jeweiligen Augenkrankheiten einführen, da er sich auf kein Werk aus früheren Jahrhunderten beziehen kann. Das häufige Auftreten von Augenkrankheiten in der arabischen Bevölkerung macht Van Dyck schon früh auf den Mangel an fachlichem Wissen aufmerksam. Während er sich im Laufe seiner ersten USA-Reise eingehend im Bereich der Mikroskopie weiterbildet und das erste Mikroskop in

396 Hūrī (1965) referiert zu jedem Werk über Van Dycks einleitende Worte.

397 Ebd., 390-391.

398 Ebd., 398, 402.

399 Kitāb ārū' al-țamā min muhāsin al-qubba al-zarqāa' (wörtl.: Den Durst nach der Schönheit des Himmels löschen), siehe Anhang I.

400 Hūūī (1965), 416.

$401 \mathrm{Im}$ Deutschen wird diese Einrichtung als Hornhautbank bezeichnet und meint Zentren für Transplantationen an den Augen. 
Syrien einführt, ${ }^{402}$ finanziert er sich während seines zweiten, zweijährigen Aufenthaltes in New York 1865-67 von dem Gehalt seiner Professur am Union Theological Seminary eine Zusatzausbildung in Ophthalmologie. ${ }^{403}$ Vermutlich entsteht das Manuskript in den Jahren danach, in denen Van Dyck bereits am SPC lehrt. Aus unbekannten Gründen geht es nicht in den Druck, obwohl der Bedarf an solch einem Lehrbuch erwiesenermaßen hoch ist. Bemerkenswert ist Van Dycks Bemühen, den Wert traditioneller Medizinkunde nicht außer Acht zu lassen. Während er ca. vierzig neue Heilmittel auf chemischer Basis zur Behandlung von Augenleiden einführt und die bisher unbekannte Anatomie des Auges beschreibt, setzt er sich auch mit den populären Heilmitteln in Syrien, i. e. Pflanzen und Kräutern, auseinander, um ihren Nutzen zu analysieren. ĞūRĞ ĞAH̄̄ betont in seinem Artikel von 1992, dass sich Van Dycks Sprache und besonders die Fachtermini auf so hohem Niveau befinden, dass das Verständnis nur denen leicht fällt, die sich ausgiebig mit dem Hocharabischen beschäftigt haben. ${ }^{404}$

Durch die Verbreitung von Van Dycks Lehrbüchern innerhalb Syriens und sogar bis nach Ägypten und Persien sowie durch die Generierung von Fachtermini für die arabische Sprache hat der Missionsarzt einige Wissenschaftsbereiche in der arabischen Welt nachhaltig geprägt. Schon im Muqtațaf, der von Van Dycks Schülern Ya' qūb Șarrūf und Fāris Nimr herausgegeben wird, finden sich im ersten Band von 1876/77 bspw. dieselben Abbildungen und chemischen Termini wie in Van Dycks Lehrbuch Ușūl al-kīmīya (1869). ${ }^{405}$ „Beide Publikationen benutzen z.B.:

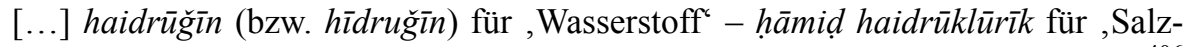
säure‘ [...] tabalwara für , sich kristallisieren' bzw. ,kristallisiert werden' [...].“406 Die wissenschaftliche Zeitschrift sorgt somit für den Transfer wissenschaftlicher Fachtermini in den Sprachschatz eines allgemein gebildeten Lesers. Van Dycks Lehrbücher finden nicht nur in Syrien Gebrauch, selbst in ägyptischen Schulen und an der Al-Azhar Universität in Kairo werden sie gelesen, was darauf zurückzuführen ist, dass die ehemaligen Schüler und Herausgeber des Muqtataf für die Bekanntmachung der neuen Lehrbücher in Ägypten gesorgt haben. ${ }^{407}$

Darüber hinaus gibt es kaum ein syrisches Periodikum von christlichen Herausgebern, das keine Artikel von Van Dyck veröffentlicht. Der Missionsarzt und Wissenschaftler ist ein gern gelesener Autor. Für die 1870 gegründete Zeitschrift al-Ğinān seines jahrelangen Freundes Būtrus al-Bustānī verfasst Van Dyck etliche Artikel und nutzt das enzyklopädisch geprägte Periodikum als Plattform seiner wissenschaftlichen Erkenntnisse in Bereichen wie Chemie oder Biologie. ${ }^{408}$

402 Sa'di (1937), 29; Penrose (1941), 37.

$403 \mathrm{Sa}^{\prime} \mathrm{di}$ (1937), 29.

404 Ğahā (1992), o.S.

405 Glaß (1998b), 193-194; dies. (2004a), 220 (Abb. 20): das „Daniellische Barometer“ aus Van Dycks Chemiebuch (S. 12); ebd., 221 (Abb. 21): die Abbildung des Barometers in al-Muqtațaf 1 (1876/77), 36-37.

406 Ebd., 204: Ebenso die im Geografiebuch erwähnten Begriffe für Ozean und Vulkan (s. o.) werden vom Muqtataf übernommen. Ausführlicher in: Glaß (1998b), 193-194.

407 Sa'di (1937), 36.

408 Vgl. z.B. „Auğuh al-mušābiha beyn al-ḥayawān wa 1-nabāt“ (Äußere Ähnlichkeiten zwischen Pflanzen und Lebewesen), in: al-Ğinān 1 (1870), 10-11; „,Fī bitrūliyūm ay al-kāz“ (Über Petro- 
An keinem anderen Ort in seiner Wahlheimat Syrien hätte sich Van Dyck wissenschaftlich mehr verwirklichen können als am Syrian Protestant College. Zusammen mit John Wortabet baut er das dortige medizinische Institut auf, ${ }^{409}$ George Post stößt später dazu. Zu Anfang lehrt er dreimal in der Woche Pflanzenkunde und Chemie. ${ }^{410}$ Dann kommen Vorlesungen zur Inneren Medizin, Pathologie und Theologie ${ }^{411}$ hinzu, während Edwin Lewis und George Post die Fächer Chemie und Pflanzenkunde übernehmen. 1873 macht Van Dyck eine weitere Leidenschaft zum Beruf und richtet den Lehrstuhl für Astronomie und Meteorologie mit einem von ihm finanzierten Teleskop ein. ${ }^{412}$ In der Beobachtung der Sterne und Vermessung von klimatischen Veränderungen findet Van Dyck Ruhe und Entspannung. ${ }^{413}$

Seit der Gründung des medizinischen Instituts verfügt das College über eine Art Ambulanz, die den Studierenden die Möglichkeit gibt, Praxiserfahrung zu sammeln. ${ }^{414} \mathrm{Da}$ zu dieser Zeit häufig Augenkrankheiten in der Bevölkerung auftreten, kommen sehr viele Patientinnen und Patienten mit den gleichen Symptomen zur Ambulanz des SPC. Dieser Umstand sowie die Unfähigkeit, von weit her angereiste Erkrankte stationär aufzunehmen, veranlassen Van Dyck 1869 dazu, die Errichtung einer Augenklinik vorzuschlagen, die mit dem College verbunden werden soll. Das Brown Ophthalmic Hospital wird noch im selben Jahr mit Hilfe von Spendengeldern aus den USA, die auf Bittstellungen von Van Dyck an Dr. Adams von der Madison Square Church New York zurückzuführen sind, eröffnet. ${ }^{415}$ Van Dyck übernimmt dafür auch die Leitung. ${ }^{416} \mathrm{Ob}$ es überhaupt administrativ und finanziell mit dem College in Verbindung steht, geht aus den Jahresberichten des SPC nicht hervor. Offenbar besteht die Augenklinik nur für kurze Zeit, da Van Dyck 1871 in Kooperationsverhandlungen mit dem seit 1866 bestehenden preußischen Krankenhaus des Johanniterordens ${ }^{417}$ tritt. Es wird ab 1867 von den Kaiserswerther Diako-

leum als Gas), in: ebd., 468-470; „Al-zayt al-Amrikānī“ (Der amerikanische Olivenbaum), in: ebd., 77-79, 112-114, 140-141, 174-175, 208-211.

409 SPC Jahresbericht (24.6.1868): ABC 16.8.2., Vol. 2, 2.

410 Hūūī (1966), 22.

411 Aufgrund der Zusammenlegung der 'Abeih Akademie und des Colleges 1881, hält Van Dyck auch zusätzlich Vorlesungen in Natürlicher Theologie und alttestamentlicher Exegese: vgl. Jes$\sup (1910 b), 496$.

412 Häufig wird Van Dycks Engagement hervorgehoben, für die Einrichtung des chemischen Labors und des Observatoriums einen großen Teil selbst finanziert zu haben. Dies trifft aber auch auf Lehrende anderer Fachbereiche zu. Das junge College hat nicht die finanziellen Mittel für eine professionelle Ausstattung und ist auch auf Spenden und Sammlungen der eigenen Professoren angewiesen: vgl. SPC Jahresbericht (Juni 1869): ABC 16.8.2., Vol. 2, 7. Da sich das Teleskop in Van Dycks Besitz befindet, wird es ihm nach seiner Kündigung 1882 (s. u.) vom Board of Trustees abgekauft: vgl. SPC Jahresbericht (10.7.1883): ABC 16.8.2., Vol. 2, 77.

413 Sa'di (1937), 32.

414 SPC Jahresbericht (24.6.1868): ABC 16.8.2., Vol. 2, 3.

415 Vgl. den Brief von Van Dyck an die Fakultät des Colleges (Beirut, 6.2.1869), zitiert in: SPC Jahresbericht (24.6.1870): ABC 16.8.2., Vol. 2, 14-15.

416 Van Dyck an den Präsidenten und die Fakultät des SPC (6.2.1869), in: SPC Jahresbericht (Juni 1869): ABC 16.8.2., Vol. 2, 9.

417 Das Krankenhaus wird häufig als Johanniterkrankenhaus bezeichnet, obwohl es nicht mehr der Leitung der deutschen Johanniter obliegt. Die Johanniter errichten 1861 zunächst in Saida ein 
nissen betreut, die sich seit 1862 in Beirut etabliert haben. ${ }^{418}$ Von nun an arbeiten die College-Professoren regelmäßig im Krankenhaus und Medizinstudenten haben die Möglichkeit, in die Praxis der Medizin einzusteigen.

Trotz seines Engagements für das Wohlergehen des Colleges, besteht Van Dyck darauf, dasselbe Gehalt wie seine Kollegen zu beziehen. ${ }^{419}$ Wie er es selbst sagt, liegt ihm das Wohlergehen des SPC am Herzen. Er ist bereit, auf Kosten seiner Gesundheit, jede Minute für dessen Fortschritt zu arbeiten. ${ }^{420}$ Van Dyck wird von seinen Studierenden für sein Wissen, seine Großzügigkeit und sein Bemühen um deren erfolgreiches Studium verehrt („The students adored van Dyck; they praised his virtues, merits and kindness" $).{ }^{421}$ Seine Beliebtheit geht über die Mauern des Colleges hinaus. Im Volksmund meint man, Van Dyck sei der Begründer des SPC und nennt es hin und wieder Madrasat Fāndayk (Van Dyck-Schule). ${ }^{422}$ Die große Lücke, die Van Dyck nach Verlassen des Colleges Ende 1882 hinterlässt, ist durch keinen neuen Dozenten zu beheben. Es scheint verwunderlich, dass ein so renommiertes College wie das SPC, den Rücktritt des besten Dozenten zulässt, um seinen religiösen Prinzipien treu zu bleiben. Die Umstände für Van Dycks, William Van Dycks $^{423}$ sowie Edwin Lewis' Rücktritt rühren von der in Abschnitt I.1.5 bereits beschriebenen Lewis-Affäre her, die sich im Zuge der Rede des Chemie- und Geologieprofessors entwickelt hat. Wegen der neuen Lehren des britischen Forschers Charles Darwin entfacht ein Konflikt zwischen dem liberalen und konservativen Lager des SPC. Die Evolutionstheorie Darwins kann Van Dycks religiöse Überzeugungen keinesfalls erschüttern. Als Wissenschaftler sieht er sich jedoch in der Pflicht, diese zu respektieren und sich mit ihr rational auseinanderzusetzen. ${ }^{424}$ Schließlich ist es die Freiheit des Denkens und der Äußerung, die er auch vor seinen Studierenden proklamiert. ${ }^{425}$ In diesem Punkt ist er seinen konservativen Kollegen weit voraus. Van Dycks Entscheidung, seinen Lehrstuhl aufzugeben, ist sicherlich nicht erst auf die jüngsten Ereignisse zurückzuführen. Am 18. Dezember 1882 schreibt er in seiner Rücktrittserklärung an den Board of Trustees in New York:

The course taken by Dr. Bliss and Dr. Post for some time past in College matters, and the fact that I differ from them radically as to the principle which should guide the Faculty in the man-

Männerspital, das 1862 nach Beirut verlegt wird und aufgrund mangelnder Finanzen schließen muss. 1866 wird das Johanniterkrankenhaus in Beirut neu aufgebaut: vgl. Kaminsky (2010), 34.

418 SPC Jahresbericht (27.6.1871): ABC 16.8.2., Vol. 2, 20-21; Penrose (1941), 34-36.

419 Philipp (1979), 179.

420 Zitat von Van Dyck in: Șarrūf/Nimr (1895), 886.

421 Philipp (1979), 179.

422 Aus: Mudakirrāt Ğurğ̄ Zaydān, hrsg. von S. al-Dīn al-Munağid, Beirut 1968, S. 65, zitiert in: Ğuha (2004), 54.

423 Penrose (1941), 36-37: William studiert 1875-78 am SPC und schließt sein Medizinstudium am New York University Medical College ab. Aus den Jahresberichten des SPC ist nicht ersichtlich, ab wann er dort als Lektor eingestellt wird.

424 So Ğurğĩ Zaydān in: Philipp (1979), 180.

425 Aus: Mudakirrāt Ğurğ̄ Zaydān, S. 273, zitiert in: Huūrī (1990a), 164: Es ist in den ersten Jahren des Colleges durchaus nicht unüblich, seine Meinung frei zu äußern und für seine Rechte einzutreten, so Zaydān. Aus diesem Grund ist der Protest der Studierenden im Zuge der LewisAffäre nichts Überraschendes. 
agement of so important an institution, have led to such a divergence between us, that, finding myself powerless to remedy a state of things which I truly deplore, I can no longer consistently retain my connection with the College. ${ }^{426}$

Etliche Faktoren haben vor den Ereignissen um Prof. Lewis' Rede zur Heraufbeschwörung einer Krise im College beigetragen: zum einen der Missmut der College-Leitung über ein in ihren Augen anstößiges Verhalten von Edwin Lewis, dessen Beziehung zu Daniel Bliss in seinen ersten Jahren am College völlig unproblematisch war. ${ }^{427}$ Zum anderen die Rivalität, die der bei den Studierenden unbeliebte George Post ${ }^{428}$ gegenüber dem ruhmreichen Cornelius Van Dyck verspürt. ${ }^{429}$ Ebenso leisten William Van Dycks persönlicher Kontakt zu Charles Darwin und seine Begeisterung für dessen Lehren einen weiteren Beitrag. ${ }^{430}$ Schließlich stellt auch Cornelius Van Dycks Position im College von Anfang an ein Problem in den Augen konservativer Vertreter dar. Als Anhänger des rationalen Denkens versteckt er sich nicht hinter religiösen Fanatismen. Er spricht offen an, was manch andere seiner Kollegen nicht zu sagen wagen. ${ }^{431}$ Bliss beschwert sich mehrere Male über das Verhalten der liberaleren Professoren gegenüber David Stuart Dodge, Mitglied des Board of Trustees in New York und enger Freund von Bliss. ${ }^{432}$ Als Van Dyck

426 Zitiert in: „A Statement. 1883 by the President to the Board of Managers“: ABC 16.8.2., Vol. 2, 74.

427 In Bliss' Briefen an seine Frau Abby zwischen 1873 und 1874 finden sich keinerlei kritische Worte zu Lewis: „Dr. Lewis is most faithful in all his duties. And helps in matters that do not especially belong to his department.“ Vgl. Daniel Bliss an Abby Bliss (Beirut, 10.12.1873), in: Bliss (1993), 137-138.

Nichtsdestotrotz vertritt Lewis, der wie Van Dyck ebenfalls passionierter Wissenschaftler und ordinierter Pfarrer ist, eigene Ansichten gegenüber den strikten religiösen Regeln des Colleges. David S. Dodge, Mitglied des Board of Trustees, droht ihm bereits im Zuge eines Abendessens, bei dem Lewis Wein serviert habe, die Kündigung an: vgl. Dodge an Bliss (Bushy Hill, 5.7.1882): AA.2.3.1.4.2 (,it would be desirable for the College if he could find some other sphere of usefulness, but we must quietly wait“; siehe auch: Ğuha (2004), 56-58. Ğurğĩ Zaydān zufolge habe Lewis hin und wieder bei den Andachten, die verpflichtend waren, gefehlt: Mudakirrāt Ğurğĩ Zaydān, S. 66, zitiert in: Ğuha (2004), 57.

428 Bliss beschreibt Post als äußerst engagierten Mitarbeiter („His energy and thoroughness make the Medical Department.“). Dieser lasse es nicht zu, dass andere in ihrer Arbeit nachlässig sind. Nichtsdestotrotz empfindet Bliss Posts Beharrlichkeit und die vielen Pläne, die er für die $\mathrm{Zu}-$ kunft des SPC entwirft, als anstrengend (,One [Post] is quite enough - two would drive all things to a ,general smash'."): vgl. Daniel Bliss an Abby Bliss (Beirut, 14.11.1873), in: Bliss (1993), 118; Bliss an Abby (Beirut, 27.11.1873), in: ebd., 128-129. Dissonanzen zwischen Post, Lewis und Van Dyck bestehen offenbar schon sehr früh. Daniel Bliss berichtet, Post habe Van Dyck und Lewis einmal in ungutem Ton ermahnt, dass sie in ihrer Predigt nicht laut genug redeten, während er jedes Wort von Daniel Bliss verstünde: vgl. Bliss an Abby (Beirut, 9.11.1873), in: ebd., 115.

429 A. Rustum, Lubnān fì 'ahd al-mutașarrifǐ̀a, Beirut 1973, 254, zitiert in: Ğuha (2004), 55.

430 Ğuha (2004), 58-60.

431 Ebd., 60.

4321873 lebt Dodge für einige Zeit bei Daniel Bliss während der Abwesenheit von dessen Familie. Dodge, der zu Anfang Englisch am SPC unterrichtet, verlässt schließlich Syrien zu Bliss' groBem Bedauern („He will never know how much I shall miss him“ [21.6.1873], in: Bliss, 1993, 34). Fortan stehen die beiden in engem Briefkontakt und tauschen persönliche und berufliche Angelegenheiten aus. Bliss nennt ihn als Zeichen großen Respekts stets „the Professor“: vgl. 
davon erfährt, dass Bliss institutsinterne Konflikte mit Dodge bespricht, ${ }^{433}$ ohne sie vorher vor der Lehrerschaft und dem Board of Managers anzusprechen, ist er empört und legt mehrmals Beschwerde beim Board of Trustees ein. ${ }^{434}$ Dodge schreibt Bliss zu den Ereignissen von 1882, dass er sich von Van Dycks impulsivem Verhalten und dessen Beschwerden über die „,burning wrongs at Râs-Beirût" während eines Stationstreffens der Mission sowie den „terrors of more resignations and wholesale desertions" nicht einschüchtern lassen soll. Was den talentierten, jungen William Van Dyck anbelangt, so ist Dodge nicht davon überzeugt, dass er den für diese Institution erforderlichen Missionsgeist besitzt. „[I]f difficulty would come from rejecting him, I have little doubt, more would eventually come from accepting him. “435 Bliss solle lieber langsamer und mit weniger Personal fortfahren: „Better run at half-speed [...] than make sixteen knots with the aid of atheistic, materialistic or non-religious boilers. “436

Nur ungern möchte das SPC mit Van Dyck seinen besten Professor verlieren. Von New York aus versucht man ihn dazu zu überreden, sich zu entschuldigen schon ein Ausspruch des Bedauerns über die vergangenen Ereignisse hätte ihn rehabilitiert. ${ }^{437}$ Dodge rät Bliss dazu, auf Van Dyck einzuwirken:

No matter what he may think personally of Darwinism etc., he may be able to see and feel that an Institution like this College is already and absolutely committed to an outspoken and unquestionable orthodoxy etc.etc. [...] We do not want to separate from such a man as Dr Van Dyck hastily. We want, if possible, to save him from the disgrace and injury to himself and the cause, of deserting the college on any such ground. He must strain every nerve to prevent such a catastrophe for a man whose name for learning and piety is known throughout the World. ${ }^{438}$

Bliss schreibt schließlich lakonisch, dass die Konditionen, die Van Dyck für eine Rückkehr gestellt habe, ,inadmissable“ seien. ${ }^{439}$ Im Fall von William Van Dyck sieht der Board of Trustees einer Kündigung von dessen Seite mit Wohlwollen entgegen. Keiner der Rücktritte kommt unverhofft und es gibt wenig Bedauern von Seiten des Colleges und seiner Leitung in Beirut und in Übersee. Cornelius Van Dyck scheut sich nun nicht mehr davor, das konservative Lager anzugreifen. Seinen

Bliss an Abby (4.6.1873), in: ebd., 23. Ein großer Teil des Briefnachlasses von Daniel Bliss, der sich im Archiv der AUB befindet, besteht aus Briefen von David Stuart Dodge.

433 Dodge an Bliss (Watch Hill, 21.8.1882): AA.2.3.1.4.3: Obwohl der in Beirut ansässige Board of Managers über die Gehälter im College zu entscheiden hat und gegenwärtig über die Gehaltserhöhung der Tutoren Șarrūf und Nimr debattiert, tauschen sich Bliss und Dodge zu dieser Sache aus. Dodge ist der Meinung: „The increase of the Tutor's salaries is certainly unnecessary. I fear it is only done to give false hopes to these young men or to embitter them against those, who will oppose the proposition and so to bind them more closely to a party!"

434 Auch Lewis beschwert sich über diesen Sachverhalt: Dodge an Bliss (Weatogue/Conn., 19.7.1882): AA.2.3.1.4.2; siehe auch: Ğuha (2004), 60-61.

435 Dodge an Bliss (Bushy Hill, 1.8.1882): AA.2.3.1.4.3.

436 Ebd.

437 Ebd.

438 Dodge an Bliss (Watch Hill, 21.8.1882): AA.2.3.1.4.3.

439 „A Statement. 1883 by the President to the Board of Managers“: ABC 16.8.2., Vol. 2, 74. 
Gefährten rät er, sich von den Pastoren ${ }^{440}$ und ihrer übertriebenen, vorgetäuschten Gottesfurcht fernzuhalten. Diese halten so sehr an den religiösen Prinzipien fest, dass wissenschaftliche Denkweisen, die äußerlich widersprüchlich erscheinen, von ihnen als weltlich abgetan werden. ${ }^{441}$

Das College, das die Kündigung von vier Dozenten überbrücken muss - im März 1883 tritt ebenso der die Fächer Geburtshilfe sowie Kinder- und Jugendmedizin lehrende Amerikaner Richard Brigstocke zurück $-{ }^{442}$ droht in Verruf zu geraten, weil Studierende ihre Abschlüsse nicht machen können, wenn nicht umgehend Nachfolger gefunden werden. ${ }^{443}$ Noch im Verlauf des Jahres 1882 verspricht Van Dyck seinen Studierenden, dass er sie im Falle einer Suspendierung vom College in seinem Haus privat unterrichten werde. Bliss, der dies für ein Gerücht zu halten glaubt, wird von Van Dyck vom Gegenteil überzeugt. ${ }^{444}$ Zwölf suspendierte Studenten werden schließlich von Van Dyck, seinem Sohn William sowie Edwin Lewis auf das medizinische Examen in Istanbul vorbereitet. ${ }^{445}$ Laut offizieller Erklärung des College-Präsidenten von 1883 werden die von Van Dyck an die Studierenden verliehenen Zertifikate in Istanbul nicht akzeptiert, sodass viele Schüler zum College zurückkehren müssen, um zum Examen zugelassen zu werden. ${ }^{446}$ Ğurğ̄ Zaydān hingegen schreibt in seiner Biografie, ein Komitee bestehend aus Van Dyck, Lewis, Wortabet, Brigstocke und zwei syrischen Medizinern habe die Examina der Studierenden abgenommen, die schließlich in Istanbul ihr Diplom absolvieren konnten. ${ }^{447}$ George Post versucht dies als diplomatischer Vertreter des Colleges noch zu verhindern, indem er Kontakt mit dem medizinischen Institut in Istanbul aufnimmt - anscheinend ohne Erfolg. ${ }^{448}$

Der Umstand, dass kein geeigneter Professor gefunden werden kann, der Van Dycks Lehrinhalte in ihrer Komplexität in arabischer Sprache darzustellen vermag, führt schließlich zur Ausweitung des Beschlusses von 1874, Englisch als HauptUnterrichtssprache einzuführen, ${ }^{449}$ auf die medizinische Fakultät 1883. Es wurde im Nachhinein häufig angenommen, dass Van Dyck, so wie sein Kollege John Wortabet u. a. ${ }^{450}$ gegen die Umstellung auf Englisch gewesen sei, da er Arabisch in so umfangreicher Form beherrscht habe. ${ }^{451}$ Der Protest gegen die Umstellung

440 Damit meint Van Dyck vermutlich nicht nur die Missionare, sondern auch Lehrende des Colleges, die ebenso zur Mission gehören (z. B. Daniel Bliss).

441 So Hūrrī $(1966,20)$ über die Gründe, die Van Dyck zur Kündigung bewogen haben.

442 Brigstocke an Bliss (5.3.1883): AA.2.3.1.9.4.

443 „A Statement. 1883“: ABC 16.8.2., Vol. 2, 75

444 Ebd., 72.

445 Unter ihnen auch der spätere Historiker Ğurğ̄ Zaydān.

446 „A Statement. 1883“: ABC 16.8.2., Vol. 2, 75.

447 Philipp (1979), 203.

448 Scholz (1997), 169; Khalaf (1994), 74.

449 Ğuha (2004), 152.

450 Näheres dazu in Abschnitt III.2.4.

451 Glaß (2004b, 438) schreibt, dass sich Van Dyck, Fāris Nimr, Ya qūb Șarrūf u.a. 1879 gegen Englisch ausgesprochen haben. Der Umstand trifft zwar auf Nimr und Șarrūf zu, die diese Entscheidung auch im al-Muqtațaf thematisieren (siehe Abschnitt I.1.5), jedoch nicht auf Van Dyck. 
am College, der in einem ersten Brief des Missionars William Eddy vom 30. Juli 1878 zum Ausdruck kommt, wird fälschlicherweise auf Van Dycks Initiative zurückgeführt. Es ist jedoch Tatsache, dass Van Dyck in allen Gremien, die über die Sprachumstellung beraten, anwesend ist, sie z. T. als stellvertretender Präsident des SPC aufgrund von Daniel Bliss' Abwesenheit zwischen 1874 und $1876^{452}$ sogar leitet. Der Mehrheitsbeschluss des Gremiums wird ebenso von Van Dyck und seinem Sohn William unterschrieben. ${ }^{453}$ Mit einer Umstellung in der medizinischen Fakultät war man bisher nur zögerlich, da es sich auf die Praxisarbeit der jungen Ärzte in der arabischen Bevölkerung negativ auswirken könnte. Der englischen Unterrichtssprache am gesamten College steht mit dem Wegfall etlicher Lehrender, die Arabisch beherrschten, nun nichts mehr im Wege.

Seinen Ruf als al-Hakīm hat sich Van Dyck ebenso als praktizierender Arzt verdient. Das Aussenden von Missionsärzten ist ein fester Bestandteil der Auslandsmissionen. Man erhält nicht nur besseren Zugang zur Bevölkerung, sondern bringt auch neueste Erkenntnisse der medizinischen Praxis dort zur Anwendung, wo zumeist Laien die einheimische Bevölkerung ärztlich versorgen. Abermals nehmen die Amerikaner auf dem Gebiet der Medizin in Syrien eine Vorreiterstellung ein allen voran Cornelius Van Dyck. Die Bestückung des sozialen Sektors durch Krankenhäuser, Ambulanzen und Ausbildungsstätten für Krankenschwestern machen sich bis zum Ende des 19. Jh.s zunehmend christlich-europäische Gesellschaften zu Eigen. ${ }^{454}$ Immer wieder ist es Van Dyck, der die Anbindung einer Ambulanz bzw. eines Krankenhauses an das College vorantreibt. Aus dem anfänglichen dispensary des Colleges wird das Brown Ophthalmic Hospital, über dessen Verbleib jedoch nichts bekannt ist. Schließlich kommt es 1871 zur Kooperation mit dem Preußischen Johanniterkrankenhaus. ${ }^{455}$ Der Andrang zu den Sprechstunden des beliebten Arztes, die zweimal wöchentlich abgehalten werden, ist sehr groß. Obwohl Van Dyck 1882 das College verlässt und der Kooperationsvertrag nur für Lehrende des SPC gilt, darf er weiterhin für einige Zeit im Krankenhaus arbeiten. ${ }^{456}$ Daniel Bliss schreibt in einer Stellungnahme zu den Ereignissen am SPC im Jahr 1883, dass eine lokale Zeitung von der Gründung eines neuen einheimischen Krankenhauses durch

Schon in früheren Jahren betont Van Dyck immer wieder die Notwendigkeit für Studierende im Seminar und in den Sekundarschulen, die englische Sprache zu beherrschen. Während der ABCFM Englisch als Unterrichtssprache völlig vermeiden möchte, argumentiert Van Dyck, dass Englisch einen höheren Wert als Latein habe: vgl. Van Dyck an Anderson ('Abeih, 5.10.1847): ABC 16.8.1., Vol. 5 (313); Van Dyck an Rev. L. Bacon (Sidon, 14.6.1856): ebd. (342).

452 Daniel Bliss an Abby (Beirut, 25.1.1874), in: Bliss (1993), 177.

453 Ğuha (2004), 163-164.

454 Die Bewegung des Social Gospel nimmt mit den 1860ern in den USA ihren Anfang. Näheres dazu in: C.H. Hopkins, The Rise of the Social Gospel in American Protestantism 1865-1915, New Haven 1940.

455 Siehe dazu Abschnitt I.1.5.

456 SPC Jahresbericht (15.12.1883): ABC 16.8.2., Vol. 2, 82. Jessup (1910b, 666) hingegen schreibt, dass die Arbeit im Krankenhaus für Van Dyck nun nicht mehr möglich sei. Letztere Aussage mag sich auf ein langfristiges Arbeitsverhältnis mit dem Krankenhaus beziehen. Widersprüchliche Aussagen in verschiedenen Dokumenten sind diesbezüglich keine Ausnahme. 
Van Dyck und Lewis berichtet habe. Befürchtungen, Van Dyck werde eine Institution errichten, die zur Konkurrenz des Krankenhauses des SPC werden könnte, ebben schnell ab, als bekannt wird, dass das besagte Krankenhaus seine Pforten nach etwa drei Wochen wieder schließen muss. Die Gründe dafür werden hier jedoch nicht angeführt. ${ }^{457}$ Bliss' Aussagen darüber, in welchem Krankenhaus Van Dyck nun weiter praktiziert sind äußerst widersprüchlich. Schließlich steht fest, dass Van Dyck nach 1882 einen neuen Vertrag mit dem rum-orthodoxen St. George Krankenhaus in Beirut schließt. ${ }^{458}$ Aus dem Jahresbericht des Krankenhauses von 1885 geht hervor, wie der amerikanische Arzt für sein fachliches und menschliches Engagement gelobt wird. Er behandle nicht nur mit Medizin, sondern finde auch tröstende Worte, wo sie angebracht seien. ${ }^{459}$ Die Patienten, so der Bericht, blickten ihn manchmal an, als sei er Moses. Für weitere zehn Jahre widmet sich Van Dyck voll und ganz dem rum-orthodoxen Krankenhaus. ${ }^{460}$ Obwohl er zwei Meilen vom Spital entfernt wohnt, fährt der nun schon betagte Arzt mehrmals in der Woche dorthin. Aus eigener Tasche finanziert er den Ausbau des Krankenhauses um einen weiteren Flügel, damit die Kapazitäten erhöht werden können. ${ }^{461}$

Nicht nur das College, auch die Mission ist enttäuscht darüber, dass sich Van Dyck nun ,dem Feind' zuwendet. Er behindere damit die Legitimität der amerikanischen Mission, so William Eddy in einem Brief vom 18. Februar 1882 an den PBCFM: „We are terribly hampered in our dealings with the natives by the course of Dr. Van Dyck. An open enemy would do us less harm. ... He oposes our choicest plans..." "462 Schon 1890 scheinen alle Ärgernisse vergessen zu sein. Die Syrienmission schenkt Van Dyck zum fünfzigjährigen Jubiliäum seines Syrienaufenthaltes Sonderausgaben all seiner Werke auf Arabisch. Henry Harris Jessup wird später in seinem Buch Fifty-Three Years in Syria (1910) voller Begeisterung von Van Dycks Arbeit für das rum-orthodoxe Krankenhaus sprechen: ,[he] aided not only in raising its character, but in inducing the wealthy Syrian Greeks to contribute to its enlargement and its higher efficiency. “463 Das Krankenhaus errichtet zu Ehren von Van Dycks Jubiläum eine marmorne Büste des Arztes im Innenhof der Einrichtung, wie Jessup weiter berichtet. „It was the first memorial bust in Syria in modern times, and the Greek Society have shown great liberality and sincere gratitude by setting it up to commemorate the labours and life of an American Protestant missionary physician.“464

Anlässlich der Feierlichkeiten von 1890 erweisen Anhänger verschiedener Konfessionen und Vertreter von vielerlei Institutionen in Syrien Van Dyck die Ehre.

457 „A Statement. 1883“: ABC 16.8.2., Vol. 2, 74.

458 Jessup (1910a), 109; Tibawi (1966), 245.

459 Mațar (1966), 38. Bei Mațar handelt es sich um einen Tippfehler: Der Ausschuss tagt nicht 1875 , sondern 1885 .

460 Jessup (1910a), 109

461 Jessup (1910b), 667.

462 W.W. Eddy (Beirut, 18.2.1888): PBCFM Archiv, Index VII (64), zitiert in: Tibawi (1966), 245.

463 Jessup (1910a), 109.

464 Ebd. Die zweite Statue dieser Art wird Daniel Bliss 1904 gewidmet. Jessup (1910b, 742) kommentiert: „These statues prove that the people of the East are not ungrateful for what men of the West have done for them." 
Von einem offiziellen Grußwort von Daniel Bliss und den Lehrenden des Colleges ist jedoch nicht die Rede. ${ }^{465}$ Letztlich ist Van Dyck zu bedeutend, als dass das SPC nicht mehr mit ihm in Verbindung gebracht werden möchte. 1913 werden ihm und Wortabet zu Ehren zwei Büsten auf dem Grundstück des SPC feierlich enthüllt.t ${ }^{466}$ Die suspendierten Schüler der Abschlussklasse von 1882, die nicht zurückgekehrt sind und anderorts ihren Abschluss gemacht haben, werden aus feierlichem Anlass nachträglich als Absolventen für das Jahr 1883 eingetragen. ${ }^{467}$ Es ist eine Art posthume Entschuldigung für die persönlichen Kontroversen, die Van Dyck dazu bewogen haben, das College zu verlassen.

\section{Von Ahbār 'an Intišāar al-Inğ̄ll fì Amākin Muhtalifa zu al-Našra al-Usbu '̄yya}

Zwölf Jahre nachdem Smith eine Pionierleistung in Syrien vollbracht und mit Mağmū' Fawā'id das erste, gedruckte arabische Periodikum herausgebracht hat, ruft die Mission 1863 ,ein kleinformatiges, illustriertes Blatt“468 ins Leben, das sich im Laufe der Jahrzehnte zu einer Zeitschrift entwickelt, die bis heute besteht: 1863 wird Cornelius Van Dyck Herausgeber von Ahbār 'an Intišăr al-Inğ̄ll fí Amākin Muhtalifa (Kunde über die Verbreitung des Evangeliums an verschiedenen Orten). ${ }^{469} \mathrm{Zu}$ Beginn ist die Zeitschrift eher eine Art monatliches Mitteilungsblatt im Umfang von vier Seiten. In den ersten Jahren beschränkt man sich, wie der Name es schon sagt, thematisch allein auf Mitteilungen über die Verbreitung des Evangeliums in der ganzen Welt. Somit werden dem Leser je Ausgabe drei bis vier Artikel dargeboten, die man eher als Kurzgeschichten bzw. Anekdoten aus der Welt der Missionsarbeit auffassen kann. Die Rettung einer heidnischen Kultur - sei es im Südpazifik, in Indien oder auf Madagaskar - aus ihrer „Verrohtheit“ und Unwissenheit durch die christliche Botschaft ist ein immer wiederkehrendes Motiv der christlich-moralischen Unterweisung. Es finden sich dabei die Orte wieder, zu denen der ABCFM seine Missionare entsandt hat. Daher ist zu vermuten, dass die Anekdoten den im Missionary Herald abgedruckten Missionarsberichten entnommen sind und das Beiruter Missionsblatt demnach als verkürzte, arabische Form des Missionary Herald gelten kann. Smiths Mağmū' Fawā'id präsentiert sich hier-

465 Bei Jessup $(1910 a, 109)$ ist lediglich davon die Rede, dass ehemalige und aktive Studierende des Colleges anwesend sind. Vgl. auch Presbyterian Church in den USA (1890) und (1891). Laut Șarrūf und Nimr $(1896,1)$ sei das Verhältnis zwischen der College-Leitung und Van Dyck bis zu seinem Tod getrübt gewesen.

466 Hūrūi (1992), 175.

467 Aus einer Rede von Y. Șarrūf anlässlich der Einweihung der Büsten von Van Dyck und Wortabet 1913, in: Al-Kullīya 4/6 (April 1913), zitiert in: ebd., 180.

468 Glaß (2004a), 77 (Tabelle 4).

469 Wie auch bei Smith ist nicht klar, ob Van Dyck der alleinige Herausgeber des Missionsblattes ist. Zuständigkeitsbereiche innerhalb der Mission sind nie klar getrennt. Da William Thomson und Van Dyck im Jahr 1863 zum editing committee der Mission gehören, das für die Herausgabe missionarischer Literatur verantwortlich ist, könnte Thomson ebenso zu den Herausgebern zählen: vgl. Syrienmission an Anderson (Beirut, 6.2.1863): ABC 16.8.1., Vol. 6 (21). Die Herausgeberschaft des Blattes wechselt in den folgenden Jahren stetig (s. u.). 
bei zwar als vielfältiger, da es auch nicht-christliche Themen enthält, der Fokus liegt aber auch in Smiths Missionsblatt auf der Verbreitung der christlichen Botschaft. Die Pionierleistung der ab 1863 erscheinenden Zeitschrift Ahbār 'an Intišār besteht darin, als erstes arabisches Periodikum Bilder abgedruckt zu haben. ${ }^{470}$ In der zweiten Ausgabe vom 1. Mai 1863 findet sich eine Zeichnung zu einer Zeremonie beim Tempel des „Ğakkarnūt“ (Jagannātha), einer indischen Gottheit. ${ }^{471}$ Beim Durchblättern des Periodikums wird deutlich, dass man auf derartige Illustrationen großen Wert gelegt hat. Da die Stempel der Bilder aus den USA kommen, ${ }^{472} \mathrm{kann}$ davon ausgegangen werden, dass der ABCFM sie ebenso für eigene Publikationen verwendet hat.

Zwar kommen auch in Van Dycks Missionsblatt ab 1866 zunehmend informative Artikel hinzu, die keine christliche Botschaft vermitteln wollen, jedoch bleibt man dem Konzept treu, mit dem Periodikum ein Sprachorgan der Syrienmission zu haben. Ab Juni 1868 ändert sich der Name des Missionsblattes: Van Dyck gibt nun die al-Našra al-Šahrīya (Monatliche Zeitschrift) heraus, ${ }^{473}$ die äußerlich in neuer Form erscheint, inhaltlich jedoch dem Vorgängerblatt entspricht. ${ }^{474}$ Der alte Titel wird für einige Zeit noch als Untertitel der Zeitschrift weiter geführt. Ab Januar 1871 erscheint al-Našra nun wöchentlich und heißt fortan al-Našra al-Usbu ‘̌ya (Wöchentliche Zeitschrift). Statt der bisherigen zweiten Titelüberschrift finden sich nun auf dem Bild einer aufgeschlagenen Bibel die Worte aus Psalm 119, 130 ,fatah kalāmika yunayir" (wörtl.: das offenbar Werden deiner Worte ist erleuchtend). ${ }^{475}$ (Abb. 6)

Zunehmend wird die Zeitschrift zu einem Sammelsurium von verschiedenen Genres: Zwar besteht sie weiterhin hauptsächlich aus Artikeln über das Christentum und dessen Verbreitung in Form von kurzen Geschichten mit gesellschaftlich moralischer Botschaft, aber es kommen mehr und mehr wissenschaftliche Berichte inklusive spezifischer Abbildungen aus den Bereichen Biologie, Geschichte, Philosophie sowie Poesie hinzu - Van Dycks Handschrift ist unverkennbar. Ab der Juliausgabe von 1871 werden sogar unter dem bereits bekannten Titel Fawä id Bibelverse, Sentenzen ${ }^{476}$ sowie Bekanntgaben von aktuellen Ereignissen angeführt. All

470 Glaß (2001), 41 (Anmerkung 54); Țarrāzī (1913), 66.

471 Im Englischen wird die Vishnu-Gottheit abwertend Juggernaut (Götze) genannt, was die arabische Bezeichnung erklärt. Kulke (1979), 216-219: Zur Festigung ihres politischen Einflusses in der Region Orissa, erobern die Briten Anfang des 19. Jh.s Puri und übernehmen die Aufsicht über den Jagganatha-Tempel. Britische Missionare missbilligen schließlich die Kooperation der Briten mit Anbetern von Götzen und die Angelegenheit erreicht das britische Parlament, wo Juggernaut von nun an sinnbildlich für Götzendienst stand.

472 Ṭarrāzī (1913), 66.

473 Našra hat dieselbe Bedeutung wie ğarīda (Zeitung, Zeitschrift), wird jedoch seltener verwendet: vgl. Glaß (2004a), 70.

474 Hūūī (1990a), 67.

475 Die Missionszeitschrift wird durch die häufigen Namensänderungen oftmals in drei, als verschieden geltende Zeitschriften aufgeteilt (siehe z. B. Țarrāzī, 1913, 20; al-Huūrī, 1990a, 66-68; Ayalon, 1995, 34). Es handelt sich aber um ein Periodikum, das sich über mehrere Jahrzehnte weiterentwickelt.

476 Als Liebhaber von Sprichwörtern und Sentenzen (s. o.) hat vermutlich Van Dyck die Idee zu dieser Rubrik. 


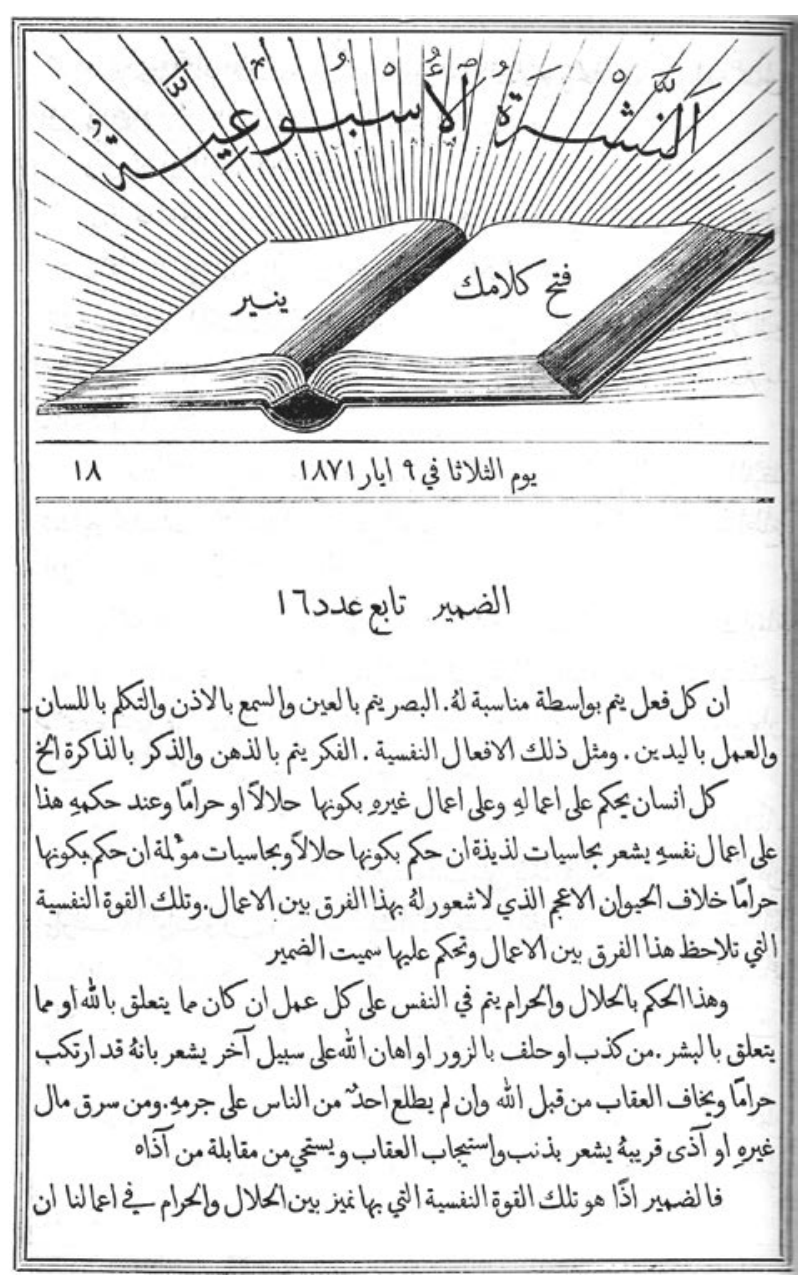

Abb. 6: Titelseite von Al-Našra al-Usbū ìya (9. Mai 1871)

dies, so V.F. DĪ ṬARRĀZI, in einer einfachen Sprache, die für das Lesepublikum, sei es gebildet oder ungebildet, als geeignet erscheint. ${ }^{477}$ Der Historiker YūSUF QASMĀ HữRI urteilt über die Darstellung wissenschaftlicher Sachverhalte in der Našra, dass sie zur Förderung von Projekten junger syrischer Wissenschaftler beigetragen habe. Dazu zählen z.B. Van Dycks Lobrede in der Zeitschrift über das neue Geografiebuch von Salīm al-Hūūī und Salīm Šahāâ sowie die Gründung der literarisch-wissenschaftlichen Zeitschrift al-Muqtațaf durch die Van Dyck-Schüler Ya' qūb Șarrūf und Fāris Nimr. ${ }^{478}$ 
Mit der wöchentlichen Herausgabe von al-Našra setzt sich darüber hinaus eine in europäischen und amerikanischen Literaturjournalen übliche Darstellungsform von neu erschienenen Büchern durch: Christliche Literatur, die auch in arabischer Übersetzung von der American Mission Press herausgegeben wird, kann in Form von Leseserien in jeder Wochenausgabe studiert werden. Bücher wie Jean-Henry D'Aubignés Geschichte über die Reformation oder Elisabeth Rundle-Charles' Chronik über die Schoenberg-Cotta Familie werden über Jahre in Teilen abgedruckt. ${ }^{479}$ Auch informative Artikel über die Bergpredigt, die Verfolgung der ersten Christen oder ein Lexikon der Reliquien von Heiligen sind in Serienform zu lesen. ${ }^{480}$ Polemische Schriften gegen die römisch-katholische Kirche, insbesondere gegen die ebenfalls in Syrien missionierenden Jesuiten, werden zwar besonders in den ersten Jahrzehnten der Mission häufig gedruckt, jedoch verfolgt al-Našra unter der Leitung von Cornelius Van Dyck einen weniger konfrontativen Kurs, den Hुūrī als „respektvolles Schweigen“ (al-suküt al-mauwaqqar) bezeichnet. ${ }^{481}$ Man versucht nun, sich auf der sachlichen Ebene mit einem Thema wie z. B. der Unfehlbarkeit des Papstes auseinanderzusetzen, ohne bestimmte Personen der katholischen Kirche direkt anzugreifen. ${ }^{482}$ Als der jesuitische Pater Van Ham die Übersetzung der Bibel durch die Amerikaner in der jesuitischen Zeitung al-Baš̌ ${ }^{483}$ (Der Bote) attackiert, antwortet al-Našra al-Usbū ‘̀ya mit einer Serie von Artikeln genannt „Abwehr der Pfeile des Jesuiten Van Ham“ (irtidā' al-sihām 'alā al-yasū '̄ Fān Hām). ${ }^{484}$ Das jesuitische Periodikum al-Bašǐr ist in seiner Zeit für religiös motivierte Diskussionen und Angriffe gegen Zeitschriften wie Bustānīs al-Ğinān oder Șarrūfs und Nimrs al-Muqtațaf besonders bekannt. ${ }^{485}$

Im Vergleich zu Smiths Zeitschrift sind die Ausgaben der ersten Jahre durch eine ähnlich unstrukturierte Formatierung gekennzeichnet. Zwar werden mit zunehmendem Umfang von al-Našra ab November 1867 auch Seitenzahlen verwendet, jedoch bleiben die Autoren der Artikel unbekannt. Ebenso wenig sind in dieser Zeit Hinweise auf Quellenangaben für die jeweiligen wissenschaftlichen Artikel

479 Huūrī (1990a), 69-71: D’Aubignés Geschichte der Reformation erscheint als Leitartikel in 246 Teilen zwischen 1872 und 1877. Schließlich werden sie zu jeweils einem Buch zusammengefasst und 1877 (Geschichte der Reformation) sowie 1885 (Chronik der Schoenberg-Cotta Familie) von der Amerikanischen Druckerei herausgegeben. Van Dyck wird dabei als Übersetzer angeführt, Jessup u. a. erwähnen jedoch, dass Bustānī an der Übersetzung von D’Aubignés Werk mitgewirkt habe: vgl. Jessup (1910b), 484; Ṭarrāzī (1913), 90 (siehe auch Anhang I). Die Veröffentlichung von Geschichten oder ganzen Büchern in Serienform ist eine gängige Praxis im europäischen Zeitungswesen des 19. Jh.s, wodurch Leserinnen und Leser dazu animiert werden, die Zeitungen und Zeitschriften zu abonnieren: vgl. Holt (2009), 38.

480 Hुürī (1990a), 67.

481 Ebd., 68.

482 Al-Našra al-Šahrīya (September 1870), 1-4.

483 Glaß (2004a), 79-80: Al-Bašĭr wird von den Jesuiten 1870 gegründet und besteht bis 1947. Die darin abgedruckten Illustrationen und Bilder machen al-Bašīir zu einem Periodikum mit hohem technischen Standard.

484 Hūūrī (1990a), 68.

485 Ayalon (1995), 34: „This kind of heated encounter, endemic to the Lebanese scene, had constructive results in generating a seminal educational and cultural contest of ideas in the nineteenth century." 
üblich. Die Reihenfolge der sehr vielseitigen Artikel folgt in den ersten Jahrzehnten keiner erkennbaren Logik, was man schon bei Smiths Magazin beobachten konnte. Bei allgemeinen Bekanntmachungen tauchen mit den Jahren zunehmend Namen von Missionaren bzw. syrischen Protestanten auf, die für die jeweilige Mitteilung in diesem Blatt verantwortlich sind (Henry Harris Jessup am 3. November 1871; Ibrahīm Sarkis ${ }^{486}$ am 21. Januar 1873; Yuhannā Abkāriyūs ${ }^{487}$ am 3. Mai 1875). So wie es auch schon bei Smiths Mağmū' Fawā'id vermutet wird, besteht die Redaktion der al-Našra sehr wahrscheinlich aus verschiedenen Missionaren und Syrern, die - vermutlich in einem häufig variierenden Redaktionsteam - an der Herausgabe einer Zeitschrift mitgewirkt haben. Nassīm al-Helū, der ab 1891 Mitarbeiter in der Redaktion der Zeitschrift wird, erwähnt bspw., dass die Syrer Ibrahīm Sarkīs, Rizq Allah Barbārī ${ }^{488}$ und As 'ad al-Šadūd ${ }^{489}$ maßgeblich an der Entwicklung der Našra mitgewirkt haben. ${ }^{490}$

Warum Van Dyck 1879 die Herausgeberschaft des Missionsblattes entzogen wird, kann nur vermutet werden. ${ }^{491}$ William Eddy, der ab 1880 neuer Herausgeber wird, schreibt in der Einleitung zur Ausgabe vom 1. Januar desselben Jahres, dass al-Našra al-Usbū ‘̄ya eine religiös ausgerichtete Zeitschrift bleiben wird. Man werde sich nicht damit begnügen, eine wissenschaftliche Zeitschrift wie al-Ǧinān oder al-Muqtataf zu sein, noch ein Handelsblatt wie al-Ğanna oder Lisān al-Hāal, so Eddy. ${ }^{492}$ Van Dycks Themenspektrum für die Našra ist dem Kreis der Syrienmission vermutlich zu weltlich geworden, weshalb al-Hakim Van Dyck von seiner Aufgabe zurücktreten muss. William Eddy wird 1883 von Samuel Jessup abgelöst, bis schließlich Henry Harris Jessup von 1889 bis 1902 Herausgeber der Missionszeitschrift sowie dessen Supplement-Serie (al-Mulhaq al-Našra al-Usbū '̌ya) wird. ${ }^{493}$ Im 20. Jh. wird al-Našra zu einem ,semi-monthly review“ und einer ,collection of articles on the many different phases of family life". ${ }^{494}$ Unter der Leitung von Rev. Adīb Awwād wird Al-Našra heute von der Evangelical Synod of Syria and Lebanon herausgegeben.

486 Siehe Anhang II, Nr. 53.

487 Siehe Anhang II, Nr. 1.

488 Siehe Anhang II, Nr. 17.

489 Anhang II, Nr. 55.

490 Ṭarrāzī (1913), 20; al-Ḥelū (2010), 146-147. Näheres zu den Personen in Anhang II.

491 Laut Glaß (2004a, 78) wird Van Dyck von Ibrāhīm al-Haurān̄̄, einem griechisch-katholischen Lehrer aus Aleppo, abgelöst. Haurānī arbeitet zuvor als Übersetzer und Korrektor der American Mission Press und lehrt arabische Rhetorik, Mathematik sowie Logik am SPC. Er hat zwar an der Entwicklung des Magazins von 1880 bis 1915 mitgewirkt, ist jedoch nicht Herausgeber. Ab 1880 übernimmt William Eddy die Herausgeberschaft: vgl. al-Helū (2010), 147.

492 (Ohne Titel) al-Našra al-Usbū '̄yya 1 (1.1.1880), 1.

493 Jessup berichtet, dass er die Arbeit als Herausgeber übernehmen muss, da sein Bruder Samuel und William Eddy in den USA sind: Jessup (1910b), 572. Al-Mulhaq besteht nur bis 1902. Originaldokumente fast aller monatlichen Ausgaben der Supplement-Serie befinden sich im Besitz der N.E.S.T.

494 AA.7.1/American Mission Press Beirut, Box 1 (Bericht von George A. Ashkar, o. D.). 


\section{6. „Die Freuden an der Wissenschaft“ - \\ Van Dyck und die wissenschaftlichen Gesellschaften}

Angesichts Van Dycks Leidenschaft für alles, was mit Wissen und Wissensaneignung zu tun hat, ist es nur selbstverständlich, dass er ein gern gesehenes Mitglied in der American Oriental Society ${ }^{495}$ und der $\mathrm{DMG}^{496}$, aber vor allem in den neuen Beiruter wissenschaftlichen Gesellschaften ist, die ab den 1850er Jahren, zumeist nur für wenige Jahre, zum Vorschein treten, um dann von einer besser strukturierteren und umfassenderen Gesellschaft abgelöst zu werden. ${ }^{497}$

Als Gründungsmitglied der Syrischen Gesellschaft für Wissenschaften und Künste kann Van Dyck schon früh unter Beweis stellen, dass er einen wissenschaftlichen Vortrag auf Arabisch halten kann. In seiner Rede „Fī lad dat al- ilm wa 'awa' $d i h i$ '“ (Über die Freuden an der Wissenschaft und ihren Nutzen) ${ }^{498}$ wird deutlich, was Van Dyck beschäftigt und wofür er sich einsetzen möchte: Jeder Mensch sollte seinen Horizont durch Wissenschaft erweitern. Er ermutigt daher seine Zuhörer, sich in ihrer Freizeit mit Wissenschaft zu beschäftigen und jeden anderen ebenso dazu zu motivieren. ${ }^{499}$ Dabei unterscheidet er zwischen zwei Arten von Menschen: die einen sehen keinen Sinn darin, ihr Wissen durch Neues zu erweitern oder gar zu ersetzen. Sie verlassen sich auf das, was die Geschichte überliefert und nennen jene ignorant, die diesen Status quo verändern wollen. Andere wiederum empfinden Freude an der Aneignung von Wissen, weil es ihr Leben und ihren Alltag, oder gar ihre handwerkliche Arbeit erleichtert. Ein Gedanke, der später von den Herausgebern des Muqtataf wieder aufgegriffen wird. ${ }^{500}$ Van Dyck belehrt nicht nur zum Umgang mit Wissen, sondern er redet zweifellos auch von sich selbst,

495 Van Dyck wird ca. 1847 Korrespondenzmitglied der Bostoner American Oriental Society. An Anderson schreibt er diesbezüglich: „If I know my own feelings I have only one motive in preparing anything for the Oriental Society and that is to contribute what little may be in my power towards causing in literary men an interest in Missionaries and Missions." Vgl. Van Dyck an Anderson ('Abeih, 8.10. und 12.11.1847): ABC 16.8.1., Vol. 5 (314 und 316).

496 Laut Auskunft des Archivs der Deutschen Morgenländischen Gesellschaft (verwaltet von der Bibliotheksuniversität Halle) gibt es einen Antrag von Heinrich Leberecht Fleischer an den Vorstand der DMG im Jahr 1858, Van Dyck als korrespondierendes Mitglied und damit als Nachfolger von Eli Smith aufzunehmen. Es existiert jedoch keine handschriftliche Beitrittserklärung Van Dycks. Laut Sa'di $(1937,29)$ ist Van Dyck seit seiner Deutschlandreise 1860 Mitglied der DMG, in deren Zeitschrift er auch bis zu seinem Tode unter der Mitgliederliste aufgeführt wird. Anders als bei Smith sind weder in der ZDMG, noch im Nachlass der Gesellschaft Berichte oder Briefauszüge von Van Dyck zu finden.

497 Näheres dazu in Abschnitt I.2.4.

498 In: Huūrī (1990b), 27-32.

499 Van Dyck, „Fī ladddat al- 'ilm wa 'awā' dihi“, in: ebd., 31: „Vielmehr ist es meine Absicht, dass Sie [Ihre] Freizeit, die jeder zweifellos hat, dafür verwenden, den Verstand zu trainieren und das Wissen zu erweitern und zu vermehren."

500 Ya 'qūb Șarrūf und Fāris Nimr, die zu den ersten 16 Studierenden des SPC gehören und später dort als Dozenten arbeiten, sind die Herausgeber des Muqtațaf, der ,ğarìda 'ilmìyya wa șinā 'ìya" (Zeitschrift für Wissenschaft und Handwerk) mit dem Emblem einer Schreibfeder und eines Hammers. Der Untertitel ändert sich 1888 in „Zeitschrift für Wissenschaft, Handwerk und Landwirtschaft". 
wenn er über Wissen aus Gegenwart und Vergangenheit spricht - eine Einstellung, die sich durch seine gesamte Karriere zieht:

Wenn er [sc. der Freund der Wissenschaft] die Dinge beobachtet, die in seiner Zeit passieren, so erfreut es ihn und er nutzt sie zum Vergleich mit Ereignissen vergangener Generationen und kann so die Gemeinsamkeiten und Unterschiede zwischen den Epochen erkennen. Er richtet seine Schritte nach der Wahl [der Schritte] anderer Menschen aus, die vor ihm gelebt haben und deren Lebenswerk entweder als Vorbild gesehen wird, dem es nachzueifern gilt oder als Lektion, die man berücksichtigen sollte. ${ }^{501}$

Wie bereits häufig in dieser Untersuchung erwähnt, steht das Thema Wissen immer wieder im Fokus der Gelehrtenkreise jener Zeit. Auch Van Dycks zweite Rede für die Syrische Gesellschaft $F \bar{\imath}$ faḍl al-muta'ahirrīn 'alā l-mutaqaddimīn (Der Vorzug der heutigen ${ }^{502}$ Menschen gegenüber den früheren Menschen) ${ }^{503}$ handelt davon, dass die gegenwärtigen Generationen auf die Erkenntnisse ihrer Vorfahren aufbauen oder sie revidieren müssen, wenn sie nicht korrekt sind. Ein Bezug zur Vergangenheit muss jedoch in jedem Fall aufrechterhalten werden.

1882 wird die al-Mă̌ma' al-'Ilmī al-Šarqī (Orientalisch-Wissenschaftliche Vereinigung) in Beirut gegründet. Bekannte Persönlichkeiten wie Ya 'qūb Șarrūf, Fāris Nimr, Salīm al-Bustān̄̄, Ibrahīm al-Yāziğōi, William Van Dyck und Ğurğì Zaydān zählen zu ihren Mitgliedern, Van Dyck und Wortabet werden zu Vorstandsvorsitzenden gewählt. So wie ihre Vorgängergesellschaften widmet sich auch diese Vereinigung der Wissenschaft und ihrer praktischen Anwendung. ${ }^{504}$ Mit dem Weggang des Muqtataf ins ägyptische Exil 1884/85 505 scheint das Fundament der Orientalisch-Wissenschaftlichen Vereinigung ins Wanken zu geraten, ca. 1885 löst sich die Gesellschaft auf. ${ }^{506}$ Dabei hat Van Dyck noch 1883 in der Rede zur Jahresversammlung der Gesellschaft betont, dass der Erfolg einer solchen wissenschaftlichen Vereinigung an das Ziel geknüpft sei, dauerhaft zu bestehen. ${ }^{507}$

\section{Schlussbetrachtung}

Dauerhaften Bestand hat jedoch zweifelsohne Van Dycks Lebenswerk. Der junge Arzt aus Kinderhook wird zu einer Ausnahmefigur der amerikanischen Mission in Syrien. Als Missionar der sogenannten zweiten Generation kann er auf der Basis aufbauen, die die Missionare vor ihm geschaffen haben. Dann entwickelt er sich jedoch in eine Richtung, für die ihn der ABCFM nicht bestimmt hat: „He was a

501 Van Dyck, „Fī laḍdat al- 'ilm wa 'awā' dihi“', in: Huūrī (1990b), 28.

502 Aus heutiger Sicht würde man al-muta'ahirrīn mit „moderne Menschen“ übersetzen. Es ist jedoch unwahrscheinlich, dass Van Dyck hier schon den im 19. Jh. erst neu aufkommenden Begriff der „Moderne“ im Sinn hat.

503 In: Hūrū (1990b), 79-82.

504 Philipp $(1979,25)$ erwähnt, dass es sich hierbei um die Folgeorganisation der 1868 gegründeten Ğam '̀yat al- 'Ilmìya al-Sürīya handelt, die nur ein Jahr existiert (siehe auch Abschnitt I.2.4).

505 Glaß (1998b), 191.

506 Zaydān (1913), 73.

507 Van Dyck (1883), 241-247 (hier: 242). 
foreigner who went native. “508 Van Dycks Qualitäten liegen eher im Dienst für Bildung und Wissenschaft denn in der Missionierung. Dessen sind sich der ABCFM und später der PBCFM bewusst. ${ }^{509}$ Die jahrzehntelange Arbeit für die Syrienmission verändert den einst jungen, häufig impulsiven und temperamentvollen Missionsarzt. $\mathrm{Zu}$ Beginn wünscht er sich nichts sehnlicher, als die arabische Sprache zu beherrschen, um die Menschen zu bekehren, die er ärztlich behandelt. Doch die Begeisterung für die eigentliche Missionsarbeit lässt allmählich nach und Van Dyck findet zurück zu seinen Wurzeln in der Wissenschaft. Er erkennt, dass er in seiner zweiten Heimat Syrien etwas zur kulturellen Erweckung beitragen kann. Liberales Denken und säkulare Bildung werden zu einem wichtigen Bestandteil seiner missionarischen Arbeit. ${ }^{510}$

UsSAMA MAKDISI ist der Meinung, dass Van Dycks Wirken vom „militanten Enthusiasmus der protestantischen Missionare“ überschattet wurde. ${ }^{511}$ Dieses Urteil mag für die ersten Jahrzehnte gelten, in denen Van Dyck in enger Verbindung mit der Mission steht. Das Bild des erfolgreichen Cornelius Van Dyck jedoch, das man sich in der damaligen arabischen Welt von ihm macht, wird immer weniger in Verbindung mit der amerikanischen Mission gebracht. Van Dyck hat eine hohe Stellung in der Gesellschaft erreicht. Man nennt ihn den Patron der nahda und alle, ${ }^{512}$ die mit ihm gearbeitet haben, verehren ihn zutiefst für seine Fähigkeiten und seinen Einsatz für die Syrer. Letztlich bleibt nicht viel vom „Missionar“ Van Dyck, was daran liegen mag - wenn man Makdisis Metapher erneut aufgreift -, dass Van Dycks wissenschaftliches Wirken seine Fähigkeiten und Überzeugungen als Missionar völlig in den Schatten stellt. Bis zum Ende seines Lebens ist Van Dyck ein frommer Mann und ein leidenschaftlicher Prediger. Anderson kann sich keinen besseren Mann auf der Kanzel vorstellen als diesen Missionsarzt, der Arabisch perfekt beherrscht. ${ }^{513}$ Dennoch passt er nicht in das Schema eines typischen Missionars. Er kommt nämlich nicht aus dem Milieu eines neuenglischen, theologischen

508 Makdisi (2010), 76.

509 Dennis (1895), 36: „He chose to dedicate his abilities to the intellectual advancement of the people, to humanitarian ministry, and to the production of instructive and helpful literature, rather than to the department of evangelistic effort."

510 Sa'di (1937), 25.

511 Makdisi (2010), 80.

512 Glaß (2004a), 199. Es existiert keine Studie über die nahḍa, in der Van Dyck nicht erwähnt wird, so Ibrahīm Mațar (1966), 13.

513 Anderson an die Syrienmission (Boston, 27.6.1850): ABC 2.1.1., Vol. 13 (HHL): „I have felt that Dr. Van Dyck ought to make Arabic preaching his great business; and he is ready I doubt not to reside where he can preach at the best advantage." Anderson an die Syrienmission (Boston, 23.2.1859): ebd., Vol. 25 (HHL): „I hope the good brother [Van Dyck] will continue to exercise the gift of preaching that is in him."

Daniel Bliss schreibt dazu an seine Frau Abby am 1. März 1874: „We had a very interesting sermon this morning from Dr. Van Dyck. He was truly eloquent. He stood out in the broad platform, with his small Testament in hand, and poured forth the truth with an animation accompanied with gestures unusual for him. [...] Some of the Maronite young men told Faris Sahyun that such preaching would make all Protestants." Vgl. Bliss (1993), 209. 
Seminars, ${ }^{514}$ sondern hat sich in seiner Jugend der Wissenschaft und dem rationalen Denken gewidmet. In jedem Fall lässt er nicht zu, dass seine persönlichen religiösen Überzeugungen seine wissenschaftliche Arbeit behindern könnten. ${ }^{515}$ Das bedeutet jedoch keinesfalls, dass Van Dyck seine christlichen Prinzipien aufgeben würde, sollten diese der Wissenschaft widersprechen. ${ }^{516}$ Im Allgemeinen ist er jedoch davon überzeugt, wie er es in der letzten am SPC gehaltenen Predigt bekräftigt, dass korrekte Wissenschaft und wahrer Glaube von Gott gegeben sind und „zwei Dinge, die wahr sind, können einander nicht widersprechen" (fa-lā yumkin an yatanāqiạ̄ $m \bar{a}$ zālan șādiqīn). ${ }^{517}$ Die Gratwanderung zwischen persönlicher Spiritualität und rational-liberalem Denken ist das Geheimnis für Van Dycks Erfolg in Syrien. Trotz seiner Tätigkeit als Arzt und Lehrender sowie seiner Beliebtheit bei den Menschen, die ihn häufig um einen Rat ersuchen, ${ }^{518}$ bevorzugt Van Dyck den Rückzug in sein Studierzimmer. ${ }^{519}$ Gegenüber seinen Studierenden vertritt er die Einstellung: „Intolerance cannot be tolerated. “520 Es gehört zum Essentiellen eines Menschen, sich, in welchem Umfang auch immer, mit Wissen zu beschäftigen und seine Welt verstehen zu lernen. Van Dyck ist kein Wissenschaftler der Entdeckungen. Die meisten seiner Lehrbücher sind Sammelwerke verschiedener Sachliteratur, deren Besonderheit es jedoch ist, in verständlicher arabischer Sprache verfasst worden zu sein. Benötigt man zu jener Zeit einen ungewöhnlich umfangreichen Sprachschatz und etliche Lexika, um ein klassisches arabisches Werk aus den früheren Jahrhunderten $\mathrm{zu}$ verstehen, so sind Van Dycks Bücher für ein normal gebildetes Lesepublikum verfasst. ${ }^{521}$ Somit kann ihm zu Recht das Prädikat zugesprochen werden, dass er das Wissen nicht „popularisiert“", sondern „,humanisiert“ hat. ${ }^{522}$ Yusūf al-Asīr, der Van Dyck bei der Übersetzung der Bibel assistiert hat, sagt einige Jahre nach Van Dycks Tod zu dessen Tochter: ,Your father taught me, by his published writings, that it is possible to write good Arabic, correct in grammar and in idiom, in a style so simple and so clear as to be easily understood by an intelligent reader, whether learned or unlearned." 523

Seine Lehrbücher sind bahnbrechend und nicht nur in Syrien, sondern auch Ägypten beliebt. Dabei geht der Bekanntheitsgrad seiner Schriften auch über den christlichen Rahmen hinaus. An der Kairoer Al-Azhar Universität sind Van Dycks Werke ebenso angesehen wie unter muslimischen Reformern wie Muhammad Rašīd Riḍā oder Muḥammad 'Abduh. 524

514 Makdisi (2010), 46: Van Dyck wächst somit nicht in einem evangelisch-orthodoxen Kontext auf.

515 So das Urteil seines Schülers Ğurğĩ Zaydān, in: Philipp (1979), 34.

516 Ebd., 179.

517 Zitiert in: Hūūī (1990a), 73.

518 Dennis (1896), 36: „Many were accustomed to visit him for counsel and cheer in their perplexities and troubles."

519 Al-Barūdī (1895), 215.

520 Sa'di (1937), 37.

521 Ebd., 35.

522 Ebd., 36.

$523 \mathrm{Ebd}$.

524 Șarrūf/Nimr (1896), 1; Sa'di (1937), 36; Glaß (1998b), 189. 
Mehr als zwei Drittel seines Lebens verbringt Van Dyck, der sich schon früh im traditionellen Gewand zu kleiden pflegt, ${ }^{525}$ in Syrien. Das trifft zwar auch auf viele seiner Missionskollegen zu, aber von keinem von ihnen behaupten die Syrer, dass es scheint, als sei er einer von ihnen. ${ }^{526}$ Die beschränkten Mittel des ABCFM lassen es nicht zu, dass die Missionare ihr Arbeitsfeld häufig verlassen können, um in die Heimat zu reisen. Mehrere Male bittet Van Dyck Rufus Anderson darum, in die USA reisen zu dürfen. Gründe dafür sind nicht nur Überarbeitung und der Wunsch nach körperlicher Erholung, sondern auch die Befürchtung, die Verbindung zu Amerika zu verlieren. 1852 schreibt er nach Boston:

I consider such a visit desirable in order that I may become re-Americanized. I find that I have already lost a large part of my American notions, feelings and sympathies. I have become very much Syrianized, and cannot say that I feel it be much of an acquisition. I no longer feel that interest in American affairs, or even in the affairs of the Board which I once felt and which every missionary ought to feel. ${ }^{527}$

Jessup berichtet, dass Van Dyck kurz vor seinem Tode gesagt habe: „I have made a great mistake. I should have improved my regular vacations. I have lost touch with the American Church and American life. " ${ }^{2528}$ Es ist demnach auch den Umständen zuzusprechen, dass sich manche Missionare mehr oder weniger mit der neuen Kultur zu identifizieren beginnen.

Ein besonderes Ereignis spricht für Van Dycks Bekanntheitsgrad in der syrischen Bevölkerung, in vielen Religionsgruppen und unter osmanischen Politikern: 1890 wird, wie bereits erwähnt, sein fünfzigjähriges Jubiläum in Syrien begangen. Es gibt kaum eine arabische Zeitung in Beirut, die darüber nicht berichtet. Van Dyck, der eigentlich wenig von großen Feierlichkeiten hält, ist überwältigt von der Anteilnahme. ${ }^{529}$ Tagelang erhält er offizielle Besuche: Die Missionare überreichen ihm eine gebundene Gesamtausgabe seiner arabischen Werke, ${ }^{530}$ Kaiserswerther Diakonissen, zu denen Van Dyck einen guten Kontakt hat, ${ }^{531}$ kommen mit einigen Schülerinnen und erweisen ihm die Ehre, ebenso Mitglieder der einheimisch-protestantischen Kirche und ein Komitee der „Sons of Syria and Egypt“, deren Rede John Wortabet für Van Dyck, den Liebhaber einer einfachen, aber ästhetischen Sprache, bearbeitet, ,that it should contain none of the extravagant Eastern expressions which are so painful and often shocking to our severer, simpler tastes“" ${ }^{532}$ Ein

$525 \mathrm{Sa}$ 'di (1937), 26.

526 Jessup (1910a), 107.

527 Van Dyck an Anderson (Sidon, 30.9.1852): ABC 16.8.1., Vol. 5 (327).

528 Jessup (1910a), 366: Auch William Thomson und William Bird haben sich ähnlich geäußert.

529 Șarrūf/Nimr (1890), 320-323; dies. (1895), 888: Grußworte kommen auch vom Prinzen 'Abd al-Qādir al-Ḥuseynī al-Ğasā' irī sowie dem Muftī von Damaskus Maḥmūd Ḥamza. Sogar der ägyptische Reformdenker Muhammad 'Abduh beteiligt sich an den Vorbereitungen: vgl. Glaß (1998b), 189.

530 Dennis (1896), 35.

531 Gemäß Julia Hauser, die sich in ihrer Dissertation den Kaiserswerther Diakonissen in Beirut widmet, gehören u. a. Van Dyck sowie Daniel Bliss zum engeren ,Kundenkreis‘ der Diakonissen. Jasmīn Šarrūf, ehemals in der Ausbildung bei den Kaiserswerthern, arbeitet im Hause Van Dyck als Haushaltsgehilfin: vgl. dies. (2014), 139, 168.

532 Presbyterian Church in the USA (1891), 484-485. 
Grußbrief des griechisch-orthodoxen Patriarchen von Antiochien erreicht ihn sowie eine von Sultan 'Abul Hamīd II. gesandte Reichsmedaille dritten Ranges zu Ehren von Van Dycks humanen, wissenschaftlichen und literarischen Leistungen. ${ }^{533}$

Fünf Jahre später sind die Zeitungen erneut gefüllt von Artikeln über den berühmten Amerikaner, dieses Mal sind es Todesanzeigen. ${ }^{534}$ Am 13. November 1895 verstirbt Van Dyck im Alter von 77 Jahren. ${ }^{535}$ Ya qūb Șarrūf und Fāris Nimr schreiben im Muqtațaf, dass Van Dyck zu den wichtigsten Personen zähle, die aus dem Ausland nach Syrien gekommen sind. Neben vielen anderen habe auch er Syrien zur wissenschaftlichen und literarischen Erweckung geführt. ${ }^{536}$

Es fällt den Syrern nicht leicht, Van Dycks ausdrücklichem Wunsch nachzukommen, zu seinem Begräbnis keine der in der arabischen Welt gebräuchlichen Eulogien mit ihrer poetischen und oft sehr tragenden Sprache zu halten. Etliche verfassen solche Eulogien, die Van Dycks Kollege am SPC Iskandār al-Barūdī schließlich in einem gesonderten Band herausgibt. ${ }^{537}$ Etwa eine Woche nach Van Dycks Begräbnis werden unter der Leitung von Henry Harris Jessup Gedenkgottesdienste in verschiedenen Gemeinden in Syrien abgehalten, „,in all these places men of all sects, Oriental Christians, Moslems and Druses were among the hearers" “. 538

533 Presbyterian Church in the USA (1890), 289; dies. (1891), 485; 'Ağulūnī (1964), 21; Makdisi (2010), 76-77.

534 Ebd., 76.

535 Noch heute kann man Van Dycks Grab auf dem Anglo-American Cemetery in Beirut besuchen. Der Grabstein wurde von John Wortabet und vielen weiteren Weggefährten Van Dycks errichtet: vgl. Jessup (1910a), 111.

536 Șarrūf/Nimr (1895), 882.

537 Jessup (1910a), 110.

538 Jessup (1910b), 613-614. 


\section{KAPITEL III}

\section{DIE GEMEINSCHAFT SYRISCHER PROTESTANTEN IN DER CONTACT ZONE}

$[T]$ he missionaries $[\ldots]$ are always referred to as the sole founders of this or that school or university, as though they had done this entirely independently and alone. Not enough credit for the creation of modernity has ever been given to those who pressed them to open schools, send their children, gave them the land, ${ }^{2}$ built the buildings, taught in the schools, and in general participated in the enterprise. ${ }^{3}$

Missionsgeschichtliche Studien haben sich aus diesem Grund in den letzten Jahren vermehrt den Biografien einheimischer Konvertiten gewidmet. Diejenigen, die sich dem Glauben der Missionare anschließen und sie in ihrer Arbeit unterstützen, stehen oftmals im Schatten der Errungenschaften westlicher Missionen. ${ }^{4}$ Zwar gilt das „Andere“ als exotisch und dient häufig als Subjekt unterhaltsamer oder außergewöhnlicher Geschichten, ${ }^{5}$ aber die einheimische Bevölkerung zu generalisieren, statt individuelle Charaktere herauszustellen, ist ein verbreitetes Phänomen in der religiös und nicht-religiös animierten Reiseliteratur des 19. Jh.s. ${ }^{6}$ Die Syrienmission ist daher ein Beispiel unter vielen dafür, dass der Werdegang einheimischer Missionare, Lehrerinnen und Lehrer, Übersetzerinnen und Übersetzer oder Helferinnen und Helfer oftmals schwer zu rekonstruieren ist. Selten gehen die Quellen

1 Zur contact zone siehe Abschnitt 1 der Einleitung; vgl. Pratt (1991).

2 Vgl. dazu Lindner (2011a), 38: „The History of both the Mission House and the Old Susa House demonstrates that the ABCFM missionaries were inherently dependent upon Syrians to acquire dwellings for them, even if the original details of these alliances are lost."

3 Makdisi (2007), 142. Diese einseitige Darstellung wird von der Mission im 20. Jh. relativiert und den syrischen Protestanten die gebührende Anerkennung zugesprochen: vgl. McGilvary (1920); PBCFM (1923). Siehe auch das unten angeführte Zitat aus dem Jubiläumsband der American Mission Press.

4 Siehe dazu: Christine Lindner, Negotiating the Field: American Protestant Missionaries in Ottoman Syria, 1823-1860 (2009); dies., The Flexibility of Home: Exploring the Spaces and Definitions of the Home and Family Employed by the ABCFM Missionaries in Ottoman Syria from 1823 to 1860 (2011); Fruma Zachs, Building a cultural identity: the case of Khalil alKhūrī (2004); Andrew Witmer, „Agency, Race, and Christianity in the Strange Career of Daniel Flickinger Wilberforce“, in: Church History 83/4 (Dezember 2014), 884-923.

5 Bhabha (2000), 99: Die „Andersheit“ ist stets „Objekt des Begehrens wie der Belustigung“.

6 Bspw. Ida Pfeiffer, Reise einer Wienerin in das Heilige Land, Wien 1846; Colonel Churchill, Mount Lebanon: A Ten Years' Residence from 1842 to 1852. Describing the Manners, Customs, and Religion of its Inhabitants, 3 Bde., London 1853. Die Historikerin Xue Li macht derzeit ähnliche Beobachtungen in ihrer Doktorarbeit „Making local China: The case of the Protestant Church in Yangzhou". In einem 1884 veröffentlichten Artikel englischer Missionare in Yangzhou ist lediglich von „native preachers“ die Rede bzw. von „four men“ oder „a mandarin's son“, die den Kontakt zu den Missionaren suchen: vgl. Taylor (1884), 67. 
über eine allgemein gehaltene ${ }^{7}$ oder erbauliche Beschreibung hinaus, in der es vor allem um das Bekehrungserlebnis geht. ${ }^{8}$ Sehr ausführlich berichtet der Missionary Herald daher über die Geschichte von As 'ad al-Šidyāq, der früh konvertiert, jedoch in Gefangenschaft des maronitischen Patriarchen 1830 stirbt und damit für die Mission zum ersten Märtyrer wird. ${ }^{9}$ Auch hierbei steht weniger die Person als vielmehr ihre religiöse Neuorientierung im Vordergrund. ${ }^{10}$ Erwähnenswert sind darüber hinaus Henry Harris Jessups Monographien Women of the Arabs (1874) mit drei Kapiteln über die syrischen Protestantinnen Lucīya Šikkūr, Rāḥ̄il 'Ațā und Miryam Nahass sowie sein Buch über den Konvertiten Kamil Abdul Messiah El Aietany (1898). In diesen Biografien ist es Jessup offenkundig ein Anliegen, die sozialen und familiären Probleme der Konvertitinnen und Konvertiten für die Leserschaft auf spannende und unterhaltsame Art und Weise zu beschreiben.

In der öffentlichen Darstellung der Mission stehen in jedem Fall die amerikanischen Missionare als Hauptakteure im Vordergrund. Ihre einheimischen Mitarbeiter werden zumeist als native helpers, und in seltenen Fällen als native assistants bezeichnet, obwohl viele von ihnen die Bildungsinstitutionen der Mission durchlaufen oder zuvor renommierte christliche Hochschulen in Syrien besucht haben. Die Namen von Būṭrus al-Bustān̄̄, Tannūs al-Ḥaddād, Elyās Fawāz, die jahrzehntelang im Dienste der Mission stehen, werden in vielen Berichten des Missionary Herald entweder durch Bezeichnungen wie „,native brother“ ersetzt oder es bleiben ihre Initialen stehen, was sie für amerikanische Leser zu Unbekannten macht. ${ }^{11}$ Die Rollenverteilung in der Mission ist über Jahrzehnte definiert und deutet auf ein dauerhaftes Mentor-Schüler-Verhältnis hin, das die Notwendigkeit missionarischer Präsenz ${ }^{12}$ rechtfertigt und die Kontrolle über die Entwicklung eines evan-

7 Im jährlichen Bericht der Syrienmission werden die einheimischen Mitarbeiter nur der Anzahl, aber nicht dem Namen nach aufgeführt.

8 Ebenso verhält es sich mit den von deutschen Missionaren in Tranquebar geschriebenen Lebensläufen über ihre „Nationalmitarbeiter“: vgl. Liebau (2008), 96. Geschichten über Konvertiten finden sich in protestantischen Missionsperiodika viel häufiger als in katholischen, was mit dem Interesse der Protestanten am Zusammenspiel von Glaube und Individualität zusammenhängt, so Wu (2014), 79-80.

9 MH 23 (1827), in: ROS 1, 437-449, 456-468; siehe auch Isaac Birds The Martyr of Lebanon (1864) oder Būṭus al-Bustān̄is Qissat As 'ad al-Šidyāq (Die Geschichte von As 'ad al-Šidyāq, 1860).

10 Makdisi (2008, 103-137) hat sich kritisch mit As 'ads Beweggründen und der verklärten Wahrnehmung der Ereignisse durch die Mission auseinandergesetzt.

11 MH 34 (1839), in: ROS 3, 158; MH 41 (1845), in: ebd., 401, 416: „They were instructed by B. B. In the afternoon T.H. assisted me [...]. "Van Dyck schreibt am 9.11.1846 an Rufus Anderson: ,the instruction being given during one half of the day by Butrus el-Bistany in Arabic Grammar“, vgl. ABC 16.8.1., Vol. 5 (315). Der Missionary Herald (Bd. 43, 1847) fasst zusammen: ,being given one half of the day by our native brother", zitiert in: $\operatorname{ROS} 4,3$.

Gleiches gilt für die Berichte dänisch-deutscher Missionare in der Tranquebarmission, besonders ab dem 19. Jh. (vgl. Liebau, 2008, 95) sowie für die Mission des ABCFM im osmanischen Bulgarien (vgl. Reeves-Ellington, 2013, 128-130).

12 Hauser (2011), 28: In der Berichterstattung von Theodor Fliedner und den Kaiserswerther Diakonissen werden Stereotype und Beschreibungen der Syrer aus einer Überlegenheit heraus bewusst eingesetzt, um das Missionsunternehmen zu rechtfertigen. 
gelischen Christentums in Syrien erlaubt. Für die einheimischen Mitarbeiter ist es sehr schwer, diese Verhältnisbestimmung aufzubrechen, um schließlich auf gleicher Ebene mit den Missionaren zu stehen wie aus den Biografien von Bustānī und Wortabet ersichtlich wird.

Protokollmitschriften der Jahresversammlungen sowie der regelmäßigen Treffen der Missionare machen deutlich, dass einheimische Mitarbeiter nie daran teilnehmen. Im Falle eines Anliegens, das der Mission vorgestellt werden soll, wird dies schriftlich von einem der Missionare vorgetragen und in Abwesenheit des Antragstellers besprochen. Ein weiterer Punkt, der bei Bustānī und Wortabet immer wieder zu Disputen führt, ist ihre direkte Anstellung bei der Mission, jedoch nicht beim ABCFM. ${ }^{13}$ Auf diese Weise gelten sie nicht als vollwertige Mitarbeiter der Syrienmission und die Bezahlung der Gehälter erfolgt nicht durch den ABCFM, sondern setzt sich z.T. aus Spendengeldern der amerikanischen Bibelgesellschaften zusammen. ${ }^{14}$ Ein weiteres Problem ist die Höhe des Gehalts: Während die Amerikaner ein Jahresgehalt von ca. $\$ 800$ bis $\$ 1000$ beziehen, erhalten einheimische Mitarbeiter je nach Arbeit in etwa $\$ 100$ bis $\$ 300 . .^{15}$

Die eigentlichen Adressaten der Mission spielen auch in den Korrespondenzen der Missionare häufig nur eine untergeordnete Rolle. Im Vordergrund stehen persönliche Erfahrungen und Probleme, die mit dem Verlauf der Mission zusammenhängen. Syrische Helfer, und in seltenen Fällen Helferinnen, werden darin oftmals beiläufig erwähnt. In keinem der Dokumente findet sich eine Liste der einheimischen Konvertitinnen und Konvertiten, Mitarbeiter oder Helfer - nicht einmal für einen bestimmten Zeitraum. Die zusammengestellte Liste in Anhang II soll aus diesem Grund eine Hilfestellung geben.

Erst mit Beginn des 20. Jh.s finden syrische Protestanten, die für die Mission arbeiten oder bestimmte Arbeitsbereiche nun selbst leiten, mehr und mehr öffentliche Anerkennung. Zum einhundertjährigen Jubiläum der American Mission Press 1922 schreibt der amerikanische Missionar George Ford rückblickend:

It need not be said, to be surely and fully known, that it has not been the American missionaries who have done the bulk of this work. They would have been powerless and helpless but for the capable and reliable men of the country who have done most of the work and done it well. ${ }^{16}$

13 Anderson an die Syrienmission (On board the Turkish Steamer, 23.4.1844): ABC 16.8.1., Vol. 8.

14 „General Meeting of the Syria Mission“ (Beirut, 24.4.1842): ABC 16.8.1., Vol. 1. 1848 fordert Bustānī eine direkte Anstellung beim ABCFM, was jedoch nicht gewährt wird: vgl. Badr (1992), 296.

15 Tibawi $(1966,210)$ setzt die Missionarsgehälter zwischen 1000 und 1200 Dollar an. Laut Quellen des ABCFM ist dieser Wert jedoch zu hoch. In den ersten Jahren beziehen die Missionare zwischen 600 und 800 Dollar mit leichter Steigerung in den nächsten Jahrzehnten: vgl. Bericht an das Prudential Committee (Beirut, 24.4.1842): ABC 16.8.1., Vol. 1 (29).

Die Ungleichheit der Gehälter hat u. a. damit zu tun, dass die Lebenshaltungskosten der Missionare höher geschätzt werden als die der Einheimischen, die sich bestens mit den lokalen Gegebenheiten auskennen. Zudem wird für die Ausstattung der Missionsfamilien Verschiedenes aus den USA per Schiff versandt. Vgl. Liebau (2008), 132.

16 PBCFM (1923), 14. In diesem Jubiläumsband werden etliche bedeutende syrische Autoren, Übersetzer und Übersetzerinnen sowie Mitarbeiter der Druckerei namentlich genannt. 
Das Heranwachsen einer indigenen protestantischen Gemeinschaft wird neben der herkömmlichen Missionsarbeit besonders durch zwei Aspekte gefördert, die hier nicht unerwähnt bleiben sollen. Zum einen durch die Heirat innerhalb des neu entstehenden protestantischen Zirkels. Zum anderen durch die Aufnahme syrischer Mädchen, seien sie Waisen, Halbwaisen oder aus armen Familien, in die Missionsfamilien. ${ }^{17}$

Die Heirat innerhalb der syrisch-protestantischen Gemeinschaft hängt zwar mit dem neuen Gemeinschaftsgefühl zusammen, das sich durch gemeinsame Religion und Bindung zur Mission entwickelt, ${ }^{18}$ sie bedeutet aber den Bruch mit der traditionellen Verheiratungspraxis innerhalb der Herkunftsreligion. ${ }^{19}$ Būtrus al-Bustān̄̄, ehemals Maronit, heiratet Raḥ̂̄ 'Ațā, die in der Familie von Eli Smith aufwächst und jegliche Bestrebungen ihrer eigenen Familie, innerhalb des griechisch-orthodoxen Clans zu heiraten, ablehnt. ${ }^{20}$ John Wortabets Mutter, Susan, heiratet nach dem Tod ihres ersten Mannes, Jacob Gregory, den evangelischen Diakon Elyās Fawāz. Salome Carabet, Tochter des Konvertiten John Carabet wächst schon als Kind in die evangelische Gemeinschaft hinein und heiratet schließlich John Wortabet, der von Kindheit an mit der Mission in Verbindung steht. ${ }^{21}$

Die Aufnahme syrischer Mädchen in den Missionarsfamilien Smith, Whiting, Van Dyck, Calhoun, De Forest u.a. ist eine gängige Praxis in den Missionen, wie MARILYN BoOTH es beschreibt: „Because missionaries viewed the family as key to conversion, and women as key to the family, it was thought that the most efficient means of instilling the missionaries' brand of belief in the field was to train young girls in missionary homes. "22 Wie bei den Whitings, die selbst fünf Mädchen aufnehmen (Salome und Melita Carabet, Hannī Wortabet, Rufka und Sada Gregory), ${ }^{23}$ helfen syrische Pflegekinder in den Schulen und Gemeinden aus, um später selbst als Lehrerinnen zu arbeiten oder ihren zukünftigen syrisch-protestantischen Männern unterstützend zur Seite zu stehen. ${ }^{24}$ Missionarsfrauen sollen den syrischen Mädchen bessere Vorbilder als Ehefrau und Mutter sein als die eigenen Mütter, von denen sie getrennt werden. ${ }^{25}$ Besonders für die Ehefrauen der Missionare werden

17 Van Dyck (o.J.), 6: ,some of the children were taken into Mission families and put into the Mission Seminary“; Lindner (2009), 236: „Another orphan was the Druze ,Sitt Abla“. This young woman rejected the care provided by her biological family and ,took refuge" in the house of the Van Dyck family, thus becoming an adopted boarding student in the Van Dyck family.“

18 Liebau (2008), 192-193.

19 Lindner (2009), 132: Die einzige Ausnahme bildet Hannī Wortabet, John Wortabets Schwester, die den deutschen Missionar Heinrich Reichardt heiratet.

20 MH 39 (1843), in: ROS 3, 381-382; Lindner (2009), 93-94. Mehr über Rahị̂l 'Ațā al-Bustān̄̄ in: Lindner (2014a).

21 Näheres dazu in III.2. und Anhang II.

22 Booth (2002), 434.

23 Jessup (1874), 54, 64; Lindner (2009), 236-237, 273.

24 Missionarsfrauen, die sich um die Erziehung einheimischer Mädchen kümmern, gehören ebenso zur Bildungselite ihrer Zeit, da sie in den USA auch Seminare besucht haben. Das Gleiche gilt für Generationen von syrisch-protestantischen Frauen, die ihre Ausbildung in Missionsschulen und Missionarsfamilien erhalten haben. Näheres dazu in Lindner (2011).

25 Reeves-Ellington (2013), 33: „They also feared that the girls would revert to their traditional religious customs if they returned home to live." 
die neuen Familienmitglieder, die ihnen in vielen Fällen ans Herz wachsen, als Adoptivkinder betrachtet. ${ }^{26}$ Jedoch verläuft diese „Adoption“ nicht immer im völligen Einverständnis zwischen biologischen Eltern und Missionarsfamilie. Dies zeigt bspw. der Umgang der Missionarsfrau Matilda Whiting mit Susan Wortabet, John Wortabets Mutter, die ihre Tochter Hannī nicht freiwillig in die Obhut der Whitings geben möchte, wie LINDNER in ihrer Untersuchung herausstellt:

Her unequal status was emphasised during Susan's conflict with Matilda Whiting. The missionaries assumed that Susan would automatically and unreservedly place her daughter Hannie under Matilda's care and were shocked when Susan refused to do so. Despite Susan's contestation however, Hannie was relocated to Jerusalem and resided with Matilda Whiting. ${ }^{27}$

In den Missionarsfamilien sowie in den Schulen wachsen die Kinder von Beginn an im Kontext eines westlich-protestantischen Wertesystems auf. Dass hierbei eine neue Generation syrischer Kinder heranwächst, die sich sozusagen zwischen den Kulturen bewegt, ist unausweichlich. Nicht jeder syrische Protestant, der seine Schullaufbahn bei den Amerikanern absolviert, wird von den Missionaren als geeignet für die evangelische Gemeinschaft befunden, trägt aber dennoch zur Veränderung syrischer Bildungskultur bei. LinDNER nennt sie die von der Mission unabhängige „Protestant Levantine community“ ${ }^{28}$ In den Augen der Mission sind deren Anhänger ohne Frömmigkeit und Spiritualität, sie benutzen das Ansehen der Amerikaner, um nach Reichtum und Prestige zu streben. ${ }^{29}$ John Wortabets Bruder, Gregory, der ebenso das Beiruter Jungenseminar besucht, scheint den Missionaren von Beginn an als Nachwuchsprediger ungeeignet. Umso größer ist die Empörung über seine, weltliche" Laufbahn, die ihn nach England und in die USA führt, jedoch von einer beträchtlichen Karriere zeugt. ${ }^{30}$ Eine solche, sich aus der

26 Lindner (2014a), 52: Sarah Lanman Smith, die Bustān̄̄’s spätere Frau Raḥ̄l 'Ațā als junges Mädchen in die Familie aufnimmt, sieht Raḥil ebenso als Adoptivkind (vgl. Hooker, 1839, 377). „It is most likely that Rahil's parents viewed this arrangement as an apprenticeship, rather than adoption, as the former were common in early nineteenth century Ottoman Syria." Sarah Smith betrachtet Rahịl darüber hinaus als sei sie „between a daughter and a servant": vgl. Hooker (1839), 371.

27 Lindner (2009), 181-182, 185.

$28 \mathrm{Ab}$ den 1850er Jahren machen sich etliche Syrer, die aus dem Umkreis der Mission stammen, durch unabhängige Publikationen in Europa und Amerika einen Namen. Vgl. Lindner (2009), 22: ,these publications were either academic studies or ,travellers accounts' and followed the narrative styles that were popular in contemporary Europe and America." Dazu zählen: Gregory Wortabet, Syria and the Syrians (1856); John Wortabet, Researches into the Religions of Syria (1860); Habeeb Risk Allah Effendi, The Thistle and the Cedar of Lebanon (1854); Assaad Y. Kayat, A Voice from Lebanon, With The Life and Travels of Assaad Y. Kayat (1847).

29 Lindner (2009), 159. Vgl. dazu das Abwerben der Schüler des Mission Seminary in Beirut durch ausländische Geschäftsleute und Militärs: W. M. Thomson, „The Committee in the results of the Seminary submit[s] the following report" (6.4.1844): ABC 16.8.1., Vol. 1 (23).

30 Als Gregory Wortabet 1855 nach wohlwollenden Unterstützern in England sucht, versucht Smith zu intervenieren und klarzustellen, dass man jemandem, der eine Gruppe syrischer Tänzerinnen geleitet habe und nun in England und Amerika erfolgreich werden möchte, nicht trauen könne: vgl. Smith an Young (Beirut, 21.7.1855): ABC 60 (105), (HHL). Gregory Wortabet wird jedoch auch als Autor und Lektor in England und den USA erfolgreich. Näheres dazu in Anhang II, Nr. 66. 
„Wiege der Mission“ heraus entwickelnde Selbstständigkeit stellt einen der Hauptkonflikte dar, in denen sich selbstbewusste, syrische Protestanten wiederfinden. Die von den Missionaren propagierte Freiheit des Denkens und Emanzipierung von falschen christlichen Traditionen muss sich im Rahmen der Kontrolle durch die amerikanische Mission bewegen. Divergierende theologische Ansichten oder unabhängige Lebenspläne außerhalb der Mission werden nicht akzeptiert und führen unweigerlich zum Ausschluss aus der Mission, wenn auch nicht aus der indigenen protestantischen Gemeinschaft. Darüber hinaus wird eine unter syrisch-protestantischen Intellektuellen stattfindende Reflektion über die eigene religiöse und wissenschaftsbezogene Kultur von den Missionaren erschwert. Zum einen wird der Bruch mit der traditionellen und als verwahrlost eingeschätzten Religion gefordert, die aber eng mit der kulturellen Identität zusammenhängt. Zum anderen soll eine „DeNationalisierung" und das Annehmen eines Habitus westlicher Kulturen vermieden werden, damit die indigene kulturelle Identität nicht verloren geht. ${ }^{31}$ AnNe FolKe Henningsen hat die Situation, in der sich Menschen unter Einfluss der Missionare wiederfinden als „,double bind situation“ bezeichnet. ${ }^{32}$ Am Beispiel der Mission der Böhmischen Brüder in Südafrika berichtet sie von den Konvertiten, sie seien „never quite, white' enough and never quite ,native“ enough to be properly categorised and dealt with accordingly" ${ }^{33}$ Dies trifft in jedem Fall auch auf die syrischen Konvertitinnen und Konvertiten zu. Was Henningsen bei einem südafrikanischen Pfarrer beobachtet, findet auch Parallelen bei John Wortabet: William S. Mazwi sieht sich ebenbürtig mit den europäischen Missionaren (,Sir, remember you are a minister and I am also a minister.“). HeNNINGSEN spricht hierbei von der ,strategy of sameness". ${ }^{34}$ Auch John Wortabets Konflikt mit der amerikanischen Mission ist geprägt von der Forderung nach Gleichbehandlung. Auf der anderen Seite lassen sich aber auch Verhaltensparellen zu den Missionaren in Ansichten über orientalische Christen erkennen. ${ }^{35}$ John, der eigentlich den arabischen Namen Yuhannā trägt, akzeptiert die Anglisierung seines Namens - was übrigens auf viele Kon-

31 Samir Khalaf (2001, 150), der diesen Punkt ebenfalls anführt, argumentiert, dass die Missionare die Einheimischen auffordern, den Schleier ihrer verwahrlosten Kultur abzulegen. Es wird allerdings die Religionspraxis der orientalischen Kirchen von den Missionaren als anstößig empfunden, nicht die Kultur selbst, wie man bei Smith und Van Dyck sieht.

Im Verhalten gegenüber den Konvertiten gibt es Ähnlichkeiten zu Bhabhas Beschreibung der „Kolonialisierten“, die als „menschliches Chamäleon“ (mimic man) des Kolonialisierers erscheinen und dennoch nicht wie er sind: vgl. ders. (2000), 129.

32 Henningsen (2011), 152.

33 Ebd., 153.

34 Ebd., 139-140. Als weiteres Beispiel dafür gilt die Mission der London Missionary Society im südlichen Botswana im 19. Jh. Von den einheimischen Predigern wird erwartet, dass sie zu „Sprachrohren der Wahrheit“" werden, jedoch ohne kritische Reflektion und Abweichung von ihren Mentoren. Das führt sogar dazu, dass sie die Predigten der Missionare wortwörtlich rezitieren und ihre Gesten nachahmen: vgl. Comaroff/Comaroff (1997), 82.

35 Wortabet (1860), 14:,[I]t is certain that, among all the clergy of the Greek Church in Syria, there is not more than one or two that can be called learned men." Mazwi z. B. berichtet von der Gewaltbereitschaft, die seinen südafrikanischen Landsleuten zu Eigen ist und spricht von ihnen als den ,natives“: vgl. Henningsen (2011), 143. 
vertiten zutrifft ${ }^{36}$ - und nutzt ihn zur Signierung seiner englischen Schriftstücke. Somit dient die Anglisierung der Namen nicht nur der Vereinfachung, sondern wird bei manchen syrischen Protestanten auch Teil der eigenen Identität. Die Namen der Missionare, ihrer Frauen und Kinder werden nicht selten von syrischen Protestantinnen und Protestanten an ihre Kinder weitergegeben, was ebenso als besondere Wertschätzung der amerikanischen Mission gesehen werden kann. ${ }^{37}$

Werden nun die Syrerinnen und Syrer, deren Lebenswege durch die Erziehung in den amerikanischen Bildungseinrichtungen nachhaltig geprägt sind, zu HybridGestalten, d.h. zur Artikulation von kulturellen Inhalten der Autorität [sc. Missionar] mit einheimischen Kenntnissen, wie Номі Внавна es definiert? ${ }^{38}$ Welcher Kultur fühlen sie sich zugehörig, wenn sie äußerlich westlich wirken, jedoch auf die Originalität ihrer Herkunft bestehen? Zwar möchten die Missionare eine Verwestlichung der Konvertiten sowie freiheitliches, von missionarischer Ideologie unabhängiges Denken, vermeiden, dennoch wird das Ineinanderfließen zweier oder mehrerer Kulturen bei den syrischen Protestanten von den Amerikanern unbewusst geradezu gefördert, wie man bei Bustān̄̄ und Wortabet sehen kann. Dabei ist die Integration verschiedener intellektueller und kultureller Einflüsse ein verbreitetes Phänomen in vielen Ländern der Welt, die sich im 19. Jh. ebenso in einer Phase des Umbruchs und der Fortführung der Aufklärung befinden. ${ }^{39}$ Solche Kulturkontakte sind unumkehrbar und demnach darf eine gegenseitige Einflussnahme (die es auch bei Smith und Van Dyck gegeben hat) nicht als hegemonial oder kulturimperialistisch abgetan werden. Syrische Protestanten, ob männlich oder weiblich, nehmen aus eigenen Stücken westlich-protestantische Denk- und Verhaltensweisen an. In vielen Fällen entscheiden sich syrische Mädchen bewusst für die Aufnahme in die Missionsfamilien, auch syrische Jungen und Männer profitieren in ihrem beruflichen Werdegang von der in den Schulen vermittelten Arbeitsamkeit und Bildung. ${ }^{40}$ Formal gesehen hat für syrische Konvertitinnen und Konvertiten eine Entfremdung von ihrer Herkunft stattgefunden, da sie durch Exkommunikation oder Austritt aus der Kirche zu Andersgläubigen in der eigenen Familie werden. Andererseits finden sie Zuflucht und Sicherheit in der neuen Glaubensgemeinschaft, ohne sich von ihrer Herkunft zu distanzieren oder ihre Wurzeln völlig zu verleugnen. ${ }^{41}$ Die kulturelle

36 Aus Ğurğ wird bspw. George oder Gregory, aus Sardas Susan. Nicht in jedem Fall werden die Namen anglisiert, Kinder syrischer Protestanten erhalten jedoch häufig englische Namen. Vgl. dazu die Namen in Anhang II.

37 Zum fünfzigjährigen Jubiläum von Cornelius Van Dyck in Syrien schreibt William Eddy über dessen Frau Julia: „not without reason is ,sit Julia“ a name honored and loved in Syria, and proudly worn by many Syrian girls“. Vgl. Presbyterian Church in the USA (1890), 289. John Wortabet nennt z. B. zwei seiner Söhne William Thomson (nach dem Missionar William M. Thomson) sowie Erwin Whiting (nach dem Missionar George B. Whiting). Būṭrus al-Bustān̄̄ gibt einer seiner Töchter den Namen von Eli Smiths erster Frau, Sarah Huntington.

38 Bhabha (2000), 170.

39 Conrad (2012), 1014.

40 Lindner (2014a), 52-53: Durch Sarah Smith „Rahil was [...] encouraged to embody a hybrid identity that fused elements of American evangelical Protestantism, particularly its view of piety, industriousness and literacy, with her Ottoman Syrian culture and Arabic language."

41 Semaan (1985), 5. 
Identität vermischt sich mit neu angeeigneten Werten zu einer Art hybrider Identität. Im Folgenden soll gezeigt werden, zu welchen Erkenntnissen Bustānī und Wortabet im Zuge dieses Vorgangs gelangen.

\section{III.1. „EIN MANN, DER SEINER ZEIT VORAUS IST“42? MU'ALLIM ${ }^{43}$ BUṬRUS AL-BUSTĀNĪ (1819-1883)}

\section{Kurzbiografie}

Im November 1819 wird Buṭrus al-Bustānī in Ḍbayye, nordöstlich von Sidon, geboren. Seit Generationen bekleiden Mitglieder seiner Familie ${ }^{44}$ geistliche Ämter innerhalb der Maronitischen Kirche und auch Bustānī besucht die priesterliche Hochschule 'Ayn Warqa in Ġasțā. Dort lernt er Arabisch, Syrisch-Aramäisch, Italienisch und Latein und ist später selbst als Lehrer tätig. 1840 verlässt er die Hochschule, um nach Beirut zu gehen, wo er mit der Amerikanischen Mission in Kontakt kommt und wenig später konvertiert. Die Missionare stellen ihn 1841 als Privatlehrer für Arabisch sowie als Mitarbeiter im Beiruter Seminar ein. ${ }^{45}$ In dieser Zeit begegnet er Raḥil 'Ațā, die seit ihrer Kindheit in verschiedenen Missionsfamilien lebt und von ihnen ausgebildet wird. ${ }^{46}$ Sie heiraten 1843 und bekommen neun Kinder. ${ }^{47}$

1846 bis 1848 leitet er mit Cornelius Van Dyck das Seminar in 'Abeih und verfasst dafür etliche Lehrbücher. Er gehört zu den Gründungsmitgliedern der einheimischen evangelischen Kirche in Beirut (Beirut Church) und ist bis 1878 Mitglied des dazugehörigen Ältestenrates. ${ }^{48}$ Bustān̄̄ hat zwar eine theologische Ausbildung bei den Missionaren genossen, er entscheidet sich jedoch gegen die Ordination. Stattdessen beginnt er eine erfolgreiche Karriere als Übersetzer, Autor und Journalist. Er gehört zu den Schlüsselfiguren der syrischen nahḍ und zählt heute zu den bekanntesten syrischen Gelehrten des 19. Jh.s. Am 1. Mai 1883 stirbt er an einem Herzinfarkt ,,pen in hand, surrounded by his books and manuscripts““ ${ }^{49}$ (Abb. 7)

42 So der Titel von Yūsuf Qasm Huūrīs Dissertation im Neudruck von 1995 (Rağul al-sābiq li'așrihi).

43 Arabisch für „Meister“ (s.u.).

44 Über Bustānīs Geschwister ist nahezu nichts bekannt: Laut Lindner (2014b) heißt ein Bruder Kanaan. Șarrūf/Nimr $(1883,2)$ sprechen von insgesamt drei Brüdern. 1858 besuchen Missionare einen der Brüder von Buțus, den sie namentlich nicht nennen: vgl. Bird, Journal: 1.1.1854-10.12.1867: ABC 76 (1), (HHL).

45 MH 37 (1841), in: ROS 3, 297.

46 Näheres zu Raḥil 'Ațā in: Jessup (1874), 120-139; Booth (2002), 433-438; Linder (2014a).

47 Laut Lindners Recherchen (2014a, 8) heißen die Kinder Sarah Marie (1844-1866), Salim (1846-1884), Adelaide (oder: Idlid), Martha (1849-1933), Louise Kathrine (1853-1923), Emma, Amīn Judson (1859-?), Nağib William (1862-1919), Nașīb (1866-?), Alice (18701926). Sarah Bustān̄̄, benannt nach Sarah L. Smith, die Raḥīl als erstes in die Familie aufnahm, stirbt 1866 an Typhus: vgl. Jessup (1874), 137-138.

48 NECB Protokolle (21.6.1878), 32.

49 Jessup (1910b), 484. Seine Frau Raḥīl stirbt im Jahr 1894: vgl. Lindner (2014a), 62. 


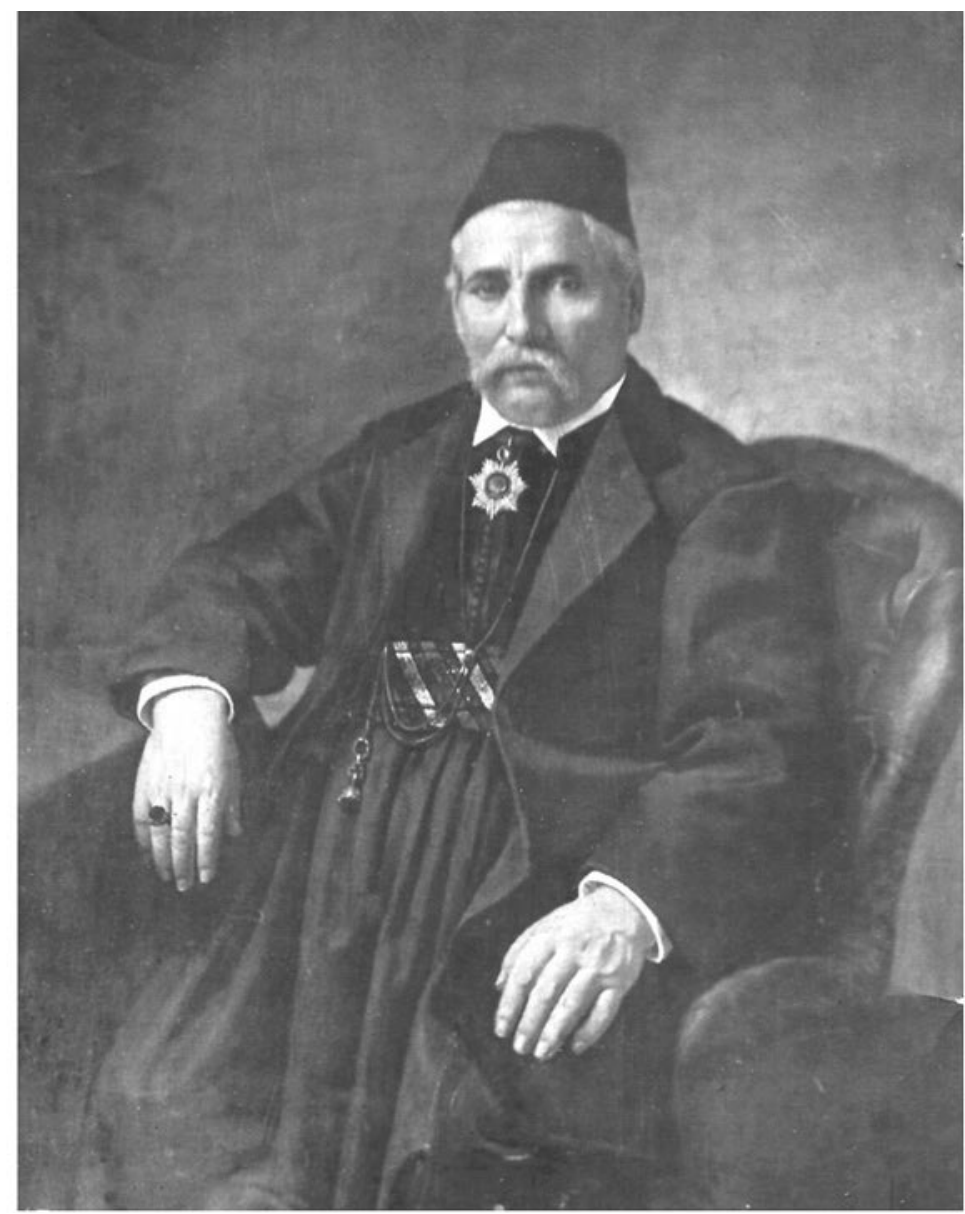

Abb. 7: Butrus al-Bustān̄̄

2. „May [he] live as burning and shining light [...] in this dark land“50_Bustān̄̄s Arbeit für die Mission

Als Bustān̄̄ mit 21 Jahren nach Beirut kommt, sind die Missionare - wie zu Anfang bei vielen einheimischen Helfern - viel mehr an seinen Fähigkeiten interessiert als ihn für den evangelischen Glauben zu gewinnen. ${ }^{51}$ So wie As' ad al-Šidyāq, Jacob

50 MH 37 (1841), in: ROS 3, 297.

51 Vgl. dazu Liebau (2008), 138. Als Lehrer im Seminar lobt ihn die Mission 1841 in den höchsten Tönen: „The exception above referred to is Butrus el-Bistany, teacher of Arabic in the Seminary. His case is of great interest [...] and uniting uncommon capacity with professional zeal, he has elevated the character of the Seminary. His grammatical attainments are thorough a branch of knowledge which is exceedingly rare in the country, and in which the boys have 
Wortabet oder Bischof Dionysios Carabet, die geistliche Ämter innehatten, bevor sie für die amerikanische Mission arbeiten, ${ }^{52}$ ist Bustān̄̄ mit seiner Ausbildung in 'Ayn Warqa eine gute Karriere innerhalb der maronitischen Kirche beschieden. Dass er 1840 nach Beirut kommt, mag vielen Umständen geschuldet sein. Zum einen führt der Abzug der ägyptischen Truppen zu einer Entspannung der politischen Lage im Land, was viele Menschen dazu veranlasst, aus den Bergen in die Stadt zu kommen. ${ }^{53}$ Zum anderen kann Bustānīs verwitwete Mutter verhindern, dass ihr Sohn für eine weitere Ausbildung nach Rom gesandt wird, da sie finanzielle Unterstützung für sich und zwei weitere Söhne benötigt. Der junge Syrer geht daraufhin vermutlich auf die Suche nach einer geeigneten Arbeit in der Stadt. ${ }^{54}$ Mit Vorsicht sind Henry Harris Jessups Erläuterungen in einem Nachruf zu lesen, Bustānī habe bei der Lektüre des Neuen Testaments in Syrisch-Aramäisch die Rechtfertigungslehre entdeckt und sei nach Beirut geflohen, wo er für zwei Jahre Schutz in Smiths Haus gesucht habe, ,lest he be shot by spies of the Maronite Patriarch“. ${ }^{55}$ Zum einen verwundert es nicht, dass Bustānīs Ortswechsel in den Augen der Missionare mit einer religiösen Sinnsuche verbunden ist, die ihn zu den Missionaren führt. Zum anderen kann Bustānī Smith erst im Jahr 1841 begegnen als dieser aus den USA zurückkehrt. ${ }^{56}$

Seien es nun praktische oder religiöse Gründe, die Bustānī nach Beirut führen. Nachdem er für zehn Jahre in 'Ayn Warqa studiert und selbst gelehrt hat, scheint er auf der Suche nach neuen Herausforderungen zu sein. Bereits ein Jahr nach seiner Ankunft in der Stadt zeichnet sich ab, dass Bustānī eine distanziertere Haltung zu seiner Heimatkirche eingenommen hat: Während der maronitische Patriarch versucht, ihn zurückzugewinnen, verfasst er ein Traktat über die Korruptionen des Papsttums. ${ }^{57}$ Zwischen 1843 und 1844 konvertiert Bustānī und geht mit William M. Thomson und Cornelius Van Dyck, mit dem er seit 1841 eng befreundet ist, nach 'Abeih, um dort eine Missionsstation und eine Schule aufzubauen. ${ }^{58} 1845$ setzt ihn

never before had suitable instruction. His department has been exemplary, and of his own accord he has conducted the usual Arabic religious exercises of the school - reading the Scriptures, with exposition and prayer. [...] If he remains steadfast, we can do no less than generously sustain him, both for the value of his services and the great importance of his example. We must at all events be enabled to secure as far as possible the instruction which he now furnishes, or the Seminary must languish." Vgl. Syrienmission an Anderson (Beirut, 24.4.1841): ABC 16.8.1., Vol. 1.

52 Semaan (1986), 45, 78. Näheres zu den Personen in Anhang II. Zur Theorie, dass das Konvertieren oftmals als Ausweg aus bestimmten Lebensumständen und Chance für eine bessere Zukunft gesehen wird: vgl. Thomas O’Dea, The Sociology of Religion (1966), 60, zitiert in: Semaan (1986), 93.

53 Glaß (2004a), 76.

54 Laut Tibawi $(1976,228)$ gibt es für die häufige Behauptung, Bustānī sei bei der britischen Armee als Übersetzer angestellt gewesen, keine Beweise. Laut Smith habe sich Bustānī erst mit der Zeit Englisch angeeignet: vgl. Smith an Anderson (Beirut, 31.12.1842): ABC 16.8.1., Vol. 1 (159).

55 Jessup (1883/84), 275.

56 MH 37 (1841), in: ROS 3, 309.

57 Ebd., 297.

58 MH 40 (1844), in: ROS 3, 389. 
die Mission in Hāṣbeiyā ein, wo eine neu aufgekommene Bewegung von Dorfbewohnern ihrem griechisch-orthodoxen Glauben absagen will und nun die Unterstützung der Mission benötigt. Die dortige neu gegründete Missionsschule wird unter Bustānīs Leitung in Sachen Disziplin und Ordnung die am besten geführte Schule der Mission. ${ }^{59}$ Eli Smith nimmt sich 1841 des begabten jungen Mannes an. Es entsteht zwischen beiden eine enge Beziehung, in der Smith die Rolle des Mentors und Förderers zugeschrieben werden kann. ${ }^{60} 1845$ schreibt er über den jungen Syrer:

$[\mathrm{He}]$ is remarkable for his sprightliness $[\ldots]$ he showed a good mind, susceptible of serious impressions, and he particularly distinguished himself by the ease and perfect accuracy with which he committed to memory the Assembly's Catechism. In decision and boldness as a Protestant, he was surpassed by none. ${ }^{61}$

In Hạș̣beiyā, wo die Lage aufgrund der Anfeidungen durch den griechisch-orthodoxen Patriarchen weiterhin sehr angespannt ist, hält sich Bustān̄ für einige Zeit allein auf, da die Anwesenheit von ausländischen Missionaren seiner Meinung nach nicht ratsam sei, wie er schreibt: „Not that you would be in personal danger, but your presence would more and more incense the Greeks; and if any disorders should occur, the missionaries would be blamed as disturbers of the peace. "62 Die Mission befolgt Bustān̄̄s Rat und es zeigt sich einmal mehr, dass die Amerikaner ohne ihre einheimischen Mitarbeiter wenig ausrichten können. Sehr bald schon gehört der junge Syrer aus Ḍbayye zu den wenigen viel versprechenden Kandidaten für das einheimische Pastorenamt. ${ }^{63} 1847$ und 1848 wird von einem Komitee einheimischer Protestanten, dessen Vorsitz Bustān̄̄ innehat, in mehreren Sitzungen die Petition für die Gründung der Beiruter Kirche erarbeitet. Besonders an einer Stelle der Schrift entsteht der Eindruck, allein der evangelische Glaube könne die konfessionellen Rivalitäten des Landes überwinden:

We were indeed of different sects: Greeks, Greek Catholics, Latins, Maronites and Armenians: but we have abandoned all the animosities and jealousies existing between the sects, wishing them no more to be mentioned among us, inasmuch as we have become members of one body in Christ [...] all believers in him should be one in faith and love. ${ }^{64}$

Parallelen zu Bustānīs Schriften in den 1860er und 1870er Jahren, in denen es um die Liebe zur Heimat und das friedliche Zusammenleben geht (s. u.), sind unverkennbar. Es scheint, als biete der evangelische Glaube die Möglichkeit, die Harmonie, sprich das Gefühl eine Einheit zu sein, bestimmen zu lassen. Schon jetzt wird deutlich, dass die Begegnung mit der Mission Bustānīs Leben ideologisch prägen wird.

Als Bustān̄̄, Elyās Fawāz sowie 16 weitere Konvertitinnen und Konvertiten, deren Namen nicht genau bekannt sind, die Petition verfassen, sind sie davon über-

59 MH 41 (1845), in: ROS 3, 411.

60 Smith traut ebenso Raḥ̂l 'Aț̣a mit Buṭrus al-Bustān̄̄ im Sommer 1843: Smith an Anderson ('Abeih, 3.8.1843): ABC 60, Box 2 (105). Da Hetty Smiths und Rahīls Kinder in etwa gleich alt sind, haben die Familien sehr engen Kontakt: vgl. Lindner (2014a), 57.

61 MH 41 (1845), in: ROS 3, 411.

62 Ebd., 434.

63 Vgl. auch N.A. Keyes Bericht über die „Native Helpers“: ABC 16.8.1., Vol. 1 (21).

64 „Translation of a Petition from the Native Protestants at Beirut to the American Missionaries": ABC 16.8.1., Vol. 4 (23). 
zeugt, dass sie einen Pastoren aus den eigenen Reihen haben werden, der natürlich die Unterstützung der Mission ,,in counsel and labors [...] as a matter of necessity at the beginning" 65 benötige.

Als die Beirut Church zwischen Februar und Mai 1848 gegründet wird, ${ }^{66}$ ist Bustānī bereits für die Assistentenstelle der Bibelübersetzung bei Smith im Gespräch. Nicht vor dem Sommer desselben Jahres kann Bustān̄i, der immer noch in 'Abeih lehrt, nach Beirut geholt werden. ${ }^{67}$ Seine federführende Rolle in der Gründung der einheimisch-protestantischen Gemeinde bringt ihn vermutlich für das Pastorenamt ins Gespräch, ${ }^{68}$ jedoch gibt es dazu in den Quellen keinerlei Hinweise. Im Jahr 1844, als Rufus Anderson die Mission in Beirut besucht, berichtet ihm Bustān̄, dass es ihm ein wichtiges Anliegen sei, vor den Menschen zu predigen. ${ }^{69}$ Jedoch noch am Ende desselben Jahres, wie Smith später berichtet, wechselt Bustānī seine Meinung:

He then claimed that, as ordination would give him a permanent character, and cut him off from ways of acquiring a living now open to him, he must have a permanent lien for an adequate support, upon our society, or upon a parish, before taking upon himself the vows of the ministry. ${ }^{70}$

Unter diesen Umständen sollte seine Ordination nicht angestrebt werden, ist Andersons Antwort gegenüber Smith ca. 1847. ${ }^{71}$ Letzterer gibt Bustān̄ jedoch nicht auf und drängt ihn dazu, seine theologischen Studien bei ihm fortzusetzen, in der Hoffnung, dass sein Schüler die Meinung ändere. 1850 scheint Anderson Bustānīs zuvor gestellte Bedingungen vergessen zu haben und drängt erneut auf die Ordination des Missionshelfers. Das Argument, dass Bustānī neben dem Übersetzungsprojekt keine Zeit habe, werde nicht akzeptiert, so Anderson. ${ }^{72}$ Einige Missionare fordern, dass Bustānī die Anstellung bei Smith beenden müsse, um sich seiner theologischen Ausbildung zu widmen, auch wenn ihnen bewusst sei ,that this would involve the abandonment of the translation altogether". Smith hält dem entgegen: „I declared my belief that Butrus was not available.“ Ist es schließlich Smith, der die Ordination verhindern möchte, da ihm die Übersetzung so sehr am Herzen liegt oder will er Bustānī, der sich seiner Ziele noch nicht sicher zu sein scheint, in Schutz nehmen? Smith antwortet ausweichend und uneindeutig: „I do not think he had changed the views which led him to abandon the ministry so long ago." ${ }^{\text {"73 }}$ Van

65 Ebd

66 Ein genaues Gründungsdatum ist nicht bekannt. Am 9.2.1848 wird die Petition bei der Mission eingereicht (vgl. MH 44, 1848, in: ROS 3, 50) und am 19. Mai 1848 trifft sich zum ersten Mal der Ältestenrat der Kirche (vgl. NECB Protokolle, 19.5.1848, 1).

67 Smith an Rev. D. Brigham (Bhamdūn, 26.10.1848): ABC 16.8.1., Vol. 5 (173). Anstelle von Bustān̄̄ wird nun Mih̄à'îl 'Aramān (s. Anhang II, Nr. 9) im Seminar eingesetzt: vgl. Tibawi (1966), 123.

68 Badr (1992), 294.

69 Anderson an die Syrienmission (On board the Turkish Steamer, 23.4.1844): ABC 16.8.1., Vol. 8 .

70 Smith an Anderson (Beirut, 17.6.1851): ABC 16.8.1., Vol. 5 (199).

71 Diese Worte äußert Anderson gegenüber Smith bei dessen letzten Besuch in den USA 1846/47: ebd.

72 Anderson an die Syrienmission (Boston, 27.6.1850): ABC 2.1.1., Vol. 13 (HHL).

73 Smith an Anderson (Beirut, 17.6.1851): ABC 16.8.1., Vol. 5 (199). 
Dycks Ansicht nach scheint das Hindernis für ein geistliches Amt des syrischen Gelehrten innerhalb der Mission zu liegen. In seinem bereits zuvor erwähnten Brief an Anderson von 1850, in dem er die Vorgehensweisen seiner Kollegen gegenüber den syrischen Protestanten kritisiert, geht er fest davon aus, dass Bustānī Pastor der Beiruter Kirche wird, ,but whether there will not be a practical difficulty made about it remains to be seen. I have great fears that such will be the case". ${ }^{74}$ Laut Van Dyck ist Bustānī in Bezug auf das Pastorenamt entmutigt, da dieses innerhalb der einheimischen Kirche (in Beziehung zur Mission) nicht genügend Freiheiten berge, um sich der Arbeit voll und ganz widmen zu können. ${ }^{75}$

Darüber hinaus ist das zu geringe Gehalt für syrische Mitarbeiter der Mission ein wichtiger Punkt für Bustān̄i. Aus diesem Grund strebt er die Anstellung als Übersetzer beim amerikanischen Konsulat in Beirut an, möchte aber nebenher weiterhin für die Mission arbeiten. Smith berichtet Anderson 1851, Bustānī habe ihm vorgeworfen, von zusätzlichem Gehalt durch andere Tätigkeiten abgehalten worden zu sein. Daher möchte sich Smith nicht zu Bustānīs neuem Plan äußern. ${ }^{76}$ Aus einem privaten Brief von Smith an Bustānī bereits im Jahr 1850 geht jedoch hervor, dass Smith sehr wohl die Absicht habe, mit dem Konsul „respecting yourself“ zu sprechen und sich demnach für eine andere Anstellung seines Schülers einzusetzen. ${ }^{77}$ Es liegt die Vermutung nahe, dass Smith Bustānī in jeder Hinsicht unterstützt, dies jedoch gegenüber dem ABCFM anders darstellt. Van Dyck, der Bustānīs Entscheidung, für den amerikanischen Konsul zu arbeiten, sehr begrüßt, ${ }^{78}$ schreibt im Oktober 1850, dass dieser die Anstellung im Konsulat nun angenommen habe. ${ }^{79}$ Smiths Darstellungen über die Angelegenheit lassen Widersprüche aufkommen: Im selben, bereits erwähnten Brief an Anderson von 1851, in dem er dementiert, dass Bustān̄̄ überhaupt eine Pastorenstelle anstrebe, schreibt er einige Seiten später: „Indeed I think he really looks forward to being a pastor of the church at Beirut, but he is fully conscious of his superior talents, and my apprehension is that he will not give them to the pastoral office, until his expectations ${ }^{80}$ are realized [...]. "Smith fragt Anderson schließlich: „Shall we meet his wishes?“81 Nach diesem Schreiben ist auch in Andersons Korrespondenz nichts mehr dazu zu lesen. Der Fall scheint

74 Van Dyck an Anderson ('Abeih, 27.8.1850): ABC 16.8.1., Vol. 5 (320). Weiteres zu diesem ausführlichen Brief in Abschnitt II.2.2 und III.2.3.

75 Van Dyck an Anderson ('Abeih, 21.10.1850): ABC 16.8.1., Vol. 5. Thomson berichtet, dass Bustān̄̄ nicht bereit sei, seine Meinung hinsichtlich des Pfarramtes zu ändern, bis eine merkliche Veränderung in der Mission eintritt: vgl. Thomson an Anderson ('Ayṭāt, 2.9.1850): ABC 16.8.1., Vol. 5 (254); Badr (1992), 294.

76 Smith an Anderson (Beirut, 17.6.1851): ABC 16.8.1., Vol. 5 (199).

77 Smith an Bustānī (Bhamdūn, 12.10.1850): ABC 50 (HHL).

78 Smith an Anderson (Beirut, 17.6.1851): ABC 16.8.1., Vol. 5 (199). Auch Van Dyck hat laut Smith ein gutes Wort beim Konsul für Bustānī eingelegt.

79 Bustānī ist bis 1862 Mitarbeiter im Konsulat und besetzt 1857 sogar den Interimsposten des Konsuls, der neu ausgeschrieben wird. Sein Sohn Salīm al-Bustānī übernimmt ab 1862 die Stelle seines Vaters: vgl. Tibawi (1963), 167-168.

80 Diese Erwartungen beziehen sich sowohl auf ein höheres Gehalt als auch auf die berufliche Verwirklichung in anderen Bereichen.

81 Smith an Anderson (Beirut, 17.6.1851): ABC 16.8.1., Vol. 5 (199). 
vorerst $\mathrm{zu}$ ruhen. $\mathrm{Zu}$ viele Forderungen gehen von diesem selbstbewussten Syrer aus, den man auch im Pastorenamt vorerst unter Kontrolle halten möchte. 1852 zeigt sich Bustān̄̄ resigniert und erklärt: „,[M]y present resolution is to accept of [sic] no office either religious or secular that is public, for many reasons which I wish to keep to myself." 82

In den kommenden Jahren setzt Bustān̄̄ seine Arbeit für die Mission zwar fort, scheint jedoch immer wieder aufs Neue mit dem Gedanken der Ordination ins Pastorenamt $\mathrm{zu}$ spielen. Vermutlich hofft er auf bessere Bedingungen für ein hohes Amt innerhalb der syrisch-protestantischen Kirche. 1854 äußert die Beirut Church den Wunsch, Bustānī als ihren Pastor einsetzen zu dürfen. Die Angelegenheit wird unter den Missionaren ohne Bustānīs Beisein besprochen. ${ }^{83}$ Nachdem man Bustān̄̄ über seine Ansichten zum geistlichen Amt befragt hat, kommt das Komitee zu dem Schluss, dass man „insuperable objections“ sehe, der Sache weiter nachzugehen. Über die Argumente, die zu diesem Entschluss geführt haben, schweigt das Protokollbuch der Mission. ${ }^{84}$ Bustān̄̄ ist empört und schreibt Smith kurz darauf:

I would be $[\ldots]$ grateful if you can, provided you have the time and the will, explain to me in a clear and detailed manner the reasons behind the negative response with which you have provided the church and the impediments you found in me. A lot of unreliable rumors related to the matter have been circulating and I fear that this might result in a misunderstanding. You are well aware that this is a highly important matter that has serious consequences, including on myself, and makes room at times for people meddling in matters that do not, otherwise, concern them. Since I know that the mission must have valid reasons for this delay, and in case there is no harm in sharing them with me, I hope that you clarify them to me, so that I can provide an informed and confident answer. ${ }^{85}$

Im Herbst 1854 treffen sich Bustānī und John Wortabet, um über den Vorfall zu sprechen. Wie aus einem Brief von Wortabet an Smith kurz darauf hervorgeht, nimmt Wortabet eine Art Mittlerposition ein, da sich Bustān̄̄ völlig missverstanden fühlt. Zwar seien ihm die Gründe für die Ablehnung immer noch nicht mitgeteilt worden, jedoch vermutet er, dass die Mission der Meinung sei, Bustānī würde eine enge Kooperation ablehnen und daher für ein von der Mission unabhängiges geistliches Amt plädieren. Laut Wortabet ist dies jedoch nicht der Fall: Beide, Wortabet und Bustān̄̄, seien der Meinung, ,missionaries are ever [sic] to be looked to, and especially during the infantile condition of the native church for consultation, advice, and direction $[\ldots]$ a certain kind and amount of supervision ought to be conceded of the native Evangelists to the missionaries."

Wortabet betont, dass das Engagement einheimischer Pastoren in der missionarischen Arbeit notwendigerweise eine direkte Zusammenarbeit erfordere. Dies bedeutet jedoch, dass Syrer und Amerikaner auf gleicher Ebene zusammenarbeiten

82 Bustān̄̄ an Smith (Beirut, 6.1.1852): ABC 60 (12), (HHL).

83 Wie bereits in der Einleitung zu Kapitel III erläutert, nehmen die syrischen Mitarbeiter nicht an den Besprechungen der Mission teil. Persönliche Anliegen werden in den jeweiligen Sitzungen schriftlich vorgetragen.

84 „Records of the Syria Mission and the Holy Land 1853-1860“ (30.8.1854): ABC 16.8.1., Vol. 8.1., 27.

85 Bustānī an Smith ('Abeih, 5.10.1854): ABC 50 (HHL). (TA) 
müssen. Die Zusammenarbeit hat laut Wortabet insofern ihre Grenzen, als syrische Protestanten das Gefühl haben sollten, ,that [they] hold our Commission in the Gospel Ministry from God himself and that to Him primarily [they] are accountable for the expiation of [their] office“" .86

Während Anderson bezüglich der Gehaltsfrage 1851 schreibt: „The preaching of the gospel is a work, to be done at all hazard, and not a profession, a living, to be taken up and secured as a life estate“, 87 argumentiert Wortabet in eben jenem Brief an Smith 1854, ,as soon as we consider ourselves as mere employees, we shall degrade the ministry into a profession for livings very little different from the corrupted system which we are seeking to abolish. Better form no native ministry if such is to be its character".

Bustān̄̄ äußert gegenüber Wortabet, dass er sich seiner Standhaftigkeit bewusst sei, die ihn oft dazu gebracht habe, nicht von seinen Meinungen abzukommen oder sich respektlos gegenüber manchen Missionaren zu verhalten. Zudem mangelte es ihm manches Mal an der gewünschten Zuverlässigkeit. Er nimmt sich daher vor, als „minister“ an seinen Defiziten zu arbeiten. Bustānī bedaure es, nicht die Gelegenheit gehabt zu haben, sich vor der Mission zu erklären - ein weiterer Hinweis, dass derartige Probleme nie zusammen mit syrischen Mitarbeiterinnen und Mitarbeitern besprochen werden. Schließlich bittet er Wortabet, folgende Erklärung an die Mission weiterzuleiten:

I feel it to be my duty to preach the Gospel of Christ to sinners, for this object I am ready to sacrifice worldly interests, personal views, and whatever stands in the way, that so far from falling out with the missionaries, I intend to cooperate harmoniously with them; and as my superiors in experience, knowledge and ability I will ever consider it a privilege to have access to their advice and judgement $[\mathrm{sic}]{ }^{88}$

Im April 1855 stellen die Mitglieder der Beirut Church erneut einen Antrag an die Mission, ihre Entscheidung bezüglich der Ordination von Bustānī zu überdenken. ${ }^{89}$ Smith verspricht, dass sie den Fall nochmals eingehend prüfen werden, gesteht jedoch ein: ,In the discussion then, it is my wish not to take a leading part, and I hope to be able to concur in whatever decision the Mission may arrive at." Ist er in den Jahren 1850/51 noch sehr verschlossen, was seine Meinung über Bustānīs Berufung für das geistliche Amt anbelangt, so spricht er nun erstmals offen und ausführlich über seine Bedenken in dieser Sache: Smith ist nicht der Meinung, dass sein Schüler und Mitarbeiter für das Amt des Pastors in der Beiruter Kirche geeignet sei. Zum einen stelle man keine Bedingungen, ${ }^{90}$ wenn man sich für dieses Amt berufen fühlt. Zum anderen erkennt Smith, dass Bustānīs Stärke im säkularen Bereich

86 Wortabet an Smith (Hāạsbeiyā, 20 October 1854): ABC 60 (98), (HHL).

87 Anderson an die Syrienmission (Boston, 6.11.1851): ABC 2.1.1., Vol. 15 (HHL).

88 Wortabet an Smith (Hāṣbeiyā, 20 October 1854): ABC 60 (98), (HHL).

89 „Records of the Syria Mission and the Holy Land 1853-1860“ (5.4.1855): ABC 16.8.1., Vol. 8.1., 32 .

90 ,[The conditions] have related chiefly to permanent connection with some responsible body, to support or to place of labor.“ Letzteres meint Bustānīs Wunsch, als Pfarrer an keinen anderen Ort außer Beirut berufen zu werden. Vgl. Smith an Bustānī (Beirut, März 1855): ABC 60 (105), (HHL). 
liegt, ,and I use that word with no obnoxious meaning, I say, rather secular, than spiritual". Auch die Gemeindemitglieder in Beirut würden erkennen, dass nicht das spirituelle Wohlergehen der Menschen und die Vorbereitungen auf das Königreich Gottes Bustānīs primäres Anliegen ist, sondern seine persönlichen Interessen in anderen Bereichen: „Would your talent and aspiration for the extension and multiplicity of labor, find scope enough within so limited a sphere to satisfy you, and make you contended?“91

Bustānī und die Mission haben verschiedene Vorstellungen von Berufung und Beruf. Bustān̄̄ möchte einer Gemeinde vorstehen, ohne finanziell davon abhängig sein zu müssen, was bedeutet, den Lohn mit anderen Tätigkeiten zu verdienen. Smith hingegen erklärt, dass der ,genuine immoral call“ bedeute, ganz für die Gemeinde da zu sein und damit auch von ihr finanziell abhängig. Smith möchte seinen Freund nicht für die Arbeit, der er nachgeht, verurteilen, im Gegenteil. Er ist von Bustānī überzeugt und weiß, dass jeder in der Stadt ihn respektiert und dass er ein Mann mit großem Einfluss ist. ${ }^{92}$

Wie das Komitee der Missionare letztlich abstimmt, geht aus den Protokollbüchern nicht mehr hervor. Der letzte Eintrag zu dieser Thematik notiert, dass Smith sich mit den führenden Personen der Beiruter Kirche unterhalten hat, ohne Hinweise auf das Ergebnis zu geben. ${ }^{93}$ Es ist zu vermuten, dass die Mission letztlich gegen die Einsetzung Bustānīs zum Pastor der einheimischen Gemeinde in Beirut stimmt. Vielleicht kommt auch Bustānī zu der Erkenntnis, dass es für den erfolgreichen Verlauf seiner Karriere die richtige Entscheidung ist. ${ }^{94}$ Wie aus Smiths Berichten in den folgenden Jahren hervorgeht, setzt Bustān̄̄ seine Arbeit in der American Mission Press und im Besonderen an der Bibelübersetzung fort. Die Angelegenheit bedeutet nicht, zumindest vorerst, sich von der Mission abzuwenden. ${ }^{95}$ Bustān̄̄ kann sich schließlich auch ohne Pastorenamt als führendes Mitglied in der Beirut Church behaupten (s.u.). Doch mit Smiths Tod 1857 verliert sich langsam die Spur des Missionshelfers Bustānī, v. a. in den Quellen des ABCFM. ${ }^{96}$ An der Fortführung der

91 Ebd.

92 Ebd.

93 „Records of the Mission to Syria and the Holy Land 1853-1860“ (6.7.1855): ABC 16.8.1., Vol. 8.1., 39. Dies ist auch der letzte Eintrag zu Buțus al-Bustān̄i in den Protokollbüchern der Mission.

94 Allerdings muss Walid Semaan Recht gegeben werden, wenn er behauptet, dass die Entwicklung einer indigenen protestantischen Gemeinschaft an der Hinauszögerung der Ordination eines einheimischen Pastoren gelitten hat: ,[I]f the mission had ordained him, and if his far-reaching talents had been fully utilized, the new roots which were struck in the Lebanese-cultural religious soil at that time could have been more authentically Lebanese." Vgl. Semaan (1986), 90.

95 Im September 1855 schreibt Bustānī einen sehr freundlichen Brief an Rufus Anderson, dem er einige Souvenirs aus Olivenholz aus Jerusalem beifügt: vgl. Bustānī an Anderson (Sūq al-Ġarb, 28.9.1855): ABC 16.8.1., Vol. 4.1. (103).

96 Lindner (2014a), 58: Smiths Witwe und die Kinder gehen daraufhin zurück in die USA. Auch die Familie De Forest, mit der die Bustān̄is ein gutes Verhältnis haben, verlassen Syrien im Jahr 1854: ,[T] $[$ he Bustanis lost their closest associates and ties to the Mission.“ 
Bibelübersetzung durch Van Dyck ist er nicht mehr beteiligt. ${ }^{97}$ Nach einem letzten Brief $^{98}$ an Rufus Anderson sind keine persönlichen Aufzeichnungen Bustānīs im ABCFM-Archiv mehr zu finden. In den 1860er Jahren erwähnt ihn der Missionary Herald bezüglich der Native Missionary Society, die Bustān̄̄ 1862 gründet, sowie seiner Nationalschule (Madrasa Wațanīya), die 1862 ihre Pforten in Beirut öffnet (s. u.). Bustānī verfolgt nun eigene Ziele und steht nicht mehr im Dienst der amerikanischen Syrienmission. ${ }^{99}$

Über die Native Missionary Society, oder, wie TIBAWI sie nennt, Ğam ‘̄yat Beyrūt al-Inǧilīya (Beiruter Bibelgesellschaft), ${ }^{100}$ ist bedauerlicherweise fast nichts bekannt. Jessup berichtet, dass Männer, Frauen und Kinder (!) der evangelischen Gemeinschaft zu den etwa 200 Mitgliedern zählen. ${ }^{101}$ Die Mitgliederversammlungen finden regelmäßig am ersten Montag des Monats statt. Als Präsident der Gesellschaft unterrichtet Bustānī102 die Mission sogar schriftlich über die Arbeit der Native Missionary Society: Wie auch die Syrienmission sendet sie eigene Missionare in verschiedene Regionen aus, beauftragt Kolporteure und gibt einen monatlichen Missionary Herald auf Arabisch heraus (500 Exemplare pro Auflage). ${ }^{103}$ Es ist erstaunlich, dass man in der Syrienmission nur sehr wenig über das einheimische ,Pendant' zu berichten weiß, ist es doch das oberste Ziel, die Missionierung des Landes durch einheimische Mithilfe voranzutreiben. ${ }^{104}$

Bustānī gehört zu den führenden Figuren der indigenen protestantischen Gemeinschaft, aber es scheint, als versuche man von Seiten der Mission - und später von Seiten des Colleges - seinen Einfluss einzudämmen. Während Henry Harris Jessup offenbar ein großer Verehrer von Bustānī ist, gehört Daniel Bliss, später Präsident des SPC zweifelsohne zu denen, die Bustānī den Erfolg missgönnen. In ei-

97 Obwohl Van Dyck und Bustānī enge Freunde sind, scheint die Arbeit innerhalb der Mission für Bustānī nicht mehr möglich.

98 Bustānī an Anderson (Beirut, 25.1.1860): ABC 16.8.1., Vol. 6 (124): „I have the honor to acknowledge the receipt of your kind letter from Boston and that of Mrs. Anderson addressed to me and to my wife accompanied by the two parcels which she kindly sent to me and to the (?) members of my family."

99 Shaw (2014, 82-83) plädiert dafür, dass sich Bustānī weder von der Mission abgewendet, noch distanziert habe, da er auch nach der Gründung seiner Nationalschule mit den Amerikanern kooperiert. Von einer Abwendung kann in der Tat nicht die Rede sein, eine emotionale Distanzierung ist jedoch aufgrund der Ereignisse in der zweiten Hälfte des 19. Jh.s durchaus zu bemerken (s.u.).

100 Tibawi (1963), 171 (Anm. 120). Im Missionary Herald von 1864 ist von „friends of Syrian evangelization“ die Rede: vgl. MH 60 (1864), in: ROS 5, 91.

101 „Annual Report of the Beirut Station of the Syrian Mission for the year 1862“: ABC 16.8.1., Vol. 6 (32): Bei den Frauen handelt es sich um etwa 40 Witwen aus Hāş̦̣beiyā, die 25 Kinder werden als Waisenkinder bezeichnet und gehören vermutlich zum Waisenhaus der Kaiserswerther Diakonissen.

102 Laut Jessup soll Bustān̄̄ die Gesellschaft sogar 20 Jahre lang geleitet haben: vgl. Jessup (1910b), 484.

103 MH 58 (1862), in: ROS 5, 49; MH 60 (1864), in: ebd., 91.

104 In den Jahresberichten der Beiruter Missionsstation findet die Gesellschaft hin und wieder Erwähnung. 1869 wird in Kooperation mit der amerikanischen Syrienmission ein Kolporteur eingestellt, was auf eine brüderliche Zusammenarbeit der beiden Missionsvereinigungen schließen lässt: „Annual Report of Beirut Station, 1869“: ABC 16.8.1., Vol. 6 (39). 
nem der Briefe an seine Frau Abby, die 1993 neu herausgegeben wurden, verurteilt Bliss die häufige Abwesenheit Bustān̄̄s in den Gottesdiensten der Beiruter Kirche:

It is a great pity that such a man should be the leading man on all church matters, but no changes will be made. [...] The truth will prevail notwithstanding the selfishness, pride and excessive vanity of Butros and all like him. So it has been in all ages of the church, those who seem to be the most powerful, the most influential are the feeblest elements in the church if not counted absolute hindrances. ${ }^{105}$

In einem Vorfall von 1874, bei dem der osmanische Pascha die Schließung der Amerikanischen Druckerei fordert, ${ }^{106}$ soll Bustān̄̄ die Gelegenheit ergriffen haben, eine Art Hetzartikel gegen ausländische Einflüsse - insbesondere ausländische Schulen - zu schreiben, wie Bliss berichtet:

The whole city is discussing his meanness in doing it - when his position in society has been made by his connection with Americans. He has lost character in this. Some of our students are full of wrath and will show him up if not in the Beirut papers of the Constantinople Arabic paper, through some articles which they will get published and circulate. He is a bad, bold man - a stumbling block. He is not nearly so well liked as formerly. ${ }^{107}$

Bustān̄̄s Entmutigung hinsichtlich ausländischer Schulen mag mit der Auseinandersetzung um die misslungene Kooperation zwischen seiner Nationalschule und dem SPC zusammenhängen, wie im Folgenden noch zu sehen sein wird. Doch offenbar wird in den 1870ern auch eine offene Auseinandersetzung zwischen ihm und der Mission ausgetragen. Während des Vorfalls um die Druckerei, die auf Anordnung des Paschas vorübergehend geschlossen werden soll, kann die Mission eine Schließung abwenden. Laut Bliss verbreitet Bustānī dennoch in der Presse die Botschaft, die Druckerei habe geschlossen und müsse ein Bußgeld bezahlen. Bustān̄̄, der, so Bliss, bedauerlicherweise immer noch die Führung in der Kirche inne habe

has lost friends by this last move of his but will gain back all the feeble minded ones. I think just as much of him as I have for years - I shall stand firm if all forsake him! He is a bad man. This Church will go to pieces if he rules it much longer. Neither Dr. Thomson nor Dr. Jessup have the courage to take the Bull by the horns. It is too bad to take up so much space in my letter with the Pasha and Bustany. ${ }^{108}$

Kein anderer findet solch kritische Worte gegenüber Bustān̄̄ wie Daniel Bliss. Bustān̄̄s einflussreiche Position ist vielen Missionaren offenbar ein Dorn im Auge. Als engagierter Presbyter ist er vermutlich ein Hindernis für die immer noch bestehende Einflussnahme der Mission auf die einheimische Gemeinde. Aus Mangel an Quellen finden sich dafür jedoch keine weiteren Hinweise. Am 21. Juni 1878 nimmt Bustānī zum letzten Mal an der Sitzung des Ältestenrates der Beirut Church teil und zieht sich aus ungeklärten Gründen aus seinem Engagement für die syrischevangelische Gemeinde zurück. ${ }^{109}$

105 Daniel Bliss an Abby Bliss (10.8.1873), in: Bliss (1993), 46.

106 Näheres zum Vorfall in Abschnitt I.2.5.

107 Daniel Bliss an Abby Bliss (16.3.1874), in: Bliss (1993), 225. Leider gibt es vom Herausgeber keine Hinweise, um welchen Artikel es sich handeln könnte.

108 Daniel Bliss an Abby Bliss (18.3.1874), in: Bliss (1993), 227.

109 NECB Protokolle (21.6.1878), 32. 


\section{Al-Madrasa al-Wațan̄ya - Modell für Säkularismus und nationale Verbundenheit}

Im Rückblick auf das Jahr $1862^{110}$ berichtet Henry Harris Jessup in seinen FiftyThree Years in Syria, dass die Engländerin Mrs. Watson mit dem Geld eines Londoner Komitees etwa im September des Jahres eine Jungenschule in Bustānīs Haus im Beiruter Stadtteil Zoqāq al-Blāt eröffnet habe. ${ }^{111}$ Wenig später übernimmt Bustānī die ca. 30 Jungen und gibt der Schule den Namen „Nationalschule“ (alMadrasa al-Wațanīya). ${ }^{12}$ Laut Jahresbericht der Syrienmission von 1863 beträgt die Zahl der Schüler Ende des Jahres bereits $115 .{ }^{113}$ Will man Näheres über diese Schule erfahren, muss man sich mit den wenigen vorhandenen Aufzeichnungen von Zeitzeugen zufrieden geben. ${ }^{114}$ Protokolle, Jahresberichte oder Schülerlisten, die es mit Sicherheit für die Madrasa Watanīya gegeben hat, sind nicht mehr auffindbar und vermutlich verloren gegangen.

Es ist sehr wahrscheinlich, dass die Initiative für diese Schulgründung nicht allein von Mrs. Watson, sondern auch von Bustānī ausgeht, ${ }^{115}$ der auf viele Jahre Lehrerfahrung in 'Ayn Warqa, im Beiruter Seminar und schließlich im Seminar in 'Abeih zurückblicken kann. Zudem ist Bustānī seit 1856 Mitglied und Sekretär des Aufsichtsrates für die englischen Libanonschulen. ${ }^{116}$ Für diese sowie für die 1862 gegründete Schule des drusischen Gouverneurs (mutașārrif) des Libanongebirges Dawūd Pāšā in 'Abeih erstellt er Stundenpläne, was ihm den würdevollen Beinamen mu 'allim (Meister/Lehrer) einbringt, für den er Zeit seines Lebens bekannt ist. $^{117}$

Jessup berichtet, dass bereits fünf Jahre vor der Gründung des SPC, im Jahr 1861, innerhalb der Mission die Rede davon gewesen sei, zusammen mit Bustānī ein College aufzubauen. Auf dem Plan steht, Bustānī und George Ford nach England zu schicken, um Spendengelder für das Projekt zu sammeln. Es regen sich jedoch Vorbehalte bei den Missionaren, was eine binationale Zusammenarbeit

110 Es gibt widersprüchliche Aussagen zum Gründungsjahr. Häufig wird in der Sekundärliteratur von 1863 gesprochen, wie es auch der Jahresbericht der Beiruter Missionsstation von 1863 schildert (vgl. ABC 16.8.1., Vol. 6 [33]). Sowohl Buțrus al-Bustān̄̄s Artikel in al-Ǧinān (Bd. 4, 1873, S. 626) als auch Jessups Aufzeichnungen $(1910 \mathrm{~b}, 484)$ benennen 1862 als Gründungsjahr.

111 Jessup (1910a), 270. Ohne Referenzangabe behauptet Hitti (1957, 462), Bustān̄̄ habe die Schule zunächst in 'Abeih errichtet und sei dann nach Beirut gezogen. Laut Missionary Herald befindet sich die Schule im offiziellen Gründungsjahr 1863 aber in Beirut.

112 In der Sekundärliteratur hat sich die Übersetzung des Schulnamens mit „Nationalschule“ durchgesetzt, obwohl schon Tibawi $(1963,171)$ darauf hinweist, dass watan in jener Zeit noch nicht mit Nation, sondern eher mit „Heimat“ oder „Vaterland“ übersetzt werden kann. Unter diesem Vorbehalt und mit Rücksicht auf die Sekundärliteratur wird die gängige Übersetzung „Nationalschule“ hier beibehalten.

113 MH 60 (1864), in: ROS 5, 91.

114 Jens Hanssen hat in seiner Untersuchung zum Beiruter Stadtteil Zoqāq al-Blāt solche Zeitzeugen studiert: vgl. Hanssen (2005), 152-154.

115 Jessup schreibt ebenfalls, dass Bustānī die Schule aus eigener Tasche sowie durch finanzielle Hilfen aus Amerika und England errichtet habe: vgl. Jessup (1910b), 484.

$116 \mathrm{Zu}$ den Libanonschulen siehe Abschnitt I.2.3.

117 Ṭarrāzī (1913), 89; Hitti (1957), 445; Huūrī (1995), 53-54. 
anbelangt. Schließlich tritt Ford 1862 die Reise allein an. ${ }^{118}$ Dass Bustān̄̄ schon 1862, ebenfalls mit englischer Unterstützung, die Nationalschule ins Leben ruft, mag sicher kein Zufall sein. Wie bereits in Abschnitt I.1.5 geschildert, beginnen die Vorbereitungen für die Gründung des SPC unter amerikanischer Leitung im Jahr 1862. Liest man den Jahresbericht der Beiruter Missionsstation von 1863, so zeigt sich keinerlei Argwohn gegenüber Bustānīs Einrichtung. Weil Mitglieder verschiedener Religionsgemeinschaften willens sind, für die Ausbildung ihrer Kinder in einer protestantischen Schule Geld zu bezahlen, scheint der Weg für die Gründung des SPC geebnet: ,[I]t is plain that the movement for a College was not commenced a moment too soon." "119 Im Laufe der kommenden Jahre wird sich die Meinung gegenüber Bustānīs Institution innerhalb der Mission jedoch erheblich ändern.

„It is not a Missionary school nor connected with our work", wie der Jahresbericht 1863 weiterhin schreibt, „,but the Bible is read at morning and evening prayer which all the pupils are obliged to attend". ${ }^{120}$ Zwar wird die Nationalschule von einem der angesehensten Protestanten der Stadt geleitet, doch ist sie nicht religiös ausgerichtet. Laut DĀYAs Recherchen sei sich Bustān̄̄ zu Beginn unsicher gewesen, ob er bestimmte Reformideen in die Leitung der Schule einbringen solle. Daher bittet er die Missionare, ihm beratend zur Seite zu stehen. Als er erkennt, dass die Amerikaner dabei nur eigene Interessen verfolgen, bricht er die Zusammenarbeit ab. Die daraus resultierenden Anfeindungen von Seiten der Mission seien ihm gleichgültig, so DĀYA. ${ }^{121}$ Es ist fraglich, ob Bustān̄̄ auf derartige Hilfe durch die Missionare angewiesen ist. Er bewegt sich in dieser Zeit bereits in den Kreisen der wichtigsten christlichen und muslimischen Intellektuellen und Reformdenker, die ähnliche Ziele verfolgen. ${ }^{122}$ Zweifelsohne ist die Madrasa Wațañya ein Wagnis. Die Multikonfessionalität der Schule besteht darin, die Schüler in ihrer jeweiligen Religion zu unterweisen und ihnen in Begleitung einer Lehrkraft die Teilnahme an Festen und Gottesdiensten zu gewähren. ${ }^{123}$ Das hat es zuvor noch in keiner Bildungseinrichtung in Syrien gegeben. Jahre nach den religiös motivierten Gräueltaten während des Bürgerkriegs von 1860 wird die Nationalschule zum Vorzeigemodell für eine säkulare Gesellschaft: ,[D]ie Gestalt unserer Gesellschaft ist wie die der Nationalschule. Die Schüler [...] sind Geschwister einer Heimat, die Unterschiede in den Religionen haben keinen Einfluss auf ihre Arbeiten, Studien und Lebensweisen." $" 124$

118 Jessup (1910a), 240.

119 „Annual Report of Beirut Station for 1863“: ABC 16.8.1., Vol. 6 (33).

120 Ebd.

121 Dāya führt hier jedoch keine Quelle an und fügt hinzu, dass der maronitische Metropolit alDabas aufgrund der geschilderten Ereignisse geäußert habe, Bustānī werde noch vor seinem Tod zur maronitischen Kirche zurückkehren: vgl. ders. (2008).

122 Hanssen (2005).

123 Bustānī (1873), 627 (TA); Tibawi (1967), 275-276. Ca. 30 Schüler besuchen daher auch regelmäßig den Gottesdienst der evangelischen Beiruter Gemeinde: vgl. MH 60 (1864), in: ROS 5, 91.

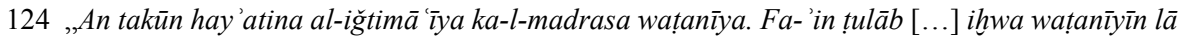
ta 'ațīr li-ihtilāf al-adiyān fì a mālihim wa durūsihim wa ma ‘̄šatihim." Vgl. Salīm Bustānī, „Buțrus Bustānَ̄“, in: al-Ğinān 14 (1883), 321, zitiert in: Huūrī (1995), 68. 


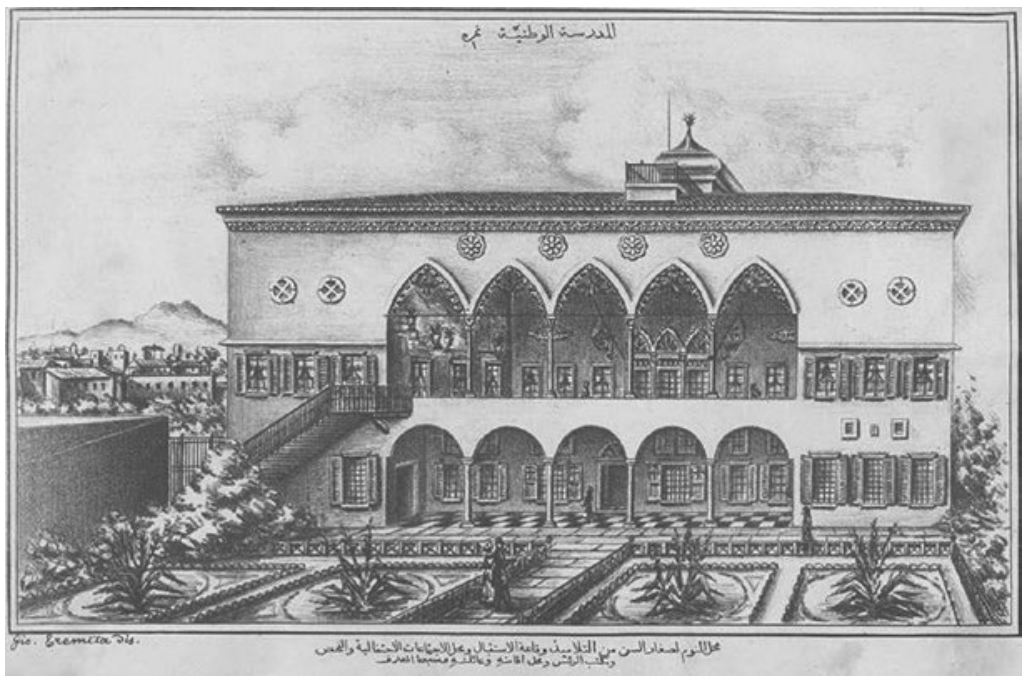

Abb. 8: Al-Madrasa al-Wațan̄ya (Schlafsäle für die jungen Schüler, Empfangshalle, Festsaal und Prüfungsraum, Büro und Wohnhaus des Präsidenten und seiner Familie)

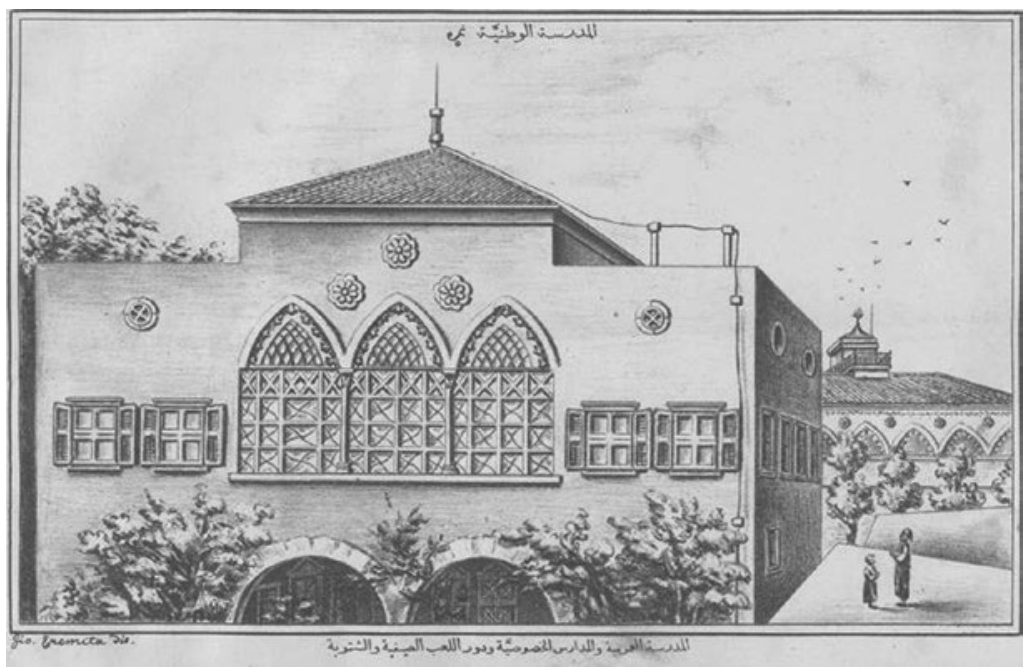

Abb. 9: Al-Madrasa al-Wațan̄ya (Grundschule und Privatschulen sowie Spielräume für Sommer und Winter)

Lehrer und Schüler aus den verschiedenden Religionsgemeinschaften des Landes verfolgen ein gemeinsames Ziel, nämlich Bildung jenseits der Grenzen von religiösen Streitigkeiten:

Die Schule heißt Schüler aus allen Religionsgruppen (tauwä'if), [mit allen] Bekenntnissen (milal) und Herkünften (ağnās) willkommen, ohne sich gegen ihre jeweiligen Überzeugungen zu stellen und ihnen eine andere Konfession aufzuzwingen (tağabarhum bi-itbā' madhab gayr 
mad $h a b) .[\ldots]$ die Söhne der Nation verdienen es, Teil der Spitze dieser Generation zu sein, egal welchen Bekenntnisses und welcher Religion sie sind. Durch fundierteres Wissen und Fortschritt sehen und hören sie, welche Schäden dem Vaterland durch religiöse Fanatismen und feindselige Elemente (ta 'așubāt al-țâ 'ifíya wa l- 'anāșir al-ḍddìya) zugefügt wurden und wie man sich verpflichten muss, dem Anderen zu vertrauen, ohne [dass] das Land in Rückschritt verfällt und Schande über das Vaterland kommt. ${ }^{125}$ (Abb. 8 und 9)

Eine Vielfalt von Unterrichtsfächern kennzeichnet den Lehrplan: Als Sprachen werden Arabisch, osmanisches Türkisch, Französisch, Englisch, Griechisch und Latein gelehrt. $\mathrm{Zu}$ den herkömmlichen Unterrichtsfächern werden auch kreatives Schreiben, Rhetorik sowie Musik und Fotografie auf Nachfrage angeboten. ${ }^{126}$ Die nationale und internationale Lehrerschaft besteht aus angesehenen Gelehrten und trägt zum guten Ruf der Schule bei: Auch der berühmte Poet und Schriftsteller Nāṣịf al-Yāziğì, der jahrelang für die Mission gearbeitet hat, unterrichtet Arabisch an der Nationalschule, später ist es Yūsuf al-Asīr, bekannt durch die Bibelübersetzung unter Van Dycks Leitung, der dieses Fach lehrt. Anfang der 1870er Jahre wird Ahmad 'Abbās, der von der Al-Azhar Universität in Kairo kommt, als Lehrer für islamische Theologie und Philosophie eingestellt. Viele der Schüler, die ihre Ausbildung in der Madrasa Watanīya absolviert haben, „bec[o]me leading Beirut intellectuals, working as educators, publishers, journalists and Beirut municipal councillors“. ${ }^{127}$ Bustānī ist sich des Potentials seiner Schüler und Absolventen für den Aufbau einer Zukunft des Landes bewusst und möchte sie daher ausreichend darauf vorbereiten. 1873 gründet er für sie die Ğam 'iyat Zahrat al-Adab, die Gemeinschaft für die Blüte der Bildung, deren Ziel es ist, das Studium und die Erlangung von Wissen voranzutreiben sowie die Fähigkeiten, sich in Debatten sprachlich zu behaupten, zu fördern. Es gehört daher zum Programm dieser Gesellschaft, dass Schüler und Absolventen der Nationalschule Theaterstücke verfassen und diese dann aufführen. ${ }^{128}$

Obwohl Bustānīs säkulare Schule gegenüber anderen religiösen und v. a. missionarischen Schulen eine besondere Rolle einnimmt, wird 1865 ein Kooperationsvertrag mit dem im Aufbau begriffenen SPC geschlossen. Jessup sowie der Board of Managers plädieren für eine dreijährige Zusammenarbeit, ${ }^{129}$ in der Räumlichkeiten der Schule angemietet werden, um dort das Preparatory Department für das

125 Bustānī (1873), 627.

126 Ebd.

127 Zaydān (1900/1901), 238: Salīm Bek Taqlā wird Herausgeber der heute noch bestehenden ägyptischen Zeitung al-Ahrām; Hanssen (2005), 152 (Anm. 33): Sulaymān al-Bustānī (18561925), Buțrus' Cousin, wird Minister der Jungtürken sowie Senator und Übersetzer von Homers Odyssee. Siehe auch Cioeta (1982), 43 (Anm. 5); Hanssen (2006), 169-170: 'Abd alQādir al-Qabbāni, späterer Begründer der islamisch-wissenschaftlichen Gesellschaft Ğam 'iyat al-Funūn (Gesellschaft der Künste) und Herausgeber der dazugehörigen Zeitschrift Tamarāt al-Funūn (Früchte der Kunst) besucht ebenfalls Bustānīs Schule.

128 Raffoul (2014), 150.

129 Jessup an Anderson (Beirut, 27.1.1865): ABC 16.8.1., Vol. 6 (215): „I think appearances strongly indicate that the school will be brought into connection with the college without difficulty.“ Jessup an Bliss (23.11.1865): AA.2.3.1.10.2: „Mr. Bistany, is accepted, and I see nothing in the way of cooperation at once $[\ldots]$. . 
SPC einzurichten. ${ }^{130}$ Die Schüler sollen nun durch von Bustānī bereitgestellte Lehrkräfte und Materialien inhaltlich auf die Anforderungen des SPC vorbereitet werden. ${ }^{131}$ Jedoch birgt diese Vereinbarung von Anfang an Potential für Meinungsverschiedenheiten zwischen den selbstbewussten Präsidenten der beiden Institutionen: Buțrus al-Bustān̄̄ und Daniel Bliss. ${ }^{132}$ Schon 1864 schreibt William Thomson im Namen des Board of Managers des SPC an Bliss, der sich noch auf Reisen befindet, dass eine Zusammenarbeit mit Bustānī nicht möglich sei, ,unless he will consent to greatly modify his present operations. It is my opinion that matters will very likely take such a turn as will enable us to make a profitable use of his tallents [sic], energy and experience, but things are not yet ripe for such measures". ${ }^{133}$

Obwohl die Kooperation 1865 zustande kommt, steht sie bereits zwei Jahre später kurz vor dem Aus: Im SPC hat sich die Befürchtung bewahrheitet, dass sich Bustān̄̄ nicht den im College geltenden Prinzipien anpassen werde. Schüler, die auf das College vorbereitet werden, lernen unter demselben Dach wie die der Madrasa Wataniya, die aber anderen Regeln folgen: „Discipline was very hard to maintain, to say the least." 134 Doch die Meinungsverschiedenheiten sind vielschichtiger und machen deutlich, dass es um die Kontrolle der Nationalschule durch das SPC geht. Dies wird für Bustān̄̄ verständlicherweise zu einer Belastungsprobe. Als er vier neue Lehrer für das Preparatory Department einstellt, ohne Rücksprache mit dem SPC gehalten zu haben, hält der Board of Managers aus Protest die versprochenen Gehälter zurück. Auch Spendengelder von Mrs. Watson, die das Unternehmen Madrasa Wațanīya weiterhin finanziell unterstützt, werden vom SPC nicht vollständig ausgezahlt. Bustān̄̄ legt Beschwerde ein, woraufhin der Board of Managers ihn auffordert, die genaue Verwendung der Gelder aufzulisten. Schließlich richtet sich Bustān̄̄ Anfang März 1867 in einem Beschwerdebrief an das SPC. Dort zeigt man sich entrüstet und wehrt die Kritiken als grundlos ab. Die Verbindung zum College empfindet Bustān̄̄ als schädigend für seine eigene Einrichtung, da Proselytismus und Unfreiheit nicht zur Weltanschauung der Nationalschule passen. Aufgrund einiger Übereinstimmungen im Lehrplan der Nationalschule und des SPC sieht er die amerikanische Institution zudem als Konkurrenz an. Darüber hinaus beschwert er sich ,that the discipline of the College is less strict, in some respects, than that of said Institution, and therefore demoralizing to it; in that students from

130 Penrose (1941), 25. In seinen Reminiscences schreibt Bliss in einer kurzen Notiz, ohne einen Namen zu erwähnen: „We were housed for two years in four or five rooms of an insignificant building“. Bliss’ Antipathie gegenüber Bustānī wird hier sehr deutlich: vgl. Bliss (1920), 187.

131 Schüler für das College werden jedoch auch von anderen indigenen, konfessionell ausgerichteten Schulen oder vom Missionsseminar in 'Abeih aufgenommen: vgl. Bliss, „A Statement" (Beirut, 31.12.1866): AA.2.3.1.10.4.

132 Hier wie im Fall von John Wortabet (siehe Abschitt III.2.) lässt David Stuart Dodge (zunächst Englischlehrer und später Mitglied im Board of Trustees des SPC) in seiner Korrespondenz mit Daniel Bliss keinen Augenblick aus, Bustānī in schlechtem Licht darzustellen. „Dodge [...] lambasted Bustani as a tricky and underhanded child of the East. ,He must be assigned a place and be kept there $[\ldots]$ and never be regarded as one whom we can fully trust in any particular'." Vgl. Dodge an Bliss (25.7.1865): AA.2.3.1.5., zitiert in: Makdisi (2008), 211.

133 Thomson an Bliss (Šimlān, 20.7.1864): AA.2.3.1.10.1.

134 Penrose (1941), 29. 
said Institution have been covertly enticed to enter the College [...]." ${ }^{\text {(135 }}$ Der Board of Managers bekräftigt daraufhin, dass der für drei Jahre bestehende Vertrag nur die Miete der Räume garantiere, jedoch nicht Dienste und Gehälter für den Direktor und sein Personal. ${ }^{136}$ Dennoch hofft man, das Preparatory Department bis 1869 halten zu können, da das SPC sonst keine vorbereitende Schule mehr hat. ${ }^{137} \mathrm{Da}$ Ende 1867 Vereinbarungen zwischen Bustān̄̄ und dem Board of Managers über Gehaltskürzungen getroffen werden, scheint die Zusammenarbeit bis ca. 1868/69 bestanden zu haben. ${ }^{138}$ In den Protokollen des Board of Managers finden sich weder 1868 noch 1869 Aufzeichnungen zur Madrasa Wațanīya. Als Jessup 1874 sein Buch Women of the Arabs veröffentlicht, gibt es die Nationalschule noch und zählt in etwa 150 Schüler. ${ }^{139}$ Im Jahr 1877 muss sie jedoch schließen, da die Zahl der Schüler aufgrund der vielen Neugründungen von religiösen Schulen in der Umgebung stetig sinkt. ${ }^{140}$ Dieser Umstand und der Rat seiner Freunde haben Bustānī zu diesem Schritt bewogen. ${ }^{141}$ Dennoch erscheint das plötzliche Ende der Nationalschule, für deren Errichtung Bustān̄̄ sogar einen Orden erhält, ${ }^{142}$ und die von Seiten der Regierung als äußerst erfolgreich und einzigartig gelobt wird, ${ }^{143}$ als seltsam. Vermutlich hängt die Aufrechterhaltung der Institution zu stark von Bustānīs Engagement ab. Schließlich widmet er sich ab 1875 seiner groß angelegten Enzyklopädie Dā'irat al-Ma 'ärif (s.u.). Auch finanzielle Gründe könnten eine Ursache sein. In seinem Artikel zur Madrasa Wațan̄ya im Journal al-Ǧinān weist Bustān̄̄ darauf hin, dass Eltern die Schulgebühren nicht immer zahlten. ${ }^{144}$ Zudem habe er einmal gesagt, dass er für den Erhalt der Schule sogar sein eigenes Haus verkaufen würde. ${ }^{145}$ Of-

135 „Report of the Committee on the Preparatory Department of the Syrian Protestant College, adopted by the Board of Managers“ (Beirut, 8.3.1867), in: „Records of the Board of Managers of the Syrian Protestant College“: AA.2.1.2., Ordner 1, 59-60. Ein undatiertes Schreiben namens „Memorandum“ aus den Unterlagen des Board of Managers liest sich wie eine Liste von Beschwerden gegenüber dem SPC (,4th Seducing the pupils and teachers of the Madrasat Wataneah and Prept. Dept. to leave the same and enter the College“ etc.). Es ist daher zu vermuten, dass das Dokument aus dem Jahr 1867 stammt und mit Bustānīs Anschuldigungen zu tun hat: vgl. AA.2.1.2., Ordner 8 .

136 „Record of the Board of Managers of the Syrian Protestant College“ (Beirut, 8.3.1867): AA.2.1.2., Ordner 1, 46.

137 Daraufhin steht zur Debatte, das Seminar in 'Abeih als Prepartory Department zu integrieren. Noch 1874 scheint die Frage ungelöst. Bliss fordert, dass die Mission für die Kosten selbst aufkommen soll, wenn das Seminar nicht direkt dem SPC angegliedert wird: Daniel Bliss an Abby Bliss (Beirut, 6.1.1874), in: Bliss (1993), 166: „We shall not consent to pay for anything over which we have not absolute control.“

138 Board of Managers an das Executive Committee (Beirut, 29.10.1867): AA.2.1.2., Ordner 2.

139 Jessup (1874), 136.

140 Makārīūs (1883), 390. Jessup bestätigt die Schließung der Schule nach 15 Jahren: vgl. Jessup (1910b), 484. Jens Hanssens Angabe, dass die Schülerzahl der Madrasa Wațanīya 1910 über 300 beträgt, scheint in diesem Zusammenhang falsch zu sein: vgl. Hanssen (2005), 147.

141 Șarrūf/Nimr (1883), 5.

142 Jessup (1883/84), 275.

143 Vgl. den Dankesbrief des Gouverneurs von Beirut Muhammad Ru'ūf Pāšā an Bustānī in: alĞinān 2 (1871), 17, zitiert in: Ḩūrī (1995), 65.

144 Bustānī (1873), 628; Jandora (1981), 154.

145 Șarrūf/Nimr (1883), 5. 
fenbar ist der Kreis der Gönner dieses bis dahin einzigartigen Schulmodells nicht so groß wie der Ruf der Schule es vermuten lässt.

\section{Hubb al-wațan (Die Liebe zur Nation) - Bustān̄̄s Karriere als Autor, Journalist und Herausgeber}

Ab den 1860er Jahren vollzieht sich eine bemerkenswerte Wende in Bustān̄̄s Karriere. Er widmet sich überwiegend säkularen Tätigkeiten, zu denen die Gründung der Nationalschule, der Aufbau von drei Periodika sowie die Herausgabe zahlreicher sachlicher Literatur zählen. Auch wenn sich die Wege mit der Mission in den späteren Jahren nicht mehr unmittelbar kreuzen, so haben die Amerikaner Bustānīs Karriere und seine Gedankenwelt zweifelsohne beeinflusst. Als Enzyklopädist und Journalist erlangt Bustān̄̄ zu seiner Zeit noch größeren Ruhm. Das 1869/70 herausgegebene, zweibändige Wörterbuch Muḥit al-Muḥ̄ṭ (Der Umfang des Ozeans) sowie die ab 1870 zweimal im Monat erscheinende Zeitschrift al-Ǧinān (Die Gärten $)^{146}$ gehören zu den Meilensteinen seines Lebens. Dabei nehmen diese Projekte viel früher als bisher dargestellt ihren Anfang: Wie bereits in Abschnitt II.1.8 angedeutet, geht aus der Korrespondenz mit seinem Mentor Eli Smith im Jahr 1855 hervor, dass Bustān̄̄ die Herausgabe eines Wörterbuchs für den Schulgebrauch „nach dem Aufbau ausländischer Wörterbücher“ plant. ${ }^{147}$ Nicht nur Bustānī, sondern vermutlich das gesamte Team der Bibelübersetzung haben erkannt, dass der Gebrauch klassischer Wörterbücher für jede Art von Lesepublikum zu schwierig ist. Araber würden dadurch davon abgehalten, ihre Sprache richtig zu erlernen, was das Erstellen von einfacheren und schneller zu erfassenden Wörterbüchern notwendig mache, so Bustānī in einer Rede im Jahr 1859. ${ }^{148}$ Bereits in der Syrischen Gesellschaft der Wissenschaften und Künste (1847-1852) wurde darüber gesprochen, dass die klassische Literatur von Leserinnen und Lesern der Gegenwart wegen der schwierigen Worte nicht verstanden werde. ${ }^{149}$ In seinem Brief an Smith von 1855 berichtet Bustān̄̄, dass bereits ein Konzeptentwurf existiere, den Smith beurteilen

146 Zur Namensgebung schreibt Bustān̄̄ in der ersten Ausgabe, dass die Zeitung wie ein Paradiesgarten sein soll, in dem es vieles zu sehen und zu hören gibt und köstliche Früchte wachsen: zitiert in: Țarrāzī (1913), 45. Dāya weist auf die Ähnlichkeit zu Bustān̄̄s Familiennamen hin, der ebenfalls „Garten“ bedeutet. Dies gilt auch für die folgenden zwei Periodika al-Ğanna und al-Ğunayna (s. u.): vgl. Dāya (2008).

147 Bustān̄̄ an Smith (Sūq al-Ġarb, 18.7.1855): ABC 50, Box 3, (HHL). Auch im Nachruf auf Bustānī von Ya 'qūb Șarrūf und Fāris Nimr $(1883,2)$ wird erwähnt, dass die Arbeit am Wörterbuch bereits während der Bibelübersetzung beginnt. Glaß (2008), 111: „,[Bustānī] reihte die Lemmata nicht wie in der klassisch-arabischen Lexikographie üblich nach dem Reimprinzip, sondern alphabetisch nach Wurzeln. Auch ordnete er die zu einer Wurzel gehörigen Wortformen innerhalb eines Stichwortes neu an.“

148 Bustānī (1859), 23.

149 Van Dyck, „Fī lad̄āt al- 'ilm wa fawā' idihi“, in: Hūūī (1990b), 31: „Wieviele Einheimische lesen mit Vergnügen Makame [d.h. arabische Poesie] von al-Harīrī oder den Diwan von al-Mutanabbī oder andere Diwane und Gedichtbände? Ich denke, dass die meisten, wenn sie diese [Werke] lesen würden, sie nach kurzer Zeit zur Seite legten, da es viele Wörter [darin] gibt, deren Bedeutung sie nicht verstehen." 
soll. Darüber hinaus bestehe ein Vertrag mit der Amerikanischen Druckerei, laut dem die Einnahmen gleichmäßig geteilt werden sollen. ${ }^{150}$ Es scheint, dass die Kooperation mit der Mission für dieses Projekt nach Smiths Tod ebenso aufgegeben wird. 1869 veröffentlicht Bustān̄̄ den ersten Band seines Muhit al-Muhit noch in der American Mission Press, der zweite erscheint bereits in seiner eigenen Druckerei, der Mațba 'at al-Ma 'ārif (Druckerei des Wissens) ${ }^{151}$. In der Einleitung der ersten Ausgabe beschreibt Bustān̄ sein Werk als ,a small service from a lover of the fatherland (muhibb lil-wațan) whose highest ambitions and aims are to witness the progress of his compatriots in learning and civilization through the medium of their noble language“. ${ }^{152}$ Für seine Veröffentlichung erhält Bustān̄ einen Geldpreis sowie einen Ehrenorden, der auf seinem berühmtesten Portrait zu sehen ist (s. o.). ${ }^{153}$

Auch die Idee, ein Periodikum ins Leben zu rufen, in dem Wissenswertes aus allen Bereichen abgedruckt werden soll, ist nicht erst Ende der 1860er Jahre entstanden. Laut eines Briefes von Smith an Bustani im März 1855 planen beide eine gemeinsame Zeitschrift herauszugeben, für die Smith englische Artikel aus den USA besorgen möchte. ${ }^{154}$ Aufgrund der Ereignisse um Bustānīs Kandidatur für ein Pastorenamt in der Beiruter Kirche schlägt Smith jedoch vor, das Projekt vorerst auszusetzen. Im Januar 1870 erscheint unter Leitung von Bustān̄̄ und seinem Sohn Salīm die erste Ausgabe von al-Ǧinān, einer Art enzyklopädischen Zeitschrift ${ }^{155}$, ,,illustrated by wood-cuts made by a native artist, and having a circulation of about 1500 “156. Schon bei den Missionaren hat Bustānī die potentielle Kraft des Druckwesens kennengelernt, die er nun wirksam einsetzen kann. ${ }^{157}$ Es folgen ebenfalls aus der Hand von Salīm al-Bustāni 1870 die zweimal wöchentlich erscheinende Zeitung al-Ğanna (Der Garten) ${ }^{158}$ sowie unter Mitarbeit von Butrus' Cousin Sulaymān das viermal wöchentlich herausgegebene Handelsblatt al-Ǧunayna (Der Garten). ${ }^{159}$

150 Bustān̄̄ an Smith (Sūq al-Ġarb, 18.7.1855): ABC 50, Box 3, (HHL); Tibawi (1963), 172-173.

151 Bustān̄̄ gründet die Druckerei 1867 zusammen mit Hुal̄il Sarkīs: vgl. Tibawi (1966), 166.

152 Muhīṭ al-Muḥiṭ, Bd. 1, 848, übersetzt und zitiert von: Tibawi (1963), 172-173.

153 Zaydān (1903), 27; Tibawi (1963), 173.

154 Smith an Bustān̄i (Beirut, März 1855): ABC 60 (105), (HHL).

155 Bustān̄̄ selbst nennt al-Ǧinān in der ersten Ausgabe ğarīda (Zeitung), da der Begriff mağalla für Zeitschrift erst ab 1884 gängig wird. Herausgeber wie Hुalīl al-Hūīī (Hadīqat al-Ahbār) bedienen sich auch mit der Bezeichnung ğurnāl der europäischen Sprachen: vgl. Dāya (2008). Zur Bedeutung von mağalla siehe auch Glaß (2004a), 8.

156 Jessup (1874), 136.

157 Jandora (1981), 146.

158 Glaß $(2001,41)$ zitiert dazu aus einem illustrativen Bericht von Alfred von Kremer, ,Ein Jahr in Beirut“, in: Das Ausland Nr. 7 (12.2.1872), 151: „Eine beachtenswerte Erscheinung ist es aber, wie rasch sich ein anderes etwas unabhängigeres Blatt einen großen Leserkreis zu erringen wußte. Es ist dies Bistany’s Zeitung, die den Namen ,Dschenne‘, d. i. der ,Garten“ führt. Es ist geschickt redigiert, bringt Telegramme, Leitartikel und reiche Correspondenzen, selten versteigt es sich zu einer schwachen Kritik an Regierungsmaßregeln. [...] Es ist recht überraschend, wenn man die engen, überfüllten Bazare von Beirut durchwandelt, zu sehen, wie allenthalben in den Buden die arabischen Kaufherren mit ihrer Dschenne in der Hand dasitzen und mit großer Aufmerksamkeit ihre Zeitung lesen."

159 Näheres zu diesen Journalen in: Jessup (1874), 136; Ayalon (1995), 34-36; Glaß (2004a), 135139. 
Der zunehmende Import und Export von Handelsgütern steigert das Bedürfnis der Menschen über Handel, Politik und Wissenswertes informiert zu werden. ${ }^{160}$

Seine Vorbilder findet al-Ǧinān in den europäischen Zeitschriften, die sich ebenfalls wissenschaftlichen, kulturellen, historischen, wirtschaftlichen und kommerziellen Themen widmen, und wo der Nutzen dieses Wissens bereits Früchte getragen hat, wie Bustān̄̄ in der ersten Ausgabe von al-Ǧinān schreibt. ${ }^{161}$ Viele Artikel über Europa oder Amerika sind Übersetzungen aus westlichen Periodika, eine Praxis, die auch in den arabischen Missionsblättern der Syrienmission üblich ist. ${ }^{162}$ Auch wenn nur wenige Artikel aus der Feder von Bustānī stammen, so hat er - laut der Analyse des Journals durch JOHN W. JANDORA - dafür Sorge getragen, ,that the articles and editorials of al-Jinān were consistent with - or, at least, not contrary to - his own social philosophy“" ${ }^{163}$ Hier wie in vielen seiner anderen Projekte versteht er es, Kollegen zur Zusammenarbeit zu ermutigen und sie in ihren eigenen Vorhaben zu unterstützen. ${ }^{164}$

Das Titelblatt jeder Ǧinān-Ausgabe trägt die programmatischen, sogar dem islamischen Hadith entnommenen, Worte hubb al-watan ${ }^{165}$ min al-īmān $^{166}$ (Die Liebe zur Nation ist ein Grundsatz des Glaubens). ${ }^{167}$ Es ist eine Fortführung des Gedankens, der zuvor zur Gründung der Madrasa Watanīya geführt hat und erstmals in den 1860 von Bustān̄̄ verfassten elf Pamphleten Nafìr Surīya (Syriens Weckruf) zum Ausdruck kommt. ${ }^{168}$ Der Bürgerkrieg von 1860, in dem konfessionelle Fehden einmal mehr einen Höhepunkt erreichen, führt Bustānī zu den Gedanken, dass religiöse Streitigkeiten durch Unwissenheit und Intoleranz entstehen und man ihnen nur mit Wissen und Aufklärung entgegentreten könne. ${ }^{169}$ An dieser Stelle vollzieht sich bei Bustānī eine Wende zum Säkularismus. Die Förderung von Bildung, wie

160 Sarrūf/Nimr (1883), 6.

161 Al-Ǧinān 1 (1870), 1, zitiert in: Ayalon (1995), 34. Die Popularisierung von Wissenschaft und Literatur führt im 19. Jahrhundert zu einer großen Bandbreite von Periodika wie z. B. der Illustrirten deutschen Monatshefte oder dem Grenzboten: vgl. Nissen, M., Wissenschaft für gebildete Kreise. Zum Entstehungskontext der Historischen Zeitschrift, in: Stöckel (2009), 30-31.

162 Ayalon (1995), 34: „Summaries of current events in Europe, chapters from its history, and translations from the European press and its literature were presented along with Arab literary and historical pieces." Vgl. dazu die Schilderungen zu Mağmū' Fawā'id und al-Našr $r a$ in den Abschnitten II.1.5 und II.2.5.

163 Jandora (1981), 148.

164 Ebd., 148, 194: Autoren in al-Ǧinān sind u. a. Cornelius Van Dyck, Ibrahīm al-Yāziğī (Sohn von Nāṣîf al-Yāziǧīi) sowie Lūwīs Sabūnğî, Lehrer am SPC und Herausgeber der Journale alNaḥla und al-Nağăḥ, vgl. Tibawi (1967), 277; Holt (2009), 63.

165 Wațan meint ursprünglich „Wohnort“. Durch europäische Einflüsse bezüglich der Ideen von Nation und Nationalität wird der Begriff nun häufig für „Heimat“ oder „Vaterland“ verwendet. Eine Person fühlt sich der eigenen Heimat sozial zugehörig und ist moralisch und politisch von ihr geprägt: vgl. Philipp (1979), 87.

166 Zitiert in: Țarrāzī (1913), 45.

167 Nafïr Surīya, Nr. 4 (25.10.1860): „In fact, was it not stated in the Hadith that the love of fatherland is an article of faith?" (TA)

168 Eine sprachliche Analyse der Flugblätter findet sich in: Jandora (1981), 76-97 sowie S.P. Sheehi, ,Inscribing the Arab Self: Buțrus al-Bustānī and Paradigms of Subjective Reform“, in: British Journal of Middle Eastern Studies 27/1 (2000), 7-24.

169 Antonius (1938), 50. 
sie dem Protestantismus und der Mission zu Eigen ist und in jenen Tagen von vielen syrischen Intellektuellen gepredigt wird, kann durchaus übernommen werden. Bildung unter dem Deckmantel der Religion, die darauf abzielt, sich von anderen Glaubensgemeinschaften zu distanzieren, ist jedoch keine Lösung für die Probleme im osmanischen Syrien. Einzig der Gedanke, dass man zu einer Nation gehöre, egal welche Religion man praktiziere, könne zum Frieden in der Region führen. „An die Söhne der Heimat“ ist die Anrede in den elf Pamphleten, die zwischen 1860 und 1861 entstehen, und die Bustān̄ jeweils mit muhibb al-wațan (der, der die Heimat liebt) unterschreibt. Der Autor bleibt anonym, zeigt sich als säkular orientierter Patriot ${ }^{170}$ und präsentiert sich nicht als Mitglied der protestantischen Gemeinschaft. „Syria, known as Barr al-Šām or 'Arabistān, is our fatherland“, 171 so Bustān̄̄. In dieser Heimat gelte es eine zivilisierte Gesellschaft ${ }^{172}$ aufzubauen und für das gemeinsame Wohl zu kämpfen. ${ }^{173}$ Dafür seien drei Bedingungen erforderlich: (1.) Wahre Religion, die für Toleranz, Frieden und Brüderlichkeit steht, ${ }^{174}$ (2.) Politische Regeln, ,which care [...] for the good of its people and their welfare, success, wealth, knowledge, and civilization“, ${ }^{175}$ und (3.) Quellen des Wissens „such as schools, printing presses, journals, and commerce, which get people closer like one family“"176. Brüderlichkeit und Gerechtigkeit seien für die Schaffung eines Nationalgefühls von oberster Priorität. Die Menschen müssen lernen, dass sie Geschwister im Glauben sind, und es dürfe nicht mehr Vergeltung an einer ganzen Gruppe geübt werden, wenn sich einzelne Personen darunter eines Verbrechens schuldig gemacht haben. ${ }^{177}$ Schließlich plädiert Bustānī für einen säkularen Staat, in dem geistliche und politische Gewalten klar getrennt sind: „For religion is inherently concerned with inner or personal matters, unchanged through time and place, while politics is concerned with external matters, changeable through time and place." "178

Die elf Pamphlete werden nicht nur im osmanischen Syrien, sondern auch in Ägypten, Griechenland, am Bosporus, im Irak und in persischsprachigen Gebieten gelesen. ${ }^{179}$ Nafïr Surīya ist kein Aufruf, sich völlig an der westlich-säkularen, zivi-

170 Makdisi (2008), 207.

171 Nafīr Surīya, Nr. 4 (25.10.1860). (TA)

172 Für Zivilisation steht hier tamaddun, ein Wort, das ursprünglich von madina (Stadt) hergeleitet wird ,and now means achieving internal and external refinement and acquiring knowledge, manners, and virtues. "Vgl. Nafïr Surīya, Nr. 11 (22.4.1861). In der Zeitschrift al-Ǧinān finden sich etliche Diskurse über diesen Begriff (Bd. 3/6, 1872, S. 201-204; Bd. 2/13, 1871., S. 447452): vgl. Zachs (2005), 71.

173 Nafîr Surīya, Nr. 5 (1.11.1860): „Should you not revive that old amiability and roll up your sleeves to face these problems, compensate for the damage, and work together for the good of this land, knowing that you are not enemies but friends?" (TA)

174 Bustānī legt sich hierbei auf keine Konfession fest. Sein Religionsbegriff scheint universal gefasst zu sein: Jede Religion, die die Regeln einer zivilen Gesellschaft unterstützt und Gott dabei treu bleibt, ist eine wahre Religion.

175 Nafīr Surīya, Nr. 11 (22.4.1861). (TA)

176 Ebd. (TA)

177 Nafīr Surīya, Nr. 7 (19.11.1860).

178 Nafīr Surīya, Nr. 10 (23.2.1861). (TA)

179 Șarrūf/Nimr (1883), 3. 
lisierten Gesellschaft zu orientieren. Bustānī verlangt von seinen Lesern einen kritischeren Blick auf Europa und auf sich selbst. Zwar ist man in Europa zivilisierter als in der Levante, aber „most of its civilized people seek their own interest more than the development of their people in terms of knowledge and manners" ${ }^{180}$ Die Aneignung eines europäischen Habitus ist nur äußerer Natur und genügt nicht für den Aufbau einer zivilen Gesellschaft in einem kulturell anderen Kontext: ${ }^{181}$

Although we think that it is useful and rational to learn from others and that most of the benefits of civilization are the product of the West and that most Europeans deserve utmost respect, we cannot assert that every product is useful in itself and fit for the success of people of the East and for their environment $\left[\ldots . .{ }^{182}\right.$

Eigenverantwortung und die Abwehr von Fremdbestimmung sind Maßnahmen, die es laut Bustānī zu ergreifen gilt. Einmal mehr zeigt sich, dass er zwar stark von der Gedankenwelt der Missionare geprägt ist, daraus jedoch jeweils positive oder negative Schlüsse zieht: Was die Syrienmission ihren einheimischen Helferinnen und Helfern an Verantwortungsbewusstsein abspricht, fordert Bustān̄̄ explizit von seinen Landsleuten, jenseits von Hierarchie und religiösem Fanatismus. ${ }^{183}$ Bustān̄̄ ist in der Lage, die Dinge in positive Selbstkritik umzuwandeln, die die Missionare als Teil der minderwertigen und fehlerhaften Mentalität der Araber betrachten. ${ }^{184}$ Andererseits darf nicht übersehen werden, dass sich auch die Amerikaner stets respektvoll gegenüber der osmanischen Regierung und ihren lokalen Verwaltern verhalten. Laut Jessup ist jeder Missionar dazu aufgefordert ,[to] steer clear of all these rational and sectarian political jealousies and try to teach loyalty to the ,power that be', the common brotherhood of man, and offer to all a common saviour". 185 Parallelen zu Gedanken in Nafir Surīya sind hier eindeutig zu erkennen.

Bustānī zeigt sich stets loyal gegenüber der osmanischen Regierung. In nahezu allen Veröffentlichungen nach 1859 werden Dankesworte an den Sultan und

180 Nafïr Surīya, Nr. 11 (22.4.1861). (TA)

181 Ebd.: ,[S]ince every strange and new thing becomes popular and since we are living in the age of Europe and European taste and habits are overshadowing those of the East, we fear that most of the people of our land, who are among the most to be drawn to imitation, might settle for imitating European habits, clothing, and traits, thinking that this is enough to be considered civilized and superior to the rest of their people, oblivious to the fact that such an imitation distances them from their own people and turns them into unworthy imitators in the eyes of foreigners." (TA)

182 Ebd. (TA)

183 Makdisi (2008), 198.

184 Nafïr Surīya, Nr. 5 (1.11.1860): „O sons of the fatherland, what excuse for our acts could we give the foreigners but being stupid and uncivilized and allowing our emotions to take precedence over our mind? Their taking place under extraordinary circumstances might be accepted as an excuse. What can be expected from a land whose people are formed of clans with different origins, mentalities, goals, and interests? Most of them do not care about the common good of this region and a good number does not consider it to be their fatherland." (TA)

Vgl. dazu Shaw (2014), 76-77: Bustānī befürwortet hierbei durchaus den von den Missionaren propagierten kulturellen Verfall (inhițatt) Syriens und weiß die Kritik für seine Botschaft in Nafir Surìya anzuwenden.

185 Jessup (1910b), 593. 
andere Mitglieder der Regierung gerichtet. ${ }^{186}$ „He was obviously seeking official favour and patronage“, urteilt dazu TiBAWI. ${ }^{187}$ Angesichts der Zensurbestimmungen, mit denen auch die Missionare Probleme haben, erscheint diese Geste als hilfreich. Für seine Veröffentlichungen ist Bustānī nicht nur auf die Erlaubnis durch die zuständige Behörde angewiesen, sondern auch auf finanzielle Unterstützung. Seine Enzyklopädie Dā'irat al-Ma 'ârifi ${ }^{188}$ - Encyclopédie arabe, die er von 1875 bis 1882 herausgibt, kann nur durch die finanzielle Hilfe des ägyptischen Khediven Ismā̄̄il entstehen, da sich Bustānī schon seit Nafìr Surīya in Ägypten großer Beliebtheit erfreut. ${ }^{189}$ Ismầ $\mathbf{1}$ veranlasst zudem, dass hunderte von Exemplaren des Lexikons nach Ägypten verkauft werden und der Herausgeber mit Referenzliteratur aus Būlāq versorgt wird. ${ }^{190}$ Mit der Machtübernahme von Sultan Abdülhamid II. (1876-1909) führt die verschärfte Pressezensur zum Einfuhrverbot von Enzyklopädien, in denen kritische Artikel über die osmanische Regierung enthalten sind. Das hat zur Folge, dass Enzyklopädien häufig mit ausgeschnittenen Seiten importiert werden. ${ }^{191}$ Bustānī bemüht sich in seinem Projekt um einen politischen und sozialen Brückenschlag. Seine Enzyklopädie richtet sich an jede Art von Lesepublikum ${ }^{192}$ (kitāb 'umūmì li-kull al-milal wa l-madăhihib, ein Buch für alle Klassen und Konfessionen) ${ }^{193}$ und versucht, für die Hauptthemenbereiche moderne Naturwissenschaften, Technologie, europäische und arabische Geschichte und Literatur in ausgeglichener Weise westliche und arabische Quellen hinzuzuziehen. ${ }^{194}$ Henry Harris Jessup lobt das Werk in den höchsten Tönen:

186 So z. B. in seiner Rede Huṭa fi àdāa al- 'arab (1859, siehe Anhang I): vgl. Tibawi (1963), 166; Nafïr Surīya, Nr. 2 (8.10.1860): „Sultan 'Abd al-Mağid [...] in the firman he issued [...] ordering to take all measures to eradicate corruption, put an end to these events, and restore security, also demonstrates that he considers this matter to be of utmost importance and that he cares for the good of his people and sympathizes with them." (TA) Vgl. auch Tibawi (1963), 170: In seiner Grammatik Kitāa miftāh al-mișbāḥ (1862, siehe Anhang I) schließt Bustānī mit den folgenden Worten: ,the Caliphate of His Majesty of the two seas, Sultan 'Abdul-'Azīz...May God establish his state with glory and prosperity, and perpetuate his power and victory."

187 Tibawi (1963), 166.

188 Der vollständige Titel ist Kitāb dā'irat al-ma ārif wa huwa qāmūs 'ilm li-kull fann wa mațlab (Der Kreis des Wissens, ein Wörterbuch des Wissens von jeder Kunst und Sache). Ausführlicher zur Enzyklopädie siehe Glaß (2008).

189 Șarrūf/Nimr (1883), 3.

190 Tibawi (1963), 179.

191 Jessup (1910b), 434.

192 Ebd., 484: 500 Exemplare werden vom ägyptischen Vizekönig geordert. Weitere Bestellungen gehen an syrische Paschas, Patriarchen, Bischöfe, Priester, Schulleiter, Muftis, Sheikhs, Händler, Bauern, Lehrer, Studenten, Mönche, ausländische Missionare in Indien und Syrien sowie an Gelehrte aus Deutschland, Frankreich, England und Amerika.

Anders als in europäischen Enzyklopädien fallen Artikel zu arabischen Dichtern und islamischen Denkern oder zur lokalen Geografie viel umfangreicher aus: vgl. Hourani (1994), 212.

193 So das Vorwort in Dā' rat al-Ma ārif 1, 4, zitiert in: Glaß (2008), 125.

194 Tibawi (1963), 180; Hourani (1994), 210. Als einer der ersten arabischen Autoren stellt Bustān̄i die USA und ihre Einwohner sachlich dar. Vgl. Makdisi (2010), 55-56: „Bustani’s description of the United States was schematic, but his precise enumeration of the country's population represented the beginnings of a modern Arab understanding of America." 
It is a compilation and translation of the best French, English, and American encyclopedias, and the geographical and historical parts are enriched from the best works of the most eminent Arabic authors. The illustration were furnished by Messrs. Appleton and Co. ${ }^{195}$ of New York and the book as far as printed is a monument of industry and literary ability. ${ }^{196}$

Für die Recherche der lokalen Kultur- und Religionsgeschichte nimmt Bustānī zudem Kontakt mit namhaften Vertretern auf, um biografische Informationen über Patriarchen und Priester zu erhalten und seinen Artikeln die größtmögliche Authentizität zu verleihen. ${ }^{197}$

Bustānī kann bis zu seinem Tod 1883 immerhin sechs der zwölf geplanten Bände veröffentlichen, die unter Mitarbeit fast aller Familienmitglieder entstanden sind. ${ }^{198}$ Den siebten Band kann er nur bis zur Hälfte fertig stellen. ${ }^{199}$ Laut Jessup seien die Entwürfe für die anderen Bände nahezu vollständig gewesen. ${ }^{200}$ Sein Sohn Salīm gibt nur einen weiteren Band heraus, bis auch er 1884 verstirbt. Bustānīs jüngere Söhne Nașīb und Naǧīb führen die Enzyklopädie weiter bis zum 11. Band (1900), der beim arabischen Buchstaben 'ayn, dem 18. von 28 Konsonanten, endet. ${ }^{201}$

\section{Für Frauenbildung und kulturellen Fortschritt - Bustānī und die literarischen Zirkel}

Angesichts seines ohnehin schon vielseitigen Engagements in verschiedenen Bereichen der intellektuellen Szene Beiruts stellt sich die Frage, wie Bustānī ebenso maßgeblich am Aufbau verschiedener literarischer und intellektueller Gesellschaften beteiligt sein kann. ${ }^{202}$ Der al-Muqtataf schreibt 1883, dass es kaum vorstellbar sei,

195 Hourani (1994), 210: Die Illustrationen in den ersten drei Bänden stammen von einem lokalen Künstler namens Mihāàîl Farāh.

196 Jessup (1910b), 484.

197 Bustānī an den maronitischen Metropoliten Yūsuf al-Marīd (18.1.1883): AA.6.1/Buṭrus alBustānī. (TA)

198 Hourani (1994), 210.

199 N.N., „Al-āsif al-'azīm““ (Großes Bedauern), in: al-Našra al-Usbu '̄ya 19 (7. Mai 1883).

200 Jessup (1883/84), 276. Im o. g. Brief an den Metropoliten Yūsuf al-Marīd Anfang 1883 schreibt er, schon bald beim Buchstaben „M“" angekommen zu sein, der im arabischen Alphabet der fünftletzte Buchstabe ist: Bustān̄i an Yūsuf al-Marīd (18.1.1883): AA.6.1/Buțrus al-Bustān̄̄. TA)

201 Hourani (1994), 204: Die letzten beiden Bände müssen aufgrund der Zensur in Kairo gedruckt werden. „Der letzte Artikel behandelte die Dynastie der Osmanen, was vielleicht passend war, denn die zunehmenden Schwierigkeiten, im Hoheitsgebiet von Sultan Abdülhamid frei zu publizieren, in Verbindung mit den finanziellen Problemen hatten zu den langen Verzögerungen zur Verlegung des Unternehmens von Beirut nach Kairo geführt.“

Laut Aussage von Claude Boustany Hajjar, einer Nachfahrin der Bustānī-Familie, wurde die Enzyklopädie innerhalb der Familie weitergeschrieben.

202 Bustānī ist Gründer bzw. Mitglied in etlichen literarischen und wissenschaftlichen Gesellschaften: Mağma' al-Tahd̄īb (Gesellschaft für Bildung, 1846-47); al-Ğam 'ìya al-Surīya li l- 'Ulūm wa l-Funūn (Syrische Gesellschaft der Wissenschaften und Künste, 1847-52); al-Ǧam '̀̃ya al'Ilmīya al-Surīya (Die Syrisch-Wissenschaftliche Gesellschaft, 1857-60 und 1867-69); al'Umda al-Adabīya li Išhār al-Kutub al- 'Arabìya (Die literarische Unterstützung für die Verbreitung arabischer Bücher, 1860-?); Ğam '̀yyat Beyrūt al-Inǧilīya (Beiruter Bibelgesellschaft, 
was diese eine Person geleistet habe, ein Gelehrter habe ihn sogar „den Riesen“ ( $a l$ ğabbār) genannt. ${ }^{203}$ Erste Gehversuche in der Etablierung einer Zusammenkunft, die sich intensiv mit Wissen und Wissenschaft befasst, unternimmt er, wie zuvor dargestellt, mit der 1846 gegründeten Mağma' al-Tahd̄̄ b (Gesellschaft für Bildung) in 'Abeih, ${ }^{204}$ die sich wenig später als Beiruter al-Ğam 'ìya al-Surīya li l- 'Ulūm wa l-Funūn (Die Syrische Gesellschaft der Wissenschaften und Künste) neu formiert. Vier seiner Reden, die er in den dortigen Versammlungen gehalten hat, sind überliefert: (1.) Hițāb fì ta 'alìm al-nisā' (Rede über die Bildung von Frauen), ${ }^{205}$ (2.) F̄̄ madīna Beyrūt (Über die Stadt Beirut), ${ }^{206}$ (3.) Amālī falkīya (Astronomische Betrachtungen), ${ }^{207}$ (4.) Al-Harīrī ([Über den arabischen Dichter] al-Harīīī) ${ }^{208}$. Die letzten drei zählen zu rein informativen Vorträgen wie sie für die Themenvielfalt in den Sitzungen der Gesellschaft typisch sind. Bustānīs Rede über Frauenbildung, die er am 14. Dezember 1849 hält, erregt noch heute große Aufmerksamkeit. In seinem kulturellen Umfeld gilt dieser Gedanke als neu. Der Muqtațf wird später schreiben, Bustānī sei der Erste im Osten gewesen, der das Thema Frauenbildung in einer Rede angesprochen hat (,wa kān awwal min hututub fì $l$-šarq bi-hādā $\left.l-b \bar{a} b^{\circ}\right){ }^{209} \mathrm{Die}$ Maxime, die er am Ende dieser Rede äußert („She who rocks the cradle with her right hand moves the world with her arm“) ${ }^{210}$ wird später zum Mantra unter syrischen Intellektuellen. ${ }^{211}$

Die Bildung von Frauen ist jedoch längst kein revolutionärer Gedanke mehr in der arabischen Welt jener Zeit, denn kirchliche Bildungseinrichtungen für Mädchen hat es schon im 17. Jh. in Syrien gegeben. Wie bereits beschrieben, integrieren auch die amerikanischen Missionare die Ausbildung von jungen Syrerinnen als selbstverständliche Notwendigkeit in ihr Evangelisierungsprogramm. ${ }^{212}$ Bustān̄̄,

1862-?); Ğam 'iyat Zahrat al-Adab (Gemeinschaft zur Blüte der Bildung, 1873-?); al-Mağma al- 'Ilmī al-Šarqī (Die Östlich-Wissenschaftliche Gesellschaft, 1882-ca. 1885).

203 Șarrūf/Nimr (1883), 4.

204 Siehe Abschnitt I.2.4.

205 In: Hुūrī (1990b), 45-53. Eine englische Übersetzung befindet sich ebenso in: Jessup (1874), 159-162. Die Rede wird leicht verändert nochmals 1876 in Bustānīs Journal al-Ǧinān abgedruckt: vgl. Lindner (2014a), 63.

206 In: Hūrī (1990b), 71-72: Ein kurzer Überblick über die Geschichte Beiruts und wichtige Persönlichkeiten von der Antike bis ins frühe Mittelalter.

207 Glaß (2004a), 126: In dem Vortrag geht es um die Vorstellung der Planeten „Sonne (̌́ams), Venus (zuhra), Mars (mirrīh ), Jupiter (muštarī), Saturn (zuḥal), Uranus (ūrānūs), Erde (arḍ) und Mond (qamar).“

208 In: Hūūī (1990b), 77-78.

209 Șarrūf/Nimr (1883), 6.

210 ,'[A]n allatī tahazzu al-sarīr bi-yamīnihā hiya allatī taharraku al-maskūna bi-dirā 'ahā.": vgl. B. al-Bustān̄̄, „Hițāb fì ta 'alīm al-nisā'“, in: Hुūrī (1990b), 53, übersetzt und zitiert in: Zachs (2014), 124.

211 Zachs (2014), 124. Jessup $(1874,195)$ zitiert bspw. in seinem Buch The Women of the Arabs aus einem in der Zeitschrift al-Ǧinān (1.9.1872) veröffentlichten Artikel eines gewissen „Frances Effendi Merrash“, der Bustānīs Zitat aufgreift: „Woman is the one fountain from which is derived the life of man in its earliest periods. [...] Have you not heard that she who rocks the cradle, moves the world?"“

212 Siehe Abschnitt I.1.2. 
der 1843 Raḥīl heiratet, die selbst eine hohe Ausbildung bei den Missionaren genossen hat, bewegt sich bereits in einem Sozialgefüge, aus dem Schulbildung für Frauen nicht mehr wegzudenken ist. Es verwundert daher auch nicht, dass drei von Bustānīs Töchtern sich beruflich als Schreiberinnen bzw. Autorinnen engagieren. ${ }^{213}$

In der Kritik an denen, die Frauenbildung für unnötig halten, beginnt Bustānī in seiner Rede bei den - wie er selbst sagt - „Barbaren“ und heidnischen Völkern, nämlich den Indern und Indianern. MAKDIsI hat bereits gezeigt, dass diese Klassifizierung von Völkern den Vorstellungen der Missionare entspricht. Menschen im arabischen Kulturkreis, so stellt es auch Bustānī dar, befinden sich demnach auf der mittleren Stufe zwischen den barbarischen Völkern und den zivilisierten Gesellschaften der westlichen Welt. „But for Bustani, such descriptions were literary devices to help clarify an Arab predicament, not discourses rooted in the experience and practice of racial discrimination and domination“", 214 schlussfolgert MAKDISI. Obwohl es den Frauen in Syrien besser ergeht als jenen in Indien, die schwere körperliche Arbeit an ihrer Männer Statt verrichten müssen, haben sie ,noch nicht die erforderliche Stufe an Wissen und Zivilisiertheit (al-ma'arifa wa l-tamaddun) erreicht, wie es für den Erfolg des Landes und den Fortschritt der Menschen notwendig wäre“. ${ }^{215}$ Bustānī begründet die Stellung der Frau biblisch, denn Gott hat sie zur Mutter der Schöpfung gemacht (,,al-mawlan [...] aqāmahā ummam li-l-halīqa“"). Ihre physische Beschaffenheit sei nicht dazu bestimmt, schwere körperliche Arbeit zu leisten. Ihre Aufgabe ist es, die Nachkommenschaft aufzuziehen und zwar mit dem Wissen und den Werten, die sie sich selbst durch Bildung angeeignet hat. Deutlich tritt hier das bereits in Abschnitt I.1.2 beschriebene Bild der Republican Mother zutage. ${ }^{216}$ Eine neue, für den Aufbau des Landes hilfreiche Generation kann nur heranwachsen, wenn die wahre religiöse und allgemein bildende Erziehung bereits im Elternhaus stattgefunden hat. ${ }^{217}$ Eine Frau müsse daher Lesen und Schreiben können sowie in Religion, Pädagogik, Geschichte, Geografie, Handarbeit und sonstigen Tätigkeiten im Haushalt bewandert sein. ${ }^{218}$ Es handelt sich um die Fächer, die auch in den missionarischen Mädchenschulen angeboten werden und die Mutter-

213 Zachs (2014), 128-129: Dazu zählen Adelaide (Idlid), die ihre Novelle „Hinrī wa Imīlya” (Henri und Emilia) in Bustānīs Zeitschrift al-Ğinān 1/12, 13 (1883-84) veröffentlicht; Sarah, die für eine ältere Dame als Schreiberin arbeitet; sowie Alice, die 1891 ihren Roman „Riwāyat Șā'iba“ (etwa: Ein zweckmäßiger Roman) herausgibt.

214 Makdisi (2008), 207. In der Tat setzt sich Bustānī nirgends mit dieser Thematik auseinander.

215 Bustānī, „Hițāb fī ta 'alīm al-nisā'،, in: Huūrī (1990b), 47.

216 Siehe dazu auch Lindsay (1965), 126: „Bustani's paper is also a correct summary of the purposes which the missionaries held in 1850 toward female education. There was no thought of the current concept of self-actualization for women, no idea of educating them equally with men, no idea of professional or career training, but only the positive goal of training girls to become mothers who could offer an enlightening influence upon the children, complementing that of the educated fathers."

217 „Denn die Frau wendet alles, was sie an Wissen, Bildung und Zivilisiertheit besitzt, bei ihren Kindern an. [...] Zu diesem Zeitpunkt prägt sich auf das leere Herz des Kindes [ihre] sanfte Freundlichkeit [und] alles, was sie an Gutem besitzt und ihrem Geschmack entspricht": vgl. Bustān̄̄, „Hitāāb fì ta 'alīm al-nisā' “, in: Hūūī (1990b), 51.

218 Bustānī, „Hițāb fī ta 'alīm al-nisā'“, in: Huūrī (1990b), 49-50. 
schaft sozusagen als Berufsfeld etablieren. ${ }^{219}$ Bustānī mag das Thema Frauenbildung als erster Gelehrter im Nahen Osten angesprochen haben, ${ }^{220}$ die inhaltlichen Bezüge zur Gedankenwelt der Missionare sind jedoch kaum zu verkennen.

1859 wird von der American Mission Press Bustānīs sehr ausführliche „Rede über arabische Kultur" (Huțba fì ādāb al- 'arab) herausgegeben, die er vermutlich vor der Ğam 'īyat al- 'Ilmīya al-Sūrīya (Die Wissenschaftlich-Syrische Gesellschaft; 1857-1860, 1867-1869) $)^{221}$ am 15. Februar 1859 hält. ${ }^{222}$ Inhaltlich knüpft die Rede stark an die für die Syrische Gesellschaft der Wissenschaften und Künste verfassten Vorträge von Smith, Van Dyck oder Wortabet an. Es geht um die Betonung, dass Wissen und Wissenschaften für die gesellschaftliche Entwicklung unerlässlich sind. In einem geschichtlichen Überblick über die Zeit vor und nach der Einführung des Islam stellt Bustānī die herausragenden Leistungen der Abassiden im Bereich der Wissenschaften heraus. Werke aus jener Zeit wurden in Europa rezipiert und sind dadurch erhalten geblieben. Der Neudruck dieser Werke in den Zentren arabischen Buchdrucks in Europa, wie Smith es bereits in seiner Jahresrede von 1852 erwähnt, ${ }^{223}$ ermöglicht die neue Lektüre klassischer, arabischer Literatur. Was die arabische Sprache anbelangt, so gibt es ebenfalls Ähnlichkeiten zu Van Dycks Rede „Über die Freuden an der Wissenschaft und ihren Nutzen“: Bustān̄̄ und Van Dyck betonen beide, dass die Vernachlässigung von klassischer Literatur dazu geführt habe, dass solche Texte ohne geeignete Wörterbücher von der allgemein gebildeten arabischsprachigen Bevölkerung nicht mehr verstanden werden können. ${ }^{224} \mathrm{Die}$ Integration fremdsprachiger Termini in die arabische Sprache ist sinnvoll, wenn dadurch Defizite ausgeglichen werden (,al-iqtiṣār mā lā wuğid lahu fì aṣl tilka l-lug்a"), so Bustān̄̄. ${ }^{225}$ Im Austausch mit anderen Kulturen kann das Erbe der arabischen Sprache jedoch nur erhalten bleiben, wenn man sie nicht zugunsten der europäischen Sprachen vernachlässigt. ${ }^{226}$ Schließlich macht er die „Söhne der Nation" darauf aufmerksam, nicht nur die vergangenen Errungenschaften der arabischen Kultur wertzuschätzen, sondern auch die Vorteile zu sehen, die der Kontakt mit „zivilisierten Völkern“ (bi-šu 'ūb mutamaddina) mit sich gebracht habe: Aufsätze, Reden und Debatten zu Literatur, Religion, Politik und Frauenbildung führen schließlich zu einer fortschrittlichen Gesellschaft. ${ }^{227}$

219 MH 46 (1850), zitiert in: ROS 4, 107; Zachs (2014), 125.

220 Bustān̄is Gedanken werden in Qāsim Amīns Werk „Tahrīr al-Mar'a“ (Die Befreiung der Frau) von 1899 erneut aufgegriffen und zu einem neuen Konzept zur Rolle der Frauen in der Gesellschaft weiterentwickelt: vgl. Zachs (2014), 129.

$221 \mathrm{Zu}$ den zwei Schaffensperioden siehe Abschnitt I.2.4. Sheehi $(2004,19)$ spricht von der Syrischen Gesellschaft der Wissenschaften und Künste. Dies ist jedoch nicht korrekt, da die Gesellschaft zu diesem Zeitpunkt nicht mehr existiert.

222 Eine eingehende Analyse der Rede findet sich in Jandora (1981), 37-62.

223 Smith, „Huṭba al-ra'īs al-sanawīya sana 1852“ (Jahresrede des Vorsitzenden für das Jahr 1852), in: Hūrūi (1990b), 25.

224 Van Dyck, „Fī lad̄āt al- 'ilm wa fawā' idihi“, in: Hōūrī (1990b), 31.

225 Bustānī (1859), 20.

226 Ebd., 19.

227 Ähnliche Aussagen über die positiven und nützlichen Einflüsse westlicher Kulturen trifft Bustān̄̄ in der 1869 gehaltenen Rede Hițāb fì l-hay'a al-iğtima '̄ya wa l-muqābala beyn al- 
Wissen, das durch verschiedene Medien - seien sie ausländisch oder indigen der arabischen Gesellschaft präsentiert wird, erhält nun eine soziale Dimension. Wissen ist das sine qua non des kulturellen Erfolgs. ${ }^{228}$ Die essentielle Verbindung von Bildung und Protestantismus, die die Missionare leben, wird von Bustānī aufgelöst. Bildung wird zu einem reinen Kulturgut, für das sich die „Söhne der Nation“ einsetzen sollen. Nur durch Fortschritt und Zivilisation können die Fehler der Vergangenheit beseitigt werden.

Bustānīs Trennung von der Syrienmission Ende der 1850er Jahre ist daher nicht nur äußerlich, sondern sie findet auch in seinen Vorstellungen über die Kultur und die Zukunft der arabischen Nation statt. Die Missionare nehmen darin keine tragende Rolle mehr ein und gelten für Bustānī lediglich als brauchbare Helfer neben anderen Europäern. Bemerkenswert ist schließlich, dass Bustānī in seiner Rede der seit 1821 in Ägypten bestehenden Druckerei in Būlāq die meiste Anerkennung zuspricht, statt der American Mission Press, für die er fast zwei Jahrzehnte gearbeitet hat. Die ägyptische Druckerei trete durch ihre exzellente Organisation (hassan nizām) hervor und habe durch den Druck von originalen Schriften und Übersetzungen Großartiges ('azam fầ'idatihā) geleistet. ${ }^{229}$

\section{Schlussbetrachtung}

YũsuF QASM Hुỗī betitelte den Neudruck seiner Dissertation über Buṭrus al-Bustānī von 1976 mit Rağul al-säbiq li- 'așrihi, ein Mann, der seiner Zeit voraus ist. ${ }^{230}$ Ist Bustānī mit seinem Lebenswerk und den darin vielfach erörterten Gedanken in der Tat seiner Zeit voraus? Seine Pionierleistungen, sprich das erste moderne, arabische Wörterbuch, die erste arabischsprachige Enzyklopädie und die erfolgreichen, säkularen arabischen Periodika, geben ihm zweifelsohne eine besondere Stellung in der syrischen nahda des 19. Jh.s. Wie hier dargestellt wurde, lässt er sich sowohl von menschlichen Begegnungen als auch geschichtlichen Ereignissen für seine Projektvorhaben inspirieren. Bustānī bereut in keinem Fall seine Zusammenarbeit mit den amerikanischen Missionaren, auch wenn sich ihre Wege in den späteren Jahren kaum noch kreuzen. Es wurde gezeigt, dass Bustānī ein überzeugter Befürworter und Förderer kultureller Kontakte ist. Die Amerikaner geben Hilfestellungen, von denen die Menschen in Syrien nur profitieren können. So schreibt er im vierten Blatt der Nafir Suriya: ,We seize this opportunity to thank our brothers on the other side of our sea and beyond the Atlantic Ocean as well as their sons, who are guests in our fatherland, for the continuous assistance they provide us with.“'”231

'awā'id al-'arabìya wa l-infranğìya (Abhandlung über die Berührungspunkte und Kontraste zwischen den arabischen und westlichen Gewohnheiten). Näheres dazu in: Jandora (1981), 63-70.

228 Sheehi (2004), 34.

229 Bustānī (1859), 35

230 Hūūī (1995).

231 Nafïr Surīya, Nr. 4 (25.10.1860). 
Bustānī lebt in einer Generation des politischen, sozialen und kulturellen Umbruchs und reagiert durch sein Schaffenswerk auf die dadurch entstehenden Möglichkeiten, aber auch Defizite. So gesehen ist er seiner Zeit nicht voraus. „[He] was a quintessential product of his time“, urteilt MAKDIsI zu Recht. ${ }^{232}$ Auch wenn er zu den charismatischen Figuren zählt, die das kulturelle Leben Syriens neu gestalten, darf man ihn nicht als Ausnahmecharakter darstellen, ,rather that he was an exemplary liberal product of the commingling of American and Arab histories that legitimated new identities, allowed for new histories, and made possible new, and often contradictory, conceptions of the modern world." 233

Bustānīs in mehreren Werken immer wiederkehrender Aufruf an die Söhne der Nation, die eigene Kultur voranzubringen, setzt stets die Begegnung mit anderen Kulturen voraus, da nur so eine kritische Selbstbetrachtung möglich ist. ${ }^{234}$ Eine derartige Reflektion über die positiven Effekte kultureller Begegnung, wie man sie in Bustānīs Schriften und Reden häufig findet, gilt im Osmanischen Reich, in dem man gegen Ende des 19. Jh.s die Einflussnahme des Westens als zunehmend bedrohlich empfindet, als nicht selbstverständlich. Andererseits kritisiert er auch die Affinität seiner Landsleute zu ausländischen Sprachen als Modeerscheinung und zeigt durch seine Schriften, dass der Fortschritt einer Kultur nur durch die Beherrschung der eigenen Muttersprache gewährleistet ist. ${ }^{235}$

An den Entscheidungen, die er im Verlauf seines Lebens trifft, kann man sehen, dass er, fern von Fremdbestimmung, allein seinem Gewissen und seiner Überzeugung folgt. ${ }^{236}$ Trotz der religiösen Tradition, in der er aufwächst, entscheidet er sich für den evangelischen Glauben. ${ }^{237}$ Als eine Zusammenarbeit mit der Mission nicht mehr möglich ist, da für Bustān̄̄ Unabhängigkeit und Eigenverantwortung auf dem Spiel stehen, hat er bereits neue Ziele im Blick und widmet sich seinen Gedanken über syrischen Patriotismus, kulturelle Erweckung und liberale Reformen. ${ }^{238} \mathrm{Ne}$ ben der in der Einleitung zu Kapitel III beschriebenen strategy of sameness, nach der sich einheimische Missionshelfer ebenbürtig mit den Missionaren sehen, verfolgt Bustānī eine strategy of difference, die, von HENNINGSEN herausgearbeitet, das Eingeborensein (,,aboriginality“) als Unterscheidung zum ausländischen Missionar besonders in Konfliktsituationen hervorhebt. ${ }^{239}$ Für Bustānī ist die arabische Heimat (watan al-'arabì), zum Ende des 19. Jh.s zunehmend als „arabische Nation“ bezeichnet, der Schlüssel zur Suche nach der eigenen Identität in einer sich mehr und mehr globalisierenden Welt. Ungeachtet der religiösen Herkunft sprechen die

232 Makdisi (2008), 181.

233 Ebd., 215.

234 Ebd., 213.

235 Bustānī (1873), 626.

236 Auch Șarrūf und Nimr schreiben über ihn, dass Bustānī bereit war, jede Hürde zu nehmen und sich nicht für das zu schämen, was er tat: dies. (1883), 4.

237 Hourani (1994), 207.

238 Shaw (2014), 88.

239 Henningsen (2011), 145. 
Menschen eine gemeinsame Sprache und haben ein gemeinsames kulturelles Erbe, wie er es in seiner 1859 gehaltenen Rede darstellt. ${ }^{240}$

Der Kreis seiner Bewunderer innerhalb und außerhalb Syriens ist groß, das zeigen schon allein die 1883 in etlichen arabischen Journalen und Zeitungen auf den verstorbenen $\mathrm{Mu}$ 'allim al-Bustānī verfassten Nachrufe. ${ }^{241}$ Freunde und Förderer findet er ebenso unter den Missionaren, allen voran Eli Smith und Cornelius Van Dyck. Sogar Henry Harris Jessup, der als konservativ-religiös und wenig kulturell sensibel gilt, sucht häufig die Gesellschaft des syrischen Gelehrten. ${ }^{242}$ Bustānī bleibt bis zu seinem Lebensende einer der einflussreichsten Männer der syrischprotestantischen Gemeinschaft, wobei er durch sein Selbstbewusstsein und seine Standfestigkeit in Bezug auf die eigene Meinung, wie er es 1854 selbst zugibt, nicht nur Befürworter findet. Es bleibt im Verborgenen, welche Auseinandersetzungen zwischen ihm (als Vertreter der einheimischen Gemeinde) und der Mission bestehen, von denen Daniel Bliss 1873 schreibt. ${ }^{243}$ In Bliss’ Augen ist Bustānī ein „,böser, dreister Mann - ein Hindernis“, der längst nicht mehr so sehr gemocht werde wie früher. ${ }^{244}$ Selbst die Herausgeber von Bliss' Letters from a New Campus (1993) lassen sich zu der Behauptung hinreißen, auch Van Dyck habe in den letzten Jahren vor Bustānīs Tod keine freundschaftlichen Gefühle mehr für den erfolgreichen und daher, laut Bliss, ${ }^{245}$ überheblich gewordenen Gelehrten gehabt. Jessups Zitat, Van Dyck habe bei der Beerdigung, nichts weiter sagen können als „Oh, friend of my youth!“ ${ }^{246}$, interpretieren die Herausgeber RUGH und Howell folgendermaßen:

$240 \mathrm{Zu} a b n \bar{a}$ ' al- 'arab (Söhne der Araber) vgl. Jandora (1981), 96: „Al-Bustānī introduced that term as a necessary consequence of endeavor to redirect loyalties."

2411883 beherrschen Eulogien auf Bustānī die Zeitungen. Adīb Isḥāq, Journalist und Autor, überhäuft den verstorbenen Bustān̄̄ während seiner Beerdigungsrede mit lobenden Worten: „What literary work do we see, and you are not the originator or proponent of it? What beneficial enterprise do we witness, and you are not the initiator or supporter of it? [...] What effect of your continuous pioneering endeavor do we mention and not find it great? Is it your persistence in the service of knowledge and culture for forty years or more? Or your compositions and literary works, which by their renown need no description?“' Aus: Dā' irat al-Ma 'ārif 7 (1883), 594596, übersetzt und zitiert von Jandora (1984), 79. Siehe auch Salīm Bustānī, „Buțrus alBustān̄̄“, in: al-Ǧinān 14 (1883), 321; Șarrūf/Nimr, „Al-marḥūm al-mu'allim Buṭrus alBustān̂’”, in: al-Muqtațaf 8/1 (1883), 1-7.

242 So schreibt es Bliss an seine Frau Abby (10.8.1873 und 18.3.1874), zitiert in: Bliss (1993), 46, 227. Jessup schreibt im selben Jahr, in dem sich Bustān̄̄, laut Bliss, durch sein Verhalten viele Feinde gemacht haben soll: ,There is not a more industrious man in Syria than Mr. Bistany, and he is doing a great work in the enlightenment of his countrymen."Vgl. Jessup (1874), 136.

243 Daniel Bliss an Abby Bliss (10.8.1873), zitiert in: Bliss (1993), 46.

244 Daniel Bliss an Abby Bliss (16.3.1874), zitiert in: ebd., 225. Die Beschreibungen der arabischen Journalisten und Autoren Șarrūf, Nimr und Zaydān zeigen jedoch einen ganz anderen Bustānī: Dieser sei sehr großzügig, aufrichtig, sanftmütig und harmoniebedürftig gewesen, jede Art von Schmeichelei war ihm jedoch zuwider. Begabte Schüler werden von ihm gefördert und mit wichtigen Aufgaben betraut. Bustānīs größte Befürchtung sei das Ausbleiben seines Erfolgs gewesen, so Șarrūf und Nimr (1883, 5); siehe auch Zaydān (1913), 29.

245 In einem Brief an seine Frau Abby vom 10.8.1873 fallen die Worte ,selfishness, pride and excessive vanity of Butros", zitiert in: Bliss (1993), 46.

$246 \operatorname{Jessup}$ (1910a), 106. 
$1883^{247}$ was, after all, the year of the Darwin incident when Van Dyck resigned from S.P.C. Van Dyck therefore had chosen this way of gratifying the sensibilities of the Arabs, and all Bustani-worshippers, while side-stepping the morally distasteful necessity of delivering an insincere eulogy for one toward whom he indeed had had most cordial regards in his youth, but which he no longer held. 248

Dieser Aussage muss ich in zweifacher Hinsicht widersprechen: Auch Van Dycks Verhältnis zur Mission und vor allem zum SPC ist in der Zeit alles andere als harmonisch. Dass er, was die Ressentiments gegenüber Bustānī betrifft, auf der Seite der Mission steht, scheint unwahrscheinlich. Darüber hinaus ist es vermutlich Jessups Intention, seinen Leserinnen und Lesern die Emotionalität des Momentes nahezubringen, als er schreibt, dass Van Dyck nur diese wenigen Worte herausgebracht habe. In der Tat hält Van Dyck während des Beerdigungsgottesdienstes, der von den Missionaren durchgeführt wird, ${ }^{249}$ eine kleine Rede, in der seine wahren Gefühle für Bustānī deutlich hervortreten:

Es ist nicht gerecht, dass ich hier heute stehe und rede, da mir dieser Ort ${ }^{250}$ [nahe] liegt [...]. Nun stehe ich in eurer Mitte und weine bitterlich. Mein Bruder, mein lieber Freund, der uns genommen wurde, er war vielmehr mein Meister, mein Lehrer, mein Freund! Wieviele Nächte haben wir gemeinsam mit Studieren, Lesen und Schreiben verbracht? Es war eine schöne Zeit zusammen, denn [wir hatten] die gleichen Ziele und Vorhaben. Wie kann ich nun bei seinem Leichnam stehen und reden, statt an seiner Seite vor Trauer und Bedrückung niederzuknien?251

Nur wenige Wochen später, am 25. Mail 1883, eröffnet Van Dyck die Jahresversammlung der o.g. Mağma' al-'Ilmī al-Šarqī mit einigen Worten des Gedenkens an Bustānī, der ebenfalls Mitglied dieser Gesellschaft war. Van Dyck deutet darin an, dass Bustānīs Weg des Erfolgs von vielen Hindernissen gekennzeichnet gewesen sei. Sein unermüdliches Engagement und der Kampf gegen viele Widerstände (,al-zurūf al-muḍ̄adda“) gingen auf Kosten seiner Gesundheit. Nichtsdestotrotz gelte er als einzigartiges Vorbild für nachfolgende Generationen. ${ }^{252}$ So sieht es auch der unbekannte Autor des Nachrufs auf Bustānī in der Missionszeitschrift alNašra al-Usbu '̌ya, der nur lobende Worte für den verstorbenen Gelehrten findet. ${ }^{253}$ Van Dyck fügt seiner Rede hinzu, dass Bustān̄̄ es verdient habe, unter den Persönlichkeiten im von Ya 'qūb Șarrūf übersetzten und 1880 herausgegebenen Buch „Das Geheimnis des Erfolgs“ (Sirr al-nağāh $)^{254}$ erwähnt zu werden. Er hinterlasse

247 Schon allein die Jahreszahl lässt auf eine schlechte Recherche schließen. Der Vorfall um Prof. Lewis ereignet sich 1882 (siehe Abschnitt I.1.5).

248 Bliss (1993), 240 (Nr. 36).

249 Jessup (1883/84), 276. Allerdings wird Bustānī in den Aufzeichnungen der Anglo-Amerikanischen Kirche von 1883 bei der Erwähnung der verstorbenen Personen nicht genannt: vgl. „Report of the Pastor's Committee of the Anglo-American Congregation, Beyrout for the year 1883“, in: AAC Protokolle (1868-1891), 242: NEST/SC.

250 Sc. die Kirche.

251 Zaydān (1903), 29-30: Im selben Artikel findet sich ebenfalls eine Eulogie von Adīb Asḥāq, Journalist und Autor (ebd., 30-31). Salīm al-Bustānī fasst im Band 7 der Dā' irat al-Ma 'ārif von 1883 etliche Eulogien und Todesanzeigen über seinen Vater zusammen: vgl. ebd., 589-608.

252 Van Dyck (1883), 641.

253 N. N., „Al-āsif al- 'aẓ̄m"“ (Großes Bedauern), in: al-Našra al-Usbu īya 19 (7. Mai 1883), 149.

254 Hūūrī (1992), 211. 
eine große Gemeinschaft, die ihre Heimat liebe (,fa-tarak ğumhüran kabīran min muhabbi al-wațan") und die diesen Verlust so sehr bedaure. ${ }^{255}$

So wie Bustānīs Vorstellung von einem arabischen Vaterland kennt auch seine Popularität keine Grenzen. Nach seinem Tod kondoliert seinem Sohn auch der katholische Patriarch von Antiochien, Alexandria und Jerusalem. Bustān̄̄, einstmals Maronit und später Protestant, ist ihm ein Freund und Bruder geworden: „[T|he whole nation mourns your father's death. Literature, education, learning, and every good cause laments his departure [...]. “256

Bis heute ist der syrische Gelehrte eine namhafte Größe, sowohl in der protestantischen Gemeinschaft des Libanon als auch bei Wissenschaftlern der Arabistik und Geschichte. Zwar findet er in zahlreichen, vor allem arabischsprachigen Werken Erwähnung, doch wegen unauffindbarer oder verloren gegangener Quellen können viele der hier angesprochenen Konflikte wohl nie untersucht werden. Die Biografie des Mu'allim al-Bustān̄̄ wird wohl unvollständig bleiben.

\section{III.2. „HE WAS TRULY THE CHILD OF THE MISSION“ ${ }^{257}$ - REV. JOHN WORTABET, M. D. (1827-1908)}

\section{Kurzbiografie}

John Wortabet ist der Sohn des zum evangelischen Glauben konvertierten Armeniers Jakob Gregory Wortabet (1798-1833) und Susan (englische Form für Sardas) Wortabet, die später als Lehrerin in der 1834 errichteten Mädchenschule der Missionare in Beirut unterrichtet. ${ }^{258} 1827$ wird John (englische Form für Yuhannā) in Sidon geboren, wo sein Vater als Prediger für die Syrienmission arbeitet. Da er bereits sehr früh verstirbt, ${ }^{259}$ erhalten John und seine Geschwister ihre Schulerziehung bei den amerikanischen Missionaren. Daraufhin studiert er bei den Amerikanern für weitere acht Jahre alte Sprachen, Theologie und Medizin. ${ }^{260}$ Nach einer medizinischen Weiterbildung in Schottland, bewirbt er sich 1860 bei der United Presbyterian Church of Scotland als Missionar und Arzt und wird für sechs Jahre zur Missionierung der Juden nach Aleppo gesandt. Nachdem er zwischen 1866 und 1867 seine Medizinkenntnisse in England und den USA vertieft, wird er 1867 als Professor für Anatomie und Physiologie am SPC eingestellt. ${ }^{261} 1886$ verlässt er das College, gibt dort aber zeitweise weiterhin Vorlesungen und arbeitet privat als Arzt. ${ }^{262}$ Am 21. November 1908 stirbt Wortabet in Beirut im Alter von 81 Jahren

255 Van Dyck (1883), 641.

256 Zitiert in: Jessup (1910b), 484-485.

257 Tibawi (1966), 132.

258 MH 31 (1835), in: ROS 2, 420.

259 MH 29 (1833), in: ROS 2, 336-339.

260 Anderson (1872a), 377; Tibawi (1966), 132.

261 Y. Sarrūf, „Duktūr Yuḥanna Wūrtabāt, 1829-1908“, aus: al-Muqtațaf 30 (1905) und 34 (1909), zitiert in: Hูūrī (1992), 183.

262 D. S. (1938), 4. 


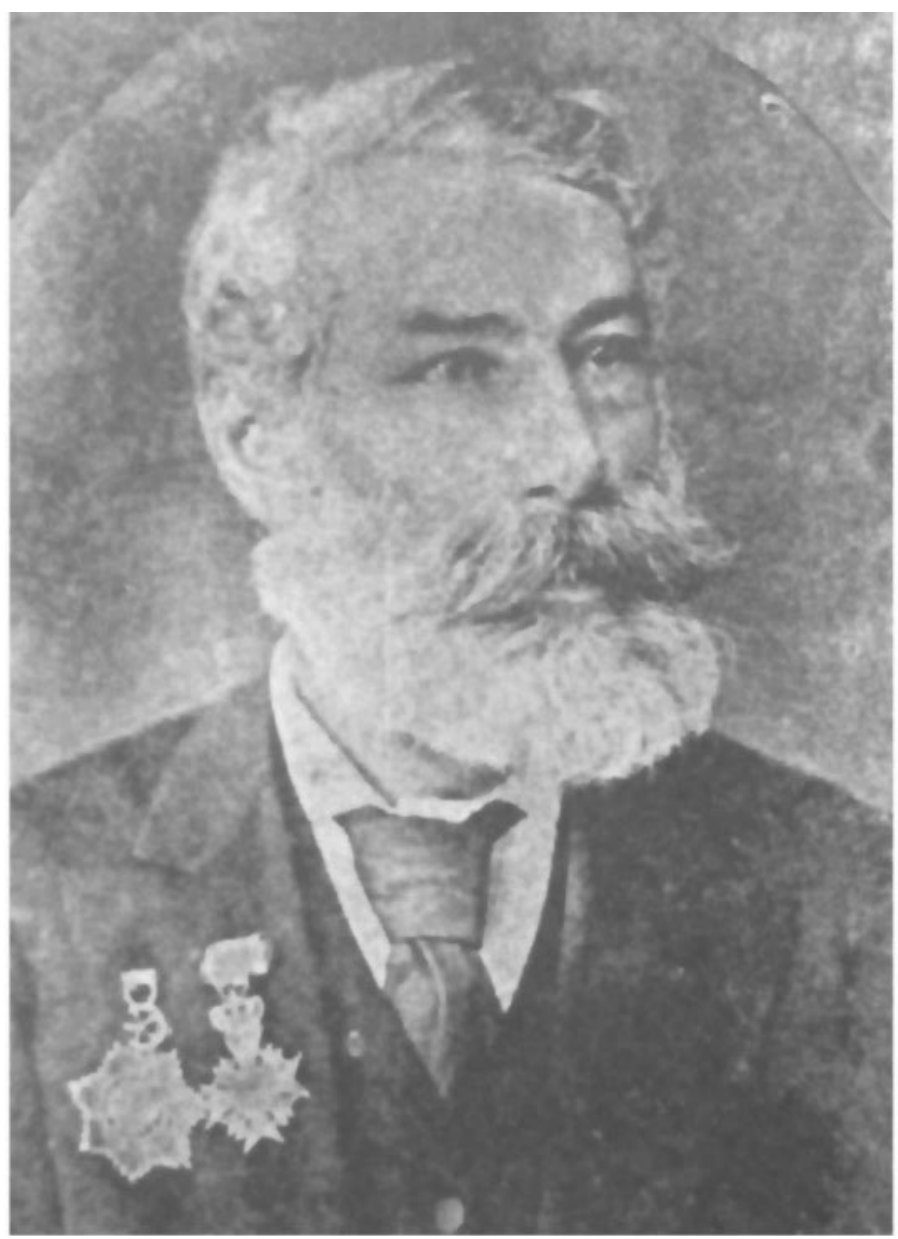

Abb. 10: Rev. John Wortabet, M.D.

in Folge eines Kehlkopfleidens und hinterlässt seine Frau Salome und die gemeinsamen zehn Kinder. ${ }^{263}$ Er wird auf dem Anglo-Amerikanischen Friedhof in Beirut begraben. (Abb. 10)

263 Sophie Gräff an Bertha Kuhr (Beirut, 12.12.1908): AFKSK AKD 243. Die Kinder heißen: Henry George Luther (1853-?, geboren in Hasbeiyā, lehrt von 1871-72 ebenfalls am SPC); Erwin Whiting (1856, geboren in Ḥasbeiyā); William Thomson (1855-?, geboren in Ḥāșbeiyā); Elda Ralūr (1862-?, geboren in Aleppo); James Rašīd (1864-?, geboren in Aleppo, absolviert 1891 seinen Bachelor in Medizin und Master in Chirurgie); Mathilda Dora (1867-?); Susan Mary (1871-71), Lucy Macarthy (1875-1948); Pauline?, Jessie Eliza: vgl. Zaydān (1982), 427; Lindner (2014b); University of Glasgow, The University of Glasgow Story, URL: http:// www.universitystory.gla.ac.uk/biography/ $\mathrm{id}=\mathrm{WH} 17766 \&$ type $=\mathrm{P} \& \mathrm{o}=\& \operatorname{star}=1020 \& \max =20$ $\& \mathrm{l}=\mathrm{W}$ (Stand: Juni 2013). 


\section{Ein Kind der Mission?}

Yuhannā - oder wie die Amerikaner ihn nennen - John wird aufgrund seiner ausgezeichneten Ausbildung ein guter Missionar und sehr erfolgreicher Arzt. Jedoch ist auch seine Biografie geprägt von Problemen, die im Zusammenhang mit seiner Stellung innerhalb der Syrienmission stehen. Daher ist es wichtig zu erörtern, warum Wortabet, der eine wichtige Rolle für die Mission einnimmt, sich schließlich von den amerikanischen Missionaren distanziert.

John Wortabet ist der Sohn des ehemals armenischen Geistlichen Jacob Gregory Wortabet, ${ }^{264}$ der zu den ersten Konvertiten und Helfern der Mission zählt, ein Umstand, der Johns Jugendjahre prägen wird: Jacob Gregory wird sehr früh Waise und folgt dem Wunsch seines Vaters, ein „Wurtabād“, ein Geistlicher „similar to Rabbi among the Jews or D. D. in England and America“ zu werden. ${ }^{265}$ In seinem Kirchenkreis in Jerusalem wird er sogar zum bischöflichen Stellvertreter. Während der vielen Jahre, die er in einem armenisch-orthodoxen Konvent in Jerusalem verbringt, wird er Zeuge, wie Ordensmitglieder, Bischöfe und sogar der Patriarch von Jerusalem Frauen und Jungen in ihren Kammern verstecken. Seine Rebellion gegen diese ,satanistischen “ Vorgehensweisen christlicher Oberhäupter erschüttern seinen Glauben an die eigene Kirche und führen schließlich zur Suspension aus dem Orden. Zusammen mit anderen armenischen Geistlichen kommt er in die Region um Beirut und schreibt sich fortan „Wortabet“. In Beirut trifft er im März 1825 auf den Missionar William Goodell, der ihn zum Sekretär machen möchte „to copy Turkish-Armenian Tracts, and to arrange all the Turkish words in alphabetical order for a dictionary“ “266 Nicht sofort führt diese Begegnung zur Konvertierung. Erst nach eingehendem Bibelstudium ist er überzeugt, dass die Amerikaner in Wort und Tat mit der Heiligen Schrift übereinstimmen. ${ }^{267}$ Für ihn besteht nun kein Zweifel mehr, dass diese von Gott gesandten Engel (,,he sends them from America as from heaven") an diesem Ort missionieren müssen, der, wie er es selbst im Kloster erlebt hat, „under the dominion of satan“ stehe. Als ausgestoßener Priester ist Jacob Gregory finanziell nun völlig auf die Hilfe der Missionare angewiesen: „[W]e had not been able to obtain the comfort for our life in these countries had not Mr. Goodell do alms for us. “268 In den kommenden Jahren pflegt Jacob Gregory Wortabet ein enges und freundschaftliches Verhältnis mit den Amerikanern, sogar Eli Smith lebt

264 Die armenische Schreibweise seines Namens wäre Hagop Krikor Vartabed. In den Quellen der Mission gibt es dafür jedoch keine Hinweise.

265 „A brief memoir of Gregory Wortabet“: ABC 16.6.3., 1.

266 Ebd., 26. Auszüge dieser Memoiren sind ebenfalls abgedruckt im MH 24 (1828), in: ROS 2, 44-51.

267 „A brief memoir of Gregory Wortabet“: ABC 16.6.3., 27-28.

268 Gregory Wortabet an Jeremiah Evarts (Beirut, 31.1.1828): ABC 16.6.3. (231). 
sechs Monate bei Wortabet, seiner Frau Susan ${ }^{269}$ und ihren Kindern. ${ }^{270}$ Mit diesem so gewissenhaften und integren Mann sehen die Missionare einen großen Erfolg für ihre Arbeit garantiert.

It is not too much to say that there is not another individual in Syria, so well qualified in all respects for the work of preaching the gospel to the people of various languages and religions [...] His perfect knowledge of the Turkish and Armenian languages gave him ready access to numbers with whom we can hold little or no communication. ${ }^{271}$

Als die politische Instabilität durch die griechische Revolte das Leben der Missionare in Beirut zu gefährden droht, ziehen sie sich zwischen 1829 und 1830 nach Malta zurück. Dionysios Carabet und Jacob Wortabet begleiten die Amerikaner sogar mit ihren Familien. Wortabet kehrt aber schon ca. 1829/1830 aufgrund eines Augenleidens nach Beirut zurück, wie sein Sohn Gregory später schreibt. Doch scheint es auch zu Spannungen gekommen zu sein, weil Wortabet und Carabet bereits im Oktober 1829 aus der Mission Church austreten. Einer von ihnen soll laut Aufzeichnungen der Kirche sein Kind getauft haben. ${ }^{272}$ Die freundschaftliche Bindung und die große Unterstützung bei Goodells Übersetzungsarbeit sollen nicht darüber hinweg täuschen, dass Wortabet - mit Ausnahme von Spendengeldern in den ersten Jahren - kein richtiges Gehalt von den Missionaren für seine Arbeit bezieht. Jacob Wortabet bleibt ein unbezahlter, einheimischer Helfer, und das obwohl ihn die Mission anlässlich seines Todes 1832 als ,,very promising ally of the mission in Syria“" erinnert. ${ }^{273}$

Nach Jacob Wortabets Rückkehr von Malta beginnt er selbstständig in Beirut zu missionieren. ${ }^{274}$ Eine vermutlich erneute Erkrankung am Auge „reduced him to poverty“. ${ }^{275}$ Das Ehepaar zieht mit seinen Kindern nach Sidon, wo der Missionar William Bird sie 1831 besucht, and found him and his wife destitute of the good things of this life, but contended and cheerful" 276 John Wortabets Vater ist jedoch in der Lage, die Lebensumstände der jungen Familie schnell zu verbessern. Als ein von der Mission unabhängiger Missionar wird er zu einem angesehenen

269 Jacob Gregory Wortabet heiratet Susan bzw. Sardas, wie sie in manchen missionarischen Quellen auch genannt wird, im Jahr 1825: vgl. MH 24 (1828), in: ROS 2, 50. Susan ist die Tochter des einheimischen Helfers der Mission Nicola Laflūtī: vgl. MH 23 (1827), in: ROS 1, 471; Lindner (2009), 191; Lindner (2014b); siehe Anhang II, Nr. 71.

270 MH 32 (1836), in: ROS 3, 6: Vermutlich ist dies im Zeitraum zwischen 1827 und 1829, in dem sich Smith für Sprachstudien in Ägypten und Syrien aufhält und ebenfalls in der Familie von Tannūs al-Haddād für einige Monate lebt (siehe Abschnitt II.1.2).

271 MH 29 (1833), in: ROS 2, 338.

272 „Records of the Missionary Church at Beirut, meeting (in Malta) of October 20th, 1828“: ABC 16.8.1., Vol. 8, zitiert in: Badr (1992), 109; Copeland (1974), 6.

273 MH 29 (1833), in: ROS 2, 336. Jacob Wortabets Sohn Gregory betont später, dass sein Vater weder als Pensionist etwas von den amerikanischen Missionaren erhalten habe, noch jemals für seine Dienste für die Syrienmission entlohnt wurde: Wortabet (1856a), 56-57.

274 Wortabet (1856a), 56.

275 Anderson (1872a), 226.

276 Anderson (1872a), 226. Gregory Wortabet berichtet, sein Vater sei aufgrund eines großen Widerstands, auf den er in Beirut traf, dem Rat seiner Freunde gefolgt und nach Sidon gegangen: vgl. ders. (1856), 56. 
Mann im Umkreis von Sidon. Da er Armenisch, Türkisch und Arabisch fließend beherrscht, ist er in der Lage mit denen zu kommunizieren, die für die Missionare in den frühen Jahren der Syrienmission unerreichbar bleiben. ${ }^{277}$ Um sich und seine Familie versorgen zu können, muss Jacob Gregory Wortabet einen kleinen Laden in Sidon betreiben, mit dem er allerdings so erfolgreich ist, dass er bald zu einem gut verdienenden Geschäftsmann wird. Im September 1832 verstirbt er in Folge einer Cholera-Erkrankung überraschend und hinterlässt seine Frau mit den gemeinsamen vier Kindern, von denen das letzte, ein Mädchen namens Hannī, erst nach seinem Tod geboren wird. ${ }^{278}$

Es kann nur vermutet werden, dass sich die Missionare aufgrund der herausragenden Leistungen Jacob Wortabets, des „,faithful brother and fellow-laborer“, 279 wie sie ihn nennen, in der Pflicht sehen, sich um seine Witwe und deren vier Kinder zu kümmern. Als Konvertitin von ihrer Gemeinschaft verstoßen, sind sich die Missionare bewusst, dass Susan Wortabet Unterstützung benötigt. ${ }^{280}$ Bereits ein Jahr nach Jacob Wortabets Tod arbeitet Susan als Assistentin der Missionsfrauen Mrs. Dodge und Mrs. Smith in der Beiruter Mädchenschule (,We have much complacency in her as a Christian sister"). ${ }^{281}$ Für die Kinder richtet die Mission einen sogenannten „Wortabet Children's Fund“ ein, wobei unklar ist, aus welchen Geldern dieser sich zusammensetzt. ${ }^{282}$ Mit dem Geld dieses Fonds werden der neunjährige John Wortabet und seine Brüder Gregory (armen.: Krikūr) und Ya 'qūb ab 1836 für sechs Jahre am amerikanischen Jungeninternat in Beirut ausgebildet. ${ }^{283} \mathrm{Im}$ Jahr 1843 soll dann der „Wortabet Children's Fund“ an den jeweiligen Vormund der Kinder ausbezahlt werden. ${ }^{284}$ Während Gregory in einer Missionsfamilie unterkommen und Ya qūb einem nützlichen Beruf nachgehen soll, wollen die Missionare in Johns Weiterbildung investieren. ${ }^{285}$ Für 26 Dollar, wie der Missionar Thomson

277 Whiting und Bird an Anderson (Beirut, Januar 1833): ABC 16.8.1., Vol. 01 (4).

278 Nur einmal erwähnt der Missionary Herald, Susan habe drei Kinder: vgl. MH 29 (1833), in: ROS 2, 334. Alle anderen Quellen sprechen von vier Kindern: vgl. MH 31 (1835), in: ROS 2, 420; MH 32 (1836), in: ROS 3, 7; Wolcott an Anderson (1.6.1842): ABC 16.5, Vol. 3.

Die Kinder sind John, Gregory, Ya qūb und ihre Schwester Hannī. In seinen Reminiscences erwähnt Van Dyck einen Henry Wortabet, der ebenfalls das Jungenseminar besucht habe: vgl. Van Dyck (o. J.), 12. Es bleibt unklar, wer damit gemeint ist. Zaydān sowie die Protokolle des ABCFM sprechen von den Brüdern John, Gregory und Ya qūb (bzw. Jacob): vgl. „Records of the Syria Mission 1842“(11.8.1842): ABC 16.8.1., Vol. 8.1., 105; Zaydān (1982), 425.

279 MH 29 (1833), in: ROS 2, 339.

280 Ebd., 334: „Wortabet's widow is now left entirely without any temporal resources whatever. Her relations have long considered and treated her as a perfect alien, because she had left their communion, and there is reason to suppose they will not be kinder now."

281 MH 31 (1835), in: ROS 2, 420.

282 „Records of the Syrian Mission“ (20.3.1843): ABC 16.8.1., Vol. 8.1., 111.

283 Gregory Wortabet weiß später in seinem Buch Syria and the Syrians nur positiv von dieser Zeit zu berichten: ,the goodly Hebard and his wife looking down from its [sc. Mission House] terrace on their children, as they called us. [...] But I will not weary the reader with the associations of my early life, the days of my sweet childhood“: ders. (1856a), 70.

284 „Records of the Syrian Mission“ (25.3.1843): ABC 16.8.1., Vol. 8.1., 115.

285 „Records of the Syrian Mission 1842“ (11.8.1842): ABC 16.8.1., Vol. 8.1., 105. 
berichtet, wird dem Jungen neue Kleidung gekauft. ${ }^{286}$ Ya ' qūb Șarrūf, der später bei John Wortabet am SPC studiert, schreibt 1905 über seinen Lehrer, dass dieser im Beiruter Missionsseminar ein derart fehlerfreies Englisch gelernt habe, dass man meinen könne, er sei Muttersprachler. ${ }^{287}$ Auch wenn das Beiruter Seminar aufgrund des Misserfolgs 1842 schließen muss, so hofft die Mission, dass John Wortabet bald in die Fußstapfen seines Vaters treten werde. ${ }^{288}$ In weiteren acht Jahren wird er von den Missionaren persönlich ausgebildet: Smith, Whiting und Thomson unterrichten ihn in Theologie, Hebräisch und Griechisch, bei Van Dyck und De Forest studiert er Medizin und Latein. ${ }^{289}$ Johns Bruder Gregory sieht seine Zukunft nicht im Kreise der Mission und verlässt Syrien Anfang der 1850er Jahre, um in England ebenfalls Medizin zu studieren. ${ }^{290}$

John Wortabet gehört zu den wenigen vertrauenswürdigen Konvertiten, wie Samuel Wolcott es 1842 beurteilt: „I name him [...] as an exemplary lad of whom we have considerable hope. "291 1847 wird er offiziell in die Kirchengemeinde der Mission Church (später Anglo-American Congregation) aufgenommen, in der er bis zu seinem Tod sehr aktiv bleibt. ${ }^{292}$ William Thomson, der sich auch in späteren Jahren noch oft für Wortabet einsetzen wird (s.u.), schreibt in dieser Zeit: „He is a promising young man, and we hope to see him a preacher of the gospel before a long time shall have elapsed. [...] We hope he may be ready to accompany any new missionaries to Aleppo, or wherever a new mission shall be established.“293

Im Jahr 1848 wird Wortabet gemeinsam mit den Missionaren Benton und Ford für sechs bis acht Monate nach Aleppo gesandt, wo sie an der Errichtung einer festen Missionsstation arbeiten. ${ }^{294}$ Die Anforderungen an die Missionare und ihren Mitarbeiter John Wortabet sind hoch. Statt zu wachsen, bleiben der dortigen Gemeinde immer mehr die Mitglieder aus: „We have quite a spiritual death at present." ${ }^{295}$ Wortabet, von Smith gerade erst umgestimmt, hegt weiterhin Zweifel an seiner Berufung. Er schreibt an seinen Lehrer und Mentor Smith: „It is evident,

286 Thomson an n.n. (Beirut, 30.12.1835), zitiert in: Tibawi (1966), 83.

287 Tibawi (1966), 132; Y. Sarrūf, „Duktūr Yuhanna Wūrtabāt, 1829-1908“, in: al-Muqtaṭaf 30 (1905), zitiert in: Hūūī (1992), 183.

288 So William M. Thomson in: ,The Committee in the results of the Seminary submit[s] the following report" (6.4.1844): ABC 16.8.1., Vol. 1 (23).

289 Anderson (1872a), 377; Tibawi (1966), 132.

290 Zaydān (1982), 427. Siehe die Einleitung zu Kapitel III und Anhang II, Nr. 66.

291 Wolcott an Anderson (1.6.1842): ABC 16.5, Vol. 3. Wolcott lässt in diesem Schreiben an fast keinem der einheimischen Gemeindemitglieder ein gutes Haar. Für seine äußerst kritische Einstellung ist er in der Mission bekannt. Wolcott hat selbst nie Arabisch gelernt und bittet nach dem Tod seiner Frau um Versetzung aus Syrien: Van Dyck (o. J.), 17.

292 MH 43 (1847), in: ROS 4, 28; ,Report read at the Annual Meeting hold in the Memorial Hall““ (9.2.1894), in: AAC Protokolle (1881-1905), 42: NEST/SC.

Von 1850 bis vermutlich 1859 ist er aufgrund seiner Pfarrstelle in Hāạbeiyā Mitglied der einheimischen Beirut Church.

293 MH 43 (1847), in: ROS 4, 25.

294 Ebd; Anderson (1872a), 369. Statt Wortabet soll zunächst Elyās Fawāz mit nach Aleppo gehen, was dieser jedoch ablehnt: vgl. „Records of the Syrian Mission 1848“: ABC 16.8.1., Vol. 8.1., 185.

295 Wortabet an Smith (Aleppo, 30.8.1848): ABC 60 (98), (HHL). 
however, that the work is too gigantic for one like me, in point of competency and physical ability to meet its duties. [...] I have fallen short of every duty."

Unter Smiths Anleitung führt Wortabet sein Theologiestudium in Aleppo fort. ${ }^{296}$ In den wenigen Monaten seines Aufenthaltes arbeitet er sich durch die drei Bände von Mosheims Kirchengeschichte („I have finished Mosheims Eccl[esiastical] Hist[ory] some days ago"), studiert Griechisch und Hebräisch, nimmt bei seinem Kollegen Ford Unterricht in biblischer Auslegung und widmet sich dem Fach Logik (,,it must be a good discipline to the mind"). ${ }^{297}$ Bemerkenswerterweise nutzt Wortabet, der mit Arabisch aufgewachsen ist, seinen Aufenthalt in Aleppo, um mehr fachliche Kenntnisse über seine Muttersprache zu erlangen. Sein Privatlehrer „Sheikh Akeel“" gibt ihm den Koran und Schriften über Prophetie und Mohammed zur Lektüre und unterweist ihn in Verslehre. ${ }^{298}$ Der junge Missionar erhofft sich jedoch mehr Instruktion in theologischen Fachbegriffen und arabischer Rhetorik: „I do not know what to study. It seems to me that my Arabic studies, at present, should be such as to give me an additional stock of words, especially of theological technical terms. [...] What do you think I had better study?“299

Wortabets Fall zeigt, dass Eloquenz in der arabischen Sprache, wie bei Nāṣîf alYāziğī und Bustānī, für angehende syrisch-protestantische Theologen nicht selbstverständlich ist. Es wird dabei deutlich, warum sich die Mission für Arabisch als Unterrichtssprache im Missionsseminar in 'Abeih entscheidet. Um das Predigen auf Arabisch zu trainieren, übersetzt Wortabet sogar eigene englische Predigttexte. Darüber hinaus versucht er, seine Lesefähigkeit sowie seinen Sprachstil durch regelmäßige arabische Lektüre zu verbessern. ${ }^{300}$ Wortabet lässt seinem Mentor Smith ebenfalls regelmäßig verschiedene Schriften zukommen, die von Interesse sind und vermutlich zur Erweiterung der Beiruter Missionsbibliothek dienen. Darunter befindet sich z.B. die Kopie eines Manuskripts von Naum al-Hūrī („Essahâ Mualakat" $)^{301}$ sowie Abschriften von muslimischen Epitaphen, die Wortabet angefertigt hat. ${ }^{302}$ Eine weitere arabische Übersetzung des fünfbändigen Werkes von „Antoine“ über römisch-katholische Theologie beurteilt Wortabet zwar als sprachstilistisch wertlos, empfiehlt jedoch die Bände als Referenzliteratur. ${ }^{303}$

Vermutlich verbringt Wortabet nach dem Aufenthalt in Aleppo die Wintermonate zwischen 1848 und 1849 zum Studium in 'Abeih wie er es in einem Brief aus

296 „I have received your favor of the 4th [...] \& am much obliged for the instruction it contains.“ Vgl. Wortabet an Smith (Aleppo, 24.7.1848): ABC 60 (98), (HHL).

297 Wortabet an Smith (Aleppo, 3.10.1848) und (Aleppo, 9.11.1848): ABC 60 (98), (HHL).

298 Wortabet muss den Unterricht immer wieder abbrechen, da er weder Zeit noch Geld dafür hat und darüber hinaus die Kompetenz von Šeih Akīl infrage stellt: Wortabet an Smith (Aleppo, 11.8.1848) und (Aleppo, 31.8.1848): ABC 60 (98), (HHL).

299 Wortabet an Smith (Aleppo, 3.10.1848): ABC 60 (98), (HHL).

300 Wortabet an Smith (Aleppo, 11.8.1848): ebd.

301 Wortabet an Smith (Aleppo, 21.6.1848): ebd.

302 Wortabet an Smith (Aleppo, 3.10.1848): ebd.

303 Wortabet an Smith (Aleppo, 9.11.1848): ebd. Weder Mosheims Kirchengeschichte noch alHūūīs oder Antoines Werk tauchen im Katalog der amerikanischen Druckerei auf: vgl. PBCFM (1896). 
Aleppo vom 30. August schreibt. ${ }^{304} \mathrm{Im}$ Jahr darauf scheint Wortabet sein Studium vorerst zu unterbrechen. Es zieht ihn nach Tripoli, um sich neben seiner Anstellung als Missionshelfer als Arzt Geld dazu zu verdienen. Obwohl er hofft, sein Theologiestudium währenddessen fortführen zu können und in der Mission auszuhelfen, scheint der Gedanke, als Pfarrer ordiniert zu werden, in immer weitere Ferne zu rücken. ${ }^{305}$ Smith, der von Anfang an von Wortabet überzeugt ist, kann ihn jedoch umstimmen und im Sommer des Jahres 1850 kehrt der junge Arzt zur Mission zurück. Thomson ist jedoch wenig zuversichtlich „to get his heart and soul back where it was in relation to the preaching of the Gospel“", man könne Wortabet noch keine Verantwortung übertragen. ${ }^{306}$ Obwohl sich Wortabet auch in den kommenden Wintermonaten unentschlossen zeigt, ob er jemals als Prediger weiterarbeiten werde, ${ }^{307}$ kann er seine Unsicherheit überwinden. 1851 wird er zusammen mit William Thomson, Cornelius Van Dyck und Tannūs al-Haddād in die Region von Sidon (Șaidā) im Süden des Landes berufen. „Wortabet seized hold of this mighty truth with amazing earnestness", wird William Thomson noch im selben Jahr schreiben. ${ }^{308} \mathrm{Im}$ südöstlich von Sidon gelegenen Hāṣbeiyā soll, so wünscht es sich Rufus Anderson schon 1848, eine Kirche mit einem einheimischen Pastor etabliert werden. ${ }^{309}$ Am 5. Juli 1851 wird die Gemeinde mit 18 Mitgliedern gegründet, gegen Ende des Jahres sind es bereits $25 .{ }^{310}$ Der kleine Ort sorgt schon im Jahr 1844 für Aufregung in der Syrienmission, da sich eine Gruppe von ca. fünfzig bis sechzig Einwohnern dem evangelischen Glauben zuwendet und mit den Amerikanern Kontakt aufnimmt. ${ }^{311}$

Die Reise in den Süden des Landes führt Wortabet wieder in die Region seiner Kindheit zurück. Das stetig wachsende Interesse der Bevölkerung an der neuen Religion ist für die Missionare eindeutig auf die Arbeit von Wortabets verstorbenem Vater zurückzuführen: „For many years there have been in Sidon cases of interest, mostly traceable to the self-denying labors of the pious and zealous [Jacob] Gregory Wortabet." 312 Van Dyck und Thomson zeigen sich äußerst zufrieden mit Wortabets missionarischer Arbeit und sind besonders von seinen Fähigkeiten als Prediger angetan:

[I]t is surprising how he runs every line to his glorious centre, from whatever point in the circumference of theology he may set out. No sooner do our friends hear of an inquirer than they visit him; and those short missionary tours often result in far more than was anticipated. ${ }^{313}$

304 Wortabet an Smith (Aleppo, 30.8.1848): ABC 60 (98), (HHL).

305 So Smith an Anderson (Beirut, 17.6.1851): ABC 16.8.1., Vol. 5 (199).

306 Thomson an Anderson ('Ayṭât, 2.8.1859): ABC 16.8.1., Vol. 5 (254).

307 Smith an Anderson (Beirut, 17.6.1851): ABC 16.8.1., Vol. 5 (199).

308 Thomson an Anderson (Hāṣbeiyā, 9.10.1851): ABC 16.8.1., Vol. 5 (257).

309 Anderson an die Syrienmission (Boston, 27.5.1848): ABC 16.8.1., Vol. 8.1.

310 „Report of the Hasbeiyan Station for 1851“: ABC 16.8.1., Vol. 4.1. (164).

311 Vgl. z.B. MH 40 (1844), in: ROS 3, 391-392.

312 MH 47 (1851), in: $\operatorname{ROS} 4,146-147$.

313 MH 48 (1852), in: ROS 4, 157. Anderson (1872a, 377) urteilt, dass Wortabet die Fähigkeiten seines Vaters in dieser Hinsicht geerbt habe. 
Die Arbeit als Prediger, Lehrer und Arzt verhelfen Wortabet zu großem Ansehen in der Kirchengemeinde. Van Dyck und Thomson betonen mehrmals in ihren Korrespondenzen, dass sie hoffen, diesen vielversprechenden Mann bald als ordinierten Pastor zu sehen. ${ }^{314}$ Die vielen lobenden Worte verwundern nicht, denn zu dieser Zeit ist Wortabet der einzige Kandidat der Amerikaner, der für das Pfarramt infrage käme. Bereits 1849, ein Jahr nach der Gründung der einheimischen Kirche in Beirut, sind John Wortabet und Miha' îl 'Aramān für die einheimische Pastorenstelle im Gespräch, allerdings befinden die Missionare ihre Ausbildung als noch ungenügend. ${ }^{315}$ Um Wortabet nun in Hāṣbeiyā einsetzen zu können, planen Thomson, Smith und Whiting ihn zur Vorbereitung erneut für einige Zeit nach Beirut zu schicken, damit er dort seine Studien wieder aufnehmen kann. Van Dyck protestiert gegen dieses Vorhaben: „When working men are wanted, how long shall the only one we now have be kept at study?" 316 Van Dyck kann sich offenbar nur zum Teil durchsetzen. Wortabets Ordination wird aufgeschoben und er wird neben seiner Arbeit in Hāṣbeiyā vermutlich weiter studieren. ${ }^{317}$ Es scheint verwunderlich, dass sich Wortabet trotz anfänglicher Zweifel gegenüber dem Pfarramt diesen Entscheidungen beugt. Schließlich ist es umso überraschender, dass John Wortabet am 27. März 1853 im Rahmen der Jahresversammlung der Syrienmission in Beirut nicht etwa zum native pastor, sondern zum Evangelist ordiniert wird. ${ }^{318}$ Nach einer langjährigen akademisch-theologischen Ausbildung wird Wortabet zwar dazu berufen, das Evangelium zu verkündigen, jedoch kein höheres kirchliches Amt zu bekleiden. Dieses Ergebnis steht schließlich in keinem Verhältnis zum Aufwand der Prüfung, dessen Gremium aus den Missionaren Eli Smith, William Thomson, Cornelius Van Dyck, Simeon Calhoun, William Benton, George Whiting und H. Bood besteht: Nach der Prüfung in den alten Sprachen Hebräisch und Griechisch und in verschiedenen theologischen Disziplinen sowie nach Wortabets Predigt über 1 Kor 2,2 kommt das Gremium zu dem Schluss: „,[T]his examination of Mr. Wortabet is highly satisfactory and that we proceed to his ordination [...] at the Mission chapel."319 Als Evangelist bzw. Prediger wäre es Wortabets Aufgabe, die Evangelisierung der syrischen Bevölkerung durch eine hohe Reisetätigkeit voranzutreiben. Da Wortabet jedoch schon lange für den Aufbau der Kirchengemeinde in Hāṣbeiyā vorgesehen ist, wird er allein dort eingesetzt. Demnach erfüllt er zwar die Aufgaben eines einheimischen ordinierten Pfarrers und wird von den Missionaren auch als

$314 \mathrm{MH} \mathrm{49,} \mathrm{1853,} \mathrm{in:} \operatorname{ROS} 4,188$.

315 Badr (1992), 291, 294. Bustān̄̄, Fawāz und Ḥaddād sind schon seit Anfang 1844 für dieses Amt im Gespräch: vgl. Anderson, „Memorandum of my visit to the Levante“: ABC 30.10., Vol. 3, 38 (HHL). Auch Elyās Yaqūb, so berichtet Van Dyck 1850, könnte ein Kandidat für das Pfarramt in Hāạsbeiyā sein. Zusammen mit zwei anderen aus Hāṣbeiyā will er dort eine Kirche gründen: vgl. Van Dyck an Anderson ('Abeih, 21.10.1850): ABC 16.8.1., Vol. 5.

316 Van Dyck an Anderson ('Abeih, 21.10.1850): ABC 16.8.1., Vol. 5.

317 In den Jahresberichten der Hāṣbeiyā-Station wird schließlich berichtet, dass Wortabet dort seit 1851 eingesetzt wird: vgl. ABC 16.8.1., Vol. 4.1. (164 und 165).

318 Die Predigt während des Ordinationsgottesdienstes hält William M. Thomson. Sie wird auch in der American Mission Press gedruckt: vgl. Ellis (1901), 770.

319 Thomson und Whiting an Anderson (Beirut, 18.4.1853): ABC 16.8.1., Vol. 4 (34). 
solcher bezeichnet, ${ }^{320}$ besitzt offiziell aber nur den Titel eines Predigers. Nichtsdestotrotz kann Wortabet einmal mehr beweisen, dass seine Kompetenzen die Erwartungen der Missionare übersteigen. Die unsichere politische Lage in Hāṣbeiyā und Umgebung ab Ende des Jahres 1851 sowie heftige Anfeindungen von Seiten der griechisch-orthodoxen und -katholischen Kirchen stellen die junge Gemeinde und ihren Prediger auf eine harte Probe. Nur langsam wächst die Kirchengemeinde, die sich aus Ermangelung einer Kapelle in Wortabets Privathaus versammelt, ${ }^{321}$ und immer wieder müssen Mitglieder suspendiert werden. Thomson schreibt voller Bewunderung über Wortabet:

[He] continued his labours in Hasbeiya and vicinity during all these troubles. And this experience of his courage and ability to sustain himself in times of perplexity and alarm will enable the mission to commit the church in Hasbeiya to his care with the greater confidence. ${ }^{322}$

Anderson lobt vor allem Wortabets eigenständiges Handeln: „When there was a call for discipline, it was carried through firmly and wisely, without assistance from the mission." ${ }^{\text {"323 }}$

Im Januar 1853 heiratet Wortabet Salome Carabet, die Tochter des armenischen Bischofs Dionysios Carabet, der 1827 konvertierte und mit Johns Vater für den Missionar William Goodell arbeitete. ${ }^{324}$ Auch Salome Carabet, später Wortabet, ist ein Ziehkind der Mission. Sie und ihre kleine Schwester Melita ${ }^{325}$, sowie Johns Schwester Hannī (auch Hannie oder Hanne) kommen mit etwa fünf bis sechs Jahren in die Familie des Missionars Whiting, ${ }^{326}$ ebenso die Töchter des armenischen Konvertiten Yakob Gregory, Rufka und Sada. ${ }^{327}$ Die Missionarsfrau Matilda Whiting, die selbst keine Kinder hat, erzieht die Mädchen nach protestantischen Prinzipien. Sie assistieren zunächst in der Schule des Ehepaars in Jerusalem und gehen dann mit ihnen nach 'Abeih, wo Mrs. Whiting die Leitung einer Mädchenschule

320 MH 49 (1853), in: ROS 4, 188; Smith an Anderson (Beirut, 19.10.1855): ABC 60 (105), (HHL): ,J. Wortabet [...] our first native pastor“; ,Hasbeiya (Station Report for the year 1855)“ von Thomson und Van Dyck (Sidon, 1.1.1856): ABC 16.8.1., Vol. 4.1. (170): „Mr. Wortabet, the pastor of the church at Hasbeiya".

321 „Report of the Hasbeiya station for the year 1853“: ABC 16.8.1., Vol. 4.1. (167).

322 „Report of the Hasbeiya station for the year 1852“: ABC 16.8.1., Vol. 4.1. (165). Auch für das folgende Jahr notiert Thomson: ,[S]ince our excellent young brother has proved entirely competent to fulfill the duties of his important station, and throughout all the dangers and trials of a very disturbed and critical year has maintained his position with courage, and presents his labours with unabated zeal." Vgl. „Report of the Hasbeiya station for the year 1853": ABC 16.8.1., Vol. 4.1. (167).

323 Anderson (1872a), 377.

324 MH 23 (1827), in: ROS 1, 425-426, 469.

325 Melita Carabet (1832-1902) arbeitet später in der von Hannī Wortabet geleiteten Mädchenschule in Hāsşbeiyā. Als die Kaiserswerther Diakonissen 1860 in Beirut ihre Arbeit aufnehmen, nimmt Melita als ,,native teacher“" eine wichtige Vermittlerrolle zwischen den einheimischen Schülerinnen und den Diakonissen ein. Ihre wenigen Ersparnisse lässt sie nach ihrem Tod der deutschen Mädchenschule in Beirut zukommen: Hauser, J. / Lindner, C. B. / Möller, E., „Introduction“, in: Hauser/Lindner/Möller (2016), 11; vgl. Hauser (2015), 109-112.

326 Jessup (1874), 54, 64.

327 Lindner (2009), 236-237, 273: Die Eltern versterben 1836, woraufhin die beiden Mädchen in die Whiting-Familie aufgenommen werden. 
übernimmt, in der Salome und Hannī unterrichten. Noch bevor John und Salome heiraten, ist sie selbst als Missionarsgehilfin in Mosul tätig. Als John schließlich als Prediger nach Hasbeiyā gesandt wird, leiten seine Verlobte Salome und seine Schwester Hannī dort eine Schule. ${ }^{328}$

Die wenigen Berichte und Notizen über Wortabet im Missionary Herald oder in privaten Briefen der Missionare an den Sekretär Rufus Anderson zeigen, dass es über den syrischen Pastor in Hāașbeiyā zunächst nichts Auffälliges zu berichten gibt. Wortabet zeigt sich pflichtbewusst, fromm und konform mit den Ansichten seiner Mentoren - so scheint es zunächst. Selbst Van Dyck, der Wortabet in Medizin gelehrt hat und viele Jahre mit ihm im Süden des Landes arbeitet, weiß in seiner Korrespondenz mit Anderson zwischen 1851 und 1858 nur wenig über den jungen Theologen zu schreiben. Erwähnenswert ist für Van Dyck jedoch eine Auseinandersetzung zwischen Wortabet und dem maronitischen Bischof Buțrus, einem Verwandten von Buṭrus al-Bustānī, im Jahr 1857. Als dieser nach Hāạbeiyā kommt, um mit Wortabet über Religion zu debattieren und diesen mit seinen Argumenten zu vertreiben, muss der Bischof eine herbe Niederlage einstecken. Ein Emir soll Wortabet sogar zugeflüstert haben, dem Bischof nicht zu sehr zuzusetzen. Der Maronit reist vorzeitig ab und verbreitet, um sein Gesicht zu wahren, das Gerücht, man habe Wortabet in die Flucht geschlagen. ${ }^{329}$

Wortabet ist zwar allein in Hāṣbeiyā stationiert, da er jedoch nicht direkt beim ABCFM angestellt ist, werden - bis auf eine Ausnahme ${ }^{330}$ - keine von ihm verfassten Jahresberichte für Hāṣbeiyā dem ABCFM zugetragen. Obwohl Wortabet regelmäßig in schriftlicher Korrespondenz mit Van Dyck und Thomson steht, mit denen er ein gutes Verhältnis hat, zitieren beide selten aus Wortabets Briefen gegenüber dem ABCFM. ${ }^{331}$

Wortabet hat nun die Ausbildung bei den Amerikanern abgeschlossen und bekleidet als einziger Syrer offiziell das Amt des ordinierten Evangelisten mit den Aufgaben eines ordinierten Pastors. Dieser Umstand ist jedoch keine Garantie dafür, dass er und die Amerikaner sich nun auf Augenhöhe begegnen. Gregory Wortabet, der seinen Bruder John um 1854 in Ḥāșbeiyā besucht, bringt auf den Punkt, was in den folgenden Jahren für Wortabet zum Problem werden wird: „I could tell no difference between this congregation and a New England one, except it was in the dress and language, and the earnestness of the minister." 332

328 Jessup (1874), 63-66. Sie führen Rahīl 'Ațās (Bustān̄is Frau) Lehrtätigkeit unter den Protestanten in Ḥāșbeiyā seit 1844 fort: Lindner (2009), 178.

329 Van Dyck an Anderson (Sidon, 23.4.1857): ABC 16.8.1., Vol. 5 (343).

330 „An. Report Hasbeiya for 1858. Rec'd. Feb 25 1859“: ABC 16.8.1., Vol. 4.1. (173).

$331 \mathrm{Im}$ Bericht von 1853 wird ein kleiner Teil aus Wortabets Stationsbericht zitiert, 1855 zitiert Thomson fast den ganzen Bericht: ABC 16.8.1., Vol. 4.1. (167 und 170).

332 Wortabet (1856a), 271. 


\section{Die Distanzierung vom ABCFM}

Im Frühjahr 1860 beendet John Wortabet sein Arbeitsverhältnis mit der Syrienmission und bewirbt sich stattdessen bei der United Presbyterian Church of Scotland (UPC), um für sie als Missionar zu arbeiten. Was war geschehen?

Bereits 1855, d.h. zwei Jahre nachdem John Wortabet ordiniert worden ist, tritt er in Kontakt mit Dr. Coldstream, dem Sekretär der Edinburgh Medical Missionary Society. Der junge Pfarrer hat das Gefühl, dass er für seine Tätigkeit als Arzt, die er neben der Pastorenstelle weiterhin ausübt, einer Weiterbildung bedürfe, da er sein medizinisches Wissen für zu lückenhaft hält. Wortabet ist fest davon überzeugt, dass ein Aufenthalt in Schottland ihn zu einem besseren Missionar machen würde: ,[M]y motives in this step are [...] a sincere desire of improvements, with the object of becoming better qualified to labor for the spiritual and physical good of my countrymen." 333

Dass sich Wortabet bezüglich einer Weiterbildung nicht an den American Board wendet, hat mit den Prinzipien des Board zu tun, eine Ausbildung von Einheimischen in den USA nicht zu fördern, da sie sich aufgrund einer möglichen kulturellen Entfremdung für eine Arbeit in der Heimat disqualifizieren würden. Wortabet macht gegenüber Coldstream klar, dass der ABCFM in diesem Fall nicht über seine Bestrebungen entscheiden könne: „As I endeavour however, to act in this matter as a conscientious Christian, and from a strong sense of duty, I do not feel myself bound by the principles and rules of the Board." ${ }^{334}$ Da Coldstream sich im Klaren ist, dass eine Unterstützung Wortabets nicht möglich sei, ohne Rücksprache mit den Missionaren in Syrien gehalten zu haben, wendet er sich an Cuthbert G. Young, der mit Smith in direktem Briefkontakt bezüglich der Libanonschulen ${ }^{335}$ steht. Mit der Bitte Smith zu fragen, was Wortabet zu diesem Reisewunsch bewogen hat, schreibt Coldstream an Young, dass man Wortabets Studium - jedoch nicht seine Familie mit Einverständnis des ABCFM unterstützen könne. Auch Young ist der Meinung, dass Wortabet nach ein bis zwei Jahren Weiterbildung zu einem noch nützlicheren Mitarbeiter werden könne. Seiner Bereitschaft, weiterhin für die Amerikaner zu arbeiten, sollte dies keinen Abbruch tun. Doch der ABCFM und die Missionare in Syrien, in deren Namen Smith antwortet, haben die Befürchtung ihren einzigen ordinierten, einheimischen Prediger durch diese Reise zu verlieren. William Thomson ist durchaus im Bilde über Wortabets ,,,uncontrolled“ desire to visit Scotland for some time". Thomson hofft, so Smith, dass Wortabet nicht die finanziellen Mittel findet, um reisen zu können. Smith versucht die Sache abzuwenden: „Can you not set the matter right in England?“ ${ }^{336}$ Offensichtlich zeigt Smiths Bitte Wirkung. Wortabets Wunsch, nach Schottland zu gehen, bleibt vorerst unerfüllt.

333 Cuthbert G. Young, Sekretär der Free Church of Scotland, die missionarische Unternehmungen im Osmanischen Reich fördert, fügt seinem Brief an Eli Smith Wortabets Brief an Dr. Coldstream (Hāṣbeiyā, 4.7.1855) bei: Young an Smith (London, 12.9.1855): ABC 60 (99), (HHL).

334 Ebd.

$335 \mathrm{Zu}$ den Libanonschulen der Șalībī-Brüder: vgl. Abschnitt I.2.3.

336 Smith an Anderson (Beirut, 19.10.1855): ABC 60 (105), (HHL). 
Im April 1858 jedoch deutet Van Dyck in einer kurzen Bemerkung gegenüber Rufus Anderson an, dass Wortabet Hāạbeiyā verlassen wird: „We are about to lose Mr. Wortabet. This we regret much: but perhaps the Lord designs to do his work by the most feeble instruments, that more glory may occure to his own Holy Name. "337 Erst im August desselben Jahres geht er in einem anderen Brief näher darauf ein. Wortabet habe ihn besucht und angekündigt, dass er seine Gemeinde in Hāṣbeiyā nicht verlassen werde, solange die Mission die Unterstützung der einheimischen Kirche nicht garantiere. Erst wenn dies geklärt sei, werde er nach Schottland reisen.

Doch es scheint, als käme Wortabets Entscheidung dem ABCFM nicht ungelegen. Genauso wie im Fall von Bustān̄̄, der sich 1854 nochmals für die Pastorenstelle in der Beirut Church bewirbt, wird auch bei Wortabet argumentiert, dass theologische Differenzen schon seit Langem bestünden und für die Mission untragbar seien. ${ }^{338}$ Als Wortabet 1858 zum ersten Mal seinen persönlich verfassten Jahresbericht für Hāṣbeiyā einreicht, wird dieser vor der Weiterleitung zum ABCFM von William W. Eddy, seit 1858 in Sidon stationiert, mit einer Notiz versehen: „Send this as it is yet. I doubt the justness of some [of] his inferences and should regret to have it published [for] American Christians. "339 Grund für diese Notiz sind Wortabets Äußerungen im Jahresbericht über einen griechisch-orthodoxen Christen, der sich dem evangelischen Glauben zugewandt habe, jedoch vor seinem Tod der Heimatkirche nicht mehr den Rücken zugekehrt hat. Wortabet gibt offen zu, dass er hoffe, ,that [the] knowledge [of Jesus Christ] is attended with the sanctifying form of the Holy Spirit - even where the subjects of this change continue out of the pale of Protestantism and of the Protestant church“. ${ }^{340}$ Seiner Meinung nach dürfe der verstorbene Mann nicht von der Heilsgemeinschaft ausgeschlossen werden, auch wenn er nicht aus seiner Kirche ausgetreten sei (,who on earth is competent to shut him out for that reason [...]?“). Dass Wortabet hierbei der ursprünglichen Intention amerikanischer Mission im Orient folgt, die Kirchen von innen heraus reformieren zu wollen, scheint für die Syrienmission, vor allem für William Eddy nicht mehr relevant. In seiner bereits erwähnten Randnotiz in Wortabets Jahresbericht fährt er fort, dass man amerikanischen Christen nicht berichten könne, ,that there [are] as good Christians in the Greek church as in those that have separated from it. A true Christian would not stay and could not be (?) in the Greek church nor in any other of the nominally Christian churches". 341

Damit wäre schließlich der Wahrheitsanspruch evangelischer Religion ad absurdum geführt. Doch theologische Meinungsverschiedenheiten sind nicht der einzige Grund, warum Eddy Anfang 1859 dafür plädiert, Wortabets Wunsch nachzukommen, seine Schottlandreise anzutreten. Wortabet, der schon im Frühjahr 1858 einen Antrag auf Abreise stellt, erhält von der Mission weder finanzielle Unterstüt-

337 Van Dyck an Anderson (Beirut, 15.4.1858): ABC 16.8.1., Vol. 5 (346).

338 Bereits 1851 berichtet Smith: „He had, for example, difficulties about inspiration, and he would not see that infants ought to be baptized." Vgl. Smith an Anderson (Beirut, 17.6.1851): ABC 16.8.1., Vol. 5 (199).

339 „An. Report Hasbeiya for 1858. Rec’d. Feb 25 1859“: ABC 16.8.1., Vol. 4.1. (173).

340 Ebd.

341 Ebd. 
zung noch eine Antwort. Er ist zutiefst enttäuscht und muss seine Pläne erneut aufschieben. Eddy ist nicht nur der Meinung, dass Wortabets mittlerweile halbherzige Arbeitseinstellung für die Mission kein Gewinn mehr sei, sondern dass die Mission im Allgemeinen drei schwere Fehler in Bezug auf diesen einheimischen Helfer begangen habe, nämlich ,in giving him the kind of education he has, in giving him so unusually large a salary, 1000 piastres a month, ${ }^{342}$ and Mr Ford adds a third mistake in his being left to act so independently in Hasbeiya. I hope we shall avoid these mistakes in our future dealings with native helpers". 343

Auch Rufus Anderson, der in Wortabet so viel Hoffnung gelegt hat, ${ }^{344}$ zeigt sich äußerst enttäuscht:

From the account given of Mr. Wortabet I incline to the opinion that it will be advantageous to the mission and the cause to be rid of him and his great salary. I have not been able to recover the confidence I lost in his integrity in 1855 by his conversing with a whole hour or more as if he were intent on his work at Hasbayya, when, as it afterwards appeared, he was then fully resolved on going to Edinburgh to perfect himself as a physician! ${ }^{345}$

Ähnliche Vorkommnisse in Indien lassen Anderson jedoch zu der Einsicht kommen: „There is, however, one good result from these cases; we see that the native intellect is susceptible of high culture and development." Das Resultat ist schließlich ernüchternd: Die Unabhängigkeit, für die sich Wortabet als Pastor in Hāạbeiyā eingesetzt hat, führt die Mission, aber auch Anderson zu der Einsicht, dass man einheimischen Protestanten weiterhin nicht zu viel Verantwortung überlassen sollte. Van Dycks knapper Kommentar zu den Ereignissen („Our experiment of a native pastor has proved a failure" $)^{346}$ lässt viele Fragen offen und es ist nicht klar, wie dieser sich hier positioniert.

Das eigentliche Problem, mit dem sich Wortabet in Syrien konfrontiert sieht, ist auch an Anderson nicht vorübergegangen. Zwar beschreiben die Missionare Wortabets Gründe als ,kind of restlessness in being in a subordinate position, and under the supervision of the missionaries", 347 aber Anderson fragt sie auch, was geschehen wäre, wenn man Wortabet ,really and fully“ als Pastor in Hāṣbeiyā eingesetzt hätte. Was wäre gewesen, ,if he and the church had then been distinctly informed, that the responsibility of self-government was thence forward to devolve upon them; saving

342 Im Vergleich dazu erhält der einheimische Helfer Daher 'Abūd, der ebenfalls für das Pastorenamt in Frage kommt, 250 Piaster im Monat: Eddy an Anderson (Sidon, 8.1.1859): ABC 16.8.1., Vol. 4.2. (434).

343 „An. Report Hasbeiya for 1858. Rec’d. Feb 25 1859“: ABC 16.8.1., Vol. 4.1. (173).

344 „I hope much from the example of Wortabet, \& pray that he may prove himself at Hasbeiya a good soldier of the Lord Jesus." Vgl. Anderson an die Syrienmission (Boston, 6.11.1851): ABC 2.1.1., Vol. 15 (HHL).

345 Anderson an die Syrienmission (Boston, 23.2.1859): ABC 2.1.1., Vol. 25 (HHL). Zwar ist auch William M. Thomson der Meinung, dass Wortabet einen Fehler begehe, jedoch setzt er weiterhin große Hoffnungen in ihn: ,[I] do not abandon the hope that he may yet do a good service for the cause of Christ in Syria. He is a good man, and an able preacher": vgl. Thomson an Anderson ('Abeih, 12.7.1859): ABC 16.8.1., Vol. 5 (319).

346 Eddy an Anderson (Sidon, 8.1.1859): ABC 16.8.1., Vol. 4.2. (434).

347 Anderson an die Syrienmission (Boston, 8.6.1860): ABC 2.1.1., Vol. 26 (HHL). 
only that accountability to the Mission [...]?"348 Auch wenn Eddy mahnt, man habe Wortabet zu viel Verantwortung überlassen, sieht sich Wortabet nicht in vollem Maße unabhängig und frei, seine eigenen Entscheidungen zu treffen.

Schließlich kommt Wortabet in seinem bekannten Werk Researches into the Religions of Syria (s.u.) in dieser Sache selbst zu Wort. In seinem Kapitel über Protestantismus in Syrien äußert er sich ausführlich über die Probleme, die ausländischen Missionaren sowie einheimischen Konvertitinnen und Konvertiten begegnen. Ohne direkt vom American Board zu sprechen, ist der Bezug eindeutig. Es ist die Rede von einer übertriebenen Disziplinierung, die Wortabet sicher auch selbst erfahren hat. Sie lasse das Wachstum einheimischer Gemeinden stagnieren und desillusioniere hoffnungsvolle Protagonisten:

\begin{abstract}
In churches of modern growth particularly, the benefit of discipline is of the utmost importance; and for this reason, among others, that it is absolutely necessary to the proper and healthy development of the Church itself $[\ldots]$. But $[\ldots]$ there is a danger, into which some are very apt to fall, of carrying this matter to an injurious extreme. We do not believe that a rigid and uncharitable system of surveillance is either more scriptural or more successful in preserving the purity of the Church, than a lax watchfulness over its interests. For while the latter policy often receives children of the world who will bring into the Church a worldly spirit with all its baneful effects, the former rejects weak but sincere Christians, induces many to put on the cloak of hypocrisy, and fosters a spirit of self-righteousness, which is so abominable in the sight of God, and so destructive of all Christian efforts in the promulgation of the true religion. ${ }^{349}$
\end{abstract}

Aus eigener Erfahrung weiß Wortabet von einer Art Frömmigkeit von Seiten des American Board und seinen Missionaren zu berichten, nach der mit „mürrischer Art und Weise, harsch über andere geurteilt wird“. Es ist eine Ablehnung all derer, die in unbedeutenden theologischen Punkten, so Wortabet, eine andere Meinung haben und den Missionaren nicht immer bedingungslos folgen wollen. ${ }^{350}$ Wortabet distanziert sich entschlossen von einer bestimmten Gruppe christlicher Missionare, die er als Pharisäer bezeichnet (,Stand by thyself, come not near to me; for I am holier than thou."), Rauheit und Misanthropie treten hier zutage statt christlicher Nächstenliebe, „the evils of this spirit“ vertreiben die neuen, unerfahrenen Christen. ${ }^{351}$ Schließlich sieht er einen Erfolg nur durch die Handlungskompetenz der einheimischen Protestanten garantiert. So wie Luther in Deutschland, Zwingli in der Schweiz und Knox in Schottland, können nur syrische Protestanten qualifiziert genug dafür sein, ,to labour to the best advantage only in the land of their birth and education". 352 Die Freiheit der Missionare und der einheimischen Gemeinden steht für Wortabet, wie auch für Cornelius Van Dyck und William Thomson an erster Stelle. Somit schlussfolgert der armenische Syrer:

[T] he moral strength of converts to Protestantism [...] cannot be promoted to that degree of solidity [...], unless they have an important share in the evangelisation of their country and a

348 Ebd.

349 Wortabet (1860), 382.

350 Ebd., 383.

351 Ebd., 383-384.

352 Ebd., 391-392. 
respectable position in the ranks of the ministry of the Gospel. They must feel $[\ldots]$ a freedom from anything like a system of suspicious surveillance $[\ldots] .{ }^{353}$

Aufgrund der dennoch bestehenden Unerfahrenheit der jungen Gemeinden in ihrem „kindlichen Stadium“ ist eine Wachsamkeit von Seiten der Missionare nötig, ,which [...] must be paternal in its spirit, flowing from, and manifested by genuine love". ${ }^{354}$ Wortabet und die Missionare gehen keineswegs im Unguten auseinander, später wird man schreiben, ,that he parted with the Society on the most friendly terms". 355

1859 verlässt er Syrien und reist nach Glasgow und Edinburgh, um dort Medizin zu studieren. Da die Syrienmission jegliche finanzielle Unterstützung für dieses Unternehmen abgelehnt hat, ${ }^{356}$ erhält Wortabet vermutlich von anderer Seite Unterstützung. Doch sowohl dies als auch die Frage, ob seine Frau Salome und die Kinder ihn begleiten, bleibt ungeklärt. Im April 1860 reicht Wortabet seine Bewerbung bei der UPC sowie zwei Empfehlungsschreiben (von Dr. Hanna, Pfarrer der Free Church of Scotland sowie vom Geschäftsmann John Henderson) ein. ${ }^{357}$ Wortabet ist bereit, für die UPC als Pfarrer und Arzt zu arbeiten. In seiner Bewerbung schildert er nicht nur seinen biografischen Hintergrund und die beruflichen Erfahrungen, sondern begründet auch einerseits das Ende der Arbeit für den ABCFM mit seinem langjährigen Wunsch, Großbritannien zu besuchen, und andererseits mit einer „peculiar relation, implying missionary supervision, in which the native ordained minister stood to the missionaries of the Board" ". ${ }^{358}$ Eine Anstellung bei der UPC könne er sich jedoch nur unter zwei Bedingungen vorstellen:

1st That he be equal to a European Collegue in standing and office, there being no supervision of one over the other, and 2nd that he be equal with him in the matter of salary, being sensitive to this point as he considers that inferiority of salary implies inferiority of position or of qualification on the score of nationality, but at the same time that he would not make perfect equality of stipend a necessary or indispensable condition. ${ }^{359}$

Obwohl die Missionskonferenz in Liverpool 1860 erklärt, dass einheimische Mitarbeiter materiell und sozial von den Missionaren im Abstand zu halten seien (,since to do otherwise would seriously diminish their effectiveness") ${ }^{360}$ stimmt die UPC Wortabets Bitte zu. Wortabet muss der UPC beitreten und wird dem Missionar R. Grant Brown zur Missionierung der Juden in Aleppo zur Seite gestellt. Die UPC gewährt ihm das übliche Gehalt von $£ 200$ mit der Aussicht, das Gehalt bei Bedarf aufstocken zu können. ${ }^{361}$ Aus Boston kommt umgehend Protest: Rufus Anderson,

353 Ebd., 393.

354 Ebd., 394.

355 UPC-GMBM, Vol. 2 (3.4.1860), 232.

356 Eddy an Anderson (Sidon, 8.1.1859): ABC 16.8.1., Vol. 4.2. (434).

357 UPC-GMBM, Vol. 2 (1.5.1860), 234. Über Wortabets Zusammenarbeit mit der UPC berichtet auch Michael Marten (2006), 49-51.

358 UPC-GMBM, Vol. 2 (3.4.1860), 232.

359 UPC-GMBM, Vol. 2 (1.5.1860), 234.

360 Bonk (1989), 38.

361 UPC-GMBM, Vol. 2 (1.5.1860), 235. 
der durchaus über Wortabets Situation im Bilde ist, setzt sich mit dem Sekretär der UPC Andrew Somerville in Verbindung, ${ }^{362}$

\begin{abstract}
describing minutely the policy of the Board with regard to native agents. - and expressing a fear that if the native agents trained in the Mission and ordained as Pastors, shall by coming to England, Scotland or America, be accepted by other Protestant Societies and have given to them the standing and salary of Missionaries, this procedure will have a very inferious effect upon their large expensive and highly promising Mission among the Armenians in Turkey, as it will tend to induce the native Agents to leave their service or to make them discontented with their position and with the amount of support which the Board think it right to give them $[\ldots] . .^{363}$
\end{abstract}

Somerville antwortet, dass die UPC durch diesen Vorgang keineswegs in die Arbeitsbereiche der Mission interveniere, da Wortabet schließlich nach Aleppo gesandt wird, wo die amerikanische Mission keine Station habe. ${ }^{364}$ Am 30. Juli 1860 antwortet Anderson: ,we anticipate no interference with our Mission“. ${ }^{365}$ Wortabets Arbeit in Aleppo steht nun nichts mehr im Wege. Seine Pläne, über Beirut und Hāạbeiyā nach Aleppo zu reisen, werden vom in Syrien seit einigen Monaten währenden Bürgerkrieg durchkreuzt. Wortabet muss in Beirut bleiben und sieht sich als Arzt dazu verpflichtet, in Zusammenarbeit mit den Amerikanern vom Krieg Versehrte ärztlich zu versorgen. ${ }^{366}$ Dabei übernimmt er auch arabische Gottesdienste für die Mission in Beirut. ${ }^{367}$ In einem Brief an die UPC bittet er darum, die Medizin, die er auf Kosten der schottischen Mission in Edinburgh besorgt hat, bereits in Beirut verwenden zu dürfen. ${ }^{368}$ Bei der UPC begrüßt man zwar Wortabets humanitäre Arbeit, jedoch äußert sich dessen Verwaltung nicht dazu, ob er die Medizin verwenden dürfe. Stattdessen rät ihm Somerville, nach Aleppo weiterzureisen, sobald

362 Anderson schreibt 1860 an die Syrienmission, dass er im schriftlichen Kontakt mit Dr. Somerville stehe: vgl. Anderson an die Syrienmission (Boston, 8.6.1860): ABC 2.1.1., Vol. 26 (HHL).

363 UPC-GMBM, Vol. (3.7.1860), 253. Vgl. dazu den Brief von Anderson an Somerville (Boston, ca. Juni 1860), zugänglich im Archiv der Presbyterian Historical Society in Philadelphia, PA (RG 115.5.25), zur Verfügung gestellt von Christine Lindner. Lindner weist zudem darauf hin, dass Anderson in diesem Schreiben deutlich zwischen „Native Agency“ und „Missionary“ unterscheidet. Einheimische Protestanten können demnach keine „Missionare“ sein, diese Bezeichnung ist nur den Amerikanern vorbehalten. Wie bereits in anderen Fällen dargestellt, zeigt sich auch hier eine Diskrepanz zwischen der Missionstheologie des ABCFM und der Praxis im Missionsfeld. Bustānīs 1862 gegründete Ğam '̌̀yat Beyrūt al-Inǧilīya wird im Missionary Herald durchaus als „Native Missionary Society“ übersetzt. Die von dieser Gesellschaft ausgesandten Evangelisten werden ebenso als „Missionare“ bezeichnet: vgl. MH 58 (1862), in: ROS 5, 49.

364 UPC-GMBM, Vol. (3.7.1860), 253.

365 UPC-GMBM, Vol. 2 (2.10.1860), 268.

366 Somerville an Wortabet (4.10.1860): NLS, MS 7643. Siehe auch Lindner (2009), 268.

367 Jessup (1910a), 194: „On Sunday, July 1st, no church bells were rung in Beirut. I preached in English, and Mr. Araman and Dr. Wortabet in Arabic." Auch gegenüber der UPC gibt Wortabet $\mathrm{zu}$, ,that he had been occupied in preaching for the American Missionaries“. Vgl. UPC-GMBM, Vol. 2 (2.10.1860), 268.

368 Ebd.: Wortabet schreibt im August an die UPC, ,that he had taken charge of two wards in an hospital which has been erected for the sick multitudes". 
die Straßen sicherer seien. ${ }^{369}$ Ende Oktober 1860 erreicht Wortabet schließlich mit seiner Familie Aleppo.

In Aleppo, Killis und Idlib ist seine Arbeit in den nächsten fünf Jahren jedoch von wenig Erfolg gekrönt. Die ohnehin schon erfolglose Mission unter der Leitung des Missionars R. Grant Brown kann auch vom gut ausgebildeten und erfahrenen Wortabet nicht profitieren. Ab 1863 verlässt Brown die Mission und kehrt nach Schottland zurück. John Wortabet ist nun der alleinige Missionar, unterstützt von einheimischen Helfern. Statt sich um die Zielgruppe zu kümmern, um derentwillen er nach Aleppo gesandt wurde, die Juden, interessiert er sich für die Christen, die seiner Meinung nach, direkter missionarischer Arbeit bedürfen: ${ }^{370},[\mathrm{O}]$ ur various Agencies if turned to the Jews would not work at all“", berichtet er 1866. ,We turned our efforts to the nominally Christian Churches because to them alone was there any door of access. “371 Als Ende 1865 auch in Aleppo die Cholera ausbricht, sieht sich Wortabet gezwungen, im Herbst desselben Jahres mit seiner Familie, dem britischen Konsul sowie einem syrischen Helfer für neun Wochen in die Berge zu gehen. In Edinburgh zeigt man sich darüber erschüttert, dass Wortabet, ohne vorher um Erlaubnis zu bitten, seine Station verlasse, besonders da seine Arbeit als Arzt vor Ort dringender denn je gebraucht werde. Wortabet versucht, sein Handeln zu begründen: Er und seine Familie befanden sich in einem gesundheitlich derart schlechten Zustand, dass eine Abreise unumgehbar gewesen sei. ${ }^{372} \mathrm{Im}$ gleichen Schreiben, in dem er die UPC über die Vorfälle in Kenntnis setzt, bittet Wortabet darum, seine Söhne mithilfe des ,fund for aiding in the education of the children of Foreign Missionaries“" zur Ausbildung nach Edinburgh schicken zu dürfen. Dieses Mal zeigt sich die UPC weniger kooperativ. Mit der Begründung, dass diese Geldmittel nur für schottische Missionare gedacht seien, wird Wortabets Antrag abgelehnt, „on the ground that Syria is his native country“. ${ }^{373}$ Auch für die UPC hat die Gleichbehandlung offensichtlich ihre Grenzen. Wortabet versucht noch eine Gehaltserhöhung von $£ 50 \mathrm{zu}$ erwirken, da er sich sonst eine Ausbildung seiner Söhne am SPC oder am amerikanischen College in Istanbul nicht leisten könne. ${ }^{374}$ Aus den Protokollen der schottischen Mission geht schließlich nicht mehr hervor, ob diesem Antrag stattgegeben wird.

Im Juni 1866 schreibt John Wortabet an die UPC:

I cannot conceal the fact that I am disheartened and discouraged, and that the hopes I had formed all along as to the prospective results of the Mission are beginning to fail. As a Jewish Mission I have already written to you, our work is a complete failure so far. ${ }^{375}$

Weder die Arbeit unter den Juden, noch die unter anderen christlichen Konfessionen werde in der Zukunft Ergebnisse bringen, so Wortabet weiter. Angesichts der Ereignisse in den vergangenen Monaten fürchtet Wortabet, das Vertrauen der UPC

369 Somerville an Wortabet (4.10.1860): NLS, MS 7643.

370 UPC-GMBM, Vol. 2 (27.10.1863), 588.

371 UPC-GMBM, Vol. 2 (26.6.1866), 740.

372 UPC-GMBM, Vol. 2 (27.3.1866), 724-725.

373 UPC-GMBM, Vol. 2 (27.3.1866), 726.

374 Ebd.

375 UPC-GMBM, Vol. 2 (26.6.1866), 740. 
verloren zu haben, was Somerville jedoch dementiert. ${ }^{376}$ Während die UPC entscheidet, die Judenmission in Aleppo zu beenden und Wortabet für ein anderes Missionsfeld vorzusehen, ${ }^{377}$ erhält dieser ein Angebot vom SPC in Beirut, dessen Gründung noch im selben Jahr bevorsteht. ${ }^{378}$ Schon im Jahr 1862 unterrichtet ihn Jessup darüber, dass die Missionare in Erwägung ziehen, ,a large Protestant native institution in Beirut of a high order" aufzubauen. ${ }^{379}$

\section{Die Rückkehr nach Beirut als Mediziner}

Für seinen Artikel über die Fieberkrankheiten in Syrien im American Journal of Medical Science 1853 wird John Wortabet vom Yale College der Doktortitel in Medizin verliehen. ${ }^{380}$ In Vorbereitung auf seine Stelle am SPC reist er 1866 nach England und New York, um sein medizinisches Wissen auf den neuesten Stand zu bringen und am New York University Medical College im März 1867 seinen Abschluss als Medical Doctor zu absolvieren. ${ }^{381}$ Johns und Salomes Situation, die sie bei ihrer Rückkehr nach Beirut antreffen, ist, wie LINDNER es beschreibt, nicht vergleichbar mit der von 1860, als sie Beirut in Richtung Aleppo verlassen hatten:

This was a new phase for the Protestant community, one which was not defined by the work of ABCFM missionaries to convey their definition of Protestantism to the residents of Syria who then negotiated and adapted this faith and culture. Rather, the Wortabets' return occurred when the now established, but refined, Protestant community sought to positively influence the Syrian region through re-negotiating and re-defining its position within this dynamic milieu. ${ }^{382}$

In der Tat zeigt sich die syrisch-protestantische Gemeinschaft selbstständiger und unabhängiger denn je, doch dies bedeutet nicht, dass Wortabets Probleme mit den Amerikanern nun nicht mehr existieren. Bevor er am SPC zu lehren beginnt, wird unter den Verantwortlichen des Colleges eine lange Debatte über seine Einstellung geführt und die Erfahrungen des ABCFM mit Wortabet spielen dabei eine wichtige Rolle. Federführend in dieser Debatte ist der bereits erwähnte David Stuart Dodge, zunächst Dozent am SPC für moderne Sprachen und später Schatzmeister des Board of Trustees in New York. Der Missionar William M. Thomson, der Wortabet über

376 Somerville an Wortabet (28.6.1866): NLS, MS 7640.

377 Somerville an Wortabet (3.10.1866): NLS, MS 7640. Im Dezember 1866 geht ein letztes Schreiben von Wortabet an die UPC, in dem er sich für die Offenheit und Freundlichkeit der schottischen Mission bedankt. Für den Umzug nach Beirut gewährt ihm die UPC einen letzten Zuschuss von $£ 25$ : vgl. Somerville an Wortabet (18.2.1867): NLS, MS 7647.

378 Marten (2006), 60.

379 Jessup (1910a), 239.

380 Anderson (1872a), 377 (Anm. 1). In einem Brief von Wortabet an Smith aus Ḥāṣbeiyā vom 26.8.1852 bittet dieser um die Weiterleitung eines Paketes mit seinem Artikel an einen gewissen Dr. Robinson, der die Arbeit vor der Fakultät des Colleges vorstellen möchte. Wortabet erhofft sich dadurch, den ihm versprochenen Titel zu erhalten: „There are many circumstances, in which such a testimony will be very convenient, if not extremely necessary.“ In: ABC 60 (98), (HHL).

381 Bliss (1920), 189; Penrose (1941), 37.

382 Lindner (2009), 269. 
viele Jahre begleitete, setzt sich für die Einstellung Wortabets als Lehrender an der Medizinischen Fakultät ein. Bisher sind Van Dyck, Thomson ${ }^{383}$ und George Post für dieses Institut vorgesehen, doch es fehlt mindestens ein weiterer Mitarbeiter. Im Juli 1866, d. h. fünf Monate bevor das SPC eröffnet wird, äußert Dodge zum ersten Mal seine Zweifel zum Fall Wortabet und bittet Daniel Bliss darum, keine voreiligen Schritte diesbezüglich zu unternehmen. ${ }^{384}$ Etwa einen Monat später legt Dodge seine Bedenken ausführlich dar. Für die Einstellung des Theologen und Mediziners gibt es einige Einwände, auch wenn Dodge nicht am ,moral character“ Wortabets zweifle, aber er verließ die Mission ,when they had justly looked upon him, for years, as one, who was to prove an earnest useful a laborer in the field". ${ }^{385}$ Wortabet hat die Mission demnach im Stich gelassen. Weiterhin führt Dodge Wortabets Position in Aleppo ins Feld: ,the salary and authority he has posessed, the unhappy facilities about him. I should be slow to believe that he is fitted for the high position proposed". Dodge ist demnach nicht willens, Wortabet eine gleichwertige Position als Lehrender wie Van Dyck, Thomson oder George Post zuzusprechen. Wortabet würde demnach die gleiche untergeordnete Position einnehmen, wie er sie zuvor als Pastor in Hāṣbeiyā schon innehatte. Für Wortabet eine undenkbare Sache. Zudem, so bemerkt Dodge, zweifle er an Johns medizinischen Fertigkeiten: ,What does he know of years of observation in Hospitals of great cities? What wide acquaintance has he with the best literature and living men in the Professors either in England or America?" Genau aus diesem Grund ist Wortabet willens, für ein weiteres Jahr, nach England zu gehen, um das zusätzliche nötige Wissen zu erlangen, doch das ist Dodge nicht genug (,Is a simple year to give him all that?“). Diese Zusatzausbildung müsste vom Kuratorium im New York finanziert werden, dessen ist sich Dodge bewusst. Für die geringwertige (,,inferior") Leistung, die man von ihm nur erwarten könne, möchten sie eine solche Geldsumme aber nicht aufbringen. Wenn überhaupt ein einheimischer Lehrer für die ausgeschriebene Stelle in Frage käme, so räumt Dodge jedoch ein, wäre es Wortabet. ${ }^{386}$

Es stellt sich die Frage, was hinsichtlich der Theorie- und Praxiserfahrung im medizinischen Bereich Wortabet von Van Dyck unterscheidet. Van Dyck ist das letzte Mal im Jahr 1854 in den USA, um sich dort medizinisch weiterzubilden. ${ }^{387}$ Dodge hat vermutlich vielmehr die englischen und amerikanischen Geldgeber im Sinn, die ihre großzügigen Geldspenden richtig eingesetzt wissen wollen. Ein Amerikaner auf dem Stuhl eines Professors kommt eher gelegen, als ein Syrer, dessen berufliche Laufbahn zwar erfolgreich, in den Augen der Amerikaner jedoch, als zu sprunghaft angesehen werden kann. „Our leading Pastors and benevolent men have

383 Obwohl bisher unbekannt blieb, dass William M. Thomson einen Abschluss in Medizin hat, führt ihn Dodge als möglichen Kandidaten ins Feld: vgl. Dodge an Bliss (Hastings, 3.7.1866): AA.2.3.1.3.1. William M. Thomson ist in jedem Fall Mitglied des Board of Managers des SPC: vgl. American University of Beirut, Directory of AUB Faculty Members, Staff Members, and Officers, 1880-, URL: http://aubdirectory.aub.edu.lb/Pages/MembersListing.aspx.

384 Dodge an Bliss (Hastings, 3.7.1866): AA.2.3.1.3.1.

385 Dodge an Bliss (North Wales, 5.8.1866): AA.2.3.1.3.1.

386 Ebd.

387 Siehe Abschnitt II.2.2. 
no sickly sentimentality of enthusiasm about, real, live natives of the Holy Land'. $[\ldots]$ to entrusting them with funds or [...] sending such sums as will be necessary [...] I can [...] say, I fear that", so Dodge an Bliss in einem weiteren Brief. ${ }^{388}$ Dodge rät Daniel Bliss schließlich, die Sache ruhen zu lassen, da bereits genügend andere Probleme der Eröffnung des SPC im Wege stünden und es nicht klar sei, ob die medizinische Fakultät sogar später eröffnet werden müsse als vorgesehen. Wortabet, so Dodge, solle sich vorerst nicht von der UPC lösen, bevor der Board of Trustees darüber ausführlich beraten habe. ${ }^{389}$ Doch die Sache lässt Dodge keine Ruhe: am 21. August 1866 berichtet er Daniel Bliss in einem weiteren Brief von einer Begegnung mit einem gewissen Mr. Hengh aus London, der über Wortabets Pläne nach England zu kommen, nicht begeistert sei. Dieser berichtet von unangenehmen Erinnerungen an dessen ,two worthless [...] vagabund brothers“ sowie an Johns ersten Aufenthalt in England. In einem weiteren Satz über Hengh wird deutlich, was damit gemeint ist: „He also spoke strongly of the Jerusalem troubles and attributes much of the difficulty there to natives, who had gained positions of influence and became ambitious for increased power etc. “390

Hat sich also in Beirut für die Wortabets doch nichts verändert? Als William M. Thomson, der sich für Wortabet eingesetzt hat, davon erfährt, dass Johns Nationalität ein Hinderungsgrund sei, zeigt er sich enttäuscht: „If the appointment of native professors is to be impossible simply because they are native, I must decline to have anything more to do with the college. ${ }^{\text {"391 }}$ Doch es geht hier nicht allein darum, dass Wortabet als Einheimischer nicht eingestellt werden soll. Vielmehr hat das College mit einem einheimischen Lehrenden einen Ruf zu verlieren. Dodge schreibt, ob es nicht so sei, ,that to have any native, whatever his talents or position, represent us in this country is to lower the enterprice in the eyes of the public [...]?“392 Noch dazu zweifle der Board of Trustees daran, dass, wie Erfahrungen es gezeigt haben, Menschen verschiedener Nationalitäten gut zusammenarbeiten könnten. ${ }^{393}$ Mag sich die allgemeine Situation für die Wortabets in Beirut verändert haben, in den USA hat sie es nicht: Alte Vorurteile und überholte Meinungen beherrschen nach wie vor jenseits des Ozeans die Köpfe hoher Verantwortlicher, die sich mit großem Enthusiasmus für Bildungsinstitutionen im Ausland einsetzen, ohne diese in den kulturellen Kontext integrieren zu wollen. Trotz aller Widerstände und der im SPC für Jahrzehnte bestehenden, ungeschriebenen Klausel, keine einheimischen Professoren zu ernennen, wird Rev. John Wortabet M.D. doch im September 1866 als erster und vorerst einziger syrischer Professor am SPC eingestellt, woraufhin er ein Jahr zur Vorbereitung in England und in den USA beurlaubt wird. Nach seiner

388 Dodge an Bliss (o. O., 21.8.1866): AA.2.3.1.3.1.

389 Dodge an Bliss (North Wales, 5.8.1866): AA.2.3.1.3.1. In der Tat erhält Wortabet noch bis zum Ende des Jahres 1866 sein reguläres Gehalt von der UPC: vgl. Somerville an Wortabet (Edinburgh, 3.10.1866): NLS, MS 7646.

390 Dodge an Bliss (o. O., 21.8.1866): AA.2.3.1.3.1.

391 Jessup (1910a), 303.

392 Dodge an Bliss (o. O., 21.8.1866): AA.2.3.1.3.1.

393 Jessup (1910a), 303-304: Das zeigen bekannte Fälle, in denen Deutsche und Engländer nicht gut zusammen gearbeitet haben. 
Rückkehr am 1. September 1867 wird er Professor in den Fächern Anatomie und Physiologie. ${ }^{394}$ Auch wenn die Belege dafür fehlen, so scheint es, dass Bliss und der in Beirut ansässige Board of Managers des Colleges sich gegen das Kuratorium in New York hat durchsetzen können. Es ist darüber hinaus zu vermuten, dass Wortabet von dem Briefwechsel zwischen Dodge und Bliss zunächst nichts erfahren hat. Angesichts seiner zuvor bewiesenen Entschlossenheit hätte er bei den Gegenargumenten David S. Dodges die Einstellung vermutlich abgelehnt.

Diejenigen, die ihr Vertrauen in Wortabet gesetzt haben, behalten Recht: „, [he] did excellent work as a teacher". ${ }^{395}$ Jahresberichte des SPC und Kollegen in der Mission wissen nichts Schlechtes über Wortabet zu berichten. Er wird zum Sekretär und Schreiber des Fakultätsvorsitzenden Daniel Bliss gewählt und leitet zusammen mit Van Dyck und Post für die ersten fünf Jahre das medizinische Institut, bis der Arbeitsaufwand weitere Stellen erfordert. ${ }^{396}$

Obwohl Wortabet ein wenig im Schatten seines ehemaligen Lehrers Van Dyck steht, wird er von seinen Studierenden respektiert und hoch angesehen. Wie seine beiden Kollegen Post und Van Dyck verfasst auch er Lehrbücher für den Unterricht am SPC (s. u.) und engagiert sich in weiteren wissenschaftlichen Projekten. Jessup schreibt 1910 nach dessen Tod: „He was a man of great industry, an exact scholar, and successful physician. He was especially kind to the sick poor, and had a wide reputation throughout Syria.“397 Jessup nutzt die Gelegenheit, Wortabet kurz nach seiner Einstellung am SPC im Jahr 1867 aufzusuchen, um ihn dazu zu überreden, die Pfarrstelle in der Beirut Church zu übernehmen. Bisher hat sich niemand gefunden und selbst der ABCFM sieht Wortabet als einzig qualifizierten Mann für dieses Amt. ${ }^{398}$ Aber er ist überhaupt nicht interessiert, „he absolutely refused“. 399 Jessup schreibt dazu: „He was receiving a salary equal to, if not greater, than that of Dr. Thomson, Dr. Post, or myself, and could not expect as much from the native church, ${ }^{400}$ yet this was probably not the chief reason for declining the office. ${ }^{\text {"401 }}$ Doch die Mission kann sich ein weiteres Mal auf Wortabet verlassen: Während Henry Harris Jessups Abwesenheit 1868 predigt er an dessen Stelle in der einheimischen Gemeinde. Van Dyck teilt allerdings seinen Kollegen von der Mission mit, dass Wortabet nur temporär aushelfe: „It's useless to hope that he will be the Pastor of this church. [...] He gets $£ 300$ from the College and deserves it, for

394 John Wortabet an Daniel Bliss (Beirut, 22.1.1868): AA.2.3.1.10.2: Auch am College dauert es offenbar eine Weile bis Wortabet überhaupt sein Gehalt erhält. Im Januar 1868 bittet er darum, seinen Lohn rückwirkend ab dem 1. September 1867 erhalten zu dürfen, da er sehr viele Ausgaben getätigt hat und seine Anstellung zu dieser Zeit beginnt. Der Board of Trustees hat das Geld vermutlich nicht sofort bereitgestellt.

395 Jessup (1910a), 304.

396 Penrose (1941), 21, 42.

397 Jessup (1910b), 781.

398 Ebd., 344.

399 Jessup (1910a), 313.

400 Die Mission bietet ihm 500 Piaster für die Predigttätigkeit in der Beiruter Kirche an: „Records of the Syria Mission and the Holy Land 1867-1870“ (17.1.1868): ABC 16.8.1., Vol. 8.1., 194.

401 Ebd., 344. 


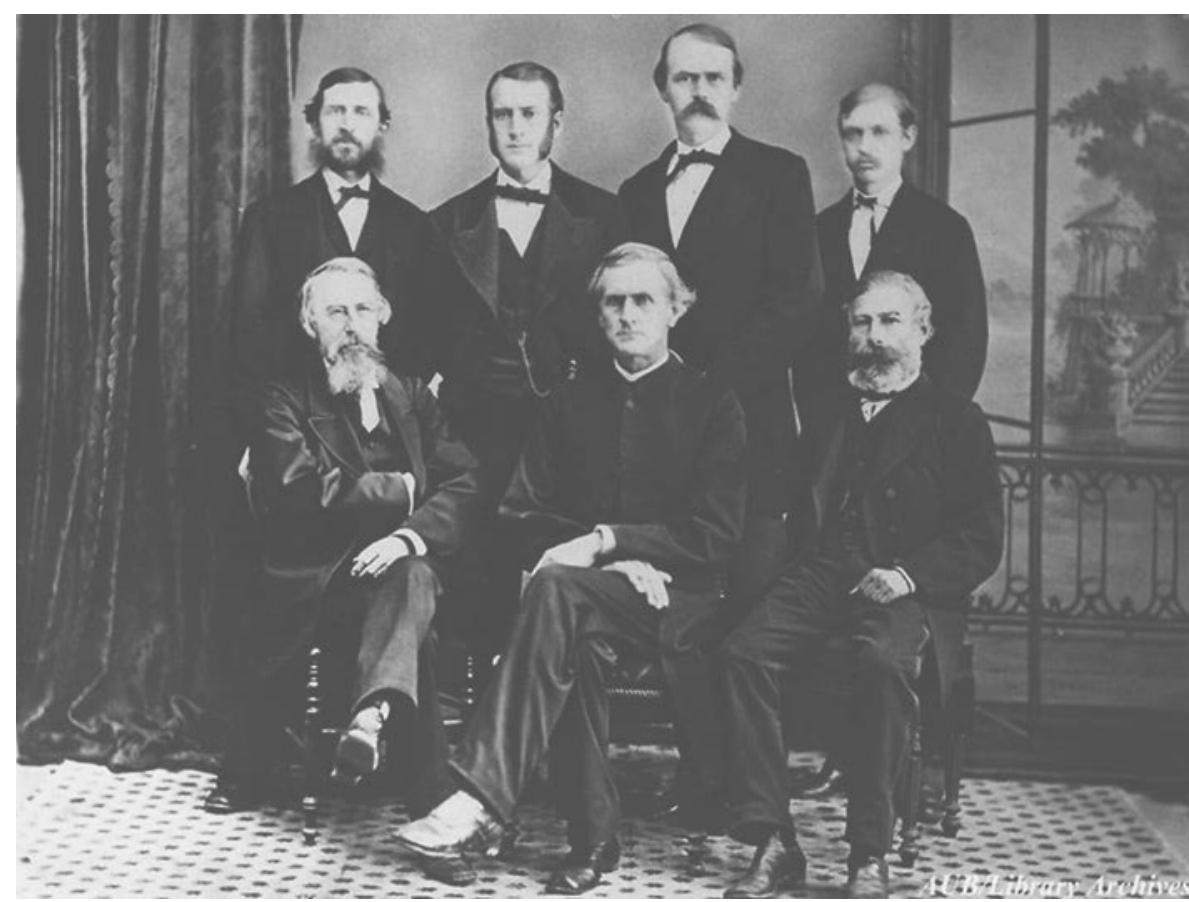

Abb. 11: Die ersten Professoren des Syrian Protestant College, 1870-1874

(1. Reihe v.l.: Cornelius Van Dyck, Daniel Bliss, John Wortabet; 2. Reihe v.l.:

David Stuart Dodge, George Post, Edwin Lewis, Harvey Porter)

he gives all his time to it and works hard." "402 Stattdessen engagiert sich Wortabet nebenbei weiterhin in der Anglo-American Congregation, ${ }^{403}$ der ehemaligen Missionskirche, in die er 1847 eintrat, aufgrund seiner Anstellung in Hāasṣbeiyā jedoch der syrischen Kirche beitreten musste. ${ }^{404}$ Offenbar ist die ehemalige Missionskirche für ihn wie eine Heimatkirche. Aus Wortabets Handlungen ist deutlich herauszulesen: er möchte seinen englischen und amerikanischen Kollegen auf Augenhöhe begegnen. (Abb. 11)

Das Lehren am College wird für den Mediziner und Theologen zur neuen Passion. Sein Schüler Ya 'qūb Șarrūf berichtet, Wortabet übertreffe sogar Van Dyck, da er Sachverhalte im Klassenraum besonders klar darzustellen vermag, vor allem im

402 Van Dyck an Clark (Beirut, 25.1.1868): ABC 16.8.1., Vol. 7.2. (515). In einem Brief an Somerville vom 12. September 1866 schreibt Wortabet, dass das SPC ihm ein Gehalt von $£ 350$ (bei der UPC erhielt er zuletzt £ 250) versprochen habe: NLS, MS 7646.

403 Laut Jahresberichten der Anglo-American Congregation nimmt er an etlichen Gremien teil und ist bis Februar 1894 „English representative“ im „Pastor’s committee“ der Kirche: vgl. „Minutes of the Meeting of the Anglo-American Congregational Committee held 30 March 1871“, in: AAC Protokolle (1868-1891), 19; „Report read at the Annual Meeting held in the Memorial Hall“" (9.2.1894), in: AAC Protokolle (1881-1905), 42: NEST/SC.

404 Als Angestellter der syrisch-protestantischen Kirche ist eine dortige Kirchenmitgliedschaft natürlich Grundvoraussetzung. 
Fach Anatomie. ${ }^{405}$ Wortabet legt Wert darauf, Unterrichtsinhalte so lange zu wiederholen, bis jeder der Studierenden sie verstanden hat. Der ungewöhnlich lange Titel seines 1871 erschienen Anatomiebuches zeigt den Lesenden unmissverständlich, was sie von diesem Lehrbuch zu erwarten haben:

Verdeutlichung der Grundlagen der Anatomie. Insgesamt wurde es als Hilfe für arabische Muttersprachler erstellt [und] von den neuesten Büchern übernommen, die in den englischen und amerikanischen Schulen anerkannt sind. Es beinhaltet alle für die Studierenden nötigen Fragen, frei von Komplikation und Unklarheit, leicht zu ordnen, zu verstehen und zu merken; verdeutlicht in 364 Abbildungen ${ }^{406}$

Fachlich hat sich Wortabet jedoch nicht völlig der modernen Schulmedizin verschrieben, sondern bezieht sich auch auf jahrhundertealte Lehrweisen der Griechen, Römer und Araber. ${ }^{407}$ So wie sein Vorbild Ibn Sīna bzw. Avicenna setzt er auf die natürlichen Heilmittel des Menschen. ${ }^{408}$ Vor seinen Studierenden wie auch bei öffentlichen Vorträgen wird er nicht müde zu lehren, dass körperliche Bewegung und eine gesunde Ernährung vielen Krankheiten vorbeugen können. ${ }^{409}$ Neben seiner Lehrtätigkeit arbeitet er für etwa fünfzehn Jahre als Arzt im Preußischen Krankenhaus der Kaiserswerther Diakonissen. ${ }^{410}$ Für diese Leistungen erhalten er und seine Kollegen Cornelius Van Dyck und George Post vom Osmanischen Reich einen Verdienstorden. ${ }^{411}$ Weitere zwei Orden werden ihm für seine Arbeit während der Cholera-Epidemie 1875 sowie seine wissenschaftlichen Werke (s. u.) verliehen. In der Fachwelt der Medizin ist Wortabet mittlerweile ein angesehener Mann und engagiert sich als Mitglied in der Medizinisch Chirurgischen Gesellschaft in Edinburgh, der Londoner Gesellschaft des Wissens um Krankheiten sowie der Medizinischen Akademie in New York. ${ }^{412}$

Wortabets Verbindung zum College verändert sich im Jahr 1882 mit der LewisAffäre und dem Weggang fast aller seiner Kollegen an der Medizinischen Fakultät. ${ }^{413}$ Im Zuge der Ereignisse sieht er sich genötigt, am 10. Juli 1883 zurückzutreten. ${ }^{414}$ Ende 1882 steht die College-Verwaltung vor einem großen Problem: es gibt

405 Aus einer Rede von Y. Șarrūf anlässlich der Einweihung der Büsten von Van Dyck und Wortabet 1913, in: Al-Kullīya 4/6 (April 1913), zitiert in: Hūurī (1992), 178.

406 Näheres dazu in Anhang I.

407 Wortabet (1905), 610.

408 Ebd., 542. Avicenna sowie griechisch-medizinische Werke der Antike sind sehr beliebt bei praktizierenden Arabern: vgl. Van Dyck (1853), 561-562.

409 Y. Sarrūf, „Duktūr Yuḥanna Wūrtabāt, 1829-1908“, aus: al-Muqtațaf 30 (1905) und 34 (1909), zitiert in: Huūrī (1992), 183, 185; Wortabet (1905).

410 Näheres zum Krankenhaus in II.2.4.

411 Wortabet (1879/80), 195.

412 Y. Sarrūf, „Duktūr Yuhanna Wūrtabāt, 1829-1908“, aus: al-Muqtațaf 30 (1905) und 34 (1909), zitiert in: Huūrī (1992), 184.

413 Van Dyck und sein Sohn William verlassen das SPC bereits 1882 (siehe Abschnitt II.2.4); Richard W. Bridgestocke, ebenfalls Lehrender an der Medizinischen Fakultät, sowie John Dickson, Mitglied des Board of Managers, reichen 1883 ihren Rücktritt ein: vgl. Dr. Richard W. Bridgestocke an Daniel Bliss (o. O., 5.3.1883) und John Dickson an Daniel Bliss (Damaskus, 7.5.1883): AA.2.3.1.9.4.

414 John Wortabet an den Board of Managers (Beirut, 10.7.1883): AA.2.3.1.11.12. 
28 Medizinstudierende, aber nur zwei Professoren, George Post und John Wortabet. So schnell kann die Lücke mit einem Professor, der auf Arabisch lehren kann, jedoch nicht gefüllt werden. Auch Wortabet möchte offenbar die Verbindung zu dieser herausragenden Institution nicht einfach aufgeben, obwohl er mit deren Führung nicht einverstanden ist. In seinem Kündigungsschreiben im Juli 1883 willigt er ein, weitere drei Jahre als Lektor zu arbeiten und zudem die Pathologieklasse von Van Dyck zu übernehmen. ${ }^{415}$ Mit dem Mangel an kompetenten Lehrkräften, die Medizin in der arabischen Sprache unterrichten können, kommt erneut die Frage der Umstellung auf die englische Unterrichtssprache auf. In den anderen Instituten wird sie bereits 1879 eingeführt, lediglich die medizinische Fakultät ist aufgrund ihrer kompetenten Lehrerschaft von dieser Änderung ausgenommen. Seit 1883 wird auch hier mit den neu eingestellten Professoren aus Amerika auf Englisch unterrichtet. Wortabet ist mit dieser Regelung nicht einverstanden: Die Studierenden seien mit der Erwartung zum SPC gekommen, in ihrer Muttersprache unterrichtet zu werden. Daher erklärt er, die Fächer Anatomie, Physiologie und Pathologie weiterhin auf Arabisch zu unterrichten, willigt aber ein, Studenten in seine Klasse aufzunehmen, die Medizin auf Englisch studieren. „But it is to be understood that I shall not be held responsible for their proficiency in their studies“, fügt er hinzu. ${ }^{416}$

Als der Board of Managers 1883 Wortabets Kündigung und Einverständniserklärung erhält, weiterhin als Lektor zu arbeiten, wird erwartet, dass sich Wortabet dazu verpflichte, wie bisher regelmäßig Andachten und Predigten zu halten. ${ }^{417}$ Doch dieser sieht sich in keiner Pflicht mehr gegenüber dem College. Er ist gern bereit, ab und an zu predigen, aber er sieht es als Angelegenheit „,for my own conscience, not for others to dictate“. 418

Seine Anstellung als Lektor dauert bis zum Jahr 1886, in den kommenden zehn Jahren hilft er immer wieder bei Engpässen aus. ${ }^{419}$ Als der Deutsche Theophilus Waldmeier mit Hilfe von Geldern aus Europa und Nordamerika 1896 eine psychiatrische Klinik in 'Așfūrīya eröffnet, wird Wortabet zum Präsidenten des Verwaltungsgremiums gewählt, in dem ebenfalls Missionare und angesehene Protestanten sitzen. ${ }^{420}$ Die angemessene Behandlung von psychischen Krankheiten ist bis zu diesem Zeitpunkt völlig unbekannt in Syrien, was die Eröffnung der Klinik umso

415 „A Report of the Faculty 1883 to the Board of Managers of the Syrian Protestant College“: ABC 16.8.2., Vol. 2., 76.

416 Wortabet an den Board of Managers (Beirut, 10.7.1883): AA.2.3.1.11.12.

417 James S. Dennis an die Fakultät des SPC (o. O., 27.11.1883). Es ist unklar, warum das Schreiben so spät datiert ist, da Wortabet bereits am 16. Juli 1883 auf dessen Inhalt gegenüber Dennis reagiert hat (s. u.).

418 John Wortabet an James S. Dennis (Beirut, 16.7.1883): AA.2.3.1.11.2.

419 SPC Jahresbericht (1888): ABC 16.8.2., Vol. 2, 107; SPC Jahresbericht (Juli 1890): ebd., 119; Penrose (1941), 38.

420 Jessup (1910b), 521-523: Die Institution ist die erste ihrer Art in Syrien und muss auf Spendenbasis aufrechterhalten werden, da es keine staatliche Unterstützung gibt. Patienten kommen aus allen Teilen Asiens und auch aus Europa. „The work is international and undenominational, and appeals to the liberal in all lands and of all forms of religious faith“ (ebd. 523). Jessup betont, dass die Einrichtung das Ergebnis christlich missionarischer Arbeit sei (ebd. 524). 
nötiger macht. ${ }^{421}$ Bis zu seinem Tode im Jahr 1909 unterhält Wortabet ebenfalls eine private Arztpraxis in der Zeytūn̄i Straße in Beirut. ${ }^{422}$

Nach etwa 20 Jahren Lehrtätigkeit bleibt Wortabet für den Board of Trustees das, was er nicht mehr sein wollte, ein ,native“. David S. Dodge, für seine scharfzüngigen Bemerkungen bekannt, äußert im Jahr 1886 - als Wortabets Lektoratsvertrag endet - gegenüber Bliss: „, do not keep him“. ${ }^{423}$ Einige Monate später lässt sich Dodge zu der abfälligen Bemerkung hinreißen: „What a blessing to be rid of the last of that half-hearted, half-educated (in the best sense), unwilling, unamerican, of missionary line of professors. “424

Anders denken über ihn die Kaiserswerther Diakonissen, in deren Waisenhaus er seit 1871, neben der Lehrtätigkeit am SPC, als Arzt arbeitet. In den 1880er Jahren vertritt er regelmäßig den leitenden Arzt des Krankenhauses Dr. L’Orange, der sich jeden Sommer in Europa aufhält. Als dieser seinen Dienst kündigt, sind Dr. William Van Dyck, Cornelius Van Dycks Sohn, und John Wortabet im Gespräch. ${ }^{425}$

\section{John Wortabet als Autor und Übersetzer}

In Anbetracht von John Wortabets Büchern, Artikeln und Übersetzungen wird deutlich, dass er ebenso vielseitig belesen und engagiert ist wie seine amerikanischen Kollegen. Durch seine Bildung hat er das Privileg, theologische, medizinische und auch kulturanthropologische Werke in der englischen und arabischen Sprache zu verfassen bzw. zu übersetzen. Zu seinem bekanntesten Buch im englischsprachigen Raum zählt das Kompendium Researches into the Religions of Syria (1860), das er noch in Hāṣbeiyā verfasst und in England schließlich drucken lässt. Es ist dem Autor darin ein Bedürfnis, durch das Studium von Originalquellen der Religionen des Nahen Ostens theologische Inhalte und den spirituellen Habitus der Religionsgemeinschaften darzustellen. Das Buch soll einen großen Beitrag zum Studium der orientalischen Religionen leisten und bisher dargestellte Irrtümer über die Religionen aus dem Weg räumen, wie es im Vorwort heißt. ${ }^{426}$ Wortabet widmet sich darin den griechisch-orthodoxen, griechisch-katholischen und maronitischen Kirchen, sowie dem sunnitischen, wahhabitischen, schiitischen (Metawileh) Islam, den Alawiten (Nusairiyeh) und den Drusen. Da Wortabet diese religionsgeschichtliche Studie innerhalb kürzester Zeit niederschreibt und vor dem Druck nicht einmal mehr Korrektur lesen kann, muss das geplante Kapitel über das Judentum ausbleiben.

421 Van Dyck (1853), 591: „Insanity is generally attributed to Satanic possession, and no remedies used for it, except confinement, exorcising, or a pilgrimage to the shrine of some saint."

422 D.S. (1938), 4.

423 David S. Dodge an Daniel Bliss (Washington, 29.4.1886): AA.2.3.1.5.3. (Auf dem Originaldokument befindet sich ein Fehler: statt 1886 steht 1866, was dem Inhalt nach jedoch völlig unmöglich ist.)

424 David S. Dodge an Daniel Bliss (o. O., 15.7.1886): zitiert in: Zahlan (1965), 114b. Zahlan führt hier an, dass sich der Brief im AUB Archiv befindet. Während der Recherchen war er jedoch nicht auffindbar.

425 Sophie Gräff an Julius Disselhoff (Beirut, 7.1.1887): AFKSK AKD 243.

426 Wortabet (1860), v. 
Jedoch schließt er seine Studien mit einer ausführlichen Analyse zum Protestantismus in Syrien ab. Nicht nur der Aufbau verrät, dass der evangelische Glaube als der für den Autor letztgültige anzusehen ist. Es ist das Ziel des Missionars und Theologen Wortabet, mit der Einführung in die verschiedenen Glaubensgemeinschaften zu zeigen, ,that all false creeds must ultimately give place throughout the world to the religion of Christ". ${ }^{427}$ Dabei verzichtet er zumeist, wenn auch nicht immer, auf eine offensive Polemik und möchte dem Leser zeigen, dass die Theologien, die er den anderen religiösen Quellen entnommen hat, per se den falschen Weg deutlich machen. ${ }^{428}$ Zwar verwendet er auch europäische und amerikanische Sachliteratur besonders für geschichtliche Darstellungen -, aber er ist durch seine Sprachkenntnisse und lokalen Kontakte in der Lage, Manuskripte, historische Dokumente und liturgische Schriften in griechischer und arabischer Sprache zu verwenden und daraus zu zitieren. ${ }^{429}$ Durch immer wiederkehrende bürgerkriegsähnliche Zustände im Libanongebirge gelingt es Franzosen, geheime theologische Schriften der Drusen zu entwenden. Aus diesem neuen Fund kann Wortabet nun sogar für sein Werk zitieren. ${ }^{430}$ Researches into the Religions of Syria ist keine simple Zusammenfassung europäischer Werke über den Orient, sondern versteht sich als deren Ergänzung und Korrektur. Durch eigene Erfahrungen, jahrzehntelange Beobachtungen und aus einer gewissen Perspektive der Erhabenheit, wie sie aus den Schriften der Missionare bekannt ist, werden die Mentalitäten der jeweiligen Konfessionen sowie ihr alltäglicher Umgang mit dem eigenen Glauben dargestellt. ${ }^{431}$ Sein Schlusskapitel über den Protestantismus kommt verständlicherweise ohne die Beschreibung der amerikanischen Mission nicht aus (,,we cannot do any justice to our subject without a constant reference to the actors whom it has pleased God to employ in this work"). ${ }^{432}$ Die negativen Erfahrungen mit dem American Board haben Wortabets Dankbarkeit gegenüber den Leistungen der Missionare (,the resources of all kinds which time has brought under their command are many and highly important") sowie seine tiefe religiöse Überzeugung keinesfalls gemindert. Anders als in den Darstellungen von Theologie und Liturgie in den anderen Kapiteln konzentriert sich Wortabet in diesem Abschnitt ausschließlich auf die Aktivitäten verschiedener evangelischer Missionen, um daran einen langen Essay über die dabei angewandten Strategien anzuschließen (1. Circulation of the Bible; 2. Preaching of the word; 3. Organisation of converts into churches; 4. Common schools; 5. The press; 6. Native agency; 7. Medical agency). Was die Punkte 3 und 6 anbelangt, so findet

427 Ebd., vi.

428 Ebd., 63-64: „In the preceding concise sketch of the errors of the Greek Church, we have rarely made a remark of our own on the important subjects at which we have glanced. We have preferred to let it speak from the books which hold a prominent and authoritative place."

429 Laut Zaydān veranlasst Wortabet nach der Veröffentlichung dieses Kompendiums die Herausgabe einiger religiöser Schriften dieser Konfessionen (Zaydān, 1982, 429).

430 Wortabet (1860), 328; Zaydān (1982), 426.

431 Zur Messe in der Rum-Orthodoxen Kirche schreibt er: „the service is read as fast as possible, giving the appearance of the utmost irreverence, and making the worship of God as senseless and formal as could be intentionally done“, (Wortabet, 1860, 69-70). Die Schiiten ,in their habits, dress, and mode of living, are by far the most filthy race in the country“, (ebd., 281).

432 Wortabet (1860), 360. 
der Autor sehr persönliche und kritische Worte, die sich deutlich auf die eigenen Erfahrungen mit dem ABCFM beziehen. Es gilt daher nicht nur, die Verbreitung des evangelischen Glaubens in Syrien als Rettung der dort lebenden Menschen darzustellen, sondern auch die Gefahren aufzuzeigen, die westlichen Missionaren in einer fremden Kultur und Syrern im Umgang mit einer wiederum für sie fremden Kultur begegnen. Diese Probleme trüben jedoch keineswegs die Zuversicht des Autors, dass eine solche Arbeit ihre Früchte tragen wird. Wenn die richtigen Voraussetzungen geschaffen sind, ${ }^{433}$ so könne er sagen,

that reformation begin[s] first with individuals, and then, by acting on small bodies, scattered here and there, reach and affect the whole mass. [...] But the issue of this matter does not lie altogether at the mercy of civilization, liberty, and knowledge: there is a gracious God above who has promised that the time shall surely come $[\ldots] .^{434}$

Wortabets Researches richten sich an ein englischsprachiges Lesepublikum und reihen sich somit in die damals sehr gefragte Literatur über den Vorderen Orient ein. Bemerkenswert ist die Analyse westlicher Missionspraktiken in Syrien, die erstmals aus der Perspektive eines „native“ sachlich dargestellt werden.

Im Zuge der amerikanischen Mission gibt es immer wieder Ansätze, Wörterbücher für die türkische, ${ }^{435}$ armenische ${ }^{436}$ und arabische ${ }^{437}$ Sprache zusammenzutragen. Nachfolgende Generationen von Missionaren, aber auch Philologen, sollen davon einen Nutzen haben. Wortabet, sein Sohn William Thomson sowie sein Kollege am SPC Harvey Porter erarbeiten daher ein ausführliches Englisch-Arabisches,

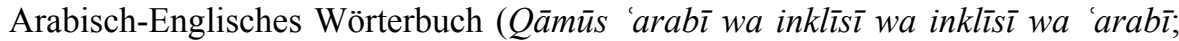
Ersterscheinung unbekannt), das bis heute in vielerlei posthum erschienenen Neuauflagen erhältlich ist. William Thomson, Wortabets Sohn und Hauptherausgeber des Lexikons, schreibt in seinem Vorwort:

The object of the present work is to supply the want, long felt by many, of an accurate Arabic-English Dictionary, which shall contain within a moderate compass, the words most in use among Arabic classical writers [...] it is hoped that Oriental Scholars will approve the result.

Kurz vor seinem Tod beteiligt sich John Wortabet an der englischen Buchserie Wisdom of the East, indem er eine Sammlung arabischer, persischer und ägyptischer Weisheitssprüche aus dem Koran und weiterer Weisheitsliteratur thematisch geordnet in einem Band herausgibt: Arabian Wisdom. Selections from the Arabic

433 Vor allem sind hierbei die Freiheit und Eigenverantwortlichkeit syrischer Protestanten gemeint, die ihnen von den Missionaren zugestanden werden müssen.

434 Wortabet (1860), 71.

435 MH 1826 (22), in: ROS 1, 345: Der Missionar William Goodell berichtet, dass er zusammen mit Bischof Dionysius Carabet ein Türkisches, ein Italienisch-Türkisches sowie ein TürkischItalienisches Wörterbuch erarbeitet.

436 John Wortabets Vater Gregory arbeitet zusammen mit William Goodell an einem ArmenischTürkischen Wörterbuch: vgl. „A brief memoir of Gregory Wortabet“: ABC 16.6.3., 26.

437 MH 22 (1826), in: ROS 1, 360: Pliny Fisk kann das geplante Englisch-Arabische Wörterbuch vor seinem Tod nicht mehr fertigstellen. Yuhannnā Abcāriūs (siehe Anhang II, Nr. 1) lässt in der American Mission Press die verkürzte Form eines Englisch-Arabischen Wörterbuchs drucken, die später von Van Dyck neu überarbeitet herausgegeben wird (siehe Anhang I). Das Erscheinungsjahr ist jedoch unbekannt: vgl. PBCFM (1896), Nr. 225. 
(1910) ${ }^{438}$ Bereits vor dieser Ausgabe hat sich Wortabet mit der Übersetzung von Weisheitsliteratur aus dem Englischen ins Arabische ${ }^{439}$ und Arabischen in Englische $^{440}$, aber auch mit talmudischer Weisheit befasst. Mit dieser Veröffentlichtung bekräftigt er das im Vorwort beschriebene Ziel der Buchserie: ,these books shall be the ambassadors of good-will and understanding between East and West - the old world of Thought and the new of Action".441

Nicht nur in medizinischen Gesellschaften ist Wortabet höchst engagiert. Als Mitglied der Syrischen Gesellschaft der Wissenschaften und Künste hält er u.a. eine Rede über das „Ausmaß des Wachstums der Wissenschaft in Syrien in diesem Jahrhundert und seine Ursachen“" (Miqdār ziyādat al- 'ilm fì Sūrīya fì had̄ā ğ̄l wa 'ilallahā $).{ }^{442}$ Zeitweise ist er sogar Präsident der 1882 gegründeten Wissenschaftlich-Orientalischen Gesellschaft (Mă̌ma 'at al- 'Ilmī al-ŠSarq $\bar{\imath})^{443}$. In der Jahresrede dieser Gesellschaft von 1884 redet Wortabet, nun selbst sehr erfahren im Bereich der Pädagogik, über Schulerziehung (Al-tarbìya al-madrasìya) und ihre große Bedeutung für die Zukunft Syriens. ${ }^{444}$

Wortabets ausgezeichnete Englischkenntnisse qualifizieren ihn auch für die Übersetzung von englischsprachiger, christlicher Literatur für die Missionsdruckerei in Beirut. Da es nur wenig Informationen über den Entstehungsprozess vieler Übersetzungen gibt, ist zu vermuten, dass Wortabet an weitaus mehr Büchern

438 Vor diesem Band existiert bereits eine Rohfassung, deren Kopien so schnell vergriffen sind, dass der Verlag den Neudruck eines noch ausführlicheren Bandes vorschlägt, der schließlich 1910, also zwei Jahre nach Wortabets Tod, herausgegeben wird: vgl. Y. Șarrūf, „Duktūr Yuhannā Wurtabāt, 1827-1908“, aus: al-Muqtațaf 30 (1905) und 34 (1909), zitiert in: Ȟūrī (1992), 184.

439 Wortabet (1910), 12: z. B. von Marc Aurelius, Shakespeare, Tennyson u. a.

440 Wortabet (1910), 12: Wortabet berichtet hier von einer kürzlich in arabischen Magazinen erschienen Serie von Weisheiten (,The Instruction of Ptah-Hotep“; ,Sadi's Scroll of Wisdom“), die mit viel Interesse von Christen, Muslimen und Juden in Ägypten und Syrien gelesen werden.

441 Wortabet (1910), 10.

442 In: Hūrrī (1990b), 33-35: Darin wird das Wachstum des Bildungsgrades und des Interesses für die Wissenschaft durch vielerlei Ursachen begründet: die wirtschaftliche Öffnung des Landes und dadurch die Begegnung mit anderen Kulturen; die Verbreitung von Büchern durch Druckereien im In- und Ausland; das zunehmende Interesse für Bildung in den herrschenden, aristokratischen Familien sowie die Schulgründungen. Am Ende appelliert Wortabet an die Syrer, dass es noch viel zu tun gebe, um die Entwicklung des Landes voranzubringen und dass alle daran arbeiten müssen, das Erwünschte zu erreichen (ebd., 35). Zur Syrischen Gesellschaft der Wissenschaften und Künste siehe Abschnitt I.2.4.

443 Die nur kurz bestehende Gesellschaft wird 1882 von Ya 'qūb Șarrūf und Fāris Nimr gegründet. Van Dyck und Wortabet stehen ihr als Präsidenten vor, bekannte Gelehrte wie William Van Dyck,

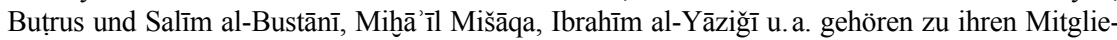
dern. So wie ihre Vorgängergesellschaften hat sie sich dem Dienst an der Wissenschaft verschrieben: vgl. Zaydān (1913), 73. Wortabet ist zudem auch Mitglied der 1867 gegründeten Wissen-

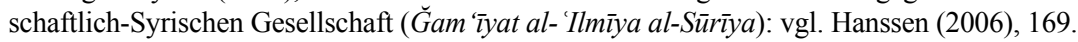

444 Abgedruckt in: al-Muqtațaf 8 (1884), 449-464, 543-544: In seiner Rede betont Wortabet die Bedeutung einer angemessenen Schulbildung für das Wohl der kommenden Generationen. Das Wichtigste sei dabei, gut ausgebildete Fachkräfte zu haben, die das Wissen nicht nur verständlich vermitteln sollen, sondern den Schülerinnen und Schülern auch als Mentoren dienen sollen. Bildungseinrichtungen in der Antike und im gegenwärtigen Europa gelten für Wortabet als Vorbilder für Unterrichtsinhalte und -methoden. 
mitarbeitet als in Anhang I dieser Arbeit angegeben wird. Ohne Zweifel ist er der Übersetzer folgender zwei theologischer Werke: Archibald Alexander, A Brief outline of the evidence of the Christian Religion (Dalīl al-șawāb ila șadiq al-kitāb), $1851{ }^{445}$ sowie Carl Heinrich von Bogatzky, Güldenes Schatz-Kästlein der Kinder Gottes (Kitāb al-hizānat al-ḍahabìyat usw.), 1870. ${ }^{446}$ Als Mediziner und Professor am SPC trägt er ebenfalls zur Produktion neuer Lehrbücher auf Arabisch bei, die das College dringend benötigt, ,[i]n 1867 there were practically no medical text books in Arabic" ${ }^{447}$ Somit verfasst Wortabet zwei umfangreiche Lehrbücher für die Fächer Anatomie (Al-taudīh fì uṣull al-tašrīhh, 1871) ${ }^{448}$ und Physiologie (Ușūl al-fisyūlüğiya, 1877$),{ }^{449}$ die er zum Teil aus dem Englischen übertragen hat. ${ }^{450}$ Darüber hinaus werden etliche arabische Aufsätze Wortabets vor allem im alMuqtataf $f^{451}$ und im medizinischen Journal des SPC $a$-T $T a b i ̄ b^{452}$ abgedruckt. Für englischsprachige Periodika verfasst er eine Serie über besondere Krankheiten wie Pest, Lepra, Typhus, Cholera etc. ${ }^{453}$

\section{Schlussbetrachtung}

John Wortabet eine bestimmte kulturelle Zugehörigkeit zuzuweisen fällt schwer. In seinem Heimatland Syrien wächst er von Anfang an in einem westlich geprägten Kontext auf, die ersten Jahre seiner Schulbildung sind auf Englisch und es folgen

445 Näheres dazu in Anhang I.

446 Wortabet übersetzt hier aus der englischen Fassung des Werkes, siehe dazu Anhang I.

447 Penrose (1941), 32.

448 PBCFM (1896), Nr. 195.

449 Ebd., Nr. 194.

450 Weitere Sachbücher von Wortabet für das SPC: „Abriss über die Teile des menschlichen Körpers“" (Muhtașar fí a 'ḍ̄à al-ğasad al-bašarī wa wad̄ā'ifihi), 1872; einen umfangreichen „Atlas der Anatomie und Physiologie“" (Ațlas fì l-tašrīh wa l-fisyūlūğiyā wa ma 'ahu muhtașir fì ā 'ḍā' al-ǧisd al-bašrī wa waẓ̄ î ifahā), 1878; sowie Ratgeber für ein allgemeines Lesepublikum: „Hygiene für den Erhalt der Gesundheit und als Maßnahme bei Krankheiten“ (Kifāyat al-

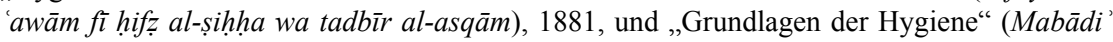
ilm al-ṣaha), o. J. Siehe dazu Anhang I.

451 Viele dieser Aufsätze enthalten vor allem moralische Aussagen: z. B. „Huṭba“ (Rede [zur Examensfeier am SPC]), in: al-Muqtataf 5/3 (1880), 57-61: Wortabet bekräftigt darin, dass man am SPC nicht nur Wissen erlerne, sondern für das Leben ausgebildet werde. Im Vordergrund stehen Gottesfurcht, Fleiß und Nächstenliebe statt Faulheit, Selbstliebe und Gewinnsucht. In „al-Tahd̄īb“ (Die Erziehung) spricht er vor jungen Menschen über die Erziehung des Körpers, des Verstandes sowie des Geistes. Körperliche Betätigung, gesunde Ernährung, Fleiß, Eifer und positive Charaktereigenschaften spielen hierbei die Hauptrolle: vgl. Wortabet (1905). Siehe auch „Wașāyā Mufĩda“ (Nützliche Empfehlungen), in: al-Muqtațaf 31/6 (1906), 505-506.

452 Die Zeitschrift wird ab 1874, zunächst unter dem Namen Ahbār al-tibbìya, herausgegeben und entwickelt sich bald zu einer umfangreichen Fachzeitschrift über medizinische Neuigkeiten im In- und Ausland sowie einer Plattform, in der sich praktizierende Ärzte austauschen können.

453 Y. Șarrūf, „Duktūr Yuhannā Wurtabāt, 1827-1908“, aus: al-Muqtațaf 30 (1905) und 34 (1909), zitiert in: Hūrī (1992), 184. Im Journal of the Royal Geographic Society of London 31 (1862) veröffentlicht Wortabet zudem eine Reisebeschreibung: „The Hermon, and the Physical Features of Syria and Northern Palestine“ (ebd., 100-108). 
das Studium von Medizin und Theologie bei amerikanischen Missionaren. Wortabet vermag es, sich fließend auf Englisch zu unterhalten und kleidet sich europäisch. Doch so sehr ihn die westliche Kultur auch geprägt hat, bleibt er für Europäer und Amerikaner ein „native“. Um jeden Preis will der ABCFM, dass sich Wortabet von seiner, eigenen' Kultur nicht entfremdet. Konvertiten sollen zwar in ihrer kulturellen Eigenständigkeit gefördert werden, beginnen sie jedoch, wie Wortabet und Bustānī, eigene Wege und Ansichten zu entwickeln, so wird jegliche Unterstützung durch den ABCFM abgelehnt. Durch seine Ausbildung stehen Wortabet alle Türen offen und er zeigt sich über viele Jahre unsicher, was seine Berufung für die $\mathrm{Zu}$ kunft anbelangt. Um 1850 hat sein langjähriger Mentor Eli Smith die Befürchtung, Wortabet könne die falsche Richtung einschlagen, wenn man ihn nicht ausführlich mit den verschiedenen Fachgebieten der Theologie vertraut mache, „sufficiently to give his thoughts a right direction". 454

Warum sich John Wortabet 1860 gerade für die Judenmission in Aleppo bewirbt, ist fraglich. Bisher ist dieser kein Erfolg unter den Juden beschert und selbst in seinem 1860 veröffentlichten Buch Researches into the Religions of Syria beschreibt er zwar etliche Missionen in dieser Region, jedoch nicht die der UPC. ${ }^{455}$ Seine Bewerbung ist zu diesem Zeitpunkt bereits bei der UPC eingegangen und Wortabet wird vermutlich schon vorher Kontakt mit dem schottischen Missionar Brown in Aleppo aufgenommen haben. Kann die Bewerbung nach Schottland als Flucht vor dem ABCFM gewertet werden? Wortabets jahrelanger Wunsch nach Großbritannien zu reisen, hängt aber auch mit seinem Bruder Gregory zusammen, der schon Anfang der 1850er Jahre in die USA und nach England reist und ab ca. 1855 Medizin in London studiert. ${ }^{456}$ Wortabet sehnt sich nach einer beruflichen Weiterentwicklung, die es für ihn in Syrien nicht gibt.

Als Arzt und Lehrer findet er schließlich seinen Platz in der syrischen Gesellschaft. Seine Patienten schätzen an ihm, dass er jeden behandelt, auch wenn der Patient nicht in der Lage ist, dafür zu zahlen. ${ }^{457}$ Bescheidenheit, Fleiß, Gottesfurcht und Nächstenliebe sind Botschaften, die er seinen Studierenden mit auf den Weg gibt. Nur wer sein Geld ehrlich verdient und sich dabei nicht selbst verliert, werde ein erfolgreiches Leben haben, so Wortabet. Wohltätige Menschen sind diejenigen, die „Säulen des Wissens“ (,'a 'midat al- 'ilm“) errichten, Schulen, Krankenhäuser sowie Armenunterkünfte bauen und damit die Zivilisation voranbringen (,yarfa al-tammadun"). ${ }^{458}$ Wortabet zeigt sich überaus dankbar für das, was Missionare in Syrien geleistet haben.

Dass seine Kinder auch das Privileg einer hohen Ausbildung bekommen, ist für John Wortabet selbstverständlich. Nachdem die UPC die Förderung seiner zwei Söhne (vermutlich Henry und Erwin) abgelehnt hat, ist Wortabet wohl erst mit seiner Anstellung am SPC in der Lage, ihr Medizinstudium in Großbritannien

454 Smith an Anderson (Beirut, 17.6.1851): ABC 16.8.1., Vol. 5 (199).

455 Marten (2006), 60 (Anm. 244); Wortabet (1860), 358-368.

456 Smith an Young (Beirut, 21.7.1855): ABC 60 (105), (HHL).

457 Zaydān (1903), 428; Y. Șarrūf, „Duktūr Yuhannā Wurtabāt, 1827-1908“, aus: al-Muqtațaf 30 (1905) und 34 (1909), zitiert in: Hūrīi (1992), 183.

458 Wortabet (1895), 5. 
zu finanzieren. ${ }^{459}$ Während sein Sohn Henry ab 1872 als Lehrer für Englisch und Latein am SPC eingestellt wird, ${ }^{460}$ gehen zwei seiner Töchter in die Ausbildung bei den Kaiserswerther Diakonissen, ${ }^{461}$ die 1860 eine Waisenanstalt in Beirut errichten, um junge, syrische Mädchen, z. T. auch Halbwaisen, zu Schwestern auszubilden. ${ }^{462}$ Zudem gründen die Schwestern 1864 die Höhere Töchterschule in Beirut, ein Internat, in dem sowohl Mädchen als auch Jungen ausländischer Diplomaten und Geschäftsleute sowie Kinder der neuen syrischen Mittelklasse aufgenommen werden. ${ }^{463}$ Jahrzehntelang unterhält er guten Kontakt zu den deutschen Schwestern, da er neben seiner Tätigkeit als Arzt im Preußischen Krankenhaus auch für die Diakonissen als Hausarzt arbeitet. ${ }^{464}$ Als die Kaiserswerther ihr 25-jähriges Jubiläum in Syrien feiern, gehört Wortabet zu den Festrednern. ${ }^{465}$ Zum Tod Wortabets weiß die Diakonissin Sophie Gräff zu berichten, dass eine seiner Töchter, die in England zur Krankenschwester ausgebildet wurde, ihn bis zum Ende gepflegt habe. Seine anderen Kinder sind „,bis nach Indien hin“ zerstreut. ${ }^{466}$ Bei Wortabet kann man gewiss von Multikulturalität sprechen: Er ist das Kind eines Armeniers und einer Syrerin, wird von den Amerikanern ausgebildet und nimmt ca. in den 1870er Jahren die britische Staatsbürgerschaft an ${ }^{467}$ Die Vorzüge westlicher Ausbildung möchte er schließlich auch seinen Kindern nicht vorenthalten. In Beirut verlebt er als erfolgreicher Arzt die letzten Jahrzehnte seines Lebens und scheint damit die Verbindung zu seiner Heimat zwar formal, nicht jedoch emotional aufgegeben zu haben. Nach seinem Begräbnis berichtet die Diakonissin Sophie Gräff: „Das Leichenbegräbnis, an dem auch viele Moslems Teil nahmen, zeugte davon, in welchem Ansehen der gute, alte Herr hier stand und wie ihm die allgemeine Achtung und Liebe fast der ganzen Stadt zu Teil wurde.“468

1913 werden in einem feierlichen Rahmen die Büsten von John Wortabet und Cornelius Van Dyck von Lehrenden und ehemaligen Studierenden enthüllt. Ya'qūb Șarrūf, einst Schüler der beiden und später Kollege, äußert sich in seiner Rede über die Charaktereigenschaften des Syrers mit britischem Pass: Während Van Dyck dem Orient zugetan war und die arabische Sprache beherrschte, war

459 N. N. (1909), 70. Zu den Söhnen siehe Anm. 263 in dem Teilkapitel.

460 „Minutes of General Faculty, 1867-1887“ (6.11.1872): AA.2.4.3.

461 Louise Kayser an Julius Disselhoff (Beirut, 3.10.1890): AFKSK AKD 245.

462 Kaminsky (2010), 33-34.

463 Hauser (2015), 253, 259.

4641902 beendet er seine Hausbesuche im Waisenhaus: vgl. John Wortabet an Wilhelm Zoellner (Beirut 31.12.1902): AFKSK AKD 246.

465 Hedwig Francke an Julius Disselhoff (Beirut, 29.11.1885): AFKSK AKD 243.

466 Sophie Gräff an Bertha Kuhr (Beirut, 12.12.1908): AFKSK AKD 243.

467 D. S. (1938), 4. 1872 lässt Wortabet vier seiner Kinder im britischen Konsulat in Beirut registrieren, was darauf hindeutet, dass er die britische Staatsbürgerschaft angenommen hat: vgl. [British] Public Record Office: FO 615/5, zitiert in: Lindner (2009), 259 (Anm. 209). In den Protokollen der Anglo-American Congregation wird er als englischer Vertreter im „Pastor's Committee“ angegeben: „Minutes of the Meeting of the Anglo-American Congregational Committee held 30 March 1871“, in: AAC Protokolle (1868-1891), 19: NEST/SC.

468 Sophie Gräff an Bertha Kuhr (Beirut, 12.12.1908): AFKSK AKD 243. 
Wortabet dem Westen zugetan und beherrschte die englische Sprache fehlerfrei. ${ }^{469}$ Genauso wie Van Dyck strebte auch Wortabet nach der Wahrheit, jedoch wollte er sie nicht so vehement gegen die Anhänger des ,Bösen“ durchsetzen (,lam jakun šadìd al-wața' hu 'ala ahl al-šir"), wie es die Amerikaner taten. In vielerlei Hinsicht seien sich Van Dyck und Wortabet sehr ähnlich gewesen: in ihrer Wissenschaft und

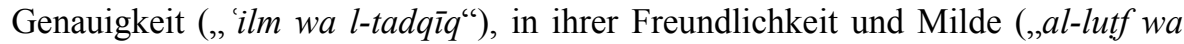
l-da' $\left.a^{\prime c}\right)$, in der Liebe zur Wahrheit und Gottesfurcht (,muhabat al-haq wa hauf Allāh") sowie in ihren guten Taten (,'amal al-heyr"). ${ }^{470}$ Bedauerlicherweise ist nicht viel über die Art der Beziehung dieser beiden Missionsärzte bekannt. Über Jahrzehnte kreuzen sich ihre Wege, jedoch fehlt es an persönlichen Briefen.

In einem Artikel über John Wortabet in der Zeitschrift der Amerikanischen Universität Beirut, Al-Kulliyah von 1936 äußert der Autor sein Bedauern darüber, dass man zu einer der wichtigsten Gründungsfiguren des SPC kaum Information finde. ${ }^{471}$ Noch zu Lebzeiten lehnt es Wortabet vehement ab, dass Ya 'qūb Șarrūf und andere ehemalige Studenten eine Biografie über ihn verfassen. ${ }^{472}$ John Wortabet, der erste syrisch-protestantische Pastor, bleibt ein leiser Charakter in der Geschichte der Syrienmission.

469 Șarrūf in: N. N., Tamḍalā al-marḥūmeyn al-Duktūr Fān Dayk wa 1-Duktūr Wurtabāt, zitiert in: Hūrūi (1992), 178.

470 Ebd., 179.

471 D. S. (1938), 4.

472 Y. Șarrūf, „Duktūr Yuḥannā Wurtabāt, 1827-1908“, aus: al-Muqtațaf 30 (1905) und 34 (1909), zitiert in: Hูūrī (1992), 183. 


\section{FAZIT}

\section{ZWISCHENMENSCHLICHE INTERAKTION IM FOKUS MODERNER MISSIONSGESCHICHTE}

I do not desire they should become English in their [Roman Catholic] religion; no, nor do I desire this of you; but I desire that both you and they, and all the inhabitants of the earth, should become true and sincere Christians, according to the Gospel of our adorable Lord and Saviour Jesus Christ. ${ }^{1}$

Diese Worte schrieb der in Syrien stationierte amerikanische Missionar Jonas King im Jahr 1825. Der Text wurde später erneut aufgelegt und in der American Mission Press 1860 gedruckt. Es war das erste Schriftzeugnis der Mission, das die eigenen konfessionellen Standpunkte gegenüber den lokalen, christlichen Kirchen darstellte. ${ }^{2}$

Der ABCFM war in Syrien 47 Jahre darum bemüht, das von King benannte Ziel mit allen Mitteln missionarischer und zivilisatorischer Arbeit zu erreichen. Welchen Einfluss die Arbeit der Amerikaner in der Levante auf die kulturtransformatorischen Prozesse hatte, wurde hier ausführlich dargestellt. ${ }^{3}$ Am Ende waren es etwa 1000 Konvertitinnen und Konvertiten, die als „true and sincere Christians“ die syrisch-protestantische Kirche aufbauten. Heute sind evangelische Christen ein fester Bestandteil religiöser Vielfalt und Koexistenz im Libanon und in Syrien. Nimmt man alle protestantischen Missionen (d.h. amerikanisch, englisch, irisch, schottisch, niederländisch und deutsch) zusammen, so gab es um die Jahrhundertwende im Nahen Osten 395 einheimische Gemeinden, darunter 34606 Gemeindemitglieder und 94428 Anhänger, 975 Grund- und Oberschulen, 15 Colleges, in denen 64000 Studierende untergebracht waren, sowie 49 Krankenhäuser und 63 Ambulanzen, in denen etwa 650000 Patientinnen und Patienten behandelt wurden. ${ }^{4}$ Der Einfluss misst sich jedoch nicht nur an Zahlen, er fand auch im Alltag statt. In den Schulen galt die Disziplinierung nach westlichen Maßstäben, neue Lehrmethoden, -materialien und Unterrichtsfächer wurden eingeführt. Missionarsfrauen galten als

1 MH 24 (1826), in: ROS 2, 38.

2 Ellis (1894), 860; Badr (1992), 97; Roper (1998), 53, 56. As' ad al-Šidyāq, einer der ersten Konvertiten (s. Anhang II, Nr. 60), übersetzte die Schrift unter dem Titel Widā' Yunus Kìn ila aḥbābihi fi filasțin wa sūrìya (Abschied des Jonas King von seinen Freunden in Palästina und Syrien) in die arabische Sprache.

3 Matthews/Akrawi (1949), 407: „Lebanon has the highest rate of literacy among the Arab states. [...] The second remarkable fact is that this comparatively advanced stage has been accomplished largely through the efforts of private and foreign schools rather than through publicly supported schools."

4 Makdisi (2010), 79-80. 
Vorbilder eines gut organisierten protestantischen Haushalts. Kinder wurden in den Schulen mit neuen Wertesystemen konfrontiert, die sich im Elternhaus mit den traditionellen Ansichten vermischten. Besonders kritisch betrachteten Einheimische und Amerikaner in gleicher Weise die äußerliche Europäisierung derjenigen Syrerinnen und Syrer, die sich westlich kleideten und kaum noch Arabisch sprachen. Trotz allem veränderte sich auch die arabische Sprache, sie wurde flexibler und leichter einsetzbar und rückte zunehmend ins Zentrum schriftlicher Medien. Das Arabischsein, das Bewusstsein, Syrerin oder Syrer und nicht mehr nur Teil des Osmanischen Reiches zu sein, standen mehr und mehr im Vordergrund. ${ }^{5}$

Aus Sicht der heutigen interdisziplinären Missionsforschung genügen verallgemeinernde Aussagen nicht, um die Syrienmission des ABCFM und die darin implizierte kulturelle Arbeit zu analysieren. Zwischenmenschliche Interaktionen und Reaktionen bilden das eigentliche Zentrum missionarischer Arbeit. Gegenwärtige missionsgeschichtliche Untersuchungen orientieren sich zunehmend an einzelnen Missionaren oder einheimischen Konvertiten, deren Biografien nicht in Vergessenheit geraten sollten. Mithilfe dieses Ansatzes ergab sich in dieser Forschungsarbeit ein deutlich klareres Bild der Syrienmission, mit all ihren strukturellen und theologischen Problemen.

$\mathrm{Zu}$ den wichtigen Ergebnissen dieser Untersuchung gehört, dass die Entsendung der ABCFM-Missionare in das osmanische Syrien viele Möglichkeiten der Weiterentwicklung und Selbstverwirklichung bot. Dies wurde besonders durch die Erwartung an die Missionare, die Heimat hinter sich zu lassen, verstärkt: Eli Smith, zurückhaltend, sensibel, fleißig, kompromissbereit und dennoch ehrgeizig, wurde aufgrund seiner außerordentlichen Sprachkenntnisse eingestellt, um den arabischen Buchdruck zum wichtigsten Hilfsmittel der Syrienmission werden zu lassen. Smith entdeckte dabei seine Liebe für die arabische Sprache und widmete ihr mehr Zeit als es dem ABCFM und vielen seiner Kollegen in Syrien recht war. Alles, was er leistete, musste bis zur Perfektion ausgeführt werden. Smith erwies sich darüber hinaus als Mittler zwischen den Kulturen, für viele Syrer wurde er zum Mentor und Freund.

Cornelius Van Dyck war vielseitig gebildet, von Haus aus Mediziner, temperamentvoll und selbstbewusst. Es war ihm schon in den frühen Jahren der Syrienmission anzumerken, dass er seinen Weg für sich noch nicht gefunden hatte. Er versuchte, gleichzeitig theologisch und wissenschaftlich zu arbeiten, erkannte jedoch, dass die Verbindung von frommem Glauben und freiem, rationalen Denken innerhalb der Mission kaum möglich war. Sein Platz war im Studierzimmer und das Beobachten der Sterne mit dem Teleskop auf dem Dach seines Hauses wurde ihm zum wirklichen Ausgleich. Im Zusammenfließen von westlichem Denken und wissenschaftlich-arabischer Literatur der vergangenen Jahrhunderte entdeckte er seine Passion. Auch in seiner Persönlichkeit fanden die Kulturen zueinander. Bereits früh begann er, sich bei bestimmten Gelegenheiten im traditionellen Gewand zu kleiden, rauchte Wasserpfeife, zitierte frei arabische Reime und Weisheitssprü- 
che. Am Ende wurde Syrien zu seiner wahren Heimat und Syrerinnen und Syrer sagten: „He is one of us. ${ }^{\circ 6}$

Während der ABCFM seine Vorstellung des Miteinanders, des Dialogs auf ein millenaristisches Weltbild und somit den Versuch aufbaute, möglichst viele Seelen durch die Verbreitung der christlichen Botschaft zu retten, traten Eli Smith und Cornelius Van Dyck aus persönlichem Interesse in den Dialog. Sie eigneten sich an, was man heute als kulturelle Sensibilität betrachten könnte, jedoch jeder auf seine Art und Weise. ${ }^{7}$

Auch Buțrus al-Bustānī und John Wortabet vollzogen im Rahmen der Syrienmission eine individuelle Weiterentwicklung, wie diese Untersuchung gezeigt hat. Durch den Kontakt mit kulturfremdem Wissen konnten sie die eigene Gesellschaft von einer Außenperspektive betrachten, ohne sich selbst völlig zu verleugnen. Sie wurden sozusagen zu indigenen cultural brokers. ${ }^{8}$ Sie waren hoch gebildet, charakterstark und selbstbewusst - Eigenschaften, die sich durch die Zusammenarbeit mit der Mission nur verstärkten. Beide haben gezeigt, dass sie Willens waren, ihre Zukunft als evangelische Christen selbst zu bestimmen, auch wenn dies bedeutete, sich von der amerikanischen Mission zu distanzieren. Erst durch diesen Schritt war es ihnen möglich, eine unabhängige und sehr erfolgreiche Karriere zu absolvieren. In späteren Veröffentlichungen machten sie stets auf die fruchtbare Begegnung mit den Missionaren und deren Engagement aufmerksam, aber sie übten auch Kritik an bestimmten missionstheologischen Standpunkten. Durch das Augenmerk auf individuelles Denken sowie auf die Entwicklung einer eigenen Persönlichkeit innerhalb der Glaubensgemeinschaft stand evangelischer Glaube auch für Individualismus und Subjektivität ${ }^{9}$ - bis dahin unbekannte Größen in der arabischen Gesellschaft, in der die Familie und die Gemeinschaft das Zentrum bildeten. In die syrisch-protestantische Glaubensgemeinschaft aufgenommen zu werden, bedeutete, auf eine persönliche Erfahrung der religiösen Wiedergeburt zurückzublicken, eine individuelle Beziehung zu Gott aufzubauen und sich persönlich mit der Heiligen Schrift auseinanderzusetzen. ${ }^{10}$ Auch im Bildungsbereich wurde die individuelle Beschäftigung mit Wissen und somit die eigene Meinungsbildung über unterschiedliche Sachverhalte gefördert.

Auf diese Weise wurden die Biografien der beiden syrischen Männer stark beeinflusst: Bustānī gehörte zur ersten Generation syrischer Protestanten, die in einem anderen religiösen und sozialen Kontext aufwuchs und in einheimischen Bildungseinrichtungen ausgebildet wurde. Wortabet hingegen gehörte der zweiten Generation an und wurde sozusagen in die evangelische Gemeinschaft hineingeboren. In der kulturellen Renaissance Syriens, der nahḍ, nahm Bustānī eine Schlüsselposition ein, in der er das Printmedium, mit dem er durch die Mission vertraut gemacht

6 Jessup (1910a), 107.

7 Einen verallgemeinernden Blick darauf hat Habib Badr. Seiner Meinung nach waren die Missionare in ihrer Ideologie und in ihren Pflichten gegenüber dem ABCFM gefangen, sodass sie kulturell unsensibel blieben: vgl. ders. (1992), 308-309.

8 Comaroff/Comaroff (1997), 79.

9 Wu (2014), 80-81.

10 Womack/Lindner (2014), 143. 
wurde, richtig einzusetzen wusste. Wie bei Smith und Van Dyck ging es Bustānī ebenso um den Fortschritt der arabischen Gesellschaft und Kultur, allerdings unter dem Aspekt der Liebe zum Vaterland (hubb al-watan) und nicht allein durch den Glauben an das wahre Christentum. Folgt man Andersons Theorie, so hat sich Bustani nie „de-nationalisiert“, im Gegenteil. Einige Jahre nachdem seine Anstellung im amerikanischen Konsulat endete, musste er das Zertifikat zurückgeben, das ihm ausländisches Protektorat gewährt hatte. Bustānī äußerte seine Erleichterung über das Aushändigen des Dokumentes in einem Artikel der Zeitung al-Ğanna und bekräftigte schließlich, dass er es ablehnte als Ausländer im eigenen Land zu leben. ${ }^{11}$

Im Fall von Wortabet ist dies jedoch anders. Der frühe Tod seines Vaters sowie die westlichen Bildungsideale, mit denen Wortabet von Kindheit an konfrontiert war, mögen dazu beigetragen haben, dass er sich seiner Heimat weniger verbunden fühlte als Bustānī. Er erkannte bald, dass er als syrischer Protestant niemals ein erfolgreicher Arzt und Missionar werden könnte, der ausländischen Kollegen auf Augenhöhe begegnete. Obwohl er die gleiche Ausbildung erhielt, dieselben Aufgaben erfüllte und fließend Englisch und Arabisch sprach, wurde ihm aufgrund seiner Nationalität nicht derselbe Status und damit auch nicht dieselbe Bezahlung und Unabhängigkeit zuteil. Trotz guter Erfahrungen mit der schottischen Mission in Aleppo, erschien es ihm als notwendige Konsequenz, in den 1870er Jahren die britische Staatsbürgerschaft anzunehmen. Nach seiner Rückkehr nach Beirut 1867 wurde er nicht Mitglied der einheimischen Beirut Church, sondern trat der AngloAmerican Congregation bei. Im dortigen „Pastor's Committee“ engagierte er sich als britischer Reverend. Das Jubiläumsheft der American Mission Press von 1922 führte ihn schließlich als ausländischen Übersetzer neben Van Dyck, Jessup und vielen anderen an. ${ }^{12}$ Wortabet vereinte in sich verschiedene kulturelle Einflüsse und äußerte sich nie darüber, wo er seine wahre Heimat sah.

Der Erstkontakt amerikanischer Missionare mit der syrischen Kultur hat die amerikanisch-arabischen Beziehungen nachhaltig geprägt, und durch die herausragenden Arbeiten von Smith, Van Dyck und anderen engagierten Missionaren auch im positiven Sinne. Nicht zuletzt durch die Dominanz der protestantisch-frommen Sichtweise auf die ,unzivilisierte" Welt, blieb die amerikanische Missionsarbeit eine Gratwanderung zwischen kulturimperialem Verhalten und kulturellem Austausch, wobei es sich nie um ein uneingeschränktes Geben und Nehmen zwischen den Kulturen handelte, da die eine der anderen von Anfang an überlegen war. In den Missionen des 19. Jh.s ging es zwar um die „Gleichmachung“ im Glauben, jedoch nicht um die Gleichbehandlung in allen weltlichen Belangen. Die Aufrechterhaltung einer gewissen Hierarchie war Garant für die Rechtfertigung des Missionsunternehmens. Jeder erfolgreiche und beruflich unabhängige Konvertit wurde zum Störfaktor der eigenen Autorität. ${ }^{13}$ War ein syrischer Protestant bspw. in einem

11 „La yarg̉ub fī an yakūn ağnabīyan fī wațanihi“, so Dāya (2008) nach einem nicht genau datierten Artikel aus al-Ğanna.

12 „Minutes of the Meeting of the Anglo-American Congregational Committee held 30 March 1871“, in: AAC Protokolle (1868-1891), 19: NEST/SC; PBCFM (1923), 42.

13 Bhabha (2000), 131. 
weltlichen Beruf sehr erfolgreich, so wurde stets der Verlust seines Glaubens durch äußere Einflüsse befürchtet. ${ }^{14}$ Van Dyck und Smith haben gezeigt, dass nicht jeder Missionar diese Standpunkte vertrat, und kamen nach jahrelanger Zusammenarbeit mit den native helpers zu einem anderen Schluss. Was sie leisteten und schriftlich festhielten führte zwar einerseits zu einem Wendepunkt im amerikanischen Denken über die arabische Welt, ${ }^{15}$ sodass Kooperationen und Freundschaften zwischen Missionaren und der einheimischen Bevölkerung keine Seltenheit mehr waren. ${ }^{16}$ Andererseits sollte es noch einige Jahrzehnte bis in das 20. Jh. hinein dauern, bis der Anspruch der syrischen Protestanten auf Eigenverwaltung und gleichberechtigte Behandlung unter amerikanischen Missionaren Gehör fand. ${ }^{17}$

Der interkulturelle Kontakt sollte schließlich auch aus einem weiter gefassten Blickwinkel betrachtet werden. Im globalen Kontext der Geschichte leisteten die Missionare einen wertvollen Beitrag zum zunehmenden Austausch von Kulturgütern und der damit einhergehenden Globalisierung. ${ }^{18}$ Die Vernetzung von institutionalisiertem Wissen durch Missionen ist daher zu einem wichtigen Thema der Interkulturellen Theologie geworden und die Möglichkeiten für weitere Untersuchungen darüber sind längst nicht ausgeschöpft.

Aus heutiger Sicht ist Andersons Forderung, die „De-Nationalisierung“ der Einheimischen in jedem Fall zu vermeiden - auch wenn sie während der Syrienmission zu Widersprüchen führte - ein guter Ansatz für den interkulturellen Dialog. Sein Gegenüber an den jeweiligen Kulturgütern teilhaben zu lassen, ohne dabei die Entfremdung des Anderen von der eigenen Herkunft zu forcieren, ist meines Erachtens die wichtigste Grundlage des interkulturellen Miteinanders.

14 So wie im Fall des amerikanischen Vizekonsuls in Tripoli Antonius Yannī (s. Anhang II, Nr. 73) oder bei John Wortabet, der Ende der 1840er Jahre für etwa ein Jahr als Arzt nach Tripoli ging und seine theologischen Studien unterbrach.

15 Makdisi (2010), 47.

16 Bonk (1989), 44; McGilvary (1920), 18: „The American Mission could never have been what it is were there not men like [Assad Kheirallah] and his predecessors [...]. Such men as Assad Kheirallah, and the pioneers of the Protestant faith in Syria are the most brilliant examples of what a liberal and tolerant religious education can accomplish with such gifted and plastic materials as the Syrian race."

17 Deanna Ferree Womack widmet sich in ihrer Dissertation eingehend dieser Thematik und analysiert bisher kaum beachtete Quellen der Syrienmission um die Jahrhundertwende: vgl. Womack (2015), 98-160.

18 Holtwick (2009), 247; siehe auch Dunch (2002), 320. 


\title{
BIBLIOGRAFIE
}

\section{ARCHIVE}

\subsection{Archiv des ABCFM in der Harvard Universität/Cambridge, USA (ABC)}

- Originalmanuskripte in der Harvard Houghton Library (HHL)

\author{
$\mathrm{ABC} 1$ - Letters to domestic correspondents \\ $\mathrm{ABC} 2$ - Letters to foreign correspondents \\ $\mathrm{ABC} 10$ - Letters received from domestic correspondents \\ ABC 30 - Rufus Anderson, Vol. 10: Memorandum of Discussions with the Missionaries during my \\ visit to the Levant in 1843-1844 \\ ABC 50 - Eli Smith - Arabic Papers, ca. 1826-1857; Syria \\ ABC 60 - Eli Smith Papers, 1819-1869 \\ ABC 76 - Personal Papers / Daniel Bliss \\ ABC 77.1 - Biographical Collection: Collective and Individual Biography / Cornelius Van Dyck \\ $\mathrm{ABC} 88$ - A brief Chronicle of the Syriamission \\ - Manuskripte auf Mikrofilm in der Harvard Lamont Library \\ ABC 16.5.1, Vol. 1 - Communications of the Mediterranean, 1817-1837 \\ ABC 16.6.3, Vol. 3 - Palestine Mission, 1824-1830 (Letters, Journals) \\ ABC 16.8.1, Vol. 8.1. - Records of the Syria Mission and the Holy Land, 1836-1870 \\ ABC 16.8.1, Vol. 18 - Syria Mission, 1830-1870 \\ ABC 16.8.2, Vol. 2 - Annual Reports of the Boards of Managers of the Syrian Protestant College
}

\subsection{Archiv der Amerikanischen Universität Beirut / Jafet Library (AA)}

AA.2.3.1./Daniel Bliss Collection

AA.6/John Wortabet

AA.6/Cornelius Van Allen Van Dyck

AA.6.1./Butrus al-Bustani

AA.7.1./American Mission Press Beirut

\author{
1.3. Archiv der Near East School of Theology, Beirut (NEST/SC) \\ Anglo-American Congregation, Records (1868-1905) (=AAC Protokolle)
}

\subsection{Archiv der National Evangelical Church Beirut (NECB)}

National Evangelical Church of Beirut, Siğil al-waqā ' $i$ 'umdat kanīsa al-inğilīya al-wațanīya, min 19 ayār 1848 ilā 9 ayār 1922 (Verzeichnis der Protokolle des Komitees der Nationalen Evangelischen Kirche, vom 19. Mai 1848 bis 9. Mai 1922) (=NECB Protokolle) 


\subsection{Archiv der National Library of Scotland (NLS)}

MS 7642-7647 - Briefe von Andrew Somerville (UPC) an John Wortabet UPC-GMBM - United Presbyterian Church of Scotland, General Minute Book Missions

1.6. Archiv der Fliedner-Kulturstiftung Kaiserswerth, AKD, Düsseldorf (AFKSK AKD) 243, 245, 246 - Briefe der Diakonissen Hedwig Francke, Sophie Gräff, Louise Kayser sowie von John Wortabet (Mit Erlaubnis der Kulturstiftung zur Verfügung gestellt von Dr. Julia Hauser, Kassel)

\section{DEUTSCH-, ENGLISCH- UND ARABISCHSPRACHIGE ZEITSCHRIFTEN DES 19. JAHRHUNDERTS}

Ahbbār 'an Intišār al-Inğīl fī Amākin Muhntalifa (später: Al-Našra al-Šahrīya; al-Našra al-Usbū 'īya), u. a. hrsg. von Cornelius Van Dyck, William Eddy, Henry Harris Jessup, Beirut 1863-.

Al-Ǧinān, hrsg. von Buțrus und Salīm al-Bustānī, Beirut 1870-1886.

Al-Muqtațaf, u. a. hrsg. von Ya qūb Șarrūf, Fāris Nimr, Šahīn Makārīyūs, Beirut und Kairo 18761951.

Journal of the American Oriental Society, hrsg. von der American Oriental Society, Boston 1843/1849, 1851-. (hier: JAOS)

Mağmū' Fawā' id, hrsg. von Eli Smith, Beirut 1851-1856.

The Missionary Herald, hrsg. vom American Board of Commissioners for Foreign Missions, Boston 1819-. (hier: MH)

Zeitschrift der Deutschen Morgenländischen Gesellschaft, hrsg. von der Deutschen Morgenländischen Gesellschaft, Leipzig 1847-. (hier: ZDMG)

\section{ABCFM UND PBCFM PUBLIKATIONEN}

ABCFM (1810): The Panoplist and the Missionary Magazine United. For the Year Ending, June 1, 1810, Volume II. New Series, Boston.

- (1810-1897): Annual Report of the American Board of Commissioners for Foreign Missions, Cambridge.

- (1834): First Ten Annual Reports of the American Board of Commissioners for Foreign Missions, with other Documents of the Board, Boston.

- (1835): Constitution, Laws, and Regulations of the ABCFM, Boston.

- (1853): Missionary Tract, No. 10, The Missionary Age. A Half Century Discourse, by one of the Secretaries of the Board, in: Missionary Tracts of the American Board of Commissioners for Foreign Missions, Boston.

- (1856): Minutes of the Special Meeting of the Syrian Mission, held in September and October, 1855, on Occasion of the Visit of one of the Secretaries, Boston.

- (1863): Memorial Volume of the First Fifty Years of the American Board of Commissioners for Foreign Missions, Fifth Edition, Boston.

PBCFM (1896): Illustrated Catalogue and Price List of Publications of the American Mission Press of the Presbyterian Board of Foreign Missions, Beirut, Syria.

- (1923): Centennial of the American Press of the Board of Foreign Missions of the Presbyterian Church in the U.S.A., Beirut. 


\section{WEITERE LITERATUR}

Anderson, R. (1838): Missionary Schools, in: American Biblical Repository 11, 87-113.

- ders. (1844): Report to the Prudential Committee of a visit to the missions in the Levant, Boston.

- ders. (1869): Foreign Missions: Their Relations and Claims, New York.

- ders. $(1872 \mathrm{a}+\mathrm{b})$ : History of the Missions of the American Board of Commissioners for Foreign Missions to the Oriental Churches, 2 Bde., Boston.

Abu-Husayn, A. R. (1998): The „Lebanon Schools“ (1853-1873): A Local Venture in Rural Education, in: The Syrian Land: Processes of Integration and Fragmentation. Bilād al-Shām from the 18th to the 20th Century, hrsg. von T. Philipp / B. Schaebler (= Berliner Islamstudien 6), Stuttgart, 205-219.

Abunassr, M. B. (2013): A Making of Ras Beirut: A Landscape of Memory for Narratives of Exceptionalism, 1870-1975 (unveröffentlichte Dissertation).

Al-Aḥmar, N. (2002): Madrasa 'Abeih al-inğilīya wa atarha al-taqāfì 'ala lubnān (Die evangelische Schule in 'Abeih und ihr kultureller Einfluss auf den Libanon), in: Wilāda al-Ğāmi'a alAmrikīya. Watāâ' iq al-liqā' al-țaqāfĩ haul wilāda al-ğāmi'a al-amrikīya „Masīra 'ilmīya mahdaha 'Abeih", hrsg. von Ǧam 'iya Aḥiyā tarāt 'Abeih, (6.10.2002), 46-78, in: AA.6/Van Dyck, Ordner 1.

Antonius, G. (1938): The Arab Awakening. The Story of the Arab National Movement, Beirut.

Atiyeh, G.H. (1995): The Book in the Modern Arab World: The Cases of Lebanon and Egypt, in: The Book in the Islamic World. The Written Word and Communication in the Middle East, hrsg. von G. H. Atiyeh, New York, 233-253.

Auji, H. (2013): Between Script and Print: Exploring Publications of the American Syria Mission and the Nascent Press in the Arab World, 1834-1860, Ann Arbor (Dissertation).

Ayalon, A. (1995): The Press in the Arab Middle East. A History (= Studies in Middle Eastern History 2), New York.

'Abdul-Hai, M. (1976): „A Bibliography of Arabic Translations of English and American Poetry (1830-1970)“, in: Journal of Arabic Literature 7, 120-150.

'Ağulūn̄̄, N. (1964): „Qissat al-Duktūr Kurnīlīyūs Fān Dayk“ (Die Geschichte von Dr. Cornelius von Dyck), in: Medīkūs 8 (April-Mai), 4-6, 20-21, in: AA.6/Van Dyck, Ordner 1.

Badr, H. (1992): Mission to „Nominal Christians“": The Policy and Practice of the American Board of Commissioners for Foreign Missions and its Missionaries concerning Eastern Churches which Led to the Organization of a Protestant Church in Beirut (1819-1848), Princeton (unveröffentlichte Dissertation).

- ders. (2006): American Protestant Missionary Beginnings in Beirut and Istanbul: Policy, Politics, Practice and Response, in: New Faith in Ancient Lands. Western Missions in the Middle East in the Nineteenth and Early Twentienth Centuries, hrsg. von H. Murre-van den Berg (= Studies in Christian Mission 32), Leiden u. a., 211-239.

Al-Bārūdī, I. (1895): „Fāqīid Sūrīyan. Ustāzanā al-marhūùm al-Duktūr Kurnīlīyūs Fān Dayk“ (Ein Syrer ist verstorben. Unser verehrter Professor Cornelius Van Dyck), in: al-Ṭabīb 7/7 (1895), 193-198; al-Ṭabīb 7/8 (1895), 215-220.

Beaver, R. P. (Hg.) (1967): To Advance the Gospel. Selections from the Writings of Rufus Anderson, Grand Rapids.

Beshara, A. (Hg.) (2014): Butrus al-Bustani. Spirit of the Age, Melbourne.

Bhabha, H. (2000): Die Verortung der Kultur, Tübingen.

Binay, S. / Leder, S. (Hg.) (2012): Translating the Bible into Arabic: historical, text-critical and literary aspects (= Beiruter Texte und Studien 131), Beirut.

Binay, S. (2012a): Introduction, in: Translating the Bible into Arabic: historical, text-critical and literary aspects, hrsg. von S. Binay / S. Leder (= Beiruter Texte und Studien 131), Beirut, 11-17.

- dies. (2012b): Revision of the manuscripts of the „so-called Smith-Van Dyck Bible“. Some remarks on the making of this Bible translation, in: Translating the Bible into Arabic: historical, 
text-critical and literary aspects, hrsg. von S. Binay / S. Leder (= Beiruter Texte und Studien 131), Beirut, 75-84.

Bird, I. (1864): The Martyr of Lebanon, Boston.

- ders. (1872): Bible Works in Bible Lands; or, Events in the History of the Syria Mission. Fully Illustrated, Philadelphia.

Bliss, F. J. (1920): Reminiscences of Daniel Bliss, New York.

Bliss, D. (1993): Letters from a New Campus. Written to his wife Abby and their four children during their visit to Amherst, Massachusetts 1873-1874, collected and annotated by Douglas and Belle Dorman Rugh and Alfred H. Howell, Beirut.

Bonk, J. J. (1989): The Theory and Practice of Missionary Identification, 1860-1920 (= Studies in the History of Missions 2), Lewiston u.a.

Booth, M. (2002): „She Herself was the Ultimate Rule“: Arabic Biographies of Missionary Teachers and Their Pupils, in: Islam and Christian-Muslim Relations 13/4, 427-448.

Boyer, P. S. (1999): „Chiliasmus, IV. Nordamerika“, in: Religion in Geschichte und Gegenwart, Bd. 2, 4. Auflage, Tübingen, 140-141.

Brockelmann, C.u.a. (1935): Die Transliteration der arabischen Schrift in ihrer Anwendung auf die Hauptliteratursprachen der islamischen Welt. Denkschrift, dem 19. Internationalen Orientalistenkongreß in Rom vorgelegt von der Transkriptionskommission der Deutschen Morgenländischen Gesellschaft, Leipzig.

Brown, C. G. (2004): The Word in the World: Evangelical Writing, Publishing, and Reading in America, 1789-1880, Chapel Hill u.a.

Bustān̄̄ B. (1859): Huṭba fĩ ādāb al- 'arab (Rede über die arabische Kultur), Beirut.

- ders. (1860-1861): Nafïr Surīya (Syriens Weckruf), Nr. 1-11, Beirut.

- ders. (1860): Qissat As'ad al-Šidyāq. Munāẓara wa ḥiwār multahib hạawla ḥurrīyat al-ḍamīr (Die Geschichte As`ad al-Šidyāqs. Spannende Debatten über die Freiheit des Gewissens), Beirut.

- ders. (1873): „Al-Madrasa al-Wațanīya“ (Die Nationalschule), in: al-Ǧinān 4, 626-628.

Bustān̄̄, S. (1883): „Dā' irat al-Ma ārif“, in: Dā’rat al-Ma'ārif 7, 589-608.

Cioeta, D. J. (1982): „Islamic Benevolent Societies and Public Education in Ottoman Syria, 1875 1882“, in: Islamic Quarterly. A Review of Islamic Culture 26/1, London, 40-55.

Coakley, J.F. (1998): „Printing Offices of the American Board of Commissioners for Foreign Missions, 1817-1900: a Synopsis“, in: Harvard Library Bulletin 9/1, 5-34.

Collani, C.v. (2012): The Exchange of Knowledge between Europe and China by Missionaries, in: Missionsgeschichte als Geschichte der Globalisierung von Wissen. Transkulturelle Wissensaneignung und -vermittlung durch christliche Missionare in Afrika und Asien im 17., 18. und 19. Jahrhundert, hrsg. von U.v.d. Heyden / A. Feldtkeller, Stuttgart, 111-126.

Comaroff, J. / Comaroff, J.L. (1997): Of Revelation and Revolution: The Dialectics of Modernity on a South African Frontier, Bd. 2, Chicago u. a.

Conrad, S. (2012): „Enlightenment in Global History: A Historiographical Critique“, in: American Historical Review 117/4, 999-1027.

Copeland, R. (1974): Sequicentennial History of the Community Church of Beirut, 1823-1973, Beirut: Community Church of Beirut

Daccache, Frère S. (2005): Catholic Missions in the Middle East, in: Christianity: A History in the Middle East, hrsg. von H. Badr u. a., Beirut, 688-705.

Daniel, R.L. (1964): „American Influences in the Near East Before 1860“, in: American Quarterly 16/1 (Spring), 72-84.

Dāḡīr, Y.A. (1978): Qāmūs al-ṣihāâa al-Lubnānīya (Lexikon libanesischer Periodika), 1858-1974, Beirut.

Dāya, Ğ. (2007): „'Ilmānīyū bilād al-Šām al-muslimūn fī 'așr al-nahḍa“ (Muslimisch-geistliche Gelehrte in Syrien im 19. Jahrhundert), in: Mağala al-Tahạolāt 24 (Juli), URL: http://www. tahawolat.com/cms/article.php3?id_article=1339 (Stand: Dezember 2012).

- ders. (2008): Al-mu'allim Buțrus al-Bustān̄̄ 125 'āman 'alā wafātihi: Inn̄̄ li-ḩidmat hāḍa l-wațan wa arfạ̣u an akūn ağnabīyan fīhi (Der Gelehrte Butrus al-Bustani 125 Jahre nach sei- 
nem Tod: Denn ich diene dieser Nation und ich lehne es ab, ein Ausländer darin zu sein), in: al-Ğama a (14.3.2008), o. S., in: AA.6/Bustān̄̄.

De Forest, H.A. (1851): „Notes of a Tour in Mount Lebanon and to the Eastern Side of Lake Hûleh“, in: JAOS 2, 237-247.

- ders. (1853): „Notes on the Ruins in the Bûķa 'a and in the Belâd Ba' albek“, in: JAOS 3, 349366.

- ders. (1856): „Phoenician Inscriptions of Sidon“, in: JAOS 5, 227-259.

Deguilhem, R. (1998): State Civil Education in Late Ottoman Damascus: A Unifying or a Separating Force?, in: The Syrian Land: Processes of Integration and Fragmentation. Bilād al-Shām from the 18th to the 20th Century, hrsg. von T. Philipp / B. Schaebler, (= Berliner Islamstudien 6), Stuttgart, 221-250.

Dennis, J. S. (1872): A Sketch of the Syria Mission, New York.

- ders. (1896): „C.V.A. Van Dyck, M.D., D.D., LL.D.“, in: Church at Home and Abroad 19 (January 1896), 35-36.

Dexter, F. B. (1913): „Eli Smith“, in: Biographical Notices of Graduates of Yale College, New Haven, 80-82.

Diab, H. / Wåhlin, L. (1983): „The Geography of Education in Syria in 1882. With a Translation of ,Education in Syria“ by Shahin Makarius, 1883“, in: Geografiska Annaler 65B/2, 105-128.

DMG (Hg.) (1846): Jahresbericht der Deutschen Morgenländischen Gesellschaft für 1845-1846, Leipzig.

- dies. (Hg.) (1847a): Jahresbericht der Deutschen Morgenländischen Gesellschaft für das Jahr 1846, Leipzig.

- dies. (Hg.) (1847b): „Die orientalischen Studien in Nord-Amerika“, in: ZDMG 1, Leipzig, $87-88$.

Doğan, M.A. / Sharkey, H. J. (Hg.) (2011): American Missionaries and the Middle East: Foundational Encounters (= Utah Series in Turkish and Islamic Studies), Salt Lake City, ix-xliii.

Doumato, E.A. (2002): „Missionary Transformations: Gender, Culture and Identity in the Middle East“, in: Islam and Christian-Muslim Relations 13/4, 373-376.

D. S. (1938): „Biography - Rev. John Wortabet“, in: Al-Kulliya 3/2 (Nov.), 4.

Dunch, R. (2002): Beyond Cultural Imperialism: Cultural Theory, Christian Missions, and Global Modernity (= History and Theory. Studies in the Philosophy of History 41), Middleton, 301-325.

Eddy, D. C. (1850): Heroines of the Missionary Enterprise: or Sketches of Prominent Female Missionaries, Boston.

Effendi, H. R.A. (1854): The Thistle and the Cedar of Lebanon, London.

Ellis, A. G. (1894): Catalogue of Arabic Books in the British Museum, Bd. 1, London.

- ders. (1901): Catalogue of Arabic Books in the British Museum, Bd. 2, London.

Elshakry, M. S. (2007): „The Gospel of Science and American Evangelism in Late Ottoman Beirut“, in: Past and Present 196, 173-214.

Fāris, N.A. (1958): „Amīrikā wa l-nahụa al-'arabīya al-ḥadīta“a (Amerika und die moderne arabische Kulturrenaissance), in: Al-Abḥāt 21/3, Beirut, 379-395.

Finnie, D. H. (1967): Pioneers East. The Early American Experience in the Middle East (Harvard Middle Eastern Studies 13), Cambridge/Mass.

Fleischer, H. L. (1848): „Gesellschaft der Künste und Wissenschaften in Beirut“, in: ZDMG 2, 378 388.

Fleischmann, E. (2006): Evangelization or Education: American Protestant Missionaries, the American Board, and the girls and women of Syria (1830-1910), in: New Faith in Ancient Lands. Western Missions in the Middle East in the Nineteenth and Early Twentieth Centuries, hrsg. von H. Murre-van den Berg, Leiden u. a., 263-280.

Fontana, M. (2012): Matteo Ricci and the Use of Science in Cross Cultural Understanding, in: Europe in China - China in Europe. Mission as a vehicle of intercultural dialogue, hrsg. von P. Widmer (= Missionsgeschichtliches Archiv 18), Stuttgart, 22-32.

Free Church of Scotland (Hg.) (1857): „Dr. Eli Smith“, in: The Home and Foreign Board of the Free Church of Scotland, Vol. 1: New Series (August 1856 - July 1857), Edinburgh, 237-239. 
Glaß, D. (1998a): Malta, Beirut, Leipzig and Beirut again: Eli Smith, the American Syria Mission, and the Spread of Arabic Typography in 19th Century Lebanon, Beirut.

- dies. (1998b): Der Missionar Cornelius van Dyck (1818-1895) als Lehrbuchautor und Förderer des arabischen Wissenschaftsjournalismus, in: Annäherung an das Fremde, XXVI. Deutscher Orientalistentag vom 25. bis 29.9.1995 in Leipzig, hrsg. von H. Preissler / H. Stein (= ZDMGSuppl. 11), Stuttgart, 185-198.

- dies. (2001): Von Mir'ät al-Aḥwāl zu Tamarāt al-Funūn: Anfänge der freien arabischen Presse im osmanischen Syrien, in: Amtsblatt, vilayet gazetesi und unabhängiges Journal: Die Anfänge der Presse im Nahen Osten, hrsg. von A. Pistor-Hatam (= Heidelberger Studien zur Geschichte und Kultur des modernen Vorderen Orients 27), Frankfurt a. M., 29-45.

- dies. (2002): Arabischer Buch-und Zeitungsdruck in der Arabischen Welt, Teil II: Arabischer Zeitungsdruck in der Arabischen Welt, in: Sprachen des Nahen Ostens und die Druckrevolution. Eine interkulturelle Begegnung. Katalog und Begleitband zur Ausstellung, hrsg. von E. Hanebutt-Benz u. a., Mainz, 207-216.

- dies. (2004a+b): Der Muqtațaf und seine Öffentlichkeit. Aufklärung, Räsonnement und Meinungsstreit in der frühen arabischen Zeitschriftenkommunikation, Bd. 1: Analyse medialer und sozialer Strukturen, Bd. 2: Streitgesprächsprotokolle (= Mitteilungen zur Sozial- und Kulturgeschichte der Islamischen Welt 17), Würzburg.

- dies. (2008): Butrus al-Bustani (1819-1883) als Enzyklopädiker der arabischen Renaissance, in: Studien zur Semitistik und Arabistik: Festschrift für Hartmut Bobzin zum 60. Geburtstag, hrsg. von O. Jastrow u. a., Wiesbaden, 107-139.

Glaß, D. / Roper, G. (2002): Arabischer Buch- und Zeitungsdruck in der Arabischen Welt, Teil I: Arabischer Buchdruck in der Arabischen Welt, in: Sprachen des Nahen Ostens und die Druckrevolution. Eine interkulturelle Begegnung. Katalog und Begleitband zur Ausstellung, hrsg. von E. Hanebutt-Benz u. a., Mainz, 177-206.

Grabowski, B. / Fick, B. (2010): Drucktechniken. Das Handbuch zu allen Materialien und Methoden, Köln.

Goodsell, F.F. (1959): You shall be my witness. An Interpretation of the History of the American Board, 1810-1960, Boston.

Grabill, J. (1971): Protestant Diplomacy and the Near East. Missionary Influence on American Policy, 1810-1927, Minneapolis.

Graf, G. (1951): Geschichte der christlichen arabischen Literatur, Bd. 4: Die Schriftsteller von der Mitte des 15. bis zum Ende des 19. Jahrhunderts. Syrer, Armenier, Kopten, Missionsliteratur, Profanliteratur, Città del Vaticano.

Grafton, D. D. (2009): Piety, Politics and Power: Lutherans Encountering Islam in the Middle East, Eugene.

Ğuha, Š. (2004): Dārwin wa azma 1882 bi 1-dā'ira al-țibbīya wa awal țaura țulābīya fĩ 1- ālam al'arabī bi l-Kullīya al-Surīya al-Inğilīya (al-ān al-Ğāmi a al-Amīrikīya fỉ Beyrūt) (Darwin und die Krise in der medizinischen Fakultät 1882 und die erste Studentenrevolution in der arabischen Welt im Syrisch-Protestantischen College [heute Amerikanische Universität Beirut]), Beirut.

Hall, I.H. (1885): „The Arabic Bible of Drs. Eli Smith and Cornelius Van Dyck“, in: JAOS 11, 276-286.

Hanssen, J. (2005): The Birth of an Education Quarter: Zokak el-Blat as a Cradle of Cultural Revival in the Arab World, in: History, Space and Social Conflict in Beirut. The Quarter of Zokak elBlat, hrsg. von H. Gebhardt u. a. (= Beiruter Texte und Studien 97), Beirut.

- ders. (2006): „Fin de siècle“ Beirut. The making of an Ottoman provincial capital, Oxford.

Harris, P. W. (1999): Nothing but Christ. Rufus Anderson and the Ideology of Protestant Foreign Missions, New York u. a.

- ders. (2004): Denominationalism and Democracy: Ecclesiastical Issues Underlying Rufus Anderson's Three Self Program, in: North American Foreign Missions, 1810-1914. Theology, Theory, and Policy, hrsg. von W. R. Shenk (= Studies in the History of Christian Missions), Grand Rapids u. a., 61-85. 
Hauser, J. (2008): „... das hier so furchtbar verwahrloste weibliche Geschlecht aus dem Stande heben zu helfen". Der emanzipatorische Auftrag Kaiserswerther Diakonissen im Osmanischen Reich (1851-1918) und seine Ambivalenzen, in: Transkulturalität. Gender- und bildungshistorische Perspektiven, hrsg. von W. Gippert u. a., Bielefeld, 219-236.

- dies. (2011): Waisen gewinnen. Mission zwischen Programmatik und Praxis in der Erziehungsanstalt der Kaiserswerther Diakonissen in Beirut seit 1860, in: Soziale Missionen, hrsg. von R. Hölzl (= WerkstattGeschichte 57/1), 9-30.

- dies. (2015): German Religious Women in Late Ottoman Beirut. Competing Missions (=Studies in Christian Mission 45), Leiden.

Hauser, J. / Lindner, C. B. / Möller, E. (Hgg.) (2016): Entangled Education: Foreign and Local Schools in Ottoman Syria and Mandate Lebanon (19th-20th centuries), (= Beiruter Texte und Studien 137), Beirut.

Henningsen, A.F. (2011): On Difference, Sameness and Double Binds. Ambiguous Discourses, Failed Aspirations, in: Protestant Missions and Local Encounters in the Nineteenth and Twentieth Centuries. Unto the Ends of the World, hrsg. von H. Niellsen u. a. (= Studies in Christian Mission 40), Leiden-Boston, 131-155.

Heyden, U.v.d. / Feldtkeller, A. (Hg.) (2012): Missionsgeschichte als Geschichte der Globalisierung von Wissen. Transkulturelle Wissensaneignung und -vermittlung durch christliche Missionare in Afrika und Asien im 17., 18. und 19. Jahrhundert (= Missionsgeschichtliches Archiv 19), Stuttgart.

Hitti, P. K. (1957): Lebanon in History. From the Earliest Times to the Present, London.

- ders. (1959): Syria: A Short History, London.

Hock, K. (2011): Einführung in die Interkulturelle Theologie, Darmstadt.

Holt, E. M. (2009): „Narrative and Reading Public in 1870 s Beirut“, in: Journal of Arabic Literature $40,37-70$.

Holtwick, B. (2004): Licht und Schatten. Begründungen und Zielsetzungen missionarischen Aufbruchs im frühen 19. Jahrhundert, in: Weltmission und religiöse Organisation. Protestantische Missionsgesellschaften im 19. und 20. Jahrhundert, hrsg. von A. Bogner (= Religion in der Gesellschaft 16), Würzburg, 225-247.

Hooker, E. W. (1839): Memoir of Mrs. Sarah Lanman Smith. Late of the Mission in Syria, Under the Direction of the American Board of Commissioners for Foreign Missions, Boston.

Hopkins, S. (1811): System of Doctrines. Contained in Divine Revelation, explained and defended. Shewing their Consistence and Connexion with each other. To which is added, A Treatise on the Millenium, Bd. 1, Boston, 2. Auflage.

Hourani, A.H. (1954), Syria and Lebanon: A political essay, London, 3. Auflage.

- ders. (1994): Die Enzyklopädie von Butrus al-Bustani, in: Der Islam im Europäischen Denken. Essays, hrsg. von A. H. Hourani, Frankfurt a. M., 203-214.

Hutchison, W. R. (1987): Errand to the World. American Protestant Thought and Foreign Missions, Chicago u. a.

Höh, M.v. d. / Jaspert, N. / Oesterle, J. (2013): Courts, Brokers and Brokerage in the Medieval Mediterranean, in: Cultural Brokers at Mediterranean Courts in the Middle Ages, hrsg. von M.v.d. Höh u. a., Paderborn, 9-31.

Ḥaddad, F. S. (1973): 'Ibar min ihtibār Fān Dayk fĩ tadrīs al-țib bi-lugia al- arabīya fĩ Kullīya alSūrīya al-Inğilīya fī Beyrūt (Lektionen von Van Dycks Erfahrungen im Unterrichten von Medizin auf Arabisch am Syrian Protestant College), in: Annual Report Oriental Hospital (Arabic Section), 2-8, in: AA.6/Van Dyck, Ordner 2.

Al-Helū, N. M. (2010): Muẓakirrāt al-mu allim Nassīm al-Helū, 1868-1951 (Memoiren des Gelehrten Nassīm al-Helū), Damaskus, Neudruck von 1950, in: AA.7.1., Box 1 und 2 (nur Ss. 131, 145-147, 311).

Hูūrī, Ġ.Y. (1992): Al-rawād al-mu' assasūn li l-Ğāmi a al-Amīrikīya bi-Beyrūt / The founding fathers of the American University of Beirut: Biographies, Beirut, in: AA.6/John Wortabet. 
Huūrī, Y. Q. (1965): „Kurnīlīyūs Fān Dayk, Mu'alafāt al- 'ilmīya al-'arabīya“ (Cornelius Van Dyck: Wissenschaftliche Werke auf Arabisch), in: al-Abhāât 18/3.4 (Dezember), 389-418, in: AA.6/ Van Dyck, Ordner 2.

- ders. (1966): „Našaṭ al-Duktūr Kurnīlīyūs Fān Dayk fī 1-Kullīya al-Surīya al-Inǧilīya“ (Dr. Cornelius Van Dycks Engagement im Syrisch-Evangelischen College), in: Al-Kullìya, Centennial Commencement (Spring 1966), 22-19.

- ders. (1990a): Al-Duktūr Kurnīlyūs Fān Daik wa nahḍat al-Diyār al-Šāmīya al- ilmīya fī l-qarn al-tāsi' 'ašar (Dr. Cornelius Van Dyck und die kulturelle Erweckung der Wissenschaften in Syrien im 19. Jh.), London (Druckfassung der Magisterarbeit von 1965).

- ders. (Hg.) (1990b): A 'māl al-Ğam '̄ya al-Surīya li 1- 'Ulūm wa 1-Funūn (Akten der Syrischen Gesellschaft der Wissenschaften und Künste), 1847-1852, Beirut.

- ders. (Hg.) (1990c): A 'māl al-Ğam 'ìya al- 'Ilmīya al-Surīya (Akten der Syrisch-Wissenschaftlichen Gesellschaft), 1868-1869, Beirut.

- ders. (1995): Rağul sābiq li-'așrihi. Al-Mu'allim Buṭrus al-Bustān̄̄ (Ein Mann, der seiner Zeit voraus ist. Der Gelehrte Buțrus al-Bustān̄i), Beirut (neue, überarbeitete Auflage der Dissertation von 1976).

- ders. (2003): Mudawwanat șaḥāfat Lubnān (Auflistung libanesischer Zeitungen), Kyoto.

Jandora, J.W. (1981): Buṭrus al-Bustānī: Ideas, Endeavors, and Influence, Chicago (unveröffentlichte Dissertation).

- ders. (1984): Butrus al-Bustani, Arab Consciousness and Arabic Revival (= Muslim World 74/2), Hartford, 71-84.

Jessup, H.H. (1874): The Women of the Arabs. With a Chapter for Children, London.

- ders. (1883/84): „Muallim Butrus el-Bistany - The Learned Syrian Elder“, in: Foreign Missionary $42,275-276$.

- ders. (1898): The Setting of the Crescent and the Rising of the Cross; or Kamil Abdul Messiah. A Syrian Convert from Islam to Christianity, Philadelphia.

- ders. (1910a+b): Fifty-Three Years in Syria, 2 Bde., New York.

Kades, T. (1997): Die arabischen Bibelübersetzungen im 19. Jahrhundert (= Studien zur Interkulturellen Geschichte des Christentums 140), Frankfurt am Main.

Kahle, P. (1904): Die Arabischen Bibelübersetzungen. Texte mit Glossar und Literaturübersicht, Leipzig.

Kaminsky, U. (2010): Innere Mission im Ausland. Der Aufbau religiöser und sozialer Infrastruktur am Beispiel der Kaiserswerther Diakonie (1851-1975) (= Missionsgeschichtliches Archiv 15), Stuttgart.

Kawerau, P. (1958): Amerika und die Orientalischen Kirchen. Ursprung und Anfang der amerikanischen Mission unter den Nationalkirchen Westasiens (= Arbeiten zur Kirchengeschichte 31), Berlin.

Kayat, A. Y. (1847): A voice from Lebanon. With the Life and Travels of Assaad Y. Kayat, London.

Khalaf, S. (1994): New England Puritanism and Liberal Education in the Middle East: The American University of Beirut as a Cultural Transplant, in: Cultural Transitions in the Middle East, hrsg. von S. Mardin (= Social, Economic and Political Studies of the Middle East 48), Leiden u. a., 50-85.

- ders. (2001): Cultural Resistance: Global and Local Encounters in the Middle East, London.

Khoury, R. G. (2000): „Al-Yāziğ̄̄, Nāṣîf“, in: Metzler Lexikon Christlicher Denker, hrsg. von M. Vinzent, Stuttgart, 20-21.

Klaiber, I. (2009): Women's Roles in American Society: Difference, Separateness, and Equality, in: A Companion to American Cultural History. From the Colonial Period to the End of the 19th Century, hrsg. von B. Engler / O. Scheiding, Trier, 303-330.

Koschorke, K. (2012): Weltmission, Globale Kommunikationsstrukturen und die Vernetzung der indigen-christlichen Eliten Asiens und Afrikas im 19. und frühen 20. Jahrhundert, in: Missionsgeschichte als Geschichte der Globalisierung von Wissen. Transkulturelle Wissensaneignung und -vermittlung durch christliche Missionare in Afrika und Asien im 17., 18. und 19. Jahrhundert, hrsg. von U. v.d. Heyden / A. Feldtkeller, Stuttgart, 193-212. 
Krek, M. (1992): „Some Observations on Printing Arabic in America and by Americans abroad“, in: Manuscripts of the Middle East 6, Leiden, 71-87.

Kulke, H. (1979): Jagannātha-Kult und Gajapati-Königtum. Ein Beitrag zur Geschichte religiöser Legitimation hinduistischer Herrscher (= Schriftenreihe des Südasien-Instituts der Universität Heidelberg 23), Wiesbaden 1979.

Lake, A. (2013): „The First Protestants in the Middle East: The English Aleppo Chaplains (15971782)“, in: The Near East School of Theology Theological Review 34/1, 39-49.

Laurie, T. (1866): Historical Sketch of the Syria Mission, Boston.

- ders. (1881): The Ely Volume; or, The Contributions of our Foreign Missions to Science and Human Well-Being, Boston.

Leavy, M. (1993): Eli Smith and the Arabic Bible (= Yale Divinity School Library Occasional Publication 4), New Haven.

- dies. (1995): The Making of a Missionary: Eli Smith at Yale, 1817-1821, in: Journal of the New Haven Colony Historical Society 41/2, 21-37.

Liebau, H. (Hg.) (2006): Geliebtes Europa - Ostindische Welt. 300 Jahre interkultureller Dialog im Spiegel der Dänisch-Halleschen Mission. Jahresausstellung der Franckeschen Stiftungen zu Halle 2006 (= Kataloge der Franckeschen Stiftungen 16), Halle.

- dies. (2008): Die indischen Mitarbeiter der Tranquebarmission (1706-1845), Katecheten, Schulmeister, Übersetzer (= Hallesche Forschungen 26), Tübingen.

Lindner, C. B. (2009): Negotiating the Field: American Protestant Missionaries in Ottoman Syria, 1823-1860, Edinburgh (unveröffentlichte Dissertation).

- dies. (2010): ,,Long, Long Will She Be Affectionately Remembered“: Gender and the Memoralization of an American Female Missionary“, in: Social Sciences and Missions 23, 7-31.

- dies. (2011a): The Flexibility of Home: Exploring the Spaces and Definitions of the Home and Family Employed by the ABCFM Missionaries in Ottoman Syria from 1823 to 1860, in: American Missionaries and the Middle East: Foundational Encounters, hrsg. von M.A. Doğan / H. J. Sharkey (= Utah Seris in Turkish and Islamic Studies), Salt Lake City, 33-62.

- dies. (2011b): „,Making a way into the heart of the people': Women of the Early Protestant Church in Beirut", in: The Near East School of Theology Theological Review 32/2 (2011), 71-96.

- dies. (2014a): Rahil 'Ata al-Bustani: Wife and Mother of the Nahda, in: Butrus al-Bustani. Spirit of the Age, hrsg. von A. Beshara, Melbourne, 49-67.

- dies. (2014b): Syrian Protestant Families (unveröffentlichte Liste, Stand: 23. Mai 2014).

Lindsay, R.H. (1965): Nineteenth Century American Schools in the Levant: A Study of Purposes, Ann Arbor.

Makārius, Š. (1883): „Al-ma ārif fĩ Sūrīya“ (Das Wissen in Syrien), in: al-Muqtațaf 7/7 (1883), 385-392, 460-476, 529-537.

Makdisi, U. (2000): The Culture of Sectarianism. Community, History, and Violence in NineteenthCentury Ottoman Lebanon, Berkeley u.a.

- ders. (2004): Rethinking American missionaries and the nineteenth-century historiography of the Middle East, in: From The Syrian Land to the States Of Syria and Lebanon, hrsg. von T. Phillip / C. Schumann (= Beiruter Texte und Studien 96), Beirut, 209-224.

- ders. (2008): Artillery of Heaven. American Missionaries and the Failed Conversion of the Middle East (= The United States in the World), Ithaca u. a.

- ders. (2010): Faith Misplaced. The Broken Promise of U. S.-Arab Relations: 1820-2001, Public Affairs.

Malick, D. G. (2008): The American Mission Press, a Preliminary Bibliography, Atour Publications.

Marten, M. (2006): Attempting to Bring the Gospel Home. Scottish Missions to Palestine, 18391917 (= International Library of Colonial History 3), London u.a.

- ders. (2011): Re-Imagining ,Metropole“ and ,Periphery“ in Mission History, in: Protestant Missions and Local Encounters in the Nineteenth and Twentieth Centuries. Unto the Ends of the World, hrsg. von H. Nielssen u. a. (= Studies in Christian Mission 40), Leiden u. a., 293-315. 
Matthews, R. D. / Akrawi, M. (1949): Education in Arab Countries of the Near East. Egypt, Iraq, Palestine, Transjordan, Syria, Lebanon, Washington.

Mațar, I. (1966): Al-Duktūr Kurnīlìyūs Fān Dayk, in: Ha'ulā' hadamū al-šarq al-'arabī / Those served the Arab East, hrsg. von Rābița al-Kitāb bi l-Masīhịiyīn fī Šarq al-Adnā / The Christian Writers Fellowship (= Evangelical Pioneers 7), Beirut, in: AA.6/Van Dyck, Ordner 1.

Mcgilvary, M. (1920): Story of Our Syria Mission, New York.

Mišāqā, M. (1988): Al-ǧawāb al-iqtirāḥ al-aḥbāb (Beirut 1873). Murder, Mayhem, Pillage and Plunder: The History of the Lebanon in the 18th and 19th Centuries. Translated from Arabic by W. M. Thackston, New York.

Morison, S.E. (1956): The Intellectual Life of Colonial New England, 2. Auflage, New York.

Murre-van den Berg, H. (2005): Nineteenth-century Protestant Missions and Middle Eastern Women, in: Gender, Religion and Change in the Middle East, hrsg. von I. M. Okkenhaug, Oxford, $103-122$.

- dies. (2006a): Introduction, in: New Faith in Ancient Lands. Western Missions in the Middle East in the Nineteenth and Early Twentieth Centuries, hrsg. von H. Murre-van den Berg (= Studies in Christian Mission 32), Leiden u. a., 1-17.

- dies. (2006b): „Simply by giving to them macaroni ...“ Anti-Roman Catholic polemics in early Protestant missions in the Middle East, 1820-1860, in: Christian Witness Between Continuity and New Beginnings. Modern Historical Missions in the Middle East, hrsg. von M. Tamcke / M. Marten (= Studien zur Orientalischen Kirchengeschichte 39), Münster, 63-80.

- dies. (2011): A „Good and Blessed Father“. Yonan of Ada on Justin Perkins, Urmia (Iran), 1870, in: Protestant Missions and Local Encounters in the Nineteenth and Twentieth Centuries. Unto the Ends of the World, hrsg. von H. Nielssen u. a. (= Studies in Christian Mission 40), Leiden u. a., 187-206.

Nielssen, H., u. a. (Hg.) (2011): Protestant Missions and Local Encounters in the Nineteenth and Twentieth Centuries. Unto the Ends of the World (= Studies in Christian Mission 40), Leiden u. a.

Penrose, S. B. L. (1941): „That they may have life": The Story of the American University of Beirut, 1866-1941, Beirut.

Perry, A. F. (1974): The American Board of Commissioners for Foreign Missions and the London Missionary Society in the Nineteenth Century: A Study of Ideas, Ann Arbor (unveröffentlichte Dissertation).

Philipp, T. (1979): Ğurğī Zaidān. His Life and Thought (= Beiruter Texte und Studien 3), Beirut.

Pratt, M.L. (1991): „Arts of the Contact Zone“, in: Profession / Modern Language Association of America (o.Nr.), New York, 33-40.

- dies. (2008): Imperial Eyes. Travel Writing and Transculturation. Second edition, London-New York.

Presbyterian Church in the USA (Hg.) (1841): The Form of Government, the Discipline, and the Directory for Worship, Philadelphia.

- dies. (1890): „Dr. Van Dyck’s Semicentennial“, in: The Church at Home and Abroad 8 (Oktober 1890), 289-292.

- dies. (1891): „Dr. Van Dyck and the Syrians“, in: The Church at Home and Abroad 9 (Juni 1891), 483-486.

Pritchard, J. (1958): Archaeology and the Old Testament, Princeton.

Rabinovich, I. (1992): Syria and the Syrian Land: The 19th Century Roots of 20th Century Developments, in: The Syrian Land in the 18th and 19th Century: The Common and the Specific in the Historical Experience, hrsg. von T. Philipp (= Berliner Islamstudien 5), Stuttgart, 43-54.

Raffoul, P. G. (2014): Butrus al-Bustani's Contribution to Translation, Journalism, and Cultural Activities, in: Butrus al-Bustani. Spirit of the Age, hrsg. von A. Beshara, Melbourne, 131-155.

Reeves-Ellington, B. (2011): Petko Slaveykov, the Protestant Press, and the Gendered Language of Moral Reform in Bulgarian Nationalism, in: American Missionaries and the Middle East. Foundational Encounters, hrsg. von M.A. Doğan / H. Sharkey, Salt Lake City, 211-236.

- dies. (2013): Domestic Frontiers. Gender, Reform, and American Interventions in the Ottoman Balkans and the Near East, 1831-1908, Amherst u.a. 
Reuben, J.A. (1996): The Making of the Modern University: Intellectual Transformation and the Marginalization of Morality, Chicago u.a.

Richter, D. J. (2006): Allgemeine Evangelische Missionsgeschichte. Band II: Mission und Evangelisation im Orient, Neudruck der 2. Auflage von 1930, Hamburg.

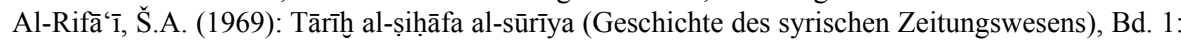
Al-ṣihạâfa al-sūrīya fī 'ahd al-'uțmānī (Das syrische Zeitungswesen im osmanischen Zeitalter), 1800-1918, Kairo.

Robinson, E. / Smith, E. (1860a+b): Biblical Researches in Palestine, and in the Adjacent Regions. A Journal of Travels in the Year 1838. With New Maps and Plans, 2 Bde., Boston, 2. Auflage.

Roeber, K. (2012): Missionare der Gossner Mission als Forscher und Wissenschaftler, in: Missionsgeschichte als Geschichte der Globalisierung von Wissen. Transkulturelle Wissensaneignung und -vermittlung durch christliche Missionare in Afrika und Asien im 17., 18. und 19. Jahrhundert, hrsg. von U.v.d. Heyden / A. Feldtkeller (= Missionsgeschichtliches Archiv 19), Stuttgart, 339-357.

Roper, G. (1998): „The Beginnings of Arabic Printing by the ABCFM, 1822-1841“, in: Harvard Library Bulletin 9/1, 50-68.

Rugh, D. (Hg.) (1956): The Voice of Daniel Bliss, Beirut.

Rzepkowski, H. (1995): Missionsgeschichte im Wandel der Motivationen und Perspektiven, in: Einleitung in die Missionsgeschichte. Tradition, Situation und Dynamik des Christentums, hrsg. von K. Müller / W. Ustorf, Stuttgart u. a., 258-285.

Sabra, G. F. (2009): Truth and Service. A History of the Near East School of Theology, Beirut.

Salibi, K. S. (1965): The Modern History of Lebanon, London.

Salibi, K.S. / Khoury, Y.K. (Hg.) (1995): The Missionary Herald. Reports from Ottoman Syria 1819-1870 (hier: ROS), 5 Bde., Beirut 1995.

Sa’di, L. M. (1937): „Al-Hakîm Cornelius Van Allen Van Dyck (1818-1895)“, in: ISIS 27, 20 -45.

Sarkis, Y. I. (1929): Mu 'ağam al-mațbu 'āt al- 'arabīya wa l-mu 'araba (Sammlung arabisch verfasster und ins Arabische übersetzter Druckwerke), Bd. 6, Kairo.

Schlesinger, A. (1974): The Missionary Enterprise and Theories of Imperialism, in: The Missionary Enterprise in China and America, hrsg. von J. Fairbank (= Harvard Studies in American-East Asian Relations), Cambridge/MA, 336-376.

Scholz, N. J. (1997): Foreign education and indigenous reaction in late Ottoman Lebanon: Students and Teachers at the Syrian Protestant College in Beirut, Washington.

Semaan, W.A. (1986): Aliens at Home: A Socio-Religious Analysis of the Protestant Church in Lebanon and its Backgrounds, Beirut.

Sharkey, H. J. (2011): Introduction, in: American Missionaries and the Middle East: Foundational Encounters, hrsg. von M.A. Doğan / H. J. Sharkey (= Utah Series in Turkish and Islamic Studies), Salt Lake City, ix-xliii.

Shaw, J. (2014): Butrus al-Bustani and the American Missionaries: Towards a Harmony of Understanding of the Advent of the Nahda, in: Butrus al-Bustani. Spirit of the Age, hrsg. von A. Beshara, Melbourne, 68-89.

Sheehi, S. (2004): Foundations of Modern Arab Identity, Gainsville/Florida.

Smith, E. (1832): Trials of Missionaries. An Address Delivered in Park-Street Church, Boston, on the Evening of October 24, 1832, to the Rev. Elias Riggs, Rev. William M. Thomson, and Doct. Asa Dodge, About to Embark as Missionaries to the Mediterranean, Boston.

- ders. (1833): Missionary Sermons and Addresses, hrsg. von H. Perkins, Boston.

- ders. (1840): The Missionary Character. An Address Delivered before the Society of Inquiry in the Theological Seminary in New Haven, April 1, 1840, New Haven.

- ders. (1846): „The Wines of Mount Lebanon“, in: Bibliotheca Sacra and American Biblical Repository 3, 385-389.

- ders. (1851): „A Treatise on Arab Music, Chiefly from a Work by Mikhâil Meshâkah, of Damascus. Translated from the Arabic, by Eli Smith“, in: JAOS 1, 173-217.

Smith, E. / Van Dyck, C. (1900): Brief Documentary History of the Translations of the Scriptures into the Arabic Language, Printed for the Syria Mission, Beirut. 
Somel, S.A. (2001): The Modernization of Public Education in the Ottoman Empire, 1839-1908: Islamization, Autocracy, and Discipline, Leiden.

Stöckel, S. u. a. (2009): Das Medium Wissenschaftszeitschrift seit dem 19. Jahrhundert. Verwissenschaftlichung der Gesellschaft - Vergesellschaftung von Wissenschaft (= Wissenschaft, Politik und Gesellschaft 5), Stuttgart.

Stoddard, R. D. (2009): „The Rev. Eli Smith, 1801-1857: Evangelical Orientalist in the Levant“, in: The Near East School of Theology Theological Review 30/2, 202-222.

Syrienmission (Hg.) (1886): Fī darūrīya iqāmat hidmatin li-l-inğîl min ahl al-wațan taqūm bilawāzihim al-kanā' is al-wațaniya (Über die Notwendigkeit des Dienstes am Evangelium durch die Einheimischen als Bestandteil der einheimischen Kirchen), Beirut (vermutlich die 2. oder 3. Auflage).

Șarrūf, Y. / Nimr, F. (1883): „Al-marḥūm al-mu 'allim Buṭrus al-Bustānī“ (Der verstorbene Gelehrte Buțrus al-Bustānī), in: al-Muqtațaf 8/1, 1-7.

- dies. (1890): „Al-Duktūr Fān Dayk“, in: al-Muqtațaf 14/6, 320-323.

- dies. (1895): „Al-Duktūr Kurn̄̄liyūs Fān Dayk“ [Teil 1], in: al-Muqtațaf 19/12, 881-888.

- dies. (1896): „Al-Duktūr Kurn̄̄liyūs Fān Dayk“ [Teil 2], in: al-Muqtațaf 20/1, 1-5.

Tafîlī, F. (2007): „Kurnīlīyūs Fān Dayk ḍud Dānīl Bliss fỉ Beyrūt. Muwāăğaha 1882 asqațat munadِdarī al-lībaralīya wa ğa'at bi 1-dā în ilā mumārasatiha“" (Cornelius Van Dyck gegen Daniel Bliss. Die Konfrontation von 1882 stürzt die Vertreter des Liberalismus und bringt sie dazu, sich [mehr] dafür einzusetzen), in: al-Mustaqbal (2.12.2007), (o. S.), in: AA.6/Van Dyck, Ordner 1.

Tamcke, M. (2012): Gleichzeitig-Ungleichzeitiges Wissen im Austausch. Exemplarisches zu Grundfragen transkulturellen Wissensaustausches am Beispiel der deutschen Kurdenmission in Mahabad, in: Missionsgeschichte als Geschichte der Globalisierung von Wissen. Transkulturelle Wissensaneignung und -vermittlung durch christliche Missionare in Afrika und Asien im 17., 18. und 19. Jahrhundert, hrsg. von U.v. d. Heyden / A. Feldtkeller (= Missionsgeschichtliches Archiv 19), Stuttgart, 389-399.

Taylor, J.H. (1884): China's Millions, London.

Tibawi, A. L. (1963): „The American Missionaries in Beirut and Butrus al-Bustani“, in: St. Antony’s Papers / Middle Eastern Affairs 16, 137-182.

- ders. (1966): American Interests in Syria, 1800-1901: A Study of Educational, Literary and Religious Work, Oxford.

- ders. (1967): The Genesis and Early History of the Syrian Protestant College, in: American University of Beirut (Festschrift), hrsg. von F. Sarrūf / S. Tamim, Beirut, 257-294.

- ders. (1969): A Modern History of Syria Including Lebanon and Palestine, Edinburgh.

- ders. (1971): „Some Misconceptions about the Nahda“, in: Middle East Forum 47, Beirut, $15-22$.

Tjelle, K.F. (2014): Missionary Masculinity, 1870-1930. The Norwegian Missionaries in SouthEast Africa (= Genders and Sexualities in History), New York.

Tomiche, N. (1993): „Nahḍa“, in: Encyclopedia of Islam 7, Leiden u. a., 900-903.

Traboulsi, F. (2007): A History of Modern Lebanon, London u. a.

Trepp, A.-C. (2010): Von der Missionierung der Seelen zur Erforschung der Natur. Die DänischHallesche Südindienmission im ausgehenden 18. Jahrhundert, in: Mission und kulturelle Globalisierung, hrsg. von S. Conrad / R. Habermas (= Geschichte und Gesellschaft 36/2), Göttingen, 231-256.

Thompson, J.A. (1956): The Major Arabic Bibles. Their Origin and Nature, New York.

Ṭarrāzī, P.D. (1913): Tārīh al-ṣihāafa al-'arabīya (Geschichte des arabischen Zeitungswesens), Bd. 1/1, Beirut.

- ders. (1914): Tārīh al-ṣiḥāfa al-'arabīya, Bd. 1/2, Beirut.

Union Theological Seminary (Hg.) (1937): Alumni Catalogue of the Union Theological Seminary in the City of New York, 1836-1936, New York.

Vander-Werff, L. L. (1977): Christian Missions to Muslims: The Record, South Pasadena.

Van Dyck, C. V.A. (o. J.): Reminiscences of the Syrian Mission from 1839-1850, unpublished, typewritten (zu Verfügung gestellt von Dr. G. Sabra, Präsident der N.E. S. T.). 
- ders. (1853): On the Present Condition of the Medical Profession in Syria, in: JAOS 3, 561591.

- ders. (1883): „Al-ḩuṭba al-sanawīya (huț̣abihā fị ğalasa al-iḥtifălīya al-Mağma‘ al-'Ilmī alŠarqī fĩ 25 ayār 1883)“ (Jahresrede [gehalten vor der feierlichen Sitzung der OrientalischWissenschaftlichen Gesellschaft am 25. Mai 1883]), in: al-Muqtațaf 7/11, 641-647.

Verdeil, C. (2006): Between Rome and France, intransigent and anti-Protestant Jesuits in the Orient: The beginning of the Jesuit's mission of Syria, 1831-1864, in: Christian Witness Between Continuity and New Beginnings. Modern historical missions in the Middle East, hrsg. von M. Tamcke / M. Marten (= Studien zur Orientalischen Kirchengeschichte 39), Münster 2006, $23-32$.

Walker, M. (1967): „The American Board and the Oriental Churches. A Brief Survey of the Policy Based on Official Documents“, in: International Review of Mission 56, 214-223.

Wendt, R. (2001): Einleitung: Missionare als Reporter und Wissenschaftler in Übersee, in: Sammeln, vernetzen, auswerten. Missionare und ihr Beitrag, zum Wandel europäischer Weltsicht, hrsg. von R. Wendt, Tübingen, 7-22.

Widmer, P. (Hg.) (2012): Europe in China - China in Europe. Mission as a Vehicle of Intercultural Dialogue (= Missionsgeschichtliches Archiv 18), Stuttgart 2012.

Witmer, A. (2014): ,Agency, Race, and Christianity in the Strange Career of Daniel Flickinger Wilberforce“, in: Church History 83/4, 884-923.

Womack, D. F. (2012): „Lubnani, Libanais, Lebanese: Missionary Education, Language Policy and Identity Formation in Modern Lebanon“, in: Studies in World Christianity 18/1, 4-20.

- dies. (2015): Conversion, Controversy, and Cultural Production: Syrian Protestants, American Missionaries, and the Arabic Press, 1870-1914 (Manuskript der Dissertation, eingereicht im April 2015, Princeton Theological Seminary/NJ).

Womack, D. F. / Lindner, C. B. (2014): „Pick up the pearls of knowledge and adorn ourselves with the jewelry of literature": An analysis of three Arab women writers in al-Nashra al-Usbu 'iyya, in: Living Stones Yearbook 2014. Christianity engages with Islam: contexts, creativity and tensions, hrsg. von L. Harrow u. a., England, 125-157.

Wortabet, G. (1856): Syria and the Syrians, 2 Bde., London.

Wortabet, J. (1860): Researches into the Religions of Syria: Or, Sketches, Historical and Doctrinal, of Its Religious Sects. Drawn from Original Sources, London.

- ders. (1879/80): „Lā yaḍī faḍl al-fuḍalā““ (Das Verdienst der Verdienstvollen geht nicht verloren), in: al-Muqtațaf 4/7, 195.

- ders. (1880): „Huțba“ (Rede [zur Examensfeier am SPC]), in: al-Muqtațaf 5/3 (1880), 57-61.

- ders. (1895): „Wașāyā al-šuyūh̆ li 1-šabān“ (Empfehlungen der Ältesten an junge Menschen), in: al-Muqtațaf 19/1, 2-5, 107-111.

- ders. (1905): „Al-Tahdīib“ (Die Erziehung), in: al-Muqtațaf 30/7, 537-544; al-Muqtațaf 30/8, 606-617.

- ders. (1990): „Miqdār ziyādat al- 'ilm fī Sūrīya fĩ hāḍa l-ğīl wa 'ilaluhā“ (Das Ausmaß des Wachstums der Wissenschaft in Syrien in diesem Jahrhundert und seine Ursachen), in: 'Amāl al-Ğam' ìya al-Surīya li l- 'Ulūm wa l-Funūn, 1847-1852, hrsg. von Y.Q. Hūrrī, Beirut, 33-35.

Wu, A. (2014): Narratives of Conversion in nineteenth-century German missionary periodicals, in: Missions and Media. The Politics of Missionary Periodicals in the Long Nineteenth Century, hrsg. von F. Jensz / H. Acke (= Missionsgeschichtliches Archiv. Studien der Berliner Gesellschaft für Missionsgeschichte 20), Stuttgart, 79-96.

Yazigi, J.M. (1964): American Presbyterian Mission Schools in Lebanon (M.A. Thesis), Beirut.

Zachs, F. (2001a): „Toward a Proto-Nationalist Concept of Syria? Revisiting the American Presbyterian Missionaries in the Nineteenth-Century Levant", in: Die Welt des Islams (New Series) $41 / 2,145-173$.

- dies. (2001b): „Mīkhā'îl Mishāqa - The First Historian of Modern Syria“, in: British Journal of Middle Eastern Studies 28/1, 67-87. 
- dies. (2004): Building a Cultural Identity: The Case of Khalīl al-Khūrī, in: From The Syrian Land to the States Of Syria and Lebanon, hrsg. von T. Phillip / C. Schumann (= Beiruter Texte und Studien 96), Würzburg, 27-39.

- dies. (2005): The Making of a Syrian Identity. Intellectuals and Merchants in Nineteenth Century Beirut, Leiden u. a.

Zahlan, A. (1965): The American University of Beirut: An Essay, Beirut.

Zaydān, Ğ. (1900/1901): „Tārīh al-nahḍa al- ilmīya al-ahīra fĩ Mișr wa 1-Šām“ (Geschichte der jüngsten wissenschaftlichen Erweckungsbewegung in Ägypten und Syrien), in: al-Hilāl 9, Kairo, 234-240.

- ders. (1903): Tarāğim mašāhīr al-šarq fĩ l-qarn at-tāsi` ašar (Biografien von berühmten Personen im Osten im 19. Jahrhundert), Bd. 2: Fī riğāal al-'ilm wa l-adab wa l-ši 'ir (Über Männer der Wissenschaft, Literatur und Dichtkunst), Kairo.

- ders. (1913): Tārīh̆ adāb al-luga al-'arabīya, al-ğiz' a al-rābi ' min sana 1801 ila awā'il al-qarn al-'ašrīn (Geschichte der arabischen Literatur, 4. Teil: 1801 bis zum Beginn des 20. Jahrhunderts), Kairo.

- ders. (1982): Al-duktur Yuhannā Wurtabāt: ustad al-tašrīḥ wa l-fīsīūlūğiya fĩ madrasa al-kullīya al-sūrīya (Dr. John Wortabet: Professur für Anatomie und Physiologie am Syrian Protestant College), in: Mu'alafăt Ğurğ̄ Zaydān al-kāmila, o. O., 422-429.

Zeuge, U. (2014): Die „Syrische Gesellschaft der Wissenschaften und Künste“ (1847-1852): Ein Wendepunkt des wissenschaftlichen Austausches zwischen West und Nahost, in: Geschichte, Theologie und Kultur des syrischen Christentums. Beiträge zum 7. Deutschen Syrologie-Symposium in Göttingen, Dezember 2011, hrsg. von M. Tamcke/S. Grebenstein (= Göttinger Orientforschungen: Syriaca 46), Wiesbaden, 447-458.

Zeuge-Buberl, U. (2015a): „,I have left my heart in Syria‘: Cornelius Van Dyck and the American Syria Mission“, in: Cairo Journal of Theology 2, 20-28. (URL: http://journal.etsc.org/2015/ uta-zeuge-buberl-i-have-left-my-heart-in-syria-cornelius-van-dyck-and-the-american-syriamission/)

- dies. (2015b): „Misinterpretations of a Missionary Policy? The American Syria Mission’s Conflict with Buṭrus al-Bustānī and Yuhannā Wurtabāt", in: Near East School of Theology Theological Review 36/1, 23-43.

Zhang, X. (2007): The Origins of the Modern Chinese Press. The influence of the Protestant Missionary Press in late Qing China (= Routledge Media, Culture and Social Change in Asia), London u. a.

N.N. (1909): „Obituary [zu John Wortabet]“, in: The British Medical Journal (2. Januar), 70, in: AA.6/John Wortabet.

\section{WEBSEITEN}

American University of Beirut, Directory of AUB Faculty Members, Staff Members, and Officers, 1880

URL: http://aubdirectory.aub.edu.lb/Pages/MembersListing.aspx.

American University of Beirut, History

URL: http://www.aub.edu.lb/main/about/Pages/history.aspx (Stand: Juli 2012).

American University of Beirut, Mission Statement

URL: http://www.aub.edu.lb/main/about/Pages/mission.aspx (Stand: Juli 2012).

American University of Beirut, Saab Memorial Medical Library: E-Historical Collection

URL: http://www.aub.edu.lb/sml/resources/Pages/HistoricalCollection.aspx (Stand: Mai 2014).

EBSCO Information Services, Thematic Collection from AAS Historical Periodicals: General Interests Christian Periodicals, 1743-1889

URL: http://www.ebscohost.com/titleLists/gic-coverage.pdf (Stand: Juni 2014).

Near East School of Theology, Preserving Protestant Heritage in the Middle East 
URL: http://www.aub.edu.lb/sml/resources/Pages/HistoricalCollection.aspx (Stand: Mai 2014). University of Oslo, Department of Culture Studies and Oriental Languages, research fellow Rana Hisham Issa

URL: http://www.hf.uio.no/ikos/english/research/doctoral-degree-and-career/phd-projects/issarana/index.html (Stand: August 2014).

University of Glasgow, The University of Glasgow Story: James Rashid Wortabet

URL: http://www.universitystory.gla.ac.uk/biography/?id=WH17766\&type $=\mathrm{P} \& \mathrm{o}=\& \mathrm{star}=102$ $0 \& \max =20 \& 1=w$ (Stand: Juni 2013).

Yale Divinity School, Special Collections, Eli Smith Family Papers, Record Group 124

URL: http://drs.library.yale.edu:8083/HLTransformer/HLTransServlet?stylename=yul.ead2002. $\mathrm{xhtml} . \mathrm{xs}$ \& $\mathrm{pid}=$ divinity: $124 \&$ query= whiting \&clear-stylesheet-cache=yes\&hlon=yes\&filter= fgs.collection:\%22Divinity\%20Library\%22\&hitPageStart=1 (Stand: August 2011). 


\title{
ANHANG I \\ DIE LITERARISCHEN BEITRÄGE VON SMITH, VAN DYCK, BUSTĀNI UND WORTABET FÜR DIE AMERICAN MISSION PRESS ${ }^{1}$
}

\author{
$\ddot{U} \quad=$ Eine Übersetzung aus dem Englischen \\ $? \quad=$ Die Verfasserschaft ist fraglich \\ $\mathrm{HG}=$ Herausgeber \\ $\mathrm{K}$ = Eine Komposition aus verschiedenen englisch- und/oder arabischsprachigen \\ Werken
}

\section{BUṬRUS AL-BUSTĀNĪ}

a) Theologische Schriften

- Rīhānat al-nufūs fi aṣl al-i tiqādāt wa l-ṭaqūs (Ü)

(Zum Trost der Seelen, über die Grundlagen der Riten und Zeremonien, nach: „History of Rites and Ceremonies“, von B. Schneider)

Beirut 1854 (180 S.)

Sowohl Nāṣif al-Yāziğĩ als auch Eli Smith haben bei dieser Übersetzung Korrektur gelesen. An dieser wie an weiteren folgenden Übersetzungen sind vermutlich mehrere beteiligt, die in den Quellen des ABCFM jedoch nicht genannt werden.

Referenzen: Smith an Anderson (Beirut, 13.3.1856): ABC 60 (105), (HHL); PBCFM (1896), 54 (Nr. 302).

- Kitāb tārīh al-fidā' (Ü)

(A History of the work of Redemption, von Jonathan Edwards)

Beirut, 1868 (403 S.)

Das Buch ist in drei Teile unterteilt: 1. Vom Sündenfall des Menschen bis zur Menschwerdung Jesu Christi, 2. Von der Menschwerdung Jesu Christi bis zu seiner Auferstehung, 3. Von der Auferstehung Christi bis zum Ende der Welt.

Die Schrift ist geprägt von antikatholischer Polemik.

Referenzen: Ellis (1894), 502; PBCFM (1896), 46 (Nr. 266); Jessup (1910b), 484; Murre-van den Berg (2006), 74.

1 Viele der Schriften sind in den Special Collections der N.E.S.T. zu finden, einige davon sogar in Manuskriptform. 
b) Lehrbücher

- Kitāb siyāḥat al-masīḥ̄ī (Ü)

(The Pilgrim's Progress, von John Bunyan, 1684)

Beirut 1844, ${ }^{2} 1859$ (537 S.)

Das Buch gehört zu den Klassikern der englischsprachigen, religiösen Literatur. Die christliche Allegorie ist in zwei Teile unterteilt und wird als beliebtes Lehrbuch im Schulunterricht verwendet. Zur Übersetzung gibt es widersprüchliche Angaben: Anderson berichtet, dass Cornelius Van Dyck den ersten Teil übersetzt habe, sonst wird al-Bustān̄̄ als Übersetzer angegeben. Die Edition wird 1859 vollendet und von der American Tract Society finanziert.

Referenzen: Rufus Anderson, „Memorandum of Discussions with the Missionaries during my visit to the Levant in 1843-1844": ABC 30.10, Vol. 8, 8 (HHL); PBCFM (1896), 58 (Nr. 327-330); Ṭarrāzī (1913), 90.

- Kašf al-hịḡāb fì 'ilm al-ḥisāb ${ }^{(K)}$

(Die Enthüllung des Schleiers von der Wissenschaft der Arithmetik)

Beirut 1848 (317 S.), ${ }^{2} 1859,{ }^{3} 1879$ u. v. m. (414 S.)

Das Lehrbuch wird für das Seminar in 'Abeih mit Unterstützung von Van Dyck erarbeitet und soll auf Materialien beruhen, die Eli Smith gesammelt hat. 1855 kritisieren die Missionare, dass das Buch kaum verwendet werde, da es zu umfangreich sei.

Referenzen: ABCFM (1856), 28; Șarrūf/Nimr (1883), 2; PBCFM (1896), 33 (Nr. 174); Jandora (1981), 24.

- Ilāğ mufĩd li 1-hawā’ al-aṣfar al-muhị̣̣ (Ü)

(Eine sinnvolle Behandlung der fatalen Cholera, von Azariah Smith)

Beirut 1848 (10 S.)

Azariah Smith ist Missionsarzt des ABCFM in Smyrna und Aintab, dort gelingt ihm die erfolgreiche Behandlung von Cholera. Es ist nicht bekannt, ob Smith seine Behandlungsmethoden auf Englisch veröffentlicht hat. Vermutlich geht die arabische Übersetzung auf ein unveröffentlichtes Papier zurück.

Referenzen: ABCFM (1856), 28; Șarrūf/Nimr (1883), 2; Jandora (1981), 24; Auji (2013), 120.

- Kitāb miṣbāḥ al-țālib fī baḥt al-matālib (Schlüssel für Studenten zur Untersuchung von Problemen)

Beirut 1854 (425 S.)

Das Buch ist eine Revision des 1836 von der Propaganda Fide in Rom veröffentlichten Werkes Kitāb baht al-mațālib wa hat al-țălib, verfasst vom maronitischen Prälaten Ǧibrīl Farḥat al-Halabī, später Germanus Farḥāt, Erzbischof von Aleppo. Bustānī erwähnt jedoch keinen Bezug zu diesem gedruckten Buch. Seine Grammatik enthält etwa zehn zusätzliche Seiten über Verslehre, die von Nāṣīf al-Yāziğ̄̄ ver- 
fasst sind. Obwohl das Buch in den Missionsschulen verwendet werden soll, enthält es keine Bibelzitate. In der Einleitung wird sogar aus dem Koran zitiert. Ein weiteres Manuskript, das eine Art Adaption der Grammatik darstellt und den Titel Bulūg al- 'arab fi naḥu al- 'arab trägt, soll Bustānīs Notizen für den Unterricht enthalten.

Referenzen: Ellis (1894), 429; Tibawi (1963), 160-161; Tibawi (1966), 144 (Anm. 3).

- Kitāb miftāḥ al-miṣbāḥ fĩ uṣūl al-ṣarf wa l-nahū li 1-mubtadi 'īn ta' alīf (Der Schlüssel zur Erleuchtung. Über die Grundlagen der Flexion und Grammatik für Anfänger des Schreibens)

Beirut 1862 (361 S.)

Eine kürzere Version ebenfalls von 1862 hat $144 \mathrm{~S}$. Vermutlich wird das Buch in der Madrasa Wațaniya verwendet. Es ist eine vereinfachte Fassung der 1854 herausgegebenen Grammatik (s.o.).

Referenzen: Ellis (1894), 430; PBCFM (1896), 30 (Nr. 143); Sarkis (1929), 559; Tibawi (1863), 170.

c) Sonstiges

- Raựat al-tāğir fī mabādi' mask al-dafātir ${ }^{(\mathrm{K})}$

(Garten des Händlers. Die Anfänge der Buchführung)

Beirut 1851

Der Band beruht angeblich auf zusammengestellten Materialien von Eli Smith.

Referenzen: Tibawi (1966), 144 (Anm. 3); Jandora (1981), 24.

- Al-ğuz' al-awwal min a 'māl fī Ğam 'īyat al-Sūrīya li 1- 'Ulūm wa 1-Funūn (HG) (Erster Band der Akten der Syrischen Gesellschaft der Wissenschaften und Künste)

Beirut 1852

Es ist geplant, dass Bustānī zwei Bände ausgewählter Reden herausgibt. Jedoch wird nur der erste veröffentlicht.

Referenzen: Tibawi (1966), 144 (Anm. 3); Hūrīī (1990b); Glaß (2004b), 683.

- Ahbār al-a yān fĩ ğabal lubnān (HG)

(Berichte über bedeutende Persönlichkeiten im Libanon, von Tannūs Ibn Yusūf al-Šìdyāq)

Beirut 1855 (Bd. 1)/1856 (Bd. 2), ${ }^{2} 1859,{ }^{3} 1863$ (44 S.)

Eli Smith schreibt am 11.6.1855 an die DMG: „,Tannûs Śidiâk hat seine Geschichte des Libanon [...] umgeschrieben und erweitert, und Herr Bistâny [...] hat sie so eben in unserer Presse drucken lassen. Für die Correctheit des Werkes an sich haben wir dabei keine Verantwortlichkeit übernommen." Darin geht es u. a. um Ereignisse in der Antike, Alexander den Großen, die Geschichte Jerusalems und des Libanongebirges. 
Referenzen: ZDMG 10 (1856), 303; Smith an die DMG (Beirut 9.5.1856), in: ebd. 813; Ellis (1894), 429; ders. (1901), 668.

- Huṭ̣ba fī ādāb al- 'arab (Rede über die arabische Kultur)

Beirut 1859

Bustānī hält die Rede am 15.2.1852 vor einem Publikum von Ausländern (ifranğ) sowie Arabern (abna' $a l$ - 'arab).

Referenzen: Bustānī (1859); Tibawi (1966), 148.

- Qișșat As' ad Šidyāq (Die Geschichte As'ad Šidyāqs)

Beirut 1860 (130 S.)

As 'ad Šidyāq ist der erste Protestant, der aufgrund seines Glaubens vom maronitischen Patriarchen eingesperrt wird und vermutlich durch Hunger und Folter 1830 stirbt. Während die Missionare ihn zum Märtyrer stilisieren, will Bustānī mit der Geschichte von Šidyāq Gedanken der Ökumene und des liberalen Pluralismus vermitteln.

Referenzen: Tibawi (1966), 148; Makdisi (2008), 181.

- Kitāba ilā l-nisāe fĩ bilād al-šarq (Schreiben an die Frauen im Vorderen Orient)

Beirut 1860

Referenzen: Tibawi (1966), 148.

- Dīwān al-țayyib Aḥmad Ibn al-Husayn al-Mutanabbīi (HG) (Der hervorragende Diwan des Aḥmad Ibn al-Husayn al-Mutanabbī)

Beirut 1860

Das Werk des Aḥmad Ibn Ḥusayn, genannt al-Mutanabbī, wird von Bustānī mit Notizen versehen und neu herausgegeben.

Referenzen: Ellis (1894), 429; Tibawi (1966), 144 (Anm. 3).

- Kitāb al-tuḥfa al-Bustānīya fĩ l-asfār al-Kurūzīya, aw, rihlat Rūbinṣun Kurūzī (Ü)

(Bustān̄̄s Meisterwerk über die Reisen von Crusoe, oder, die Reise von Robinson Crusoe; nach: „The Life and Adventures of Robinson Crusoe“, von Daniel Defoe, London 1719)

[Mitherausgeber: Salīm al-Bustān̄̄]

Beirut 1861 (Band 1 und 2)

Bereits 1835 wird das Buch von einem Unbekannten ins Arabische übersetzt und in Malta gedruckt. Bustānī übersetzt es zusammen mit seinem Sohn vermutlich er- 
neut. An Defoes Werk schätzt Bustānī v. a. den Sozialkommentar. Robinson Crusoe erscheint in zwei Bänden.

Referenzen: PBCFM (1896), 27 (Nr. 118-120); Jessup (1910b), 484; Tibawi (1963), 170; Jandora (1981), 192.

- Muhịt al-Muhịị, ay qāmūs muṭawwal li-lugat al- 'arabīya

(Der Umfang des Ozeans. Lexikon der arabischen Sprache)

Beirut 1866-70 (2308 S.), 2 Bde.

Das Wörterbuch basiert auf dem traditionellen Qāmūs (Wörterbuch) von alFīrūzābādī, führt jedoch etliche neue wissenschaftliche Begriffe, Neologismen, fremdsprachige sowie umgangssprachliche Wörter ein. Der erste Band (ca. $1200 \mathrm{~S}$.) wird in der Amerikanischen Druckerei gedruckt, der zweite erscheint in Bustānīs Mațba 'at al-Ma'ārif, später aber auch in der American Mission Press. Aus unbekannten Gründen erscheint jedoch die Amerikanische Druckerei nicht als Verlag auf der Titelseite des ersten Bandes. Das Wörterbuch existiert bis in die 1980er Jahre als Neuauflage in Beirut „und ist im arabischen Raum nach wie vor Gegenstand bzw. Hilfsmittel philologischer Studien“".

Referenzen: Ellis (1894a), 430; PBCFM (1896), 40 (Nr. 231-232); PBCFM (1923), 13; Tibawi (1963), 172; Tibawi (1966), 250; Glaß (2008), 112 (Zitat).

- Qaṭr al-Muhịt

(Der Durchmesser des Ozeans)

Beirut 1879 (2452 S.)

Eine komprimierte Fassung des neunbändigen Wörterbuchs Muhịṭ al-Muhịṭ (s.o.).

Referenzen: PBCFM (1896), 40 (Nr. 233).

\section{ELI SMITH}

a) Theologische Schriften

- Kitāb al-bāb al-maftūḥ fĩ a māl al-rūḥ (Ü)

(Die offene Tür - Die Werke des Heiligen Geistes)

Beirut 1843, ${ }^{2} 1863$ (256 S.)

An der Übersetzung ist Buṭus al-Bustān̄̄ maßgeblich beteiligt.

Referenzen: Ellis (1901), 633; PBCFM (1896), 47 (Nr. 268); Graf (1951), 284; Tibawi (1966), 85 (Anm. 3).

- Kitāb al-mabāhị fĩ itiqadāt ba 'aḍ al-kanā' is (Untersuchungen über die Dogmen einiger Kirchen) 
Beirut 1854 (156 S.)

Im Besonderen geht es um die katholische Kirche.

Referenzen: Graf (1951), 284.

- Tarnīmāt li 1-'ibāda (Ü)

(Gesangbuch für den Gottesdienst)

[Mitherausgeber: B. al-Bustān̄̄ und N. al-Yāziğ̄̄]

Beirut $1852,{ }^{2} 1857,{ }^{3} 1872$

Eine ursprüngliche Fassung wird 1836 auf Malta von der Church Missionary Society gedruckt. Das Buch erhält durch die drei Autoren eine Nachbearbeitung. Es enthält 32 Hymnen in Versen, die in ein 1872 neu herausgegebenes Gesangbuch eingearbeitet werden.

Referenzen: 'Abdul-Hai (1976), 121; Krek (1992), 82, 86.

(Eine Kopie befindet sich in der Andover-Harvard Theological Library)

b) Lehrbücher

- Kitāb dalīl al-șawāb fĩ ușūl al-hisisāb ${ }^{(H G)}$

(Den Verstand zu den Grundlagen der Arithmetik führen)

Beirut 1837 (84 S.): 1200 Kopien

Die Schrift stammt von Ruzūq (oder Rizq) al-Barbārī, der jahrelang als Lehrer für die Mission arbeitet. Smith schreibt dazu 1844: „Containing only the four ground rules. [...] Was used in the Seminary. Too simple." Laut Tibawi soll Būtrus alBustān̄̄ das Buch später in seine Arithmetik (s. o.) eingearbeitet haben. Aufgrund der hohen Nachfrage wird es bis in die 1890er Jahre aufgelegt. Eine spätere Ausgabe von Smiths Arithmetik zählt 120 Seiten.

Referenzen: Smith, „Report of Works Printed at the Missionary Press in Beirut“ (1844): ABC 16.8.1., Vol. 1 (28); PBCFM (1896), 33 (Nr. 173); Tibawi (1966), 85 (Anm. 3); Glaß (1998), 17 (Anm. 64).

c) Sonstiges

- Mağmū' Fawā'id (Sammlung nützlicher Lektionen)

Beirut 1851-1856, 6 Missionsblätter à 16-32 Seiten, Format 12,5 × $23 \mathrm{~cm}$

Eine Sammlung von predigtartigen Essays, populärwissenschaftlichen Artikeln und Kurzgeschichten mit christlich-moralischer Pointe nach Machart eines christlichen Periodikums.

Referenzen: PBCFM (1896), 104 (Nr. 668); Tarrāzī (1913), 53-54; Dāgīir (1978), 252, Nr. 1550; Hūūī (2003), 301; Glaß (2001), 35-37. 


\section{CORNELIUS VAN DYCK}

a) Theologische Schriften

- Kitāb li 1-ta' līm al-Masīḥ̄i (Ü)

(wörtl.: Unterweisung der Christen [Kleiner Katechismus der Westminster Versammlung])

Beirut 1843 o. 1844 (42 S.)

Der Katechismus enthält 107 Fragen und Antworten, die 10 Gebote und das Vaterunser. Der von 1647 stammende Katechismus wird von Van Dyck übersetzt sowie von Smith überarbeitet und teils verändert.

Referenzen: Graf (1951), 285; Hūī̄i (1990a), 60; Sabra (2009), 16.

- N.N. (Ü)

(„Natural Theology; or Evidences of the Existence and Attributes of the Deity“, von William Paley, New York 1802)

Beirut ca. 1848

Es ist die erste Übersetzungsarbeit Van Dycks. Das Buch gehört zum Standardwerk der American Tract Society.

Referenzen: Records of the Syria Mission I: Minutes for Oct. 2 1848, zitiert in: Tibawi (1966), 126.

- Kašf al-abāṭil fī 'ibādat al-șuwar wa 1-tamātil (Predigt über die Aufdeckung der Verkehrtheiten bezüglich der Verehrung von Bildern und Statuen)

Beirut $1853,{ }^{2} 1866,{ }^{3} 1889$ (46 S.)

Die Predigt baut auf Ex 20,4-6 und Offb 22,9 auf. Laut Van Dyck widerspricht es dem logischen Menschenverstand, mit Menschenhand ein Bild Gottes zu erschaffen, wenn man weiß, wer Gott ist und was er vermag.

Referenzen: Ellis (1901), 736; PBCFM (1896), 95 (Nr. 588); Graf(1951), 285; Hुūrī (1990a), 71.

- Al- 'ahd al-ğadīd li-rabbina wa muhallișina Jesū'a al-Mașị̣ (Ü)

(Das Neue Testamtent unseres Herrn und Erlösers Jesus Christus)

Beirut 1860 (ca. 500 S.), 6000 Kopien

In der Taschenausgabe gibt es keine Referenzen. Der Ausgabe folgen zahlreiche weitere Auflagen in verschiedenen Formaten, u. a. 1863 die vokalisierte Version des Neuen Testaments speziell für Muslime und für den Schulgebrauch.

Referenzen: Laurie (1881), 496; Sa'di (1937), 42 (Abb. 5).

- Al-sahm al-țayār wa 1-fah al-qarrār li tauqiyāt al-kurūm minā' al-ța 'alib alșigār 
(Fliegende Bogen und die entscheidene Falle für den Schutz des Grundstücks gegen kleine Füchse)

Beirut 1864 o. 1882 (12 S.)

Es handelt sich um eine Predigt über H1 2,15. Unter Füchsen versteht Van Dyck in seiner Predigt Laster wie Neid, Faulheit oder Maßlosigkeit.

Referenzen: Ellis (1901), 736; PBCFM (1896), 95 (Nr. 590); Tibawi (1966), 166; Hūūī (1990a), 73.

- Al-kitāb al-muqaddas ay kutub al-'ahd al-qadīm wa 1-'ahd al-ğadīd. Qad turğima hadītan min al-lug̉a al- ibrānīya wa l-lug̉a al-yūnānīya (Ư, HG)

(Die Heilige Schrift: Das Alte und Neue Testament. Neu übersetzt aus dem Hebräischen und Griechischen)

[In Zusammenarbeit mit Eli Smith]

Beirut $1865,{ }^{2} 1869,{ }^{3} 1871,{ }^{4} 1872,{ }^{5} 1889$ (AT: 1534 S., NT: 509 S.)

Die Gesamtausgabe ist unvokalisiert bis auf Ausnahmen, in denen die Wortbedeutung je nach Vokalisierung differiert. Wörter, die nicht im Originaltext stehen, jedoch für das Verständnis unabdingbar sind, werden kleiner gedruckt. Die Bibel wird - anders als die King James Bibel zu jener Zeit - in Paragraphen mit Teilüberschriften eingeteilt. Bis zum Jahr 1910 sind 32 neue Ausgaben und etwa 900000 Kopien notiert. Mit der Herstellung von wiederverwendbaren Metallplatten wird ab 1867 die arabische Bibel auch in den USA sowie von der British and Foreign Bible Society gedruckt. Die Oktavversion ist kleiner und enthält weder Referenzen noch Kapitelüberschriften (AT: 1358 S., NT: 422 S.).

Referenzen: Ellis (1901), 735; Jessup (1910a), 77; Thompson (1956), 24-25.

(Manuskripte der Übersetzung befinden sich im Archiv der N.E.S.T.)

- Maw iẓa al-iftihār bi 1-ṣalīb

(Predigt von der Prahlerei über das Kreuz)

Beirut 1874 (15 S.)

Van Dyck hält die Predigt vor der Beiruter Gelehrtengesellschaft Šams al-Birr (Sonne der Güte). Sie baut auf einen Vers aus dem Brief von Paulus an die Gemeinde in Galatien auf $(\mathrm{Gal} 6,14)$.

- Al-bayān fĩ qā’ idat al-imān (Ü)

(Erläuterung zum Fundament des Glaubens)

Beirut 1877 (239 S.)

Es handelt sich um eine Übersetzung des englischsprachigen Buches „The Rule of Faith“ (der Autor ist nicht bekannt). Die Übersetzung erscheint in Serienform im Missionsblatt al-Našra al-Usbū '̌ya zwischen 1875 und 1876. Das Fundament des Glaubens ist die Heilige Schrift, deren Wahrhaftigkeit nicht angefochten werden kann.

Referenzen: Hūūī (1990a), 70 
- Tārīḥ al-iṣlāḥ fi l-qarn al-sādis 'ašar (Ü)

(,History of the Reformation“, von Jean-Henri D’Aubigné, New York 1869) [Mitherausgeber: B. al-Bustānī]

Beirut 1877 (Bd. 1: 758 S., Bd. 2: 700 S.)

Die zwei Bände sind eine Zusammenstellung der Übersetzungsteile von D'Aubignés Werk, die zwischen 1872 und 1877 in der al-Našra al-Usbū '̌ya erscheinen. Jessup sowie Ṭarrāzī nennen Būtrus al-Bustānī als Übersetzer, obwohl die gedruckten Bände nur Van Dyck erwähnen. Sehr wahrscheinlich haben beide an der Übersetzung gearbeitet.

Das Werk enthält zudem eine Lutherbiografie und erscheint 1913 in einer einbändigen Neufassung, die von Ibrāhīm al-Haurāni herausgegeben wird.

Referenzen: PBCFM (1896), 106 (Nr. 256); Jessup (1910b), 484; Ṭarrāzī (1913), 90; Huūrī (1990a), 69-70; Glaß (1998), 187.

- Qișșat bait Šūnbirğ wa-Kuttā (Ü)

(„Chronicles of the Schoenberg-Cotta Family“, von Elisabeth RundleCharles, New York 1864)

Beirut 1885 (570 S.)

Die Übersetzung wird zuvor in Serienform in al-Našra al-Usbū ‘̄ya von 1873 bis 1875 abgedruckt. Die Chronik spiegelt die Ereignisse im Zuge der Reformation Luthers wider. Van Dyck hat sich für die Übersetzung dieses Werks entschieden, da es viele Übereinstimmungen mit der Situation im osmanischen Syrien gebe.

Referenzen: PBCFM (1896), 116 (Nr. 438); Hुūrī (1990a), 70-71.

- Buzūg al-nūr 'alā Ibn Ḥūr (Ü)

(„Ben Hur, a tale of the Christ“", von Lew Wallace, New York 1890)

[Kairo 1896 (500 S.)]; Beirut 1922 (436 S.)

Es ist Van Dycks letztes Buch vor seinem Tod. Ya qūb Șarrūf und Fāris Nimr geben seine Übersetzung posthum im Muqtataf-Verlag in Kairo heraus. Der Autor Lew Wallace war von 1881 bis 1885 amerikanischer Botschafter in Istanbul. Als Atheist möchte dieser mit dem Buch ursprünglich die Existenz Jesu Christi widerlegen, was ihm jedoch nicht gelingt, sodass er zum christlichen Glauben findet.

Referenzen: Șarrūf/Nimr (1896), 1; Jessup (1910a), 109; Hुūrī (1990a), 72-73.

- Ușūl al-īmān al-masīḥ̄

(Grundlagen des christlichen Glaubens)

Beirut o. J. (80 S.)

Referenzen: Huūrī (1990a), 69. 
b) Lehrbücher

- Kitāb al-mir'àt al-waḍīya fi 1-kurat al-arḍīya

(wörtl.: „Der klare Spiegel, der die Erde reflektiert“, d.i. Klarstellungen zur Geografie)

Beirut 1852, ${ }^{2} 1870,\left[{ }^{3} 1872\right](502 \mathrm{~S}$.

Der Titel zeigt, dass Van Dyck mit falschem Wissen über die Geografie der Erde aufräumen möchte. Er hat das Lehrbuch vermutlich unter Bustānīs Mithilfe während seines Geografiekurses im 'Abeih-Seminar verfasst. Da es zu umfangreich ist, findet es im Missionsseminar kaum Anwendung. Es ist dennoch das erste moderne Schulbuch in Syrien und entwickelt sich zum Standardwerk. Fahr al-Dīn Ibn alQāsim Gulpaigānī übersetzt es in die persische Sprache (Bombay, o. D.). Die dritte Auflage von 1872 widmet Van Dyck dem damaszenischen Historiker und protestantischen Konvertiten Mīhāà îl Mīšāqa, sie wird in der von Halīl Sarkīs gegründeten Mațba 'at al-Adabīya gedruckt.

Referenzen: ABCFM (1856), 28; PBCFM (1896), 32 (Nr. 163); Hūūī (1965), 389392; Sa' di (1937), 40 (Abb. 1 und 2); Glaß (1998), 188; dies. (2004a), 201.

- Kitāb al-rauḍa al-zahrīya fi 1-ușūl al-ğabrīya ${ }^{(K)}$

(Der Blumengarten. Die Grundlagen der Algebra)

Beirut 1853 (251 S.), ${ }^{2} 1877,{ }^{3} 1891$ (264 S.)

Van Dyck trägt darin Werke und deren Inhalte von englischen, amerikanischen und französischen Wissenschaftlern zusammen. Die Algebra stellt für ihn die Grundlage aller Naturwissenschaften dar.

Referenzen: PBCFM (1896), 33 (Nr. 176); Hū̄rī (1965), 392-394; Tibawi (1966), 148 (Anm. 2); Glaß (2004a), 200.

- Muḥ̄it al-dā'ira fî 'ilmī al- 'urūd wa l-qāfīya

(Der Umfang der Wissenschaft von Metrik und Reim)

Beirut 1857 (123 S.)

Das Manuskript ist bereits 1849 fertig, jedoch geht es erst acht Jahre später in den Druck. Darin finden sich in einfacher Ausdrucksweise Definitionen verschiedener Formen der Metrik. Das Buch ist für den Grundschulgebrauch gedacht.

Referenzen: PBCFM (1896), 31 (Nr. 153); Hुūrī (1965), 396-397; Hūūī (1992), 210.

- Kitāb fi l-uṣūl al-handasīya wa huwa muštamil 'ala kutub Iqlīdis al-sita wa muḍāātin fì tarbī' al-dā'ira wa handasīya al-ağsām wa uṣūl qiyās almutalatāt al-mustawīya wa 1-karwīya - kutub Iqlīdis al-sita (Ü)

(Buch über die Grundlagen der Geometrie: Es umfasst Euklids sechs Bücher [sowie] zusätzlich die Quadratur des Kreises, zur Geometrie von Körpern sowie zu den Grundlagen der Analogie von einfacher und sphärischer Trigonometrie - Euklids 6 Bücher) 
Beirut $1857,{ }^{2} 1875,{ }^{3} 1889(812 \mathrm{~S}$.)

Van Dycks Übersetzung aus dem Englischen besteht aus elf Kapiteln: Sechs widmen sich den sechs Büchern von Euklid, in den übrigen Kapiteln geht es u. a. um die Quadratur des Kreises, Raumgeometrie sowie um Trigonometrie. Das Buch ist wie „Die Grundlagen der Algebra“ (s.o.) aufgebaut: Es wird eine Regel anhand eines Beispiels definiert und erklärt. Van Dyck vollendet das Manuskript in Sidon.

Referenzen: Ellis (1901), 735; PBCFM (1896), 33 (Nr. 178); Sa'di (1937), 41 (Abb. 4); Hūūī (1965), 394-395.

- Ușūl al-kīmīyā'

(Die Grundlagen der Chemie)

Beirut 1869 (412 S.)

Das Buch gilt als das erste moderne Hochschullehrbuch in Syrien und wird zum Standardwerk. Es ist in vier Teile gegliedert (1. Die Schwere der Elemente, die nicht messbar ist; 2. Die Benennung der Chemikalien; 3. Die Chemie der Elemente in Verbindung [mit anderen]; 4. Die Chemie der Elemente ohne Bindung). Für die Druckkosten kommt Van Dyck selbst auf.

Referenzen: Hुūrī (1965), 397-398; Tibawi (1966), 185; Huūrī (1992), 210.

- Kitāb fī 1-ğadari wa 1-ḥaṣba li 1-Rāzī (HG)

(al-Rāzī, Über Pocken und Masern)

Beirut 1872/73 (112 S.)

Abū Bakr Muḥammad bin Zakarīyā al-Rāzī lebte von 850 bis ca. 932 n.Chr. Die Kopie des ursprünglichen Manuskripts hat Van Dyck aus Venedig. Er fügt der Neuauflage erklärende und kritische Kommentare sowie ein weiteres Kapitel über die modernen Erkenntnisse bezüglich dieser Krankheiten hinzu. Weil Van Dyck es für ein wichtiges Werk erachtet, bittet er den Board of Managers des SPC, es drucken zu dürfen. Die Kosten werden vom „Syrian Improvements Committee“ übernommen.

Referenzen: SPC Jahresbericht (27.6.1872): ABC 16.8.2., Vol. 2, 25; Hūūrī (1965), 398-400; Hūūī (1992), 210; Sa'di (1937), 31; Glaß (2004a), 200.

- Kitāb fī lugāāị̣māt ay al-ansāb wa fī masāḥa al mutalatāât al-mustawīya wa masāḥa al-suṭūḥ wa l-ağsām wa masāḥa al-arḍ̂̄ wa l-silk al-ğar wa 'ibārāt li-masāḥa al-mutalatāât al-kurawīya bi-wāsațat al-ansāb

(Teil 1: Buch über die Logarithmen jeder Herkunft, über die Fläche eines gleichseitigen Dreiecks, die Fläche einer Ebene und eines Körpers, die Fläche der Erde und Subtraktion, Erläuterungen zur Fläche einer Kugel mithilfe der Verhältnisbestimmung)

- Ğadāwil ansāb al-ğuyūb wa 1-mumāsāt

(Teil 2: Tabellen für Logarithmen, Sinus und Tangenten) 
Beirut 1873 (Teil 1: 352 S.; Teil 2: 156 S.)

Van Dyck verwendet hier dieselben Fachtermini wie in seinen Werken „Grundlagen der Algebra“ und „Grundlagen der Geometrie“ (s. o.).

Referenzen: PBCFM (1896), 33 (Nr. 179); Sa'di (1937), 44 (Abb. 9 und 10); Hūūrī (1965), 400-401; Hūrī (1992), 210; Glaß (2004a), 200.

(Das Manuskript des Werkes befindet sich im Archiv der N.E. S. T.: vgl. Ms AP-23)

- Ușūl al-tašhīị al-țabī'̄̄

(Grundlagen der physikalischen Diagnostik)

Beirut 1874 (128 S.)

Van Dyck richtet sich bei den medizinischen Begrifflichkeiten wie z. B. bei der Bezeichnung der Körperteile, nach den klassischen, arabischen Medizinbüchern. Das Buch ist für das Medizinstudium am SPC gedacht.

Referenzen: Huūrī (1965), 403-405; Hुūrī (1992), 210; Glaß (2004a), 200.

- Ușūl 'ilm al-hai'a

(Grundlagen der Astronomie)

Beirut 1874 (288 S.)

Das Werk, das für das Studium am SPC gedacht ist, bringt die Erkenntnisse der Astronomie auf den neuesten Stand. Van Dyck übernimmt arabische Namen für die in früheren Jahrhunderten entdeckten Planeten, neuere Entdeckungen (z.B. Neptun von 1859) werden transliteriert. In der Einleitung betont er, dass Astronomie ursprünglich nur die Lehre über die Sterne sei, während die Araber schon seit Jahrhunderten unter 'ilm al-hai' a die Lehre von Himmelskörpern sowie der Erde verstehen.

Referenzen: PBCFM (1896), 38 (Nr. 209); Huūrī (1965), 402-403; Sa'di (1937), 45 (Abb. 11); Hūūī (1992), 210; Glaß (2004a), 200.

(Im Archiv der N.E.S.T. befindet sich ein auf ca. 1870 datiertes Manuskript mit dem Titel Al-astirūnūmìya, ay, 'ilm al-hay'a: vgl. AP-22)

- Muhtașar tārīh 'ilm al-hai' a (Kurze Geschichte der Astronomie)

Beirut ca. 1874 (181 S.)

Vermutlich handelt es sich um eine kürzere Fassung der „Grundlagen der Astronomie“" (s. o.). Es ist ebenfalls für den Gebrauch am SPC gedacht.

Referenzen: Sa'di (1937), 45 (Abb. 11); Glaß (2004a), 200.

- Ușūl al-bātūūūğīya al-dāhilīya al-ḩașa - ay mabādī' al-țibb al-bašarī al-naẓarī wa 'amalī (Ü)

(Grundlagen der speziellen internen Pathologie - d.h. der Humanmedizin in Theorie und Praxis) 


\section{Beirut 1877 (1055 S.)}

Das Buch ist eine Übersetzung des Lehrbuchs von F.T. Roberts „Theory and Practice of Medicine“ (1874). Es ist für das Studium am SPC bestimmt. Die Druckkosten übernimmt der Theodore Publication Fund.

Referenzen: SPC Jahresbericht (1878): ABC 16.8.2., Vol. 2, 46; Hū̄rī (1965), 405406; Hūūī (1992), 210; Sa' di (1937), 43 (Abb. 8).

- Kitāb al-nafā' is li-talāmiḍat al-madāris

(Die Kostbarkeiten für Schüler [oder: Chrestomathie])

Beirut ca. 1886

Es handelt sich um eine von Van Dyck überarbeitete Fibel mit literarischen und naturwissenschaftlichen Texten für den normalen Schulgebrauch. „Es vereint klassische und zeitgenössische arabische Stücke. Der äußere Zuschnitt erinnert im Übrigen sehr an Lesebücher für europäische Bildungsvereine des 19. Jh.s.“

Referenzen: Ellis (1901), 736; Glaß (1998), 189, 194-195 (Zitat); Glaß (2004a), 200.

- Al-alfāz al- 'arabīya wa l-falsafa al-lugàwīya (?)

(Arabische Aussprache und Sprachlehre)

Beirut 1886

Die DMG erhält eine Kopie des Werkes. Es ist unklar, ob Van Dyck der Autor ist.

Referenzen: ZDMG 42 (1888), XIII (Verzeichnis der in die Bibliothek der DMG eingegangenen Schriften)

- Kitāb al-naqš fĩ 1-ḥağar (od. Silsilāt od. Mağmū'āt al-naqš fĩ 1-ḥağar)

(Die Inschrift auf dem Stein, bzw. Serien/Sammlungen über die Inschrift auf dem Stein)

Beirut, zwischen 1886 und 1889

Die Reihe besteht aus acht Teilen, die jeweils eine Wissenschaft einführen: 1. Natur und die Wissenschaft (128 S.); 2. Chemie (142 S.); 3. Physik (136 S.); 4. Geografie (102 S.); 5. Geologie (123 S.); 6. Astronomie (122 S.); 7. Botanik (132 S.); 8. Logik (112 S.)

Die Bände sind an die Reihe „Science Primers“ angelehnt, die im 19. Jh. im Macmillan and Co Verlag erscheinen. Sie sollen jungen SchülerInnen und Studierenden ein notwendiges Allgemeinwissen zu jedem Fach vermitteln, das dann in speziellen Studien vertieft werden kann. Das Studium des ersten Bandes erleichtert das Verständnis des Nächsten, da die Bücher aufeinander aufbauen. Die Bände werden am SPC und in den Schulen verwendet. Auf Empfehlung von Ya qūb al-Ṣarrūf werden sie auch in ägyptischen Schulen eingesetzt und sind dort sehr beliebt. Y.Q. Hūrī (1965) notiert, dass alle Bände in der Mața 'at al-Adabīya gedruckt werden. Sie erscheinen jedoch auch im Katalog der Amerikanischen Druckerei von 1896. 
Referenzen: Presbyterian Church in the USA (1891), 485; PBCFM (1896), 34 (Nr. 180-183), 35 (Nr. 184-187); Hūrīi (1965), 406-115; Hūrì (1990a), 107; Glaß, 1998, 188; Glaß (2004a), 200-201.

(Das Archiv der N.E.S.T. besitzt den Entwurf des achten Bandes [Mabād $\bar{\imath}$ al-mantiq]: vgl. AO-53)

- Kitāb arwā' al-ẓamā' min maḥāsin al-qubba al-zarqā' wa huwa bimatāābat al-ğuz' al-țānī al-'amalī li-kitāb ușūl al-hai'a

(Den Durst nach der Schönheit des Himmels löschen - als zweiter praktischer Teil des Buches, Grundlagen der Astronomie)

Beirut 1893 (239 S.)

Für das Werk nimmt Van Dyck verschiedene englisch- und arabischsprachige Werke zu Hilfe, die sich mit Astronomie befassen. Neben der Aufzählung neuester Forschungsergebnisse gibt es einen historischen Abriss über arabische Gelehrte der Astronomie in den vergangenen Jahrhunderten. Die Druckkosten des Werkes trägt Van Dyck selbst.

Referenzen: PBCFM (1896), 38 (210); 'Ağulūnī (1964), 6; Hुūrī (1965), 415-417; Mațar (1966), 28.

- Aqlīis arba'a kutub (Ü)

(Vier Bücher von Euklids [Geometrie])

Beirut o.J. (125 S.)

Vermutlich fertigt Van Dyck diese Übersetzung noch vor den 1857 erscheinenden „Grundlagen der Geometrie“ (s. o.) an.

Referenzen: PBCFM (1896), 33 (Nr. 177).

c) Sonstiges

- Al-Našra Ahbār 'an Intišār al-Inğīl fĩ Amākin Muhtalifa (HG) (Nachrichten über die Verbreitung des Evangeliums an verschiedenen Orten, 1863 - Mai 1868) bzw.

- al-Našra al-Šahrīya ${ }^{(\mathrm{HG})}$ (Monatliche Zeitschrift, Juni 1868 - Januar 1871) bzw.

- al-Našra al-Usbū '̄ìa ${ }^{(\mathrm{HG})}$ (Wöchentliche Zeitschrift, Januar 1871 -)

Beirut ab 1863

1868 wird die Zeitschrift in al-Našra al-Šahrīya, 1871 dann in al-Našra al-Usbū '̌ya umbenannt. Inhaltlich liegt der Fokus auf Ereignissen und Geschichten rund um die Verbreitung der christlichen Botschaft. Im Laufe der Jahre kommen zunehmend sachliche Artikel hinzu, wobei der religiöse Charakter beibehalten wird. Van Dyck gibt das Periodikum bis Ende 1879 heraus. Spätere Herausgeber sind William 
Eddy, Samuel Jessup, sein Bruder Henry Harris Jessup, Ibrahīm Haurānī u. v.m. Der Druck wird von der London Religious Tract Society finanziert.

Referenzen: PBCFM (1896), 72 (Nr. 448); Tarrāzī (1913), 20-21, 66; PBCFM (1923), 8; Al-Rifā '̄ (1969), 89-91; Huūrī (1990a), 66-69; Glaß (2001), 41-42.

- Qāmūs inklīsī wa 'arabī muṭawwal li-Yuhannā Affandī Abkāriyūs (HG) (Englisch-Arabisches Wörterbuch, ausführliche Fassung von John Abcarius)

Beirut o.J.

Van Dyck bearbeitet und erweitert das ursprünglich vom syrisch-protestantischen Geschäftsmann John Abcarius herausgegebene Wörterbuch.

Referenzen: PBCFM (1896), 40 (Nr. 227); Jessup (1910b), 439, 499.

\section{JOHN WORTABET}

a) Theologische Schriften

- Dalīl al-șawāb ila șidq al-kitāb (Ü)

(,A brief outline of the evidence of the Christian Religion“, von Archibald Alexander, New York 1836)

Beirut 1851 (247 S.)

Alexanders Werk ist vermutlich die Kurzfassung seines 1832 erschienenen Buches „The Evidences of the Christian Religion“. Smith erwähnt gegenüber Anderson, dass sowohl Van Dyck als auch Yāziğī Wortabets Übersetzung Korrektur gelesen haben, damit der Text druckreif werden könne. Den Druck finanziert die London Religious Tract Society.

Referenzen: Smith an Anderson (Beirut, 13.3.1856): ABC 60 (105), (HHL); Ellis (1894a), 222; PBCFM (1896), 61 (Nr. 347).

- Kifaf al-ẓulām fĩ ḥaqīqa al-ṣalāt wa 1-șiyām (Ü)

(wörtl. Die Waagschale der Finsternis: Über die Wahrheit des Betens und Fastens, nach: „On Prayer and Fasting“, J.E. Ford)

Beirut ca. 1855 (134 S.)

In einem Brief an Smith vom 9.3.1855 schreibt Wortabet, dass er das von Smith an ihn gesandte Manuskript über Gebet und Fasten noch nicht vollständig übersetzt habe. „Having been so long out of the practice of translating, and indeed of Arabic Composition.“

Referenzen: ABC 60 (98), (HHL); PBCFM (1896), 57 (Nr. 323). 
- Al-kanz al-ğalīl fi tafsīr al-inğīl muğallad al-tāliț: al-A 'māl wa Rūmīya (Ü)

(Der kostbare Schatz des Bibelkommentars: Apostelgeschichte und Römer)

Beirut 1868, 2000 Kopien

1878 beginnt William Eddy eine umfassende Kommentarreihe zum Neuen Testament zu erstellen. Da Wortabet zuvor bereits die Kommentare zum Hebräerbrief, zur Apostelgeschichte und zum Römerbrief verfasst hat, werden diese zu Eddys Kommentaren ergänzend hinzugefügt.

Referenzen: „Estimate of Books to be printed by the Syria Mission in 1868“, in: ABC 16.8.1., Vol. 7.2. (517); PBCFM (1896), 47 (Nr. 271); PBCFM (1923), 8.

- Kitāb al-hizānat al-ḍahabīyat (Ü) („Güldenes Schatz-Kästlein der Kinder Gottes“, von Carl Heinrich von Bogatzky, Halle 1718)

Beirut $1870,{ }^{2} 1897$ (379 S.)

Das Buch enthält ausgewählte Texte aus der Bibel, mit Prosa- und Gedichtversen für jeden Tag.

Referenzen: Ellis (1884a), 415; PBCFM (1896), 48 (Nr. 275-276)

- Tafsīr al-risāla al- ibrānīya. Manqūl 'an al-tafāsīr al-qadīma wa 1-ḥadīta ${ }^{(\mathrm{K})}$ (Hebräerkommentar, basierend auf alten und neuen Kommentaren)

Beirut 1875

b) Lehrbücher

- Al-tauḍīh fī ușūl al-tašrīh. Waḍa 'ahu ğāmi 'ahu hidmatan li-abnā' al-lug̉a al- 'arabīya manqūlan 'an aḥdat al-kutub al-mā'awwil 'aleyha fī madāris al-inklisīya wa amīrikanīya ḥāwayan ğamī' al-masā'il allati taḥtāğ alțaliba hāāīyan min al-ta 'aqīi wa 1-ibhām sahl al-tartỉb wa 1-fahm wa 1-ḥafẓ mawḍahan bi-talāt mi' a wa 'arba 'a sitīn šaklan

(Verdeutlichung der Grundlagen der Anatomie. Insgesamt wurde es als Hilfe für arabische Muttersprachler erstellt [und] von den neuesten Büchern übernommen, die in den englischen und amerikanischen Schulen anerkannt sind. Es beinhaltet alle für die Studierenden nötigen Fragen, frei von Komplikation und Unklarheit, leicht zu ordnen, zu verstehen und zu merken; verdeutlicht in 364 Abbildungen)

Beirut 1871 (742 S.)

Das Buch dient als Lehrbuch für das SPC. Der lange Titel verdeutlicht Wortabets stetes Anliegen, sein Fach immer verständlich zu vermitteln. Die Druckkosten übernimmt der Theodore Publication Fund des SPC.

Referenzen: PBCFM (1896), 36 (Nr. 195); Zaydān (1903), 429; Tibawi (1966), 248; Huūrī (1992), 213; Glaß (2004a), 203. 
- Muhtașar fĩ a 'ḍāa' al-ğasad al-bašarī wa wad̄ā'ifihi

(Abriss über die Teile des menschlichen Körpers und ihre Funktionen)

Beirut 1873

Das Kompendium über strukturelle Anatomie wird für das SPC verfasst und später zusammen mit dem Atlas der Anatomie und Physiologie (s. u.) gedruckt.

Referenzen: Ellis (1901), 770; Glaß (2004a), 203.

- Ușūl al-fisyūlūğiyā (Ü, K)

(Grundlagen der Physiologie)

Beirut 1877 (563 S.)

Es handelt sich um die Übersetzung der achten Auflage des von William S. Kirkes verfassten Lehrbuches. Das für das SPC vorgesehene Werk ist mit vielen medizinischen Abbildungen versehen, die jeweils in Fußnoten erklärt werden.

Referenzen: Ellis (1894), 861; ders. (1901), 770; PBCFM (1896), 35 (Nr. 194); Zaydān (1903), 429; Tibawi (1966), 248; Hुūrī (1992), 213; Glaß (2004a), 203.

- Aṭlas fī 1-tašrīḥ wa 1-fisyūlūğiyā wa ma 'ahu muhtașir fĩ ā ' ḍà' al-ğisd al-bašrī wa waẓā' ifahā (Ü)

(„Atlas of Human Anatomy and Physiology“, William Turner, Edinburgh 1857)

Beirut ca. 1878

Vermutlich hat Wortabet mit Turners Lehrbuch in Edinburgh gearbeitet. Das Werk ist mit Illustrationen versehen und wird im SPC eingesetzt.

Referenzen: PBCFM (1896), 36 (Nr. 196); Tibawi (1966), 248; Huūrī (1992), 213; Glaß (2004a), 203.

- Kifāyat al-'awām fì ḥifz al-ṣiḥha wa tadbīr al-asqām

(Hygiene für den Erhalt der Gesundheit und als Maßnahme bei Krankheiten)

Beirut 1881 (281 S.)

Es ist eine Art Sammlung von nützlichen Ratschlägen, für den Fall, dass kein Arzt zugegen ist. Das Buch richtet sich daher an ein allgemeines Lesepublikum.

Referenzen: PBCFM (1896), 35 (Nr. 190); Tibawi (1966), 248.

- Mabādi' 'ilm al-ṣaḥa

(Grundlagen der Hygiene)

Beirut o.J.

Vermutlich ist es wie das o.g. Werk eine Informationsschrift für die Bevölkerung.

Referenzen: PBCFM (1896), 35 (Nr. 188). 
c) Sonstiges

- Qāmūs 'arabī wa inklīsī wa inklīsī wa 'arabī. Muḥtaṣir al-Duktūr Yuhanna Wurtabāt wa 1-Duktūr Harvey Porter

(Arabisch-Englisches und Englisch-Arabisches Wörterbuch. Kurzausgabe von Dr. John Wortabet und Dr. Harvey Porter)

[Mitherausgeber: William Thomson Wortabet]

Beirut o.J.

John Wortabet erarbeitet das Wörterbuch zusammen mit seinem Sohn William Thomson und Harvey Porter, Professor am SPC. Henry Wortabet, ebenfalls Tutor am SPC, gibt bereits zuvor unter der Mitarbeit seines Vaters ein Wörterbuch für Englisch-Arabisch heraus.

Referenzen: PBCFM (1896), 40 (Nr. 228); Penrose (1941), 38.

- Qāmūs 'arabī wa inklīsī taba 'a tānīya. Manḥaqa wa muḍāf ilayha al-Duktūr Yuhanna Wurtabāt wa 1-Duktūr Harvey Porter

(Arabisch-Englisches Wörterbuch. Ungekürzte, zweite Auflage von Dr. John Wortabet und Dr. Harvey Porter)

Beirut o. J. (818 S.)

Das Werk wird bis heute gedruckt.

Referenzen: PBCFM (1896), 40 (Nr. 229).

- Waṣāya al-šuyūh li 1-šabān. Hițāb li 1-Duktūr Wurtabāt talāhu fĩ 1-ḥafla alsanawìya al-madrasa al-kulīya

(Empfehlungen von alten an junge Leute. Eine Rede von Dr. Wortabet, gehalten zur Jahresfeier des Colleges)

Beirut 1896 (16 S.)

Wortabet hat die Schrift in Zusammenarbeit mit Harvey Porter erstellt.

Referenzen: PBCFM (1896), 103 (Nr. 665); Huūrī (1992), 213. 


\section{ANHANG II \\ NATIVE HELPERS UND PROTESTANTISCHE
KONVERTITINNEN UND KONVERTITEN (1823-1900)}

$\mathrm{N}=$ native helper

$\mathrm{P}=$ protestantische/r Konvertitin/Konvertit

\section{ABKĀRIYŪS, YUHANNĀ ODER JOHN ABCARIUS $(\dagger 1886)^{(\mathrm{P})}$}

Der Sohn von Ya 'qūb Ā $\dot{g} \bar{a}$ Abkarīyūs (Nr. 2) wird in einer amerikanischen Missionsschule ausgebildet. Als Geschäftsmann in Ägypten und Übersetzer des Botschafters wird er zu einem wohlhabenden Mann. Darüber hinaus übersetzt er viele Bücher in die arabische Sprache, verfasst ein Englisch-Arabisches Wörterbuch und ist Ältester der Beiruter Kirchengemeinde.

Referenzen: PBCFM (1896), 40 (Nr. 227); Jessup (1910b), 439, 499.

\section{2. ĀĠĀ ABKĀRIYŪS, YA 'QŪB ${ }^{(P)}$}

$\bar{A} \dot{g} a \bar{a}$ arbeitet als Agent des englischen Konsuls in Sidon und kommt mit William Goodell in Kontakt. Diesem vermittelt er die beiden armenischen Geistlichen Dionysios Carabet und Gregory Wortabet.

Referenzen: MH 23 (1827), in: ROS 1, 454; Tibawi (1966), 35.

\section{AL-ASĪR (AL-AZHARĪ), YŪSUF (1815-1889) (sunnitisch) ${ }^{(\mathrm{N})}$}

Der in Sidon geborene Syrer studiert Jura und Islamische Theologie an der AlAzhar Universität in Kairo, arbeitet daraufhin als Jurist in Tripoli und an anderen Orten. Nachdem er als Arabischlehrer in Istanbul tätig war, kehrt er nach Syrien zurück, um an der maronitischen Schule al-Hikma und Buṭrus al-Bustānīs Nationalschule zu lehren. Später hat er ebenso einen Lehrauftrag an einer griechischkatholischen Akademie sowie am SPC. Al-Asīr arbeitet ab 1857 zusammen mit Van Dyck an der Übersetzung der arabischen Bibel und ersetzt somit Buțus alBustānī und Nāṣīf al-Yāziḡī. Zudem komponiert er einige arabische Hymnen für die evangelische Kirche. Darüber hinaus ist er als Redakteur der Zeitschrift Lisān al-Hāl (wörtl.: stumme Sprache) tätig und gibt zusammen mit 'Abd al-Qādir alQabbānī ab 1875 die erste muslimische Zeitung Tamarāt al-Funūn (Die Früchte der Kunst) in Syrien heraus. Al-Asīr gehört auch zu den Gründungsmitgliedern der 
Ğam ‘yyat al-Maqāṣid al-Hayrīya al-Islāmīya (Islamische Gesellschaft für mildtätige Zwecke, 1878).

Referenzen: Zaydān (1903), 148-150; Hitti (1957), 463; Tibawi (1967), 277; Atiyeh (1995), 240; Kades (1997), 49-50; Traboulsi (2007), 65; Makdisi (2010), 86; Binay (2012b), 82.

\section{AL-AYITĀNīi, KAMĪL $(\dagger 1892)^{(\mathrm{P})}$}

Als Junge besucht al-Ayitānī eine jesuitische Schule, um Griechisch zu lernen. Dort kommt er zum ersten Mal mit der Bibel in Kontakt. Gegen den Willen seines Vaters beschäftigt er sich eingehender mit den christlichen Lehren und sucht den Kontakt zu Henry Harris Jessup. Nachdem er konvertiert, leistet er missionarische Arbeit für die Arabian Mission der Reformierten Kirche in Amerika im syrischen Busra. Nur zwei Jahre nachdem er konvertiert ist, stirbt er im Juni 1892. Es wird vermutet, dass man ihn vergiftet hat. Eine Autopsie des Körpers wird jedoch verwehrt und der Leichnam auf einem muslimischen Friedhof begraben.

Referenzen: Jessup (1898); ders. (1910b), 553.

\section{AZĀR, YUSŪF (griechisch-orthodox) ${ }^{(\mathrm{N})}$}

Als 1840 viele Drusen aus Beit al-Witwat sich der Mission zuwenden, eröffnen die Amerikaner dort eine Schule und stellen Yusūf Azār ein.

Referenzen: Van Dyck (o. J.), 6.

$$
\text { 6. AZĀR, ALLAH (Konfession unbekannt) }{ }^{(\mathrm{N})}
$$

Azār wird zur Aushilfe 1840 in der American Mission Press eingestellt.

Referenzen: Van Dyck (o. J.), 13.

$$
\text { 7. 'ABDALLAH, } \mathrm{AS}^{\prime} \mathrm{AD}{ }^{(\mathrm{N}, \mathrm{P})}
$$

Am 30.9.1891 wird er für die Gemeinde in 'Ain Zhaltā zum Pfarrer ordiniert.

Referenzen: Jessup (1910a), 577.

$$
\text { 8. 'ABŪD, DAHER }{ }^{(N, P)}
$$

'Abūd wird durch den Konvertiten Tannūs Karem bekehrt und arbeitet als Lehrer für die Mission in Ibl. Da er im Predigen und Missionieren seine Passion findet, beendet er seine Anstellung als Lehrer und wird zusammen mit dem Protestanten Ya 'qūb al-Ḥakīm nach Qānā sowie in den Hauran und östlich des Jordan gesandt. 
Beide sind ebenfalls als Ärzte ausgebildet. Später studiert 'Abūd im Seminar in 'Abeih und soll 1857/58 ordiniert werden, wozu es jedoch keine bestätigenden Angaben gibt.

Referenzen: $\mathrm{MH} 47$ (1851), in: ROS 4, 147; „Report of the Hasbeiya station for the year 1853“: ABC 16.8.1., Vol. 4.1. (167); Van Dyck an Anderson (Sidon, 23.4.1857): ABC 16.8.1., Vol. 5, Nr. 343; Anderson (1872b), 336.

\section{9. 'ARAMĀN, MIHĀ' '̄L ${ }^{(N, P)}$}

'Aramān besucht zuerst das Jungeninternat in Beirut und begleitet die Missionare um 1840 nach Jerusalem, um dort als Arabischlehrer zu assistieren. Nachdem Buțrus al-Bustān̄̄ das Seminar in 'Abeih verlassen hat, nimmt Mīhăà'l seine Stellung als Lehrer ein. 1847 tritt er der Syrischen Gesellschaft der Wissenschaften und Künste bei. Zwischen 1847 und 1848 wendet er sich erneut vom evangelischen Glauben ab, arbeitet daraufhin für die irische Mission in Damaskus und kehrt wieder zum Protestantismus zurück. Nach Gründung der einheimischen Kirche in Beirut 1848 ist er kurzzeitig sogar als Kandidat für das Pastorenamt im Gespräch, wird jedoch als zu jung und unerfahren eingestuft. Im Jahr 1858 gründet er eine private Mädchenschule, die von der Mission finanziell unterstützt und später mit amerikanischem bzw. englischem Personal ausgestattet wird. „He is, as we think, decidedly pious, and exhibits more of the experimental in religion than most of our native brethren." Um ca. 1873 lehrt er für zwei Stunden pro Woche Englisch am SPC. Bliss ist jedoch mit ihm als Lehrkraft nicht zufrieden und der Vertrag mit 'Aramān endet bereits im April 1874.

Referenzen: Van Dyck (o. J.), 8; Syrienmission an Anderson (Beirut, 20.3.1848): ABC 16.8.1., Vol. 4.1. (21); MH 46 (1850), in: ROS 4, 112 (Zitat); MH 63 (1867), in: ROS 5, 172; „Minutes of General Faculty 1867-1887“ (13.4.1874), 191: AA.2.4.2.; Tibawi (1966), 163; Hū̄rī (1990b), 18; Badr (1992), 291, 294; Daniel Bliss an Abby Bliss (Beirut, 19.10.1873), in: Bliss (1993), 98.

\section{0. 'ARAMĀN, LULU (N, P)}

Die Frau von Mīhā' ̄̄l 'Aramān (Nr. 9) gehört zu den Gründungsmitgliedern der evangelischen Kirchen in Beirut 1848. Sie ist Schülerin in der Mädchenschule von Familie De Forest, in der sie auch aufwächst. 1861 bis 1869 leitet sie zusammen mit ihrem Mann ein von der Mission unterstütztes Mädcheninternat.

Referenzen: MH 63 (1867), in: ROS 5, 172; Jessup (1910b), 672.

$$
\text { 11. 'AṬ̂, MŪSA (ursprünglich katholisch) }{ }^{(\mathrm{N}, \mathrm{P})}
$$

'Ațā hilft ab 1840/41 in der Druckerei aus und ist bis zum Jahr 1870 der einzige Konvertit in Zahle, wo die Mission erst nach Übergabe an den PBCFM aktiver 
wird. Er ist der Vater von Rạ̣̄l 'Ațā (Nr. 12), der Ehefrau von Buṭrus al-Bustānī (Nr. 20).

Referenzen: Van Dyck (o. J.), 13; Jessup (1910a), 155; Lindner (2014b)

\section{2. 'AṬ̂̄ AL-BUSTĀNĪ, RAḤĪL (1826-1894) (ursprünglich griechisch-orthodox $)^{(\mathrm{N}, \mathrm{P})}$}

Mitte der 1830er Jahre besucht Rahīl die von Sarah Smith geführte Mädchenschule in Beirut. Sarah, die Ehefrau von Eli Smith, nimmt sich des Mädchens an und betrachtet sie wie eine Adoptivtochter. Da Sarah jedoch früh verstirbt kommt Rahīl in den folgenden Jahren bei verschiedenen Missionarsfamilien unter. Sie wird als Lehrerin in den Missionsschulen eingesetzt und übersetzt Kinderschulbücher in die arabische Sprache. 1843 heiratet Rahīl Butrus al-Bustānī (Nr. 20) und sie bekommen 9 Kinder. Rahīls Einfluss in der protestantischen Gemeinschaft sowie ihr Mitwirken an der vielseitigen Arbeit ihres Mannes darf nicht unterschätzt werden. Sie hat das Privileg, zweisprachig aufgewachsen zu sein und von Beginn an die beste Bildung zu erhalten, die einer syrischen Frau in jener Zeit zuteil werden kann.

Referenzen: MH 39 (1843), in: ROS 3, 381-382; Jessup (1874), 120-139; Booth (2002), 433-438; Lindner (2009), 93-94; Lindner (2014a).

\section{3. 'AṬ̂̄YA, IBRAHĪM ${ }^{(N, P)}$}

'Atīya arbeitet zunächst als Lehrer für die amerikanische und später für die britische Syrienmission.

Referenzen: Jessup (1910a), 326

\section{BADR, HANNĀ (P)}

Hannā ist der Bruder des ersten einheimischen Pfarrers der Beiruter Gemeinde, Yūsuf Badr (Nr. 15). Er ist zunächst ein einfacher Arbeiter in den Steinbrüchen. Nachdem er die amerikanischen Missionare kennengelernt hat, konvertiert er zum evangelischen Glauben. Daraufhin studiert er in 'Abeih und predigt unter den Beduinen, bis er bereits 1871 stirbt.

Referenzen: Jessup (1910a), 324-325, 327.

\section{BADR, YŪSUF $(† 1912)^{(\mathrm{N}, \mathrm{P})}$}

Badr studiert im Missionsseminar in 'Abeih ab 1869, arbeitet als Lehrer in Zahle und 'Abeih und geht daraufhin im Dienste der Mission in die Kirchengemeinde nach Homs. Nachdem man lange nach einem einheimischen Pastor für die Beiruter Kirchengemeinde gesucht hat, erklärt sich 1890 der bereits 1872 zum Pfarrer ordi- 
nierte Yūsuf Badr einverstanden, dieses Amt zu übernehmen. Nach Beirut leitet er weitere Gemeinden in Tyros (Ṣūr) und Marğa yūn im Süden des Landes.

Referenzen: „Annual Report of Beirut Station, 1865“: ABC 16.8.1., Vol. 6 (39); Jessup (1910a), 313; al-Helū (2010), 131.

\section{BARAKAT, ك̌AHĪN ${ }^{(P)}$}

Barakat ist Presbyter in der Kirchengemeinde in Hāṣbeiyā und wird im Bürgerkrieg von 1860 bei einem Massaker während des Gebets „für den Feind“ getötet.

Referenzen: Bird (1872), 418; Jessup (1910a), 275.

\section{BARBĀRI, RIZQ (O. RAZŪQ) ALLAH († 1886) ${ }^{(\mathrm{N}, \mathrm{P})}$}

Bārbarī arbeitet für ca. 30 Jahre als Lehrer in 'Abeih und Beirut. Er ist Übersetzer und Herausgeber vieler arabischer Bücher der amerikanischen Druckerei und maßgeblich an der Entwicklung der Missionszeitschrift Ahbār 'an Intišār al-Inğīl fì Amākin Muhtalifa, später al-Našra al-Usbu ‘̄ya beteiligt. Laut Missionary Herald soll Barbārī im Sommer 1862 ins Pfarramt ordiniert werden, 1866 wird notiert, dass er nun Diakon in 'Abeih sei. H.H. Jessup schreibt, Barbārī habe aus Bescheidenheit das Amt des Pastors in der Beiruter Kirche abgelehnt.

Referenzen: MH 52 (1856), in: ROS 4, 264, 275 u. v. m.; MH 58 (1862), in: ROS 5, 42; MH 63 (1867), in: ROS 5, 168; PBCFM (1896); Jessup (1910b), 499; Tibawi (1966), 251; al-Helū (2010), 147.

\section{BEŠĀRĀ (ك̌EIḦ) (Konfession unbekannt) ${ }^{(\mathrm{N})}$}

Bešārā erscheint in der Gehaltsliste von 1842 mit einem für einheimische Mitarbeiter vergleichsweise hohem Gehalt von 300 Dollar pro Jahr. Seine genaue Tätigkeit ist nicht bekannt.

Referenzen: Bericht an das Prudential Committee (Beirut, 24.4.1842): ABC 16.8.1. Vol. 1 (29).

\section{AL-BUHĀR $\bar{I}$, BUSSA $^{(N, P)}$}

Al-Buhārī wird 1858 nach Mīhāàn 'Aramān (Nr. 9) der oberste Lehrer im Missionsseminar in 'Abeih.

Referenzen: „Abeih Seminary Records“: ABC 16.8.1., Vol. 8. 


\section{AL-BUSTĀNĪ, BUṬRUS (ursprünglich maronitisch) ${ }^{(N, P)}$}

1819 in Dbayye geboren besucht al-Bustānī das maronitische Internat 'Ayn Warqa. Nachdem er 1839 zum evangelischen Glauben konvertiert ist, wird er im Jungeninternat in Beirut eingestellt. Die Missionare unterrichten ihn in den biblischen Sprachen Griechisch und Hebräisch sowie in Englisch. Er gehört zum Übersetzungsteam für die arabische Bibel unter der Leitung von Eli Smith. Später arbeitet er als Dolmetscher im amerikanischen Konsulat. 1863 gründet Bustānī die säkulare höhere Jungenschule al-Madrasa al-Wațanīya. Er zählt zu den erfolgreichsten Gelehrten seiner Zeit und ist Herausgeber zahlreicher Zeitschriften sowie Autor einiger Sachbücher und Enzyklopädika.

Referenzen: Graf (1951), 326; Hitti (1957), 462; Laurie (1866), 24 (Näheres im Kapitel III.1.)

\section{CARABET, DIONYSIOS O. JOHN (ursprünglich armenisch-orthodox ${ }^{(\mathrm{N}, \mathrm{P})}$}

Nachdem er als Erzbischof aus seinem Konvent ausgetreten ist, trifft er drei Jahre später den Missionar William Goodell und wird dessen Lehrer für Türkisch. Goodell gibt ihm den armenischen Namen Carabet, was „Wegbereiter“ bedeutet (,with the hope, that he may be the forerunner of great good to his nation"). Zusammen mit Goodell übersetzt er religiöse Traktate in die türkische Sprache. Sie erarbeiten darüber hinaus eine türkische Grammatik auf Italienisch, ein Italienisch-Türkisches Wörterbuch sowie die Übersetzung der Bibel in die türkische Sprache mit armenischen Buchstaben. Da seine Frau früh verstirbt, gibt Carabet zwei seiner Töchter in die Obhut der Missionarsfamilie Whiting.

Referenzen: MH 22 (1826), in: ROS 1, 344-349, hier: 345 (Zitat); MH 23 (1827), in: ROS 1, 425-426, 469; Anderson (1872a), 74; Zaydān (1903), 424; Kawerau (1958), 335; Lindner (2009), 206, 245; Linder (2014b).

\section{FAWĀZ, ELYĀS (N, P)}

Während die Mission aufgrund der griechischen Revolte um 1829/1830 Syrien verlässt und auf Zypern bleibt, kümmern sich Elias Fawāz und Tannūs al-Ḥaddad (Nr. 31) um alles Nötige in Beirut. 1829 leistet er Evangelisierungsarbeit in Sidon zusammen mit Jacob Gregory Wortabet (Nr. 68). Fawāz ist zudem für das Lagerhaus der Mission zuständig, arbeitet als Vermögensverwalter und Vertreter der Mission. Mit Būṭrus al-Bustānī geht er 1843 in die wachsende Gemeinde in Ḥāșbeiyā. Nachdem Susan Wortabets (Nr. 71) Ehemann 1832 verstorben ist, heiratet sie Elyās Fawāz. 1848 wird er zum Diakon (šammās) ordiniert und geht mit Tannūs al-Haddād 1855 nach Sidon. Er ist Ältester der Beiruter Kirchengemeinde und Mitglied in der Syrischen Gesellschaft der Wissenschaften und Künste. Fawāz, dem ein aufbrausender Charakter nachgesagt wird, bricht zweimal mit der Mis- 
sion - vermutlich aus finanziellen Gründen - und kehrt schließlich zu ihr zurück, nachdem er seine „Schulden beglichen hat"“. 1854 berät der Ältestenrat der Beiruter Kirche darüber, ihn aus der Gemeinde auszuschließen.

Referenzen: Elyās Fawāz und Jacob Gregory Wortabet, „Qișșat šag̉al al-dinīyā“ (Bericht über religiöse Arbeit): ABC 50, Box 1 (HHL); Van Dyck (o. J.), 6; Wolcott an Anderson (Beirut, 1.6.1842): ABC 16.5, Vol. 3; MH 32 (1836), in: ROS 3, 3-4; MH 47 (1851), in: ROS 4, 120 u.v.m.; Laurie (1866), 25-26; Bird (1872), 403; Jessup (1910b), 439; NECB Protokolle (9.2.1854), 10; Huūrī (1990b), 18.

\section{FILBIS, DIMĪTRĪ̄̄S ${ }^{(N, P)}$}

Der Schwiegersohn von Ya 'qūb Āgāa ist Aufseher im Jungenseminar in Beirut und arbeitet daraufhin als Verwalter des Buchmagazins der Mission. Der Missionar Samuel Wolcott beschreibt ihn als sehr dickköpfig. Filbis und seine Frau haben schon sehr früh begonnen, sich westlich zu kleiden.

Referenzen: „Report to the Prudential Committee“ (24.4.1842): ABC 16.8.1. Vol. 1 (29); Wolcott an Anderson (Beirut, 1.6.1842): ABC 16.5., Vol. 3; Hūrī (1990b), 18.

\section{GREGORY, RUFKA ${ }^{(N, P)}$}

Zusammen mit ihrer Schwester Sada wächst Rufka nach dem Tod des Vaters Ya 'qūb Gregory (Nr. 61) und der Mutter in der Missionarsfamilie Whiting auf. Von 1858 bis 1868 arbeitet Rufka in der von Miȟā'īl 'Aramān (Nr. 9) gegründeten Mädchenschule, bis sie nach Ägypten auswandert.

Referenzen: Van Dyck an N.G. Clark (Beirut, 25.1.1868): ABC 16.8.1., Vol. 7.2. (515); Lindner (2009), 236-237, 273.

\section{GREGORY, YA Q QŪB ${ }^{(P)}$}

Nachdem Gregory und seine Frau 1836 verstorben sind, werden ihre beiden Töchter Rufka (Nr. 24) und Sada im Haus der Missionsfamilie Whiting aufgenommen.

Referenzen: Lindner (2009), 236-237, 273.

\section{6. ĞABŪR, ك̌IM' ŪN (N, P)}

Ğabūr ist Lehrer in der etwa 1846 in Kfaršīma gegründeten Missionsschule.

Referenzen: Bustān̄̄ an Smith (10.3.1846): ABC 50, Box 2; Jessup (1910a), 25. 
27. ĞARED, YŪSŪF (Konfession unbekannt) ${ }^{(\mathrm{N})}$

Laut Gehaltsliste von 1842 bezieht Ğared nur 160 Dollar im Jahr, was auf eine geringfügige Tätigkeit (Verteilung von Schriften, Pamphleten etc.) für die Mission zurückzuführen ist.

Referenzen: „Report to the Prudential Committee“(Beirut, 24.4.1842): ABC 16.8.1. Vol. 1 (29).

\section{8. ĞERAWĀN, SALĪBA ${ }^{(N, P)}$}

Ğerawān besucht das 'Abeih-Seminar für vier Jahre, um dann als Lehrer und Prediger zu arbeiten. Am 10. Mai 1864 wird er in 'Abeih zum Pfarrer ordiniert und ab 1865 in Homs stationiert, ab 1869 arbeitet er in Bhamdūn. Nach John Wortabet (Nr. 69) ist er der zweite einheimische Protestant, der zum Pfarrer ordiniert wird.

Referenzen: „Annual Report of Beirut Station, 1869“: ABC 16.8.1., Vol. 6, (39); MH 60 (1864), 250; „A Brief Chronicle of the Syria Mission“: ABC 88, 18-19; Jessup (1910a), 286.

\section{9. ĞIMMĀL, ĞIRĞIUS (P)}

Ğimmāl, der aus Akko kommt, wird im Dezember 1851 Mitglied der Beirut Church. Referenzen: NECB Protokolle (24.12.1851), 7; Jessup (1910a), 25.

\section{AL-HADDĀD, BEŠĀRĀ $(\dagger 1873)^{(\mathrm{P})}$}

Als Sohn des ersten syrischen Mitarbeiters der Mission, Tannūs al-Haddād (Nr. 31), ist Bešāāā das erste Kind in Syrien, das evangelisch getauft wird. Er studiert in 'Abeih und lehrt an Bustānīs Nationalschule. Al-Hạddād wird nachgesagt, nicht sehr gläubig zu sein, bis er jedoch gemeinsam mit dem syrischen Protesanten Elyās Sa' ada (Nr. 50) Ende der 1860er Jahre ein Erweckungserlebnis hat. Für die presbyterianisch-reformierte Mission geht er später ins syrische Latakia.

Referenzen: Jessup (1910a), 322-323, 326.

\section{AL-HADDĀD, TANNŪS (ursprünglich griechisch-orthodox ${ }^{(N, P)}$}

Al-Haddād wird als erster einheimischer Lehrer 1824 in der Missionsschule in Beirut eingestellt. Er unterrichtet die Missionare Smith, Thomson und Hebard in arabischer Sprache. Während der griechischen Revolte (1829/30) überwacht er mit Elyās Fawāz (Nr. 22) die Station in Beirut. 1844 beschließt die Mission, ihn als Prediger einzusetzen, der von Haus zu Haus ziehen soll. Zudem begleitet er die 
Missionare häufig auf ihren Itineraren durch Bergdörfer. Nach seiner Ordination zum Diakon 1848 geht er mit Fawāz 1855 in die neu gegründete Gemeinde in Sidon. Von 1847 bis 1852 ist er Mitglied in der Syrischen Gesellschaft der Wissenschaften und Künste.

Referenzen: MH 23 (1827), in: ROS 2, 471 (u.a.); N.A. Keyes, „Native Helpers“ (1844): ABC 16.8.1., Vol. 1 (21); Van Dyck (o. J.), 6; Laurie (1866), 17, 26; Bird (1872), 403; Hुūrī (1990b), 18.

\section{AL-HAKĪM, YŪSŪF (Konfession unbekannt) ${ }^{(\mathrm{N})}$}

Al-Hakīm ist Lehrer an einer Mädchenschule der Mission.

Referenzen: ABC 30.10., Vol. 3, S. 30, 40.

\section{HA ŠS̄M, BEŠS̄RA ${ }^{(P)}$}

Der aus Ḥāṣbeiyā stammende Syrer Ḥašīm wird 1853 Mitglied der Beirut Church. Referenzen: NECB-Protokolle (17.2.1853), 7; Jessup (1910a), 25.

\section{AL-HAURĀNī, IBRAHĪM (griechisch-katholisch) ${ }^{(N, P)}$}

Al-Haurān̄ī, der aus Aleppo kommt, ist von Haus aus Lehrer und unterrichtet arabische Rhetorik, Mathematik und Logik am SPC. Von 1880 bis 1915 ist er maßgeblich an der Herausgabe der Missionszeitschrift al-Našra al-Usbu '`ya beteiligt.

Referenzen: Glaß (2004a), 78; al-Ḥelū (2010), 147.

\section{AL-HAYĀT, AS 'AD YA 'QŪB (ursprünglich griechisch-katholisch) ${ }^{(\mathrm{N}, \mathrm{P})}$}

Als Zwölfjähriger nimmt er Kontakt mit den Missionaren Bird und Goodell auf, um Italienisch zu lernen und somit wird er der erste Schüler der Amerikaner. Für die Mission arbeitet al-Hayāṭ als Lehrer und später in deren Verwaltung. Er ist Arzt, Geschäftsmann, Autor (A Voice from Lebanon, London 1847) und sogar britischer Konsul in Jaffa von 1847 bis 1865.

Referenzen: Kayat (1847); Salibi (1965), 131; Tibawi (1966), 39 (Anm. 1).

\section{HEIR ALLAH, AS 'AD ${ }^{(N, P)}$}

Nach seinem Abschluss am SPC arbeitet er von 1881 bis 1932 als Sekretär für die amerikanische Druckerei in Beirut sowie als Lehrer in Missionsschulen in Homs und Zahle. Heir Allah ist jahrelanges Mitglied der Beiruter Kirche und engagiert 
sich dort als Schatzmeister. Neben John Wortabet gehört er zum Verwaltungsgremium des psychiatrischen Krankenhauses in 'Așfürīya. „He has never refused the delicate and dangerous task of intermediary between the Mission and the Turkish Government. During the recent war he paid for his disregard of personal safety with six months of exile in Anatolia under false charges."

Referenzen: McGilvary (1920), 17-18; al-Helū (2010), 311.

\section{AL-HŪ̃ İ, HALĪL ȘABŪR (1836-1907; griechisch-orthodox) ${ }^{(\mathrm{N})}$}

Al-Hūrī arbeitet in den 1860er Jahren als Lehrer im Missionsseminar in 'Abeih und tritt 1868 der Wissenschaftlichen Syrischen Gesellschaft bei. Mit Hadīqat alAhbār (1858-1911) ist er der Herausgeber der ersten indigenen arabischen Zeitung in Syrien. Al-Hūūī, der einen guten Kontakt zu Buṭus al-Bustānī pflegt, setzt sich Zeit seines Lebens für die Einheit der syrischen Nation und für einen syrischen Patriotismus ein. Seiner Meinung nach solle der Westen nicht einfach nachgeahmt werden, sondern es sei wichtig, dass sich im Nahen Osten eine eigene zivilisierte Gesellschaft herausbilde.

Referenzen: „Abeih Seminary Records, 1848-1878“: ABC 16.8.1., Vol. 8; Jandora (1981), 161; Hūrī (1990c), 218; Zachs (2004), 27-39.

\section{AL-KĀREM, TANNŪS ${ }^{(N, P)}$}

Al-Karem wird vom syrischen Konvertiten Ya 'qūb al-Hakīm bekehrt. Um 1840 dient der aus Safet stammende Syrer als einheimischer Helfer dem Missionar George B. Whiting in Jerusalem. Ab 1853 wird er in Safet stationiert, um dort religiöse Schriften zu verteilen.

Referenzen: MH 47 (1851), in: ROS 4, 147; MH 49 (1853), 200; Lindner (2009), 275 .

\section{LAFLŪFTĪ, NICOLA (griechisch-katholisch) ${ }^{(\mathrm{N})}$}

Der Vater von Joseph (Nr. 40) und Susan (Nr. 71), der späteren Frau des Konvertiten Jacob Gregory Wortabet, arbeitet als Missionshelfer. Er erwirbt Land für die Syrienmission, da der Eigentümer nach osmanischem Recht kein Ausländer sein darf.

Referenzen: Lindner (2009), 275; Lindner (2014b).

40. LAFLŪFTĪ, JOSEPH (evangelisch o. griechisch-katholisch) ${ }^{(\mathrm{N}, \mathrm{P})}$

Der Sohn von Nicola Laflūftī (Nr. 39) hilft den Missionaren, zusammen mit seinem Vater, Land zu erwerben und wird ab 1826 Aufseher aller Missionsschulen. Im Auf- 
trag der Mission geht er nach Ḥāṣbeiyā und in andere kleine Orte, um dort Schulen zu eröffnen. Die Missionare erhoffen von ihm, dass er die Reformierung innerhalb seiner Kirche voranbringt, 1827 wird er jedoch exkommuniziert. Da er für die Mission arbeitet, wird er verfolgt und muss über viele Jahre fliehen. Die Amerikaner sehen in ihm jedoch keinen vielversprechenden Gläubigen (,we never saw in him that prudence or that humility and sense of sin which are the necessary indications of a saving faith in the Redeemer"). Ohne Unterkunft und Einkommen sieht er sich gezwungen, zu seinem ursprünglichen Glauben zurückzukehren. 1834 wird wiederum von ihm berichtet, dass er Bibelkreise in seinem Haus für griechischkatholische Priester abhalte. Es ist nicht klar, ob er offiziell in die Missionskirche aufgenommen wird.

Referenzen: MH 23 (1827), in: $\operatorname{ROS}$ 2, 424, 471, 487 u. v.m.; MH 25 (1829), in: ROS 2, 172; MH 28 (1832), in: ROS 2, 301 (Zitat); MH 30 (1834), in: ROS 2, 358.

\section{LATŪF, NA 'AMI (ursprünglich maronitisch) ${ }^{(\mathrm{N}, \mathrm{P})}$}

Der Sohn eines maronitischen Šeihs, der den Amerikanern wohlgesonnen ist, wird zum Begleiter des Missionars Isaac Bird und hilft diesem bei Übersetzungen.

Referenzen: MH 24 (1828), in: ROS 2, 27; MH 25 (1829), in: ROS 2, 13.

\section{AL-MA'ALŪF, AS 'AD (ursprünglich griechisch-katholisch) ${ }^{(\mathrm{N}, \mathrm{P})}$}

Al-Ma alūf wird in eine griechisch-katholische Familie in einem kleinen Dorf am Berg Sannīn im Libanongebirge geboren. Er gehört zu den führenden Personen der Hāṣbeiyā-Bewegung, die ihrem eigenen Glauben absagen und sich dem Protestantismus zuwenden. Al-Ma alūf hat sich aus eigener Initiative eingehend mit der Bibel und den religiösen Schriften der Mission befasst. 1843 flieht er nach Beirut und arbeitet als Lehrer in diversen Missionsschulen sowie als Kolporteur für die Mission.

Referenzen: MH 40 (1844), in: ROS 3, 397-398; MH 44 (1848), in: ROS 4, 39; siehe sein Reisejournal in: ebd., 40-45.

\section{MAĞDALĀNİ, $\operatorname{KOSTA}^{(\mathrm{N}, \mathrm{P})}$}

Der ursprünglich aus Hasbeiyā stammende Syrer studiert zunächst in 'Abeih und arbeitet später dort sowie in Beirut als Lehrer bis zum Jahr 1886. Zusammen mit zwei syrischen Pflegetöchtern der Missionarsfamilie Whiting unterrichtet er schon in den 1840er Jahren in einer Mädchenschule.

Referenzen: Van Dyck an Anderson ('Abeih, 9.11.1846): ABC 16.8.1, Vol. 5 (315); „A Brief Chronicle of the Syria Mission“: ABC 88, 30 (HHL); Bird (1872), 418; Jessup (1910a), 25. 
Mag̉bugubb kommt aus 'Ain Zḥaltā und arbeitet dort für die Mission als Lehrer und Prediger. Am 29.4.1866 wird er zum Pfarrer ordiniert.

Referenzen: MH 58 (1862), in: ROS 5, 38; „A Brief Chronicle of the Syria Mission“: ABC 88, 20 (HHL); ABCFM, „Fifty-Eight Annual Report“ (1868), 50.

\section{MIHA'İL, NĀṢĪF ${ }^{(P)}$}

Der aus 'Aițāt stammende Syrer gehört zu den frühen Mitgliedern der Beirut Church und soll in der Gegend rund um Sidon Evangelisierungsarbeit leisten.

Referenzen: NECB Protokolle (7.8.1849), 2; Van Dyck an Anderson ('Abeih, 21.10.1850): ABC 16.8.1., Vol. 5; Jessup (1910a), 25.

46. MIŠĀQA, MĪHĀ'̄'L (1800-1888), (ursprünglich griechisch-katholisch) ${ }^{(\mathrm{N}, \mathrm{P})}$

Mišāqas Familie gehört zur wohlhabenden Mittelschicht. Seit Generationen widmet man sich dort Handelsgeschäften und steht im Dienst der adligen Šihāb-Familie, die im 18. und 19. Jh. den Libanon regiert. Nachdem er als Händler und Steuerverwalter für Amīr Bašīr II gearbeitet und sich autodidaktisch weitergebildet hat, entscheidet er sich, Medizin bei einem italienischen Arzt zu studieren. 1845 schließt er sein Studium in Ägypten ab, kann aber vom Einkommen als Arzt nicht leben. Nachdem er die amerikanischen Missionare Eli Smith und Cornelius Van Dyck kennengelernt hat, konvertiert er 1848 zum evangelischen Glauben, leistet missionarische Arbeit und wird als Lehrer beschäftigt. Für die Syrische Gesellschaft der Wissenschaften und Künste engagiert er sich als Korrespondenzmitglied. In den 1840ern arbeitet Mišāqa als Übersetzer für den britischen Konsul in Damaskus und ist dort schließlich von 1859 bis 1870 Vizekonsul der USA. Während der nahḍ prägt er mit seinem autobiografischen Werk Mašhad al-Aiyān bi Hawādiț Sūrīya wa Lubnān (Der Augenzeuge für die Ereignisse in Syrien und im Libanon, Kairo 1908) das Genre der Autobiografie. Mit Eli Smith steht er über viele Jahre in engem Briefkontakt, in dem es sehr häufig um Anfeindungen von Geistlichen geht, mit denen Mišãqa konfrontiert wird. Henry Harris Jessup nennt ihn den Martin Luther von Syrien, da er seine Werke unter gefährlichen Umständen verfasst habe. In der zweiten Hälfte des 19. Jh.s zählt Mišāqa zu den berühmtesten Intellektuellen in der Region Syrien.

Referenzen: Jessup (1910a), 238 und (1910b), 530; Graf (1951), 298; Mišāqa (1988), 1, 158, 235-238; Zachs (2001b), 69-74; Traboulsi (2007), 65. 


\section{NAUFAL, EFFENDĪ $(\dagger 1887)^{(\mathrm{P})}$}

Naufal ist Oberbeamter im Beiruter Zollamt und seiner Zeit ein bekannter arabischer Autor. 1862 wird er Mitglied der Beiruter Kirche. Als er 1868 nach Tripoli zieht, wird er in der dortigen Gemeinde zum Ältesten gewählt. Fünf seiner Bücher, darunter Aufzeichnungen zur arabischen Geschichte sowie die Geschichte der Religionen, werden in der Mission Press gedruckt.

Referenzen: MH 58 (1862), in: ROS 5, 38; Jessup (1910b), 430, 526; PBCFM (1923), 8 .

$$
\text { 48. NAUFAL, SALĪM }(1828-1902)^{(\mathrm{P})}
$$

1847 wird er Mitglied in der Syrischen Gesellschaft der Wissenschaften und Künste. Nachdem er sich einige Zeit in London aufgehalten hat, plant er, Anfang der 1850er Jahre in der amerikanischen Druckerei das erste säkulare zweisprachige Periodikum drucken zu lassen. Es gibt keine weiteren Aufzeichnungen, die erklären, warum es nicht dazu gekommen ist.

Referenzen: Naufal an Smith (London, 1.8.1851): ABC 50 (HHL); Tibawi (1966), 138; Hūrrī (1990b), 18.

\section{QĀSIM, MUḤAMMAD (ursprünglich drusisch) ${ }^{(\mathrm{N}, \mathrm{P})}$}

Qāsim nimmt Kontakt mit der Mission auf, um die Bildungssituation seiner Religionsgemeinschaft zu verbessern. 1836 wird er der erste muslimische Konvertit der Mission und trägt seine Entscheidung sogar vor einem muslimischen Rat vor („,he appeared ready to suffer martyrdom, rather than deny his Lord"). Zwei Jahre später werden er und seine Frau getauft und erhalten neue Vornamen. Der Missionar Samuel Wolcott beschreibt ihn dennoch als „of weak intellect and violent temper“; „The hardest cursing that I have received in this country was from him for an alleged offence of my servant."

Referenzen: Van Dyck (o. J.), 14; MH 35 (1839), in: ROS 3, 154, 157, 158 (Zitat); Wolcott an Anderson (Beirut, 1.6.1842): ABC 16.5., Vol. 3; Anderson (1872a), 243.

$$
\begin{aligned}
& \text { 50. SA'ADA, ELYĀS († 1902) (ursprünglich } \\
& \text { griechisch-orthodox) }
\end{aligned}
$$

Sa'ada lehrt in den 1860er Jahren in Tripoli die Missionare Henry Harris Jessup, dessen Bruder Samuel sowie Dr. George Post Arabisch. Er wird Lehrer an einer Jungenschule der Mission in Beirut ab 1866 und konvertiert noch im selben Jahr. Wenige Jahre später geht er als einheimischer Prediger in seine Heimatregion Tripoli und arbeitet ebenfalls für den britischen Vizekonsul. Auch sein Sohn Nağīb macht einen theologischen Abschluss und beginnt um 1888 als Prediger zu arbei- 
ten, 1893 verstirbt dieser jedoch frühzeitig. Elyās und seine Familie gehen einige Jahre danach in die USA, wo er Pfarrer der dortigen syrisch-evangelischen Gemeinde wird.

Referenzen: MH 63 (1867), in: ROS 5, 160; MH 64 (1868), in: ROS 5, 183; MH 66 (1870), in: ROS 5, 244-245; Jessup (1910a), 318-325; ders. (1910b), 430.

\section{AL-SABŪNĞĪ, TANNŪS AL-ŠŪRĪ (ODER ABU YŪSUF) ${ }^{(N, P)}$}

Al-Sabūnğ̄i verteilt für die Mission v.a. Bücher und Traktate. Er besucht zudem einheimische Schulen, um dort regelmäßig Religion zu lehren. Bei der Syrischen Gesellschaft der Wissenschaften und Künste ist er als Korrespondenzmitglied aufgeführt. 1858 wird er aufgrund von Verdächtigungen, zwei seiner Schüler misshandelt zu haben, von der Beiruter Kirche ausgeschlossen.

Referenzen: N.A. Keyes, „Native Helpers“(1844): ABC 16.8.1., Vol. 1 (21); Anderson, „Memorandum of my visit to the Levante“: ABC 30.10. Vol. 3, 30, 40 (HHL); Van Dyck (o. J.), 6; NECB Protokolle (14.5.1858), 15-16.

\section{AL-SALĪBĪ, SULEYMĀN ${ }^{(\mathrm{P})}$}

Als junger Mann lernt Suleymān den Engländer John Lowthian kennen, der ihm die Aufnahme im Seminar in 'Abeih ermöglicht. Zusammen mit seinem Bruder Elyās sowie Lowthian gründen sie mehrere Grundschulen im Libanon. Zunächst werden die Schulen, die ähnlich aufgebaut sind wie die Missionsschulen, von der Syrienmission unterstützt. Mit der Zeit jedoch sieht man die „Salībī-Schulen“ als Konkurrenz an. Suleymāns Verbindung zu den Amerikanern wird beendet als er das Angebot ausschlägt, lieber als Prediger in Akko zu arbeiten statt als Lehrer an seiner Schule.

Referenzen: Abu Husayn (1998), 205-219; Al-Aḥmar (2002), 66.

\section{SARKĪS, IBRAḦĪM ${ }^{(N, P)}$}

Sarkīs wird 1852 Mitglied der Beirut Church. Er komponiert hauptsächlich arabische Lieder für das evangelische Gesangbuch. Er gehört zudem zum Redaktionskreis der Missionszeitschrift al-Našra al-Usbu '̌ya.

Referenzen: NECB Protokolle (11.3.1852), 7; Jessup (1910a), 76; Lindner (2009), 275; al-Ḥelū (2010), 147.

$$
\text { 54. SARKĪS, HALĪL (1842-1915) }{ }^{(\mathrm{P})}
$$

Halīl ist der Bruder von Ibrahīm Sarkīs (Nr. 53). Als er acht Jahre alt ist, zieht seine Familie nach Beirut und er besucht die amerikanische Missionsschule. Er 
erlernt den Beruf des Druckermeisters, arbeitet zusammen mit Salīm al-Bustān̄̄ für die al-Mațba 'a al-Adabīya und gibt ab 1877 die Zeitung Lisān al-Hāl (wörtl.: stumme Sprache) heraus. Zusammen mit seinem Bruder Ibrahīm entwickelt er den Istanbuler Schriftsatz und wird dafür von der osmanischen Regierung ausgezeichnet. Darüber hinaus leitet er die evangelische Gesellschaft für mildttätige Zwecke (al-Ǧam '̌ya al-Heirīya al-Inğilīya) und macht sich ebenso als Autor einen Namen. Sarkīs heiratet Bustān̄̄s Tochter Louise.

Referenzen: Jessup (1910b), 741; al-Helū (2010), 145; Lindner (2014b).

\section{AL-ŠADŪDĪ, AS 'AD ${ }^{(N, P)}$}

Der 1826 in 'Āleih geborene Syrer besucht zunächst das Jungenseminar in Beirut, tritt 1849 der Beirut Church bei und lehrt später Mathematik und Physik im Seminar in 'Abeih. Al-Šadūdī leitet daraufhin ein drusisches Internat, ebenfalls in 'Abeih, bis er Ende der 1860er Jahre Tutor am SPC wird. Bliss schreibt über ihn „Mr. Assaad Shadoody is faithful in his labours and has evinced more than ordinary talent for the mathematics. He has assisted very materially in compiling a Natural Philosophy in the Arabic Language [...]. “Er gehört ebenfalls zum Redaktionskreis der Missionszeitschrift al-Našra al-Usbu ‘̌ya.

Unter Einfluss des ehemaligen presbyterianischen Missionars „Mr. Pinkerton“ nimmt Šadūdī fundamentalistisch-pietistische Ansichten an, nach denen alle anderen christlichen Kirchen korrupt seien und nicht existieren sollten. Die syrischprotestantische Gemeinschaft distanziert sich von den beiden und Šadūdī verliert seine Anstellung beim SPC. 1868 wird er von der Kirchengemeinde in 'Abeih ausgeschlossen.

Referenzen: Van Dyck (o.J.), 12; SPC Jahresbericht (24.6.1868): ABC 16.8.2., Vol. 2, 2; Jessup (1910a), 25; NECB Protokolle (21.11.1849), 2 und (21.1.1868), 21; Tibawi (1967), 276; Daniel Bliss an seine Frau Abby (Beirut, 27.1.1874), in: Bliss (1993), 178, 243-244 (Nr. 49), 251 (Nr. 97); Al-Aḥmar (2002), 66; al-Ḥelū (2010), 147.

\section{6. ŠAHWĀN, ELYĀS ${ }^{(N, P)}$}

Van Dyck nennt ihn „Bischof“, was auf seine frühere geistliche Position verweist. Zusammen mit Ṭannūs al-Haddād (Nr. 31) arbeitet er in Sidon.

Referenzen: Van Dyck an Anderson (Sidon, 30.9.1852): ABC 16.8.1., Vol. 5 (327).

$$
\text { 57. ŠAKKŪR, HANNA }{ }^{(P)}
$$

Šakkūr wird zusammen mit seinem Sohn Sa'da Yazbek 1855 in die Beirut Church aufgenommen.

Referenzen: NECB (16.2.1855), 12; Jessup (1910a), 25. 
58. ŠEMAYEL, MILHAM (Konfession unbekannt) ${ }^{(\mathrm{N})}$

Šemayel arbeitet für Smith in der Druckerei und liest die arabischen Übersetzungen Korrektur.

Referenzen: „Letter from Dr. Smith on the Printing Establishment“ (Beirut, 16.10.1855): ABC 16.8.1., Vol. 5 (216).

\section{9. ŠIBLĪ, MILHAM (Konfession unbekannt) ${ }^{(\mathrm{N})}$}

Šiblī wird als Arabischlehrer für die Missionare eingestellt.

Referenzen: Anderson, „Memorandum of my visit to the Levante“: ABC 30.10. Vol. , 31, 40 (HHL).

60. AL-ŠIDYĀQ, AS 'ĀD († 1830), (ursprünglich maronitisch) ${ }^{(N, P)}$

Al-Šidyāq ist aufgrund seiner tragischen Geschichte der wohl bekannteste Konvertit in der Syrienmission. Er kommt aus einer maronitischen Familie, die seit Generationen handschriftlich Bücher kopiert. Zusammen mit seinen Brüdern wird er im kirchlichen Internat 'Ayn Warqa ausgebildet. Er unterrichtet zunächst an einer 1810 gegründeten Jungenschule. Nachdem er den amerikanischen Missionar Jonas King kennengelernt hat, wird er dessen Lehrer für Syrisch und übersetzt zahlreiche Dokumente ins Arabische, die King für seine Arbeit benötigt. Al-Šidyāq ist fasziniert von der Bibel, die ihm King und der Missionar Bird nahebringen. Vor allem im Zuge der Übersetzung von Kings Abschiedsbrief, in dem die katholische Kirche harsch kritisiert wird, regen sich in al-Šidyāq starke Zweifel am katholischen Glauben. Nach seiner Konversion droht ihm der maronitische Patriarch Yūsuf Hubeyš mit Exkommunikation und veranlasst schließlich seine Gefangennahme. Unter Folter wird er gezwungen, sein Konvertieren zu widerrufen. Aufgrund der schlechten Verhältnisse in Gefangenschaft stirbt al-Šidyāq schließlich 1830. Für die Protestanten wird er dadurch zum syrischen Märtyrer ernannt, der seiner Zeit als einprägsames Beispiel für die Protestanten in Syrien und ihre Bürde gilt. Durch die vielen Berichte über sein Schicksal im Missionary Herald wird er auch in den USA zu einer bekannten Figur in der Geschichte der Syrienmission.

Referenzen: MH 23 (1827), in: ROS 1, 437-448; MH 24 (1828), in: ROS 2, 26-33; Mišāqa (1988), 146.

\section{AL-ŠIDYĀQ, FĀRIS (1805-1887), (maronitisch, dann evangelisch, dann muslimisch) ${ }^{(\mathrm{N})}$}

Zusammen mit seinem Bruder As'ad (Nr. 60) studiert Fāris in 'Ayn Warqa. Der Märtyrertod seines Bruders verändert sein Leben. Er konvertiert schließlich zum evangelischen Glauben und assistiert Smith bei Übersetzungen. Als Helfer in der 
Druckerei wird er von den Amerikanern Ende der 1820er Jahre nach Malta geschickt. Da in der dortigen Druckerei allerdings noch kein arabischer Drucksatz zum Einsatz kommt, stellt ihn die Church Missionary Society ein. Von 1834 bis 1848 unterrichtet er an der englischen Missionsschule auf Malta und ediert mehrere Bücher in der Druckerei. Unter Muhammad 'Alī gibt er amerikanischen Missionaren in Kairo Arabischunterricht und studiert darüber hinaus an der Al-Azhar Universität. Zusammen mit dem Briten Samuel Lee übersetzt er die Bibel 1857 in die arabische Sprache - eine Übersetzung, die jedoch weithin unbekannt bleibt. Nach einigen Jahren in England und Frankreich geht er nach Tunesien, wo er den Reformpolitiker Ahmad Bey trifft. Schließlich konvertiert er zum Islam und lässt sich in Istanbul nieder, wo er als Autor arbeitet.

Referenzen: Traboulsi (2007), 64; MH 24 (1828), in: ROS 2, 98; MH 25 (1829), in: ROS 2, 173 u.v.m.

\section{2. ȘARRŪF, YA 'QŪB (1852-1927) ${ }^{(\mathrm{N}, \mathrm{P})}$}

Șarrūf besucht die amerikanischen Missionsschulen in Sūq al-Ġarb und 'Abeih, später gehört er zu den ersten 16 Studierenden des SPC und schließt sein Studium $1870 \mathrm{ab}$. Er erteilt den amerikanischen Missionaren Arabischunterricht in Sidon und leitet kurzzeitig die amerikanische Mädchenschule in Tripoli. 1873 konvertiert er zum evangelischen Glauben und wird noch im selben Jahr als Dozent für Natürliche Philosophie, Mathematik und Chemie eingestellt. 1876 gründet er zusammen mit Fāris Nimr die wissenschaftlich-handwerkliche Zeitschrift al-Muqtațf (Die Auslese).

Referenzen: Glaß (2004a), 181-192; Elshakry (2007), 199 (Anm. 100).

$$
\text { 63. TĀBIT, HALED ELYĀZ }{ }^{(P)}
$$

Tābit, der aus Bḥamdūn stammt, wird im Dezember 1851 in die Beirut Church aufgenommen.

Referenzen: NECB Protokolle (24.12.1851), 7; Jessup (1910a), 25; Lindner (2014b).

\section{TĀBIT, NA'AMEH ${ }^{(P)}$}

Der Cousin von Haled Tābit (Nr. 63) wird 1851 Mitglied der Beirut Church.

Referenzen: NECB Protokolle (4.3.1851), 5; Jessup (1910a), 25; Lindner (2014b). 
65. AL-WITWĀT, 'ABDALLAH (ursprünglich drusisch) ${ }^{(N, P)}$

Der ehemalige Absolvent des amerikanischen Jungenseminars in Beirut arbeitet als Lehrer in einer Vorschule und ist ebenfalls Mitglied in der Syrischen Gesellschaft der Wissenschaften und Künste.

Referenzen: Anderson, „Memorandum of my visit to the Levante“: ABC 30.10. Vol. 3, 31, 40 (HHL); Van Dyck (o. J.), 12; Hūūī (1990b), 18.

\section{WORTABET, GREGORY M. ${ }^{(\mathrm{P})}$}

Gregory (armenisch: Krikūr) ist der Bruder von John Wortabet (Nr. 69) und erhält dieselbe Schulausbildung. Ebenso wie John ist auch er Mitglied in Bustānīs Mağma 'al-Tahd̄īb sowie in der 1847 gegründeten Syrischen Gesellschaft der Wissenschaften und Künste. In den 1850er Jahren arbeitet er in der Londoner Unterhaltungsbranche, was von den amerikanischen Missionaren scharf kritisiert wird. 1852 hält er in der New Yorker Female Academy in Brooklyn eine Vortragsreihe über Syrien, 1856 erscheint sein zweibändiges Werk Syria and the Syrians; or, Turkey in the Dependencies. Laut Ğurğī Zaydān studiert Gregory Medizin in London und spezialisiert sich auf Quarantäne. In Kerbela wird er in der Quarantänestation leitender Arzt und geht später nach Dschidda, wo er schließlich stirbt.

Referenzen: „Lectures on Syria“, in: New York Times (29. Mai 1852); Zaydān (1982), 425; Huūrī (1990b), 18; Lindner (2009), 27, 147, 192.

\section{WORTABET, HANNĪ ${ }^{(\mathrm{N}, \mathrm{P})}$}

Hannī ist die Tochter von Jacob Gregory (Nr. 68) und Susan Wortabet (Nr. 71). Zusammen mit ihrer Schwägerin Salome Wortabet (Nr. 51) leitet sie eine Schule in Hāṣbeiyā. Ein Brief von ihr an Eli Smith deutet daraufhin, dass sie auch für Smith Texte bearbeitet. Später heiratet sie den deutschen Missionar Henry Reichhardt.

Referenzen: Hanni Wortabet an Eli Smith (Hāṣbeiyā, 7.10.1852): ABC 60 (98) (HHL); Lindner (2009), 1, 132, 201.

68. WORTABET, JACOB GREGORY (1798-1833), (ursprünglich armenisch-orthodox) ${ }^{(\mathrm{N}, \mathrm{P})}$

Wortabet besucht eine kirchliche Schule, wird Sekretär des armenisch-orthodoxen Bischofs Gabriel in Jerusalem und erhält die Weihe zum Priester (armenisch: Vartabed). Ab 1825 arbeitet er zwar für den Missionar William Goodell, kopiert türkisch-armenische Traktate und ordnet alle türkischen Wörter für ein Wörterbuch, aber er konvertiert zunächst nicht. Schließlich verstößt er gegen sein priesterliches Gelöbnis und heiratet. Durch ein intensives Eigenstudium der Bibel konvertiert er schließlich doch zum evangelischen Glauben. 1833 schreiben die Missionare Bird 
und Whiting über ihn: „It is not too much to say that there is not another individual in Syria, so well qualified in all respects for the work of preaching the gospel to the people of various languages and religions, and so ready on all occasions to improve his advantages for the glory of Christ and the good of souls." Als von der Mission unabhängiger Prediger arbeitet er in Sidon, wo er 1832 an Cholera stirbt. Er hinterlässt eine Tochter, Hann̄̄ (Nr. 67), und drei Söhne, John/Yuhannāa (Nr. 69) und Gregory M./Krikur (Nr. 66) und Ya'qūb (oder Henry, Nr. 72).

Referenzen: MH 24 (1828), in: ROS 2, 44-51; MH 29 (1833), in: ROS 2, 336-339 (Zitat); Bird (1872), 213-215; Zaydān (1903), 425.

\section{WORTABET, JOHN ODER YUHANNĀ ${ }^{(\mathrm{N}, \mathrm{P})}$}

Der Sohn des armenischen Konvertiten Jacob Gregory Wortabet (Nr. 68) wächst von Anfang an in die protestantische Gemeinschaft hinein. Er besucht die Beiruter Jungenschule, die 1835 zum Internat wird. 1847 wird er Mitglied der Evangelischen Kirche Beirut und tritt ebenfalls der Syrischen Gesellschaft der Wissenschaften und Künste bei. Nach Schließung des Missionsseminars in Beirut unterrichten ihn Cornelius Van Dyck und Henry DeForest in Medizin und Latein; Eli Smith, George Whiting und William Thomson unterweisen ihn in Theologie. 1853 wird er zum Prediger ordiniert. Nach der Heirat mit Salome Wortabet (Nr. 70) wird er als einheimischer Pastor in Hāṣbeiyā stationiert. 1860 beendet er seine Arbeit für den ABCFM und geht für die United Presbyterian Church of Scotland als Missionar nach Aleppo. 1866 kehrt er nach Beirut zurück, um als Professor für Medizin am SPC eingestellt zu werden.

Referenzen: Anderson (1872a), 377, 383; Laurie (1866), 26, 27; Tibawi (1967), 264; Hūrī (1990b), 18; Lindner (2009), 1-2 (Näheres im Kapitel III.2.).

\section{WORTABET, SALOME $(\mathrm{N}, \mathrm{P})$}

Als Tochter von John Carabet (Nr. 21), einem einheimischen Protestanten, der ebenfalls für die Mission gearbeitet hat, wird sie in einer der Missionsschulen ausgebildet. Sie arbeitet später selbst als Lehrerin und geht für einige Zeit für die amerikanische Mission nach Mosul. Nach der Heirat mit John Wortabet (Nr. 69) und dem Umzug nach Hạașbeiyā leitet sie zusammen mit Johns Schwester Hannī (Nr. 67) eine Schule.

Referenzen: Lindner (2009), 1.

\section{WORTABET, SUSAN ODER SUSANNA ODER SARDAS (ursprünglich griechisch-katholisch) ${ }^{(\mathrm{N}, \mathrm{P})}$}

1825 heiratet Susan, Tochter von Nicola Laflūftī (Nr. 39) den Konvertiten Yacob Gregory Wortabet (Nr. 68). Aus der Ehe gehen vier Kinder hervor. Nach Wortabets 
Tod 1832 unterstützt Susan Wortabet Sarah Smith, die Frau von Eli Smith, in der 1834 in Beirut gegründeten Mädchenschule. Später heiratet sie den syrisch-protestantischen Diakon Elyās Fawāz (Nr. 22).

Referenzen: MH 31 (1835), in: ROS 2, 420; Hooker (1839), 383; Wolcott an Anderson (Beirut, 1.6.1842): ABC 16.5., Vol. 3; Lindner (2009), 25, 274; Lindner (2014b).

\section{WORTABET, YA 'QŪB ${ }^{(P)}$}

Über den zweiten Bruder John Wortabets (Nr. 69) ist nichts bekannt. Er erhält vermutlich, wie seine Brüder, die gleiche Ausbildung bei den Amerikanern, da Van Dyck unter den Schülern des Jungenseminars in Beirut einen „Henry Wortabet“ erwähnt. Ya' qūb wandert später in die USA aus.

Referenzen: Van Dyck (1839-1850), 12; Zaydān (1903), 425.

\section{YANNĪ, ANTONIUS ${ }^{(P)}$}

Yannī ist der Sohn eines griechisch-orthodoxen, wohlhabenden Geschäftsmannes aus Tripoli, der sich in jungen Jahren mit dem Missionar Isaac Bird anfreundet. 1845 wird Yannī amerikanischer Vizekonsul in Tripoli. Die Missionare befürchten stets, dass ihn seine Geschäfte und die vielen weltlichen Kontakte vom neu gewonnenen Glauben ablenken könnten. Er wird jedoch zum Gastgeber für viele Missionare, die sich hin und wieder in Tripoli aufhalten. Mit Eli Smith verbindet ihn ein freundschaftliches Verhältnis und sie schreiben sich regelmäßig Briefe. Yannī ist darüber hinaus Korrespondenzmitglied für die Syrische Gesellschaft der Wissenschaften und Künste. 1855 tritt er der Mission Church bei, was dazu führt, dass sich seine Frau von ihm trennt und einen anderen griechisch-orthodoxen Mann heiratet. 1857 schlägt er den Posten des Vizekonsuls für Russland aus, da dies bedeutet hätte, zur griechich-orthodoxen Kirche zurückzukehren. Hin und wieder predigt er im kleinen Kreis vor Interessenten in Tripoli. Im Zuge des Bürgerkriegs 1860 nutzt Yannī seinen Einfluss sowie sein Vermögen und setzt sich für Kriegsversehrte und Flüchtlinge ein. 1870 richtet er sich in einem Schreiben an den ABCFM und beklagt, dass die wenigen Missionare in diesem großen Gebiet kaum etwas ausrichten können: „we beg most importunately that you will favor us at the very least with three additional missionaries, for the harvest is great, and the laborers are few."

Referenzen: div. Briefe von Yannī an Smith: ABC 50 (HHL); MH 45 (1849), in: ROS 4, 85-86; MH 51 (1855), in: ROS 4, 224-225; MH 53 (1857), in: ROS 4, 284; MH 55 (1859), in: ROS 4, 324; MH 57 (1861), in: ROS 5, 8; MH 66 (1870), in: ROS 5, 247-248 (Zitat); Wortabet (1856a), 115-116; Anderson (1872b), 334; Jessup (1910a), 386-395. 


\section{YA 'QŪB, ELYĀS ${ }^{(N, P)}$}

Der aus Rašāya al-Fuhāar stammende Konvertit studiert im Missionsseminar in 'Abeih und arbeitet daraufhin in der Gegend um Ibl für die Mission. Noch vor John Wortabet ist er im Gespräch für eine Pastorenstelle in Ḥāṣbeiyā, gilt jedoch nicht als erste Wahl. Zusammen mit zwei anderen Protestanten aus Ḥāṣbeiyā treiben sie dort die Gründung einer evangelischen Kirchengemeinde voran. Er ist immer wieder für die Ordination im Gespräch, es scheint jedoch nicht dazu gekommen zu sein.

Referenzen: Van Dyck an Anderson ('Abeih, 21.10.1850): ABC 16.8.1., Vol. 5; Van Dyck an Anderson (Sidon, 14.11.1851): ebd. (325); Van Dyck an Anderson (Sidon, 30.9.1852): ebd. (327); Van Dyck an Anderson (Sidon, 23.4.1857): ebd. (343); Syrienmission an Anderson (Beirut, 22.1.1861): ABC 16.8.1., Vol. 6 (19); Jessup (1910a), 25.

\section{AL-YĀZIĞ̄̄, NĀṢ̂̄F (1800-1871), (griechisch-katholisch) ${ }^{(\mathrm{N})}$}

Al-Yāziğī wird in Kfaršìma geboren, studiert Medizin bei seinem Vater und einem Mönch und liest sich schon in jungen Jahren durch zahlreiche Manuskripte in den Bibliotheken der Klöster. Zunächst arbeitet er als Sekretär für den melkitischen Patriarchen Ignatius V. Qatțān, dann als Privatsekretär des Prinzen Haydar al-Šihābī und Bašīr Šihāb II. Am Hof verkehrt er mit zahlreichen Dichtern. Noch vor 1840 wird er der inoffizielle Sekretär von Eli Smith, was aufgrund seiner Konfession nicht an die Öffentlichkeit dringen soll. Erst im Zuge der Flüchtlingsströme von Drusen und Maroniten Richtung Beirut durch kriegerische Auseinandersetzungen in den Bergen wird er offiziell in der Mission als Arabischtutor angestellt. Eli Smith kann ihn mit Bustānī für die Arbeit an der arabischen Bibelübersetzung gewinnen. Später unterrichtet er Arabisch an Bustān̄̄s Nationalschule, am Patriarchenkolleg des melkitischen Patriarchen sowie am SPC. Trotz seiner Verbindung zur Syrienmission kehrt er seiner Konfession nie den Rücken.

Referenzen: Van Dyck (o. J.), 16; Antonius (1938), 45; Graf(1951), 318-319; Hanssen (2005), 165-167; Traboulsi (2007), 63. 


\section{ZUSAMMENFASSUNG}

Von 1819 bis 1870 leitete die protestantische Missionsgesellschaft American Board of Commissioners for Foreign Missions (ABCFM) die Syrienmission auf dem Gebiet des heutigen Libanon. Das ursprüngliche Ziel, unter Juden und Muslimen zu missionieren, stieß auf viele Hindernisse im Osmanischen Reich, weshalb die Reformierung der orientalischen Kirchen zur obersten Zielsetzung wurde. Positive Resonanz in der Bevölkerung erfuhr die Syrienmission jedoch weniger durch ihre Bekehrungsbestrebungen als im Bereich der Bildungsarbeit. Die Analyse des kulturellen Austausches zwischen der osmanischen Provinz Syrien und den Vereinigten Staaten von Amerika setzt bei vier wichtigen Akteuren an, da bisherige Studien häufig zu verallgemeinernden Aussagen tendieren, die nicht selten die Mission im Zusammenhang mit Kulturimperialismus verstehen. Aus diesem Grund wird in dieser Dissertation anhand der zwei ausgewählten Missionare Eli Smith und Cornelius Van Dyck ausführlich dargestellt, welchen positiven Einfluss engagierte Missionare auf die kulturtransformatorischen Prozesse in Syrien im 19. Jahrhundert hatten. Darüber hinaus zeigen die Biografien und Schriftstücke der syrischen Protestanten Buṭus al-Bustānī und John Wortabet, auf welche Art und Weise eine Rezeption dieser kulturfremden Einflüsse in der syrischen Bevölkerung stattgefunden hat. Im Fokus der Dissertation stehen zwei Fragestellungen: 1.) Inwiefern haben sich die vier Protagonisten auf einen transkulturellen Dialog eingelassen und: 2.) Wie wurde dadurch ihre Arbeit sowie ihre kulturell gebundene Selbstwahrnehmung beeinflusst? Bei näherer Betrachtung einzelner Protagonisten der amerikanisch-syrischen Begegnung im 19. Jh. wird erkennbar, dass die Dialogpartner auf individuelle Art und Weise von diesem regen Austausch kulturellen Wissensgutes profitieren konnten. 


\begin{abstract}
From 1819 to 1870 the Protestant missionary society American Board of Commissioners for Foreign Missions (ABCFM) directed the Syria Mission, operating mainly within the territory of present-day Lebanon. Its original aim of proselytizing among Jews and Muslims met with much resistance within the Ottoman Empire; the ABCFM therefore redirected its focus to reforming the Oriental Churches from within. Whilst achieving little success with evangelization, the American Syria Mission experienced a more positive resonance within the sector of education. The analysis of the cultural transfer between Ottoman Syria and the United States of America focuses on four relevant protagonists, in order not to digress into generalizing assertions or admonitions, tantamount to cultural imperialism. This dissertation analyzes the positive influences of the committed missionaries Eli Smith and Cornelius Van Dyck on cultural transformations in Syria in the nineteenth century, as well as the biographies and writings of the two Syrian Protestants Butrus al-Bustān̄̄ and John Wortabet, which provide insight into the reception of these cultural influences amongst the Syrian population. Two central questions lie at the heart of this dissertation: 1.) To what extent did the four protagonists get involved in a transcultural dialogue and: 2.) How did these circumstances affect their work and their culturally conditioned self-perception? A close investigation of important protagonists within an American-Syrian encounter in the nineteenth century demonstrates that the dialogue partners have individually benefited from a fruitful transfer of cultural knowledge.
\end{abstract}




\section{INDEX}

A

Abkāriyūs, Yuḥannā (John Abcarius), 166, 278, 282

'Abeih, 54, 60-64, 67, 68, 73, 81, 82, 85, 90, $93,95,135,136,138,139,180,182,184$, 191, 195n131, 196n137, 204, 217, 220, $265,273,285,286,289,291,292,295$, 296, 298, 302

'Abdallah, As'ad, 283

'Abduh, Muḥammad, 170, 171n529

Abdülhamid II, Sultan, 94, 202, 203n201

'Abūd, Daher, 283

Ā ġā Abkāriyūs, Ya qūb, 282, 288

Ägypten, 27, 44, 46, 51, 75, 76n329, 90, 91, 93n462, 95, 95n474, 103, 114, 136n282, 147, 150, 151, 154, 170, 200, 202, 207, 214n270, 239n440, 282, 288, 293,

Ahbār 'an Intišār al-Inğ̄̄l fí Amākin Muhtalifa $(\rightarrow$ al-Našra al-Usbu '̄ya)

Aleppo, 26, 30, 32, 33, 34, 54, 65, 110, 114, 137n287, 166n491, 211, 216, 217, 218, 226, 227, 228, 229, 230, 241, 247, 265, 290, 300

Al-Ğam 'ìya al-Šarqìya, 89n430, 90

Al-Ǧam 'ìya al-Surīya li l- 'Ulūm wa l-Funūn $(\rightarrow$ Syrische Gesellschaft der Wissenschaften und Künste)

Al-Ǧinān $(\rightarrow$ Bustānī, Butrus al-)

Al-Ǧunayna $(\rightarrow$ Bustānī, Salīm al- $)$

'Alī, Muhammad, 75, 76,

Al-Muqtataf, 31n87, 70, 94, 95, 154, 159n451, $164,165,166,167,168,172,203,204$, 240, 272, 298

Al-Našra al-Usbu 'ìya, 94, 99, 118, 162-166, 210, 271, 272, 277, 286, 290, 295, 296

American Arabic Type, 24, 40n52, 109-112, 134, 298

American Bible Society, 147, 148

American Board of Commissioners for Foreign Missions (ABCFM), 13, 14, 17, 18, 19, 19n36, 21, 22, 23, 25, 29, 30, 31, 32n $96,33,34,35,39,40,42,43,44,45$, $46,51,52,52 \mathrm{n} 143,53,56,58,59,60,65$, $66,67,71 \mathrm{n} 297,72,73,74,75,79,81,83$, $84,85,89 \mathrm{n} 431,90,96,99 \mathrm{n} 9 / 10,100,102$, $104,106,108,109,111 \mathrm{n} 89,113,122,129$,
$130,134,135,138,139,141,143,144$, 145, 160n451, 162, 163, 168, 169, 171, $174 \mathrm{n} 11,175,188,189,215 \mathrm{n} 278,221,222$, 223, 225, 226, 227, 229, 232, 237, 238, 241, 244, 245, 246, 264, 265, 300, 301, American Home Missionary Society, 59

American Mission Press ( $\rightarrow$ Amerikanische Druckerei Beirut)

American Oriental Society, 115, 124, 127, 128,167

American Tract Society, 118n152, 265, 270

American University of Beirut (AUB), 30, 66n255, 71, 136n282

Amerikanische Druckerei Beirut, 22n53, 24, $28,39,40-46,51,73,82,86,94,95,104$, $106,107,109,110,111,112,114,118 \mathrm{n} 148$, $121,126,127,131,134,136,143$, 146n345, 165, 165n479, 166n491, 175, 175n16, 190, 198, 206, 207, 219n318, 237, 238n437, 247, 268, 276, 283, 284, 286, 290, 294, 297, 298

Anderson, Rufus, 19, 21, 27, 43, 49, 53, 56, $57,60,65,72,85,108,111,113,124,127$, $137,184,188 \mathrm{n} 95,189,218,221,223,224$, 226, 265

Andover Theological Seminary, 103

Anglo-American Congregation, 54, 216, 233, 247

'Aramān, Lulu, 284

'Aramān, Mihā' '̄l, 52n143, 54n161, 83, 84n399, 145, 184n67, 219, 284

Archäologie, Biblische, 122

'Așfūrīya, psychiatrische Klinik, 235, 291

Asīr (al-Azharī), Yūsuf al-, 45, 83n391, 91n443, 95n473, 146, 147, 170, 194, 282

'Ațā, Mūsa, 284

'Aț̣iya, Ibrahīm, 285

Ayitān̄̄, Kamīl al-, 284

'Ayn Warqa, 37n34, 113, 180, 182, 191

Azār, Allah, 283

Azār, Yusūf, 283

B

Badger, George, 110, 111

Badr, Ḥannā, 285

Badr, Yūsuf, 54n160, 58n186, 285, 286 
Barakat, Šahīn, 286

Barbārī, Rizq (o. Razūq) Allah, 166, 269, 286

Barūdī, Iskandār al-, 172,

Beirut, 13, 24, 31, 33, 35, 36, 39n44, 40, $45 \mathrm{n} 89,46,51,60,67,73,75,76,78-80$, $81 \mathrm{n} 368,85,90,91,93 \mathrm{n} 462,94,103,106$, $109,111,112,114,143,156,167,168$, 171, 172n535, 182, 189, 191, 194, 203, 204, 229, 231, 236, 242, 271, 286, 302

Beirut Church, 54, 58, 180, 184, 186, 187, 188, 190, 216n292, 223, 232, 247, 289, 290, 293, 295, 296, 298

Bešārā (Šeih), 286

Bekehrung, 28, 39, 43, 49, 56, 69n285, 73, 109, 174 (siehe auch $\rightarrow$ Christianisierung)

Bibel, 18, 37, 43, 44, 46, 48, 55, 60n203, 61, $62,65,69,81,82,99,118,125,139,163$, 213, 266, 271, 279, 283, 292, 297, 299,

Bibelübersetzung, 21, 287; die arabische -, 39n47, 45, 46, 47, 83n391, 89, 91n443, 95n473, 96, 104, 105, 112-117, 118n148, 130, 136, 143, 144, 146-150, 165, 170, 184, 188, 189, 194, 197, 282, 298, 302

Bibliotheca Sacra, 125

Bilād al-Šām, 32, 78

Bliss, Daniel, 64, 65, 66, 68, 71, 95n473, 146, 157, 157n427/432, 158, 158n432, 159, 160, 161, 162, 169n513, 171n531, 189, 190, 195, 196n137, 209, 230, 231, 232, 236, 284, 296

Bliss, Howard, 71

Boston, 13, 27, 84, 90, 103, 138, 167n495

Briefwechsel, 113n109, 122n183, 129-133, 232

Brigstocke, Richard, 159

British and Foreign Bible Society, 37, 41, 44, 81,271

Brown, R. Grant, 226, 228

al-Buhārī, Bussa, 286

Bustān̄i, Būṭrus al-, 18, 24, 25, 25n73/76, 26, $27,28,30,31,45,51,52,54 \mathrm{n} 161,61,62$, $66,83,84,85,89,90,92 \mathrm{n} 453,94,103 \mathrm{n} 38$, $112 \mathrm{n} 96,113,114,118 \mathrm{n} 148,126,127$, 128n231, 130, 131, 133, 139, 146, 147, $150,154,165 \mathrm{n} 479,174,174 \mathrm{n} 9,175,176$, 179, 179n37, 180-211, 217, 219n315, 221, 223, 227n363, 239n443, 241, 246, 247, 264-268, 269, 272, 273, 282, 284, 287, 291, 302; Dā'irat al-Ma 'ārif, 112n97, 196, 202, 210; al-Ǧinān, 94, 118, 154, 165, 166, 191n110, 196, 197, 198, 199, 200n172, 204n205, 205n213; Muhịt al-Muhìț, 131,
197, 268; Nafir Surīya, 31, 199, 200, 201, 202, 207

Bustānī, Raḥīl 'Ațā al-, 24, 176, 177n26, 180, 183n60, 205, 221n328, 285

Bustānī, Salīm al-, 90n438, 92n453, 94, 130, 168, 185n79, 198, 203, 239n443, 296; al-Ǧanna, 94, 166, 197, 247; al-Ǧunayna, 94, 197, 198

C

Calhoun, Simeon H., 56, 62, 67, 74, 82n381, 139, 176, 219, 220, 238n435, 282, 287, 300

Carabet, Dionysios (oder John), 176, 182, 214, 300

Central Turkey College ('Aintab), 68

Christentum, 15, 18, 21, 36, 40, 75, 175, 247; orientalisches -, 21, 33, 35, 36, 48, 53n149, $81,90,141,178,239 \mathrm{n} 440$

Christianisierung, 39, 73 (siehe auch $\rightarrow$ Bekehrung)

Church Missionary Society, 33n5, 41, 109, $110 \mathrm{n} 79,126,142 \mathrm{n} 314,298$

contact zone, 16, 28, 173

cultural broker, 16, 28, 98, 101, 246

D

Damaskus, 32, 34, 75, 77, 90, 110, 113n105, 114, 126, 128n231, 139, 142, 142n314, 171n529, 284, 293

Darwin, Charles, 61, 70, 156, 157, 158, 210

De Forest, Henry, 50n128, 52n143, 74, 84, $85 \mathrm{n} 410,105 \mathrm{n} 41,117,127,128 \mathrm{n} 231,136$, $138,141,176,188 \mathrm{n} 96,216,284$

De-Nationalisierung, 60, 178, 248

Deutsche Morgenländische Gesellschaft, 31, $84,86,123,167 \mathrm{n} 496$

Diakon, 176, 286, 287, 290, 301

Dialog, interkultureller, 15n10, 16, 18, 19, $20 \mathrm{n} 45,23,28,125,246,248$

disinterested benevolence (uneigennütziges Wohlwollen), 34

Dodge, David Stuart, 71, 157, 157n427, 158, 195n132, 229, 230, 231, 232, 233, 236

Dodge, Martha, 49, 215

Drei-Selbst-Programm (three-self-program), 56,59

Druckerei, 28, 36n27, 40, 41, 41n58, 43, 44, 45, 51, 94, 99, 109, 110, 111, 112n96/99, 151, 198, 207, 298 (siehe auch $\rightarrow$ Amerikanische Druckerei Beirut)

Drucktechnik, 109-112, 149, 271 
Drusen, 36, 40, 51, 53n156, 62, 69, 75, 76, 76n335/336, 77, 79, 90, 141, 236, 237, 283, 302

Dwight, H.G.O., 72, 103, 106, 121

\section{E}

Eddy, William W., 70, 143, 143n320, 144n330, $160,161,166,179$ n $37,223,224,225,278$, 279

Edinburgh, 24n67, 30, 136n281, 222, 224, 226, 227, 228, 280

Edinburgh Medical Missionary Society, 222

Exkommunikation, 35n17, 179, 297

\section{$\mathrm{F}$}

Fawāz, Elyās, 54n161, 130, 130n238, 174, 176, 183, 216n294, 219n315, 287, 289, 290, 301

Female Seminary (Beirut), 49n124, 145n337 (siehe auch $\rightarrow$ Frauenbildung)

Filbis, Dimītrīūs, 288

Fisk, Pliny, 31n89, 34, 50n131, 102n26, 103n34, 238n437

Fleischer, Heinricht Leberecht, 110, 128, $148 \mathrm{n} 360,167 \mathrm{n} 496$

Frauenbildung, 49, 50, 51n140, 99n13, 120, 203-207

Free Church of Scotland, 82, 222, 226

Friedhof, Anglo-Amerikanischer -, 105, 212

Frömmigkeit (piety), 55, 56, 124, 125, 139, $140,141,158,177,225$

G

Ğabūr, Šim'ūn, 288

Ğam iyat al-Maqāșid al-Hayrīya al-Islāmīya (Islamische Gesellschaft für mildtätige Zwecke), 83, 283

Ğam 'ìyat al- 'Ilmìya al-Sürīya (Syrisch-Wissenschaftliche Gesellschaft), 90, 91n443, 93, 168n504, 203n202

Ğam 'iyat Zahrat al-Adab (Gemeinschaft zur Blüte der Bildung), 194, 204n202

Ğared, Yūsūf, 289

Ğerawān, Salība, 58, 289

Ğimmāl, Ğirğius, 289

Goodell, William, 35, 38, 38n39, 47, 48, 49, 54, 72, 101, 108, 127, 134, 134n267, 213, 214, 220, 238n435/436, 282, 287, 290, 299

Gregory, Rufka, 52n143, 176, 220, 288

Gregory, Sada, 176, 220

Gregory, Ya'qūb, 220, 288
$\mathrm{H}$

Ḥaddād, Bešārāā al-, 289

Ḥaddād, Tannūs al-, 47, 54n161, 84n396, $85 \mathrm{n} 410,106,110,111,130,174,218$, 219n315, 287, 296

Hadīqat al-Ahbārr, 44, 95, 117n143, 121, 198n155, 291

Hakīm, Yūsūf, al-, 290

Hašīm, Bešāra, 290

Hatt-ı Hümāyūn (Gesetz), 77, 91, 93

Hatt-l Scherīf von Gülhane (Gesetz), 77

Ḥaurānī, Ibrahīm, al-, 166n491, 287, 290

Hayāt, As' ad Ya 'qūb al-, 31, 290

Heir Allah, As'ad, 248n16, 290

Hohe Pforte, 32n95, 36, 76n335

Huūrī, Halīl Șabūr al-, 93, 94, 95, 95n473, 117n143, 121, 198n155, 291

Hybridität, 179, 180

I

Islam, 14, 36, 124n204, 147, 148, 206, 236, 298

Istanbul, 22n53, 32n96, 53n151, 68, 69, 76, $80,90,92,94,95,99,110,121 \mathrm{n} 181,159$, $228,272,282,296,298$

$\mathrm{J}$

Jerusalem, 34, 35, 35n14, 39n44, 60, 110, 114, $121,132,177,188 \mathrm{n} 95,211,213,220,231$, 266, 284, 291, 299

Jessup, Henry Harris, 35n17, 36, 51, 65, 67, $70,72 \mathrm{n} 310,79,100,102,102 \mathrm{n} 28,112$, $127,128 \mathrm{n} 224,130,132,139,160 \mathrm{n} 456$, $161,161 \mathrm{n} 464,162 \mathrm{n} 465,165 \mathrm{n} 479,166$ 171, 172, 174, 182, 189, 190, 191, 191n110/111, 194, 201, 202, 203, 209, 209n242, 210, 229, 232, 235n420, 247, 278, 283, 286; Fifty-Three Years in Syria, 161, 191; The Women of the Arabs, 174, 196, 204n211

Jessup, Samuel, 166, 278

Juden, 34, 35, 36n27, 52, 69, 211, 226, 228 , $229,236,239 \mathrm{n} 440,241$

K

Kairo, 22n53, 44, 51, 91, 109, 110, 122, 136n282, 147, 154, 170, 194, 203n201, 272, 282, 293, 298

Kaiserswerther Diakonissen, 57n184, 81n367, 171, 171n531, 189n101, 220n325, 234, 236, 242

Kārem, Tannūs al-, 291 
King, Jonas, 38n39, 55n167, 72, 244, 297

Kirchengemeinden, indigene -, 40, 52-59, 54n163, 59n195, 63, 78n348, 140, 142, 186, 219, 220, 232, 282, 285, 286, 287, 296, 302

Konsul: amerikanischer -, 39n44, 67, 78, 95, 185, 247, 248n14; britischer -, 67, 78, 136, 142n315, 228, 242n467, 282, 287, 290, 293, 294, 301

Konvertiten, 23, 178n 31 ; protestantische -, 19, $22,40,51,52,54,55 \mathrm{n} 169,56,73,74,101$, $107,108,139,141,142,173,174,175$, $176,178,179,183,213,216,220,225$, 241, 244, 245, 273, 282-302; konvertieren, $35,36,55 \mathrm{n} 169,62,131,297$

Kulturimperialismus, 15, 16, 17, 179, 247

\section{L}

Laflūftī, Joseph, 291

Laflüftī, Nicola, 291

Latūf, $\mathrm{Na}$ 'ami, 292

Lehrbücher, arabische, 25, 29, 40, 41, 42, 44, $50,51,62,96,112,127,127 \mathrm{n} 220,136$, $139,143,153,154,170,180,232,234$, 240, 265-268, 269, 273-277, 279-280, 285

Lewis, Edwin, 70, 155, 156, 157, 157n427/428, 158n434, 159, 161, 233; Affäre um -, 70, 156, 157, 210n247, 234

Lexikon, 130, 165, 202, 238, 268

Libanon, 13, 29, 30, 32, 34, 35n17, 42n64, $45 \mathrm{n} 89,75,77,91 \mathrm{n} 441,150,211,244,266$, 293, 295

Libanongebirge (Mount Lebanon), 24, 44n87, $51,75,76,77,79,126,128,191,237,266$, 292

Libanon-Schulen, 81, 81n367, 82, 82n381, 191, 222

London Missionary Society, 41, 178n34

London Religious Tract Society, 44, 68, 278

London Society for Promoting Christian Knowledge, 113

Lowthian, John, 81, 82, 295

$\mathrm{M}$

Ma'alūf, As' ad al-, 292

Mädchenschule, 49, 50, 52n144, 104, 120, $135,145,205,211,215,220,220 \mathrm{n} 325$, 284, 285, 290, 292, 298, 301 (siehe auch $\rightarrow$ Frauenbildung)

Madrasa Wațanīya (Nationalschule), 52, 90, 147, 189, 189n99, 190, 191-197, 199, 266, $287,289,302$

Maġbuġub, Hualīl, 293
Mağdalānī, Kosta, 292

Mağma 'al-Tahd̄īb (Gesellschaft für Bildung), 85, 86n412, 92, 203n202, 204, 299

Mağmū' Fawā'id (Sammlung nützlicher Lektionen), 94, 99, 117-121, 162, 166, 199n162, 269

Makārīūs, Šahīn, 81n368, 85, 89, 91n441, 96

Maroniten, 37n34/35, 44n87, 51, 53n156, 62, 75, 76, 76n $335 / 336,81 \mathrm{n} 368,95,95 \mathrm{n} 476$, $113,113 \mathrm{n} 105,150,169 \mathrm{n} 513,174,176$, 180, 182, 183, 192n121, 203n197, 211, 221, 236, 265, 267, 278, 287, 292, 297, 302

Martyn, Henry, 45n94, 103n35, 105, 106, $106 \mathrm{n} 47,112$

Mațba'at al-Amrikān $(\rightarrow$ Amerikanische Druckerei Beirut)

Medizin, 18, 21, 26, 30n84, 51, 66, 67, 79n $353,98,111,118,135,136,138,144$, $145,150,151,151 \mathrm{n} 387,152,152 \mathrm{n} 393$, $154,155,156,159,160,161,211$, 212n $263,216,222,227,229,230$, 230n383, 232, 233, 234, 234n408/413, 235 , 236, 239, 240, 240n452, 241, 245, 274, $275,279,280,293,299,300,302$

Mentor, 105, 132, 133, 174, 178n34, 183, 197, 216, 217, 221, 239n444, 241, 245

Metawileh $(\rightarrow$ Schiiten)

Miḥa'îl, Nāșīif, 293

millet, 39, 39n44, 77, 78

Mišāqa, Mīhā'îl, 126, 128n231, 130, 131, $13 \ln 252 / 254,132,133,239 \mathrm{n} 443,293$

Missionary Herald, 13, 13n1, 17, 35, 37n35, $47,51,55 \mathrm{n} 169,58,72,75,82,124$, 130n238, 134, 138, 146, 162, 174, 189, 191n111, 215n278, 221, 227n363, 286, 297

Missionarsfrau, 35, 49, 105n41, 118n150, 176, $177,220,244$

Mission Church, 54, 214, 301 (siehe auch $\rightarrow$ Anglo-American Congregation)

Missions-: arzt, 35, 102, 135, 136, 137, 138, $139,141,143,147,154,160,169,243$, 265; -assistentin, 13, 118n150; -familie, 52n143, 105n40, 175n15, 179, 180, 215, 288; -feld, 13, 17, 20, 59, 100, 101, 227n363, 229; -gesellschaft, 13, 26, 27, 35, 46n99, 100, 101, 102, 145; -haus, 36, 37, 38n41, 47n101, 84, 125; -periodika, 99, 174n8 $(\rightarrow$ Al-Našra al-Usbu ‘̀ya, Mağmū ‘ Fawä 'id); -schule, 19, 37n35, 38n41, 40n51, 46-52, 47, 48, 49, 51, 61, 64, 68, $72,73,78,79,80,81,81 \mathrm{n} 368,88,109$, 176n24, 183, 266, 285, 288, 289, 290, 291, 292, 295, 298, 300 
Missionsdruckerei ( $\rightarrow$ Amerikanische Druckerei Beirut)

Missionsseminar: - in 'Abeih, 60-64, 73, 90, 136, 138, 195n131, 216, 217, 273, 285, 291, 298; - in 'Aintab, 68; - in Beirut, 60, $300 ;-$ in Istanbul, 68

Missionsstation, 13, 33n5, 35, 38n40, 72, 79, 98, 102, 182, 189n104, 191n110, 192, 216 mutassarifitya, 77, 79, 91

\section{$\mathrm{N}$}

nahda, 25, 27, 27n79, 91-97, 169, 169n512, $180,207,246,293$

native, 45n91, 46, 51, 60, 61, 66, 68, 84, 97, 113n110, 114, 118, 136, 161, 169, 174, $178,198,224,228,229,231,236,238$, 241;-agency, 56, 57, 227, 227n 363, 237; - assistant, 29, 174; - helper, 29, 31, 129, 140, 174, 224, 248, 282-302; - ministry, 57n178, 142, 187, 226; - pastor, 57, 58, $65,133,183,219,220 \mathrm{n} 320,224$ (siehe auch $\rightarrow$ Pastorenamt $) ;-$ preacher, 58 , $173 \mathrm{n} 6$

Native Missionary Society, 189, 227n363

Nationalschule $(\rightarrow$ Madrasa Watanìya)

Naufal, Naufal Effendī, 294

Naufal, Salīm, 121, 294

National Evangelical Church of Beirut, 52

Nimr, Fāris, 31, 31n87, 70, 71, 90n436, 91n441, 94, 95, 154, 158n433, 159n451, 162n465, 164, 165, 167n500, 168, 172, 197n147, 208n236, 209n244, 239n443, 272, 298

Nusairiyeh (Alawiten), 232

$\mathrm{O}$

Orient, 14, 14n8/9, 22, 26, 71n297, 72, 129, 223, 237, 238, 242

Orientalist, 25, 45n91, 89, 110, 129, 135, 149, 149 n366

Orientalistik, 17, 21

Osmanisches Reich, 18, 19, 27, 28, 32, 33, $35 \mathrm{n} 15,36,39,69 \mathrm{n} 283,76,77,78,80-83$, 90, 91, 92n $449,93 \mathrm{n} 459,94,95,96$, 126n213, 147, 190, 201, 202, 203n201, 208, 222n333, 234, 296

$P$

Palästina, 13, 33n5, 34, 35, 44, 75, 110, 122, $150,244 n 2$

Pastorenamt, 58n192, 133, 140, 183, 185, 186, 188, 198, 284 (siehe auch $\rightarrow$ native pastor)
Panoplist, 72 (siehe auch $\rightarrow$ Missionary Herald)

Parsons, Levi, 34, 35, 50n131, 102n26, $103 n 34$

Paxton, John D., 107-108, 125

Periodika, arabische - , 30, 95, 112, 117n142, 120, 152n395, 197n146, 207, 282 (siehe auch $\rightarrow$ Al-Našra al-Usbu '̀ya; $\rightarrow$ Mağmū' Fawā' 'id; $\rightarrow$ Bustānī, Būtrus al-; $\rightarrow$ Bustānī, Salīm al-)

Post, George, 70, 82n384, 155, 156, 157, 157n428, 159, 230, 232, 233, 234, 235, 294

Postmilleniarismus, 34

Presbyterian Board of Commissioners for Foreign Missions (PBCFM), 39, 52n143, 66n255, 68n272, 71, 72n305/310, 99n9, 149n366, 161, 169

Proselytismus, 38n39, 52

Protestanten, 14, 16n22, 19, 24, 30, 33, $33 \mathrm{n} 1 / 4,35,36,39,45 \mathrm{n} 89,49,51,53 \mathrm{n} 153$, $65,75,77,78,81,89,99,105 \mathrm{n} 40$, 118n150, 120, 126, 131n252, 141, 169, 192, 200, 207, 211, 220, 223, 227, 235, $237,244,245,247$; syrische, 23, 24, 26, $28,29,31,32,52-59,62,66,83,87,101$, 130, 130n238, 141, 142n314, 150, 166, 173-180, 183, 184, 185, 186, 187, 188n94, $189,209,217,224,225,227 \mathrm{n} 363,229$, 238n433, 246, 247, 248, 267, 278, 282-302

Prudential Committee (des ABCFM), 33, 65, 73n313, 138, 142, 143

Q

qā'immaqūmìya, 76, 77

Qāsim, Muhammad, 130, 294

$\mathrm{R}$

Riḍā, Muḥammad Rašīd, 170

Republican Mother, 49, 205

Robert College (Istanbul), 68

Robinson, Edward, 104, 110, 121-124, 128

Rödiger, Emil, 89, 110, 112n99, 128, 129, 148 n360

Royal Geographic Society, 123, 240n453

$\mathrm{S}$

Sa'ada, Elyās, 289, 294

Sabūnğ̄i, Tannūs al-Šūrī al-, 295

Šadūdī, As'ad, al-, 67, 166, 296 Šahwān, Elyās, 296

Šakkūr, Hanna, 296

Salībī, Elyās al-, 81, 82, 83, 295 (siehe auch $\rightarrow$ Libanon-Schulen) 
Salībī, Suleymān al-, 81, 82, 83, 130, 295 (siehe auch $\rightarrow$ Libanon-Schulen)

Sarkīs, Halīl, 45, 112n96, 198n151, 273, 295

Sarkīs, Ibrahīm, 166, 295

Șarrūf, Ya'qūb, 31, 31n87, 70, 70n295, 71, 90n436, 91n441, 94, 95, 151n 385,154 , 158, 159n451, 162n465/467, 164, 165, 167n500, 168, 172, 197n147, 208n236, 210, 216, 233, 234n405, 239n438, 242, 243, 272, 276, 298

Schiiten, 62, 69, 76, 236, 237n431

Schriftsatz, arabischer -, 41, 43, 94, 109, 110, 110n79, 111, 112, 128, 296 (siehe auch $\rightarrow$ American Arabic Type)

Šemayel, Milham, 297

Šiblī, Milham, 297

Šidyāq, As‘āe al-, 174, 174n9, 181, 244n2, 267, 297

Šidyāq, Fāris al-, 149, 297

Smith, Eli, 14n9, 18, 24, 25, 26, 27, 28, 29, 36, $37 \mathrm{n} 33,38,38 \mathrm{n} 40,41,42,44 \mathrm{n} 88,45,46$, 48n109, 49, 50, 55n169, 56, 56n171, 72, 74, 76, 76n332, 82n381, 83, 84, 84n396, $85,86,87,87 \mathrm{n} 417,88,88 \mathrm{n} 426,89$, 89n431, 90, 94, 96, 99, 101, 102, 103-135, $136,141,142 \mathrm{n} 318,146,147,148$, 148n $360,149,150,162,163,165,166$, 167n496, 176, 178n $31,179,182,183,184$, 185, 186, 187, 188, 197, 198, 206, 209, 213, 214n270, 216, 217, 218, 219, 222, 223n338, 229n380, 241, 245, 246, 247, 248, 264, 265, 266, 268-269, 270, 271, 278, 285, 287, 289, 293, 297, 299, 300, 301, 302; Biblical Researches in Palestine, and in the Adjacent Regions, 104, 121-124

Smith, Hetty (geb. Mehitable Simpkins Butler), 105, 105n44, 183n60

Smith, Sarah Lanman, 14n9, 49, 73, 102n26, 105, 105n40, 106, 107, 177n26, 179n40, $180 \mathrm{n} 47,215,285,301$

Šūf (-gebirge), 79,

Sunniten, 62, 69, 76, 91n443, 236

Smyrna, 41, 43, 110, 111, 265

Syrian Protestant College (SPC), 25, 30, 30n $84,31 \mathrm{n} 87,44,63,64-71,80,82,88$, $94,136,136 \mathrm{n} 282,145,146,146 \mathrm{n} 345,154$, $155,155 \mathrm{n} 411 / 412,156,157,157 \mathrm{n} 427 / 428$, $158,158 \mathrm{n} 433,159,160,161,162$, 162n465, 166n491, 167n500, 170, 172, 189, 190, 191, 192, 194, 194n129, 195, 196, 196n135/137, 199n164, 210, 211, 212n263, 216, 228, 229-236, 238, 240, 240n450/451, 241, 242, 243, 274, 275, 276,
279, 280, 281, 282, 284, 290, 296, 298, 300, 302; Board of Managers, 67, 158, 194, 195, 196, 196n135, 230n383, 232, 234n413, 235, 274; Board of Trustees, 66, 67n259, 71, 155n412, 156, 157, 157n427, 158, 195n132, 229, 231, 232n394, 236; Medizinische Fakultät, 30n84, 67, 145, 155, 159, 160, 230, 231, 232, 234, 235; Preparatory Department, 64, 194, 195, 196, 196n135/137; Unterrichtssprache, 51, 51n133, 60, 61, 67, 71, 159, 160, 235

Syrienmission, 13, 14n6, 15, 19n36, 21, 23, $27,35,39,40-75,79,80,82,84,94,96$, 97, 99n10, 102, 103n34, 117, 121, 124, $126,129,135,137 \mathrm{n} 287,138,141,142$, 144, 145, 146, 151, 163, 174n7, 175, 189, 191, 199, 201, 207, 211, 213, 214n273, 215, 218, 219, 223, 226, 243, 245, 295, 297

Syrische Gesellschaft der Wissenschaften und Künste, 31, 84-90, 119, 127, 129, 167, 204, 206, 239, 266, 287, 290, 293, 294, $295,299,300,301$

Syro-Egyptian Society, 86, 127

$\mathrm{T}$

Tābit, Haled Elyāz, 298

Tābit, Na'ameh, 298

tamaddun (Zivilisation), 93n459, 200n172, 205

Tamarat al-Funūn, 83n394, 91n443, 194n127, 282

Tanżimāt - Reformen, 77, 80 (siehe auch $\rightarrow$ Hatt-l Hümāyūn; $\rightarrow$ Hatt-l Scherīf von Gülhane)

Tauchnitz, Karl, 109n75, 110, 112n99, 128

Temple, Daniel, 106

Tholuck, August, 110

Thomson, Eliza, 49, 102n26

Thomson, William M., 35n14, 50, 51n139, 54, 58n186, 61, 65, 67, 84, 85, 88, 89, 96, 127, 136, 296, 141, 142, 143, 162n469, 171n528, 179n37, 182, 185n75, 190, 215, 216, 218, 219, 220, 220n322, 221, 222, 224n $345,225,229,230,231,232,289,300$

Transkulturalität, 18-19, 20, 133

U

Union Theological College (New York), 121, 144

United Presbyterian Church of Scotland (UPC), 30, 33n5, 211, 222, 300

Urmia, 72, 99n9, 118n151 
$\mathrm{V}$

Van Dyck, Cornelius Van Alen, 18, 24, 25, 26, 27, 28, 29, 30, 41n59, 44, 45, 46, 56, 59, $61,62,63,65,67,69,70,74,83,84,85$, $88,89,91 \mathrm{n} 443,94,95,95 \mathrm{n} 473,96,99$, 102, 102n $28,103,103 \mathrm{n} 32,114,116,117$, 127, 130, 135-172, 174n11, 176, 176n17, 178n31, 179, 179n37, 180, 182, 185, 185n78, 189, 189n97, 194, 197n149, 199n164, 206, 209, 210, 215n278, 216, $218,219,221,223,224,225,230,232$, $233,234,234 \mathrm{n} 405,235,236,238 \mathrm{n} 437$, 239n443, 242, 243, 245, 246, 247, 248, 265, 270-278, 282, 293, 296, 300, 301

Van Dyck, Julia (geb. Abbott), 136, 142n315, 146, 179n37

Van Dyck, William, 70, 136n282, 236, 239n443

W

Waldmeier, Theophilus, 235

wațan (Vaterland), 92, 93n459, 197, 198, 199, 200, 208, 211, 247

Whiting, George B., 47, 52n143, 54, 111, 117, 138n296, 141, 176, 179n37, 216, 219, 220, 287, 288, 291, 292, 300

Whiting, Matilda S., 177, 220

Wissenschaftliche Gesellschaften, 84-91, 96, 127-129, 167-168, 194, 203, 203n202 (siehe auch $\rightarrow$ Ğam iyat al-Maqāṣid al-Hayrīya al-Islāmìya; $\rightarrow$ Ğam 'ìyat al- 'Ilmìya al-Sūrīya; $\rightarrow$ Ğam 'ìyat Zahrat $a l-A d a b ; \rightarrow$ Mağma 'al-Tahd̄īb)

Wissen, 28, 38n39, 66, 68, 69, 85, 86, 87, 88, 99, 108, 119, 167, 168, 170, 194, 199, 200, 205, 207, 246, 248

Wissenstransfer, 20, 98, 246

Witwāt, 'Abdallah al-, 84n399, 299

Wolcott, Samuel, 74n319, 84, 140n305, 216, 216n291, 288, 294

Wortabet, Gregory M., 30, 85n410, 177, 216, 221, 241, 299
Wortabet, Hannī, 176, 177, 215, 215n278, 220, 299, 300

Wortabet, Jacob Gregory, 130n238, 176, 211, 213-215, 218, 238n436, 282, 287, 291, 299, 300

Wortabet, John (oder Yuhannāa ), 18, 24, 26, 27, 28, 29, 30, 31, 32, 35n17, 44, 48, 54n161, 58, 65, 67, 70, 84n399, 85n410, 87n418, 90n438, 101, 130, 132, 133, 136, 140, 142, 145, 155, 159, 162, 168, 171, 172n535, 175, 176, 177, 178, 179, 179n37, 180, 182, 186, 187, 195n132, 206, 211-243, 246, 247, 248n14, 278-281, 289, 291, 299, 300, 301, 302; Researches into the Religions of Syria, 177n28, 225, 236-238, 241

Wortabet, Salome (geb. Carabet), 176, 212, 220, 221, 226, 229, 299, 300

Wortabet, Susan (Sardas), 24, 31, 176, 177, 179n36, 211, 214, 214n269, 215, 289, 291, 300

Wortabet, Ya' qūb, 215, 300, 301

Y

Yannī, Antonius, 130, 132, 248n14, 301

Ya'qūb, Elyās, 302

Yāziğī, Ibrahīm al-, 91n441, 149, 168, 199n164, 239n443

Yāziğì, Nāṣị al-, 42, 45, 67, 84, 84n396, $85 \mathrm{n} 410,93,113,115,129 \mathrm{n} 233,130,133$, 146, 147, 150, 194, 199n164, 217, 264, $265,282,302$

Young, Cuthbert G., 82n381, 222

Z

Zaydān, Ǧurǧī, 30, 92, 96, 147n355, 151, 157n427, 159, 168, 170n515, 299

Zivilisierung, 13, 15, 19, 21, 39, 39n45, 72, 73, 75, 76n 332 , 91, 92, 96, 134, 198, 200, 201, 201n181, 238

Zoqāq al-Blāt (Beirut), 105, 191 
Die christliche Missionsarbeit der vergangenen Jahrhunderte wird auch heute noch als überaus negativ wahrgenommen. Doch nicht immer hatten Missionare kulturimperialistische oder kolonialistische Bestrebungen. Aus diesem Grund zielt dieser Band darauf $\mathrm{ab}$, Mission differenzierter $\mathrm{zu}$ betrachten und zwischenmenschliche Interaktionen im Missionsfeld zu beleuchten. Im Zentrum der Untersuchung steht die Syrienmission des protestantischen American Board of Commissioners for Foreign Missions ), die sich von 1819 bis 1870 in der Osmanischen Provinz Syrien, auf dem Gebiet des heutigen Libanon, etablierte. Die Analyse des kulturellen Austausches zwischen dem Osmanischen Reich und den USA setzt bei vier wichtigen Protagonisten an, die in der bisherigen missionsgeschichtlichen Forschung nicht ausführlich bzw. gar keine Beachtung fanden: Die Missionare Eli Smith und Cornelius Van Dyck sowie die syrischen Protestanten Butrus al-Bustani und John Wortabet. Die Syrienmission des ABCFM ist ein Beispiel dafür, wie zwei verschiedene Kulturen in der sogenannten contact zone der Missionsstationen aufeinandertrafen und trotz Konflikten und Meinungsverschiedenheiten zu einem fruchtbaren Dialog gelangen konnten.

Veröffentlicht mit Unterstützung des Austrian Science Fund 